$\frac{1}{2}$ The ORNL Chemical Technology Division

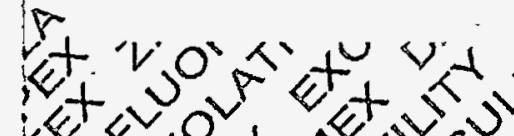

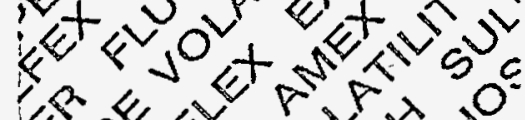

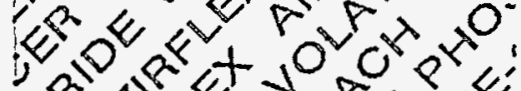

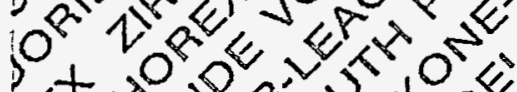

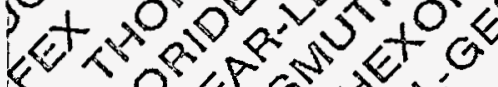

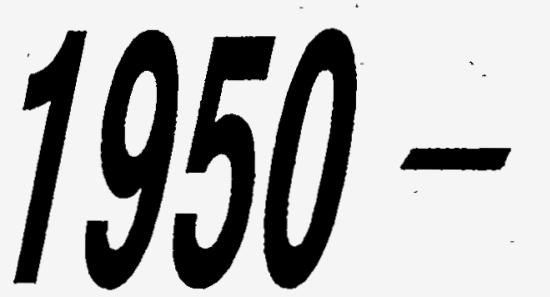

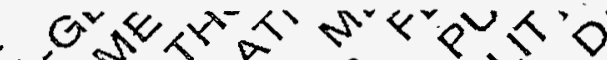

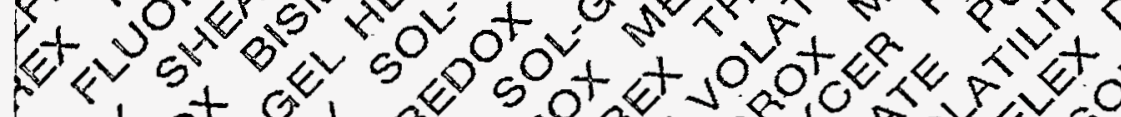

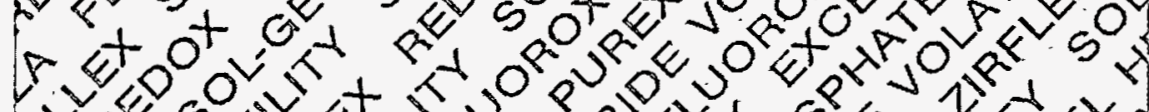

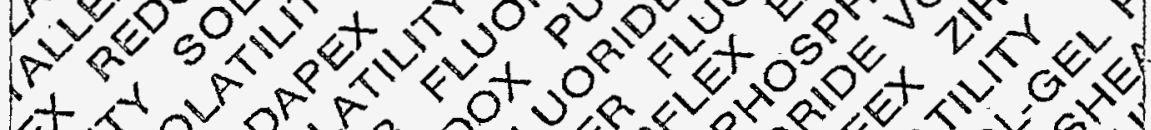

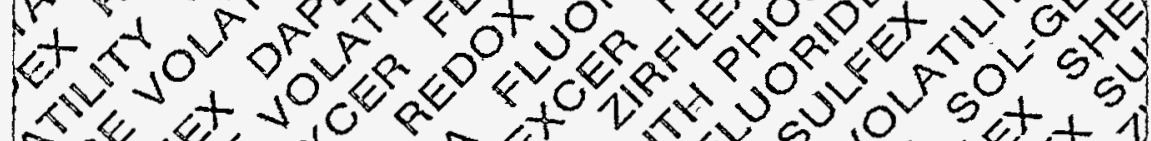
r.

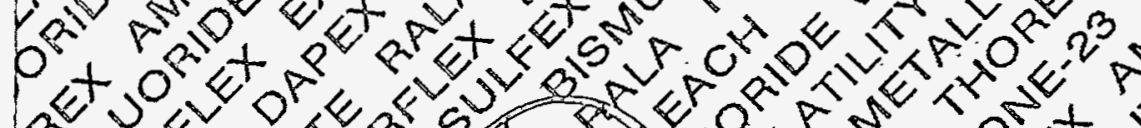

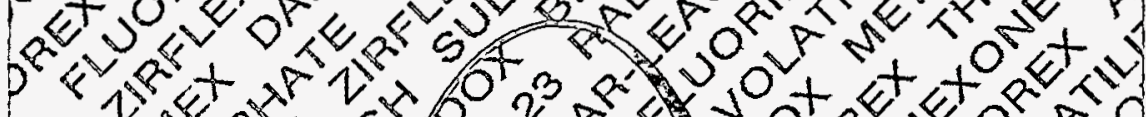

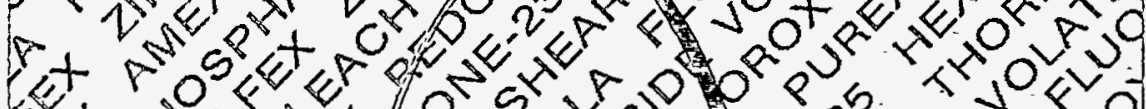

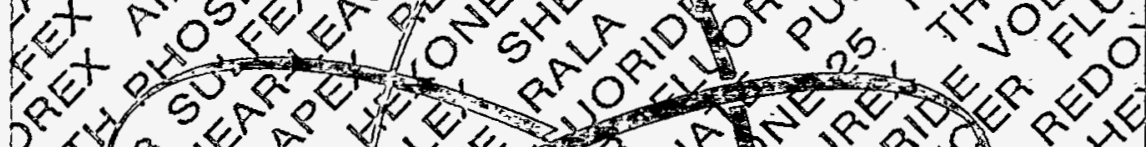

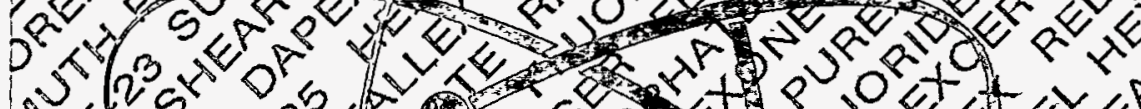

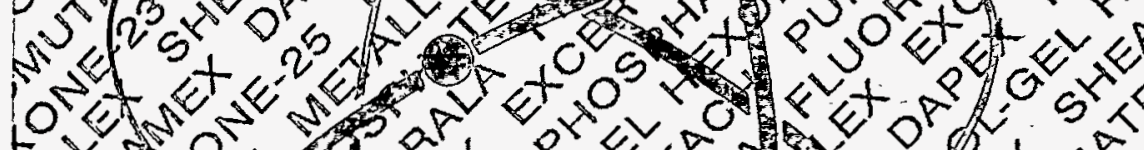

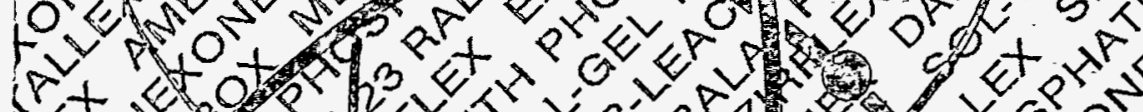

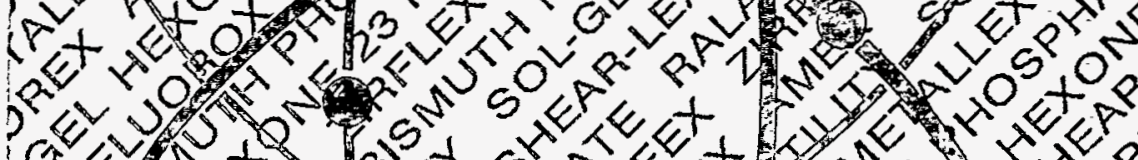

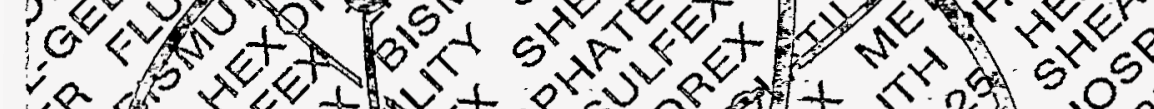
rs

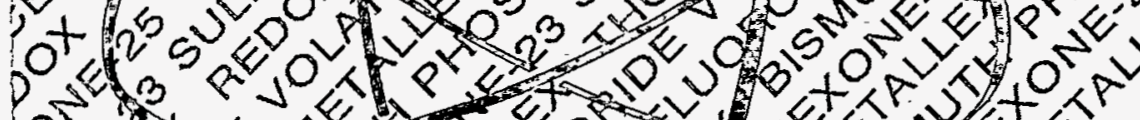
$0 \leqslant 2$ o

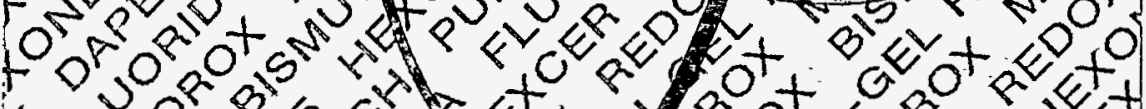

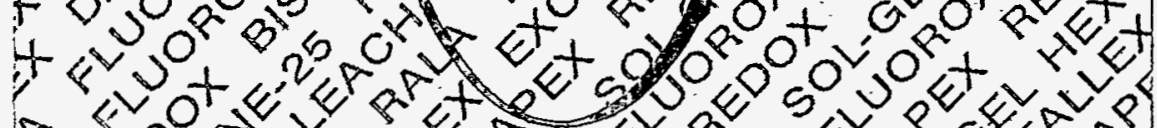

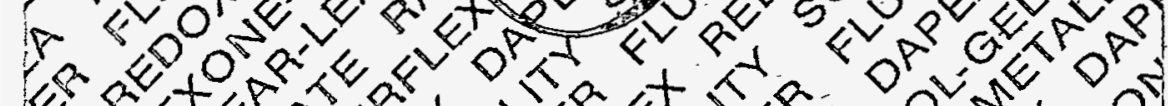
30

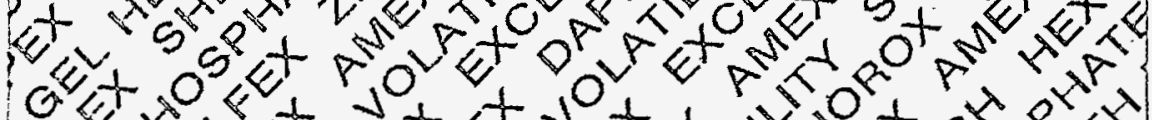

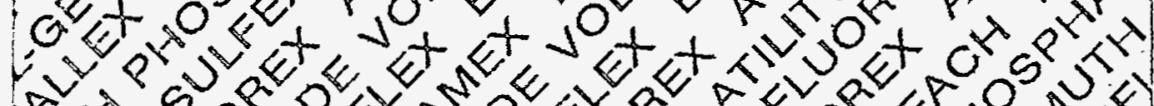

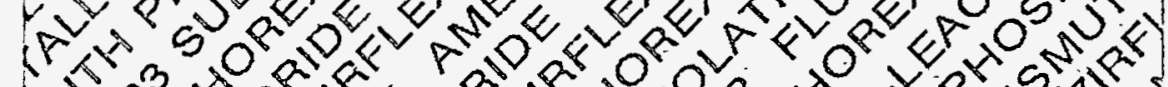

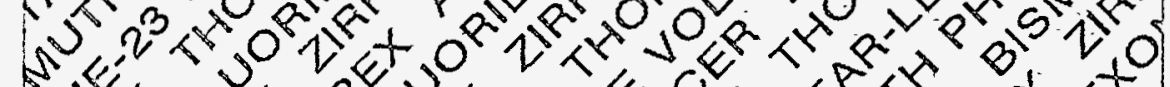

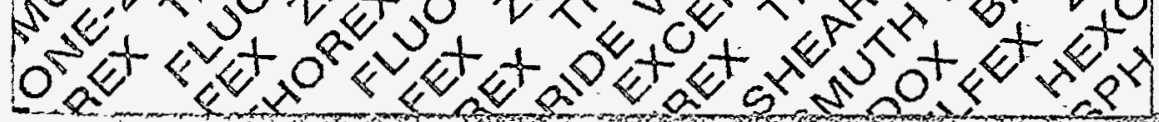
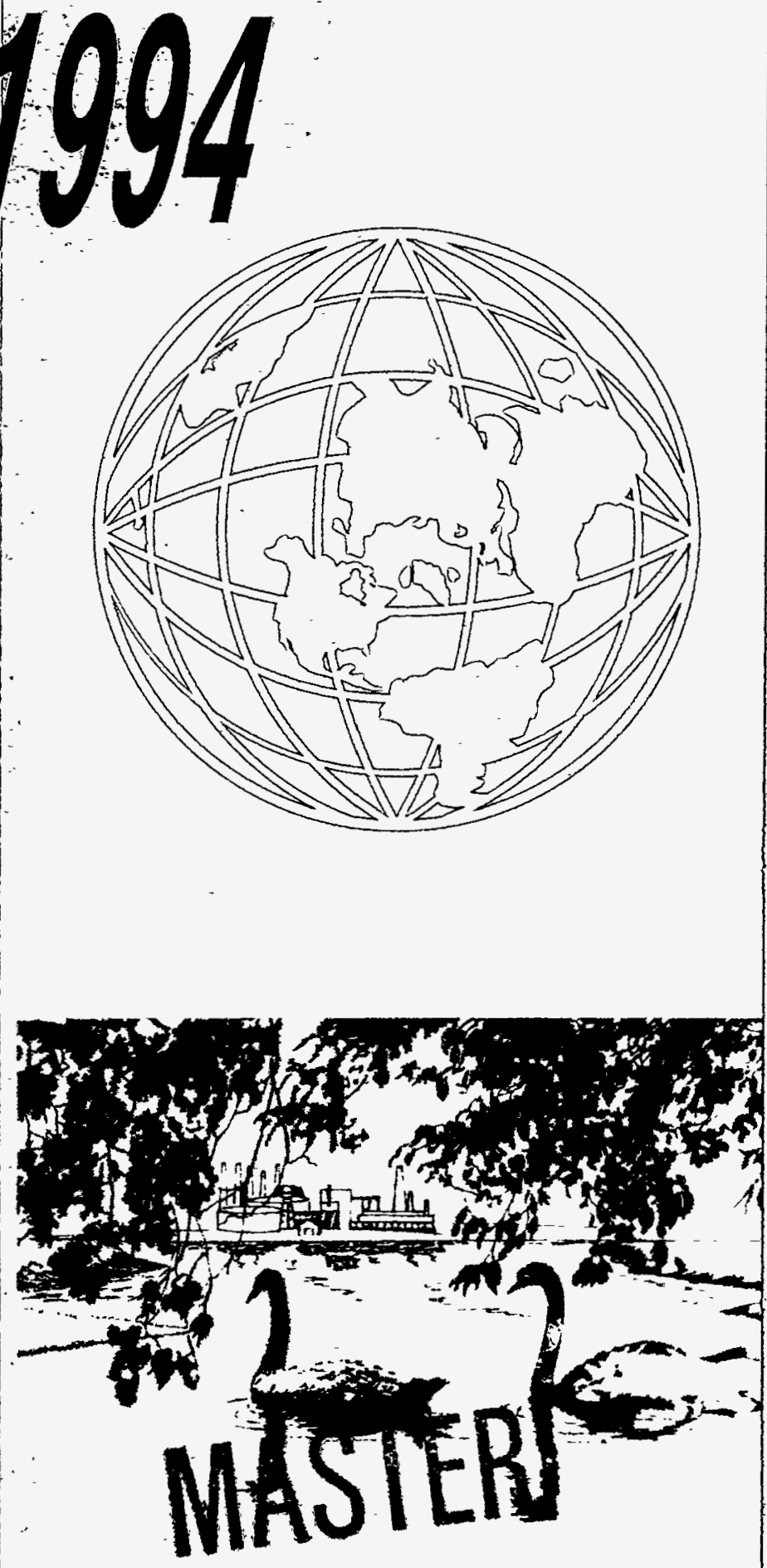
This report has been reproduced directly from the best available copy.

Avaliable to DOE and DOE contractors from the Office of Scientific and Technical Information, P.O. Box 62, Oak Ridge, TN 37831; prices available from (615) 576-8401, FTS 626-8401.

Available to the public from the National Technical Information Service, U.S. Department of Commerce, 5285 Port Royal Rd., Springfield, VA 22161.

This report was prepared as an account of work sponsored by an agency of the United States Government. Neither the United States Government nor any agency thereof, : nor, any of their employees, makes any warranty, express or implied, or assumes any legal liability or responsibility for the accuracy, completeness, or usefulness of any information, apparatus, product, or process disclosed, or represents that its use would not-infringe privately owned rights. Reference herein to any specific commercial product, process, or service by trade name, trademark, manufacturer, or otherwise, does not necessarily-constitute or imply its endorsement, recommendation, or favoring by the United States Government or any agency. thereof. The views and opinions of authors expressed herein do not necessarily. state or reflect those of the United States Government or any agency thereof.

This document was preparod using recycled paper. 


\section{DISCLAIMER}

Portions of this document may be illegible in electronic image products. Images are produced from the best available original document. 


\title{
THE ORNL CHEMICAL TECHNOLOGY DIVISION 1950-1994
}

\author{
Compilers \\ Robert L. Jolley \\ Richard K. Genung \\ L. E. (Gene) McNeese \\ John E. Mrochek \\ Chemical Technology Division
}

Date Published: October 1994

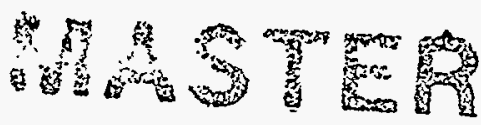

\author{
Prepared by the \\ OAK RIDGE NATIONAL LABORATORY \\ Oak Ridge, Tennessee 37831-6285 \\ managed by \\ MARTIN MARIETTA ENERGY SYSTEMS, INC. \\ for the \\ U.S. DEPARTMENT OF ENERGY \\ under contract DE-AC05-84OR21400
}

DISTRIBUTION OF THIS DOCUMENT IS UNLINITED ${ }_{k}$ SW

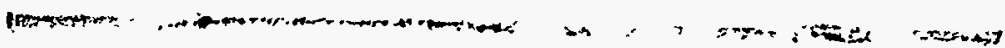




\section{CONTENTS}

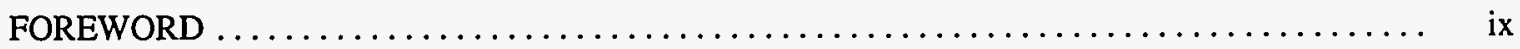

PREFACE. . . . . . . .

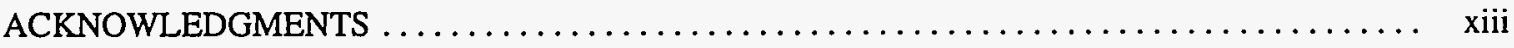

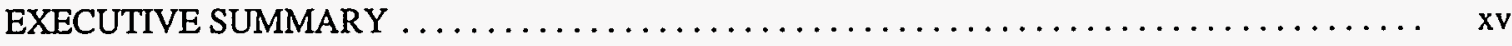

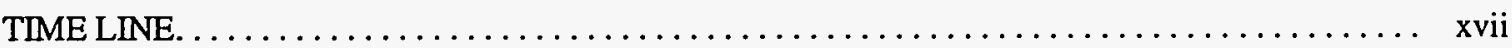

DIRECTORS OF THE CHEMICAL TECHNOLOGY DIVISION $\ldots \ldots \ldots \ldots \ldots \ldots \ldots \ldots \ldots \ldots \ldots$

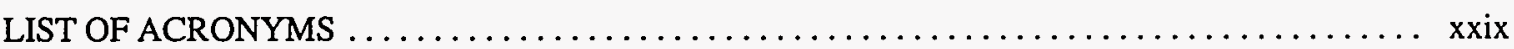

1. THE CURTAIN RISES: PROLOGUE. . . . . . . . . . . . . . . .

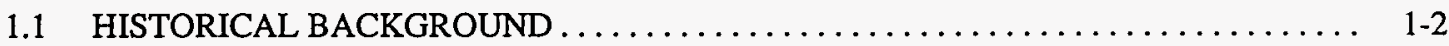

1.1.1 Early Background and the Manhattan Project $\ldots \ldots \ldots \ldots \ldots \ldots \ldots \ldots, 1-2$

1.1.2 The University of Chicago and Early Plutonium Studies............... 1-3

1.1.3 Clinton Laboratories, Du Pont, and a Pilot Plant for Production and

Separation of Plutonium. ........................... 1-3

1.1.4 Successful Plutonium Production and Isolation.................... 1-6

1.1.5 Monsanto Chemical Company, Reactors, and Fuel Processing............. 1-6

1.1.6 The Atomic Energy Commission and the Clinton National Laboratory. . . . . . . . 1-9

1.1.7 The Oak Ridge National Laboratory and Union Carbide................ 1-9

1.2 ESTABLISHMENT OF THE CHEMICAL TECHNOLOGY DIVISION . . . . . . . . . $1-9$

$1.2 .1 \quad$ Background. . . . . . . . . . . . . . .

1.2.2 Management and Organizational Evolution of Chem Tech.............. 1-10

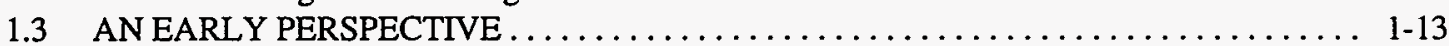

1.3.1 Clinton Laboratories-the War Years, William E. Thompson ............. 1-13

1.3.2 Miles C. Leverett, Director, Technical Division, 1943-1948, ORNL. . . . . . . . . . 1-16

1.4 PERSPECTIVES OF FORMER ORNL DIRECTORS AND

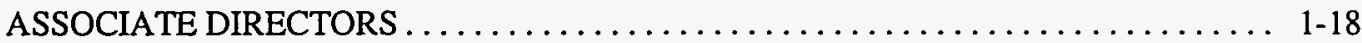

1.4.1 Alvin Weinberg, Director, ORNL, 1954-1974 ................... 1-18

1.4.2 Herman Postma, Director, ORNL, 1974-1989 ..................... 1-19

1.4.3 Donald Trauger, Associate Director, ORNL, 1970-1986................ 1-21

1.4.4 Frank Bruce, Associate Director, ORNL,1970-1978 ................ 1-22

1.5 CHEM TECH LEADERS, PROGRAMS, FACILITIES, AND ACCOMPLISHMENTS . . $1-23$

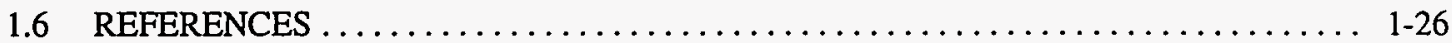

2. THE FORMATIVE YEARS: NUCLEAR FUEL REPROCESSING $\ldots \ldots \ldots \ldots \ldots \ldots \ldots \ldots$

$2.1 \quad$ EARLY HISTORY . . . . . . . . . . . . . . . . . . . .

2.2 OVERVIEW OF NUCLEAR REACTORS .......................... $2-3$

2.3 BRIEF HISTORY OF NUCLEAR FUEL REPROCESSING. $\ldots \ldots \ldots \ldots \ldots \ldots \ldots \ldots$

2.4 THE CHEMICAL TECHNOLOGY DIVISION AT ORNL FROM 1943 TO 1961:

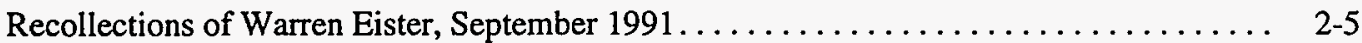

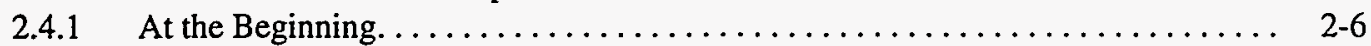

2.4.2 Chem Tech Accomplishments ............................ 2-8

$2.4 .3 \quad$ Changing Times ............................... $2-9$

2.5 THE CHEMICAL TECHNOLOGY DIVISION_A UNIQUE TEAM:

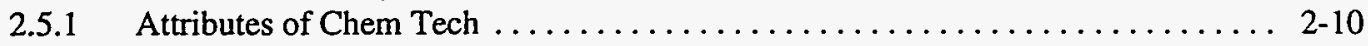


2.5.2 Personal Comments..................................... 2-11

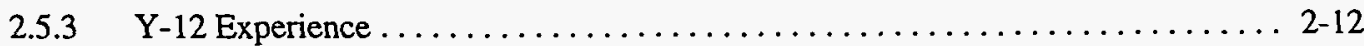

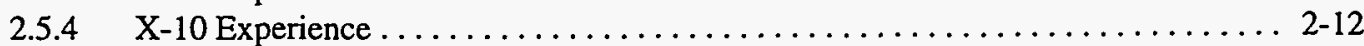

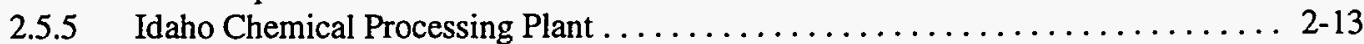

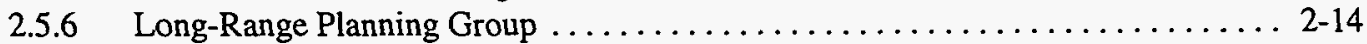

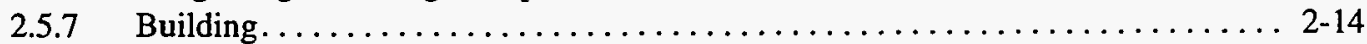

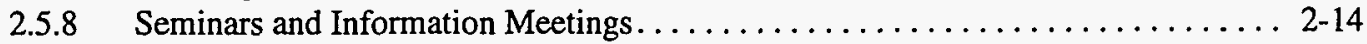

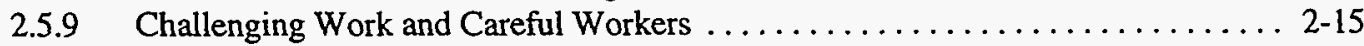

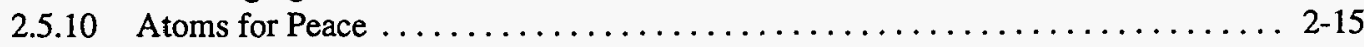

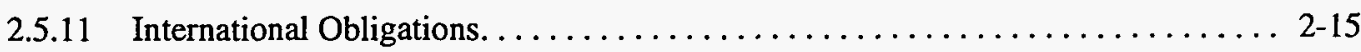

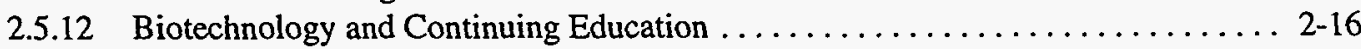

2.5.13 Environmental Impact Statements .......................... 2-17

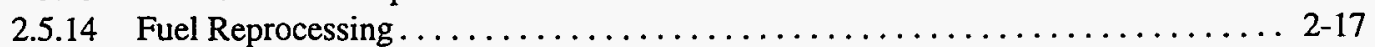

2.5.15 Nuclear Energy ................................. 2-17

2.6 THE CHEMICAL TECHNOLOGY DIVISION, FROM WARTIME SECRECY

TO THE COMING OF THE RUSSIANS: Personal Recollections of

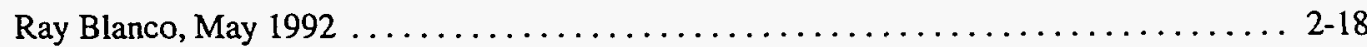

2.7 IDAHO CHEMICAL PROCESSING PLANT-DESIGN,

CONSTRUCTION, AND STARTUP: Personal Recollections of Hal Goeller,

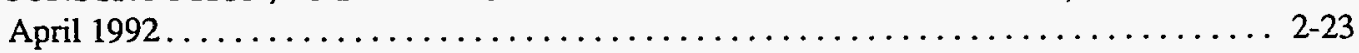

2.8 THE CHEMICAL TECHNOLOGY DIVISION FROM 1953 TO 1991:

Personal Recollections of Ray Wymer ........................ 2-24

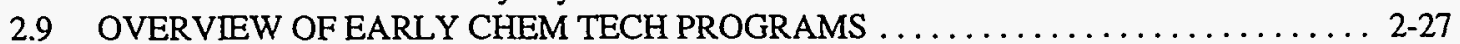

2.10 OVERVIEW OF NUCLEAR REACTOR FUEL REPROCESSING $\ldots \ldots \ldots \ldots \ldots \ldots \ldots$ 2-32

2.10 .1 ORNL Reactor Studies .............................. 2-32

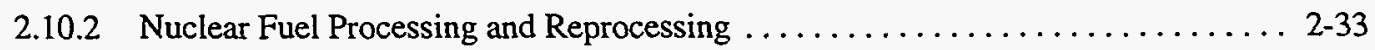

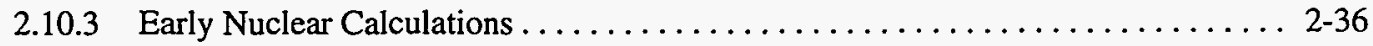

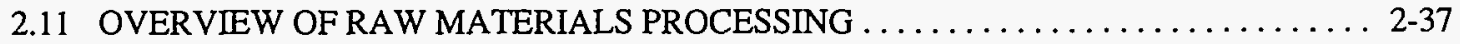

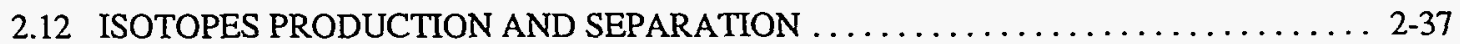

2.13 RECOLLECTIONS OF FRED C. MCCULLOUGH, May $23,1994 \ldots \ldots \ldots \ldots \ldots \ldots$. $2-38$

2.14 REFERENCES ................................................ 2-39

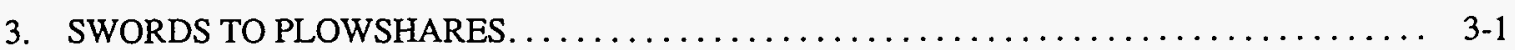

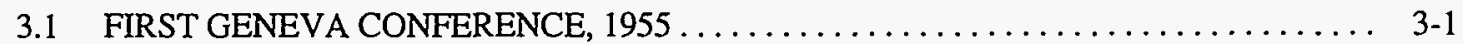

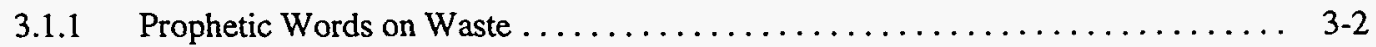

3.1.2 Chem Tech Exhibits and Papers............................. 3-2

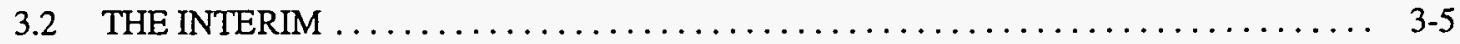

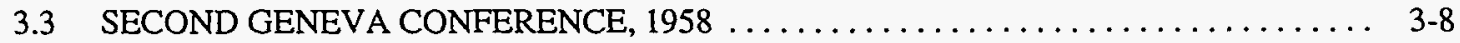

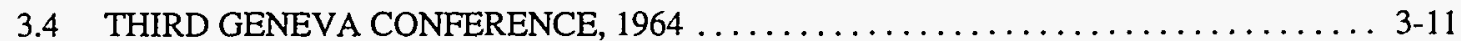

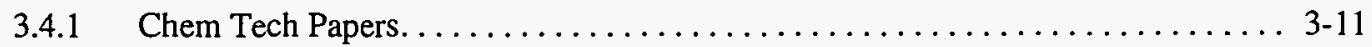

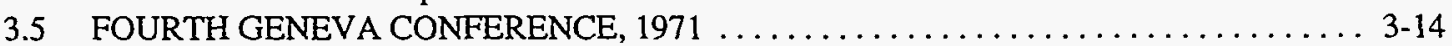

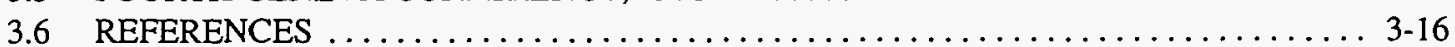

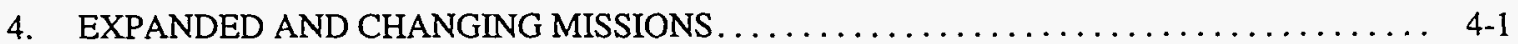

4.1 SEPARATIONS DEVELOPMENT FOR RAW MATERIALS, Charles F. Coleman,

David J. Crouse, and Fred J. Hurst . . . . . . . . . . .

4.2 FUEL PROCESSING: THE SOL-GEL PROCESS, Walt Bond and Paul Haas ......... 4-5

$4.2 .1 \quad$ Early Sol-Gel R\&D . . . . . . . . . . . . .

4.2.2 Angular Sol-Gel Particles ............................ 4.5

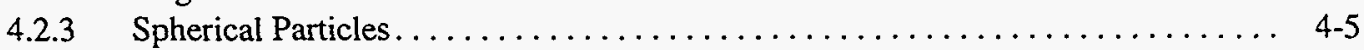

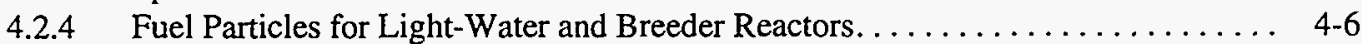

4.2.5 Sol-Gel-Derived Metal Oxides. .............................. 4 4 4

4.3 PLOWSHARE PROGRAM, Walt Bond and Bob Jolley..................... $4-7$ 
4.3.1 Tamalpais Experiment and Field Sampling Tests $\ldots \ldots \ldots \ldots \ldots \ldots \ldots \ldots$ 4-8

4.3.2 Prompt Sampler Studies ................................. 4.9

4.3.3 Project Coach ....................................... 4-11

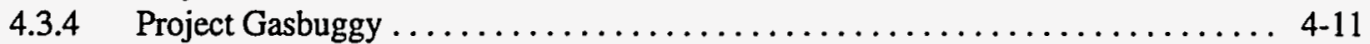

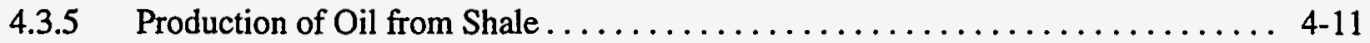

4.3.6 Copper Ores ................................... 411

4.3.7 Magnesium Ores................................. 4-11

4.4 NUCLEAR REGULATORY ASSISTANCE PROGRAMS, Ray Blanco ........... 4-11

4.5 NUCLEAR ANALYSES: THE HISTORY OF THE ORIGEN COMPUTER CODE,

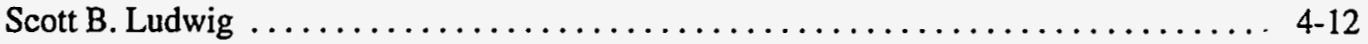

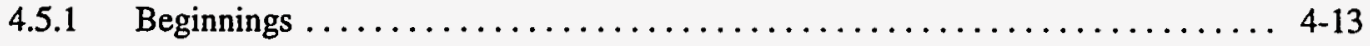

4.5.2 The Players $\ldots \ldots \ldots \ldots \ldots \ldots \ldots \ldots \ldots \ldots \ldots \ldots \ldots \ldots \ldots \ldots .4 .13$

4.5.3 ORIGEN-Supporting the Development of Nuclear Energy in the

United States. . . . . . . . . . . . . . . . .

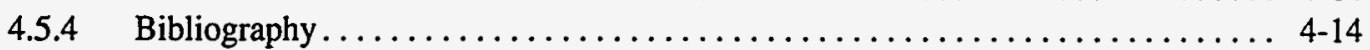

4.6 SPENT FUEL AND RADWASTE DATA BASES, Karl Notz ............... 4-15

4.6.1 Integrated Data Base.................................. 4-15

4.6.2 Characteristics Data Base.............................. 4-16

4.7 TRANSPORTATION STUDIES, Larry B. Shappert $\ldots \ldots \ldots \ldots \ldots \ldots \ldots \ldots \ldots \ldots \ldots \ldots$

4.7.1 Drop Test Facilities ................................ 4-18

4.8 REACTOR SAFETY RESEARCH, BUILDING 4501, R. A. Lorenz ............ 4-18

4.8.1 George Parker and the Manhattan Project ..................... 4-18

4.8.2 Early Fission Product Release Tests . . . . . . . . . . . . . . . . . . . . 4 4-19

4.8.3 The Chemical Development Section ......................... 4-20

4.8.4 Restart of Fission-Product Release Testing . . . . . . . . . . . . $\ldots \ldots \ldots \ldots$ 4-20

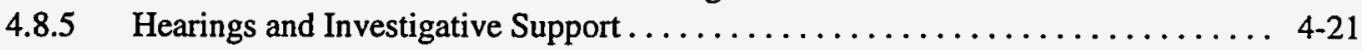

4.8.6 Response to the TMI-2 Accident ........................ 4-21

4.8.7 The President's Commission (Kemeny Commission) on the TMI-2 Accident. . . . 4-22

4.8.8 Cesium, Iodine, and Cesium Iodide Before and After the TMI-2 Accident . . . . . . 4-23

4.8.9 Post-TMI LWR Research................................. 4-24

4.8.10 Fission Product Release from Fuel. ........................ 4-24

4.8.11 Modeling of Fission Product Release at High Temperature .............. 4-24

4.8.12 Severe Accident Sequence Analysis (SASA) . . . . . . . . . . . . . . . 4-27

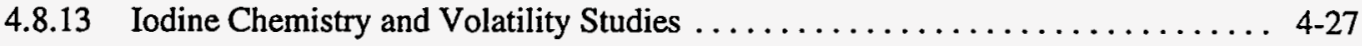

4.8 .14 Aerosol Studies..................................... 4-28

4.8.15 Response to the Chernobyl Reactor Accident ................... 4-28

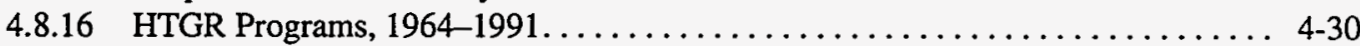

4.9 THE STABLE ISOTOPE ENRICHMENT PROGRAM: THE EARLY YEARS,

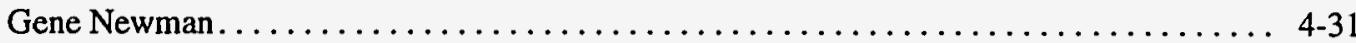

4.10 THE TRANSURANIUM ELEMENT (TRU) PROCESSING PROGRAM IN

THE CHEMICAL TECHNOLOGY DIVISION, John Bigelow . . . . . . . . . . . 4-32

4.10.1 The Early Development Years ............................ 4-34

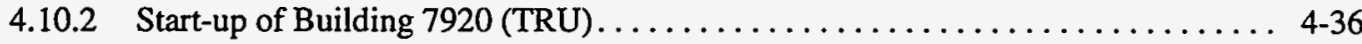

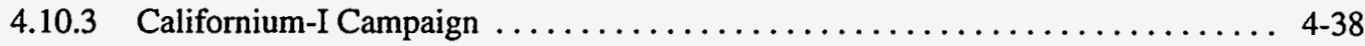

4.10.4 Maturity of the Transuranium Element Processing Program............. 4-40

4.10 .5 Other Spin-offs from the Heavy-Element Program . . . . . . . . . . . . . . 4.40

4.10.6 The Radiochemical Engineering Development Center and Its User Community .. 4-41

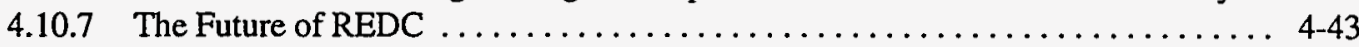

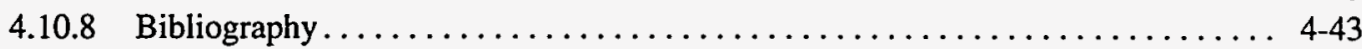

4.11 FLUORIDE VOLATILITY PROCESSING, Bob Jolley, Wilson Pitt,

Lloyd Youngblood, and Bob Hightower . ...................... 4-44

4.12 CHEMICAL PROCESSING FOR THE MOLTEN-SALT REACTOR PROGRAM,

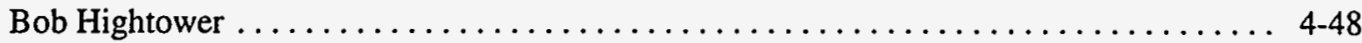


4.13 NUCLEAR WASTE PROGRAMS, Herschel Godbee and Tom Lomenick ........... 4-49

4.14 WASTE MANAGEMENT TECHNOLOGY CENTER, Bob Jolley and Suman Singh . . . . 4 4-53

4.15 THE CEUSP PROJECT: A LARGE-SCALE CONVERSION AND SOLIDIFICATION OF HIGHLY RADIOACTIVE LIQUID WASTE,

C. P. McGinnis, R. A. Jacobus, and L. H. Bell . . . . . . . . . . . . . . . . . . . . 4-57

4.15.1 CEUSP Process and Facility Design........................ 4-58

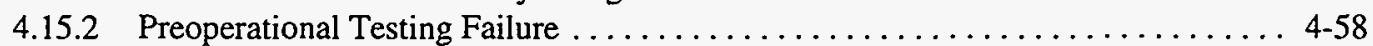

4.15.3 CEUSP Process Operation and Results ..................... 4-59

4.16 CHEMICAL ENGINEERING RESEARCH, John Mrochek, Osmond Basaran,

and $\operatorname{Tim}$ Scott. ...................................... 4-59

4.17 HISTORICAL OVERVIEW OF THE CHEM TECH PILOT PLANT

(BUILDING 3019), J. R. Hightower and R. E. Brooksbank, Sr. . . . . . . . . . . . 4 4-64

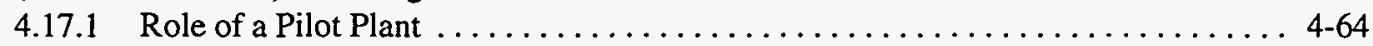

4.17.2 Role of Building 3019 in Reprocessing Technology .................. 4-65

4.17.3 Early History and Operating Philosophy Evaluation of Building $3019 \ldots \ldots \ldots \ldots$. 4-69

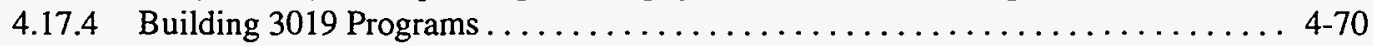

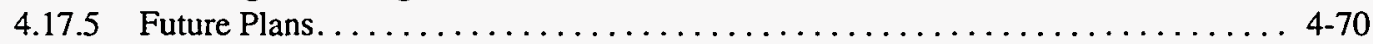

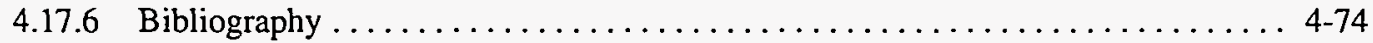

4.18 COAL TECHNOLOGY PROGRAM, Hank Cochran ................... $4-74$

4.19 BIOTECHNOLOGY R\&D IN THE CHEMICAL TECHNOLOGY DIVISION,

John Mrochek, Carl Burtis, Zane Egan, Elias Greenbaum, Bob Jolley,

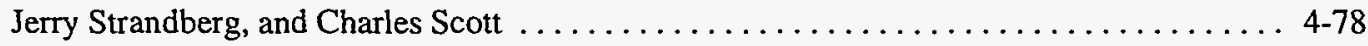

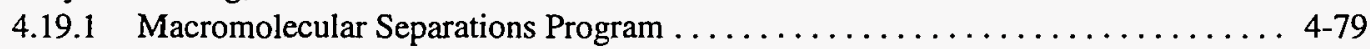

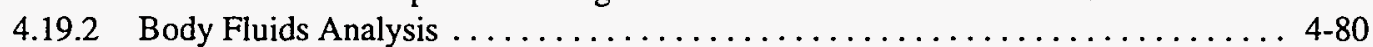

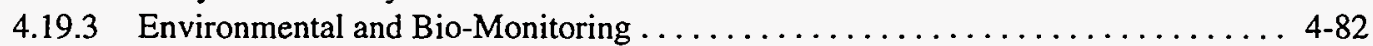

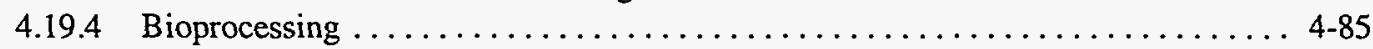

4.20 WATER CHLORINATION AND RELATED PROGRAMS, Bob Jolley ........... 4-91

4.21 BRANCHING OUT-STUDIES ON AGRO-INDUSTRIAL COMPLEXES,

Hal Goeller...................................... 4-93

4.22 ADEQUACY OF NONRENEWABLE RESOURCES, Hal Goeller.............. 4-95

4.23 WORLD ENERGY CONFERENCE-1974 SURVEY OF ENERGY RESOURCES

(1974 Enquete sur les Resources Energetiqes), Hal Goeller................. 4-96

4.24 HISTORY OF THE CHEM TECH REPORTS OFFICE, Martha G. Stewart . . . . . . . . . 4-97

4.25 A MERCIFULLY BRIEF HISTORY OF ENVIRONMENTAL CONTROL

TECHNOLOGY, John Parrott, Jr. . . . . . . . . . . . . . . . . . . . . 4-98

4.26 IMPACT OF OAK RIDGE FACILITIES ON HIGHER EDUCATION, J. J. Perona . . . . . . 4-106

4.27 A BRIEF HISTORY OF THE ISOTOPE RESEARCH MATERIALS LABORATORY,

Kermit B. Campbell ...................................... . . 107

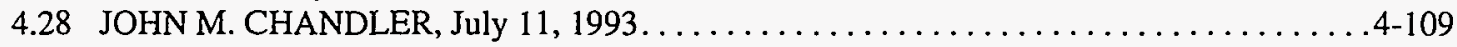

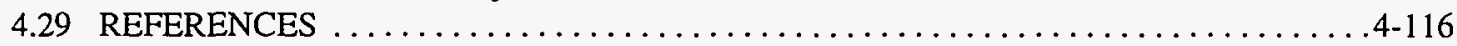

5. POTPOURRI: PERSONAL ANECDOTES, VIGNETTES, THE ST. PATRICK'S DAY

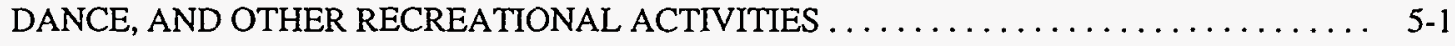

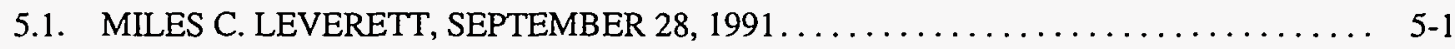

5.2 FRANK E. HARRINGTON, SEPTEMBER $12,1991 \ldots \ldots \ldots \ldots \ldots \ldots \ldots \ldots \ldots \ldots$. 5 .

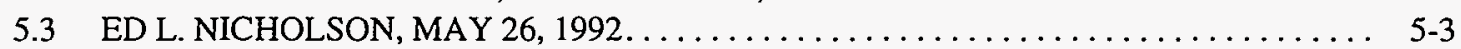

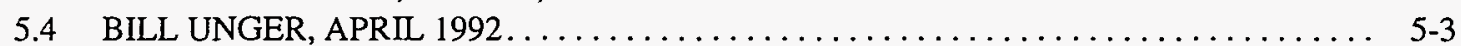

5.5 REX E. LEUZE, SEPTEMBER 1991 AND OCTOBER $1992 \ldots \ldots \ldots \ldots \ldots \ldots \ldots \ldots . .45$

5.6 PRE-CHEM TECH ERA: Thoughts From Clair W. Schersten, November 11, 1992 . . . . 5-6

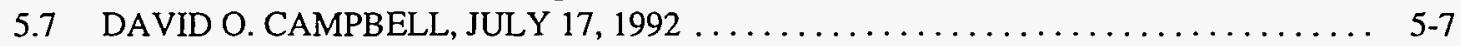

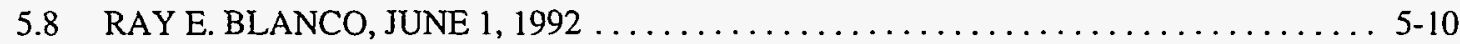

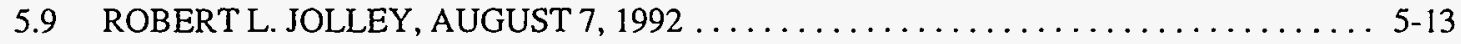


5.10 THE CREMATION OF JIM BRESEE'S R2-XG (A FANTASY):

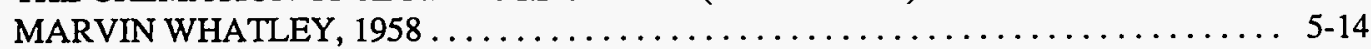

5.11 CAREER OPPORTUNITIES, 1943 , George Parker .................... $5-16$

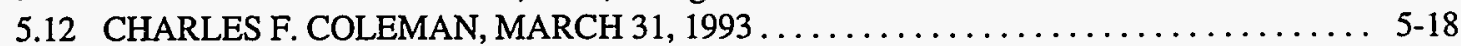

5.13 MY MANHATTAN PROJECT EXPERIENCE, Irwin R. Higgins $\ldots \ldots \ldots \ldots \ldots \ldots .5-20$

5.14 HISTORY OF THE CHEMICAL TECHNOLOGY DIVISION SAINT PATRICK'S

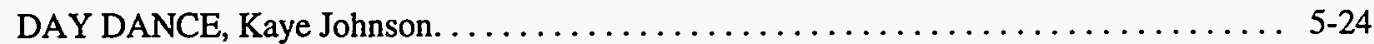

5.15 OTHER RECREATIONAL ACTIVITIES .......................... $5-29$

5.16 THE 25,000-GALLON DEMONSTRATION, July 27,1994 , Joe Perona .......... 5-32

APPENDICES: THE CURTAIN REMAINS OPEN $\ldots \ldots \ldots \ldots \ldots \ldots \ldots \ldots \ldots \ldots \ldots \ldots \ldots \ldots \ldots \ldots \ldots$

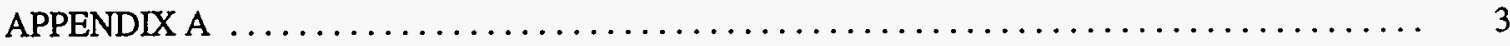

Appendix A.1 Organization Chart for the Metallurgical Project, University of Chicago,

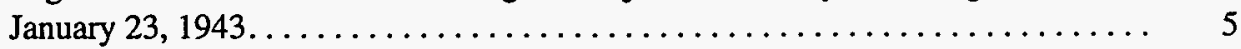

Appendix A.2 Organization Chart for the Technical Division,

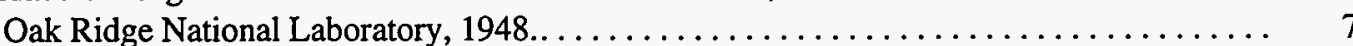

APPENDIX B. ORGANIZATION CHARTS FOR THE CHEMICAL TECHNOLOGY

DIVISION. . . . . . . . . . . . . . . . . . . . . . . . . . . . . . . . . 13

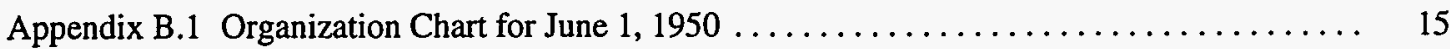

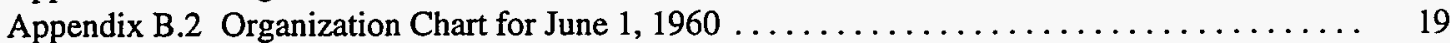

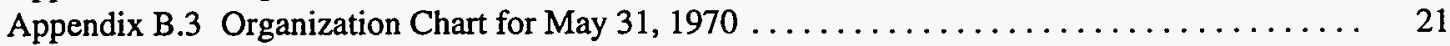

Appendix B.4 Organization Chart for July $1,1981 \ldots \ldots \ldots \ldots \ldots \ldots \ldots \ldots \ldots \ldots \ldots .23$

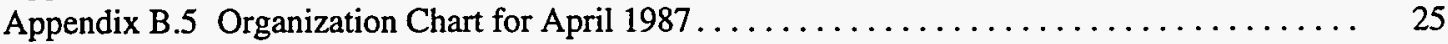

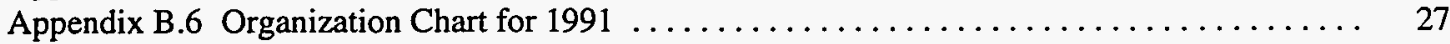

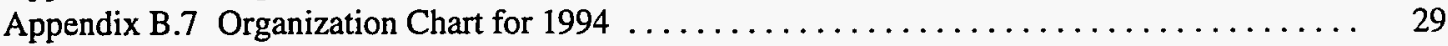

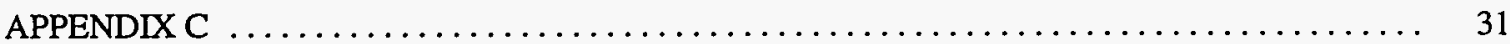

Appendix C.1 A Compilation of Chem Tech Leaders ....................... 33

Appendix C.2 Evolution of Chem Tech Programs ......................... 37

Appendix C.3 An Enumeration of Chem Tech Facilities ....................... 43

APPENDIX D. HONORS AND AWARDS RECEIVED BY CHEMICAL TECHNOLOGY

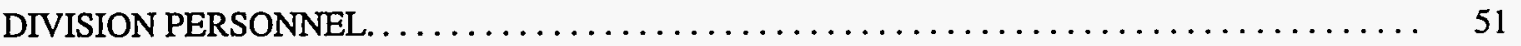

APPENDIX E. PATENTS RECEIVED BY CHEMICAL TECHNOLOGY DIVISION

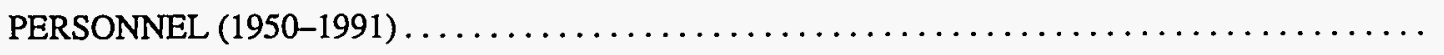


' 


\section{FOREWORD}

The vision of Oak Ridge National Laboratory (ORNL) is to be so well recognized that students in certain fields of science and engineering regard working at ORNL as an essential element in their education. Almost four decades ago, I felt this way when I was hired as a fresh-out-of-school chemical engineer into the Chemical Technology Division that epitomized this vision in chemical engineering and applied chemistry as applied to nuclear development and processing areas. My early career permitted me to hone my engineering skills and to learn a new and fascinating science dealing with nuclear reactors and fuel processing. With increasing maturity, Chem Tech continued to fulfill the vision of ORNL while diversifying into many professional fields, including separations using biological agents, development of medical and clinical chemistry technologies, coal gasification and liquefaction, photosynthetic production of hydrogen, biodenitrification, and fermentation processes. Chem Tech remains a world class organization that is not only engaged in a large number of nationally important fields, but also has consistently provided leadership within the laboratory.

As the recently appointed Division Director, it is my pleasure to dedicate this newly expanded history of the Chemical Technology Division. This history deals not only with early nuclear technology, but also presents many of the recent and widely diverse research and development activities that our division conducts. Chem Tech is indeed at the forefront of nationally and internationally important research and development.

\author{
L. E. McNeese \\ Director \\ Chemical Technology Division \\ Oak Ridge National Laboratory \\ July 1994
}





\section{PREFACE}

A new atomic era arose from the wartime activities in the 1940s. During this era, much public attention was focused on the "big science" programs, physics, and engineering technologies associated with the production of the actual hardware (e.g., weapons and nuclear power reactors). Chemical and engineering separations technologies were some of the main forces behind the success enjoyed by the atomic energy programs. Historians view the technologically successful achievements as a colossal team effort embracing not only physicists and mechanical engineers, chemists and chemical engineers, military personnel and civilians, but also a whole host of workers involved in supply, logistics, and construction.

This document attempts to reconstruct a portion of the role played in that team history by the Chemical Technology Division (Chem Tech) of the Oak Ridge National Laboratory (ORNL). Chem Tech had its early foundations in 1944 in the chemical separations studies conducted at the Clinton Laboratories under the auspices of the Manhattan Project. It actually came into existence as an ORNL division on February 1, 1950.

Chem Tech's early contributions were landmark pioneering studies. Unknown and dimly perceived problems-chemical hazards, radioactivity, and criticality-had to be dealt with. New chemical concepts and processes had to be developed to test the new theories being developed by physicists. New engineering concepts had to be developed and demonstrated in order to build facilities and equipment that had never before been attempted. These achievements were great scientific accomplishments and compare in importance to other major technological landmarks of historical significance. Since their beginnings, ORNL and Chem Tech have been at the cutting edge in research and development associated not only with chemical separations of new radioactive elements, but also with the evolution of new engineering technologies involving peaceful applications of nuclear energy.

In response to changing national objectives, ORNL and Chem Tech have diversified their objectives and missions over time. Today, Chem Tech remains a premier part of ORNL, one of the most respected research laboratories in the world.

This document is a history of the first 44 years of an ORNL division that provided pioneering national leadership in nuclear fuel reprocessing and subsequently continued its prominence as an international center of chemical engineering $R \& D$ relevant to nuclear energy, alternative energy sources, isotope production and distribution, and advanced waste management science and technology.

Richard K. Genung

Director (1988-1994)

Chemical Technology Division

Oak Ridge National Laboratory

May 1993 


\section{ACKNOWLEDGMENTS}

Special acknowledgment must be made to the U.S. Department of Energy (DOE) and previous federal sponsors: the "Manhattan Project," the Atomic Energy Commission (AEC), and the Energy Research and Development Administration (ERDA). Many current and past managers, scientists, and engineers in these organizations have made significant contributions to the research and development (R\&D) and work tasks assigned to Oak Ridge National Laboratory (ORNL) and to the Chemical Technology Division (Chem Tech). Their sponsorship has permitted Chem Tech to receive international acclaim through successful accomplishment of the work reported in this brief history.

Many individuals helped to compile this history of Chem Tech. Special appreciation is given to Alvin Weinberg, Herman Postma, William Thompson, Miles Leverett, Floyd Culler, Frank Bruce, Don Trauger, Clair Schersten, Dave Campbell, Warren Eister, Ray Wymer, Frank Harrington, Rex Leuze, Walt Bond, Paul Haas, Bill Arnold, Charles Coleman, Dave Crouse, Fred Hurst, Bill Unger, Scott Ludwig, Hal Goeller, Ed Nicholson, Ray Blanco, Gene Newman,
John Bigelow, Tom Lomenick, Emory Collins, George Parker, Karl Notz, Herschel Godbee, Kaye Johnson, Arlene Kibbey, Larry Shappert, Martha Stewart, John Parrott, Jr., Joe Perona, Elias Greenbaum, Phil McGinnis, Dick Lorenz, Hank Cochran, Carl Burtis, Charles Scott, Lloyd Youngblood, Bob Hightower, Zane Egan, Jerry Strandberg, Wilson Pitt, Bob Brooksbank, Irwin Higgins, John Chandler, and Kermit Campbell for both written and oral contributions. Because of the diversity of programs and the lengthy time involved (over 40 years), the compilers have presented a selective history.

We appreciate the editorial and publications assistance of Debbie Stevens, Becky Wilker, Larry Davis, Sandi Lyttle, Vicky Rolfe, Nancy Smith, Cheryl Buford, Frances Littleton, and other members of the Publications Division. We also appreciate the assistance of Chem Tech staff members Joy Williams, Brenda Breeden, and Beverly Mathis (Temp Systems, Inc.) for their help in preparing the draft manuscript, Jerry King for designing and preparing the cover, and Martha Stewart for editorial assistance in incorporating revisions and additions. 


\section{EXECUTIVE SUMMARY}

A significant part of the story of atomic energy occurred at the Oak Ridge National Laboratory. In 1943, the Clinton Engineering Works and Clinton Laboratories (code name, $\mathrm{X}-10$ site) were established in an unknown southern Appalachian community now known as Oak Ridge, Tennessee. This facility was later renamed the Oak Ridge National Laboratory (ORNL). The principal mission of the newly created laboratory complex was to develop separations processes for plutonium and uranium on an engineering scale and, thus, to assist in the development of the atomic bomb and, later, peaceful application of atomic energy. The Chemical Technology Division (Chem Tech) and its predecessor, the Technical Division, played major roles in this undertaking.

Throughout the ensuing years, the federal government, under the auspices of the Manhattan Project, the Atomic Energy Commission (AEC), the Energy Research and Development Administration (ERDA), and the U.S. Department of Energy (DOE), has operated ORNL using several contractors such as the University of Chicago, Monsanto Chemical Company, Carbide and Carbon Chemicals Company (a division of the Union Carbide and Carbon Corporation), and the current contractor, Martin Marietta Energy Systems, Inc.

This volume presents a selective history of Chem Tech activities from 1950 to 1994. The formation of Chem Tech is deeply intertwined with chemical separations, especially uranium and plutonium, and nuclear fuel reprocessing. The initial major activities were design of the Idaho Chemical Processing Plant, development of the tributyl phosphate process for the recovery of uranium from Hanford metal waste, development of the Purex process for the recovery of uranium and plutonium from Hanford irradiated metal, development of the RaLa process for separation of barium from fuel units, homogeneous reactor fuel studies, and design/construction of the ORNL Metal Recovery Plant. An important initial and ongoing task was the training of operators for Hanford and Savannah River projects and each of the later commercial endeavors. With diversification of national and ORNL missions, Chem Tech undertook R\&D studies in many areas, including biotechnology; clinical and environmental chemistry; nuclear reactors, safety, and regulations; effective and safe waste management and disposal; computer modeling and informational data bases; isotope production; and environmental control.

Kudos and anecdotes from ORNL leaders and notable scientists provide personal perspectives of the division and its impacts. These include contributions from Miles C. Leverett, Director, ORNL Technical Division, 1943-1948; Alvin Weinberg, Director, ORNL, 1954-1974; Herman Postma, Director, ORNL, 1974-1989; Floyd Culler, Director, Chem Tech, 1953-1965, Assistant Director of ORNL 1965-1970, and Deputy Director of ORNL 1970-1977; Donald Trauger, Associate Director, ORNL, 1970-1986; Frank Bruce, Associate Director, ORNL, 1970-1978; Ray Wymer, Director, Chem Tech, 1983-1988; and several notable Chem Tech scientists and engineers, including Warren Eister, Ray Blanco, Rex Leuze, Frank Harrington, Ed Nicholson, Clair Schersten, and Dave Campbell.

Listings of Chem Tech leaders, its everchanging operational organization, some of its numerous and diverse activities, and several facilities are provided in this document. Many of these Chem Tech activities were of considerable national importance to DOE programs. The changing missions of Chem Tech are encapsulated in the evolving activities. The following time line summarizes the activities and provides an interesting historical perspective. 



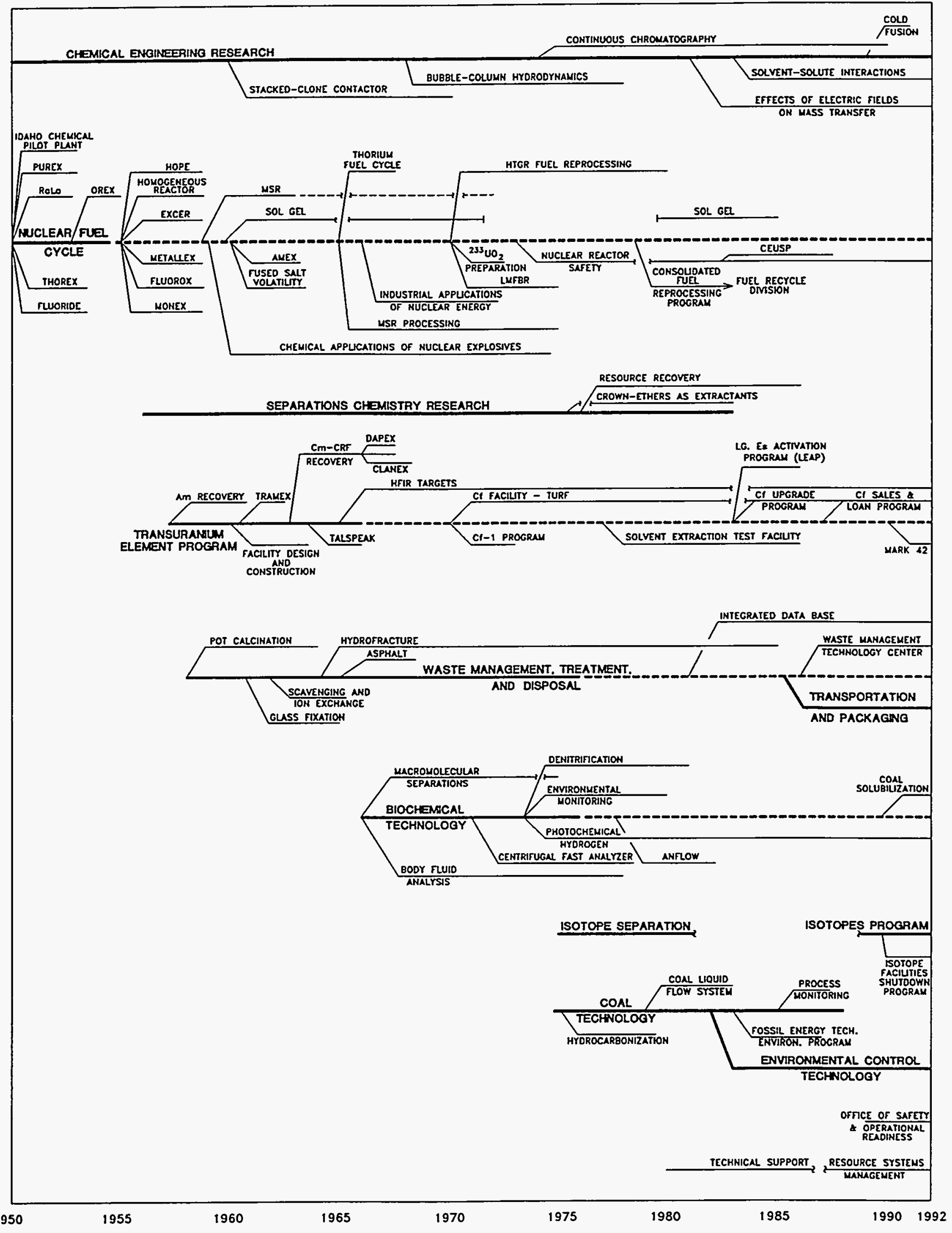

xvii 
, 


\section{DIRECTORS OF THE CHEMICAL TECHNOLOGY DIVISION}





\section{Frank L. Steahly}

Dr. Frank Steahly, a native of Portsmouth, Ohio, was born April 16, 1916. In 1937, he received a BA degree in chemistry from Ohio State University. $\mathrm{He}$ received $\mathrm{MS}$ and $\mathrm{PhD}$ degrees in organic chemistry from the University of Cincinnati in 1939 and 1941, respectively. Frank joined the Clinton Laboratories on September 20, 1943, and became the first director of the ORNL Chemical Technology Division on February 1, 1950. He served in that capacity until May 1953, when he moved to Idaho Falls to become Technical Director for American Cyanamid. In October 1953 Dr. Steahly joined the Research Center at the Union Carbide Charleston, West Virginia, site working in coal hydrogenation. He became associate director in charge of research and development of the Olefins Division of Union Carbide. Dr. Steahly died on May 19, 1967 at the age of 51. [Sources: Carolyn Ladd, Personnel Records, ORNL, October 26, 1992; Clair W. Schersten, St. Albans, West Virginia, personal communication, October 26, 1992; Oak Ridge National Laboratory News 2(3), 1 (February 24, 1950)].

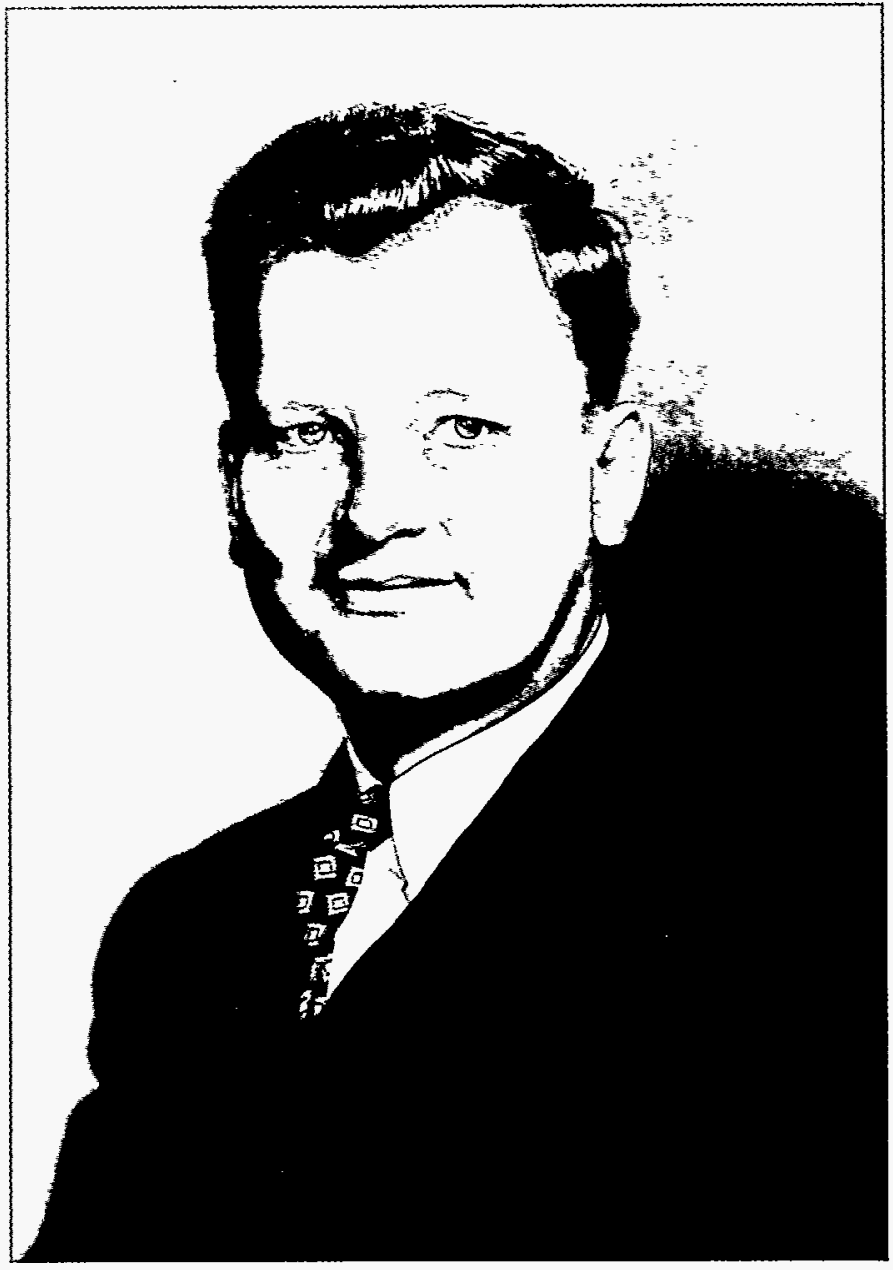




\section{Floyd Leroy Culler}

Mr. Floyd Culler was born

January 5, 1923. In 1943 he received a $B S$ degree in chemical engineering from Johns Hopkins University. After working at Eastman Kodak, Floyd was assigned to work with Tennessee Eastman on the Manhattan Project. He began working at $Y-12$, Clinton Engineering Works in 1945. Floyd transferred to ORNL on May 6, 1947, when he joined the Technical Division. He became the Chemical Technology Division Design Section Chief in 1950. In 1953 Floyd was selected to be the second division director of the Chemical Technology Division, serving in that capacity until 1965.

Subsequently, Floyd served as Assistant Director of ORNL from 1965-1970 and as Deputy Director of ORNL from 1970-1977. He retired from ORNL on December 31, 1977. In 1978 he became President of the Electric Power Research Institute, Palo Alto, California, and is currently President Emeritus of EPRI.

Mr. Culler served on the Board of Directors of the American Nuclear Society and is also active in the American Institute of Chemical Engineers and the National Academy of Engineering. He also served on the National Research Council's Committee on Science and Public Policy and the Committee on Nuclear and Alternative Energy Systems.

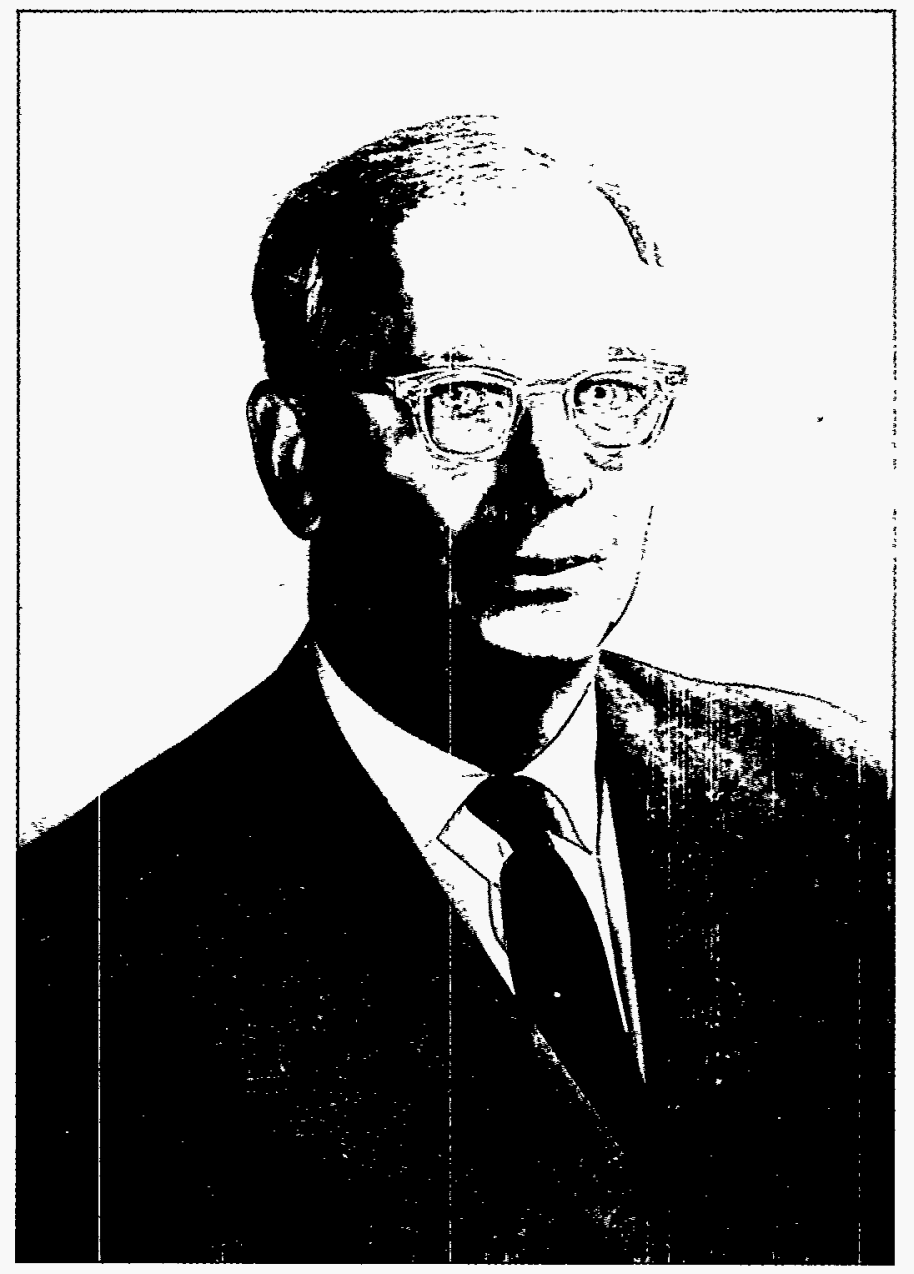

(Sources: Ann Pernet, ed., Who's Who in Atoms, 6th ed., Francis Hodgson Books Limited, Guernsey, British Isles, 1977, p. 111; International Who's Who in Energy and Nuclear Sciences, Longman Group Limited, Harlow, Essex, UK, 1982, pp. 92-93) 


\section{Don Ernest Ferguson}

Mr. Don Ferguson was born

October 12, 1923. In 1944 he received a BS degree in chemical engineering from the Tennessee Technological University in Cookeville. He received a MS degree in mathematics and chemistry from The University of Tennessee in 1950. On July 23, 1946, Don started working at the Clinton Laboratories. He was assigned to the Process Development Section of the Technical Division. Several sections of the Technical Division later became major groups in the Chemical Technology Division. Don became section chief of the Chemical Technology Division Chemical Development Section A in 1955. He was selected to be the third director of the Chemical Technology Division in 1965 and served in that capacity until 1983. In 1983 he became a technical assistant to Don Trauger, Associate Director of ORNL. Don retired from ORNL on January 31, 1987, and died June 6, 1988.

Mr. Ferguson was a charter member of the Transplutonium Program Committee. He received the Glenn T. Seaborg Award and was also presented a Silver Certificate by the American Nuclear Society for his outstanding contributions to the field of nuclear fuel processing. He attended the First, Second, and Third International Conferences on the Peaceful Uses of Atomic Energy, which were held in Geneva, Switzerland, in 1955, 1958, and 1964,

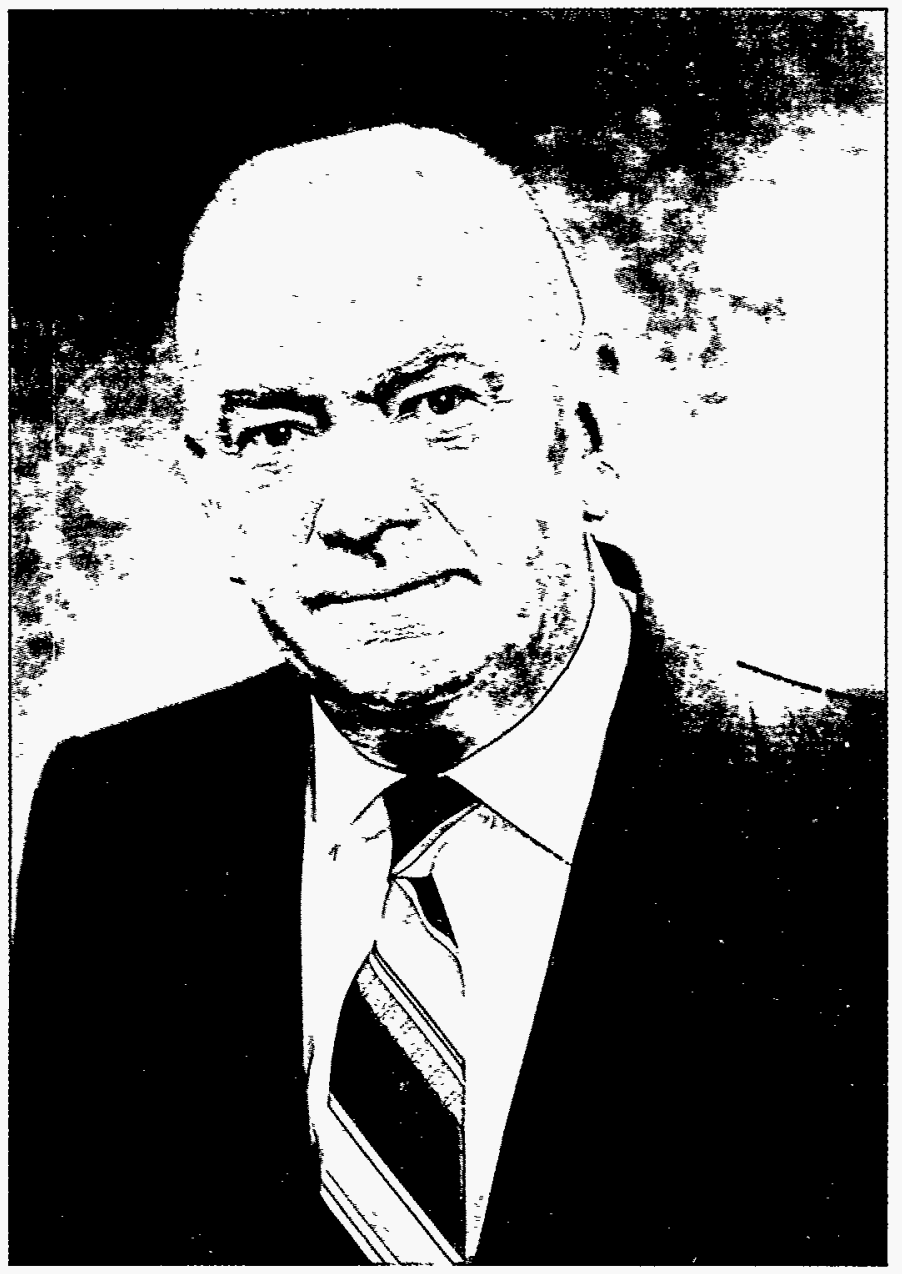

respectively, and contributed to the Fourth International Conference, which was held in 1971. (Sources: Carolyn Ladd, Personnel Records, October 16, 1993; Who's Who in Atoms, Volume I, 5th ed., Harrap Research Publications, London, 1969, p. 462) 


\section{Raymond George Wymer}

Dr. Ray Wymer was born October 1, 1927, in Colton, Ohio. In 1950 he received a BS degree in chemistry from Memphis State College, and in 1953 he received both $\mathrm{MS}$ and $\mathrm{PhD}$ degrees in chemistry from Vanderbilt University in Nashville, Tennessee. He came to work for the Chemical Technology Division in 1953. In 1956 he left ORNL to become an Associate Professor of Chemical Engineering at the Georgia Institute of Technology in Atlanta, Georgia, and served concurrently in several areas as Directors of the Radioisotopes Laboratory, Radiation Effects, and Radiochemical Separations projects. In 1958 he became Chief of Nuclear Chemistry for Industrial Reactor Laboratories, Inc., in Plainsboro, New Jersey. Dr. Wymer returned to the Chemical Technology Division in 1959. In 1964 he became section chief of the Chemical Development Section A. He was selected as the fourth division director of the Chemical Technology Division in 1983 and served in that

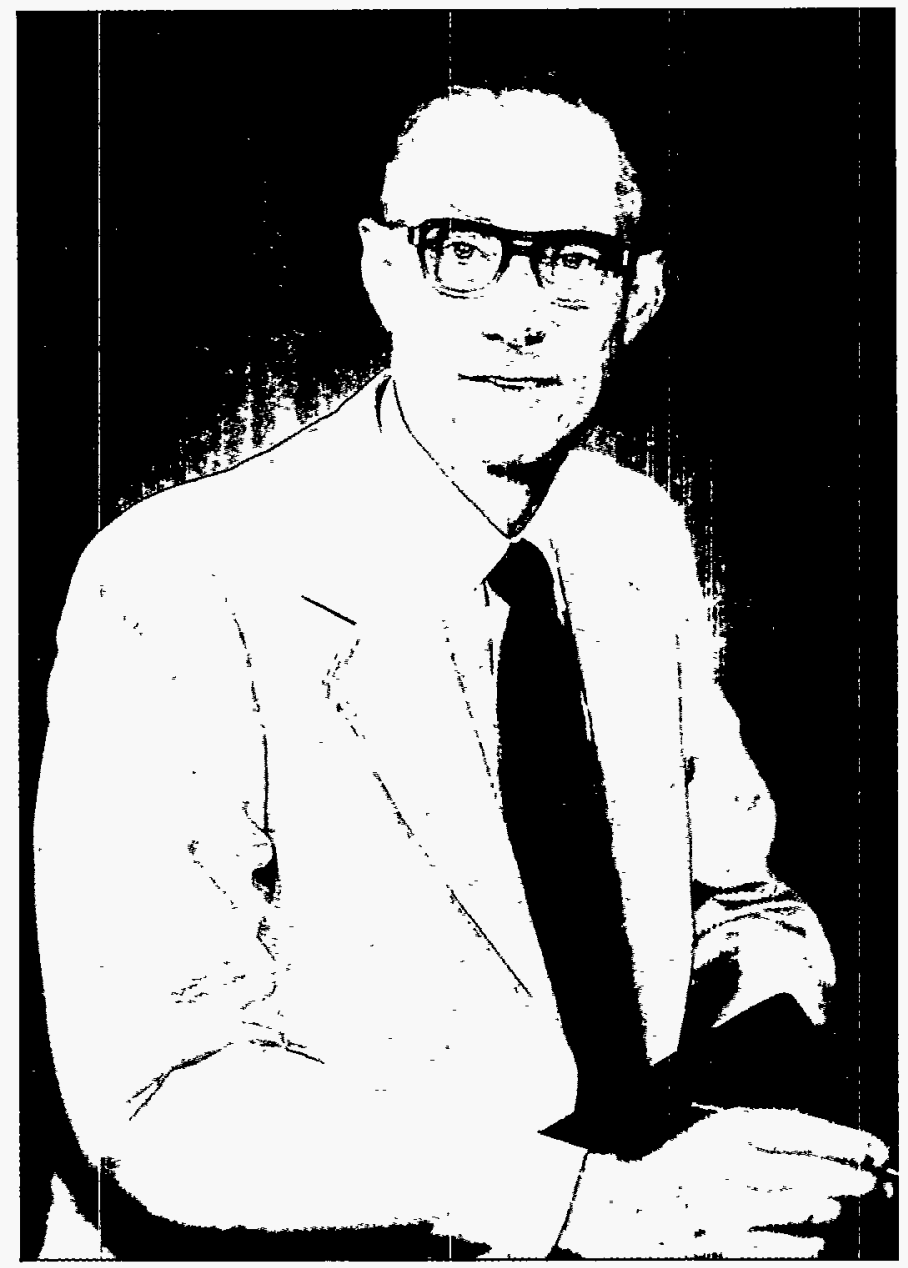
capacity until 1988 .

Dr. Wymer is active in the American Chemical Society, American Institute of Chemists, American Institute of Chemical Engineers, American Nuclear Society, and Sigma Xi. He was a U.S. representative to three International Atomic Energy Agency Panels in Vienna, Austria, and served on the National Research Council's Subcommittee on Nuclear and Radiochemistry and on several National Academy of Science panels. He has served as consultant to the U.S. Department of State on nuclear nonproliferation. He also coauthored several books, including the following:

R. G. Wymer and S. Peterson, Chemistry in Nuclear Technology, Addison-Wesley, 1963.

R. G. Wymer and B. L. Vondra, Light Water Reactor Nuclear Fuel Cycle, CRC Press, Boca Raton, Fla., 1981.

(Sources: Carolyn Ladd, Personnel Records, ORNL, October 26, 1992; Who's Who in Atoms, Volume II, 5th ed., Harrap Research Publications, London, 1969, p. 1712; R. G. Wymer and B. L. Vondra, Light Water Reactor Nuclear Fuel Cycle, CRC Press, Boca Raton, Fla., 1981) 


\section{Richard K. Genung}

Dr. Richard Genung was born September 9, 1947, in Urbana, Illinois. In 1969 he received a $B E$ degree in chemical engineering from Vanderbilt University and $\mathrm{MS}$ and $\mathrm{PhD}$ degrees from The University of Tennessee in 1972 and 1975 , respectively. He did his research as a graduate student investigator at ORNL and, subsequently, came to work in the Chemical Technology Division on July 1, 1975. Programs he worked on at ORNL include Basic Energy Sciences, Conservation and Renewable Energy, Fossil Energy, and Waste Management R\&D. He was part of the ORNL R\&D team that received an IR-100 Award for development of the portable centrifugal fast analyzer. Richard led another engineering team that demonstrated commercial application of the ANFLOW wastewater treatment process in Knoxville and was one of the leaders who helped establish waste management and environmental technology as a major mission for the Chemical Technology Division. He was named Director of the Chemical Technology Division in 1988.

Dr. Genung has held an adjunct faculty position in the Chemical Engineering Department at The University of Tennessee. He has been active in the Knoxville and Oak Ridge Chapters of Alpha Chi

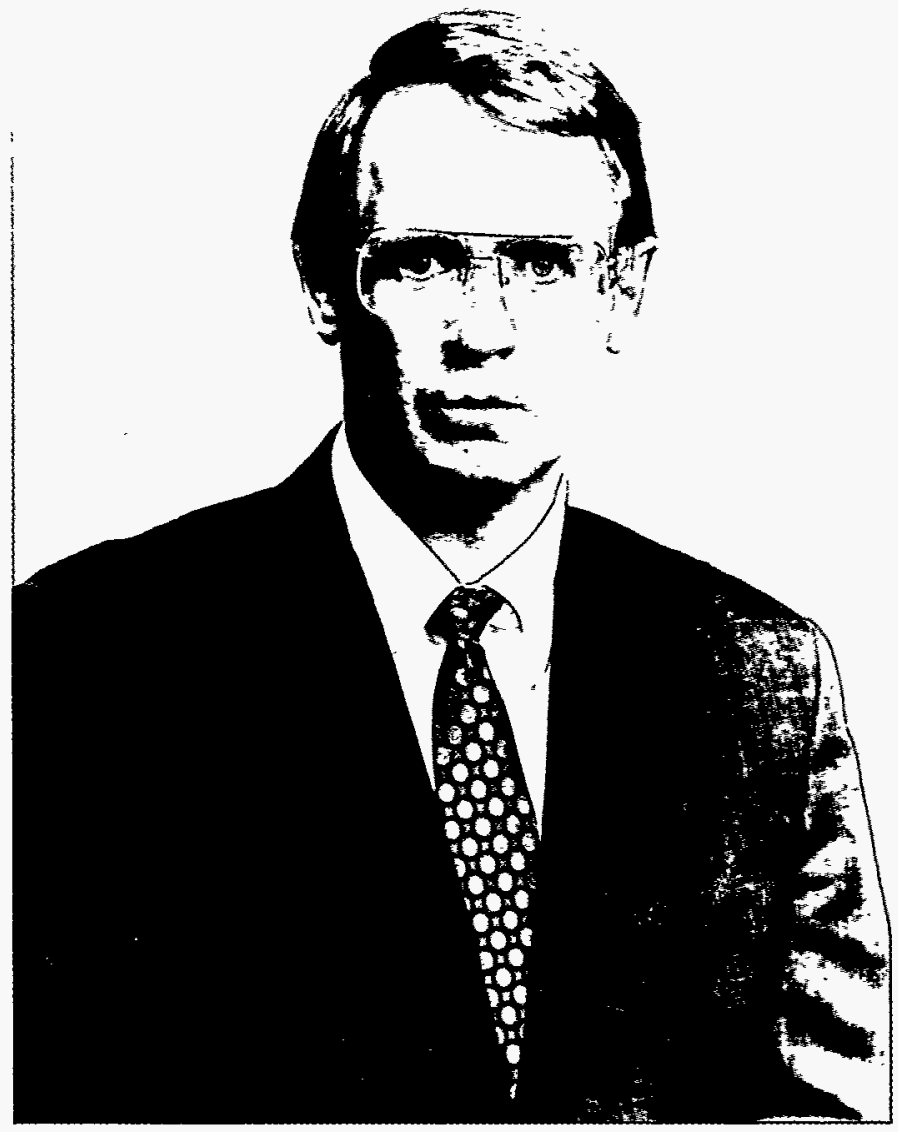

Sigma, Sigma Xi, the American Institute of Chemical Engineers, and the Energy Systems Chapter of the National Management Association. 
Allen G. Croff

Mr. Allen Croff was born July 19 , 1949, in Flint, Michigan. In 1971 he received a BS degree in chemical engineering from Michigan State University, and in 1974 he received the Nuclear Engineering Degree from the Massachusetts Institute of Technology (MIT). After completing a series of graduate studies at MIT, he became a technical staff member in the ORNL Chemical Technology Division in 1974. Concurrent with his position at ORNL, he pursued graduate study at The University of Tennessee, Knoxville, and received the MBA degree in 1981. Initial assignments in the Chemical Technology Division included updating of the ORIGEN code to ORIGEN2, evaluation of options for sequestering ${ }^{14} \mathrm{C}$ from fuel reprocessing plants, and a major study of radionuclide separation and transmutation. Subsequent assignments involved responsibility for Nuclear Regulatory Commission (NRC) waste management programs and led to the

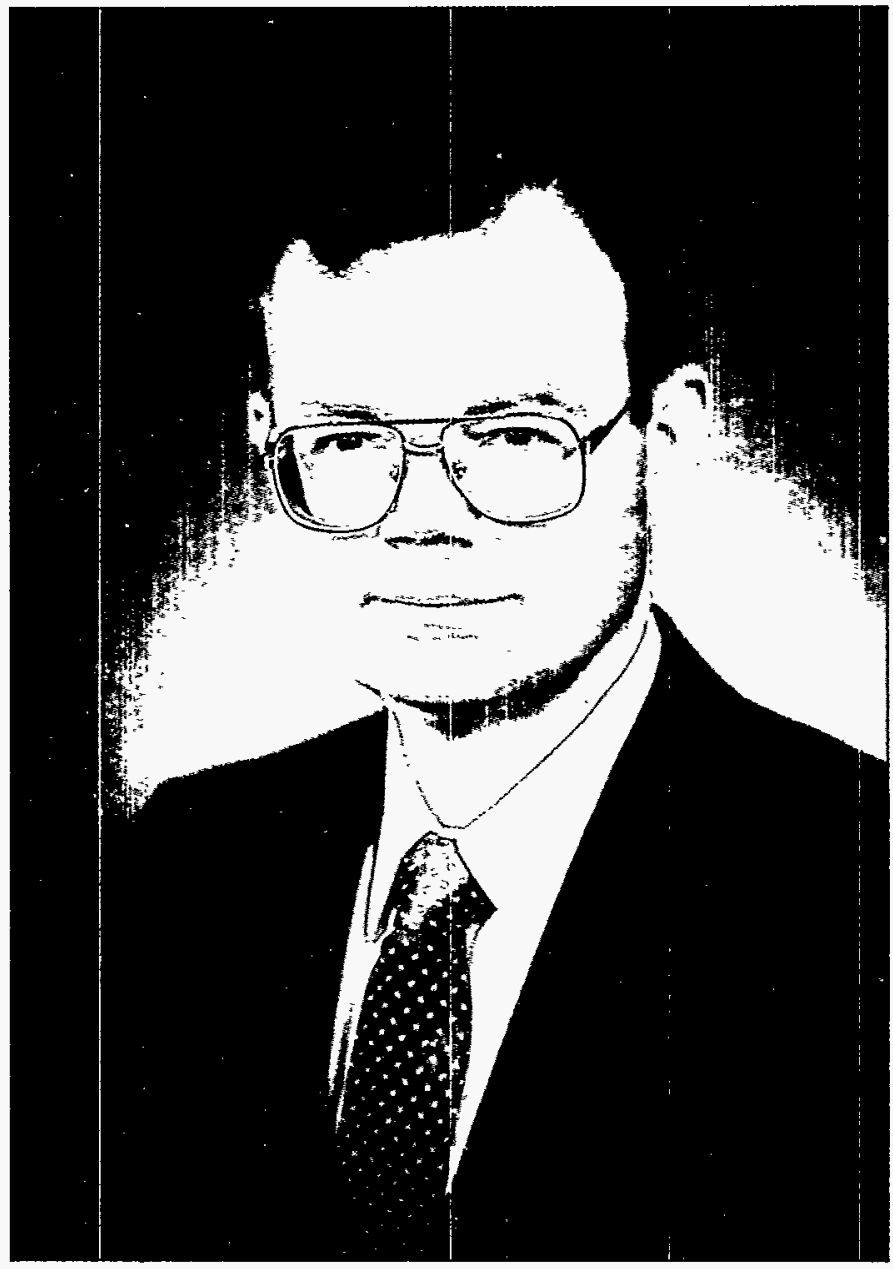
initiation of a long-term ORNL program for DOE's Office of Civilian

Radioactive Waste Management. In $1988 \mathrm{Mr}$. Croff became director of the ORNL Waste Management R\&D programs, encompassing work for all parts of DOE as well as work for non-DOE (except NRC) sponsors. He was then promoted to the position of Associate Director of the Chemical Technology Division in 1988. On March 1, 1994, he was named Acting Director of the Chemical Technology Division.

Mr. Croff is the chairperson of the Nuclear Development Committee of the Organization of Economic Cooperation and Development, Program Committee chair for the International High-Level Radioactive Waste Management Symposium,

chairperson of the National Council on Radiation Protection's Committee on Risk-Based Waste Classification, and a member of an ongoing National Academy of Sciences Panel on Separations Technology and Transmutation Systems.

$\mathrm{He}$ is active in the American Nuclear Society, American Institute of Chemical Engineers, Tau Beta Pi, and Beta Sigma Gamma. He is also the Lead Organizer and serves as the Program Committee chairperson of the International High-Level Radioactive Waste Management Symposium. 


\section{E. (Gene) McNeese}

Gene McNeese was born May 11 , 1935, in Round Rock, Texas. In 1957 he received a BS degree in chemical engineering from Texas Technological University and began work in the Chemical Technology Division in June of that year as a development engineer. In August 1963 he received a MS degree in chemical engineering from The University of Tennessee and subsequently completed the course requirements for $\mathrm{ahD}$ in chemical engineering.

Initially Gene was engaged in development studies related to the processing of nuclear feed materials and reactor fuels by nonaqueous methods. From 1965 through 1972, he directed work on the development of fuel processing methods for molten-salt breeder reactors and directed the Molten-Salt Reactor Program from 1974 to 1976 . From 1976 to 1985 , he managed the Fossil Energy Program. He has held a number of positions at ORNL, including problem leader, group leader,


section head, and Associate Division Director of the Chemical Technology Division, Director of the ORNL

Molten-Salt Reactor Program, Director of the Exxon Nuclear Assistance Program, Director of the ORNL Fossil Energy Program, Associate Director of the ORNL Environmental and Health Protection Division, Director of the ORNL Waste Management and Remedial Action Division, and Deputy Director of the Martin Marietta Energy Systems Waste Management Organization.

Gene is a member of the American Society of Mechanical Engineers (ASME); served on the ASME Advanced Reactor Subcommittee, the American Institute of Chemical Engineers (AIChE), and the American Nuclear Society (ANS); and served as chairman of the Alternative Energy Technologies and Systems Division, Tau $\mathrm{Beta} \mathrm{Pi}$, and Sigma Xi. He has published numerous reports and articles and holds five patents in molten salt and nuclear fuel reprocessing technologies. 



\section{LIST OF ACRONYMS}

$\begin{array}{ll}\text { AACC } & \text { American Association for Clinical Chemistry } \\ \text { ABR } & \text { Advanced Breeder Reactors } \\ \text { AE } & \text { Architect Engineer } \\ \text { AEC } & \text { Atomic Energy Commission } \\ \text { AERE } & \text { Atomic Energy Research Establishment } \\ \text { AGNS } & \text { Allied General Nuclear Services } \\ \text { ALARA } & \text { As Low As Reasonably Achievable } \\ \text { ANFLOW } & \text { Anaerobic Upflow Wastewater Treatment System } \\ \text { ANL } & \text { Argonne National Laboratory } \\ \text { ANP } & \text { Aircraft Nuclear Propulsion } \\ \text { ANS } & \text { Advanced Neutron Source } \\ \text { APD } & \text { Anhydrous Propylene Diamine } \\ \text { ARE } & \text { Aircraft Reactor Experiment } \\ \text { ASFI } & \text { Ashland Synthetic Fuels, Inc. } \\ \text { ASTP } & \text { Army Specialized Training Program } \\ \text { AVLIS } & \text { Advanced Vapor Laser Isotope Separation } \\ \text { BES } & \text { Office of Basic Energy Sciences } \\ \text { BFA } & \text { Body Fluids Analysis } \\ \text { BP } & \text { Bismuth Phosphate Process } \\ \text { BWR } & \text { Boiling-Water Reactor } \\ \text { CANE } & \text { Chemical Application of Nuclear Explosives } \\ \text { CDB } & \text { Characteristics Data Base } \\ \text { CEUSP } & \text { Consolidated Edison Uranium Solidification } \\ \text { CFR } & \text { Consolidated Fuel Reprocessing } \\ \text { CFRP } & \text { Consolidated Fuel Reprocessing Program } \\ \text { CMF } & \text { Containment Mockup Facility } \\ \text { CRADA } & \text { Cooperative Research and Development Agreement } \\ \text { CRBR } & \text { Clinch River Breeder Reactor } \\ \text { CRF } & \text { Curium Recovery Facility } \\ \text { CRI } & \text { Containment Research Installation } \\ \text { CTD } & \text { Chemical Technology Division } \\ \text { CWMO } & \text { Central Waste Management Organization } \\ \text { DAPEX } & \text { Dialkylphosphoric Acid Extraction } \\ \text { DF } & \text { Decontamination Factor } \\ \text { DOE } & \text { Department of Energy } \\ \text { DOT } & \text { Department of Transportation } \\ \text { DSM } & \text { Division of Security Materials } \\ \text { EBR } & \text { Experimental Breeder Reactor } \\ \text { ECT } & \text { Environmental Control Technology } \\ \text { EDS } & \text { Exxon Donor Solvent } \\ \text { EDTA } & \text { Ethylenediamine Tetraacetic Acid } \\ & \text { Experimental Gas-Cooled Reactor } \\ \text { ERCR } & \end{array}$

xxix 


\begin{tabular}{|c|c|}
\hline EPC & Emulsion Phase Contactor \\
\hline EPRI & Electric Power Research Institute \\
\hline ERDA & Energy Research and Development Administration \\
\hline ESA & Environmental and Safety Organization \\
\hline ESD & Environmental Sciences Division \\
\hline FFTF & Fast Flux Test Facility \\
\hline FP & Fission Products \\
\hline FUETAP & Formed Under Elevated Temperature and Pressure \\
\hline FVP & Fluoride Volatility Process \\
\hline GE & General Electric Company \\
\hline GRI & Gas Research Institute \\
\hline HAZWDDD & Hazardous Waste Disposal, Development, and Demonstration \\
\hline HAZWRAP & Hazardous Waste Remedial Action Program \\
\hline $\mathrm{HBCU}$ & Historically Black Colleges and Universities \\
\hline HBU & High Burnup \\
\hline HFIR & High-Flux Isotope Reactor \\
\hline $\mathrm{HI}$ & Horizontal Induction Heated \\
\hline HLW & High-Level Radioactive Waste \\
\hline HPLC & High-Pressure Liquid Chromatography \\
\hline HR & Homogeneous Reactor \\
\hline HRE & Homogeneous Reactor Experiment \\
\hline HRI & Hydrocarbon Research, Inc. \\
\hline HRT & Homogeneous Reactor Test \\
\hline $\mathrm{HT}$ & High Temperature \\
\hline HTGR & High-Temperature Gas-Cooled Reactor \\
\hline IAEA & International Atomic Energy Agency \\
\hline ICPP & Idaho Chemical Processing Plant \\
\hline IDB & Integrated Data Base \\
\hline IEA & Institute of Atomic Energy \\
\hline ILW & Intermediate-Level Radioactive Waste \\
\hline INEL & Idaho National Engineering Laboratory \\
\hline KAPL & Knolls Atomic Power Laboratory \\
\hline LANL & Los Alamos National Laboratory \\
\hline LBU & Low Burnup \\
\hline LEAP & Large Einsteinium Activation Program \\
\hline LITR & Low-Intensity Test Reactor \\
\hline LLNL & Lawrence Livermore National Laboratory \\
\hline LLLW & Low-Level Liquid Waste \\
\hline LLW & Low-Level Radioactive Wastes \\
\hline LLWDDD & Low-Level Waste Disposal, Development, and Demonstration Program \\
\hline LMFBR & Liquid-Metal Fast Breeder Reactor \\
\hline LOFT & Loss of Flow Test \\
\hline LWR & Light-Water Reactor \\
\hline $\mathrm{M} \& \mathrm{C}$ & Metals and Ceramics Division \\
\hline MAN & Molecular Anatomy Program \\
\hline
\end{tabular}




\begin{tabular}{|c|c|}
\hline MEI & Minority Educational Institutes \\
\hline MFO & Mixed Function Oxidase \\
\hline MFRP & Midwest Fuel Recovery Plant \\
\hline MPPF & Multipurpose Processing Plant \\
\hline MRS & Monitored Retrievable Storage Facility \\
\hline MSBR & Molten-Salt Breeder Reactor \\
\hline MSR & Molten Salt Reactor \\
\hline MSRE & Molten Salt Reactor Experiment \\
\hline MTHM & Metric Ton of Heavy Metal \\
\hline MTR & Materials Test Reactor \\
\hline MVST & Melton Valley Storage Tank \\
\hline NASA & National Aeronautics and Space Administration \\
\hline NBS & National Bureau of Standards \\
\hline NCI & National Cancer Institute \\
\hline NFS & Nuclear Fuel Services \\
\hline NIGMS & National Institute of Health General Medical Sciences \\
\hline $\mathrm{NIH}$ & National Institutes of Health \\
\hline NRC & Nuclear Regulatory Commission \\
\hline NRWTP & Nonradiological Wastewater Treatment Plant \\
\hline OCR & Office of Coal Research \\
\hline OCRWM & Office of Civilian Radioactive Waste Management \\
\hline OECD & Organization for Economic Cooperation and Development \\
\hline OEEC & Organization for European Economic Cooperation \\
\hline OHER & Office of Health and Environmental Research \\
\hline OPEC & Organization of Petroleum Exporting Countries \\
\hline ORAU & Oak Ridge Associated Universities \\
\hline ORNL & Oak Ridge National Laboratory \\
\hline ORR & Oak Ridge Reactor \\
\hline ORSRT & Oak Ridge School of Reactor Technology \\
\hline OSRD & Office of Scientific Research and Development \\
\hline OWI & Office of Waste Isolation \\
\hline $\mathrm{P} / \mathrm{T}$ & Partitioning/Transmutation \\
\hline PAH & Polycyclic Aromatic Hydrocarbons \\
\hline PCB & Polychlorinated Biphenyls \\
\hline PDA & Propylene Diamine \\
\hline PETC/METC & Pittsburgh Energy Technology Center/Morgantown Energy Technology Center \\
\hline PNL & Pacific Northwest Laboratory \\
\hline PP\&A & Program Planning and Analysis \\
\hline PWR & Pressurized-Water Reactor \\
\hline PWTP & Process Waste Treatment Plant \\
\hline REDC & Radiochemical Engineering Development Center \\
\hline RSIC & Radiation Shielding Information Center \\
\hline RSSF & Retrievable Surface Storage Facility \\
\hline SARPS & Safety Analyses Report on Packagings \\
\hline SASA & Severe Accident Sequence Analysis \\
\hline
\end{tabular}




$\begin{array}{ll}\text { SERI } & \text { Solar Energy Research Institute } \\ \text { SETF } & \text { Solvent Extraction Test Facility } \\ \text { SP-IX } & \text { Scavenging Precipitation Ion Exchange Process } \\ \text { SRC } & \text { Solvent-Refined Coal } \\ \text { SRS } & \text { Savannah River Site } \\ \text { STF } & \text { Small Test Facility } \\ \text { SWSA } & \text { Solid Waster Storage Area } \\ \text { TAAG } & \text { Technical Assistant and Advisory Group } \\ \text { TAG } & \text { Technical Advisory Group } \\ \text { TBP } & \text { Tributyl Phosphate } \\ \text { TCE } & \text { Trichloroethylene } \\ \text { TFBR } & \text { Tapered Fluidized-Bed Bioreactor } \\ \text { TMI } & \text { Three Mile Island } \\ \text { TNA } & \text { Thermal Neutron Analyses } \\ \text { TRU } & \text { Transuranium Element } \\ \text { TSF } & \text { Tower Shielding Facility } \\ \text { UNOP } & \text { Unit Operations } \\ \text { UT } & \text { The University of Tennessee } \\ \text { WEC } & \text { World Energy Conference } \\ \text { WIPP } & \text { Waste Isolation Pilot Plant } \\ \text { WMTC } & \text { Waste Management Technology Center } \\ \text { WMTSG } & \text { Waste Management Technology Support Group } \\ \text { WPS } & \text { Westinghouse Plasma Systems } \\ & \\ \end{array}$




\title{
1. THE CURTAIN RISES: PROLOGUE
}

\author{
Socrates: Why have you come at this hour, Crito? \\ It must be quite early. \\ Crito: Yes, certainly. \\ Socrates: What is the exact time? \\ Crito: The dawn is breaking.
}

Plato, 428-348 B.C.

Crito

Oak Ridge National Laboratory represents an experiment in scientific and governmental administration which is unique. It is a national institution operated by a private corporation for the purpose of furthering nuclear chemical technology on the one hand and basic research, in conjunction with southern universities, on the other.

Alvin M. Weinberg

History of Oak Ridge National Laboratory

April 8, 1949

Great history often results when people with unequalled talents and experience come together under extraordinary circumstances and are challenged to accomplish seemingly herculean tasks in an impossibly short time period. Such was the birth of atomic energy.

Few events in history can match the collective success story of the development of atomic energy. The management skills and enormous industrial capacity, coupled with an extraordinary pool of scientific and engineering talent, of the United States and the free world, motivated by wartime intensity to protect free society's values, accomplished the production of atomic weapons within a brief three-year period. The dawning of the atomic energy era occurred with the creation of an ultimate weapon of destruction. The creation of the atomic bomb soon evolved into a completely new source of energy production with the peacetime application of atomic energy for electric power production. The complete story involves previously unheard of international scientific and industrial collaboration. A very significant part of that story took place in an unknown southern Appalachian community now known as Oak Ridge, Tennessee. There the Clinton Engineer Works (Clinton Laboratories) was established in 1943. This facility was later to become the Oak Ridge National Laboratory (ORNL). In addition to serving as a pilot plant for plutonium production, a principal mission of the newly created laboratory complex was to develop separations processes and to apply the processes on an engineering scale to separate plutonium and other radioisotopes in sufficient quantities to permit successful development of the atomic bomb and, later, peaceful application of atomic energy. New chemistries had to be explored. New engineering techniques had to be developed. New hazards had to be understood and mitigated. The Chemical Technology Division and its predecessor, the Technical Division, were a central part of this vast undertaking.

This document presents a historical perspective of the Chemical Technology Division from inception to maturity. 


\subsection{HISTORICAL BACKGROUND}

\subsubsection{Early Background and the Manhattan Project}

Known as the Manhattan Project, a massive scientific effort was mobilized in the United States in an effort to develop atomic weapons before our then wartime enemies Germany and Japan could do so. ${ }^{1}$ The project began somewhat tenuously as a response to a thoughtful letter from Albert Einstein to President Franklin Delano Roosevelt. Einstein's letter expressed concern regarding potential development of "extremely powerful bombs" through atomic energy. Thus, in October 1939, President Franklin Delano Roosevelt approved undertaking research on uranium. The President appointed Lyman J. Briggs, Director of the National Bureau of Standards, as head of the Advisory Committee on Uranium, and in early 1940 this committee recommended that the government fund limited research on isotope separation, including research being conducted by Leo Szilard and Enrico Fermi at Columbia University on chain reactions. ${ }^{2}$

In June 1940 Roosevelt created the National Defense Research Committee, chaired by Vannevar Bush, president of the Carnegie Foundation, which reorganized the Uranium Committee to increase scientific representation. Bush appointed E. O. Lawrence, Director of the Radiation Laboratory at the University of California at Berkeley, who also researched electromagnetic production of $235 \mathrm{U}$, as advisor to Briggs. Soon thereafter, the uranium committee funded plutonium research at Berkeley (Glenn T. Seaborg and co-workers) and mass spectograph work at the University of Minnesota (Alfred O. Nier, pioneer in electromagnetic separations). ${ }^{2}$

By executive order on June 28, 1941, Roosevelt created the Office of Scientific Research and Development (OSRD) under the leadership of Bush, who by that time reported directly to the president. The National Defense Research Committee under James Conant, president of Harvard University, became the OSRD Development Section on Uranium (code name S-1). Optimistic British reports catalyzed Bush and Conant, who strengthened S-1 by the addition of Fermi as head of theoretical studies and Harold C. Urey as head of isotope separation and heavy-water research. In late 1941, Bush appointed Eger V. Murphee, a chemical engineer with Standard Oil
Company, as head of a group to oversee and supervise engineering and pilot plant studies; Urey as program chief for diffusion and centrifuge separations, including heavy-water studies; Lawrence as program chief for electromagnetic separations and plutonium studies; and Arthur Compton, from the University of Chicago, as program chief for chain reaction and weapons studies. Bush took responsibility for coordination of engineering and scientific work as well as approval of construction contracts. Roosevelt assigned all uranium policy decisions to the Top Policy Group, which consisted of Bush, Conant, Vice-President Henry A. Wallace, Secretary of War Henry L. Stimson, and Army Chief of Staff George C. Marshall. ${ }^{2}$

During the first half of 1942, Urey directed work at Columbia on gaseous diffusion and centrifuge systems, Lawrence directed work on electromagnetic separations at Berkeley, Compton directed pile experiments and plutonium production efforts at the University of Chicago Metallurgical Laboratory, and Murphree directed studies on ways to move from laboratory experiments to production facilities. Murphree coordinated efforts with E. I. du Pont de Nemours and Company (Du Pont) and the Harshaw Chemical Company for large-scale production of uranium hexafluoride. Compton funded Fermi's pile research at Columbia, Samuel K. Allison's pile experiments at Stagg Field, theoretical work of Eugene Wigner at Princeton and J. Robert Oppenheimer at Berkeley, and moved Seaborg's plutonium work from Berkeley to Chicago. ${ }^{2}$

In early 1942, Bush decided that production planning could wait no longer and arranged for Army participation in the S-1 meetings. Roosevelt had approved the Army's involvement on October 9, 1941. Bush orchestrated transfer of responsibilities for process development, materials procurement, engineering design, and site selections to the Corps of Engineers. By general order on August 13, 1942, the Manhattan Engineer District of the U.S. Army Corps of Engineers was established, and on September 17 the Army appointed Colonel Leslie R. Groves to head the atomic project. Groves was a person of decisive administrative and management skills. Within two days, Groves had secured higher priority ratings for project materials and obtained an excellent production site in Tennessee. ${ }^{2}$ Six days later, he was promoted to the rank of general. This major 
industrial, academic, and military effort became known as the Manhattan Project. ${ }^{2}$

\subsubsection{The University of Chicago and Early Plutonium Studies}

Essential to the wartime endeavor was the production and isolation of the fissionable heavy elements, uranium and the newly discovered plutonium. Using lanthanum fluoride as a carrier, Seaborg, discoverer of plutonium while at Berkeley, and his co-workers isolated a weighable amount of plutonium in August 1942 at the Metallurgical Laboratory, University of Chicago. Other separation processes under investigation at that time by several groups included use of adsorption, solvent extraction, volatility, and peroxide oxidation. The awesome challenge assigned to Seaborg and his co-workers was to develop plutonium separations processes that could be scaled up more than a billion-fold from laboratory experiments to processes capable of being used in production plants. ${ }^{1}$

Du Pont agreed to accept responsibility for the design and development of a plutonium production plant and, consequently, accepted responsibility for the design and construction of a plutonium separations pilot plant at the Clinton Engineering Works in Tennessee. Although the pilot plant was to be operated by the University of Chicago Metallurgical Laboratory, Du Pont was expected to train personnel at the pilot plant for later assignment to the production facilities scheduled for construction at Hanford. ${ }^{2}$ The industrial management capability of Du Pont contributed very significantly to the success of the atomic projects. $^{3}$

Seaborg, of the Metallurgical Laboratory, and Charles M. Cooper, of Du Pont, and their respective staffs, collaborated on establishing processes for use in plutonium separation facilities. Although Seaborg had initially favored the lanthanum fluoride carrier process, he had more recently studied phosphate processes. Research by Stanley G. Thompson indicated that bismuth phosphate as a carrier retained greater than $98 \%$ plutonium. Thus, at least two effective separations processes at the microchemistry level were available for consideration for use in the production facilities. ${ }^{2}$

\subsubsection{Clinton Laboratories, Du Pont, and a Pilot Plant for Production and Separation of Plutonium}

By late 1942 the decision was made to use the bismuth phosphate method for plutonium separations. ${ }^{2}$ The bench-scale (actually microchemistry) process was developed principally by Seaborg and his co-workers at the Metallurgical Laboratory, University of Chicago. ${ }^{1}$ In early 1943 , Du Pont began construction of the chemical separation plant in Oak Ridge, while Seaborg continued refining the bismuth phosphate method. Du Pont broke ground for the $\mathrm{X}-10$ site in February 1943. The X-10 facilities would include the air-cooled graphite pile or reactor for producing plutonium, a pilot plant for isolating plutonium, and some support facilities. The chemical separations pilot plant construction started in March, and the reactor went critical and began operation November 4, $1943 .^{2}$ Several photographs of the early construction progress on the major facilities are depicted in Figs. 1.1 to 1.4.

The Metallurgical Laboratory, University of Chicago, was chosen by the Manhattan District of the U.S. Army Corps of Engineers as the contractor to manage the Clinton Laboratories. ${ }^{4}$ Although in essence the entire facility was considered a pilot plant in plutonium production and separations, among the work tasks assigned to the University of Chicago were the following: 1

- Conduct the necessary studies and develop a workable and dependable method for chemically separating and isolating plutonium from uranium metal and from fission products.

- Develop a process for recovering the partially depleted uranium metal that had been irradiated and used in the development work at the pilot plant.

- Develop methods for producing certain other radioisotopes, such as barium and lanthanum, for use at other Manhattán project sites.

These work tasks became the foundation from which the Chemical Technology Division later arose.

The first major facility constructed at Clinton Laboratories, X-10 site, was the graphite reactor for irradiating uranium and producing plutonium. The second major facility constructed was the pilot plant (now Building 3019 but formerly Building 205), where the process for separating and 


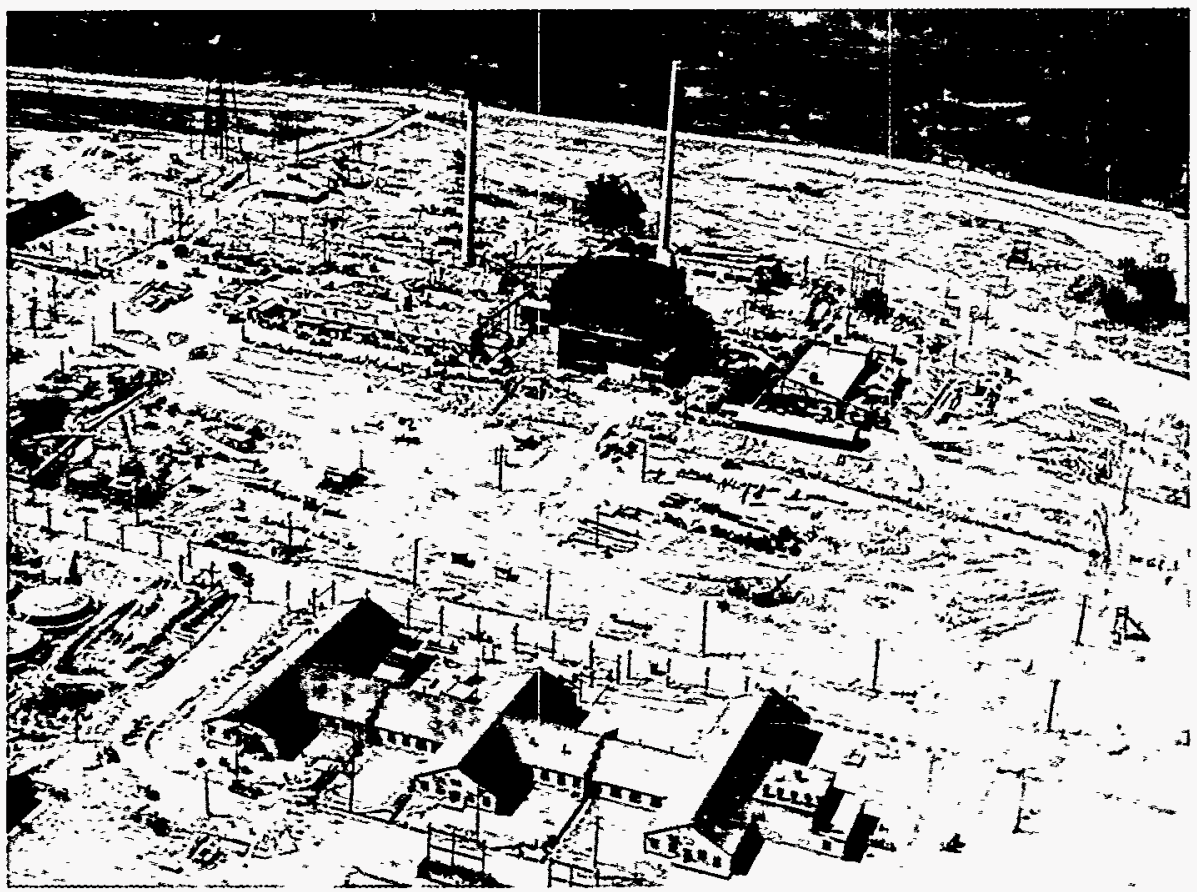

Fig. 1.1. Clinton Engineer Works, X-10 site, about September 1943, looking northwest from the main research building (706-A) in the foreground toward the graphite reactor (large dark building at upper center) and chemical separations pilot plant (to the left of the graphite reactor). Note the cells or cubicles with thick, heavy concrete shielding plainly visible in the roofless pilot plant under construction. Note also the tall stack behind the graphite reactor to release airflow used to cool the reactor and the tall stack (with the top painted black) to release exhaust gases from chemical processing in the pilot plant.

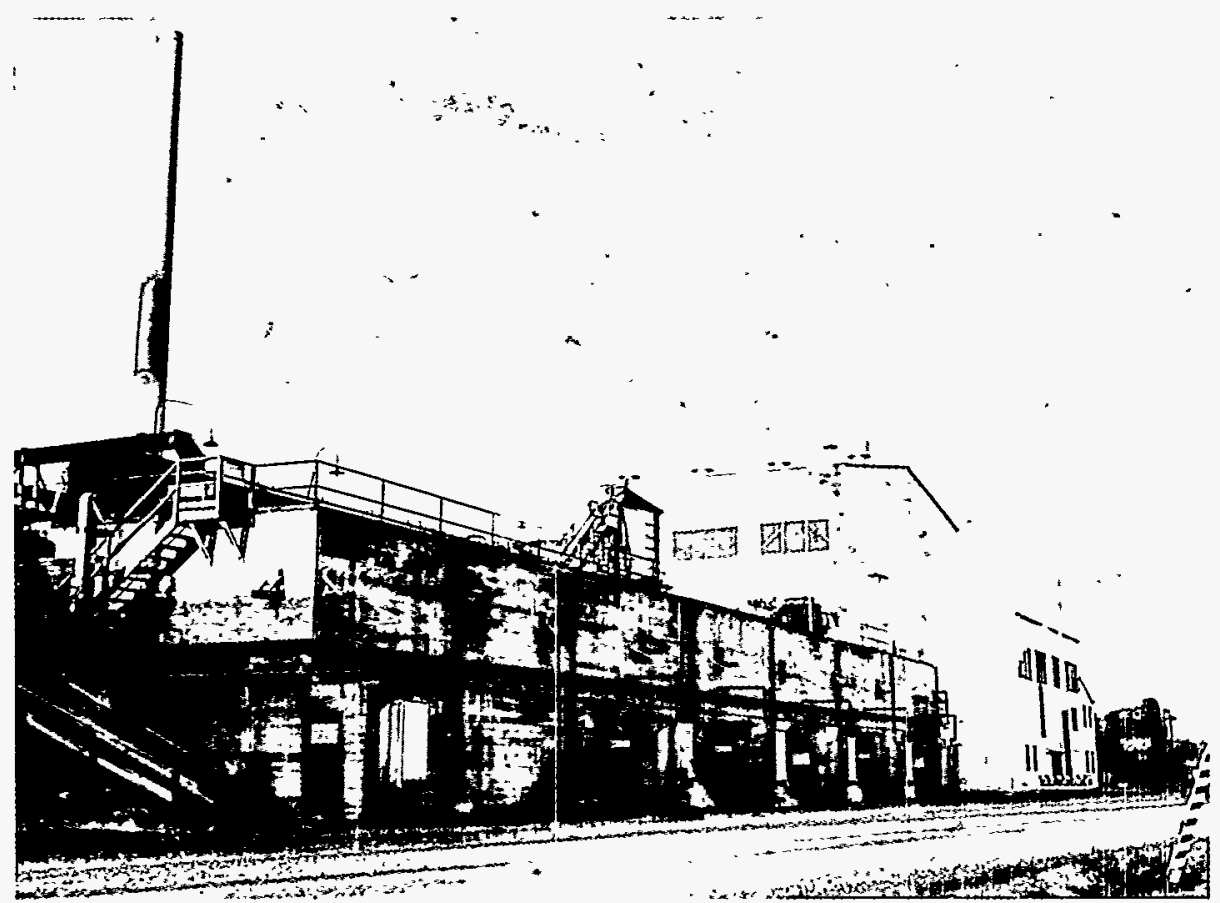

Fig. 1.2. Chemical separations pilot plant, late 1944, with graphite reactor in background. 


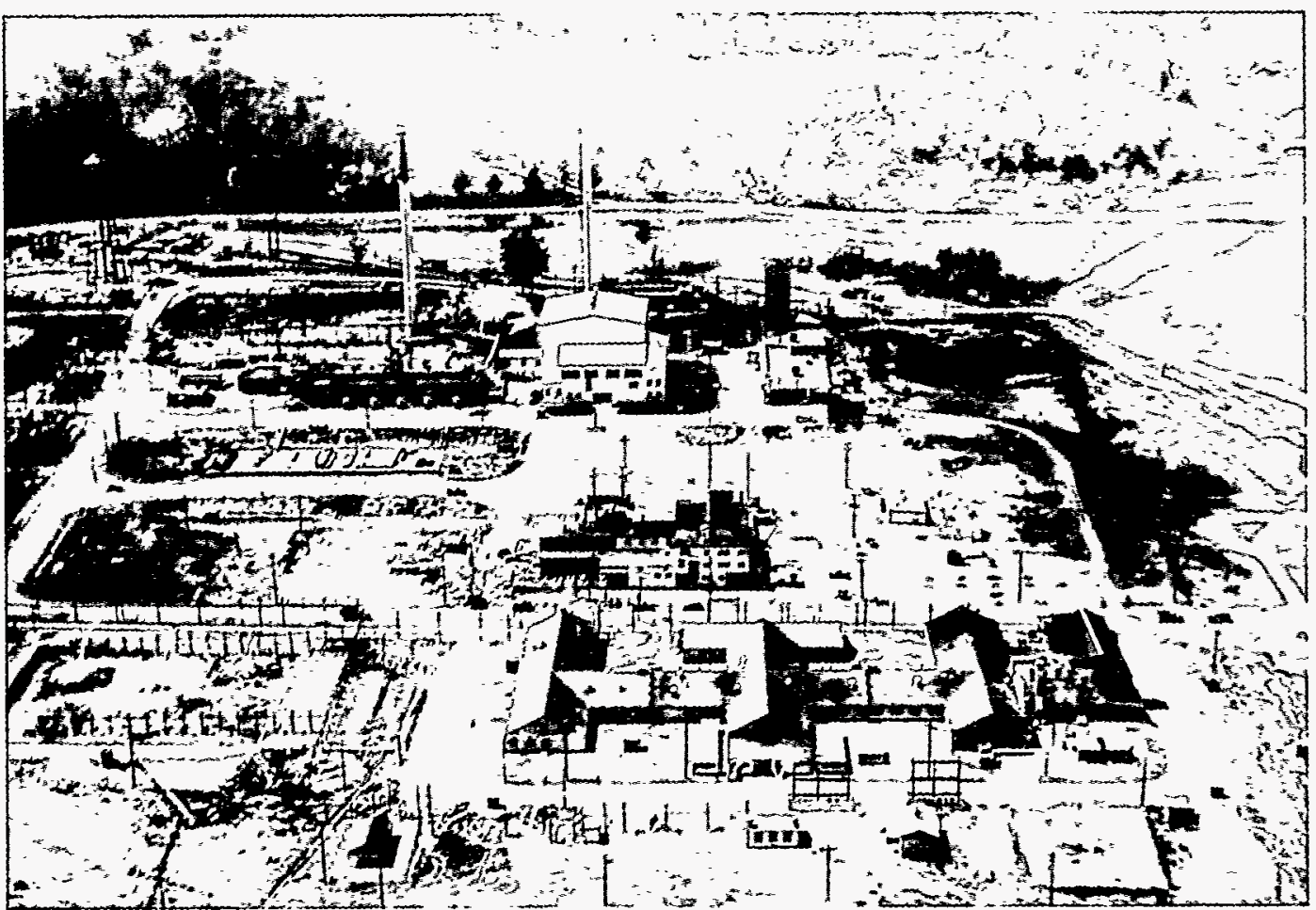

Fig. 1.3. Clinton Laboratories in May 1946, now X-10 site, looking northwest from the main research building (706-A) in the foreground toward the graphite reactor (large building at upper center now painted a metallic silver) and separations pilot plant (to the left of the graphite reactor).

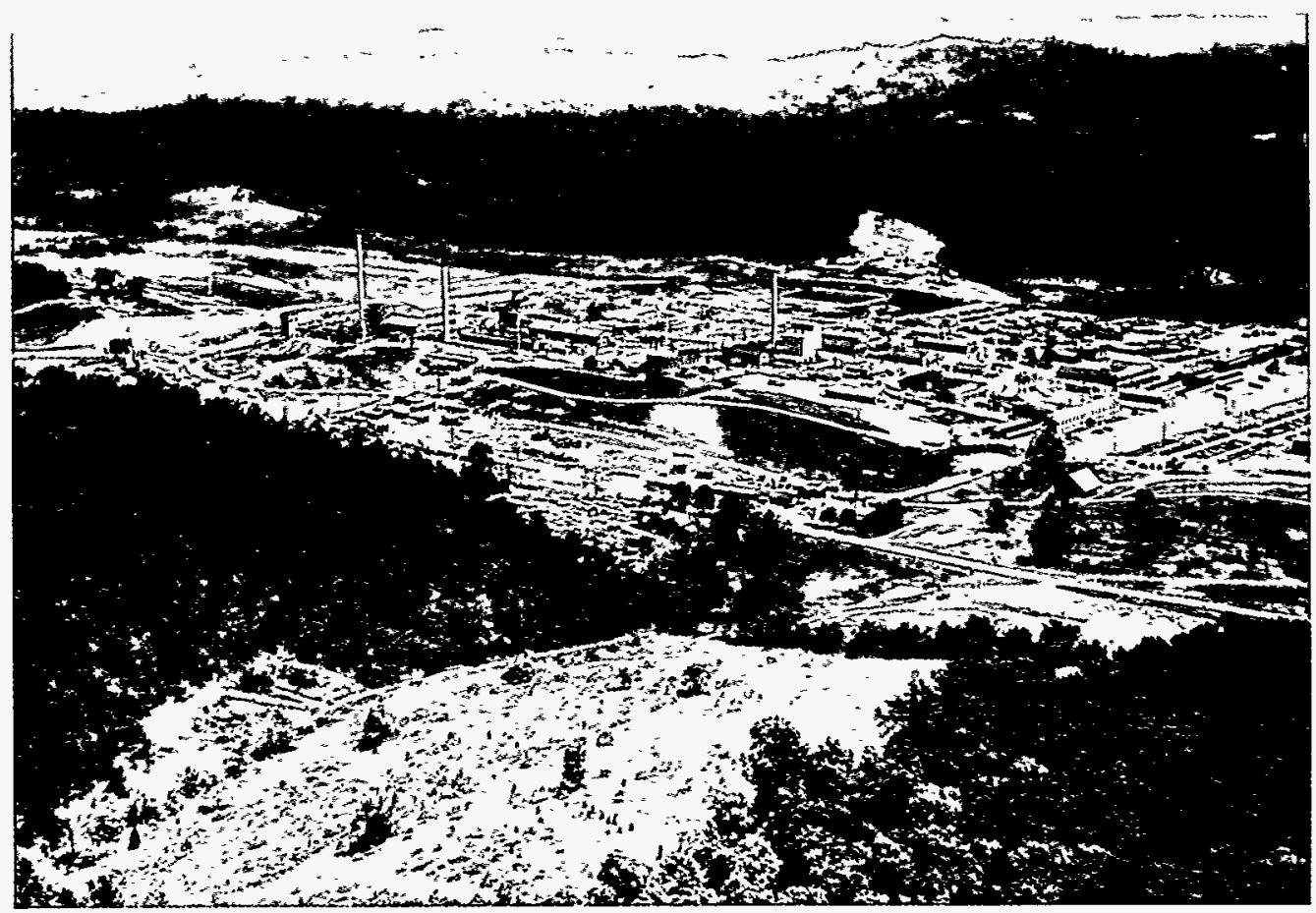

Fig. 1.4. An overall view, May 1947, of the Clinton National Laboratory (X-10 site) looking southeast showing the surrounding topography. 
purifying plutonium was to be tested (Figs. 1.5 and 1.6). The chemical operations would involve handling radioactive materials on a scale never before attempted. The design and construction of the pilot plant were engineering achievements of the first magnitude. All equipment for the operations was enclosed in "hot cells" that were surrounded by $5 \mathrm{ft}$ of concrete. Remote control was required for even the simplest operations. Most processing was accomplished by workers who could not even see the operation they were performing. Television, a relatively new development itself, was used at one critical stage of the process to allow observations of the operation. Performance of the equipment was determined by monitoring a bank of instruments in the operating gallery (Fig. 1.7). ${ }^{1}$ Processing wastes were accumulated in nearby storage tanks (Fig. 1.8).

Operational testing of the pilot plant started in December 1943 using uranium irradiated by the cyclotron at Washington University in St. Louis. The low content of fission products and radioactivity associated with this irradiated uranium sample permitted relatively safe shakedown testing and troubleshooting. From the initial test runs, a few milligrams of plutonium were produced and shipped on December 30, 1943, to the University of Chicago for research use. Following the initial test runs, the system was further tested with uranium irradiated at low power in the graphite reactor. Processing of uranium irradiated at full power rapidly followed. ${ }^{1}$

\subsubsection{Successful Plutonium Production and Isolation}

Chemical separations of plutonium from the irradiated aluminum-clad uranium metal using the bismuth phosphate process at Clinton Laboratories, $\mathrm{X}-10$, were so successful that plutonium needed for research was being shipped to Los Alamos by early summer $1944 .^{2}$ By the end of January 1944 the chemical pilot plant was processing 0.3 ton per day of irradiated uranium and had produced several grams of plutonium by March 1944. ${ }^{1}$ The Hanford chemical separations plants, completed in late 1944 and early 1945, were built based upon experience developed in the chemical pilot plant at Oak Ridge. The Oak Ridge pilot plant reported that bismuth phosphate was not suitable for the final plutonium concentration process at Hanford. ${ }^{2}$ The final concentration process (known as the cross-over cycle) at the pilot plant went to lanthanum fluoride precipitation, and peroxide precipitation was used to produce $\mathrm{PuO}_{2}$ as the final product. ${ }^{3}$ Accordingly, the Hanford separations plants adopted the lanthanum fluoride as the final concentration process as well. ${ }^{2}$

The Oak Ridge National Laboratory had its beginning in the pilot plant Clinton Laboratories designed to test plutonium production and separation methods. The need for purified fissionable material was urgent in order to accomplish the R\&D necessary to produce a bomb. Clinton Laboratories supplied the first gram quantities of plutonium for such research and also had wartime responsibility for producing thousand-curie amounts of the radioisotopes barium and lanthanum that were used at Los Alamos for research on high radiation sources. ${ }^{1}$

\subsubsection{Monsanto Chemical Company, Reactors, and Fuel Processing}

On July 1, 1945, the Monsanto Chemical Company assumed responsibility for the operation of the Clinton Laboratories, which had about completed its mission as a plutonium production pilot plant and was to begin its evolution into a nuclear energy R\&D laboratory. ${ }^{4}$ Because of the unique pilot plant and research facilities, as well as the high caliber and experience of the scientific team, the end of World War II did not also mark the end of operations at the Clinton Laboratories as originally expected. In early 1945, Oak Ridge scientists gave serious consideration to determining the most important and valid $R \& D$ activities necessary to make the greatest contributions to the new fields of nuclear science and technology. Under Monsanto, the reactor development efforts increased in scope. A major effort was devoted to $R \& D$ work leading to the design of a high-flux experimental reactor and to large-scale production of radioisotopes.

Even as early as 1943, there was interest in the possibility of developing reactors for power and research. ${ }^{4}$ A small effort was begun in April 1944, and by July, a graphite-moderated reactor had been conceptualized that used stainless-steel-clad uranium carbide fuel and high-temperature, high-pressure water to generate steam for powering turbines. ${ }^{4}$ As early as 1944 , a homogeneous reactor using uranyl sulfate, enriched in ${ }^{235} \mathrm{U}$, as fuel with a thorium reflector was proposed as a research tool to investigate breeder concepts (irradiating thorium to produce ${ }^{233} U$ ) and, also, to determine the 


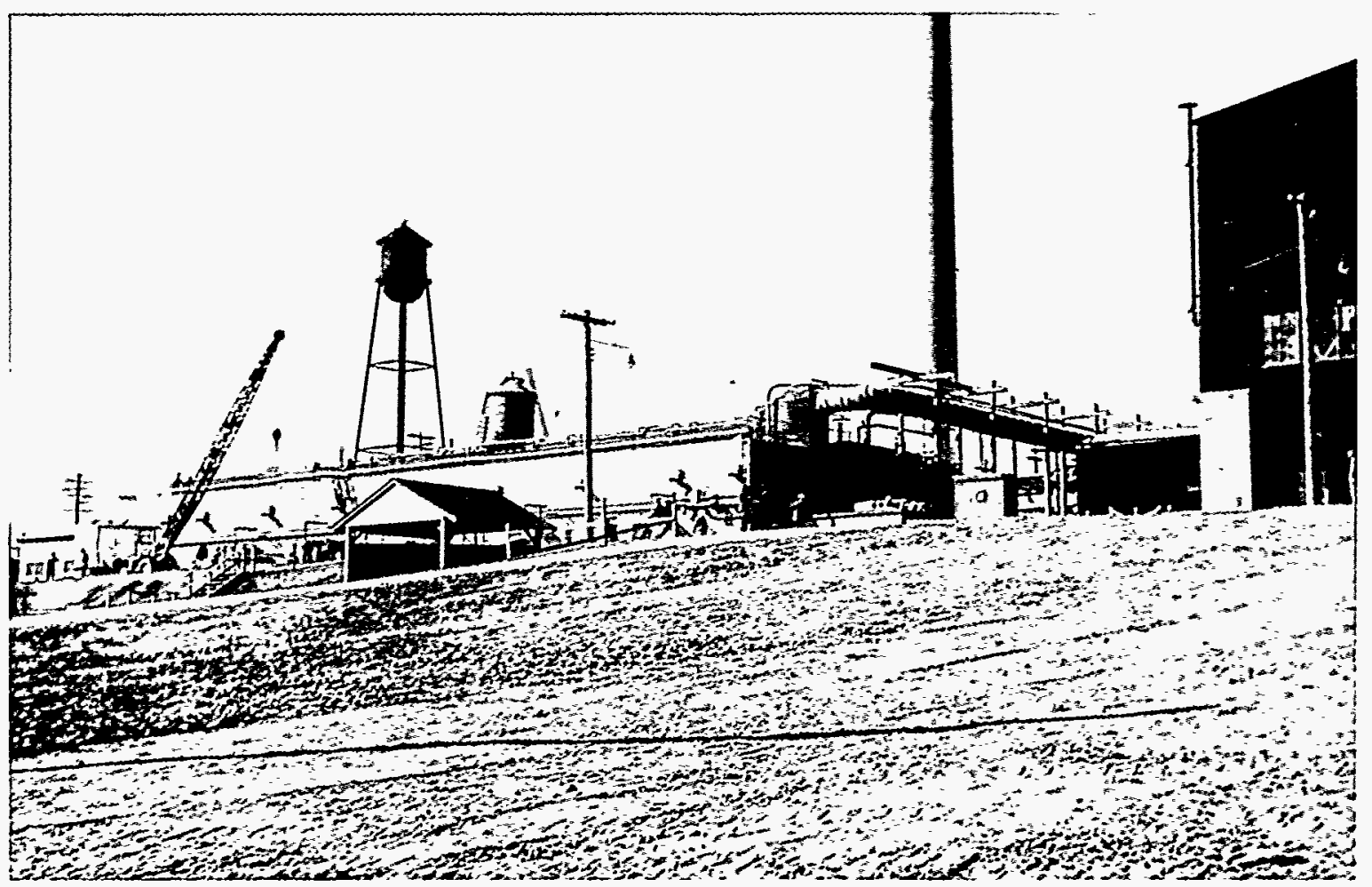

Fig. 1.5. A November 11, 1943, view (looking northwest uphill) of the pilot plant, Building 205. A corner of the graphite reactor building is visible on the right and the tall exhaust stack behind the pilot plant.

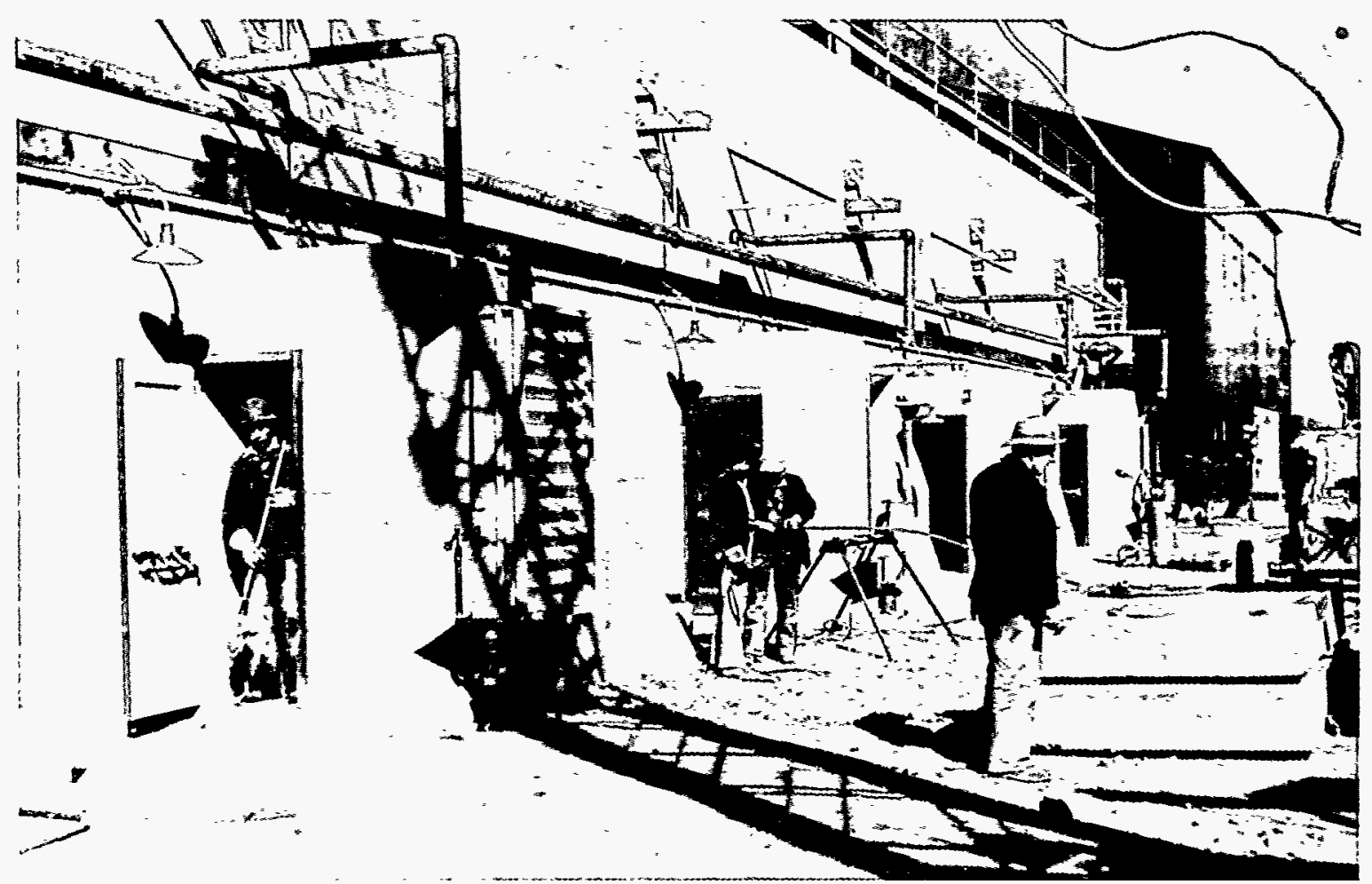

Fig. 1.6. A close-up view of pilot plant cell doors and construction activities (November 11, 1943). The graphite reactor building is visible on the right. 


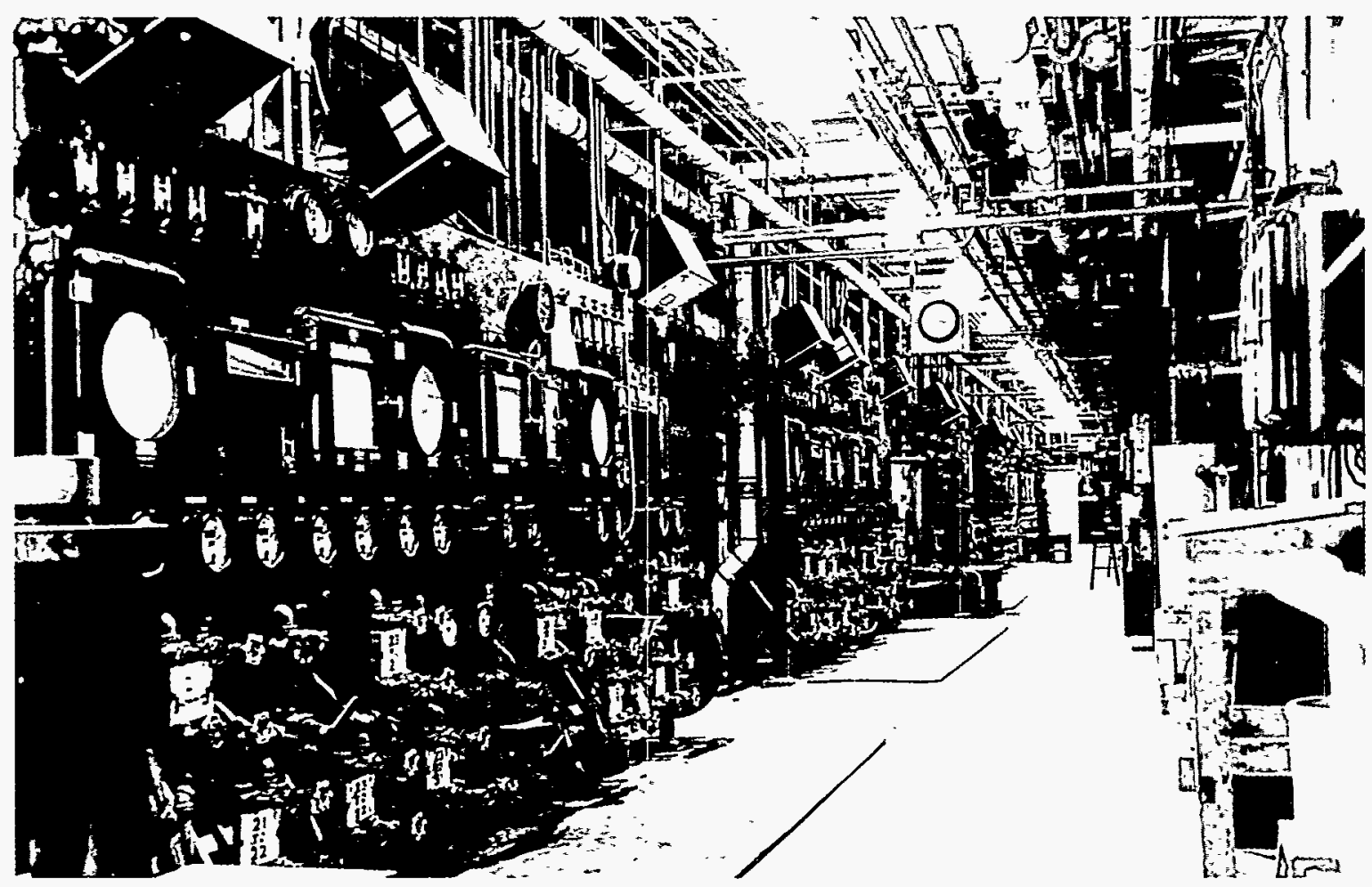

Fig. 1.7. Main control room for the chemical separations pilot plant.

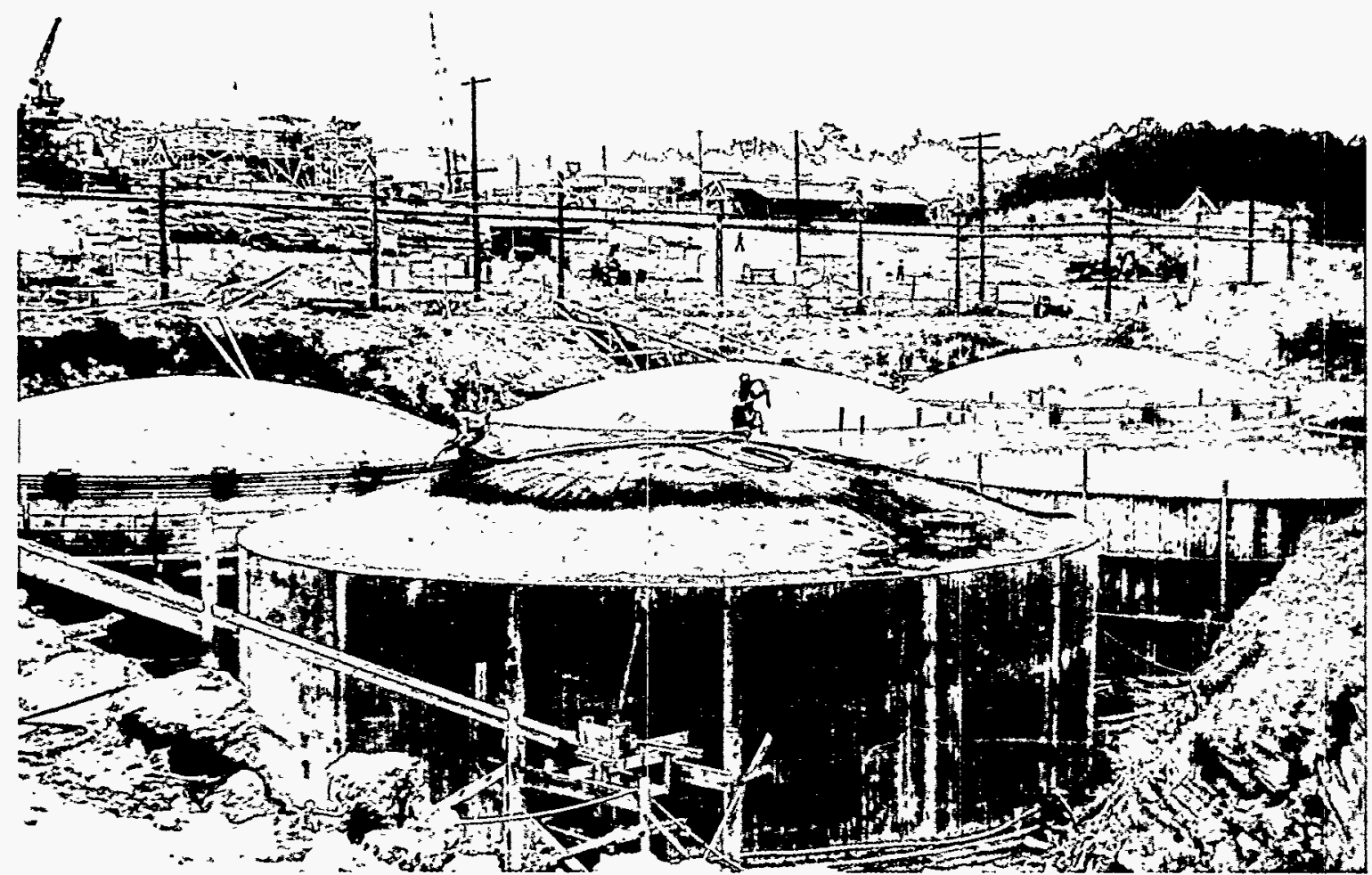

Fig. 1.8. A July 14, 1943, view (looking northeast uphill) of the process waste storage tanks during construction. The completed tall exhaust stack, the pilot plant under construction, and the graphite reactor building under construction are visible in the upper left of the picture. 
general feasibility of homogeneous reactors. ${ }^{1,4}$ Work on the homogeneous reactor was discontinued in 1945 in favor of developing a heterogeneous high-flux reactor. During 1946 and 1947, a substantial development program was undertaken in support of the high-flux reactor design. ${ }^{4}$

The work on separations processes at the Clinton Laboratories was shared between the Technical and Chemistry divisions and involved the following:

- Separation, decontamination, and recovery of ${ }^{235} \mathrm{U}$ from fission products

- Separation of ${ }^{233} \mathrm{U}$ from irradiated thorium

- Recovery of uranium and plutonium from large volumes of stored waste solution that resulted from the dissolution and chemical processing of graphite reactor slugs

The separations research involved solvent extraction, ion exchange, radiation effects, and analytical methods. 1

\subsubsection{The Atomic Energy Commission and the Clinton National Laboratory}

On January 1, 1947, the atomic energy activities were transferred from the Manhattan Project (Manhattan District of the U.S. Army Corps of Engineers) to the newly created Atomic Energy Commission (AEC). The name of the Clinton Laboratories was changed to the Clinton National Laboratory. In December 1947, the AEC consolidated reactor development activities at the Argonne National Laboratory (ANL) and announced plans to maintain the Clinton National Laboratory as a center for basic research, applied chemical research, and isotope production and research. The AEC program included a vigorous effort in applied chemical engineering directed toward the solution of current problems that were vital to the atomic energy operations. The Clinton National Laboratory was to be developed into a center of chemical technology for atomic energy activities. ${ }^{1}$ However, moving all the reactor development work to ANL proved to be impractical, and design and development work on the Materials Testing Reactor (MTR) to be built in Idaho continued in Oak Ridge until the reactor was completed in early 1952.4

\subsubsection{The Oak Ridge National Laboratory and Union Carbide}

On March 1, 1948, the name of the laboratory was changed to the Oak Ridge National Laboratory (ORNL), and Carbide and Carbon Chemicals Company (a division of the Union Carbide and Carbon Corporation) assumed responsibility for its operation. Union Carbide had a strong corporate background in chemical engineering research and development ${ }^{1}$ and was already the operating contractor for the gaseous diffusion plant (K-25) and the electromagnetic separations plant (Y-12). In early 1950 a mockup of the MTR reactor was operated at ORNL at very low power to measure neutron and gamma fluxes. This mockup evolved into the Low-Intensity Test Reactor (LITR). ${ }^{4}$ In 1949, Alvin Weinberg, director of the ORNL Technical Division and also associate director of ORNL, had suggested that a new look be taken at aqueous homogeneous reactors. Thus, construction of Homogeneous Reactor Experiment I was begun in September 1950, and the reactor was completed in January 1952. At approximately the same time, a new program of reactor development, the Aircraft Nuclear Propulsion (ANP) program, began. By 1950 , the programs in the ORNL Technical Division included the three reactor programs as well as chemical processing. On February 1, 1950, the Technical Division was divided into the Reactor Technology Division, with Alvin Weinberg as director, and the Chemical Technology Division, with Frank Steahly as director. ${ }^{4}$

\subsection{ESTABLISHMENT OF THE CHEMICAL TECHNOLOGY DIVISION}

\subsubsection{Background}

As facilities became available during the summer and fall of 1943, a few people were transferred from the Metallurgical Laboratory at the University of Chicago and from some of the $\mathrm{Du}$ Pont plants to Clinton Laboratories to staff an Engineering Development Section headed up by Miles Leverett, Section Chief. Early in 1944, the industrial staff was supplemented by personnel from the Special Engineering Detachment of the Army. The Engineering Development Section collaborated with physicists and metallurgists to upgrade the graphite reactor performance and, through simulation with the graphite reactor, 
studied the performance anticipated from the Hanford reactors under construction. The design group of the section collaborated with the Separations Development Section that supported the operation of the chemical processing plant. Collectively they designed a process and equipment for ion-exchange extraction of plutonium from uranyl nitrate solutions. A mockup was built and tested. In April 1944, it was decided that the uranium should be recovered from the process wastes that had been discharged by the chemical processing plant into underground storage tanks. Design of a solvent extraction process and pilot plant was initiated. The chemical processing plant had fulfilled its mission of demonstrating the bismuth phosphate process for extracting plutonium from reactor fuel and was being shut down. Personnel were being sent to operate the processing plant at Hanford. In October 1944, the remaining staff of the Separations Development Section, responsible for the operation of the chemical processing plant, and the Engineering Development Section were joined to form the Clinton Laboratories' Technical Division, comprised of about 50 chemists and engineers. Jim Lane was assistant director of the division, with M. D. Peterson as chief of Process Development (Section I), R. B. Briggs as chief of Engineering Development (Section II), Frank Ward, as chief of Process Design (Section III), and Don Reid, as chief of the Pilot Plant. Miles Leverett was the division director. (See Appendix A for a 1948 organization chart of the Technical Division. ${ }^{5}$ )

On February 1, 1950, the Chemical Technology Division (Chem Tech) was established at ORNL, and Frank L. Steahly was selected as its first director. ${ }^{6}$ The personnel comprising the new division formerly functioned as the Chemical Technology Department of the Technical Division. By mid-1950, the new division employed 110 people and consisted of four sections: Laboratory, Frank R. Bruce, Section Chief; Unit Operations, J. O. Davis, Section Chief; Process Design, Floyd L. Culler, Section Chief; and Pilot Plants, D. G. Reid, Section Chief. Many of the early Chem Tech staff achieved national and international prominence in the nuclear energy area as well as rising to important leadership positions at ORNL. 7,8 As an aid in tracing the historical development and changing missions of the division, organization charts for 1950, 1960, 1970, 1981, and 1991 are presented in Appendix B.
The initial major activities of the new division included design of the Idaho Chemical Processing Plant (ICPP), development of the tributyl phosphate (TBP) process for the recovery of uranium from Hanford metal waste, development of the Purex process for the recovery of uranium and plutonium from Hanford-irradiated metal, development of the RaLa process for separation of barium from fuel units, homogeneous reactor fuel studies, and design and construction of the ORNL Metal Recovery Plant (Building 3505). ${ }^{7-9}$

This brief description of initial work involvements suggests that Chem Tech was at the forefront of international activities in nuclear energy studies, and indeed it was. These initial endeavors established a solid scientific basis for separations processes used both nationally and internationally in the fledgling nuclear energy industry.

\subsubsection{Management and Organizational Evolution of Chem Tech}

Metallurgical Project. The minutes of the Metallurgical Laboratory and Project Council meetings provide considerable insight into the early organization and management of the Manhattan Project activities under the purview of the Metallurgical Laboratory. The activities were complex, diverse, and widely separated geographically. They included efforts at the University of Chicago; the $\mathrm{X}$ site (Clinton, Tennessee); the Argonne, Illinois, site; the Ames, Iowa, site; and the W site (Hanford, Washington); some activities at the Universities of California, Notre Dame, Indiana, Washington (St. Louis), Princeton, Columbia, and Rochester; and coordination with Du Pont and the U.S. Army. ${ }^{10,11}$

Arthur H. Compton, recipient of the Nobel Prize in Physics in 1927, was selected Director of the Metallurgical Laboratory and Project. Besides being technically competent, he was apparently a sound administrator and good businessman. Compton guided the research-oriented university-type team toward very practical considerations necessary for plutonium production. For secrecy purposes, plutonium was referred to as " 49 " in the University of Chicago reports.

Engineering Considerations Become Principal Concern of the Metallurgical Project. In a January 1943 memorandum concerning organizations of the "Metallurgical Unit," Compton defined the Metallurgical Laboratory Organization and duties 
of the various leaders. Soon after, Du Pont accepted the contract for design, construction, and operation of "the production unit associated with our project." Compton stated that

we are now engaged in cooperation with $\mathrm{Du}$ Pont upon the project of producing " 49 " in quantity and quality suitable for military use at the earliest possible moment .... Since the chief claim for the practical consideration of our project in comparison with others lies in the possibility of swifter completion, the direction which the design, construction, and operation program must take must be determined by engineering considerations based on the studies we have already completed ... . our major responsibility from now on must be to supply the Du Pont engineers and operators with the technical information they need ... and to maintain constant liaison with their staff while our work progresses to insure that the design at all stages meets the nuclear physics requirements. In order to meet our new responsibilities, it will be necessary for us to operate under a more specifically defined organization and under a more rigidly observed procedure than has been necessary or advisable in the past. Both the Army organization and that at $\mathrm{Du}$ Pont are of necessity complex. Unless we have a well-defined organizational procedure which is thoroughly understood by both the Army and by Du Pont, serious delays due to confusion and misunderstanding are bound to occur.

The Metallurgical Laboratory was directly responsible for its research program through the chairman of the S-1 committee to the director of OSRD. This provided administrative flexibility and convenience of an ORSD contract to the University of Chicago as compared with a direct Army contract. Matters of general policy were cleared through Compton to A. V. Peterson, the Army representative for the Manhattan District. Work at Du Pont had been set up in a new Division of Security Materials (DSM) under the Du Pont Explosives Department. Matters of policy were to be cleared through Roger Williams, assistant general manager of the Explosives Department, who was in charge of the DSM division, and C. H. Greenewalt was named technical director of the division. It was agreed that all official information and decisions from the Metallurgical Laboratory would channel through Compton to Greenewalt and, conversely, requests for information through Greenewalt to Compton. ${ }^{11}$

Laboratory Council as Management Team. A laboratory council was established consisting of laboratory and division directors and the Du Pont and Army representatives. The council had two major functions: (1) keep the administrative staff informed concerning the current status of the Laboratory's program and (2) make recommendations on policy matters. The council held a weekly meeting on policy issues and a weekly meeting on technical issues. 11

\section{Analysis of Factors Contributing to Project}

Success. A large measure of the success of the Manahattan Project is attributable to this group of dedicated scientists and engineers who were able to pull together and integrate the many disciplines and areas into the warp and woof of a finished fabric. The group was successful because each member was (1) technically sound, (2) a good manager, and (3) a team player dedicated to the accomplishment of assigned objectives. These attributes also seem to be the principal elements of the early successes achieved by the AEC and the national laboratories.

The organization of the Metallurgical Laboratory 11 is presented in Appendix A. It is interesting to note that the organizational concept of overall director; associate director; and divisions with division directors, section chiefs or heads, and group leaders is still essentially the same organizational style used by ORNL and Chem Tech. M. D. Whitaker, who later served as director of the Clinton Laboratories (now ORNL), is shown as Sub-project Director for Site X; R. L. Doan, who later served as Associate Director for Research at Clinton Laboratories, is shown as Chief Administrative Officer for Laboratory Operations; and E. P. Wigner, Research Director of Clinton Laboratories in 1946 and recipient of the Nobel Prize in physics in 1963, is shown as the section chief of theoretical physics. Miles Leverett, who later became director of the Technical Division (the forerunner of the Chemical Technology Division) for Clinton Laboratories, is shown as the section chief of Development Engineering; and C. D. Coryell and George Boyd, who later served as group leaders in the Chemistry Division at Clinton Laboratories, are shown as section chiefs of By-Products and Analytical Chemistry Control, respectively.

"X" Research Program. In July 1943, in order to facilitate the setting up of a comprehensive 
research program at "Site X," the following program activities were established: 12

- Operation and interpretation of the X pile

- Design, construction, and operation of the $\mathrm{W}$ pile

- Operation of the X separation plant

- Design, construction, and operation of the W plant

- Concentration of products

- Study of physical problems

- Study of fission products

- Study of new separations processes

- Study of the effect of radiations and products on biological tissue

- Study of the health of all employees

Future Chem Tech Staff Members. All personnel involved in the Metallurgical Project were listed in an August 1943 report. ${ }^{13}$ Research workers were scattered all over the University of Chicago quadrangles, including the north and west stands of Stagg Field, an old ice house, and a former beer brewery. Site $X$ personnel included M. D. Whitaker, Director; R. L. Doan, Director of Research; Lyle Borst, Assistant to Director of Research; Henry Newson, Physics Section Chief; Warren Nyer, Research Assistant; J. G. Stangby; and Pearl Margolis. Eight employees had already moved from Chicago to Site X: Jean Ashin, Imgrad Boeder, Melba Johnston, Haydn Jones, Wilcox Overbeck, Gerard Pawlicki, Howard Parsons, and E. Shapiro. Some future Chem Tech scientists as well as several ORNL staff members were working as research assistants in various sections: John $P$. McBride in the Chemistry Division, C-II group; George Parker in the Biology Division working with Waldo Cohn; Al Rom in the Technology Division, Section T-III; and Ed Frederick in the Technology Division, Section T-VII.

Cooperation and Communication. Management of the multi-disciplines and multi-sites involved in the Metallurgical Project became increasingly complex with the growth in worker numbers and sites. Compton and the council stated clearly the need for the closest possible cooperation between Chicago and Clinton, with information flowing freely. The following statement was prepared for the laboratories at Clinton, Ames, and the P-9 Project.

The Laboratory Director will be a member of the Project Council and will regularly present programs to council for their information and recommendation. It shall be his duty to arrange a procedure subject to the approval of the Project Director (i.e., Compton) whereby the men in his organization shall make full use of information and guidance by leaders in their technical fields elsewhere in the Project.

The statement helped directors to obtain a clear concept of what was expected of them, notified the Army that full transfer of information was needed, and emphasized availability of assistance from the most experienced and knowledgeable scientists and engineers. ${ }^{14}$

Clinton Laboratories Semi-Works, Chemical Engineering Section, and Separations Development Division. By October 1943, Whitaker reported to the council that the laboratory would need a ton of "Argonne metal" by November 15, and Fermi said it would be available. Leverett was investigating large-scale production of radioactive xenon. Compton scheduled for the next meeting further discussion on Health Group reports and the large level of effort required. O. H. Greager reported to the council that 40 men were in the Semi-works groups at $\mathrm{X}$ with about $15 \%$ of the work on alternate processes. ${ }^{15}$

The initial report of the Chemical Engineering Section at Clinton Laboratories dealt with dissolution, extraction, decontamination, and concentration of plutonium and uranium, along with wet fluoride investigations and miscellaneous engineering process studies. $\mathrm{O}$. H. Greager was director of the newly formed section, M. F. Acken was the section chief, and R. S. Apple was associate section chief. In 1944, many staff members from this section, which later became the Separations Development Division, went to Hanford to operate the large fuel processing facility, ${ }^{16}$ and the remaining staff members were merged with the Technical Division. ${ }^{5}$

Chemistry Division. Warren C. Johnson, division director, was selected by Compton and the Metallurgical Laboratory Council as the strong chemistry leader necessary for the project to succeed at Site X. Johnson pulled together teams in five major areas: Section C-I, chemistry of plutonium and uranium, Spofford English and Ray Stoughton as section chiefs; Section C-II, fission product chemistry, Charles Coryell, Harrison Davies, and Henry Levy as section chiefs; Section C-III, separations processes, George Boyd as section chief; Section C-IV, preparation of 
radioisotopes, Waldo Cohn as section chief; and Section C-V, analytical chemistry, Dave Hume as section chief. In a March 1945 progress report, it was noted that several future Chem Tech staff members were working in the Chemistry Division: Section C-I, John Blomeke was working on Hanford process problems and Frank Steahly and John McBride on the isolation of ${ }^{233} \mathrm{U}$ from thorium; Section C-III, Bob Klotzbach and Ed Nicholson on the preparation of active lanthanum; Section C-IV, George Parker on the preparation of radioisotopes from fission materials; Section $\mathrm{C}-\mathrm{V}$, Frank Bruce, Clair Schersten, Ed Beauchamp, and George Sadowski on analytical service and research and development. 17

Technical Division. Elements of each of the two major divisions, Separations Development Division and Chemistry Division, were merged into the Technical Division from which the Chemical Technology Division later evolved. In an October 1944 progress report, it was noted that several future Chem Tech staff members were working in the Technical Division. D. G. Reid was studying the corrosion of Hanford aluminum tubes and slugs under radiation; Don Overholt was studying the disposal of stack gas; Fred McCullough was studying the detection of blisters on fuel elements and also the preparation of ${ }^{140 \mathrm{La} \text {; }}$ M. D. Peterson was providing general plant assistance; and Warren Eister (Group Leader) and Joe Savolainen were working in the Semi-works product recovery. 18

A year later, future Chem Tech staff members were reported as follows: Savolainen, ${ }^{140} \mathrm{Ba}$ chemical development; Eister, ${ }^{140} \mathrm{Ba}$ equipment development and Semi-works; Leuze and Frederick, ${ }^{140} \mathrm{Ba}$ analytical service; Peterson, chemical development; Reid, extraction process engineering development; Nicholson, extraction process chemical plant design; Eister, Blomeke, Klotzbach, Morse, Overholt, Steahly, and Savolainen, extraction process chemical plant development; and McCullough, pile design. ${ }^{19}$

\subsection{AN EARLY PERSPECTIVE}

\subsubsection{Clinton Laboratories-the War Years, William E. Thompson 20}

Fifty years ago, on February 1, 1943, construction work was started at the $\mathrm{X}-10$ site. Looking back to those days, we can only feel amazement at the boldness with which the wartime atomic energy projects were planned and at the speed and success with which they were carried out.

In 1942, even before the first nuclear chain reaction had been achieved, the Corps of Engineers purchased 92 square miles of land in the area between Clinton, Oliver Springs, and Kingston, under the guise (for security reasons) of establishing the Kingston Demolition Range. This area was given the name Clinton Engineer Works and was intended for the large-scale production of enriched ${ }^{235} \mathrm{U}$ and Pu needed for atomic bombs. (The name Oak Ridge was not adopted until June 1943.) The army had originally planned to carry out all atomic bomb project activities at this site. Later, it was decided to locate the plutonium production facilities at a more remote site on the Columbia River near Hanford, Washington.

Chronology of Significant Events. The following chronology illustrates the rapid pace of early activities:

- In August 1942, the Manhattan District was organized under the Corps of Engineers to carry out the large-scale construction and production activities of the atomic bomb project.

- In September 1942, Brigadier General Leslie $R$. Groves was placed in complete charge of the

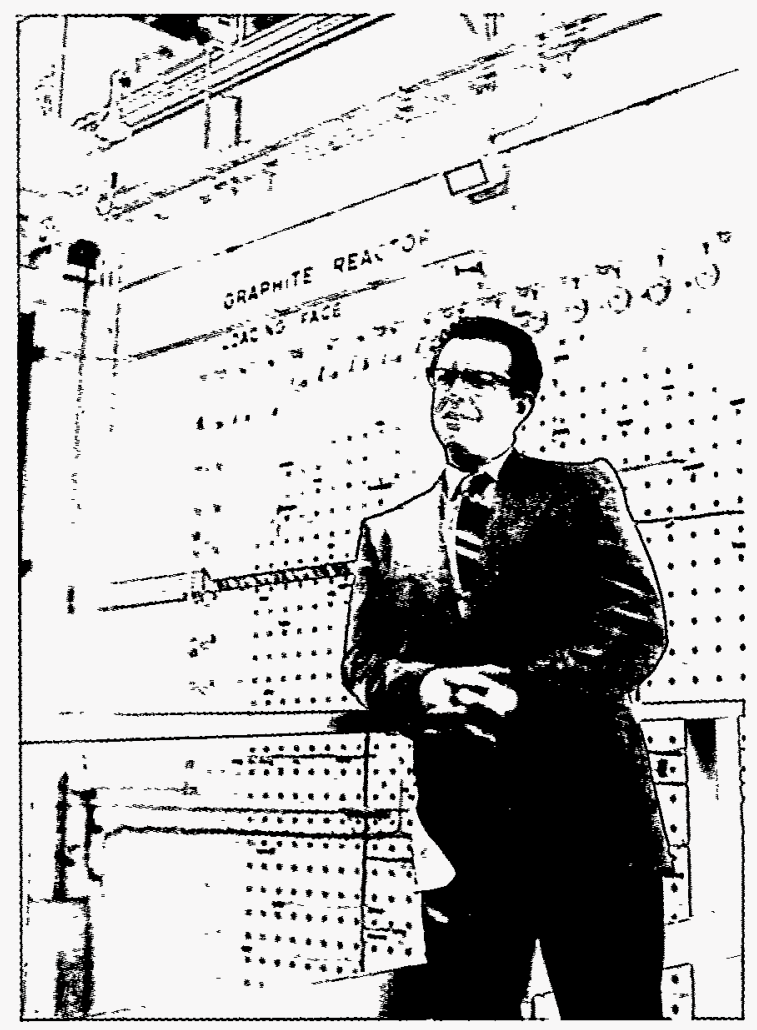

Mr. William E. Thompson, 1973 
Manhattan District. General Groves selected the Du Pont Company to design and construct the Clinton Laboratories plutonium pilot plant and the production facilities at Hanford.

- On December 2, 1942, Enrico Fermi and his colleagues on the Metallurgical Laboratory staff achieved the first nuclear chain reaction in the Chicago Pile.

- On December 16, 1942, the nation's Military Policy Committee recommended to President Roosevelt that a plutonium production pilot plant be constructed at Clinton Engineer Works. The President approved.

- On January 15, 1943, E. I. du Pont de Nemours and Company of Wilmington, Delaware, was selected to design and construct the plutonium pilot plant facilities in Tennessee, to be designated as Clinton Laboratories. The Du Pont Company arrived at the specifications of the Clinton Pile on the basis of recommendations made by the Metallurgical Laboratory staff, particularly by Eugene Wigner and Alvin Weinberg of the Theoretical Physics Group.

- By February 1, 1943, Du Pont was breaking ground for the "Clinton Pile" (now the Graphite Reactor) at a rural site which was more than five miles from the nearest electric power line.

- By February 1943, Du Pont engineers were designing the plutonium separation pilot plant, and in March, excavation for the building foundations was under way.

- The pile was complete in less than eight months, and the University of Chicago physicists had begun pre-operational testing. The plutonium separation pilot plant was nearly complete, and testing of the equipment was started in that facility also. Frank Bruce (later a Chem Tech staff member and Associate Director of ORNL), who at that time worked in the analytical lab in the pilot plant building, remembers being impressed by the smoothness and the businesslike manner with which the $\mathrm{Du}$ Pont people carried out the pre-operational tests and check-out procedures. This first large-scale radiochemical processing facility had $5 \mathrm{ft}$ of concrete shielding around all the processing equipment, making it necessary to employ remote controls and to operate the system without being able to see it; but they made it work, right from the start.

- The pile started up in November 1943, reaching criticality at 5:00 a.m. on November 4, almost exactly nine months after ground was broken. Arthur Holly Compton, director of the Metallurgical Laboratory, was spending considerable time in Oak Ridge in those days. Ernie Wollan recalls coming down by train from the Metallurgical Laboratory for the pile startup with a group that included Enrico Fermi and Norman Hilberry. Wollan looked for neutron leakage through the top of the shield and found the shielding to be adequate, as predicted. He also checked for neutrino emissions, which were expected to pass easily through the shield, if they were present. He established that the highest possible number of neutrino emissions anticipated could not present a radiation hazard.

- On December 19,1943, after the pile had been operating a few weeks, the first "hot" runs to separate plutonium in the pilot plant were conducted. Among those operating the pilot plant at the time were John Gillette, Harris Blauer, Roscoe Pressley, Stanley Rimshaw, Harvey Mahlman, D. C. King, and Claude Keck (later a Chem Tech staff member). The early research and development on fission, uranium isotopes separation, plutonium production, and on related matters had been performed mainly at Columbia University, the University of Chicago, the University of California, and Iowa State College under the Office of Scientific Research and Development, directed by Vannevar Bush.

- The first batch of irradiated fuel slugs was taken from the reactor to the chemical processing dissolver on December 20, 1943.

- On January 3, 1944, the first plutonium (1.54 mg) was shipped from Clinton Laboratories to the Metallurgical Laboratory. Although the chemical processing proceeded in batches, it was continuous in the sense that a new batch was started as soon as the previous batch had been moved to the next step in processing. The final purification of plutonium was done in the Chemistry Building by Isadore Perlman's group, which included Ray Stoughton, John McBride (later a Chem Tech staff member), Ed Bohlmann, and Joe Halperin.

- By the end of January $1944,1 / 3$ ton per day of irradiated fuel from the reactor was going through the pilot plant, although the low pile power level and short operating time had not allowed the plutonium concentration to build 
up to the planned levels. By March the production rate was up to about 8 to $10 \mathrm{~g}$ per month of purified plutonium. Through May 1944 , shipments had totaled $30.737 \mathrm{~g}$, and soon afterward, higher production rates reflected the increase in pile power.

- From December 1943 to January 1945, the pilot plant processed 299 batches of slugs: about 100 tons at $1 / 3$ ton per batch. An objective had been set to produce about $300 \mathrm{~g}$ of plutonium, and by the end of 1944, shipments had totaled $271.396 \mathrm{~g}$ of plutonium. Accordingly, plans were made for closing down the chemical pilot plant early in 1945 , by which time more than the originally planned $300 \mathrm{~g}$ would have been produced. The final regular shipment in January 1945 brought the total plutonium up to $289.438 \mathrm{~g}$, and additional plutonium reclaimed and purified in the process of closing down and cleaning out the pilot plant equipment was shipped in February 1945, bringing the grand total of plutonium production from the Clinton Laboratories pilot plant to $326.390 \mathrm{~g}$. Two years after the start of construction, the objectives had been accomplished far beyond the original expectations.

- The project cost was $\$ 12$ million for construction of all facilities at Clinton Laboratories, plus $\$ 12.5$ million for all operations through June 1945.

Historical Footnotes. The first of the production buildings to go into operation at Clinton Labs was the graphite machining shop, where craftsmen took the extruded graphite bars as they came from the manufacturers and machined them to final specifications for stacking in the pile. Finished graphite pieces went into exponential piles, from which physicists could then measure neutron diffusion lengths using indium foil. Exponential pile experiments took up July and August; in September, crews began stacking the 676 tons of graphite in the pile by hand. This took three weeks.

The design power level of the Clinton Pile, $1000 \mathrm{~kW}$, had been chosen with the knowledge that it would produce about $1 \mathrm{~g}$ of plutonium per day at that power level. Designers wanted the concentration of plutonium in the irradiated uranium fuel to be at least $1 \mathrm{ppm}$. Expecting the pile to contain about 60 tons of uranium (approximately 60 million grams), they figured that after a couple of months at $1000 \mathrm{~kW}$ the fuel would contain $1 \mathrm{ppm}$ of plutonium. They planned to process the irradiated fuel in 1/3-ton batches at the rate of one batch per day, so the nominal plutonium production capacity of the pilot plant at Clinton Laboratories was $1 / 3 \mathrm{~g}$ per day.

Higher airflows, coupled with the other improvements, permitted routine operation at power levels up to $4000 \mathrm{~kW}$. This increase to four times the design power level gave a corresponding increase in plutonium production. Even at this power level, there were no difficulties with the operation of the pile. In ease of control, steadiness of operation, and reliability of performance, the Clinton Pile achieved an impressive record. There were no failures attributable to mistakes in design or construction-a remarkable fact, considering that this plant was designed on the basis of the meager data available in 1942 and was constructed without previous experience.

Stone and Webster Engineering Corporation had originally been selected as the overall engineering and construction firm for the Manhattan District, but it soon became apparent that the various parts of the work were too widely separated physically and too complicated technically to be handled by a single company. Stone and Webster built the Y-12 Plant and some of the townsite facilities, Du Pont built the X-10 facilities, and J. A. Jones Construction Company the K-25 complex. Many subcontractors came in to build the houses, dormitories, and miscellaneous building of the town. Roane-Anderson Company, a special subsidiary of Turner Construction Company, was the rental and maintenance agent for the houses, dormitories, and the commercial property on the Clinton Engineer Works townsite.

On that February day in 1943 when construction started, several farms still occupied the $\mathrm{X}-10$ site. The Bethel Valley road was in existence, along its old route north of the present road, but it was not paved. Solway Bridge and the old wooden-planked Edgemoor Bridge were standing, but there was only a ferry at the White Wing (State Highway 95) crossing of the Clinch River. J. A. Jones Construction Company installed a pontoon bridge to replace the ferry in 1942, and this bridge continued in use, with some modifications and improvements, until the present bridge was built in 1963. Railroad spurs were built by the Louisville and Nashville (L\&N) Railroad to serve the townsite and the $Y-12$ Plant and by the Southern Railway to serve the K-25 Plant, but there was no railroad spur to the $\mathrm{X}-10$ site. All materials 
for the Clinton Laboratories had to come in by truck. Before Oak Ridge's rail spurs were built, Byington, Tenn., a small community near Karns, was the railroad destination of many L\&N shipments.

Finding enough construction workers to build all the plants of the Clinton Engineer Works plus the town was a chronic problem in 1943. The construction fell behind schedule by several months because of the shortage of workers. Since part of the trouble was lack of living quarters close to the job, the Scarboro School was once again brought into use for a while as a barracks for workers. To recruit a labor force, John Fiser, at that time a Clinton Labs personnel officer, drove a bus through rural areas of Georgia, Alabama,

Mississippi, and Tennessee, not only signing up people to work in Oak Ridge, but bringing them back with him in the bus as well.

The mud and dust of 1943 and 1944 are outstanding characteristics of Oak Ridge in everyone's memories; Larry Riordan recalls that in 1943 the Medical Department issued face masks to workers who experienced difficulties because of the dust. It was not until after the war was over and a more permanent role for Oak Ridge began to emerge that paving of the roads was started. Prior to that, Roane-Anderson leveled the town's streets with road graders from time to time, treating them with calcium chloride to allay the dust and with gravel to combat the mud. The roads on the Clinton Labs site itself were paved as a part of the program started in 1948 to make the place more permanent.

There was no air-conditioning of buildings during the war years, not even with window units. There were lots of electric fans, but when the dust outside made it impossible to have the windows open, the summer heat and humidity could be pretty oppressive. Some laboratories and instrument rooms were air-conditioned to protect electronic components from the temperature fluctuations and the high humidity of East Tennessee, but it was not until the 1950s that AEC construction criteria permitted the air-conditioning of office areas. Summer temperatures above $100^{\circ} \mathrm{F}$ in office and work areas were not rare. I can remember papers sticking to sweaty arms while working at my desk. We used lots of onionskin paper for making carbon copies, and it stuck to damp skin worst of all. Carbon copies of everything was the rule in those days, and often the number of carbons would be as high as possible. It took really strong typing fingers to make eight or ten carbons. When electric typewriters became generally available in the early 1950s, they could only be obtained to replace manual machines if there were special factors to justify the higher cost. The frequent need to make carbon copies was the justification most people used to try to get an electric typewriter.

\subsubsection{Miles C. Leverett, Director, Technical Division 1943-1948, ORNL $^{5}$}

In the beginning, the Clinton Laboratory was created primarily in response to the recognition by the chemical engineers at the Metallurgical Laboratory and those in Du Pont that there had to be a pilot plant in which the chemical separation of plutonium from the irradiated uranium and fission products could be carried out. These engineers were quick to realize that many new, unique, complex engineering problems would arise in transferring processes from the laboratory to the plant; these would have to be solved before the Hanford plant could be designed and run successfully. Therefore, the centerpiece of the laboratory in its early years was the chemical separation plant. The graphite reactor was a necessary adjunct, since no other source of irradiated uranium was available; however, the Hanford reactors could have been and largely were

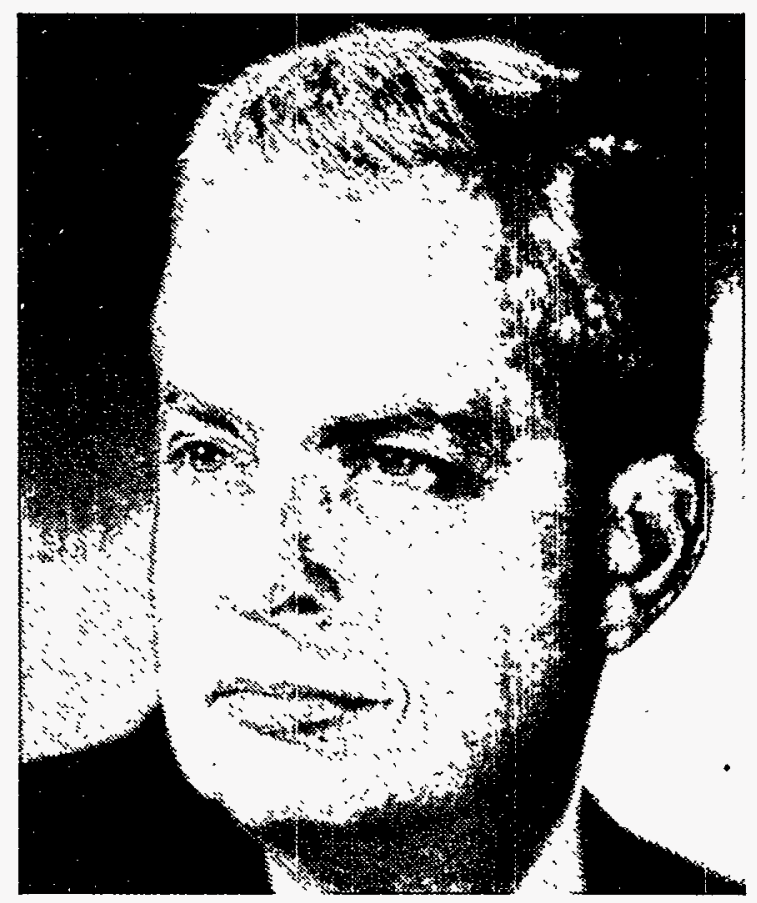

Mr. Miles C. Leverett, 1948 
designed with little reference to the graphite reactor. The chemical laboratories and their staffs were likewise vital support for the successful operation and problem solving in the 200 Area, as the separation plant facilities were known, but chemical research was not otherwise a raison d'etre for the Clinton Laboratory. Similarly, physics was a supporting function for the graphite reactor, not an independent function of the laboratory in those early days. I do not, of course, mean to demean the enormous contributions of the chemists and physicists at the Metallurgical Laboratory, where the leadership in chemistry and physics resided in this period; I wish rather to emphasize that the initial function of the Clinton Laboratory was primarily a chemical engineering one.

A few illustrations of the kinds of chemical engineering problems faced may be helpful.

- Equipment capable of performing liquid transfer, liquid/solid separation, solids dissolution, evaporation, toxic off-gas disposal, etc., remotely, had to be designed, built, and tested.

- Instrumentation capable of remotely measuring volumes, densities, temperatures, etc., in a lethally radioactive environment had to be found or developed.

- Procedures for remotely sampling, transporting, and analyzing liquids and solids remotely had to be devised, built, and proven practical.

- Techniques for separating, in relatively pure form, subgram quantities of solids from volumes of liquid thousands of times larger had to be perfected.

- Previously unknown effects of intense radiation on solvents such as were used in the process had to be coped with when they suddenly appeared.

- Heat from radioactive decay could create thermal convection currents which interfered with sedimentation processes.

- Techniques for maintaining, decontaminating, and disposing of contaminated equipment had to be devised.

- The problem of safely storing unprecedented quantities of radioactive waste had to be addressed.

Problems of these types were of little importance as long as only low-level radioactivity was being handled on a laboratory scale, but they were of great importance when the chosen separations processes were scaled up to plant scale. Suggestions for ways of dealing with these problems came from many sources, but it was the chemical engineers who had to make the tough choices and devise the ingenious solutions.

The design, construction, and successful operation of a facility for producing ${ }^{140} \mathrm{Ba}$ in kilocurie quantities (in Building 706D) in just a few months time was a job handed to me in 1945. Barium- 140 was urgently needed at Los Alamos. With great support from the Chemistry Division, my team of chemical engineers and I met the desired schedule and continued to produce the product as long as it was needed. I believe that this was the first production of a radioisotope on a large scale. Associated with me was Walton Rodger, among others.

During the war, a large contingent of young, technically trained soldiers was assigned to Oak Ridge and was used in numerous capacities of a techrical nature. Some members of this group went on to achieve notable success in nuclear work, including Sam Beall, Beecher Briggs, Bill Bigler, Bernard Manowitz, and Milton Levenson. These men were students who had been drafted, while still in school, into the Army Specialized Training Program (ASTP). Several of them worked in my group and did more than their share.

The Du Pont people assigned to Oak Ridge for training in preparation for their later transfer to Hanford were of unusually high caliber. They deserve special mention in any account of the early success of the laboratory. Several of those people were assigned to my group.

Although, as noted already above, there was no Chemical Technology Division as such until one was created by Alvin Weinberg, there was, from the first days of 1943, a group of chemical engineers charged with carrying out Semi-works-scale developmental and troubleshooting work on the chemical separations processes. For much of the time, this work was directed by Merlin Peterson; later it became my responsibility.

I arrived at the laboratory in September 1943, and I was director of the Technical Division when I left the laboratory in 1948. For this reason, my reminiscences, as reflected here, are of the period 1943-1948. Since that period, the character and mission of the laboratory, as I have observed as a visitor and consultant on numerous occasions, have changed substantially. I leave it to others to describe the changes, but I cannot close this letter 
without suggesting that, even now, chemical engineering is one of the stronger disciplines at ORNL, although it may well be applied to problem types quite different from those of 1943-1948. A 1948 organization chart for the Technical Division, valid at about the time I left the laboratory, is presented in Appendix A.

\subsection{PERSPECTIVES OF FORMER ORNL DIRECTORS AND ASSOCIATE DIRECTORS}

\subsubsection{Alvin Weinberg, Director, ORNL, 1954-1974 21}

On December 31, 1947, the ax fell on Clinton Laboratories. Jack Franklin, the AEC's manager of Oak Ridge Operations, wrote to Prescott Sandidge, Monsanto's Executive Director for Clinton Laboratories: "The Atomic Energy Commission, after very careful consideration, has decided to relocate reactor development to the Argonne National Laboratory . . . activities concerned ... the high flux reactor ... and a reactor for useful power will become part of ... Argonne ... Clinton will undertake a strong program of research on chemical process problems and on the chemical and chemical engineering phases ... of nuclear energy."

At the time, the High Flux Pile (as the MTR was then called) was Clinton's centerpiece. Wresting it from Clinton was a bitter pill for

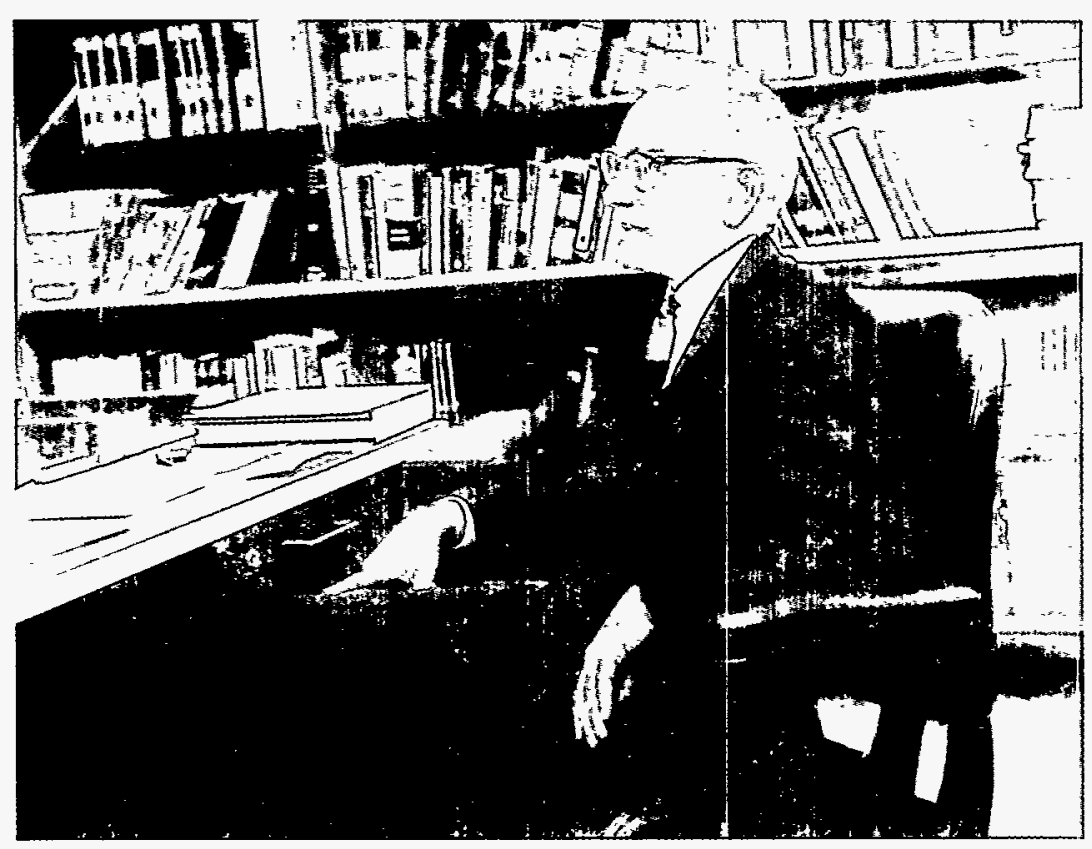

Dr. Alvin Weinberg, 1983 everybody at the Laboratory-that is, everybody except the chemical engineers. For them, designation of chemical process problems as a central mission of ORNL was welcomed as a great opportunity.

Chemical development was conducted as part of the Technical Division-first under Miles Leverett, then Merlin Peterson, and, after splitting off as the Chemical Technology Division, under Frank Steahly and then Floyd Culler. The laboratory, with its war-built concrete cells (Building 205), was uniquely able to test Redox on a pilot scale, in preparation for its use at Hanford. Redox was followed by Purex, Thorex, and other processes. The Chemical Technology Division's reputation as the leading center for development of solvent extraction in radiochemical processing became widely recognized.

Although the MTR was built in Idaho, not in Oak Ridge, Chem Tech remained responsible for the chemical reprocessing plant at Idaho Falls. This plant was entirely an Oak Ridge development. Floyd Culler directed the project, and its completion gave the division confidence in its ability to carry out big projects.

Chem Tech participated in the laboratory's efforts to develop liquid fuel reactors. Though these efforts did not culminate in successful breeders or aircraft engines, they did yield important by-products. Most notable was the sol-gel process, an outgrowth of Chem Tech's attempts to make thorium slurries for use in aqueous homogeneous reactors.

As I look back from the vantage point of forty years, I realize that Chem Tech was one of the most successful of the ORNL's divisions. It combined an admirable practicality with sophisticated chemical insights and imaginative engineering. In my later years at ORNL, when I found myself at growing odds with AEC's Division of Reactor Development, the great confidence Chem Tech enjoyed in Washington helped ORNL weather the difficult transitions of the early 
1970's. I am forever grateful to Chem Tech for its accomplishments. They have been a source of satisfaction for the members of the division and a source of strength for ORNL.

\subsubsection{Herman Postma, Director, ORNL, $1974-1989^{22}$}

The principal mission of ORNL during my tenure as director was to help ensure national security in energy independence through $R \& D$; to be a steward of large and important national physical and biological facilities; and to perform research about the environment that would allow energy development and conservation to proceed in the best possible way.

The principal missions of the Chemical Technology Division were, of course, important aspects of the ORNL mission. At the start of my tenure, Chem Tech was essentially the only place in the country that could do R\&D in several areas of importance, such as reactor technology and fuel processing. ORNL and Chem Tech had the kinds of experienced people and unique facilities that could accomplish such R\&D. In the beginning, Chem Tech performed research in chemical engineering technologies, particularly those pertinent to nuclear technology. It also operated very difficult, high-priced nuclear facilities for the purpose of producing rare isotopes, particularly

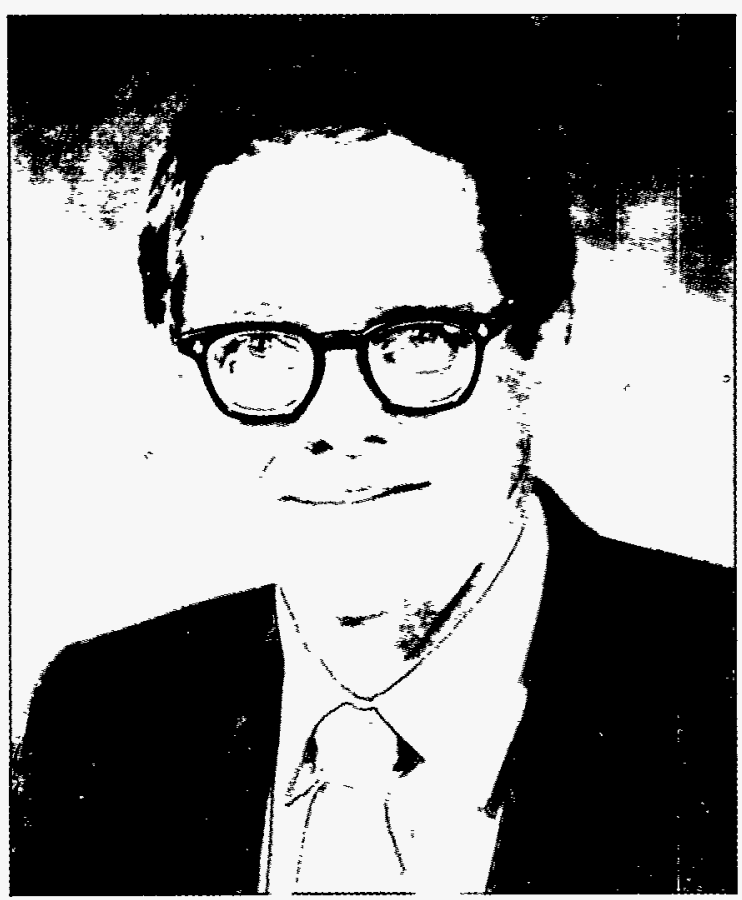

Dr. Herman Postma, 1986 transuranic elements. Later, Chem Tech started to convert from solely chemical engineering to include biological and biochemical engineering. It still retained an important mission in the supply of critical isotopes but had essentially gotten out of fuel reprocessing, at least the production and hardware aspects, except for some activities in the research end. The Chem Tech mission then began to change dramatically by becoming involved in alleviating waste problems, such as the replacement of waste, producing processes with benign processes and, also, waste minimization. Chem Tech used its chemical and engineering expertise in developing methods to deal with the already existing wastes. Such methods generally involved chemical or geological means.

There was one other mission that nobody ever really stated but that truly existed. Chem Tech managed to develop some of the very best people that ORNL ever had in terms of what they did in science, engineering, and management. I don't think they thought of that as a mission, but in fact that was one of the division's biggest contributions (i.e., training and exporting these people throughout the laboratory).

In terms of actual accomplishments, in one sense, Chem Tech founded ORNL. Essentially, the first mission of the whole laboratory was in chemical processing. We built a reactor for the purpose of producing crucial radioisotopes. So Chem Tech's fundamental contribution, which is the basis for all the processes used worldwide, was to separate the isotopes. That was started here. So that's a fundamental contribution. We created Savannah River processes. We created, essentially, the techniques used at Hanford. And, of course, we produced a lot of isotopes for research.

More recent accomplishments include conversion of biomass into alcohol, biological process development, and separation techniques. The latter has always been one of the more fundamental areas in which Chem Tech prevailed. Separations in the beginning used ion-exchange columns, but as that technology evolved, even bacterial columns were used to perform some exchanges. I think, basically, Chem Tech's overall contributions were generically in separation sciences-separations first chemically, later biologically, and sometimes physically (e.g., isotopes). Just a steady flow of improvements came along as a result of that kind of research.

What are important directions for ORNL in the future? The laboratory as a whole must provide 
responsible stewardship of national facilities in the physical and biological sciences. Other important ongoing missions include the following:

- Coal energy conversion, such as the conversion of coal into liquids, or conversion of biomass into gases or liquids for transportation

- Energy conservation

- Improved integrated utilization of nuclear materials, waste management, and separation management, including fission and fusion reactor development

- Technology transfer

- Educating future engineers and scientists through cooperative agreements with universities, colleges, and even high schools

But the subtle focus in all this is basically energy and the environmental questions that surround it.

Chem Tech will play a central role in the future missions of the laboratory, for example, the waste management effort. The size of the waste problems that the Department of Energy (DOE) has is in perhaps the $\$ 100$ billion range. The leverage that research may give to managing waste problem areas faster and more efficiently can be significant. Because the basic mission of Chem Tech is chemical and biological processing, the division will have an important role in waste research, and waste management will be a central theme for some time. Chem Tech will also continue to play an important role in the conversion of fuels.

Because of the emphasis on waste and environmental areas, it may be difficult to maintain a balanced approach with other research areas. The problem is that the people in the waste areas are not currently putting very much $R \& D$ money into waste research. Research dollars are a vital necessity. Getting the money so the people can do the right kind of basic and applied research on the separation sciences is very important to the overall waste program.

Chem Tech has been involved extensively in Work-for-Others efforts. This is an important effort. Research dollars are going to benefit a lot more than just the agencies that supply them. Work-for-Other agencies (e.g., the U. S. Environmental Protection Agency and the Department of Defense), besides meeting their R\&D needs, help cut the cost to the DOE because they utilize facilities that have essentially fixed costs. This provides spin-offs in other research areas. It provides a multitude of sources of money. Some of these sources of money may go up and others may go down, but the balance is pretty good. Whereas if you just have one source of income and the budget is slashed, then you're swinging in the wind like everybody else. Work-for-Others efforts make for good science, as well as having a good science rationale.

Chem Tech has been around longer than, I guess, almost any other division. As a division, it started around 1950, a spin-off from the Technical Division. Since that time it has retained its integrity, although many things have changed. Chemistry, fuel reprocessing, and isotopes have drifted in and out from time to time. But the core division may have been there longer than any other core division. Now, whether it's first; or second, or third, it has always been a very fundamental part of the laboratory. That is recognized purely by the fact that it has retained that status since the beginning. That means it is flexible. That means it does very good things. Otherwise, it would not have lasted as long as it has. In addition, it has been one of the safest divisions of the laboratory. As a division that deals with a lot of very sophisticated hazardous substances, it has set a standard of not having had a serious accident in 35 years. That is remarkable.

ORNL and the Chemical Technology Division were created in response to the great atomic energy effort, and they are continuing to play active roles in that area. I foresee that there will be an increase in atomic energy use in the future. The first thing that has to be done is that nuclear energy around the world, not just the United States, has to operate safely with minimum occurrences of any sort for a long enough period so that people become more comfortable with it. People sooner or later will recognize the overall environmental concerns and risks with all methods of energy production, and they will be able to make the trade-offs that are necessary. So nuclear energy will look pretty good compared with some other alternatives once all the facts are in. I think it will all come back probably within a decade, but I don't think very much sooner than that. It was thought that fusion energy was only ten years away when I started in the fusion program 30 years ago. It is safe to say that fission will make a revival before fusion will come in as a complementary energy source. 


\subsubsection{Donald Trauger, Associate Director, ORNL, 1970-1986 23}

The Chemical Technology Division is an example of dynamic enterprise that extends to the very beginning of the ORNL. Although the division was not officially organized until 1950 , its origins trace to the initial program for which the laboratory was founded during World War II. The project to develop the separation process for recovering plutonium from uranium and fission products established a major thrust for the laboratory. Thus chemical engineering, the main discipline of the division, has been and remains a major component of ORNL programs.

A most important feature of a national laboratory is the ability to anticipate and respond to national challenges. The Chemical Technology Division has exhibited such capability starting with the improvement of military nuclear fuel cycles extending through the cold-war period. These processes have proven adaptable to civilian nuclear programs, and ORNL's technologies are in use wherever nuclear fuel reprocessing is employed throughout the world. The division has continued to anticipate and respond to needs in many fields from biological technologies to improved use of fossil fuels. Although early nuclear fuel cycle work contributed to the laboratory's legacy of environmental problems, the division also was a

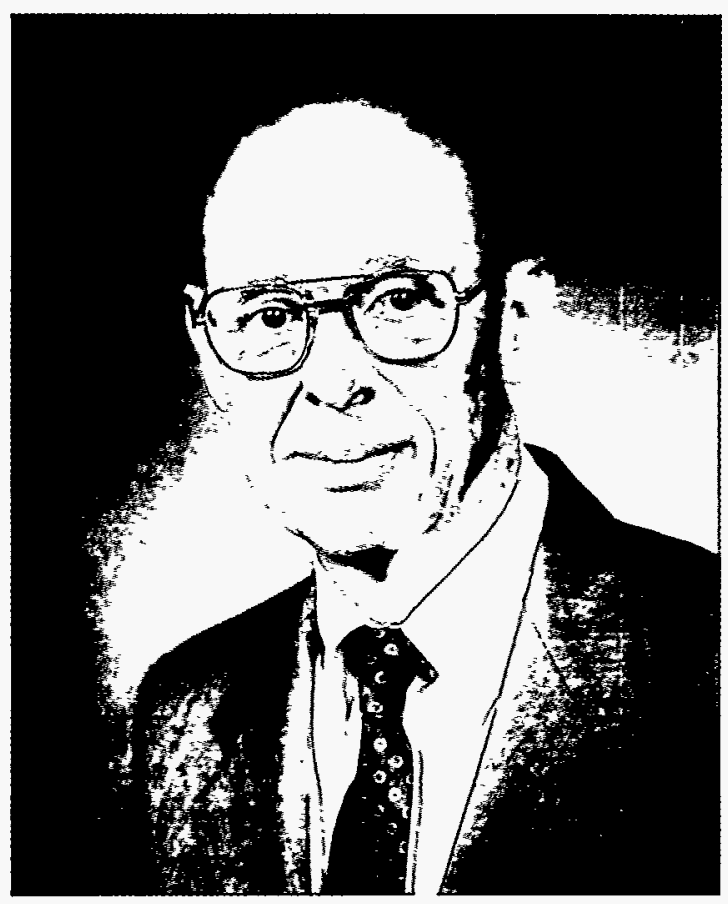

Mr. Donald Trauger, 1990 national leader in developing improved practices and corrective measures.

The importance of nuclear waste disposal was recognized early by Chemical Technology Division staff members, and much of the technology employed and that anticipated for high-level-waste disposal facilities had their beginnings here. The adaptability of the division is exemplified in its successful roles in many fields of waste technology. These include hazardous and mixed wastes, as well as high-and low-level radioactive materials. The breadth of the programs in this area was effectively articulated in the recent Showcase lecture on bioremediation for the treatment of organic-type wastes.

The excellence of Chemical Technology Division programs extending from bioengineering to operation of major hot cell complexes represents a major example of successful management of complex operations. This extends from the development of analytical systems for body fluids and studies of photosynthesis to the building and operation of large chemical separation columns.

Not the least of Chemical Technology Division accomplishments is the outstanding safety record of a great many years without a lost-time accident. This is a most impressive record in view of the nature of the hazardous materials used and the processes developed involving reactive chemicals, large amounts of radiation, and biological material. Many of these required complex engineering facilities. This accomplishment reflects the capability to adapt good practices from one technology to another. Although the aggressiveness of the division's operations has produced some near misses for serious accidents, the record is impressive and the safety discipline has continually improved.

The division also has maintained a dynamic enthusiasm and entrepreneurship. For example, when it was deemed necessary to move a section to bolster another division, and on another occasion to move a major function to create a new division, the Chemical Technology Division rallied and filled the voids with new work. The division exemplifies an appropriate level of aggressiveness in finding new and needed areas of R\&D.

The years spent working closely with the Chemical Technology Division, especially when it reported to my associate director position, were pleasant and rewarding. They also were a challenge since my training and prior experience were light in chemical engineering. The division staff served as 
excellent teachers and consultants. Chemical Technology is a great division, poised for continued good work and predictably should be reflected well when a 100-year history report is written.

\subsubsection{Frank Bruce, Associaie Director, ORNL, 1970-1978 24}

I came to the Clinton Laboratories-later to become ORNL - in December 1943 with the Du Pont Company as an analytical chemist. In 1945 I transferred to the Technical Division, which later became the Chemical Technology Division (Chem Tech). Chem Tech's mission at that time-and for many years that followed-was chiefly the reprocessing of irradiated material, to separate uranium and plutonium from fission products and from each other. I left Chem Tech in 1959 to become Assistant Deputy Director of ORNL. Accordingly, most of my very fond recollections of Chem Tech cover the period 1950-1959, a time when Floyd Culler served as division director and I as associate division director.

Looking back on those years, two things characterize Chem Tech in my mind. First, the division was highly integrated, conducting its own chemical research and development, unit operations work, design, and pilot plant operations. I believe that this integration resulted in better communications and cooperation and in better coordination of effort than I have observed more recently in projects that employ "contemporary"

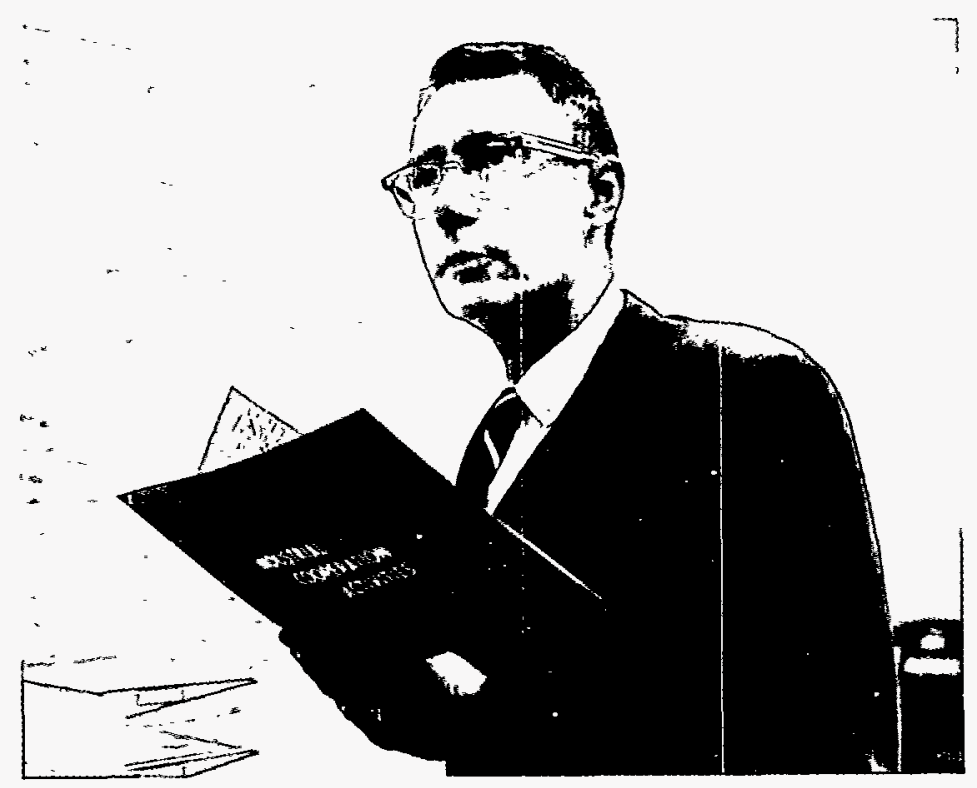

Mr. Frank Bruce, 1975 organizational styles. Second, Chem Tech had a "can do" attitude that just wouldn't quit! And seldom did the division fail in accomplishing its mission. A few of these missions seem worthy of mention.

Chem Tech developed the process that was used for the recovery of enriched uranium from spent MTR fuel and other research reactor fuel as well. It designed the reprocessing plant that was built at Idaho Falls, supervised the plant construction, and managed its startup. This project was a tour de force of Floyd Culler.

Soon after that, Argonne National Laboratory (ANL) developed the Redox solvent extraction process that was to replace the bismuth phosphate precipitation process used at that time to recover plutonium from irradiated fuel at Hanford. There existed at ORNL the pilot plant that had been used originally to demonstrate the bismuth phosphate process before it was installed at Hanford. Chem Tech was asked to modify the pilot plant and to demonstrate the Redox process in it. During the demonstration, Chem Tech discovered that the effectiveness of the ANL flowsheet could be increased more than tenfold by modifying the chemical composition of the feed solution. This modified process was chosen by Hanford as the replacement for the bismuth phosphate process.

A few years later, Chem Tech developed a much improved process for uranium and plutonium purification using TBP as the solvent. This process, the Purex process, was soon installed in Hanford as a replacement for the Redox process. When the plutonium production plant at Savannah River was built, it too used the Purex process. Chem Tech subsequently applied modified Purex processes to other separations problems, including the recovery of ${ }^{233} \mathrm{U}$ from irradiated thorium (Thorex process); the recovery of uranium from Hanford bismuth phosphate wastes; and certain recovery problems at the Fernald Feed Materials Production Center. More recently, when ORNL and Chem Tech became the center for transplutonium element production, the division developed new solvents and designed and built the TRU facility for the job.

No discussion of Chem Tech's accomplishments would be complete 
without mentioning the very important work that was done by Keith Brown and his co-workers on processes for the recovery of uranium from domestic ores. At the time of peak production, practically all of the mills in the United States used these processes.

It is safe to say that Chem Tech has played the leading role in solving the nation's reprocessing problems. When Alvin Weinberg was ORNL's director, he used to say that one purpose of the laboratory was to undertake big projects of national importance that others could not handle. Chem Tech's achievements are testimony to that and have earned the division a lasting place in the history of the country's atomic energy program.

\subsection{CHEM TECH LEADERS, PROGRAMS, FACILITIES, AND ACCOMPLISHMENTS}

Successful organizations seem to be governed by the maxim that the whole is always greater than the sum of its individual parts. It is also true that the most critically important elements in the success of any enterprise, whether research, education, commerce, industry, government, agency, or military, are the individual people staffing that organization. From its inception,
Chem Tech seems to have been favored with capable staff members possessing a rich variety of experience, training, and education. The success of Chem Tech is in no small part attributable to the individual staff members and their collective esprit de corps.

Most of the current Chem Tech staff members (as of early 1992) are shown in Figs. 1.9 to 1.13.

Many of the technical accomplishments of Chem Tech during the past four decades have been achieved because of the effective use of collective groups or research teams. This fact is a tribute not only to the research teams and individual members, but also to the technical knowledge and organizational skills of the Chem Tech leaders. The evolution of the organization and its leaders are embodied in Appendix C.1.

The numerous and diverse activities of a large and complex division such as Chem Tech are difficult to summarize. A litany gleaned from technical progress reports reveals some of that complexity (see Appendix C.2). Later in this history, selected programs and projects will be emphasized in greater detail. Many Chem Tech activities were of considerable national importance to DOE programs. The changing missions and evolving activities are summarized in the appendix.

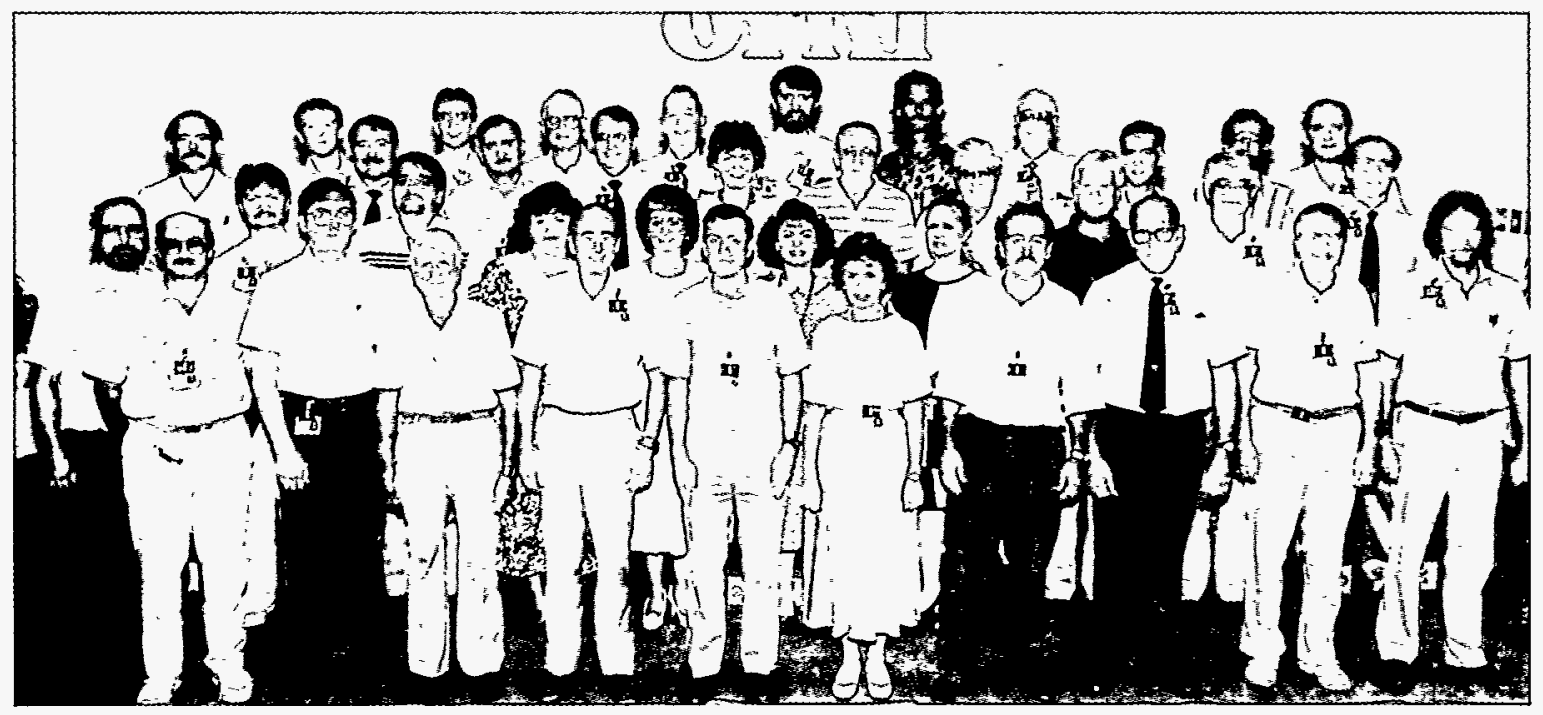

Fig. 1.9. Isotope Technology Section. First row (left to right): C. W. Evans, L. K. Felkner, D. H. Newman, D. B. Owsley, D. F. Williams, B. R. Phifer, T. T. McConnell, E. D. Collins, R. R. Laxson, and G. F. Galloway. Second row (left to right): A. E. Wayland, P. D. Bailey, M. E. Littleton, S. L. Lay, S. C. Owen, C. M. Smoot, L. J. Cotter, J. B. Knauer, J. E. Beaver, R. M. Wham. Third row (left to right): R. T. Barnett, G. L. Johnson, J. C. Glover, W. A. Brooke, J. A. Posey, J. T. Wiggins, C. E. Roberts, R. J. Vedder, S. E. Shell. Fourth row (left to right): R. G. Stacy, T. L. Turner, G. D. O'Kelley, R. G. Ross, G. D. Owen, J. W. McNeely, J. E. Bigelow, F. R. Chattin. 


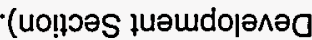

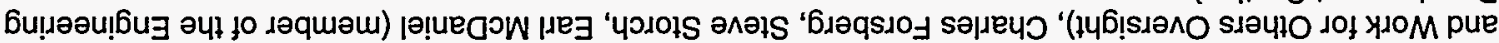

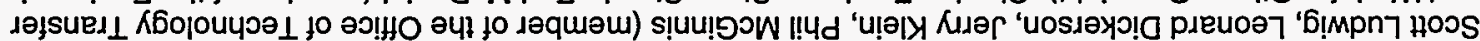

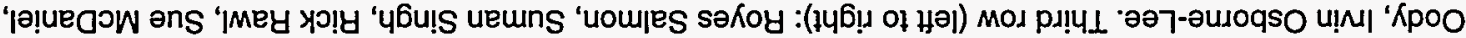

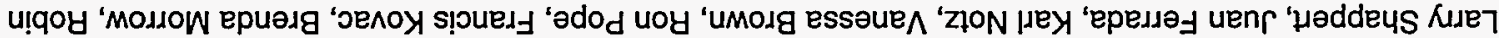

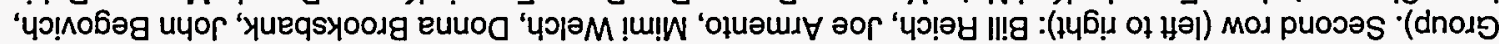

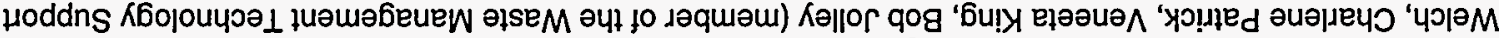

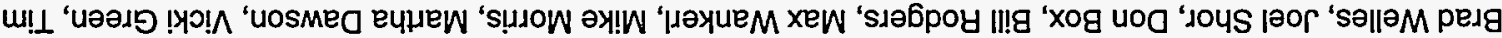

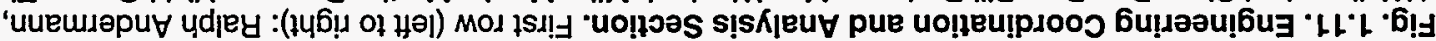

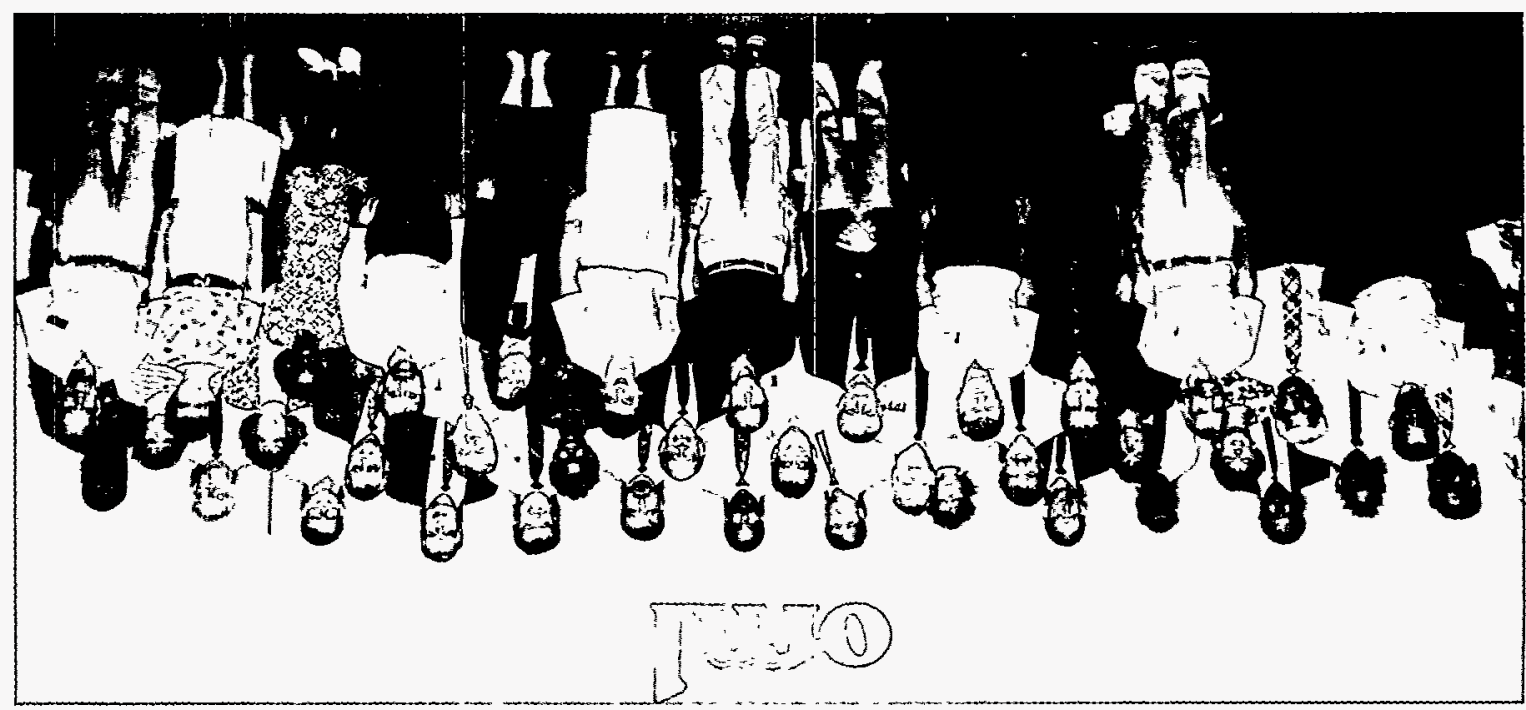

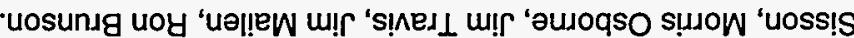

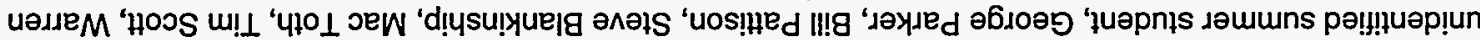

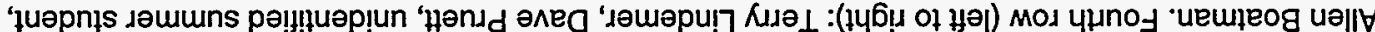

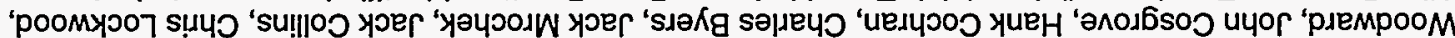

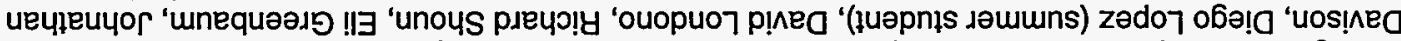

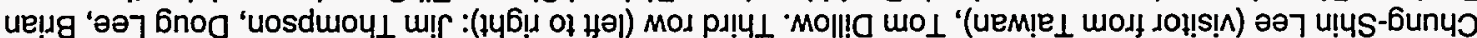
'(uем!e $\perp$ woגf dol!

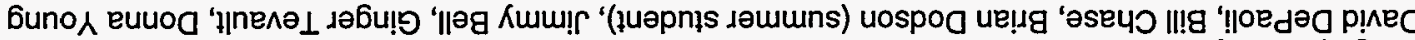

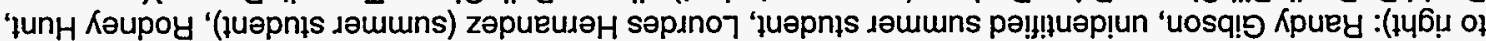
Hә|) Mod puooəs 'dedooว ueis ‘uos!e

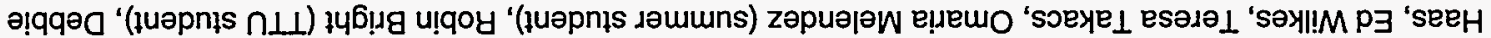

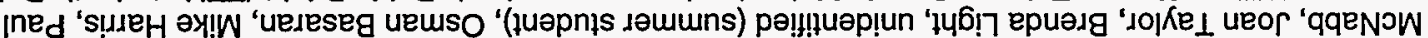

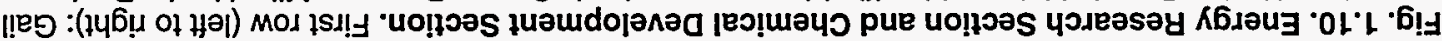

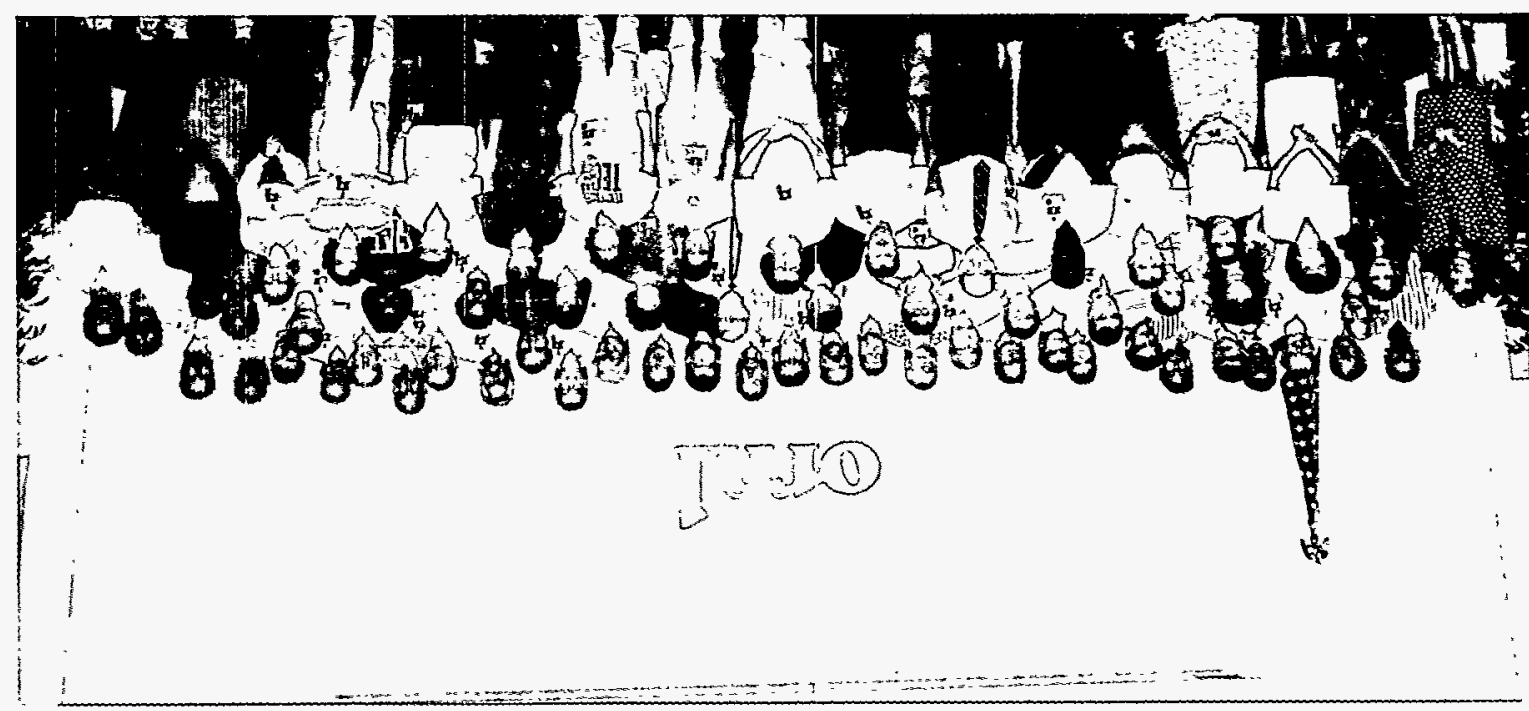




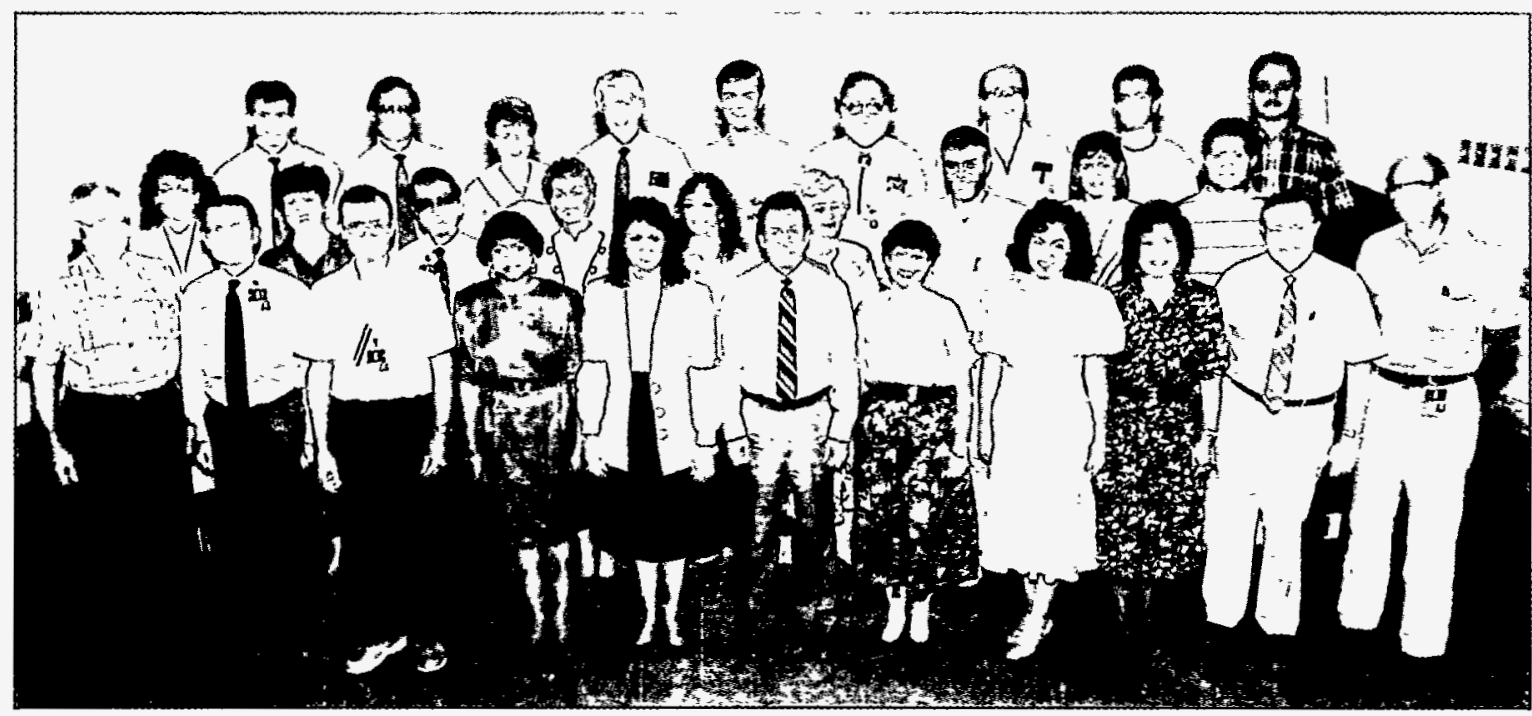

Fig. 1.12. Division Office and Resource Systems Management Section. First row (left to right): Sam Clinton (member of the Office of Safety and Operational Readiness), Allen Doucet, Allen Croff, Anita Sims, Brenda Breeden, Stan Kimmett, Donna Reichle, Debbie Stevens, Rita Camp, Tom Bayles, Norman Lee. Second row (left to right): Donna Ault, Kaye Johnson, K. H. Lin (member of the Radiochemical Processing Program), Jackie Jernigan, Chris Flannery (member of the Radiochemical Processing Program), Jerry King, Kathryn King-Jones, Danny Cochran. Third row (left to right): Ed Kosinski (summer student), Richard Genung, Alice McWilliams, Bob Hightower, Brian Copeland (summer student), Dave Holladay, Jack Maguire, Vic Pardue, Ed Benson.

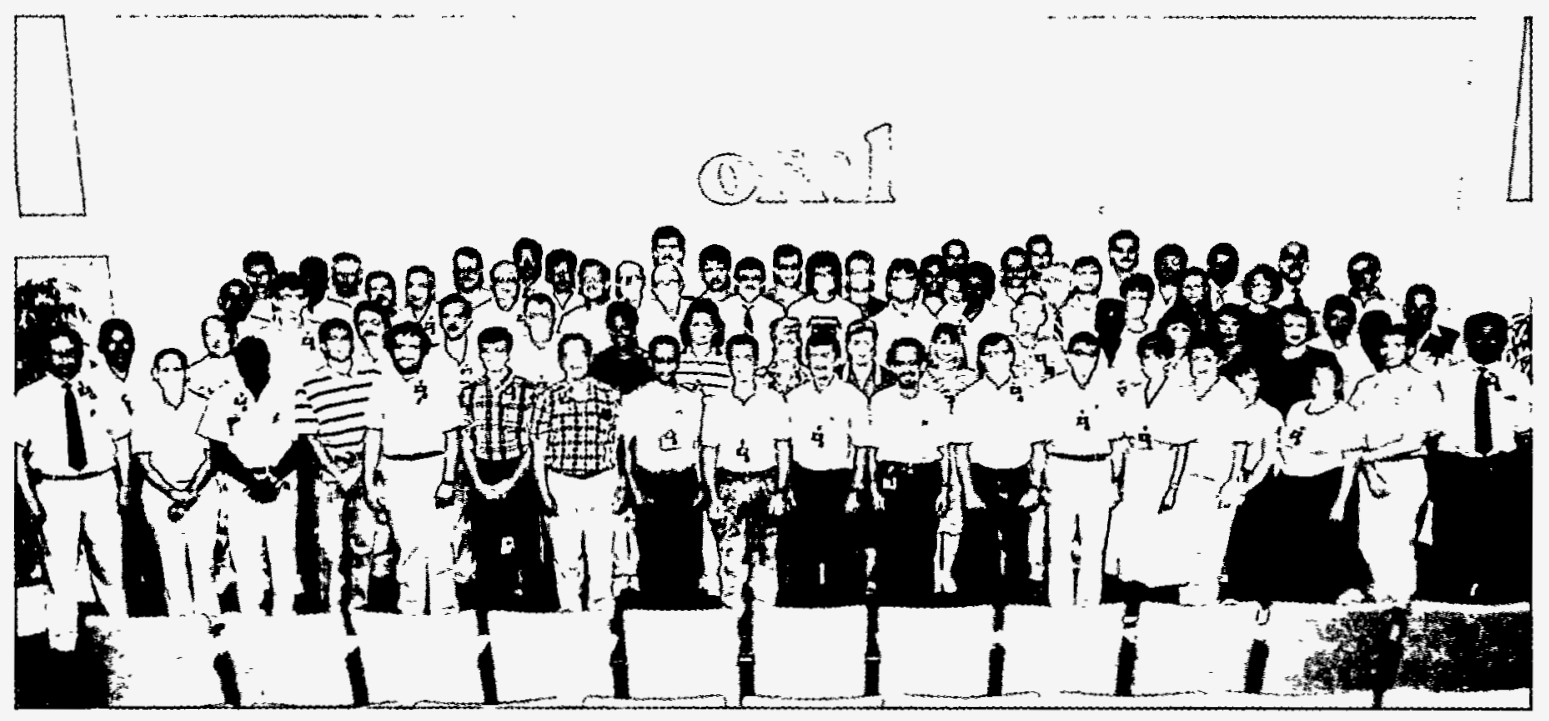

Fig. 1.13. Engineering Development Section and The Radiochemical Technology Section. First row (left to right): R. E. Rosenbaum, J. W. Snider, H. X. Phillips, S. L. Loghry, I. L. Morgan, T. D. Hylton, G. W. Strandberg, J. D. Hewitt, H. L. Jennings, J. H. Wilson, T. L. Donaldson, G. R. Herald, J. J. Perona, L. J. Fields, I. Beaty, S. M. Robinson, L. L. Farr, B. W. Starnes, A. M. Krichinsky. Second row (left to right): R. Hall, A. W. Hensley, D. E. Newton, R. L. Cummins, unidentified staff member, co-op student, B. S. Evans, D. S. Cooper, K. D. Snyder, T. C. Loftis, F. G. Kitts, I. A. Conway, A. B. Walker, M. A. Sedlmeier, C. I. Radcliffe, P. A. Taylor, S. M. Fuqua, C. W. Leinart. Third row (left to right): B. L. Byrum, M. Johnson, R. G. Grubb, C. L. Francis, S. A. Richardson, C. H. Brown, Jr., E. L. Youngblood, B. D. Patton, L. R. Conner, J. W. Shaw, Jr., J. Woodward, E. W. McDaniel, J. M. Lynch, J. M. Butler, N. D. Johnson, B. Z. Egan. Fourth row (left to right): I. G. Gross, D. Foster, Jr., unidentified staff member, S. C. Osborne, R. E. Eversole, unidentified staff member, R. C. Lovelace, M. E. Reeves, A. J. Luccero, L. A. Zevenbergen, unidentified staff member, T. D. Clure, unidentified staff member, J. R. Parrott, J. R. Gibson, R. D. Spence, M. W. Burgess, T. M. Gilliam, R. K. Kibbe, L. G. Hill. 
A large organization with varied missions requires many different types of facilities. Some of the major facilities that Chem Tech has been involved with are listed in Appendix C.3.

Chem Tech researchers have received many honors and awards and have produced numerous patents. Honors and awards are summarized in Appendix D, and patents are listed in Appendix E.

\subsection{REFERENCES}

1. W. E. Thompson, History of the Oak Ridge National Laboratory 1943-1963, ORNL Central File Number 63-8-75 (August 23, 1963).

2. F. G. Gosling, The Manhattan Project: Science in the Second World War, DOE/MA-0417P, U.S. Department of Energy, August 1990.

3. Warren $\mathrm{K}$. Eister, personal communication, February 28, 1992.

4. R. Beecher Briggs, "History of the Research Reactor/Engineering Technology Division," unpublished draft report, December 1990. Draft supplied to authors January 1992.

5. M. C. Leverett, personal communication, 1991.

6. Chemical Technology Division Progress Report for Quarter Ending February 28, 1950, W. K. Eister, Ed., ORNL-663.

7. Chemical Technology Division Progress Report for Quarter Ending May 31, 1950, W. K. Eister, Ed., ORNL-763.

8. Chemical Technology Division Progress Report for Quarter Ending August 31, 1950, W. K. Eister, Ed., ORNL-846.

9. Chemical Technology Division Progress Report for Quarter Ending February 20, 1951, W. K. Eister, Ed., ORNL-1000.

10. Laboratory Council-Policy Meeting, February 19, 1943, University of Chicago Report CS-479.
11. Organizations of the Metallurgical Unit, Development of Substitute Materials Division $O R S D$, University of Chicago Report CA-436, January 25, 1943.

12. Research Program at the Clinton Laboratories, July 6, 1943, University of Chicago Report CS-764.

13. Personnel of Metallurgical Laboratory as of August 1, 1943, University of Chicago Report CA-840.

14. Special Meeting-Project Council, August 30, 1943, University of Chicago Report CS-912.

15. Project Council-Policy Meeting, October 20, 1943, University of Chicago Report CS-1004.

16. O. H. Greager, Separations Development Division Final Report, Development of a $\mathrm{LaF}_{3}$ Concentration Cycle, University of Chicago Report CN-1420.

17. W. C. Johnson, Report for the Chemistry Division for the Month February 15-March 15, 1945, University of Chicago. Report CN-2596.

18. M. C. Leverett, Technical Division Semimonthly Report for Period Ending October 15, 1944, University of Chicago Report M-CN-2193.

19. M. C. Leverett, Technical Division Semimonthly Report for Month Ending October 20, 1945, Monsanto Chemical Company Report MonN-25.

20. W. E. Thompson, "Clinton Laboratories-the War Years," Oak Ridge National Laboratory Review 6(2): 16-22 (1973).

21. A. Weinberg, personal communication, 1991.

22. H. Postma, personal communication, August 30 , 1991.

23. D. E. Trauger, personal communication, 1991.

24. F. R. Bruce, personal communication, 1991. 


\section{THE FORMATIVE YEARS: NUCLEAR FUEL REPROCESSING}

Chem Tech possesses several attributes that contributed in a large part to its success as an ORNL division. First is that we started out small but we learned like crazy. ... Second and probably the most important is the spirit of Chem Tech. I have never thought of a better word than "gung-ho." .. . Third is that we teamed with other divisions as routinely as we worked with our own.... Everybody felt an urgency and somehow we managed to keep it alive... The reason is we kept getting big problems-one after another.

Floyd L. Culler

June 18, 1992

\subsection{EARLY HISTORY}

Even when first established in 1950, the Chem Tech Division and staff were located in several buildings because of the size and diversity of activities, namely, the director's office and the Laboratory Section, Building 3550 (formerly 706-A); the Design Section, Building 2067 (formerly 703-A Annex); the Unit Operations Section, Buildings 3502 and 3503 (formerly 706-HD and 706-HB); and the Pilot Plant Section, Building 3019 (formerly 205). ${ }^{1}$ Figure 2.1 provides an aerial view of the X-10 site taken about 1944 showing Buildings 2067, 3503, 3019, and 3550. In 1951, Building 3505 (newly constructed Metal Recovery Plant) was occupied and Building 3508 for work with high alpha activities was occupied in $1952 .{ }^{2}$ Buildings 3505 and 3508 are shown in Fig. 2.2, a photograph of the X-10 site taken about 1960.

Essentially all the activities of the Chemical Technology Department of the Technical Division were transferred to the newly created Chemical Technology Division. The major activities assigned to the new division dealt with the design of the Idaho Chemical Processing Plant (ICPP); the development of the metal recovery TBP process for the recovery of uranium from ORNL and Hanford metal waste; the development of the Purex process for the recovery of uranium and plutonium from Hanford irradiated metal; the development (with Isotopes Division) of the RaLa process for separation of barium and lanthanum from fuel units; homogeneous reactor fuel studies; and the design/construction of the ORNL Metal Recovery Plant (Building 3505). 1,2

Chem Tech work in the early 1950s was focused almost entirely on fuel reprocessing and the design and construction of particulate cleanup facilities for the graphite reactor. In addition to studying the chemical problems associated with the Purex process and the RaLa process, the Laboratory Section was concerned with the solvent extraction separation of fission products, Volatility process, TBP process, and the recovery of thorium by the Thorex process from 23 Process waste. The Process Design Section conducted studies on liquid and gaseous waste disposal for ORNL and, also, design work for the ICPP, the ORNL Metal Recovery Plant, and a RaLa plant modification. The ICPP was designed to separate ${ }^{235} \mathrm{U}$ from spent fuel from the MTR, the Enriched Breeder Reactor, and other reactors proposed to use ${ }^{235} \mathrm{U}$ for fuel. The Unit Operations Section started chemical engineering studies of radiochemical processes involving evaporation, solvent extraction, and ion-exchange and continued unit operation-scale studies of the TBP process and the RaLa process. The Pilot Plant Section completed programs on the 23 process, recovery of plutonium from the IBP waste resulting from the Redox pilot plant study, and recovery of plutonium from Chalk River irradiated metal. $1,3,4$ 


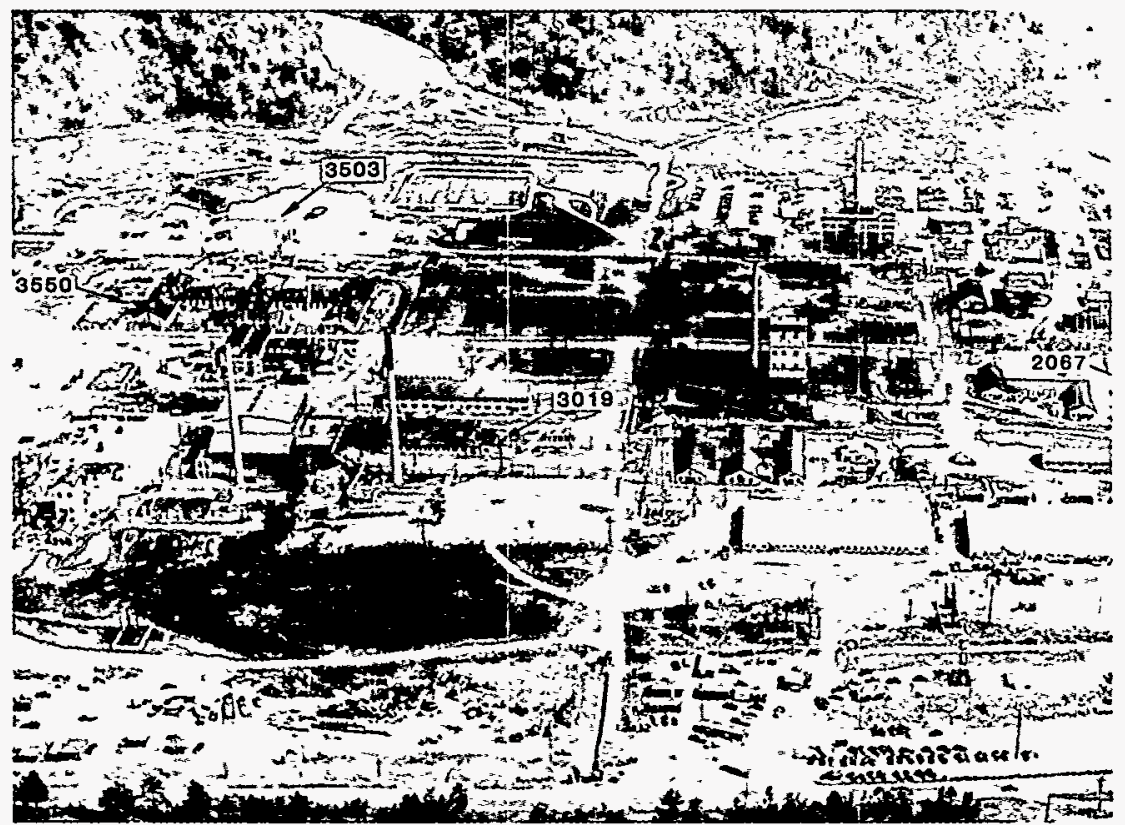

Fig. 2.1. An aerial view taken during the fall of 1944 of the Clinton Engineer Works, X-10 site, looking southward. Several buildings housing Chem Tech predecessor groups are identified: Laboratory, Building 3550 (formerly 706-A); Design Section, Building 2067 (formerly 703-A Annex); Unit Operations Section, Buildings 3502 and 3503 (formerly 706-HD and 706-HB); and the Pilot Plant Section, Building 3019 (formerly 205). Building 3502 (formerly 706-HD) had not yet been constructed but is located immediately east (to the left) of 3503 .

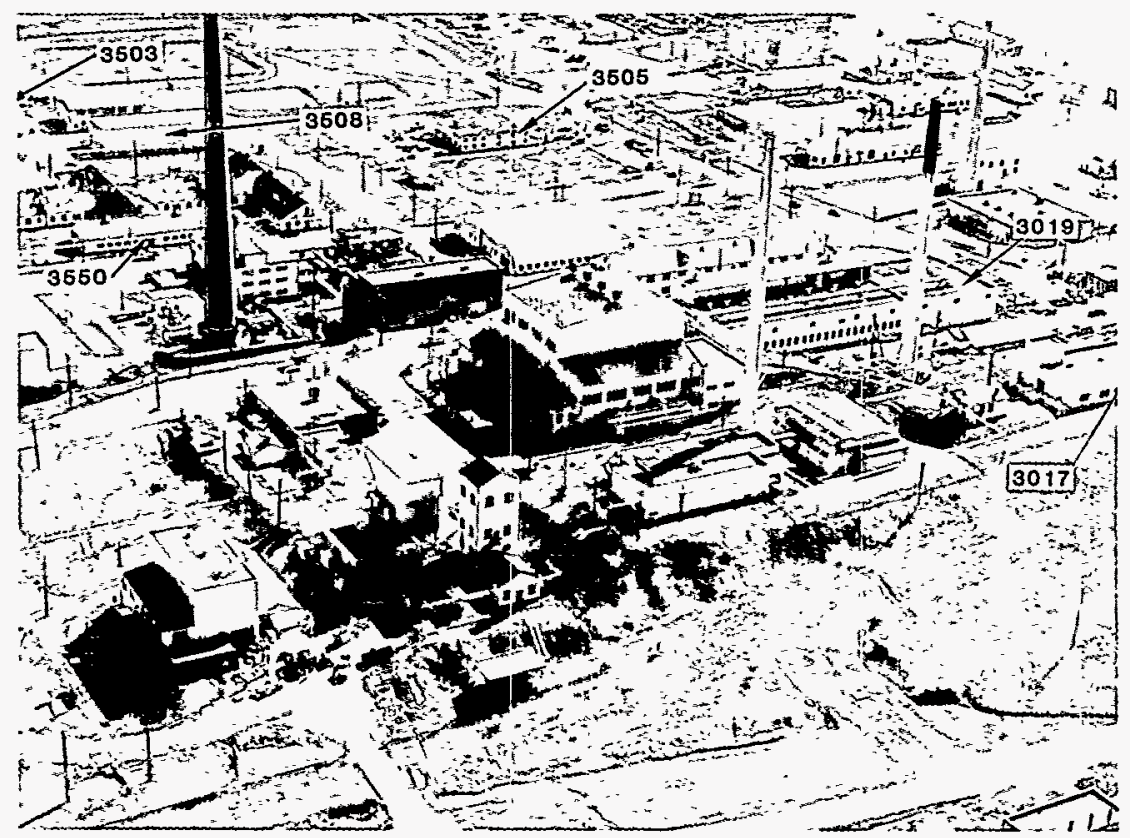

Fig. 2.2. An aerial view taken about 1960 of the Oak Ridge National Laboratory, X-10 site, looking southwesterly. The photograph shows Building 3505 (Metal Recovery Plant) and Building 3508 (High Alpha Laboratory). Also identified are 3503, 3550, 3019, and 3017 (later to be enlarged and occupied by Chem Tech personnel). 


\subsection{OVERVIEW OF NUCLEAR REACTORS}

Even though the major objective of the wartime nuclear reactor program was production of the weapons materials, the potential use of nuclear reactors for production of thermal and electric power did not escape the attention of farsighted engineers and scientists. With the cessation of wartime activities, nuclear $R \& D$ evolved rapidly toward the goal of nuclear electric power. Production reactors generally used aluminum-clad natural or low-enriched uranium fuels coupled with carbon or graphite to moderate the energy of the neutrons produced during fission of uranium, plutonium, and other fissile fuel materials. However, many different electric power reactor concepts were soon proposed, including solid fuel element, molten fuel, and fluidized-bed systems.

The worldwide preponderance of power reactors appears to employ solid fuels and may be divided into four classes: (1) pressurized-water reactors (PWRs) and boiling-water reactors (BWRs) that use light water $\left(\mathrm{H}_{2} \mathrm{O}\right)$ as both coolant and moderator; (2) heavy-water $\left(\mathrm{D}_{2} \mathrm{O}\right)$-moderated, pressure tube reactors that may use light water, heavy water, or other materials as coolants;

(3) gas-cooled graphite-moderated reactors; and

(4) fast reactors cooled by sodium or by helium. 5

Light-Water Reactors. BWRs and PWRs use $\mathrm{UO}_{2}$ pellets enriched to 2 to $4 \%$. The pellets or pins $(1 \mathrm{~cm}$ in diameter) are clad in Zircaloy and arranged in a square lattice with up to 200 pins per fuel assembly. PWRs and BWRs are depressurized every 12 to 18 months for partial refueling. BWRs operate at about one-half the pressure required in PWRs. Reactivity is controlled by burnable poisons (thermal neutron absorbers) and control rods. 5

Heavy-Water Reactors. Heavy-water reactors use natural uranium and, consequently, must be continually refueled. Fuel assemblies containing $\mathrm{UO}_{2}$ pins clad with zirconium are arranged in series within pressure tubes. Reactivity is controlled by moderator levels and control rods. 5

Gas-Cooled Reactors. Natural uranium can also be used in graphite-moderated gas-cooled reactors, such as the carbon dioxide-cooled Magnox reactor developed by France and Great Britain. The Magnox reactor was named after the magnesium-based cladding used on the uranium-metal fuel elements. Gas-cooled reactors must be refueled on a continuous basis. The high-temperature gas-cooled reactor uses helium coolant with slightly enriched uranium carbide/thorium carbide fuel in a ceramic core. 5

Fast Breeder Reactors. Fast breeder reactors use a fast-neutron spectrum.system fueled with plutonium and/or ${ }^{235} \mathrm{U}$, with ${ }^{238} \mathrm{U}$ as the fertile material. The fuel elements are uranium-plutonium oxide pellets enriched 15 to $20 \%$ in stainless steel cladding, measuring about $0.25 \mathrm{in}$. in diameter. The reactor core is surrounded by a blanket of uranium oxide pins. Both sodium and helium have been proposed as coolants. ${ }^{5}$

Nuclear Power Reactors and Supporting Industry. Nuclear power reactors require a large supporting fuel cycle industry. For example, the principal components of the complete light-water fuel cycle are the following: 6

- Mining and milling to obtain a uranium oxide concentrate

- Refining the ore and converting it to $\mathrm{UF}_{6}$

- Uranium isotopic enrichment

- Fabricating $\mathrm{UO}_{2}$ fuel elements

- Reprocessing the irradiated fuel to recover fissionable materials (uranium and plutonium) for recycle

- Long-term waste management

Chem Tech was historically involved in all aspects of the nuclear fuel cycle. However, in April 1977, U.S. President Carter implemented a new nuclear policy that deferred indefinitely the commercial reprocessing of nuclear fuels and recycle of plutonium in light-water reactors and also delayed a decision on the use of plutonium in the liquid-metal fast breeder reactor (LMFBR) then under development. ${ }^{6}$ One effect of this policy was a decrease in national emphasis on $R \& D$ in nuclear fuel reprocessing.

\subsection{BRIEF HISTORY OF NUCLEAR FUEL REPROCESSING}

Because the history of nuclear fuel reprocessing and Chem Tech are so intertwined, this section presents an overview of fuel reprocessing prepared by Chem Tech staff members J. R. Hightower and R. E. Brooksbank, Sr. ${ }^{7}$

The first large-scale nuclear reactors were built during World War II. These reactors were designed for the production of plutonium for use in nuclear weapons. The only chemical reprocessing required, therefore, was the extraction of the plutonium, free from fission product contamination, from the spent 
natural uranium fuel. In 1943, several methods were proposed for separating the relatively small quantity of plutonium from the uranium and fission products. The first method selected, a precipitation process called the bismuth phosphate process, was used at ORNL during the period 1943 to 1945 to produce quantities of plutonium for evaluation and use in weapons programs.

The bismuth phosphate process was first operated on a large scale at Hanford, Washington, in the latter part of 1944. It was successful for plutonium separation in the emergency situation existing then, but it had a significant weakness, namely, the inability to recover uranium. However, the first kilogram quantities of plutonium were produced in the half-ton-per-day pilot plant in Building 205 (now Building 3019) at ORNL.

Even before the bismuth phosphate process was chosen as the basis for the design of the Hanford plutonium separations plant, research on other methods for treating spent fuel-namely, volatility, adsorption, and solvent extraction-had been initiated. Significant advances in chemical reprocessing methods were made during the immediate postwar period, particularly with methods using solvent extraction. The basic principle upon which solvent extraction is based is that the nitrates of uranium and plutonium in the higher oxidation states are readily soluble in certain organic liquids which are immiscible with water. The nitrates of fission products are, in general, essentially insoluble in these liquids.

The first successful solvent extraction process for the recovery of both uranium and plutonium in decontaminated form was developed at Argonne National Laboratory (ANL) soon after World War II. Methyl isobutyl ketone (hexone) was used as the organic solvent, and aluminum nitrate was added to the aqueous phase to improve the separation. Pilot plant testing of this process, the Redox process, was carried out with available equipment at ORNL (Building 3019) from 1945 to 1951, and large-scale operation began at Hanford in October 1952. The Redox process offered advantages over the bismuth phosphate process of (1) continuous operation; (2) a large decrease in waste volume; and (3) the ability to recover uranium as well as plutonium.

From 1948 to 1950, while the Redox process was under development, laboratory studies were being made on an improved solvent extraction process. This new method was called the Purex process and employed TBP as the organic solvent and nitric acid rather than aluminum nitrate in the aqueous phase. The Purex process was developed by ORNL and Knolls Atomic Power Laboratory (KAPL) and was carried through the pilot-plant stage at ORNL (Building 3019) from 1949 to 1960. It offered four significant advantages over the Redox process:

1. a reduction in waste uranium,

2. greater process flexibility,

3. decreased solvent fire hazard, and

4. a decrease in operating costs.

A major driving force in the development of the Purex process was waste reduction. The aluminum nitrate used as a salting agent in the Redox process resulted in large amounts of waste whose volume was controlled by the solubility of aluminum nitrate. Purex used nitric acid instead, thereby allowing a large fraction of the salting agent to be recovered and recycled and, in turn, the volume of waste to be significantly reduced. (Contributed by W. W. Pitt, Jr., and F. E. Harrington, July 15, 1993)

The new process was put into operation at the Savannah River site at Aiken, South Carolina, in November 1954 and at Hanford in January 1956. All foreign reprocessing plants use the TBP process.

Since 1944, reprocessing has been practiced under the auspices of the government at one or more of the defense installations at the Savannah River Site near Aiken, South Carolina; at Hanford, Washington; and at Idaho Falls, Idaho. However, the growth of nuclear power generation in the 1960-1970 period prompted the government to encourage the entry of commercial firms into the reprocessing sector of the fuel cycle to recover unburned uranium and plutonium from fuel assemblies discharged from commercial power reactors. Accordingly, the first commercial reprocessing plant was constructed, and a provisional operational license was granted in 1966 to Nuclear Fuel Services (NFS) for a plant in West Valley, New York. During the period, other firms became active in pursuing commercial reprocessing of irradiated fuel from the nation's reactors. These firms include General Electric Company (GE), Allied Chemical Corporation, National Lead Company, Atlantic Richfield Company, the Gulf Oil Corporation, and Exxon Corporation. Based on a series of studies, GE elected to build the Midwest Fuel Recovery Plant (MFRP), a 1-metric-ton-of-heavy-metal (MTHM)/d plant in Morris, Illinois, employing the 
Aquafluor process, which differs considerably from the standard Purex process employed in other plants. A third plant of appreciably larger size (5 MTHM/d) was then constructed by Allied General Nuclear Services (AGNS) in Barnwell, South Carolina.

The NFS plant successfully operated for a period of 6 years, during which time a total of 641 tons of irradiated fuel was processed. In order to become more competitive, the plant was shut down in 1972 to increase its capacity from 1 to $5 \mathrm{MTHM} / \mathrm{d}$. As a result of a series of new and retroactive regulations placed on the reprocessing sector by regulatory groups, mainly in the seismic area, the owners of the plant concluded that the cost of compliance with the new regulations for an expanded plant could not be justified and decided not to reopen the plant. Under terms of its operating permit from the state of New York, plant ownership reverted to the state.

In the case of the MFRP, the company decided not to proceed with the operation of the as-built plant following a series of operational difficulties experienced after a lengthy testing period. The difficulties were associated with the operation of a new process employing complicated equipment operating in a remote mode behind heavily shielded walls. No radioactive materials were involved in checkout testing.

The third commercial plant, built during the 1971-1975 period and owned by AGNS, has been completed but has yet to operate. Efforts to license and operate this plant were terminated by a commercial reprocessing moratorium in response to proliferation concerns expressed by President Carter.

Exxon was designing a modern reprocessing plant that was scheduled to be built in Oak Ridge, Tennessee; however, because of the moratorium, it was also canceled.

In spite of the dormant conditions of commercial reprocessing in the United States, separations technology has continued to evolve throughout the world and fuel reprocessing activity has advanced in several nations. The processes used are derived from development and pilot plants demonstrated in the Chemical Technology Division. Plants currently exist in the United Kingdom, France, Japan, India, Belgium, West Germany, China, and the Soviet Union. In addition to the processing of spent fuels from light-water reactors, development of the technology necessary for the reprocessing of fast reactor fuels is advancing at a rapid pace in these nations. The United States has also been active in the development of this technology by way of research carried out in universities and government-owned laboratories.

\subsection{THE CHEMICAL TECHNOLOGY DIVISION AT ORNL FROM 1943 TO 1961: Recollections of Warren Eister, September $1991^{8}$}

Division Name. On the way to the cafeteria, I suggested to Frank Steahly we name our new organization the Chemical Technology Division. There were several reasons: Our chief competitor at Argonne had already adopted the name of Chemical Engineering; second, we had a strong group of chemists as well as chemical engineers; but foremost, Frank had just pulled together three individualistic groups that needed a clear statement of who they were going to be. I do not recall the exact time, but it probably was a few years after Monsanto took over from Du Pont. My following recollections will lack similar chronologic and factual precision.

Organization. The nucleus of Chem Tech was the chemistry laboratory and Semi-works, and to these parts were added the pilot plant and process design groups. All of these had been part of the Technical Division, which had responsibilities for both process and reactor development under Miles Leverett. To divide the reactor and process responsibilities, Frank Steahly was transferred from the Chemistry Division to the Technical Division and became one of the few Ph.D.-level staff members in the new organization. While Steahly was our first director, I don't know who originated the action.

At the beginning, Frank Bruce directed Chemistry and I directed the Semi-works, with both of us reporting to Steahly. Then Don Reid joined the organization with responsibility for the Pilot Plant and Floyd Culler for Design. Most of us had remained behind when Du Pont moved to Hanford, but Floyd hired in from Y-12. Then Jim Davis joined us from the Synthetic Rubber Program and took over the Semi-works and I became Steahly's assistant. By this time I had changed the name of the Semi-works to Unit Operations, but it might have more properly been named Unit Processes. 


\subsubsection{At the Beginning}

The Start. Going back to creation, the Technical Division, the parent of Chem Tech, had been established by Du Pont at the Clinton Laboratories, $\mathrm{X}-10$ for the engineering development of

- safety procedures for nuclear operations;

- graphite nuclear reactor for production of plutonium; and

- the bismuth phosphate process for recovering plutonium from irradiated reactor fuel.

My First Encounter. I came to X-10 from the Indiana Ordnance Works where Du Pont manufactured smokeless powder. At that location, in 1942, success meant moving back to Wilmington, Delaware. In 1943 folks were going to Chicago, and in May of that year Ted Arehart and I were the first from Du Pont to be sent to Knoxville. Our instructions were "Stand on the street corner in front of the Farragut Hotel at 7:00 a.m. on Monday and someone will pick you up. You'll contribute more than in the army." I was there on time, and at midnight that same day I trudged through rain and mud to an open-sided building to look for pimples on aluminum-jacketed slugs. I went to The University of Tennessee library on my first day off with the suspicion that uranium was in those slugs. I found a lot of information on uranium, including ${ }^{235} U$ separation in cyclotrons and driving a car around the world using a pellet as the fuel. The day after, I exchanged this knowledge with a few fellow inspectors. The next day, in a room with a drawn blind, three straight-backed chairs, and an old, bare, battered oak desk, I huddled with Julian Ellett and Jack Frame. There, in a few minutes, they introduced me to plutonium and the bomb. The slugs were the fuel to go into the graphite reactor, the pile. This revolutionary revelation frightened me! It was the easiest secret I ever kept.

\section{Bismuth Phosphate (BiP) Process and the} Semi-Works. In August, I went to the Semi-works to work for Don Johnson. There were about five of us on each of four shifts. With one craftsman from maintenance, Glen Ricker, we put together a uranium dissolver followed by six cycles of precipitators and centrifuges. When I arrived, there was a two-story room (about $60 \mathrm{ft}$ by $60 \mathrm{ft}$ ) with a balcony and a row of four concrete hot cells on the west wall. The room was crowded with a bunch of stainless steel tanks, iron drums, pipe, plastic tubing, centrifuges, valves, and other equipment.

Our group came mostly from the smokeless powder plants. There were also military servicemen who included Tex Blomeke, Nelmar Rigstad, Ed Johnson, George Havorka, and Joe Savolainen. They were chemists or engineers who had been drafted and then sent to help. Of the civilians, Irwin Higgins stands out in my memory as our welder, although he was actually a biochemist raised on a potato farm in Maine.

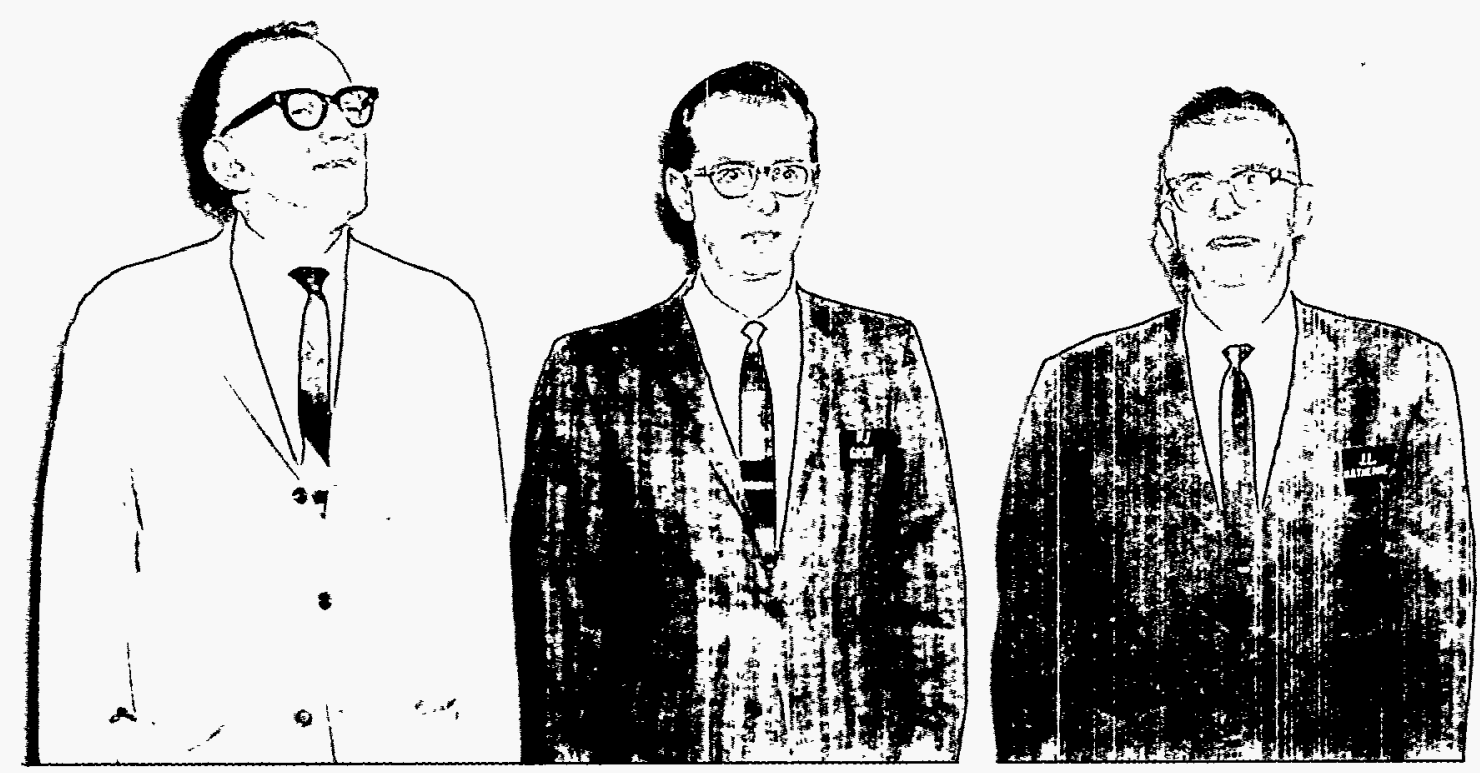

Chem Tech staff members Warren Eister (left) and Joe Matherne (right) with a Chemical Technology Division Information Meeting guest (about 1960). 
Marshall Aken, our chief, and Joe Work, the data analyst, had been members of Du Pont's group of six that evaluated the government's request to participate in the Manhattan Project. Crawford Greenwalt, later Du Pont's CEO, was the group leader. In addition, Luther Perry, Dick Apple, and Vance Cooper carried out special assignments for Aken. When Du Pont returned for the Savannah River Project, Lu Perry was the Du Pont on-site coordinator at Chem Tech. Joe Work and I were associates in the DOE high-level-waste disposal when he retired. For Joe's retirement party, I found Marshall Aken in a retirement village in Chevy Chase; Marshall was to be our mystery guest. While neither of us had seen Marshall for 40 years, Joe recognized him immediately when Marshall standing behind him said, "Hello, Joe."

It seems that by Christmas, the system was operating with natural uranium and simulated plutonium and fission products. The hot cells were closed with concrete blocks except for No. 2 , which had a lead door that I don't recall ever using. In addition, there were three concrete block cells in the middle of the room. Then the "hot" tests started using irradiated uranium slugs from the reactor. Using a 10-ft cherry picker, we hustled the slugs, one at a time, from a lead-shielded container on a flat-bed truck and dropped them into a funnel to the dissolver. We all wanted our turn at driving the truck up to the reactor. Until that time, only Maintenance had trucks.

The fission product decontamination factors for the Semi-works plutonium separations were terrible, and I remember John Swartout watching me on a midnight shift as I was enthusiastically braking the centrifuge. He suspected, correctly, that I was "throwing the baby out with the dishwater." The final demonstration employed a significant portion of the country's supply of plutonium split four ways. (I still wonder where that plutonium came from!) Everyone was there to watch the start of the operation. The plant manager, in a small midday ceremony, added the first batch to the first precipitator. His representative was there for the second batch, and our group leader for the third batch on the night shift. I don't remember the fourth batch since the third was, for me, a personal disaster. There were now three people on our midnight shift plus two recent trainees for the pilot plant. The shift leader was off at the time, and his number 2 man was in his office almost incapacitated because of a severe foot problem. Most of the cells were operating, and I was directing the activities of the trainees while running a couple myself. A trainee centrifuging Run No. 3 in Cell No. 4 called over to me that he was not getting a reading on the catch tank manometer. Many of the manometers had air leaks necessitating higher airflow, so I told him to increase the airflow. After several increases in airflow and more than half of the feed discharged, the awful truth was learned-Cell No. 4 was the only location discharging to the waste tank. The next day, Run No. 3 was scrapped. While I had dumped $25 \%$ of the world's supply of plutonium into the waste tank, it may have upgraded our controls.

Following this BiP work, Du Pont departed and planned to send me back to Indiana Ordnance for rocket powder manufacture. Pete Peterson convinced me to stay on and we started work on the thorium cycle, $\mathrm{RaLa}$, and Redox processing. It was during this time that Don Ferguson came to work with me in the Semi-works plant from Tennessee Tech. Having to work shifts and with the group leader having the only office made it a very undesirable place to work. It was known as the "salt works." Don soon wondered to me whether he shouldn't just move on. I suggested he stick it out a bit longer. In time he moved on to Frank Bruce's chemistry group where they had more desks and day work.

Redox Process and Chicago Adventures. A major development! Seaborg's group at Chicago had come up with a solvent extraction process that separated uranium as well as plutonium from the irradiated uranium. X-10 was again going to do the Semi-works and pilot plant development. Here was a chance for some chemical engineering calculations of theoretical stages in a countercurrent solvent extraction column. BiP had none of this sophistication. Also, there was now an excuse to see the West Stands, University of Chicago, where the Chicago work was being done.

On my first trip to the West Stands, I got the chance to run a model of the Fermi Pile. Using a servo, the control rod was raised and I could follow the neutron flux on a mirror-type potentiometer. However, no one at Chicago knew anything about theoretical stage calculations in the solvent extraction process. Steve Lawroski, a Ph.D. chemical engineer from Penn State, had departed for the reactor school starting up at X-10. It was a relief to find Chicago as uninformed as we were. I went out with the Chicago solvent extraction group 
for a terrific Chinese lunch, and we became "birds of a feather."

\section{Acid-Deficient Redox Process and} Three-Dimensional Designs. Nelmar Rigstad, at a drafting table in the operating area of the Semi-works plant, created a three-dimensional design of the first Redox cycle for Cell No. 2. I had recently seen something on three-dimensional design and had bought the appropriate triangles. It took Riggie about two weeks to design and Glen Ricker and a couple of helpers about three months to install. It came in over budget, costing $\$ 20,000$ instead of my estimate of $\$ 10,000$.

In the meantime, Frank Bruce's group had investigated the effect of $\mathrm{pH}$ on the decontamination factor (DF). By partially neutralizing the aluminum nitrate salting agent, the DF was increased from about 100 to about 1000 . We had invented the acid-deficient Redox process. It made us feel much better about our research. We soon developed modifications for the recovery of enriched uranium from test reactor fuel (the 25 process) and ${ }^{233} \mathrm{U}$ from irradiated thorium (the 23 process). When I started the design of the semi-works unit for the 23 process, I assigned the job to Bob Klotzbach and Bob Milford. They revolted when asked to use the three-dimensional approach and insisted on taking the job to the plant design group. They did a good job. The unit worked well, but the job took more than a year, and this installation alone cost over $\$ 100,000$. They never returned to the Semi-works group.

Hexone vs Tributyl Phosphate and Purex Revisited. The first society-type technology exchange meeting was held at the Chicago Museum of Science and Industry. Attendance was restricted since classified data were to be reported. At the meeting I met Glen Seaborg and, more importantly, Ray Fisher from the Ames Laboratory at Iowa State University. After trying to impress Ray with our contributions to the Redox process, which was replacing BiP at Hanford, Fisher asked why we hadn't used tributyl phosphate (TBP) for the solvent instead of the hexone, used in Redox since TBP was stable in nitric acid. We had to use aluminum nitrate with hexone, and this loaded up the waste tanks.

Our Chem Tech forces were devoted to Redox/hexone systems, and it was several years before TBP was seriously considered both for the recovery of uranium from the $\mathrm{BiP}$ waste and for application at Savannah River for plutonium recovery. It seems to me that uranium recovery came first. Charles Runion, Charles Ellison, and Bill Lanham were recognized on the patent. It was exciting to have Du Pont select the Purex process for Savannah River. Manson Benedict headed the selection team. He had gained recognition in the development of the gaseous diffusion process for ${ }^{235} \mathrm{U}$ separation, and I looked forward to meeting him when his team came to X-10 to review our Purex studies. I almost missed him. He was the quiet fellow taking copious notes and occasionally asking questions in this impressive group. I never did actually meet him!

Mixer-Settlers vs Pulsed Columns. It was a severe personal disappointment when they selected mixer-settlers instead of the pulsed columns used in our Chem Tech pilot plant for the solvent extraction operation. Pots Chambers, who was the technical leader of the Du Pont team, visited monthly to review the status of our Chem Tech activities. Afterward, we usually went to the Park Hotel in Clinton for steaks. It was very pleasant; however, one day in the 703A conference room he said he wanted to tell us something we were not going to like-Savannah River was going to use the mixer-settlers being developed at KAPL. Maybe that was the night at the hotel when steak juices were dumped on Pots's new dacron suit. It didn't bother him a bit. He scrubbed it with wet rags, and it dried before we got home. He wore it the next day.

Purex Model for Geneva. When the first Atoms for Peace meeting was being planned for Geneva, I recommended, designed, and took an operating model of Purex to the meeting. While Tom Cole's operating reactor exhibit received the most attention, our Purex unit with Admiral Strauss operating the manipulators was the background for the TV program, "Youth Wants to Know."

\subsubsection{Chem Tech Accomplishments}

Purex Process and Solvent Extraction. During my time, the development of the Purex process was Chem Tech's most important achievement. Earlier, the other significant development (but attributable to Du Pont's management and the University of Chicago's chemistry) was the Semi-works and pilot plant phases of the BiP process for the first large-scale plutonium recovery at Hanford. This was followed by the first solvent extraction processes, Redox-25 and -23 processes.

Idaho Chemical Process Plant. The most complete job related to the ICPP needed to recover 
the enriched uranium from test reactor fuels. This work included the chemistry and process engineering development, along with the design of the plant. The design assumed direct maintenance of the equipment as employed in the Chem Tech pilot plant. While the ICPP is still operating, remote maintenance seems more attractive to achieve reliable performance. However, at this time I am not aware of a comparative analysis of direct vs remote maintenance for radioactive operations.

Isotope Separations and Production. In addition, Chem Tech made numerous essential contributions to most of the other radiochemical process requirements of the young nuclear industry. These included the separation of thorium, ${ }^{235} \mathrm{U}$ and ${ }^{233} \mathrm{U},{ }^{238} \mathrm{Pu},{ }^{140} \mathrm{La}$, and the transuranic elements through ${ }^{252} \mathrm{Cf}$. The isotopic separation of lithium was a major activity, but a Y-12 process, COLEX, was chosen over Chem Tech's OREX process. Waste treatment, while the incentive for the Purex process, seemed always to be a secondary interest. Of course, for me, a spectacular event was the evaporator explosion at the pilot plant since, at the time, I was the Division Safety Officer.

Other Oak Ridge groups, now part of Chem Tech, contributed to uranium ore processing and radioactive and stable isotope production.

Radioisotope production was a Semi-works task until Art Rupp came back to take this work and, along with Eddie Beauchamp, form the Isotopes Group.

Ion Exchange and Fuel Element Shearing. The Higgins continuous ion-exchange column and the shear to prepare the stainless-clad power reactor fuel for dissolution seem to be the major process equipment developments of the division. Irwin Higgins developed the ion-exchange unit, patented it when the government gave him the rights, and established a company to apply and sell the technology. Clyde Watson led the shear development efforts that seem to have provided the basic technology now in use.

\subsubsection{Changing Times}

The Explosion. Upon arriving at the office one morning, our secretary told me that Floyd Culler had been there since about 4:00 a.m. following an explosion at the pilot plant. It turned out to be an evaporator in the plutonium cycle. They were decontaminating it for repair using a proprietary reagent. The reagent was very effective, but we had failed to convince the manufacturer to tell us what was in it. Their instructions warned not to boil it with nitric acid, which the operators were doing on the night shift with the cell door open. The reagent contained an organic material which, under the conditions, had been nitrated and subsequently detonated. At first, a nuclear event was suspected, but the absence of short-life activity quickly disproved that.

It was a small explosion. However, with the cell door open, the pilot plant and the immediate outside area were contaminated-an estimated 3 grams of plutonium were expelled from the pilot plant. Roofs of adjoining buildings, roads, and the general environment were contaminated. Floyd Culler assigned Jim Bresee to the cleanup, which took about a year and a lot of absorbent materials. When the costs were added up, we found that the total cost of the accident was about $\$ 1$ million per gram of plutonium. As the division's continuing safety officer, I took one trip through the "dressage" that the cleanup crew did every day. Alvin Weinberg transferred Frank Bruce from our division to his staff in order, according to Weinberg, "to ensure nothing like that happened again!" Frank took Ted Arehart and Tom Hungerford with him.

Atomic Energy Commission. It wasn't long before I was in Washington working for the Atomic Energy Commission. This was in May of 1961, and I became familiar with criticality analysis, radioisotope production, reactor effluent system analysis, waste solidification, and, finally, disposal of radioactive wastes in deep mined geologic repositories. In 1955, returning from the Atoms for Peace Conference, I reviewed the waste solidification work at Harwell. Based on this work, Floyd and I discussed with Clarence Larson a project to solidify the wastes and remove tanks from the middle of ORNL. At that time, we had other priorities! 


\subsection{THE CHEMICAL TECHNOLOGY DIVISION-A UNIQUE TEAM: Personal Comments of Floyd Culler, June $1992^{9}$}

Chemical operations and fuel reprocessing were very important factors contributing to the worldwide renown of Oak Ridge. The Chemical Technology Division (Chem Tech) received international recognition for its role in the development and use of nuclear and chemical technologies and is among the key divisions at the Oak Ridge National Laboratory. Strong continuity in engineering helped provide the impetus for the development of strong analytical chemistry capabilities, provided a focal point for the emergence of environmental work, and provided a basis for accomplishing all the AEC reactor analyses (we did 70 of them).

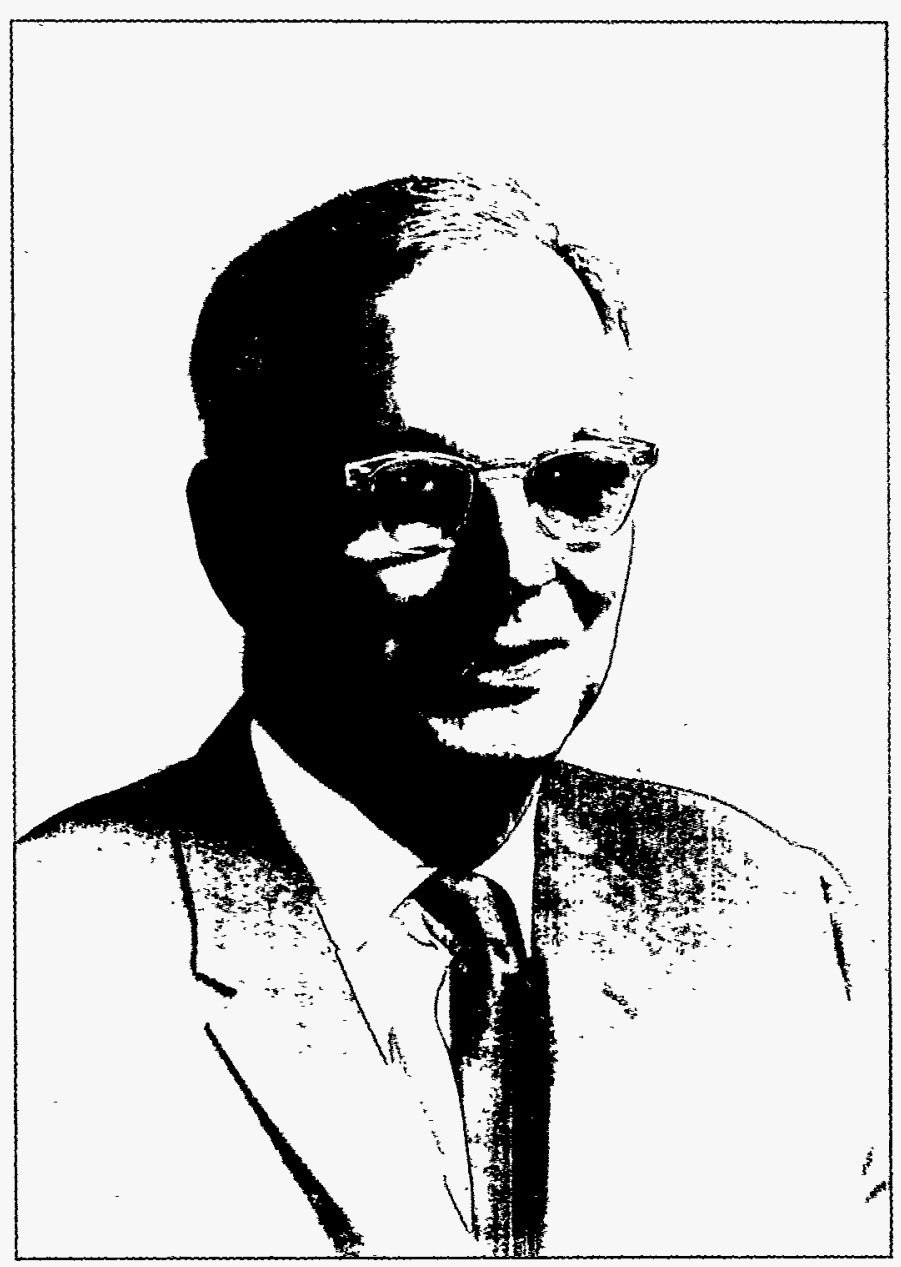

Mr. Floyd Culler as ORNL Deputy Director, about 1970.

\subsubsection{Attributes of Chem Tech}

Chem Tech possesses several attributes that contributed, in a large part, to its success as an ORNL division.

Learning and Growth Oriented. First is that we started out small, but we learned like crazy. We built more than almost anyone in the laboratory.

Chem Tech Spirit. The second feature, and probably the most important thing, is the spirit of Chem Tech. I've never thought of a better word than "gung-ho." Consequently, we were able to start up and to make contributions early on in order to get support. I think that spirit has prevailed until even now.

Teaming with Other Divisions and Industry. The third thing is that we teamed with other divisions as routinely as we worked with our own. Almost every division at ORNL has had joint programs with Chem Tech, except perhaps for the very fundamental ones, and we even worked closely with some of them: For example, we were close partners with the Chemistry Division. The Analytical Chemistry Division grew totally in parallel, and their competence grew as a result of Chem Tech's activities. The Metals and Ceramics Division was closely aligned with Chem Tech, and there were several formal agreements between John Fry and me about how we would manage.

Organizationally, we set up major and minor projects. The first major project was power reactor fuel processing. Jack Ullmann started this. From 1953 through around 1956, the Chem Tech Long-Range Planning Group had worked out the requirements for fuel reprocessing before we really got started in that area. By the time we were ready to talk about it, we had already done the primary calculations on what the actinides would be. We started the chemistry to separate them from the fission products. And when Seaborg asked to have a reactor built, we had the chemistry, not proven, but pretty well in hand. That was the plus that allowed the system to go. The consequences of these efforts at teaming were that we were able to either be a part of somebody else's program or they were a part of our 
program when multidisciplinary efforts were required.

The organizational structure that we set up with some forethought was successful. We instituted meetings once a month, including everybody in control or working on a project. The major projects were managed by people such as Murray Rosenthal or others who had the power of an associate laboratory director. The minor projects were managed by division directors. There were two rules: First of all, there was to be no arguments about territorial prerogatives. Fry and I agreed that we would cut people's salaries, if necessary, and fire them after three such arguments. Everybody had the sense that there would be no territorial arguments, and if they started, either John or I would move in and adjust them. And there were not many. The other rule was that all questions that were raised, either technically or administratively, would be resolved at the meeting following the meeting at which they were raised. If the question was carried over to a third meeting, it had to be reported to the division director for resolution. We had very few that required the latter.

The volatility project, for instance, was run within our division. The section chief in charge of the pilot plant was also in charge of the fluoride volatility program. At some point the volatility project merged with the recovery of the Molten Salt Reactor (MSR) fuel. But the decisions regarding the volatility program were a little difficult. There was considerable debate about how to go, what to do, or how good the process was. I finally was called in one time to resolve an issue. I knew what was going on because I got reports from people involved in the project.

But that mechanism of being able to pair up-to team-was important. We brought in architect-engineers (AEs) from major industries. We generally had two or three AEs in residence at one time in the Design Section. And they too fitted in. They became essential parts of the laboratory and were very well integrated by the time they left. It was this process of being able to team up with other divisions that helped us achieve our objectives. For example, we just automatically said to the Instrument Department that we wanted two guys assigned who will coordinate for your division. And it worked marvelously. The ability to team is an important attribute.

Management Acceptance. The fourth attribute of Chem Tech was that the top laboratory and AEC management accepted reasonable ideas about what we should do. The long-range planning group kept us ahead. By 1958, we were ready to do conceptual designs of power reactor processing plants and had started processing.

\subsubsection{Personal Comments}

My great advantage, I think, is that I truly like working with people. The nice thing about working at Oak Ridge and the Electric Power Research Institute (EPRI) is that the people enjoy working with me, and I don't know exactly why. If I did, and if I knew how to generate the spirit that we had in Chem Tech, I would be a billionaire. I think one little tiny inkling of what it is is that I always looked on management as a necessary evil. And I was willing to do that and to make decisions if they were clearly indicated as necessary. If they were not, I would put off making decisions until I got more information. But at other times it was necessary for me to work as part of the team. That was a real distinction between what I was doing in my mind as a manager and what I was doing to try to wrestle the problems. In that, I have been blessed with a good memory for details and numbers. When information came out of the laboratories in weekly or monthly reports, I'd read and say, "That's a new number." I'd call the responsible people and ask, "What do you think this means?" I could usually remember the pivotal numbers about when something would work. I remember when information came out of the laboratory on the effectiveness of ferrous sulfamate as a reductant. That was the key, incidentally, to a successful TBP process. I saw those data and said, "We've got the process now; it doesn't have any salting agent and it cleanly separates uranium. We've got a holding reductant that works at least, and we've got a world beating process." The TBP process immediately assumed major importance; in three months, it was the process of choice. I remember that one very well.

But I did have this fortunate ability to remember details for long enough to make sure that we focused ourselves in directions that looked to be profitable.

I was always curious about everything. That's a virtue, I guess, but it may not be. In this whole business of management, however, I think it is necessary to have people recognize that you have power but then not to exercise it. And, as I say, work as part of the group whenever it's possible. 
I'm not sure that's an accepted method of management, but it worked pretty well.

It allowed everybody to think they were an essential and productive part of the team. I never quite understood. Everyone felt so responsible for seeing that their work was done right and quickly, and that good sense was being used. They were willing to work with each other, which is something that doesn't happen too often I discovered after I left Chem Tech. We really need some kind of an emulsifier to work together to common objectives, in teams and such. I think it was carry-over from the war years. Everybody felt an urgency, and somehow we managed to keep it alive for a long time in Chem Tech. The reason is we kept getting big problems-one after the other.

\subsubsection{Y-12 Experience}

Solvent Extraction. I transferred from Y-12 to ORNL in 1947. I had just finished building the final product building for fully enriched uranium. I built Building 9212, and, basically, I operated the solvent extraction system. Actually, John Strohecker and I built the first solvent extraction column, and neither one of us knew anything about it. It used glass columns about 8-in. in diameter, and we were using diethyl ether.

The extraction of uranium from nitric acid is possible if the uranium is salted out of solution. With hexone you salt it out with aluminum nitrate. With our Y-12 solvent, we salted it out with copper nitrate. We had an absolute first call on all the pure electrolytic copper in the United States.

When we built 9212 , we had the full output of the Corning Glass Works for six months. And we built it in 9 months. I started on it in March 1945, and it was completed and running in November 1945.

Criticality. Actually the last thing that I worked on at Y-12 was criticality. Ray Murray, now a retired physicist from the University of North Carolina, was familiar with criticality. Dixon Callahan was working on that, too. The chemical systems at $Y-12$ for the calutrons, the big ones, always used big tanks, and the tanks were probably unsafe (in terms of criticality) above $6 \%$ enriched uranium. But we didn't know that for sure. The decision as to whether to use $\mathrm{K}-25$ as a bottoming cycle for the calutron was made in early 1945 . It was decided to go on up to full enrichment in the cascade. At that point, I'd been using the Fermi Age Equations for criticality calculations, along with Ray, who was teaching me this stuff. I did mostly the mechanical work and not too much of the physics. But we went over the whole plant to decide what was useful and what was not. We concluded that it would have to be totally rebuilt to go above even $6 \%$ enrichment, from what we knew. That sort of made the decision. That is when Y-12 shut down, and 25,000 people or so left.

Weapons Work and Lithium Isotope Separation. The weapons work had just started. John Strohecker was responsible for designing most of the weapons complex. There were two people who were really at the roots of it: John Googin, who was the only resident genius in Oak Ridge, and Strohecker, who did most of it.

Strohecker and Googin were essentially the abiding geniuses behind the lithium isotope work. John Strohecker was the best engineer I ever worked with. Stroh could do things in his head that nobody else could do. At least that's the way it seemed to me. He and I built the first solvent extraction column. He had more nerve than I did.

Tennessee Eastman. Strohecker and I were the only two engineers left in the Engineering Department. I was doing the airflow balances for the buildings. One of our friends, Merv Jones, along with Bill Hawkins, had left Y-12 to work for Eugene Wigner in the early layout studies for the MTR. Merv kept telling me, "My God, you ought to come over here. All this stuff you've never heard of. It's a marvelous place to work. You really ought to come over." Well in 1947, as Tennessee Eastman was pulling out of Y-12, I had to make a decision as to whether or not I would go back to Rochester. I had worked there at the Eastman-Kodak home office for six months after I got out of Johns Hopkins. I had been working, as a neophyte, in engineering design. Eastman-Kodak sent me to Oak Ridge.

I stayed at $Y-12$ until Tennessee Eastman left. Strohecker decided to stay behind at $Y-12$, and I decided to go to $\mathrm{X}-10$.

\subsubsection{X-10 Experience}

First Year. After several years' experience at Y-12, I transferred to ORNL in 1947. The thing that really helped me, and there are only two people who ever got to do it, was that the Laboratory had decided that they were going to train new technical people using a "Loop" course. I was allowed to work in Analytical Chemistry, Metallurgy, Reactor Technology, and in Unit 
Operations on shifts for Warren Eister. And it was also a year or so before the Oak Ridge School of Reactor Technology (OSORT) started. But they were giving ORSORT-type lectures with Alvin and others lecturing. So I got to attend those.

For eleven months I did nothing but attend lectures and work with different groups, making reports once a month about what I was doing. My notebooks were embargoed as classified stuff, in some respects, at Oak Ridge. However, I used them all of my life there.

Technical Division and Design Work. I went to work for Frank Ward in the Design Section of Miles Leverett's Technical Division. I was assigned responsibility for all chemical plants under Jim Lane. Jim and I got to be good friends. At that point, it was decided to go ahead with building the MTR and a chemical processing plant in Oak Ridge. It was before the decision to put it in Idaho. I started to do the materials balance flowsheet for the 25 hexone separation, including materials, heat, and activity balances. I did most of those myself.

U-235 Project/Chemical Processing Plant Design Group. As time wore on, it became obvious that the chemical processing plant was not going to be built in Oak Ridge but in Idaho. John Swartout and I went along with the team that inspected the Idaho site before there was anything there, except the beginning of construction for the Experimental Breeder Reactor (EBR 2). Harold Lichtenberger was in charge of that. I remember the first trip-we walked all over that desolate high desert, but we picked a site for the chemical plant and started in with diligence on that. At that point, I essentially got a group to work on the enriched plant there. It became a formal design section under Frank. The transition from Miles Leverett to M. D. Peterson as director of the Technical Division occurred about the same time as the decision to move the reactor and processing plant. That occurred in the 1948 to 1949 time period.

M. D. Peterson had been in charge of a large group under Leverett. Essentially it functioned as an independent unit, as did the Metals and Ceramics Group. Metals and Ceramics was under Miles, as was Chem Tech and Analyticaleverything except Chemistry, which was an independent division. But all the technical stuff was enfolded under Miles Leverett, and Peterson was the head of the Chemical Technology group. It was a big effort and became the Chemical Technology Division in about 1950.
Design Section. I essentially worked with a group on the ${ }^{235} \mathrm{U}$ project. The group grew almost immediately into the Design Section. About the time Peterson left the division and Steahly took over as Chem Tech Director, I was assigned the Design Section.

Chemical Technology Division. I became the Chem Tech Director in 1953. By then we had finished the design of the ICPP, and it was operating in 1953. I was busy like crazy during those days. We were doing a conceptual design for a thorium plant. It was thought that the military might want ${ }^{233} \mathrm{U}$ because of its lower critical mass. The thorium plant had problems, but at least we were making plans to produce large quantities of thorium, which we did. We produced the first kilogram quantities of ${ }^{233} \mathrm{U}$ in the pilot plant. The thorium was irradiated at Hanford, shipped back, and we processed the thorium.

Anecdote Concerning Processing Very Short-Cooled Irradiated Thorium. I was truly frightened when Earl called me to come to the pilot plant and we looked at the meter reading. Earl Shank was in charge of the irradiated thorium processing at the pilot plant. During the course of processing the relatively short-cooled, irradiated thorium slugs, the meter monitoring the off-gas filter in the penthouse of Building 3019 began showing extremely high radiation fields. Samples indicated the presence of radioisotopes usually found only during fission events. We were concerned that we might have a criticality event occurring. Intense research and discussion revealed that the particular isotope in question was also in the normal decay chain and not necessarily indicative of a criticality event. Thus, we were not dealing with a criticality event-just intense radiation from the short-lived activity.

\subsubsection{Idaho Chemical Processing Plant}

The ICPP was an important accomplishment. We had built a good team for that effort-a team with a gung-ho attitude.

Goeller and Radioactive Particulate Filters. During that period, no right after that, we built the first filters for radioactive particulates. Hal Goeller sketched them out over a weekend, and we had the steel up the next week for the pile filter building! Goeller was great at longhand. He could do sketches fast. He was so accurate, and he sized it. The decision to put a filter house on the graphite pile was made sometime around 1953 or 1954. 
Expansion of Plant. We were also studying the expansion of capacity of the ${ }^{235} \mathrm{U}$ plant in Idaho to take care of enriched Hanford piles. Pure ${ }^{235} \mathrm{U}$ slugs were put in the Hanford piles to increase production, and they came to Idaho for processing. Milford joined the group when we started looking at thorium.

Foster Wheeler and Bechtel. We had Foster Wheeler and Bechtel engineers in residence at that time. For both of them, it was one of the very first exposures of the AEs to nuclear power. Bechtel was working on the fast reactor design with Harold Lichtenberg. Harold and I basically got to know the Bechtels pretty well, and they offered jobs to both of us in 1953.

ICPP Design/Construction Management. Six months into the design of the plant, the division of responsibility was clear. We had overall technical authority, and my signature had to be on the bottom of every drawing, which was unusual. It's the only time we ever had that requirement, I think; but the idea of criticality control and how to manage it was such new stuff, and I did know a little bit about it from my Y-12 background. It allowed us basically to get on with that fully enriched plant pretty quickly. We had material balance flowsheets, the sizes of all the vessels, the schematic piping diagrams with all the sampler points marked, the size of the cells and all the penetrations, and everything ready to go in less than six or seven months.

New York Assignment. At that point, the problem became one of translating the information onto the construction drawings, and to accomplish that, Goeller took about ten people to New York and worked for almost another year. We got checkprints every night back in Oak Ridge that had to be back in New York in three days. We flew them up to New York.

Checkprints. Steahly decided that he wanted to look at the checkprints. There were big rolls of them. Klotzbach was in New York, too. Klotts sent me three copies of every checkprint, and we'd get a roll 6 in. in diameter. Everybody worked checking them out, and we checked everything. We wrote up the specs, we developed new standards for stainless steel welding-all that stuff. It was fun!

Steahly said that he wanted to see the checkprints before they were sent back to New York. I said okay. We put them all together for two days, and at $8 o^{\prime}$ clock in the morning, we placed them on Steahly's desk and told him that we had two days turnaround and this was the second day and he had to look at them and get them out. They came back about 15 minutes later.

Klotzbach had a great sense of humor. We sent big rolls of prints back to them in rolls, and he didn't have any way to file them. So he sent down the message, "Please send no more prints in the rolls." I guess the Idaho work made a big impression on me.

ICPP Team. I had a marvelous group of people working together-experienced engineers and good nuclear people. People like Paul Robertson, an old hard-headed piping engineer, and Bill Kearsley. All of these were older people who were on the staff, and they all worked like crazy.

\subsubsection{Long-Range Planning Group}

In 1953 we created a means of staying reasonably far ahead in thinking-the Long-Range Planning Group. We actually had the best functioning long-range group in the entire Laboratory, and we kept the same four people (Al Gresky, Chairman; Eldon Arnold; Chuck Guthrie; and Jack Ullmann) on it all the time. Over a period of five to seven years, they learned how to calculate anything. For example, they developed the ORIGEN code (Sect. 4.5).

Bob Klotzbach was on it, and Ferguson for a very brief time. Klotzbach went to Union Carbide's Sterling Forest Laboratory. He was the first employee that the corporation took from ORNL. $\mathrm{He}$ was familiar with handling radioactive materials and could do good material balances. He knew the ore chemistry pretty well, as did Keith Brown. Incidentally, Warren Grimes was a huge contributor to the chemistry effort.

\subsubsection{Building}

We learned about building by working with a relatively large number of AEs, in situ. We made arrangements to have their principal designers come and stay with us for awhile. This was Bechtel and Foster Wheeler first, then Kellogg, and later Catalytic Construction. We did conceptual designs of many things, including three repositories along with the Health Physics Division. Again, a teaming took place.

\subsubsection{Seminars and Information Meetings}

We had weekly seminars and annual information meetings. The seminars didn't take long, and everybody had an opportunity to talk about their work each year or even less than a year. 
The annual information meeting was a more formal presentation to ORNL and AEC management, to invited guests from industry and universities, and to the Chem Tech staff. It provided an opportunity to inform management and interested people concerning Chem Tech work and activities and to permit Chem Tech staff to rub elbows with important guests.

\subsubsection{Challenging Work and Careful Workers}

Chem Tech helped develop the formulation for the concrete used in the Transuranium Processing (TRU) facility. The concrete was designed to optimize radiation protection. The problem was that of building a reasonable shield for both neutrons and gamma radiation. Neutrons go through most materials. Adsorption of neutrons requires something with high hydrogen content. The gammas required high concentrations of heavy metals. We used iron punchings and little disks that were suspended in the concrete, along with a mineral from Idaho that was an iron compound with six waters of hydration. The mineral was stable in a high radiation field, and we put a large amount in the mix. The concrete had a sickly yellow cast. The TRU work that was done then was fascinating-with the metallurgy, the refabrication of the fuel, all of the remote handling gadgets, and the very dangerous materials involved. They were very careful workers, the entire crew, and all of them worked like crazy on that project.

\subsubsection{Atoms for Peace}

The Atoms for Peace conferences were born in 1955. Prior to that, one or so meetings took place in the United States, with selected countries on reprocessing and reactor technology and such. Early on, of course, the British were our partners during the war years, and there were British scientists in residence at ORNL during the war years on chemical separations and other aspects of nuclear technology.

\subsubsection{International Obligations}

In 1953, we started getting ready to meet an obligation that the United States had with Belgium. In return for the pitchblende ore from the Belgian Congo that supplied all the early uranium for the United States, we had promised to provide Belgium with processing information. Consequently, several Chem Tech staff members participated in a very important workshop in Belgium, essentially giving them all the desired information.

About the time we were finished with Idaho, we had people from France and Sweden visiting, and we gave them overviews of the kinds of technology that we were doing. In 1954, there was a conference that preceded the Geneva conference at which some of the reactor work was revealed. The reactor design work on all of the reactor types that were then current-information on the light-water reactor, the breeder, the gas-cooled reactor, the aqueous homogeneous reactor, and others - was made partially available to the Europeans on a selective basis, and the Canadians were always there.

But the international business really started heating up in return for the Belgian uranium, since the reactor work in 1955 at the Geneva conference was totally declassified. We gave descriptive papers only at Geneva. We outlined, but did not give details, of the reprocessing. For example, we did not tell them what the reducing agent was. We didn't give the mole ratios and all the necessary process information. Generally, the solvent extraction flowsheets were given in semi-cartoon-like review without specifics.

The United States government negotiated with the Belgians and released details of the reprocessing, plutonium recovery and isolation, the uranium recycle, and what we knew about waste as repayment to them for the natural uranium from the Congo. About ten months of intensive declassification, much previously classified information, including all the Hanford data, manuals, and layouts, was bundled up, and twenty of us went to Belgium for three weeks. In three or four weeks' time we described everything to the Belgians and the other OECD countries. At the time the Europeans were forming an economic community under France, Germany, and Great Britain to build the European Common Market, but this was a manufacturing community initially. As a result of our agreement with the Belgians, their atomic energy fuel processing programs were started.

During the meeting in Geneva, three people came and asked me if I thought the United States would be willing to provide assistance in the construction and formation of a central reprocessing facility. I said that I would check with Washington. AEC Headquarters said they thought it would be a good idea. With two AEC people, I 
went to France and it was agreed then that there would be an attempt made to form essentially the European Processing Plant, and later the King of Belgium gave the land at $\mathrm{Mol}$. The whole effort got started. And along with that, the same group was working toward setting up the International Atomic Energy Agency (IAEA), which came into official existence in 1957.

So it was an interesting period of emergence. Immediately after the Geneva conference, we starting getting foreigners in residence-a very large contingent from France, a relatively large one from Germany, and a few from Belgium and Holland. There were many from India, probably at least 150 to 200 Indians who went through Chem Tech. We also had the Japanese in large numbers in later years. John Grover, United Kingdom, sent over people to work in Analytical Chemistry, a few in Metallurgy, and a large number in Chem Tech. We looked at essentially all of their flow sheets for building their chemical plants. Those type of visitations continued for some time. At the same time, around 1955, Du Pont was beginning the design of Savannah River, and we had probably 50 to $60 \mathrm{Du}$ Pont people in residence all the time.

\subsubsection{Biotechnology and Continuing Education}

The initiation of biotechnology work at Oak Ridge started in an odd way. Around 1950, and the dates could be corroborated, Frank Bruce and I set up a week-long meeting in Gatlinburg to which we invited 40 separation experts from all over the world. We were finished with the war. We had tried every separation method that had been devised by man, including electrophoresis, for example. All of these had been tried and screened. We'd invented 400 new solvents that had varying capabilities for complexation. Our objective was to see what we might be able to do with the powerful separations tools we had developed. I said that I thought we had the science and, in part, the technology to separate anything from anything, including the adjacent rare earths and the big macromolecules, in an opening comment at the meeting - a foolish comment.

Now the interesting thing was that John Slusher from England, who was at the meeting with several others, went back and quoted the comment in Nature. Alex Hollaender, director of the ORNL Biology Division, read about it and came back and asked me if I had really meant it. I said, "Yes."
And he asked, "Well, why don't we do something about it?" I replied, "Well, why not?" This was a little later I suppose, probably 1951 or 1952 -no, it was after 1953 because I wasn't working as hard on Idaho.

Culler's College. I had already decided that many Chem Techers had been out of school for as long as I had, and I was getting rusty as all get-out. There were marvelous new techniques coming out, and I figured if we didn't become educated, we'd rapidly become outdated. So I set up some courses that had to be attended by people that had been out of college for ten years.

Well, there were foolish rules that I enjoyed. First of all, you could beg, borrow, cheat, or steal or anything to answer any of the homework questions. There were no quizzes. All you had to do was work all the homework; if you didn't, you were in trouble with me, but nobody ever reneged. The questions were hard, but I told everybody that I didn't care how they obtained the answers.

Incidentally, that's the way Johns Hopkins is operated, except for a few courses. You could even go in some of the classes, for example, physical chemistry, and talk to your instructor during quizzes. The questions were hard; there weren't any multiple-choice questions.

Biotechnology Courses. Now what happened was that I said to Alex Hollaender, "All right now, I think biotechnology is advancing very rapidly and Waldo Cohn and several others have been separating the amino acids by ion exchange. There are techniques you are using that we could help with. If you will agree to set up a school that will train ten people every year in the fundamentals of molecular biology, I'll assign ten people out of Chem Tech to be trained in biology. But they must have the very best people lecturing in this effort." And, in a small way, that was the beginning of the postdoctoral biomedical school, and it worked.

Dave Novelli was assigned to coordinate the educational program. Dave was working on the purification of transfer RNA. That project became our major focal point. Later, Norm Anderson came in. He was well along in the zonal gradient centrifuge program. The group picked that technology up. But it started in this "little round-robin" fashion back to Chem Tech through Alex.

We had already decided that one of the areas that was important was "big" biology. Although the biologists were geniuses at inventing separation methods, they were terrible slop-jar chemists. They 
did the right thing, but they didn't engineer them correctly. They always got mixtures of impure products. They didn't have the controls and the understanding of separations. So we put together a group of three or four physical chemists and three or four engineers. I have forgotten, but there may also have been a physicist in that first group. I have forgotten the names of these individuals.

Continuing Education. The school for training had other prerequisites. After you finished the school, and that was a full year, you had to agree for the next three years that you'd take some courses in the extension service at The University of Tennessee (UT). I indicated that I didn't care what courses were taken. You could study archaeology or animal husbandry, just as long as you enrolled in something. But most of the people went back and took additional biotechnology. It was a marvelous setup. I never expected it to work as well as it did.

One thing I do remember about the "retread" program was that at the Chem Tech dance (the first year it was on St. Patrick's Day), all the wives came up to me and said they were going mad. Their husbands were working these problems all the time. They stayed up until 12:00 o'clock at night, and the wives were really angry. Some of them were really put out. They said, "You're ruining my marriage!" I said that was too bad, I feel sorry for you, but it's necessary. After it was all over, I think it made a little better impression. But the little incidents like that were interesting.

In the last decade, math had progressed and the computers were coming in. So, I decided that refresher courses, using our own people as teachers, would be useful to hone some of the mathematical skills of the Chem Tech staff. Some of the more recent hires were quite skilled in mathematics, for example, Jere Nichols and Gene McNeese. And the courses turned out reasonably well. But the biology training was laced into that because both "schooling efforts" were going on at the same time.

The biotechnology efforts were a very important part of the division's history. I don't think Chuck Scott has ever quite got the recognition he deserves for his accomplishments in that area. There were many others who have also worked in it, but the whole program did not attract enough attention, a common failing of many advanced technologies.

Biology Division. At the height of the Biology Division's achievements, AEC Chairman
Schlessinger described the division as being the crown jewel in the AEC's programs-a really impressive statement. All of those good people from Biology are either gone or dead, except Bill Russell and Liane. However, there are still some awfully good people over there.

\subsubsection{Environmental Impact Statements}

Chem Tech played an important role in experimentation and report preparation for the environmental impact statements. Several Chem Tech people were involved in calculating release functions. There is a little bit of background that is important about the generation of impact statements. Oak Ridge, because it had a large number of engineers and the very largest Environmental Division, was assigned 55 or 60 of the impact statements that had to written. In a relatively short time, we essentially formatted an approach to impact statements, and it brought us into close contact with the Environmental Sciences Division. The Reactor and Metals and Ceramics divisions also were deeply involved.

Basically, each of the impact statements was assigned to individuals as leaders in that particular program. Tom Row cut his teeth on environmental impact statements. He was in the Reactor Division at that time. Sam Beall was also involved.

\subsubsection{Fuel Reprocessing}

The emergence of the Fuel Recycle Division under Bill Burch was important, as well as the work that led up to it. It was the last remnant of chemical processing and technology that existed in the United States, except for rebuilding Savannah River. There is no real development now in the United States, but at some point in time, it's going to be necessary.

\subsubsection{Nuclear Energy}

Nuclear energy is now a very emotional issue. We have to be able to separate the actual hazard of radioactivity from radioactive materials better than we have. One interesting comment about the state of nuclear energy, made sometime in the last two years, is that all the people who have worked on the effects of radiation now have grey hair, and none of the modern techniques of medicine and biology have been used as measurement tools in the area. Twenty-five years have elapsed with no new work. 
I think we're working on trying to achieve some new data. Basically, there are techniques like blood indicators that may be able to provide us with a better measure of radiation effects than we now have and better correlations with radiation damage. We are going to, I hope, begin to sponsor workshops among biomedical professionals. The Department of Energy has cut back, almost to nothing, studies on the effects of radiation. In fact they were doing most of the effects work on solvents and other materials, and that work has also been cut back. The ORNL Biology Division has been decimated.

Well, hopefully there is a new group being formed in the private sector. It may emerge as something called the Annapolis Center for Environmental Quality. Initially, they received a limited amount of seed money from the U.S. Manufacturer's Association. The man who is president is also on the Board of Directors at Houston Power. He was head of the University of Texas, University of North Carolina, University of Maryland, and deputy head of the University of Chicago. He will be retiring in about six months from the Houston Board, but he's the new president of this Annapolis Center for Environmental Quality. A basic precept of the center is to see whether it's possible to foster good science and to respond to the exaggerations - to begin to treat the perception with the reality. It's a very difficult operation. Chauncy Starr (former President of EPRI) and I have been trying for seven years essentially to set up a center for evaluation. Basically, it can't be within the government, and it can't be contained within one of the national laboratories because that's also within the government. It can't be set up within EPRI either because even though we are reasonably objective, we're labeled as part of the establishment.

We first attempted to set up the medical and biological engineering departments at Stanford as such a center, using Oak Ridge for information data collection. The independent center was chartered to develop policy for handling resources for the future. We (EPRI) funded that at $\$ 500,000$ per year for a few years. That got started, and it's doing very well, but the important parts-the illumination with new information, the scientific analyses, and understanding what epidemiology is-these are only beginning.

\subsection{THE CHEMICAL TECHNOLOGY DIVISION, FROM WARTIME SECRECY TO THE COMING OF THE RUSSIANS: Personal Recollections of Ray Blanco, May $1992^{10}$}

I arrived in Oak Ridge in 1944 in the army and was assigned work at Y-12. Previously, I worked at an oil refinery and then served in the infantry. Eight people were selected from my unit at Fort McClelland and sent to a secret installation (no

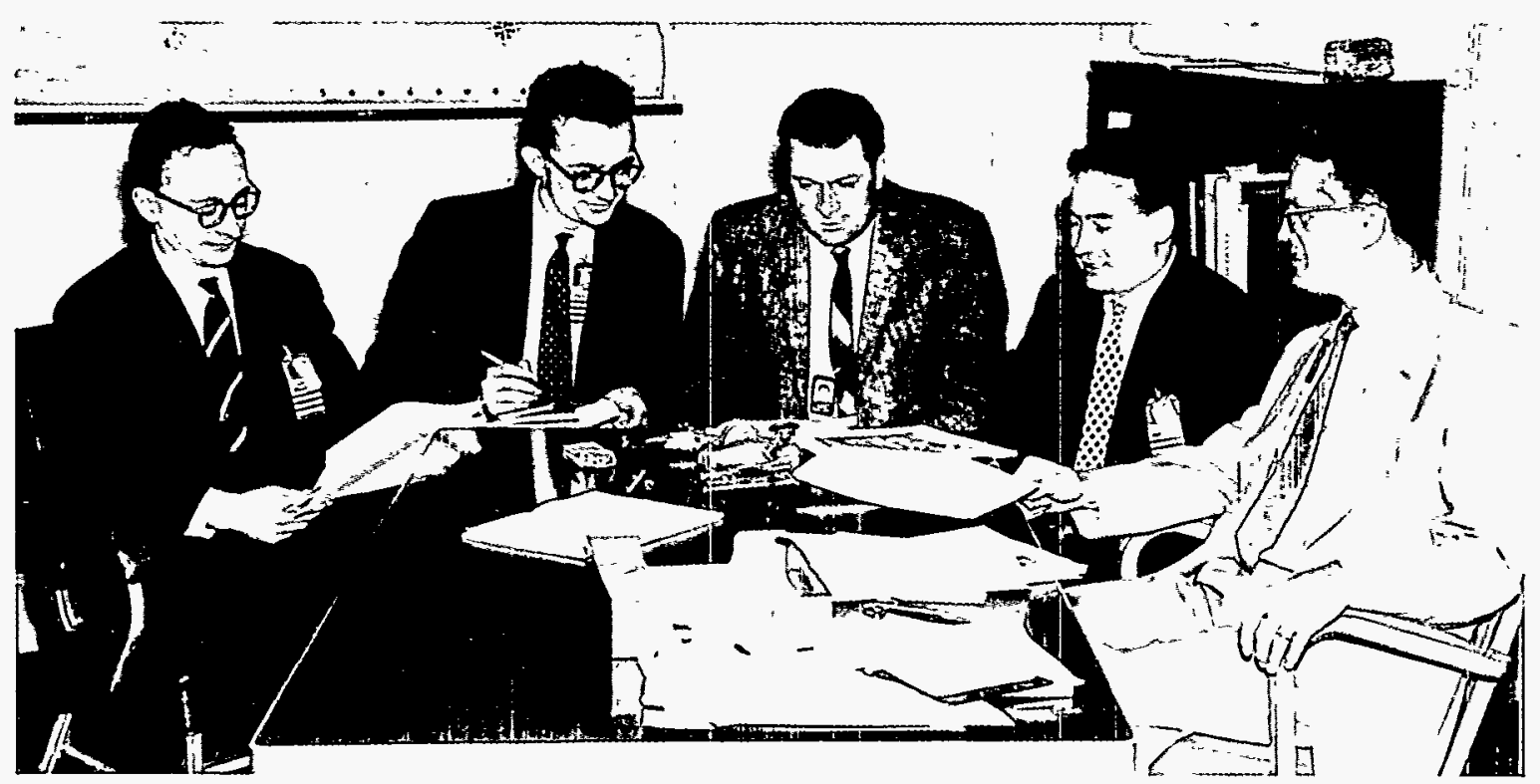

A 1958 photo of Ray Blanco (extreme right) with Wes Lewis (center), Chem Tech Pilot Plant manager, and Euratom representatives. 
leave and mail censorship) to work in our professions (a great day!). First, we were given two weeks of lectures by British and U.S. scientists on the chemistry and processing of the element $T$ (uranium), and then we started work on process development, material balances, and as shift supervisors. The barracks at Oak Ridge were new and like heaven compared to other army camps. They were located on the site of the present Oak Ridge Shopping Mall.

I started at X-10 in 1946 and worked with Frank Bruce in developing the Redox and 25 solvent extraction processes. We were in the Technical Division in the section headed by M. D. Peterson. Experimental work was simpler then. We used lead brick barriers in the hoods or on the floor and used significant amounts of radioactive tracers or irradiated uranium dissolver solution. Arlene Kibbey, Jim Farmer, and I built an enclosure for an ion-exchange column against the exterior building wall. Of course, we were careful to wear our radiation exposure pencils and rings and use our "cutie pie" hand-held monitor.

In 1946 or 1947, the "powers that be" decided the technical staff needed more training in basic nuclear physics-probably so we wouldn't kill ourselves in a criticality event. We were asked to attend 1- to 2-h lectures each day for about two weeks by the eminent physicists that were then present on the staff, including Dr. Wigner and Dr. Weinberg. We learned about criticality, cross sections, isotope and fission products production, decay schemes, and much more.

In some of the earliest waste treatment development work, we collaborated with Irwin Higgins and Bill Shockley to develop a process for reducing the volume of wastes to be stored. The early processes used aluminum nitrate as a salting agent and produced large volumes of raffinate wastes. We developed an ion-exchange process to separate the aluminum from the fission products (FPs) so that the FP waste could be evaporated to a small volume for storage or solidification. A patent was issued for this process.

RaLa Process. About 1950, we started the development of an improved RaLa process. RaLa is the separation of kilocurie amounts of ${ }^{140} \mathrm{Ba}$ from irradiated uranium dissolver solution. Barium- 140 radioactively decays with a 12.8-d half-life, thus producing ${ }^{140} \mathrm{La}$, which in turn radioactively decays with a 40 -h half-life, forming stable cerium. Los Alamos wanted the ${ }^{140} \mathrm{La}$ with its intense gamma radiation in the bomb development work. The early process, carried out in $704 \mathrm{D}$ Building, used lead as a carrier to precipitate the sulfates of $\mathrm{Pb}, \mathrm{Ba}$, and $\mathrm{Sr}$. Subsequent precipitation and separations steps using organic solvents were hampered by heating and solvent radiation decomposition problems.

Ion exchange seemed a good alternative to produce a $\mathrm{Ba}\left(\mathrm{NO}_{3}\right)_{2}$ product from the $\mathrm{Pb}-\mathrm{Ba}-\mathrm{Sr}$ sulfate precipitate of the old process. The process developed included (1) metathesis of $\mathrm{Pb}_{-} \mathrm{BaSO}_{4}$ precipitate to $\mathrm{Pb}-\mathrm{BaCO}_{3}$ with $\mathrm{K}_{2} \mathrm{CO}_{3}$,

(2) dissolution in $\mathrm{HNO}_{3}-\mathrm{NaNO}_{3}$, (3) adsorption on a column of Dowex-50 resin, (4) elution of $\mathrm{Pb}$ with $\mathrm{NaOH},(5)$ elution of Sr with EDTA (ethylenediamine tetraacetic acid), (6) elution of $\mathrm{Na}$ with $1 \mathrm{M} \mathrm{HCl}$, (7) elution of Ba with $9 M \mathrm{HNO}_{3}$, and (8) precipitation of $\mathrm{Ba}\left(\mathrm{NO}_{3}\right)_{2}$ from $85 \% \mathrm{HNO}_{3}$.

The process equipment was installed in new cells in $704 \mathrm{D}$ Building and was used successfully to produce products containing up to $40,000 \mathrm{Ci}$ of ${ }^{140} \mathrm{Ba}$, as I recall. I remember working all night during some of the runs and watching the recorder show the large radiation peaks for the elution of the $\mathrm{Sr}$ and $\mathrm{Ba}$ components.

Bill Unger and his co-workers designed the cells and equipment and got the job done successfully. He did express some resentment that chemists specified such "friendly" chemicals as $\mathrm{HCl}$ and fuming $\mathrm{HNO}_{3}$. Such chemicals appeared to cause a materials of construction problem.

Lithium Isotope Separations. In 1952, we began the development of a process for separation of the lithium isotopes ${ }^{6} \mathrm{Li}$ and ${ }^{7} \mathrm{Li}$. We first tried ion exchange based on the pioneering work of Ellison Taylor and Harold Urey using zeolites (sodium aluminosilicates) and $\mathrm{LiCl}$. We also tried other zeolites, ion-exchange resins (Dowex 50, Duolite C-6), LiEDTA, lithium acetate, and fixed columns versus continuous, moving columns of resin. It was concluded that the systems were impractical because of the low separation factors. J. Tom Roberts, Arlene Kibbey, Fred Land, Dennis Helton, Irwin Higgins, Bill Shockley, and I participated in this work, which resulted in the publication of a paper in Progress in Nuclear Energy, volume 4, 1961.

The OREX Process. After the ion-exchange effort for separation of the lithium isotopes, the emphasis turned to contacting lithium amalgams with solutions of $\mathrm{LiCl}$ in organic solvents. Previous investigators had shown that acceptable separation factors could be obtained in these systems. Of the many available, we chose $\mathrm{LiCl}$ in propylene 
diamine (PDA). A method was devised for contacting the amalgam with LiCl-PDA in a packed column. The crucial issue was the development of a successful method for recycling the mercury and PDA at each end of the system. Thus, we had a true continuous countercurrent system with a relatively high separation factor operating in a packed column - the OREX process was born. In contrast, the COLEX process, developed at $\mathrm{Y}-12$, contacted lithium amalgams with aqueous $\mathrm{LiCl}$ in a countercurrent mixer-settler system. A race developed between teams using the two processes. This effort to produce ${ }^{6} \mathrm{Li}$ for thermonuclear devices had national priority, and both systems were rushed into pilot plant tests. I was a participant in the chemical development along with Ray Wymer, Arlene Kibbey, Fred Land, and Dennis Helton.

A design/construction contractor was hired to work with the Design, Pilot Plant, and Unit Operations sections of the Chemical Technology Division and rush a large pilot plant to completion. Dick Lindauer was in charge of the pilot plant operation.

As I recall, enrichments of up to 15 to $18 \%$ were obtained, indicating the theoretical success of the system and the potential to obtain full enrichment. However, the system failed because of practical problems. Because of the urgency, used and unsuitable equipment (pumps, etc.) had to be used along with available new equipment; also, the system could not be maintained in an anhydrous condition (moisture caused decomposition of the amalgam and loss of separation efficiency). Finally, the engineering problem of pumping mercury to the top of tall columns and general problems with just containing mercury became horrendous. Thus, the team using the COLEX process won the race.

$R \& D$ Center for Fuel Reprocessing and Waste Management. From the late 1950 s to the early 1970s, Chem Tech was the principal R\&D center for fuel reprocessing and waste management studies in the United States. It became the focus for foreign visitors. Hanford and Savannah River were highly classified production sites, and foreign visitors were discouraged. A sampling of foreign guests Chem Tech hosted included visitors from the United Kingdom, Belgium, Italy, Japan, South Africa, West Germany, Sweden, Norway, Finland, Yugoslavia, Australia, and India. Some countries sent guest scientists and engineers to work in the Chemical Development and Pilot Plant Sections.
Most guest assignments lasted 6 to 12 months, but some were up to 2 years. Countries assigning guest scientists to Chem Tech included South Africa, Spain, India, Italy, France, West Germany, Japan, Australia, and the United Kingdom.

Sidelights. An interesting sidelight occurred at the 1958 Geneva conference. I was talking "shop" with some British and French delegates when suddenly the Britisher said, "You know we recently bought a large amount of $\mathrm{LiCl}$ on the open market for our ${ }^{6} \mathrm{Li} / \mathrm{Li}$ separations program and found that the ${ }^{6} \mathrm{Li}$ content was depleted." Of course, they suspected the United States was the culprit, but I could only smile-it was highly classified work at the time.

Another time at the 1958 conference, I visited the Russian exhibit. They had a number of interesting nuclear exhibits, but the featured item was a full-scale Sputnik highlighted in the middle of the room. There was nobody there, so I looked for a Russian to ask some questions. Finally, someone came out of a back room and I asked, "Where is everybody?" "Oh," she said, "They are all over at the U.S. exhibit taking notes."

Symposium on the Reprocessing of Irradiated Fuels, 1957. In 1957, the U.S. AEC agreed to present information on the reprocessing of fuels to its World War II allies Belgium, France, the United Kingdom (UK), the Organization for European Economic Cooperation (OEEC), and the Euratom nations. This was a very important meeting because the United States revealed for the first time the engineering details of the reprocessing methods developed in this country. The 1955 Geneva conference revealed much previously classified information, but little detail. It appeared to me to be a debt payment to the Belgians for the uranium provided from the Belgian Congo as well as to the UK for their technical support.

It was a momentous occasion for all concerned, with the Prince of Belgium opening the ceremonies-champagne and all. Speakers were present from Hanford, Idaho Falls, Argonne, Knolls Atomic Laboratory, and ORNL. Papers were presented by F. L. Culler, F. R. Bruce, G. I. Cathers, J. Ullmann, and me from the Chem Tech Division. The proceedings were published in TID-7534. Sessions included aqueous reprocessing, auxiliary processes, disposal of plant effluents, nonaqueous processing, and engineering and economics.

After the meeting, the speakers and wives were guests at tours of the French reprocessing plant at 
Marcoule, the UK processing plant at Windscale, and the UK feed materials plant at Springfield, England.

As further assistance to the Belgians and OEEC, Ed Nicholson and Earl Shank were sent by Floyd Culler to Belgium in order to assist the conceptualization and design of their new reprocessing plant at Mol. Ed had done similar work with Floyd for the Idaho Chemical Processing Plant, and Earl had pilot plant experience.

Visits with the Russians, 1964-65. In 1964-65, the United States engaged in a cultural exchange program with the U.S.S.R. As part of the program, the State Department and the AEC sponsored technical exchange visits by U.S. and U.S.S.R. scientists on nuclear waste management, but only low-level wastes, since high-level wastes were produced by fuel reprocessing and were classified secret.

ORNL was asked to participate in a U.S. visit to the U.S.S.R. in December of 1964. Floyd Culler selected Frank Parker from Health Physics Division and me from Chem Tech to go. Joe Lewin from the Thermonuclear Division also went as interpreter. Other delegates included three from AEC Washington, one from Hanford, and one from Brookhaven (Fig. 2.3).

The group departed from Paris on a Russian jet for Moscow but, because of fog, landed in Leningrad. The train to Moscow had two bunks in each compartment and was very crowded. One of the group was to share a compartment with a woman traveler-a common occurrence in Russia. The U.S. traveler, when asked if he would be embarrassed, said he would be (the woman indicated otherwise). Eventually, separate compartments were obtained.

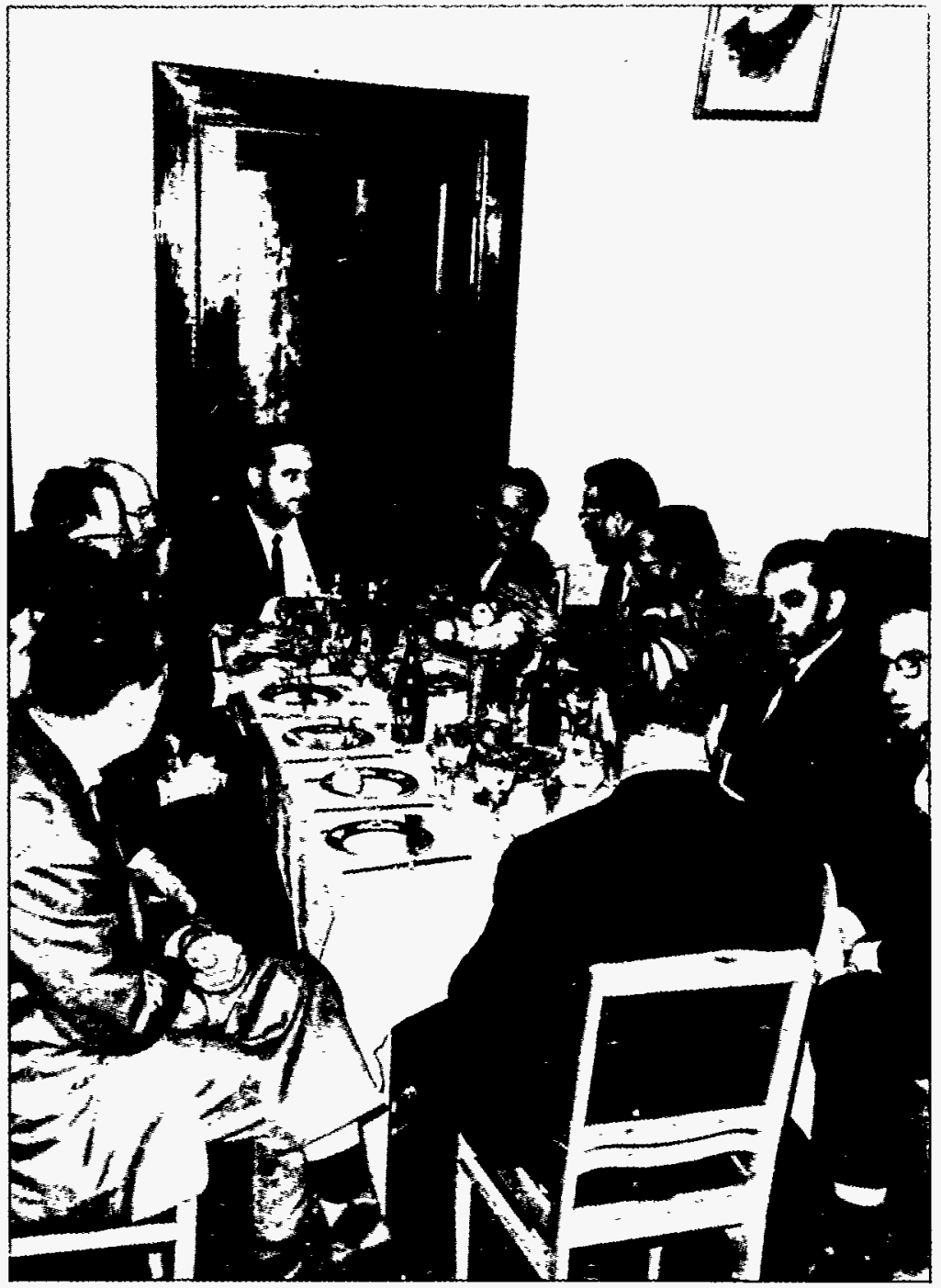

Fig. 2.3. The final 1964 technical exchange conference with the Russians took place in the Moscow office of Professor Academician Spitzen (back to camera). The delegates (clockwise from Dr. Spitzen) are Joe Lieberman, AEC; Al Platt, Hanford; L. P. Hatch, Johns Hopkins University, Alex Perge, AEC; Madame Breshneva, USSR; Ray Blanco, ORNL; Walter Belter, AEC; Joe Lewin, ORNL; and Frank Parker, ORNL.

The group visited the Atomic Research Institutes and the nuclear power reactors at Beloyarsk (near Sverdlovsk in Siberia), Moscow, Leningrad, Obninsk, Novovoranezh, and Karkov. In each case the group observed and discussed the low-level waste processing and storage facilities. They were studying scavenging-precipitation ion-exchange processes and incorporation into asphalt, the same as in our country. They were very interested in our results and freely presented their information. They even demonstrated for the U.S. 


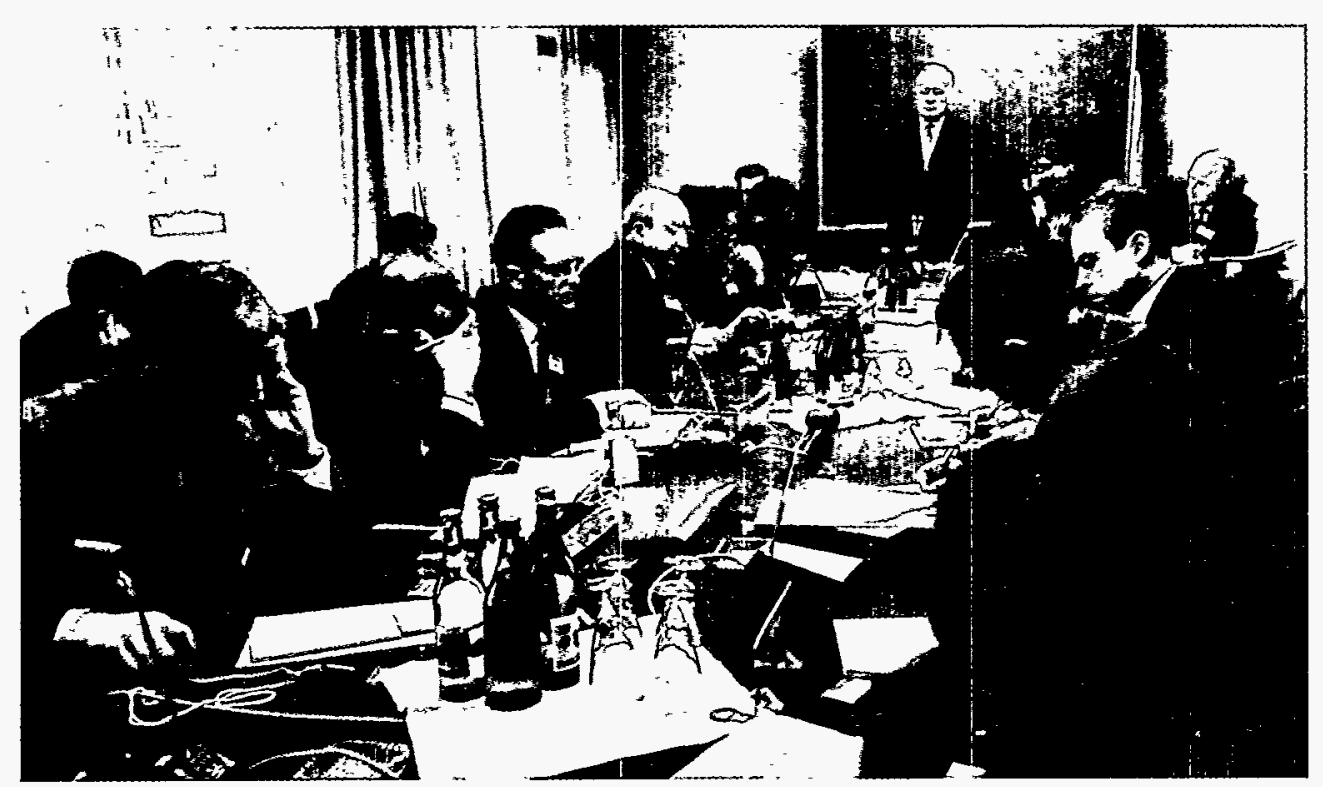

Fig. 2.4. The IAEA panel at the 1965 Low-Level Waste Conference, Subna, Russia, included W. H. Hardwick and R. H. Burns of the United Kingdom and Ray Blanco from far left to right; Professor Academician Spitzen, standing; and J. Rodler and

C. Sombret of France (with faces showing) at the right of the conference table.

group their cold pilot plant for solidification of intermediate- and low-level wastes into glass. Of course, this process could be used for high-level wastes also (Fig. 2.4).

Sidelights. The Russians were extremely gracious hosts and provided us with seats at the Bolshoi and Kirov ballets, shopping and sightseeing tours, and visits to the Kremlin and Hermitage museums. Representatives from the U.S.S.R. State Committee of International Relations were assigned to us as Visit Coordinator (A. A. Serov) and interpreter (G. V. Volkov). Fortunately, we had our own interpreter, Joe Lewin, who had lived in Leningrad until age 7. Thus, we could hear everything that was said at the conference tables. We called Serov "the man who walked on water." For example, as he led us into a very crowded department store, the crowd parted, put down the four hats they were looking at, and made room for us, with the clerk's immediate attention. Not a word had been spoken that we could detect. Special treatment on the trains was also accorded-with only two bathrooms on the sleeping cars, the eight Americans were assigned one while all the Russians had to use the other.

On arriving at Sverdlovsk by air, we loaded onto an army-type bus to ride to the nuclear power reactor at Beloyarsk —one Russian and one American per seat. Suddenly, my companion said,
"See that field out there, that's where we shot down Gary Powers. A farmer reported the downed plane and was told to be quiet but he got drunk and talked to everyone. Why do you fly over our country with spy planes?" I said, "President Eisenhower has proclaimed the freedom of the skies for everyone, including Russians." Then I countered by asking, "Why are the Russians helping the Chinese build an atom bomb?" He exclaimed, "We only help them with peaceful work—such as building bridges, etc.," but he didn't sound too sure of this. All this was said loud enough so that the entire bus heard it and a deathly silence set in until we reached our destination. All in all, they were extremely friendly and served a marvelous banquet in the evening, with toasts and speeches from both sides.

Russian Visit to ORNL, 1965. The return visit of the Russians to discuss waste management occurred in June 1965 . They were a party of ten, headed by Professor V. I. Spitsyn, a member of the U.S.S.R. Academy of Science. Frank Parker and I acted as the immediate contact hosts.

They arrived at ORNL from the Holiday Inn and were welcomed by Alvin Weinberg. A series of presentations were made in the conference room, followed by lunch and a tour of the waste facilities, including the low-level waste treatment plant, the hydrofracture plant, the Operations Division's 
waste monitoring and control building, White Oak Creek, White Oak Lake, and burial grounds. The tour route had been carefully planned as to what they could see or photograph. Much classified work was still in progress at that time.

A number of items of interest occurred. The morning meeting had barely started when a secretary came in with a message to the meeting coordinator (I believe it was Jim Cox, Operations Division Director) that a large amount of money had been found under the pillows in one of the visitors' hotel rooms (about $\$ 7000$, as I recall). This caused quite a stir, and one of the Russian visitors left immediately to get it. I guess he carried the money for the entire group.

When we arrived at the White Oak Creek bridge, every Russian raised his camera for permission to shoot. This creek was famous worldwide after the American papers at the Geneva conference had described it as the outlet for ORNL-treated low-level wastes.

I took them on a bus tour of the city of Oak Ridge. On passing the old Oak Ridge Associated Universities site, I said that the building contained a large ${ }^{60} \mathrm{Co}$ source for cancer therapy. Their question was "Did the patients have to pay for their treatment?" "Yes, they did,"I answered. The Russian said that they didn't have to pay for medical treatment and smiled. We then went to Pennsylvania Avenue and east on Outer Drive. I could hear them talking in Russian, and I gathered that they were commenting on all the cars, boats and the individual homes-not apartments.

Alvin Weinberg hosted a dinner at the Holiday Inn. The Russians had produced a quart of caviar as a gift, and when it wasn't served promptly, a Russian went into the kitchen to see if it had disappeared; it was only delayed. Afterward, the visitors and ORNL participants were divided between three homes for a visit-Frank Parker, Joe Lewin, and me. Spitsyn was in my party. I remember him saying to my wife, "I have only one request. My wife wants me to see if you have a phone in your kitchen." Fortunately, we could show him one.

Alvin Weinberg hosted a final meeting in his conference room and presented them a token of Tennessee hospitality (the encased Indian arrowheads) as a symbol of friendship and good will. At the post-visit meeting, we all decided that what our guests had liked best was the pop-open-type beer cans-just opening the cans was more fun than drinking the beer.

\subsection{IDAHO CHEMICAL PROCESSING PLANT- DESIGN, CONSTRUCTION, AND STARTUP: Personal Recollections of Hal Goeller, April $1992^{11}$}

Conception and design of the MTR had begun at ORNL toward the end of the 1940s. It was the first reactor to employ a fully enriched $\left(93 \%{ }^{235} \mathrm{U}\right)$ fuel. Since the fuel cannot be completely "burned up" during reactor operation, it must be removed from the reactor after being partially consumed and chemically processeci for re-enrichment and reuse by removal of the fission products and transuranic elements generated by burning. Such processing could not be done in the existing facilities at ORNL and Hanford, Washington, because criticality, as well as radioactive shielding, had to be considered in its design; hence, a new facility was needed. The new facility was to have been built on the side of the hill south of and facing the site of the present-day 4500 buildings. The AEC ruled, however, that a new area be set up for the MTR and the processing plant. Selection was soon narrowed to either Fort Peck, Montana, or Arco, Idaho, with the latter becoming the final choice. This area belonged to the U. S. Navy as a test firing range for 16-in. guns being made at Pocatello, Idaho. One reason for its selection was the existence of fairly extensive central facilities.

Conceptual design was started in early 1950 at ORNL on chemical process flow sheets for dissolving the fuel and solvent extraction removal of fission products and transuranics. Preliminary design of the equipment and of a processing building followed. The process dictated that all operations be done remotely behind $5 \mathrm{ft}$ of concrete shielding.

Foster Wheeler Company in New York City was selected to do the detailed design from the preliminary designs we provided them. In order to expedite this effort, about six of us worked with them in New York from April through July 1951 until detailed design was completed. In the meantime, the Bechtel Company of San Francisco was selected to do site preparation and construction, which began early in 1951. Alex MacIntosh, an ORNL architect in the Reactor Experimental Engineering Division, supervised construction of the main buildings. 
Nearly a dozen of us followed in August 1951 to supervise fabrication and installation of equipment and startup of the plant by American Cyanamid Corporation, who was selected by the $\mathrm{AEC}$ to be the plant operator. The last of us returned to ORNL during the summer of 1953. After a year on the job, Cyanamid elected to leave, and operations were taken over by Phillips Petroleum Company, who was already operating the MTR at the Idaho site.

The ORNL Idaho crew included Frank Browder, Ed Frederick, Hal Goeller, Frank Harrington, Bill Kearsley, Bob Klotzbach, Ed Nicholson, Frank Peishel, Paul Robertson, Al Rom, and John Ruch. Everyone thoroughly enjoyed their Idaho stay despite the fact that we were working a six-day week and then a seven-day week for a while. Four or five "Idaho offspring" were born during the stay.

The plant went "hot" in late 1953 with the processing of enriched slugs from Hanford. In addition, there were some enriched materials from Savannah River and from MTR fuel (Fig. 2.5). Later on, the facility processed Experimental Breeder Reactor (EBR-1) fuel. Incidentally, the EBR-1 was the first reactor in the world to produce electricity, though a minimal amount, namely, one light bulb. The Navy also built its nuclear submarine prototype reactor in Idaho during our stay (Fig. 2.6). The ICPP is still operating, and very successfully!

\subsection{THE CHEMICAL TECHNOLOGY DIVISION FROM 1953 TO 1991: Personal Recollections of Ray Wymer ${ }^{12}$}

I joined Chem Tech in October of 1953 in Chemical Development Section B. This section was one of three chemical development sections and was headed up by Ray Blanco. There was, as I recall, also a design section, a unit operations section, a pilot plant section, and a long-range planning group.

In 1953 the 4500 Building had just been completed and occupied. Up until then, the Chemical Technology Division Office was housed in Building 3550. Parts of the division were located in several other buildings around the ORNL site. Then, as now, Chem Tech was scattered all over ORNL.
Floyd Culler became Chem Tech division director in 1953. Frank Bruce was section chief of the Chemical Development Section at that time and, shortly thereafter, became associate director of the division. Don Ferguson and Ray Blanco were staff members of the Chemical Development Section, under Bruce, but later became section chiefs themselves (of Chemical Development Sections A and B, respectively). I believe that Kirk Jackson was section chief of the Pilot Plant Section and Warren Eister was section chief of the Unit Operations Section. (Back in those days we called them chiefs instead of heads.)

OREX and Mercury Amalgams. The big deal in Chem Tech in 1953 was development of a lithium isotope separation process called OREX. Y-12 was developing a competitive process called COLEX. There was a life-and-death competition between ORNL and Y-12 over which of the two competing isotope separation processes would eventually be used. The process was ultimately to be installed at $\mathrm{Y}-12$, and perhaps, not surprisingly, the Y-12 process won the competition. (I am perhaps showing a little provincial bias in the way I worded that last sentence. Actually, COLEX was probably the better process from a practical point of view, but OREX was more elegant and imaginative.)

Both isotope separation processes used equilibration of lithium isotopes between two liquid phases. The separation took place without any net transfer of moles of lithium between the phases. Only the isotopes exchanged phases. One process fluid in both processes was a liquid lithium amalgam. The other liquid was a solution of lithium chloride. The ORNL and Y-12 processes differed in the nature of the solvent used to dissolve the lithium chloride. (Lithium isotope separation using lithium amalgams was first suggested and successfully used by G. N. Lewis back in the middle 1930s. He used equilibration between a lithium amalgam and lithium chloride dissolved in diethyl ether.)

The interesting thing about this isotope-separation process development was that neither ORNL nor Y-12 had any previous experience with handling, pumping, storing, or carrying out any operations with amalgams. Of course the specific gravity of the amalgams was about 13. This is "a little" beyond the experience of most chemical engineers. The OREX pilot plant was located in Buildings 4505 and 4501. It was not uncommon to go into those buildings and see 


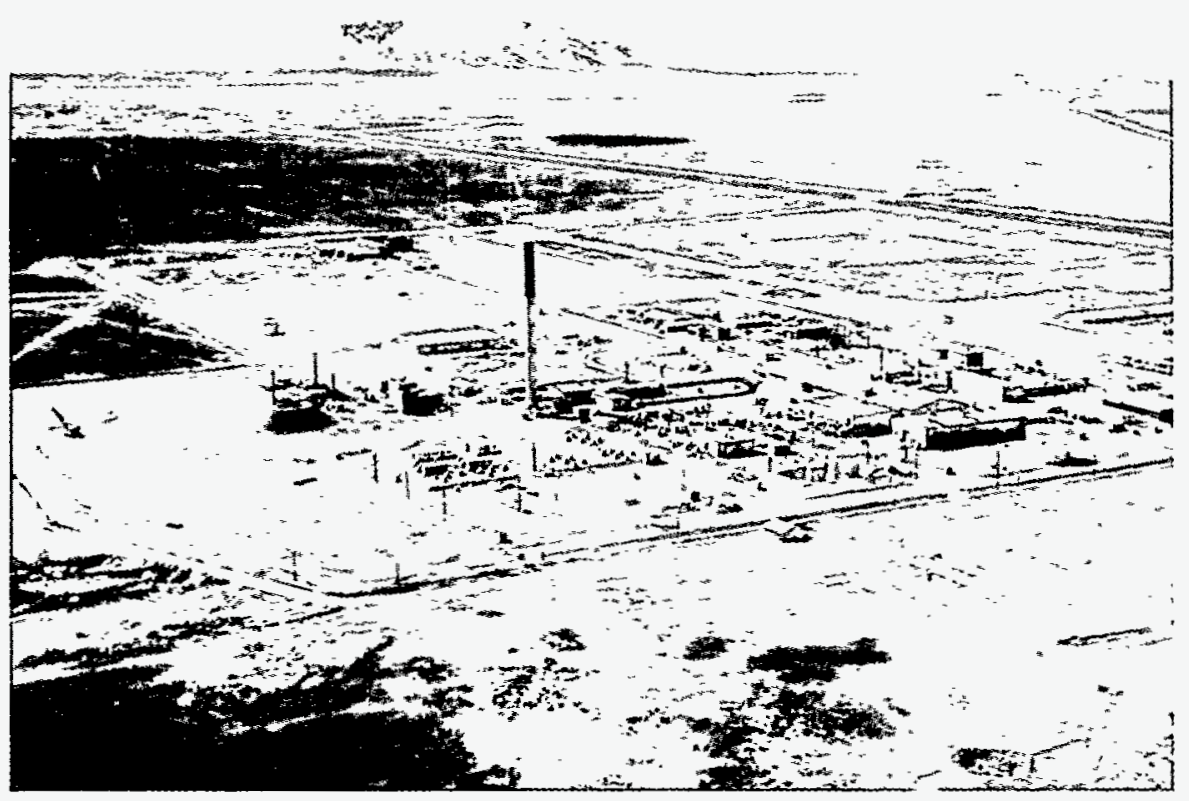

Fig. 2.5. The Idaho Chemical Processing Plant in this 1976 aerial photograph shows the plant essentially unchanged from its original design and construction. The photograph was provided through the courtesy of Lloyd McClure, Idaho National Engineering Laboratory.

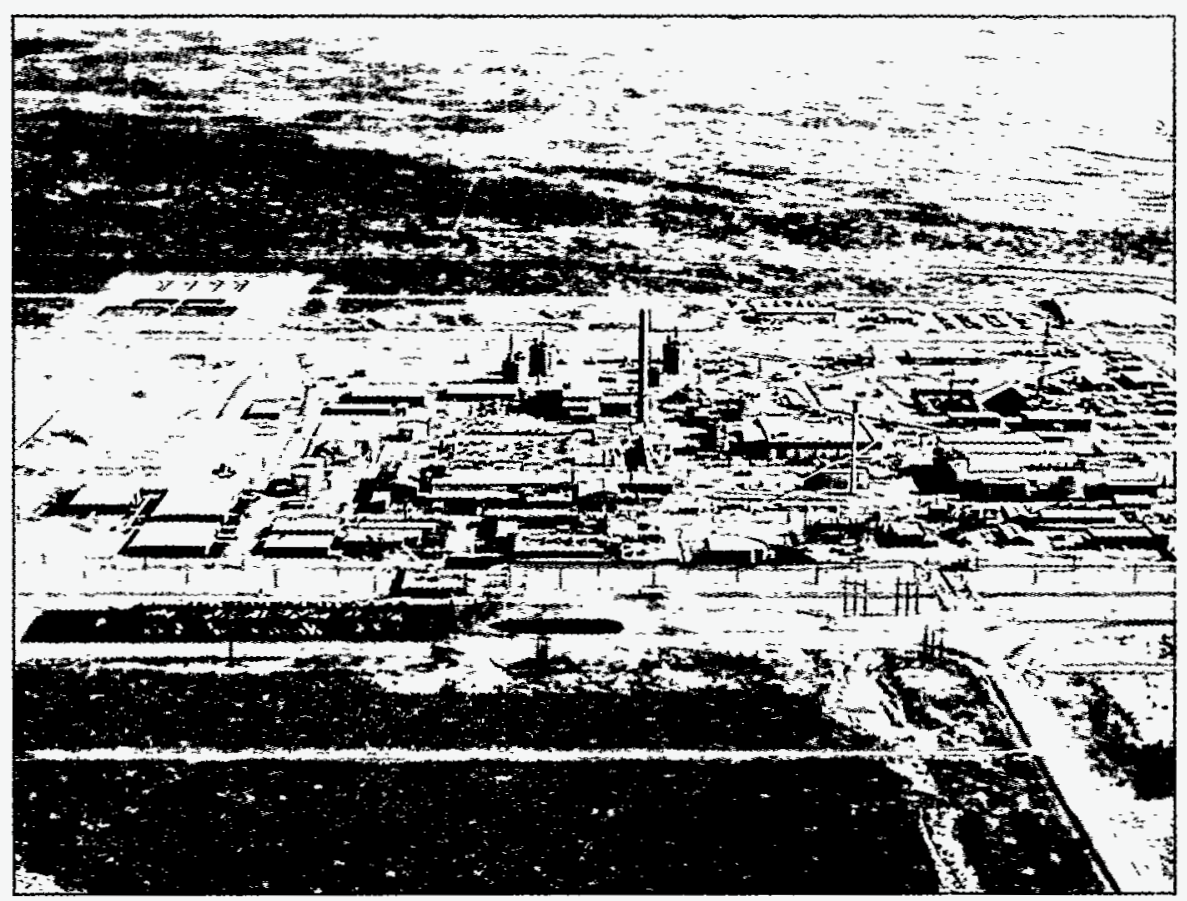

Fig. 2.6. This 1989 aerial photograph of the Idaho Chemical Processing Plant shows considerable modification and change of the original installation that were required to modernize and update the processing plant. The photograph was provided through the courtesy of Lloyd McClure, Idaho National Engineering Laboratory. 
pumps leak amalgam as they strained to lift and move them, or to see pipes at the bottom of a long vertical run burst under the extreme pressure head. Amalgam showers were frequent.

Not only were the chemical engineers not accustomed to handling mercury and its amalgams, neither were the medical nor the industrial safety departments accustomed to protecting the people who worked with them. My co-workers and I went down to a local dispensary in the 4500 Building once a week and wrote our names on a sheet of paper. Our signatures were compared with our earlier signatures to see if there were any signs of palsy! That was the test used to see if we were getting mercury poisoning! We protected ourselves from mercury vapors in the laboratories by sprinkling "flowers of sulfur" around on spills. This was supposed to convert the mercury to non-volatile mercuric sulfide. I suppose it did-eventually.

Geneva Conference. The next thing of importance that I recall is the first Geneva conference. This took place in the mid-1950s. ORNL was importantly involved. Members of Chem Tech wrote a handful of papers, and we contributed several operating exhibits, including a solvent extraction column that Fred Land and I put together that was supposed to illustrate the principles involved in solvent extraction purification of uranium and plutonium. A big secret in those days was how we took iodine out of the off-gas from a reprocessing plant. Any reference to that technology was carefully excised from the papers submitted. Presumably it was possible to take iodine release data and calculate plutonium production rates. Now, of course, we lean over backward to make sure that everyone knows how to retain iodine so that radioiodine is not released to the environment.

Reactors. All during those early days, ORNL was working on one or another of the advanced reactor programs being proposed at that time. A very early program was the Aircraft Reactor Experiment. This was a reactor that was supposed to propel an airplane. The crew was to be shielded rather than the reactor. Presumably the thing would have to land over a tunnel through which the crew would escape.

Weinberg and his associates always had a new reactor concept they were espousing. These concepts were all similar in basic outline but quite different in implementation. Weinberg used to refer to them as "a pot, a pipe, and a pump" to stress their supposed inherent simplicity. In concept they were simple. Materials problems were their undoing. I never worked on any of those programs, but a lot of Chem Tech people did. The first big one for Chem Tech was the Aqueous Homogeneous Reactor Program. People like Don Ferguson, Bob McNees (who later went on to be the mayor of Oak Ridge for many years), Chuck Schilling, John McBride, Bill Pattison, Leon Morse, and many others were in the middle of those programs.

Another reactor program that was big for Chem Tech was the Molten Salt Reactor Program. Chem Tech people a little more contemporary were involved in this program. These included $\mathrm{Bob}$ Hightower and Gene McNeese, to name two who went on to bigger and better things. All of these reactor concepts were based on the thorium-uranium fuel cycle. Since there is a huge amount of thorium in some granite rock, Weinberg talked about "burning the rocks." (He is a great phrase maker.)

Fluoride Volatility Process. An early nonaqueous process for reprocessing reactor fuels was the fluoride volatility process. ORNL was championing the use of fluorine gas to volatilize uranium as $\mathrm{UF}_{6}$. ANL was championing the use of $\mathrm{ClF}_{3}$ or $\mathrm{ClF}_{5}$ for the same purpose. This difference lead to an intense rivalry between the chemical engineering divisions at the two laboratories, which has only in the last 5 or 6 years been finally and completely laid to rest. At that time, Chem Tech and a process engineering group at K-25 were collaborating in a sort of guarded way. K-25 had a lot experience in handling $\mathrm{UF}_{6}$ and felt that they had considerable to offer ORNL. Strong personalities at both sites made collaboration rather difficult. Process equipment for a volatility pilot plant was partially installed in Building 3019, but the AEC cut off funding before the program was completed.

Waste Disposal. Starting in the 1960s, Chem Tech was playing a prominent role nationally in the waste disposal business. Geological disposal was recognized very early as the only long-term solution to disposing of high-level radioactive wastes. Chem Tech was deeply involved in a pilot project in a salt mine in Lyons, Kansas. A prominent Kansas legislator strongly objected to the idea saying, "Let those who have feasted on the atomic turkey bury its bones." However, when it was learned that the area was riddled with oil-prospecting drill holes, it became obvious that 
the proposed disposal site was not and could not be isolated from water. This was not only the death knell for the Kansas site, but also for geological disposal for the time being. Chem Tech involvement in the project was such that its shiny reputation got a little tarnished.

High-Temperature Gas-Cooled Reactor. At about this time frame, the High-Temperature Gas-Cooled Reactor (HTGR) came into the ascendancy. It was an AEC program whose principal advocate was General Atomic. Partly because it was based on the thorium fuel, a cycle to which ORNL had a major commitment, a large part of the program was given to ORNL. We worked on fuel fabrication and reprocessing, as well as having a significant role in fuel testing. (Morris Osborne and others are still doing similar testing work to this day.) Pete Lotts had the programmatic responsibility for part of the fuel fabrication work. I led the effort in Chem Tech. The whole activity was under the direction of Don Ferguson at first, and then under Paul Kasten. This work became a cropper when General Atomic couldn't get the prototype 300-MW(e) HTGR at Fort St. Vrain to operate well. Although General Atomic had accepted several orders for large HTGRs, they reneged on the orders. That was the end of the program for all practical purposes, although AEC had a collaborative program with Germany for quite a few years after that.

HTGR fuel was to be reprocessed by burning the graphite fuel elements to liberate the uranium and thorium particles, which were the actual fuel and blanket, respectively. Bob Lowrie was a key player in this aspect of the program. As I recall, Chuck Scott also had some role to play, as did Ron Canon.

Burning the graphite produced a carbon dioxide off-gas that contained ${ }^{85} \mathrm{Kr}$ that had to be removed. Ron Glass worked on this problem, along with Vic Fowler and others. For a time, Bob Merriman also worked on this part of the program. The off-gas work and the sol-gel operations were a success, even though the patient died.

Sol-Gel Process. It was the HTGR fuel fabrication work that got Chem Tech into the sol-gel process development work. Some related work had gone on before in connection with the aqueous homogeneous reactor, but it was the HTGR fuels work that brought people like Claude Haws, Paul Haas, Al Irvine, John McBride, Ken McCorkle, and many others into the sol-gel fold.
TRU Programs. About 22 years ago, the High-Flux Isotope Reactor (HFIR) and Transuranium Processing Plant (TRU) were built. TRU design and construction were major achievements of Floyd Culler, with a major assist from people like Bill Burch, Frank Peishel, Orlan Yarbro, Bill Unger, Hal Goeller, and many others. TRU [now called Radiochemical Engineering Development Center (REDC)] operations have been a mainstay in Chem Tech for more than twenty years, and TRU continues to be a major Chem Tech activity center to this day. The basic processes used in TRU in the early days are essentially the same ones that are used today. People like Rex Leuze, Russ Baybarz, Milt Lloyd, John Chilton, John Bigelow, Dave Campbell, Walt Bond and many others played key roles in developing the processes used.

Fuel Reprocessing Activities. About fifteen years ago, Bill Burch convinced Don Trauger and others that the fuel reprocessing activities in Chem Tech should be split off and put into a new division under Burch. At that point Chem Tech lost what had been a major part of its responsibility from its inception. Partly to compensate for that loss, and partly because it was the right time to do it, Chem Tech turned toward waste and the environment as major areas for its involvement. Those are major thrusts of the division to this day.

Biotechnology. Also, about that many years ago (my memory is dim on exactly when), Chem Tech started a modest effort in biotechnology under Chuck Scott. That area has been slow aborning but has been a steady activity for many years. At the present it appears to be gaining in strength.

Apologia. There are many areas that I have given short shrift to. But time available to think about the past is short, and so is my memory. At any rate, this is a personal account, not a disciplined attempt to be thorough and accurate. Please excuse the oversights and errors. Perhaps the recollections of others will fill in the gaps I have left and correct the errors.

\subsection{OVERVIEW OF EARLY CHEM TECH PROGRAMS}

Most of the early activities and programs of Chem Tech were continuations of the important R\&D activities of the Chemical Technology Department of the Technical Division. The major programs of national importance focused on reactor 
Table 2.1. Chronology of ORNL/Chem Tech reprocessing activities

\begin{tabular}{ll}
\hline Period & \multicolumn{1}{c}{ Process } \\
\hline $1943-1945$ & Bismuth phosphate \\
$1945-1951$ & Redox \\
$1945-1952$ & RaLa \\
$1946-1948$ & Hexone-25 \\
$1946-1948$ & Hexone-23 \\
$1948-1949$ & Uranyl ammonium phosphate \\
$1948-1958$ & Metal recovery \\
$1948-1953$ & TBP-25a \\
$1949-1960$ & Purex \\
$1949-1968$ & Fluoride volatility $b$ \\
$1949-1976$ & Fuel preparation ${ }^{c}$ \\
$1951-1976$ & Raw materials ${ }^{d}$ \\
1952 & TBP-Interim-23 \\
$1952-$ present & Thorex \\
$1953-1959$ & Feed materials $e$ \\
$1955-1976$ & Head-end $f$ \\
$1961-1976$ & TRUg \\
\hline
\end{tabular}

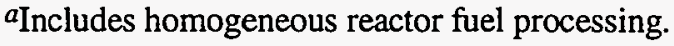

${ }^{b}$ Includes ARE and MSRE fuel reprocessing.

cIncludes aqueous sulfate fuels (HRE), sol-gel, carbide-graphite-oxide spheres (HTGR, EGCR, Rover), and molten salts (MSRE, ARE).

$d$ Includes SLURREX, AMEX, DAPEX, MONEX, and other processes.

${ }^{e}$ Includes EXCER, METALLEX, FLUOROX, DRUHM.

fIncludes mechanical methods, DAREX, ZIRCEX, ZIRFLEX, Voloxidation, etc.

8Includes TRAMEX, CLEANEX, BERKEX, PLURIX, and others.

Source: R. E. Brooksbank, Sr., Historical and Programmatic Overview of Building 3019, ORNL/CF-91/298 (July 17, 1991).

fuel reprocessing and the recovery of uranium, plutonium, and other radioisotopes. The major programs are presented chronologically in Table 2.1 and discussed briefly below. Selected facilities and other Chem Tech activities are also discussed, as appropriate, to help present a balanced picture of the division involvement.

ORNL/Chem Tech Pilot Plant. Since early 1943, the ORNL/Chem Tech-managed pilot plant, Building 3019 (formerly known as Building 205), has served as a pilot plant in the development of several radiochemical processes that have found plant-scale application in government and commercial facilities, both nationally and internationally. In addition to the process development role, the facility's operations have also produced large quantities of product materials (plutonium, uranium of all isotopes, thorium, and special isotopes) while processing highly irradiated fuel. The Chem Tech pilot plant was used for process studies and production for the following processes: Bismuth Phosphate, Redox, Purex, Fluoride Volatility, Fuel Preparation, and Thorex. The pilot plant and operations are described in detail in Sect. 4.17.

Redox Process. The Redox process separated and recovered uranium and plutonium from irradiated fuel using hexone as a solvent and $\mathrm{Al}\left(\mathrm{NO}_{3}\right)_{3}$ as salting agent. ${ }^{13}$ The solvent extraction process was developed by ANL for separating and purifying uranium and plutonium. The process promised to be more simple and economical than the bismuth phosphate process. Soon after the war, ORNL was requested to test and improve the 
Redox process in its pilot plant facility. ORNL modified the process and demonstrated production of sufficiently pure uranium. In 1952 a new $\$ 60$ million chemical plant using this process was constructed at Hanford. ${ }^{14}$

RaLa Process. Chemists in the Technical Division had developed a laboratory-scale process for extracting ${ }^{140} \mathrm{Ba}$ from fission products to provide a source of ${ }^{140} \mathrm{La}$ with its high energy radiation for use in Los Alamos studies. Engineering-scale equipment was designed and installed in hot cells of Building 706C. By September 1944, curie quantities of ${ }^{140} \mathrm{Ba}$ were being produced and design was begun on equipment for producing $1000-\mathrm{Ci}$ batches of ${ }^{140} \mathrm{Ba}$. In the first half of 1945, Building 706D and its hot cells were built, equipment was installed and tested, and two production runs were made. The second run produced $1180 \mathrm{Ci}{ }^{140} \mathrm{Ba}$. The Technical Division operated the plant until 1946, when it was turned over to the Operations Division. ${ }^{15}$ A major problem in the RaLa process was the intense radioactivity resulting in radiolysis of the water. The first RaLa process involved precipitation with gravity settling, which did not work well because of the radiolytic gas formation..$^{16}$ The experimental work sometimes involved high levels of radioactivity that glowed in the darkened laboratory. ${ }^{17}$ In 1949 ion-exchange runs were made with large amounts of radioactivity, demonstrating the feasibility of an improved RaLa process. ${ }^{18}$

"25" Process. The MTR at Arco, Idaho, required a new chemical process to recover the highly enriched uranium from irradiated uranium-aluminum alloy fuel elements. Chem Tech staff chemists and chemical engineers were principally responsible for development and pilot plant testing of the " 25 " process. ${ }^{14,18}$ The process recovered uranium from irradiated fuel by solvent extraction using hexone. ${ }^{13}$ In 1949 the Chem Tech pilot plant had successfully completed the final development of the " 25 " process through the first and second cycles and was in the final stages of development on the isolation cycle. ${ }^{18}$ The " 25 " process formed the basis for chemical separations used in the ICPP. ${ }^{14}$

Idaho Chemical Processing Plant. Initiated in 1950 , the effort to develop a fuel reprocessing plant to be sited in Idaho rapidly developed into a major program area. The Design Section of Chem Tech was given the responsibility for the process design of ICPP with Foster Wheeler Corporation as AE and Bechtel as the construction engineering firm. It was one of the earliest experiences of these AEs with nuclear technology. Design was essentially complete in 1951-1952. Management of the complex design effort involved coordination with several AEC offices, the Foster Wheeler Corporation, and other ORNL divisions. To assist in the design of the ICPP, a team of Chem Tech staff members was assigned to the New York office of Foster Wheeler. Construction of the plant had progressed to the point in early 1952 that Chem Tech staff members were then assigned to Idaho to assist in the field engineering, testing, and startup of the plant. ${ }^{2}$ The total capital cost of the ICPP was $\$ 31,106,000 .^{19}$ The philosophy of direct maintenance was used in this plant for the first time, all previous plants having used remote-control maintenance. The plant, completed in 1952, and process were sufficiently versatile to routinely process fuel elements from MTR, EBR, STR, and other reactors. ${ }^{20}$

Solvent Extraction Recovery of ${ }^{233} U$. During 1946-49, the Technical Division processed irradiated thorium oxycarbonate in 706A (part of Building 3550 that has now been razed). This work was done in equipment designed by John "Tex" Blomeke which was installed in one of the four hot cells in the Semi-works area. Some of the solvent extraction work to isolate ${ }^{23} \mathrm{U}$ was carried out in one of the hot cells in the Chem Tech Pilot Plant Building 3019 (formerly 205). One of the solvents tested was diisopropyl ether. 21

“23” Process. The "23" process was developed to separate ${ }^{233} \mathrm{U}$ from irradiated thorium by hexone extraction. Chem Tech pilot plant tests were initiated in 1949.18 The Interim-23 process for isolated ${ }^{233} \mathrm{U}$ from irradiated thorium and fission products was developed for the production of kilogram quantities of weapons-grade ${ }^{233} U$. Slugs irradiated at Hanford were shipped in special shielded carriers to the ORNL/Chem Tech pilot plant and processed at $70 \mathrm{~kg} \mathrm{Th} /$ day. In 1952, a total of $2.5 \mathrm{~kg}{ }^{233} \mathrm{U}$ was isolated. ${ }^{14}$

Purex Process. The Purex process used solvent extraction with TBP and $\mathrm{HNO}_{3}$ for salting out effects to separate and recover uranium and plutonium from irradiated natural uranium fuel. ${ }^{13,18}$ By the summer of 1949 , the process was shown to be feasible and more economical than previous processes. An additional advantage was the separation and isolation of fission products which simplified radioactive waste storage problems. In 1950, the Purex process was selected by DuPont for use in the Savannah River Project. 
The major chemical development work for the process was done at ORNL. In 1954 the Purex process was used in two separations plants at Savannah River costing $\$ 75$ million each. In 1956 a modified Purex plant was constructed at Hanford costing $\$ 78$ million. ${ }^{14}$ The Purex process is the process of choice for use in all present and planned reactor fuel reprocessing plants throughout the world. 22

TBP Process. In 1949, ORNL initiated the development of a process for the recovery and purification of uranium from its metal wastes stored in the tank farms. ${ }^{14,18}$ Many tons of metal wastes were stored in tanks at ORNL and Hanford. For example, the ORNL metal waste tanks contained 155 tons of uranium precipitated as a carbonate or hydroxide form. ${ }^{23}$ The process developed used TBP for extraction of uranium and plutonium from the waste. An early complication of the plutonium recovery from ORNL metal waste was the discovery that $40-60 \%$ of the plutonium had polymerized on storage in the alkaline metal waste and had precipitated as a sludge. Digestion at $70^{\circ} \mathrm{C}$ in $3.5 \mathrm{M}$ excess nitric acid for $4 \mathrm{~h}$ solubilized $95 \%$ of the plutonium. ${ }^{23}$ The TBP metal recovery process was installed at Hanford at a cost of $\$ 35$ million. Chem Tech designed and constructed the Metal Recovery Plant to use the TBP process. ${ }^{14}$

Metal Recovery Plant (Building 3505).

The Metal Recovery pilot plant (Building 3505) was constructed in 1951 at a cost of $\$ 500,000$. The facility was designed to demonstrate a chemical process for recovering uranium from Oak Ridge National Laboratory and Hanford tank-farm wastes by continuous extraction with TBP in a kerosene-type diluent (Amsco). The plant was expanded at a cost of $\$ 300,000$ to include a dissolver for solid materials, two additional solvent-extraction cycles, plutonium isolation equipment, and piping changes to permit processing of various feed materials for recovery of plutonium, americium, and neptunium as well as uranium. These included metallurgical wastes resulting from the reduction and calcination of plutonium compounds; ash residues from the conversion of $\mathrm{UO}_{3}$ to $\mathrm{UF}_{6}$; sodium diuranate carbonate sludge and supernatant accumulated in ORNL tanks; uranyl nitrate solutions in tank car lots and plutonium nitrate from Chalk River; and spent fuel elements from Chalk River, Clementine (Los Alamos Scientific Laboratory), Graphite, Brookhaven National
Laboratory, and ANL reactors. All the fuel elements were uranium clad in aluminum except the Clementine, which were nickel-coated plutonium alloy encased in mild steel. The maximum capacity of the plant is $450 \mathrm{~kg}$ of uranium per day, which is reached in the processing of natural-uranium fuel elements. ${ }^{24}$

The basic design philosophy for the Metal Recovery pilot plant was that the equipment would be remotely operated but directly maintained. Remote operation of radiochemical plants is necessary to prevent exposure of personnel to radiation, and in earlier radiochemical production plants, maintenance was also carried out remotely. In the Oak Ridge National Laboratory Metal Recovery pilot plant, process equipment is arranged according to its function and activity level so that only the equipment associated with that requiring maintenance must be decontaminated. The greatest source of radioactivity, the dissolver, is in a cubicle by itself. Cells containing the rest of the equipment are isolated from each other, and each contains only related parts of process equipment. Certain vulnerable pieces of equipment which might require frequent maintenance are unit-shielded with lead. The exposure of maintenance men to radioactivity in 7 years of operation averaged $60 \mathrm{mrem} /$ week, which is $20 \%$ of the permissible exposure. Because of limited shielding, the plant is restricted to the processing of materials of intermediate irradiation levels with long cooling times. ${ }^{24}$ As stated above, the ORNL Metal Recovery Plant used the TBP process. The new facility was first used in the AEC high-priority program for separating uranium and plutonium from Chalk River reactor fuel elements. ${ }^{14}$ Subsequently, ORNL metal waste was processed and it was reported that 95 tons of uranium and $208 \mathrm{~g}$ plutonium had been recovered from the waste after operating for one year. The plant was converted to process Hanford slag and crucible waste, and in three weeks of operation it had recovered $1500 \mathrm{~g}$ plutonium and $0.1 \mathrm{~g}$ americium. ${ }^{20}$ By September 1954, The Metal Recovery Plant had recovered $67 \mathrm{~kg}$ plutonium and $10 \mathrm{~g}$ americium from Hanford slag and crucible waste. Although the initially separated americium was contaminated with $3000 \mathrm{~g}$ lanthanum, the newly developed ion exchange-citrate elution process reduced the 
lanthanum contamination and yielded an americium product with a lanthanum-to-americium ratio of $1: 100 .{ }^{19}$ The facility was also used to recover uranium and plutonium from the Brookhaven National Laboratory reactor, the ANL CP-2 and CP-3 reactors, and the "Fermi pile" fuel. ${ }^{14,16}$

Thorex Process. The application of TBP extraction to thorium recovery was named the Thorex process. ${ }^{18}$ The Thorex process was developed to separate ${ }^{233} \mathrm{~Pa}$, ${ }^{233} \mathrm{U}$, thorium, and fission products from each other. Major objectives of the process included isolation of ${ }^{233} \mathrm{U}$ for weapons development, separation of ${ }^{233} \mathrm{U}$ from thorium blankets in breeder reactors, and identification of a source of ${ }^{233} \mathrm{~Pa}$ and isotopically pure ${ }^{233} \mathrm{U} .13,14$ The Thorex process pilot plant was installed and tested in 1954 on both the pilot plant and semi-production scales 14,19 During the development work, approximately $80 \mathrm{~kg}{ }^{233} \mathrm{U}$ was separated along with 45 metric tons of thorium. The separation of ${ }^{233} \mathrm{~Pa}$ as a specific product (an early objective of the Thorex program) was not achieved. However, isotopically pure ${ }^{233} \mathrm{U}$ resulting from the decay of ${ }^{233} \mathrm{~Pa}$ was recovered by reprocessing the waste. ${ }^{14}$

The Thorex pilot plant was installed in existing facilities (Building 3019) in 1955 to demonstrate the recovery of thorium and ${ }^{233} \mathrm{U}$ from irradiated thorium, decontaminated from radioactive ions, as aqueous products suitable for further direct handling. The original equipment was designed for material irradiated to $1500 \mathrm{~g}$ of ${ }^{233} \mathrm{U}$ per ton and decayed 200 days; this equipment was installed at an initial cost of $\$ 1,250,000$. The plant was expanded from a one-cycle process ${ }^{25}$ to a multicycle process, providing considerable experience with plant decontamination and equipment maintenance. The subsequent modifications made to permit processing of material irradiated to $4000 \mathrm{~g}$ of ${ }^{233} \mathrm{U}$ per ton decayed 30 days and recovery of isotopically pure ${ }^{233} \mathrm{U}$ after decay storage of the ${ }^{233} \mathrm{~Pa}$ cost $\$ 750,000$, bringing the total capital investment to $\$ 2,000,000$. The annual operating cost has been about $\$ 1,100,000$. The plant has also processed the Idaho Materials Testing Reactor assemblies for ${ }^{237} \mathrm{~Np}$ and ${ }^{235} \mathrm{U}$ recovery and is considered suitable for processing thorium oxide slurries used in homogeneous reactor development work. The maximum capacity of the plant is $150 \mathrm{~kg}$ of thorium per day with thorium metal slugs. ${ }^{24}$

Like the metal recovery pilot plant, the Thorex pilot plant is remotely operated and directly maintained. Major pieces of equipment are individually shielded by either cubicles or unit shielding and are easily accessible from a nonradioactive area. In addition, major pieces of equipment and cubicles are provided with built-in decontaminating facilities. Sample conveyors are shielded. Unique equipment items are concatenated pulsed columns, special pulse generators, and airlift-operated radioactive solution samplers. With 200-day-decayed material, radiation exposure to operating persunnel averaged $10 \%$ of permissible; even during processing of short-decayed material, exposure was below permissible amounts. ${ }^{24}$

Early Fluoride Volatility Studies. As early as 1943, the Metallurgical Laboratory initiated scouting studies at the $\mathrm{X}$ site (Clinton Laboratories) of the Dry Fluoride Process for separations purposes. ${ }^{26,27}$ Sometime around 1949, fluoride volatility studies were again started. Direct reaction of uranium metal with elemental fluoride was studied, and some work was carried out to investigate the reaction of uranium in bromine trifluoride. There may have been some early work in the 706A Semi-works (part of Building 3550 that has since been razed) that was later transferred to a laboratory in Corridor A of $4500 \mathrm{~N} .21$

Semi-Continuous Ion Exchanger. Chem Tech staff member I. R. Higgins developed a semi-continuous ion-exchange system. ${ }^{2}$ The ion-exchange system was used for a variety of separations, for example, see Sect. 2.10, Raw Material Processing.

Chalk River: Recovery of Plutonium in Chem Tech Pilot Plant. In 1950 the Chem Tech pilot plant began separating plutonium from Chalk River-irradiated uranium using the Redox flow sheet. ${ }^{23}$ Within several months, it was reported that the plutonium loss across the Redox process fuel cycle and second plutonium cycle ranged from 0.8 to $2.5 \%$, with gross fission product decontamination factors of $5 \times 10^{5}$ to $1.8 \times 10^{6}$. The pilot plant phase of the campaign was completed, yielding a plutonium product which contained 0.2 to $0.4 \mathrm{~g}$ of uranium per gram of plutonium. This product was ready for final concentration and purification. ${ }^{4}$ The ion-exchange 
isolation step for recovery of plutonium from Chalk River-irradiated metal was called the SCRUP program. ${ }^{2}$

HOPE. The original Hope Project study, which was made in the summer of 1953,28 was reactivated for a two-year Hope program during 1954-1955.29 The original objective was to think of innovative and very inexpensive ways to reprocess reactor fuels. 30,31 The Chem Tech participants in that study directed by Eugene Wigner and Bob Charpie were Hal Goeller, Bob Klotzbach, and Ed Nicholson. The original Hope study assumed that a thermal reactor power economy would use reactors with ${ }^{233} \mathrm{U}$ fuel.

The purpose of the revitalized program was to study in greater detail all ideas presented in the original work, ${ }^{29}$ plus all others that showed promise of effecting reductions in radiochemical processing costs. Much of the effort was directed toward testing features of the Hope type of design for a Savannah River ${ }^{235} \mathrm{U}$ separation facility. The overall objective of the program was to demonstrate that enriched ${ }^{235} \mathrm{U}$ could be recovered from irradiated fuel elements at a cost that was compatible with production of economically competitive power from nuclear reactors. ${ }^{28,32}$ The areas of radiochemical processing that appeared most susceptible to cost reduction and, consequently, were studied in the program were a new approach to criticality (i.e., always-safe equipment); underwater maintenance; feasibility of radioactive waste disposal methods other than storage in stainless steel tanks; a more reasonable approach to fissile material accountability; reduction of plant inventory costs; development of a continuous slug charger; and development of samplers and pumps. The Chem Tech staff members participating in the new Hope program were Baird Bottenfield, $\mathrm{Al}$ Irvine, D. O. Darby, G. W. T. Kearsley, J. P. Jarvis, and Florence Isenhour. ${ }^{29,32}$

Special Equipment Tests. Much equipment development and testing were required to ensure safe and reliable operation of the equipment under adverse environmental conditions such as high levels of radioactivity, a corrosive environment, and high temperatures. Examples of equipment tested for resistance to radiation include valves, pipe dope, hoods, lead shot transfer jets, pulsafeeder pumps, steam traps, plastic polymers, paint surfaces, pipe and tubing fittings, magnetic-induction flowmeters, spray nozzles, electrostatic precipitators, and filters. ${ }^{23,33,34}$

\subsection{OVERVIEW OF NUCLEAR REACTOR FUEL REPROCESSING}

Chem Tech has been involved in fuel preparation or reprocessing studies on most, if not all, the reactor programs that ORNL either participated in or directed. Such programs included support work for the MTR and principal responsibilities for the homogeneous reactor series, the molten salt reactor, and the aircraft reactor experiment. Later reactor-related studies included safety analyses, fuel materials and fission product behaviour, and support work for the HTGR Program.

\subsubsection{ORNL Reactor Studies}

Brief summaries of the major reactor programs follow.

Materials Test Reactor (MTR). In 1948, ORNL reactor development efforts were concentrated entirely on the design of the MTR, which was to be constructed at the new National Reactor Testing Station in Idaho. The MTR concept of parallel plates with water moderator and coolant had a profound influence on the development of power reactors. ${ }^{14}$

Homogeneous Reactor (HR). The homogeneous reactor concept had been dropped in 1945 due to what had been thought to be insurmountable engineering problems, such as the formation of bubbles in the fuel solution as a result of the decomposition of water in the strong radiation field (this was later solved using dissolved copper as a catalyst to recombine the radiolytic hydrogen and oxygen). Greater engineering experience and new conceptual designs for homogeneous reactors appeared promising in 1949. Therefore, the AEC gave approval for R\&D leading to construction of a homogeneous reactor (HRE-1). HRE-1 was completed in January 1952 and operated successfully until 1954. Design of HRE-2 was started in January 1954, and the reactor went critical December 27, 1957, operating at full power in February 1958. The homogeneous reactor test (HRT) operations achieved a unique record for reactors at that time by operating continuously for 100 days. Phase separation problems in the uranyl sulfate solution and resulting corrosion of reactor materials at the hot spots resulted in AEC discontinuing the aqueous homogeneous reactor 
program, although it continued support for thorium breeder technology. A thorium breeder reactor development became the objective of the new thorium utilization program initiated in 1961.14

Aircraft Reactor Experiment (ARE). On September 1, 1949, the AEC authorized ORNL to establish an Aircraft Nuclear Propulsion program (ANP). An experimental aircraft reactor (ARE) was completed and operated in October 1954. The ARE operated at full design power for $100 \mathrm{~h}$, as planned. The fuel consisted of $\mathrm{NaF}-\mathrm{ZrF}_{4}-\mathrm{UF}_{4}$, and operational temperatures of $1200-1500^{\circ} \mathrm{F}$ were required. The use of molten salt fuel and reliable operation at such elevated temperatures were remarkable technological achievements. Early in FY1958, the ANP was discontinued because of costs as well as changing military needs, and ongoing work was phased out by 1961.14

Molten Salt Reactor (MSR). The molten salt reactor (MSR) concept originated out of the ANP research. The MSR was attractive for civilian power production because of low fuel cost and high thermal efficiency. ${ }^{14}$ In addition to R\&D efforts on the MSR, ORNL actively engaged in the development of a molten-salt breeder reactor (MSBR) that could produce low-cost power while producing its own fuel- ${ }^{233} \mathrm{U}$ from ${ }^{232} \mathrm{Th}$ in amounts larger than it consumes. ${ }^{35}$ It would use a molten fluoride salt, $\mathrm{LiF}_{-} \mathrm{BeF}_{2}-\mathrm{ThF}_{4}$ (76-16-12 mol $\%$ ), as a fluid fuel and graphite as a moderator. The MSBR would succeed as a breeder only if the ${ }^{233} \mathrm{~Pa}$ (27.4-d half-life) could be isolated at a rate significantly higher than its decay rate and if the rare-earth fission products were removed on a cycle of between 30 and $100 \mathrm{~d}$. Chem Tech received the responsibility of developing an appropriate MSBR fuel process. ${ }^{35}$

High-Temperature Gas-Cooled Reactor (HTGR). The HTGR was considered to be a promising thermal reactor for the conversion of ${ }^{232} \mathrm{Th}$ to ${ }^{233} \mathrm{U}$ and the production of economical electric power. The Ft. St. Vrain reactor was the only HTGR reactor operated in the United States. The HTGR fissile fuels consisted of ${ }^{235} \mathrm{UC}_{2}$ particles, and fertile fuels consisted of (U,Th) $\mathrm{O}_{2}$ and $\mathrm{ThC}_{2}$ particles. The design for HTGR fuels included the use of coated (e.g., pyrocarbon layers) particles bonded into graphite sticks and inserted into holes in large graphite blocks of hexagonal cross section. ${ }^{36}$ Attaining the goals of economical power and improved utilization of uranium and thorium resources required the development of an efficient fuel cycle, including fuel reprocessing and fabrication of recycle fuel. ${ }^{36}$

Liquid-Metal Fast Breeder Reactor (LMFBR). The Liquid-Metal Fast Breeder Reactor uses plutonium rather than ${ }^{235} \mathrm{U}$ as the major fissile fuel. The content of fissionable material in the LMFBR is higher by a factor of 7 in the core section as compared with light-water reactors, and the specific power of the LMFBR is higher by a factor of 5. The reactor name is derived from its use of unmoderated or fast neutrons for fission and breeding, as well as its use of a liquid metal (e.g., sodium) for the primary coolant. The fission product content of the irradiated fuel is higher than that of light-water reactors (locally by three times higher). Because of the high fissionable material content of the reactor core (and consequent high inventory costs), processing of the LMFBR fuel after only short decay periods will be advantageous. ${ }^{37}$ Although not directly responsible for the design of the LMFBR, ORNL and Chem Tech were intimately involved as technical support in many areas. ${ }^{38}$

High-Flux Isotope Reactor (HFIR). The Transuranium Processing Plant (TRU) and the High-Flux Isotope Reactor (HFIR) were built at ORNL to produce large quantities of the heavy actinide elements as part of the AEC Heavy Element Production Program. These materials were used in basic research in laboratories throughout the country. In 1966 242Pu target irradiation was started in HFIR, and TRU began hot operations. During the first year of operation, more than 40 shipments of transuranium elements were made to other national laboratories, universities, and industries in this country. Shipments were also made to three foreign countries. The program phases managed by Chem Tech were operation of TRU, final isolation of the transuranium elements, and development of chemical separations processes and equipment ${ }^{38}$ (Sect. 4.10).

\subsubsection{Nuclear Fuel Processing and Reprocessing}

The development of reprocessing methods for nuclear power reactor fuels has been a major effort at ORNL and in Chem Tech. The principal work prior to 1961 covered dissolution procedures for stainless steel-clad and zirconium-clad fuels. The resulting solutions were processed by established solvent extraction procedures. ${ }^{14}$ An excellent and detailed summary of Chem Tech reprocessing 
experience is provided in Tables 4.1-4.5 of Sect. 4.17.

Shear-Leach Process. The shear-leach process consists of shearing stainless steel or Zircaloy-clad tubular $\mathrm{UO}_{2}$-bearing fuel elements and leaching the $\mathrm{UO}_{2}$ from the sheared fuel tube with nitric acid in preparation for solvent extraction. The process was developed by Chem Tech staff member Clyde Watson. It was used for nuclear fuel preparation by Nuclear Fuel Services at the first commercial fuel processing plant in the United States at West Valley, New York..$^{39}$ All power reactor processing plants worldwide use the shear-leach process. ${ }^{30}$

Darex Process. The Darex process was developed for stainless steel-jacketed fuels and used a mixture of boiling hydrochloric and nitric acids (aqua regia) to dissolve the stainless steel jacket. ${ }^{14}$

Sulfex Process. An alternate process for stainless steel-jacketed fuels was the Sulfex process that dissolved the stainless steel jacket in sulfuric acid and the fuel materials in nitric acid. ${ }^{14}$ The only plant-scale use of the Sulfex process was at the Eurochemic Plant in Mol, Belgium. ${ }^{30}$

Zirflex Process. Zirflex was a similar process for zirconium-jacketed fuel using ammonium fluoride-ammonium nitrate solution to dissolve the zirconium jacket followed by nitric acid dissolution of the core. Such procedures were especially applicable to fuels with uranium and thorium oxide cores such as Commonwealth Edison, Yankee Atomic, and Consolidated Edison. ${ }^{14}$

Zircex Process. The Zircex process, using $\mathrm{HCl}$ gas to remove the zirconium cladding as $\mathrm{ZrCl}_{4}$, was successfully tested on unirradiated zirconium-bearing fuel elements. ${ }^{14}$

Excer Process. The uranyl nitrate product of solvent extraction processes such as Redox and Purex is converted to $\mathrm{UF}_{4}$ in preparation for gaseous diffusion recycle as $\mathrm{UF}_{6}$. This was usually accomplished by costly reduction with hydrogen and hydrogen fluoride. The Excer process involved aqueous-phase hydrofluorination of uranium to $\mathrm{UF}_{4}$. However, the process did not have sufficient economic advantage to replace the existing gas phase plants. ${ }^{14} \mathrm{~A}$ modification, the Excer-Moving Bed process, for converting uranyl nitrate to $\mathrm{UF}_{4}$ consisted of denitration of the uranyl nitrate to $\mathrm{UO}_{3}$, reduction to $\mathrm{UO}_{2}$, and hydrofluorination to $\mathrm{UF}_{4}$. The process was successfully demonstrated in bench-scale experiments in $1954 .{ }^{19}$

Fluorox Process. The Fluorox process involved reaction of $\mathrm{UF}_{4}$ with oxygen to produce $\mathrm{UF}_{6}$ and uranyl fluoride. The process promised some economy by using oxygen instead of elemental fluorine to convert $\mathrm{UF}_{4}$ to $\mathrm{UF}_{6} .{ }^{14}$

Metallex Process. The Metallex process for conversion of thorium tetrachloride to thorium metal ingots involves dissolving thorium tetrachloride in anhydrous propylene diamine (PDA) and reducing the thorium by contact with sodium or lithium amalgam at temperatures below $100^{\circ} \mathrm{C}$. A button of thorium metal is formed from the resulting thorium quasi amalgam.by filtering, cold-pressing, and melting the metallic product. ${ }^{19}$ The process appeared to be competitive with other proposed reduction methods. ${ }^{14}$

Druhm Process. The Druhm process involves reduction of $\mathrm{UF}_{6}$ by sodium or lithium amalgam. Yields of $80-85 \%$ were obtained. ${ }^{14}$

Homogeneous Reactor Chemistry/Fuel and Blanket Processing and Development Studies. Processes for Removal of Plutonium from Homogeneous Reactor Blankets. R\&D directed at removal of plutonium from HRE blanket solutions was started sometime around 1954 or later. In 1957 , some of the laboratory-scale developments were reported. These studies were made in Building 3508 where some steel cells were built to protect personnel in case the high-pressure equipment failed. A uranyl sulfate solution containing dissolved plutonium was heated to $250^{\circ} \mathrm{C}$ under an overpressure of mixed hydrogen and oxygen. The plutonium precipitated as oxide, but considerable amounts deposited on stainless steel coupons suspended in the solution. Plans were to remove the plutonium oxide as a concentrated slurry from the HRE blanket solution with a hydroclone. 21

ARE Fuel Aqueous Processing. In 1954 fused salt fuel from the ANP-ARE was processed to recover the uranium. The fuel containing $4 \mathrm{~kg}$ of ${ }^{235} \mathrm{U}$ in open-top cans was processed in the ORNL Metal Recovery Plant (Building 3505). The uranium was extracted from an aqueous aluminum nitrate solution of the ARE fuel by TBP. ${ }^{20}$

ARE Fuel Volatility Process Study. A molten salt dissolution fluoride-volatility process for preparing fresh ARE fuel from the used material was demonstrated in preliminary tests conducted in 1954. The molten $\mathrm{NaF}-\mathrm{ZrF}_{4}-\mathrm{UF}_{4}$ salt was fluorinated, forming $\mathrm{UF}_{6}$, which was volatilized, condensed in a cold trap, resublimed, and, subsequently, dissolved in fresh $\mathrm{NaF}-\mathrm{ZrF}_{4}$. The uranium recovery was greater than $99.95 \%$, and decontamination factors (DF) of 4000-5000, 
sufficiently high for refabricating ARE fuel, were achieved. It was believed that DFs for uranium of 20,000 could be achieved by the process. 19

Fluoride Volatility Studies. In 1957 laboratory-scale development of a volatilization process was reported at the First Nuclear Engineering Science Congress in Cleveland, Ohio. Experimental work was carried out by G. I. Cathers in which uranium was dissolved at $675^{\circ} \mathrm{C}$ in a fused salt composed of $\mathrm{Zr}, \mathrm{K}$, and $\mathrm{Na}$ fluorides. Anhydrous HF was bubbled through the salt containing a piece of uranium metal to form $\mathrm{UF}_{4}$, which dissolved in the fused salt. The salt containing the $\mathrm{UF}_{4}$ was treated with elemental fluorine to distill out $\mathrm{UF}_{6}{ }^{21}$ Previous laboratory-scale studies had been conducted on the dry fluoride process using chlorine trifluoride as the fluorinating agent instead of elemental fluorine.

The purpose of the fluoride-volatility program in the United States was to develop an alternative to conventional aqueous processes for recovering uranium from spent nuclear fuels. Apparent advantages of volatility processes, compared with aqueous processes, included a high degree of separation of the uranium from its fission products, ease of processing certain refractory fuels, and increased nuclear safety. Principal disadvantages appeared to be the use of hazardous chemicals (e.g., fluorine, hydrofluoric acid) and high operating temperatures combined with extremely corrosive chemicals, which required the use of exotic metals and unique materials of construction. The Chem Tech studies progressed through all R\&D stages from the laboratory in $4500 \mathrm{~N}$, to hot-cell-level radioactivity pilot plant in Building 4507, to unit operations studies in Building 3592, and to full-scale successful operation of the Fluoride Volatility Process Plant in Building 3019 (see Sect. 4.11).

Molten Salt Reactor Fuel Processing. The method proposed in 1960 for processing fused ${ }^{7} \mathrm{LiF}-\mathrm{BeF}_{2}-\mathrm{UF}_{4}$ fuel was fluorination of the $\mathrm{UF}_{4}$, volatilization of the product $\mathrm{UF}_{6}$, and separation of fission products from the residual $\mathrm{LiF}-\mathrm{BeF}_{2}$ carrier salt by dissolution in HF. Economically the fluoride volatility process appeared adequate for uranium recovery from both fuel and blanket salts, and the HF dissolution process for ${ }^{7} \mathrm{Li}$-salt recovery, including replacement of fuel-carrier salt on a long cycle, appeared adequate for fuel-salt poison control. The first required process application would be for uranium recovery from both fuel and blanket salts which, with fuel salt replacement, would provide adequate processing for a converter reactor. Decontamination of the fuel-carrier salt would be required only with breeder reactors. It was proposed that thorium recovery and blanket-salt decontamination would not be needed for decades. Laboratory studies indicated that decontamination of the total fuel in one step was also feasible using $5 \mathrm{~mol} \% \mathrm{NO}_{2}$ in anhydrous $\mathrm{HF}$ to dissolve the $\mathrm{LiF}, \mathrm{BeF}_{2}$, and $\mathrm{UF}_{4}$ at $25^{\circ} \mathrm{C}$ and separating the materials from the insoluble rare-earth and thorium fluorides. The decontaminated fuel could be recycled after distilling off the $\mathrm{NO}_{2}$ and $\mathrm{HF} .{ }^{40}$

Chem Tech was challenged with the responsibility for developing an on-site, compact, low-inventory, high-performance, economical processing plant to process MSBR fuel. The process would be required to isolate ${ }^{233} \mathrm{~Pa}(27.4-\mathrm{d}$ half-life) at a rate significantly higher than its decay rate and remove the rare-earth fission products on a cycle of between 30 and 100 days. The process proposed employed, in addition to fluorination and $\mathrm{UF}_{6}$ recovery, liquid-liquid extraction of the reactor salt with a bismuth phase containing reductants. ${ }^{35}$

Work in support of the MSBR concept was interrupted from January 1973 to January 1974 when the Molten Salt Reactor Program was discontinued for a one-year period. ${ }^{41,42}$

Reprocessing for HTGR Fuels. The reprocessing of HTGR fuels requires the burning of graphite blocks containing coated fuel particles in the form of fuel sticks. Chem Tech studies were primarily hot-cell tests with irradiated HTGR fuel specimens, development of burner technology using unirradiated fuel, and development of methods for decontaminating the burner off-gas. Assistance in the areas of equipment flow sheets, layouts, and cost information was also provided to the ICPP in the planning of HTGR fuel reprocessing. ${ }^{43}$ Some work on development of reprocessing methods for HTGR fuel was reported in 1973. This included burning the fuel and separating krypton from the carbon dioxide off-gas by fractional distillation. 21

LMFBR Fuel Reprocessing. As early as 1967, Chem Tech was involved in studying mechanical fuel disassembly and shear-leaching, methods for disposal of residual sodium coolant, and solvent extraction processes in addition to conducting economic analyses. ${ }^{38}$

The preparation of LMFBR fuel for solvent extraction is more difficult than that of light-water 
reactor fuel because of increased heat generation, greatly increased amounts of radioiodine (if the fuel is processed after short decay periods), and the presence of substantial quantities of relatively difficult-to-dissolve plutonium and fission products. The Purex process appeared to be applicable. The treatment of off-gas is a major consideration in the processing of fuels that have been cooled less than 120 days. Removal efficiencies for radioiodine of $10^{8}$ are required for large-scale plants which process fuel that has been cooled for about 30 days. By 1971 Chem Tech's LMFBR studies had expanded significantly, including shipping of fuel; heat transport; head-end processing of fuel, including dismantling and shearing; deactivation of sodium; removal of volatile fission products; dissolution of $\mathrm{UO}_{2}$ and $\mathrm{PuO}_{2}$ fuel; solvent extraction; volatilization of radioiodine; off-gas treatment for removal of iodine; and radiation, shielding, and criticality studies. ${ }^{37}$

\subsubsection{Early Nuclear Calculations}

Nuclear scientists and engineers were quick to take advantage of the newly developing computer technology (e.g., the ORACLE, an electronic digital computer developed for ORNL), which appeared to have considerable potential for calculating fission product yields as well as the buildup of uranium and transuranic elements through neutron adsorption and decay reactions. Chem Tech engineer John "Tex" Blomeke initiated calculations of heavy-isotope buildup 44 and was assisted by Mary F. Todd, of the Mathematics Panel, in the voluminous calculations required for ${ }^{235} \mathrm{U}$ fission product production. ${ }^{45,46}$ These calculations were the forerunner, and laid the initial groundwork, for the development of the ORIGEN computer code (see Sect. 4.5).

Heavy-Isotope Buildup. Neutron irradiation of uranium results in the formation of a number of uranium and transuranic isotopes, some of which have nuclear properties that render them undesirable as reactor constituents. The effect of these isotopes on reactivity, based on single, long-term irradiation of fuel of various enrichments, has been considered by many investigators. Chem Tech engineers Jack Ullmann and Eldon Arnold investigated the buildup of ${ }^{236} \mathrm{U}$, ${ }^{237} \mathrm{U},{ }^{237} \mathrm{~Np}$, and ${ }^{238} \mathrm{Pu}$ in recycled ${ }^{235} \mathrm{U}$ fuels and showed how, even with partial removal of $236 \mathrm{U}$ in each cycle, these products could grow to such levels as to influence the type and frequency of chemical processing and fuel fabrication. 44,47

Calculations were initially made by Blomeke using an analog computer. The calculations permitted rapid estimation of heavy-isotope concentrations in uranium fuel of any likely initial isotopic composition. Thus the calculation methods were especially suitable for studying buildup in fuel recycled a number of times through chemical processing, fabrication, and irradiation. Results were presented in the form of curves expressing growth of individual isotopes from pure ${ }^{233} \mathrm{U}$, ${ }^{234} \mathrm{U},{ }^{235} \mathrm{U},{ }^{236} \mathrm{U}$, and ${ }^{238} \mathrm{U}$ during irradiation at constant flux. Curves were computed for seven values of thermal neutron flux between $10^{12}$ and $10^{15}$ neutrons $\mathrm{cm}^{2} \mathrm{~s}^{-1}$ and irradiations up to $3 \times 10^{21}$ neutrons $/ \mathrm{cm}^{2} .44,47$

Fission-Product Calculations. The production of fission products during reactor operations is an important consideration in almost every phase of atomic energy operations. The presence of fission products must be considered in the design and operation of nuclear reactors because of their contribution to neutron poisoning. However, fission products are extremely important in chemical processing facilities. Fission products and their concentrations determine the type of chemical processing necessary for separation of unused fissionable or fertile material as well as the shielding, off-gas treatment, and waste disposal methods required for successful and safe operations. Extensive information must be available on the chemical and nuclear properties of fission product mixtures to be encountered during fuel reprocessing. The fission product level in an irradiated reactor fuel is a function of three parameters: reactor operating power level, irradiation time, and decay time or time elapsed since reactor shutdown (or removal of fuel from operating reactors). Blomeke and Todd developed computer programs that computed levels of fission products resulting from thermal fission of ${ }^{235} \mathrm{U}$ in reactor fuels over a wide range of reactor operating conditions and decay times. Values for approximately 300 fission products were calculated, including gross totals for activities, radiation powers, and thermal neutron poisoning data ${ }^{45,46}$ In their voluminous report, Blomeke and Todd acknowledge the contributions of C. P. Hubbard, S. G. Campbell, and C. L. Gerberich for ORACLE code and operations assistance; H. E. Goeller, W. H. Sullivan, H. S. Pomerance, H. E. Williamson, R. A. Charpie, 
R. W. Stoughton, and J. Halperin of ORNL; and L. E. Glendenin and E. P. Steinberg of Argonne National Laboratory.

\subsection{OVERVIEW OF RAW MATERIALS PROCESSING}

Raw Materials Processing. The discovery that certain solvents and reagents could extract uranium from the sulfate solutions that were used to leach uranium from ores was an important technological achievement. The Dapex process used dialkyl phoshoric acid for both uranium and vanadium recovery. The Amex process uses a long-chain alkyl amine for uranium recovery. These solvent extraction procedures increased uranium recovery and decreased chemical costs. ${ }^{14}$ The Monex process used TBP to extract thorium from unclarified Brazilian sludge leach liquor. Operationally tested through engineering-scale studies, the Monex program was terminated when the AEC requirements for thorium were reduced. ${ }^{13}$ For uranium recovery from ore leach liquors, the Higgins continuous ion-exchange system also showed significant reduction of cost as compared with conventional processes. The ion exchanger was successfully tested at the pilot plant scale. However, because existing uranium processing plants were operating below their capacities, the system was not further evaluated. ${ }^{14}$

Slurrex Process. In 1950, the AEC requested ORNL to make a preliminary evaluation of various solvents for recovery and purification of uranium from ore concentrates. Ethyl ether, a highly volatile and flammable solvent, had been used for this purpose. ORNL showed TBP to be a promising alternative. The Slurrex process using TBP as a solvent was subsequently developed in collaboration with Mallinckrodt Chemical Works and the Catalytic Construction Co. ${ }^{14}$ The process was demonstrated at ORNL and consisted of extraction of nitric acid slurries of uranium ore with $30 \%$ TBP, scrubbing with 0.1 volume of hot water $\left(80^{\circ} \mathrm{C}\right)$, and stripping the uranium with equal volumes of hot water. ${ }^{1}$ A $\$ 20$ million plant using the Slurrex process was constructed for use at the Feed Materials Production Center, Fernald, Ohio. ${ }^{14}$

\subsection{ISOTOPES PRRODUCTION AND SEPARATION}

Because of early and major involvement in separations of uranium, plutonium, and fission product isotopes, the continuing interest and involvement of Chem Tech in isotopes separations evolved in a natural way. The major programs are summarized briefly below and discussed in some detail in Sect. 4.

Around 1954, research and process development was started on separations of alpha-emitting radioactive materials. Solvent extraction and ion exchange were the primary techniques used; however, some precipitation methods were also developed.

- Americium. By $1958,40 \mathrm{~g}$ of ${ }^{241}$ Am had been recovered from a concentrate prepared by Los Alamos from plutonium metal reduction slag. The material was processed in the Metal Recovery Building by solvent extraction and purified in Building 3508 by ion exchange. ${ }^{21}$

- Neptunium. By 1958, $670 \mathrm{~g}$ of ${ }^{237} \mathrm{~Np}$ had also been recovered from Paducah fluorination ash. The initial recovery was made by solvent extraction in the Metal Recovery Building. A precipitation method was used for the final purification in Building 3508. This was accomplished by alternate oxidation and reduction of the neptunium in a fluoride solution. 21

- Plutonium. In October 1958, plans were under way to irradiate ${ }^{239} \mathrm{Pu}$ to high burnup. These plans included irradiation of an MTR fuel element fabricated from plutonium and irradiation of $12 \mathrm{~kg}$ of ${ }^{239} \mathrm{Pu}$ at Savannah River. ${ }^{21}$

- Curium. In 1963-1964, ${ }^{242} \mathrm{Cm}$ was prepared jointly by Chem Tech and the Isotopes Division for use in heat sources. Chem Tech processed irradiated pellets of americium oxide and aluminum in the Building 4507 hot cells. The purified solution of americium and curium was delivered to the Isotopes Division. ${ }^{21}$

Preparation of ${ }^{232} U$. In $1962,{ }^{232} \mathrm{U}$ was prepared by irradiating about $40 \mathrm{~g} 231 \mathrm{~Pa}$ oxide loaned to us by the British. The irradiated material was processed in Building 4507 to produce the products shown in Table 2.2. Subsequently, a report was published on the redetermination of the ${ }^{232} U$ half-life. This was a joint study between Chem Tech and the Analytical Chemistry Division. ${ }^{21}$ 
Table 2.2. Separation of ${ }^{232} \mathrm{U}$ from irradiated ${ }^{231} \mathrm{~Pa}$

\begin{tabular}{cccc}
\hline Product & $\begin{array}{c}\text { 232U } \\
(\mathbf{m g})\end{array}$ & $\begin{array}{c}{ }^{233} \mathbf{U} \\
(\mathbf{p p m})\end{array}$ & $\begin{array}{c}\text { 235U } \\
(\mathbf{p p m})\end{array}$ \\
\hline U-1 & 4.29 & 209 & 92 \\
$\mathrm{U}-2$ & 1.51 & 317 & 112 \\
U-3 & 21.6 & 129 & 97 \\
U-4 & 5.49 & 206 & 32 \\
U-5 & 1040 & 7,300 & 14 \\
\hline
\end{tabular}

\subsection{RECOLLECTIONS OF FRED C. MCCULLOUGH, MAY 23, 1994}

I was transferred to X-10 in August 1943 by DuPont from an explosives plant. This occurred before there was a Technical Division. My first work was in a group on separations chemistry under Dr. Isadore Perlman in the main Research Building 706A, now Building 3550. When Dr. Miles C. Leverett arrived at X-10 from the Chicago Met Lab, I became a member of his group.

I designed and followed the construction of the first RaLa plant. This was a hurry-up job, and I was told the Army had to make a special trip to fly in a load of stainless-steel pipe and tubing. The chemistry is well described by Ray Blanco (Section 2.6). It was necessary to electroplate lead from the solution. A unique part of this design was putting a 4 pole permanent magnet around the stainless-steel pot. The electrodes were the pot and a concentric platinum gauze. When the current was passed through the electrodes, it formed a motor of the solution which rotated, thus it was very effectively stirred. Dr. Leverett liked the idea and said we ought to get a patent on it, but I heard no more. The equipment was installed in the old 706C Building, now Building 3026. A few months ago on a visit to X-10, I asked George Parker if he remembered my putting in the RaLa plant, and he said yes, he was there.

Sometime later, Bill Unger designed and followed the construction of a larger and better RaLa plant. Bill gave a good description of his RaLa plant. Security was very tight on RaLa, and I liked the way he covered it in Sect. 5.4.

After World War II, Dr. Leverett called me in and said the Army wanted to demonstrate that they could administer the peace-time developments of nuclear science as they had development of the nuclear bomb. I told him we could produce radioisotopes for medical treatment and scientific research. He said go ahead. Ira B. Whitney supplied the chemistry, and I designed and followed the construction of the world's first large-scale plants to produce ${ }^{131} \mathrm{I},{ }^{32} \mathrm{P}$, and ${ }^{14} \mathrm{C}$. Dave M. Boyd, a Monsanto instument engineer did the instrumentation on the ${ }^{131} \mathrm{I}$ and ${ }^{14} \mathrm{C}$, and Richard B. Lindauer, another Monsanto instrument engineer, did the instrumentation for the ${ }^{32} \mathrm{P}$ plant. These were all installed in the large cells in the 205 Building, later known as 3019 Building.

Designing and constructing these three radioisotope plants for ${ }^{131} \mathrm{I},{ }^{32} \mathrm{P}$, and ${ }^{14} \mathrm{C}$ production was a hurry-up job also. All was straightforward with no special problems except we had to use a combination of hydrochloric acid and nitric acid in the ${ }^{32} \mathrm{P}$ dissolver. I had to scrounge Y-12 to get the tantalum sheet from a discarded process vessel for this. The cooperation of the X-10 shops was excellent in building this equipment. I expect the old drawings are still on file.

A few weeks ago I was talking about the old days at X-10 with Colonel William Y. Gissel, and I mentioned that $I$ designed these three isotope plants. He said that operating them was one of his early jobs at X-10. I asked him if they ran OK, and he said everything was fine.

I believe I was the second person to see plutonium with my naked eye. Dr. Louis Werner from Berkeley was in the lab next to my lab in Building 706A. He called me into his lab to see the first visible amount of plutonium (oxide). It was in the bottom of a small centrifuge tube. The precipitate was about the size of the head of a kitchen match. As I remember, it was light grey 
green in color. I asked him what he was going to do with it. He said it would be put in a block of lucite and given to Dr. Arthur Holly Compton, Head of the Manhattan Project. Up to that time, because there was not enough material to see or weigh, it was followed by counting.

\subsection{REFERENCES}

1. W. K. Eister, Ed., Chemical Technology Division Quarterly Progress Report for Period Ending February 20, 1951, ORNL-1000.

2. Chemical Technology Division Progress Report for Period August 1, 1951 to February 10, 1952, ORNL-1311.

3. W. K. Eister, Ed., Chemical Technology Division Progress Report for Quarter Ending May 31, 1950, ORNL 763.

4. W. K. Eister, Ed., Chemical Technology Division Progress Report for Quarter Ending August 31, 1950, ORNL 846.

5. E. E. Lewis, Nuclear Power Reactor Safety, John Wiley \& Sons, New York, 1977.

6. R. G. Wymer and B. L. Vondra, Light Water Reactor Nuclear Fuel Cycle, CRC Press, Inc. Boca Raton, Florida, 1981.

7. R. E. Brooksbank, Sr., Historical and Programmatic Overview of Building 3019, ORNL/CF-91/298 (July 17, 1991).

8. Warren Eister, personal communication, 1992.

9. Floyd Culler, President Emeritus, Electric Power Research Institute, Palo Alto, California, personal communication, June 18 , 1992.

10. R. E. Blanco, personal communication, 1992.

11. H. E. Goeller, personal communication, 1992.

12. R. G. Wymer, personal communication, 1992.

13. Frank Harrington, personal communication, September 12, 1991.

14. W. E. Thompson, History of the Oak Ridge National Laboratory 1943-1963, August 23, 1963, Unpublished.

15. R. B. Briggs, "History of the Research Reactor/Engineering Technology Division," December 1990. Unpublished.

16. William E. Unger, personal communication, March 27, 1992.

17. Arlene Kibbey, personal communication, February 28, 1992.

18. W. K. Eister, Ed., Chemical Technology Department Progress Report for Month Ending December 31, 1949, ORNL-580.
19. Chemical Technology Division Semiannual Progress Report for Period Ending September 30, 1954, ORNL-1800.

20. Chemical Technology Division Semiannual Progress Report for Period Ending March 31, 1954, ORNL-1708.

21. Rex E. Leuze, personal communication, September 16, 1991.

22. W. D. Bond, "Purex Solvent Extraction Chemistry," pp. 103-162 in Light Water Reactor Nuclear Fuel Cycle, R. G. Wymer and B. L. Vondra, Eds., CRC Press, Inc., Boca Raton, Florida, 1981.

23. W. K. Eister, Ed., Chemical Technology Division Progress Report for Quarter Ending February 28, 1950, ORNL 663.

24. F. R. Bruce et al. "Operating Experience with Two Radiochemical Processing Pilot Plants," pp. 49-72 in Proceedings of the Second United Nations International Conference on the Peaceful Uses of Atomic Energy Held in Geneva, September 1-13, 1958, Volume 17, Processing Irradiated Fuels and Radioactive Materials, United Nations, Geneva, 1958.

25. A. T. Gresky, "The Separation of ${ }^{233} \mathrm{U}$ and Thorium from Fission Products by Solvent Extraction," pp. 212 and pp. 505 in Proceedings of the International Conference on the Peaceful Uses of Atomic Energy Held in Geneva, August 8-20, 1955, Volume 9, Reactor Technology and Chemical Processing, New York, United Nations, 1956.

26. A. H. Compton, "Minutes of Special Meeting of Project Council, August 30, 1943 at Argonne Laboratory," Metallurgical Laboratory, University of Chicago Report CS-912.

27. Fred McCullough, personal communication, June 1992.

28. R. A. Charpie et al., Project Hope. A Chemical Reprocessing Plant for a Nuclear Power Economy, ORNL-1638 (January 1954).

29. Chemical Technology Division Semiannual Progress Report for Period Ending September 30, 1954, ORNL-1800 (December 26, 1954).

30. E. L. Nicholson, personal communication, May 26, 1992.

31. R. A. Charpie et al., Intermediate Report of Project Hope, ORNL CF 53-10-175. 
32. Chemical Technology Division Semiannual Progress Report for Period Ending March 31, 1955, ORNL-1881 (June 10, 1955).

33. W. K. Eister, Ed., Chemical Technology Division Quarterly Progress Report for Period Ending May 20, 1951, ORNL 1061.

34. W. K. Eister, Ed., Chemical Technology Division Quarterly Progress Report for Period August 20, 1951, ORNL 1141.

35. Chemical Technology Division Annual Progress Report for Period Ending May 3I, 1969, ORNL-4422.

36. Chemical Technology Division Annual Progress Report for Period Ending May 31, 1970, ORNL-4572.

37. Chemical Technology Division Annual Progress Report for Period Ending May 31, 1971, ORNL-4682.

38. Chemical Technology Division Annual Progress Report for Period Ending May 31, 1967, ORNL-4145.

39. C. E. Stevenson, E. A. Mason, and A. T. Gresky, Eds., Progress in Nuclear Energy, Series iii, Process Chemistry, Volume 4, Pergamon Press, New York, 1970, p. 79.

40. Chemical Technology Division Annual Progress Report for Period Ending August 31, 1960, ORNL-2993.

41. Chemical Technology Division Annual Progress Report for Period Ending March 31, 1973, ORNL-4883.
42. Chemical Technology Division Annual Progress Report for Period Ending March 31, 1974, ORNL-4966.

43. Chemical Technology Division Annual Progress Report for Period Ending March 31, 1972, ORNL-4794.

44. J. O. Blomeke, The Buildup of Heavy Isotopes During Thermal Neutron Irradiation of Uranium Reactor Fuels, ORNL-2126 (December 1956).

45. J. O. Blomeke and Mary F. Todd, Uranium-235 Fission-Product Production as a Function of Thermal Neutron Flux, Irradiation Time, and Decay Time. I. Atomic Concentrations and Gross Totals, ORNL-2127, Part I (August 1957).

46. J. O. Blomeke and Mary F. Todd, Uranium-235 Fission-Product Production as a Function of Thermal Neutron Flux, Irradiation Time, and Decay Time. II. Summations of Individual Chains, Elements, and the Rare-Gas and Rare-Earth Groups, ORNL-2127, Part II, Volumes 1-3 (December 1957).

47. E. D. Arnold, Effect of Recycle of Uranium Through Reactor and Gaseous Diffusion Plant on Buildup of Important Transmutation Products in Irradiated Power Reactor Fuels, ORNL-2104 (August 1956). 


\section{SWORDS TO PLOWSHARES}

The competitive economic position of nuclear power compared to other sources of energy will depend in large measure on how the chemical problems in chemical processing are ultimately solved.

Glenn T. Seaborg

Foreword, Progress in Nuclear Energy, 1956

The transition from wartime development of atomic energy to peaceful uses of nuclear energy was welcomed by essentially everyone. The world seemed receptive to the use of seemingly limitless atomic energy to achieve anticipated energy requirements for both developed and developing nations. All that was needed was sufficient scientific knowledge and technical know-how. To foster the transition, the United Nations sponsored a series of international conferences on the peaceful uses of atomic energy in 1955, 1958, 1964, and 1971. Chem Tech staff members played important roles in those conferences. In addition to the conference proceedings, ${ }^{1-4}$ four books in the area of process chemistry resulted from the conferences and associated endeavors. ${ }^{5-8}$ Frank $R$. Bruce served as an editor for the first three volumes, $5-7$ and $\mathrm{Al} \mathrm{T}$. Gresky served as an editor for the fourth volume. 8 These collective "Geneva papers" encapsulated much of the R\&D work in the chemistry and chemical engineering required for nuclear fuel development and reprocessing until the early 1970s. Chem Tech and ORNL became the Mecca for nuclear fuel reprocessing.

The era of the Geneva conferences perhaps represents the halcyon peak of peaceful applications of nuclear energy, the beating of swords into plowshares. Exciting concepts were proposed and seemed within the grasp of society, for example, large agro-industrial complexes; supplying the increasing world population with needed freshwater through nuclear desalting of seawater; low-cost production of electrical power through "burning rocks" (i.e., use of ubiquitous thorium and uranium); international cooperation in nuclear fuel reprocessing (e.g., the Eurochemic plant at Mol, Belgium); use of nuclear explosives for excavation, mining, recovery of gas and oil, and as research tools (U.S. Plowshare Program); the use of radioisotopes in medicine ("the Humane Atom"); generation of electricity by direct thermoelectric conversion from the decay heat of radioisotopes; and practical applications of radiation in industry. 9

In Seaborg's address to the delegates at the 1964 conference, he stated, "With continued attention to reactor safety and waste management, I firmly believe that we can achieve the potential benefits of nuclear power and at the same time protect or even improve our general standards of public health and safety. The increasing use of nuclear power may indeed help to lessen atmospheric pollution, a frequent result of the widespread use of fossil fuels." 9

\subsection{FIRST GENEVA CONFERENCE, 1955}

The first United Nations-sponsored International Conference for the Peaceful Uses of Atomic Energy was held in Geneva, August 8-20, 1955 . The introductory words to the resulting volume on process chemistry are revealing.

Chemical processes form an important aspect of nuclear technology. They are involved in a number of the stages involved in the utilization of nuclear energy; for example, in the extraction, purification and preparation of natural uranium and thorium from their ores; in the preparation of the materials used in reactors; and in the production of radioisotopes and in waste disposal. 10 
Apropos to the conference theme of peaceful uses of atomic energy, Glenn T. Seaborg, a conference facilitator, stated, "The competitive economic position of nuclear power compared to other sources of energy will, in many parts of the world, depend in large measure on how the problems in chemical processing are ultimately solved."11

The need for chemical engineering and economical fuel reprocessing was also stressed by Sir Harold Hartley, another conference facilitator.

Although nuclear energy is essentially a physical process and physical data are basic for its utilization which is dependent on the most advanced engineering techniques, two of the major limiting factors in the construction and operation of economical power reactors are chemistry and chemical engineering. Success is so largely dependent on the manufacture of the materials of the pile-fissile elements, moderators, cladding and bonding of materials-to new standards of ultra-high purity to avoid wastage of neutrons. It depends too on economical methods of processing the fissioned elements to recover the fissionable materials and nuclear fuels as quickly as possible to minimize idle capital and to dispose of the radioactive products of the process. This is an even more difficult problem on account of the radioactive risks it involves. 12

\subsubsection{Prophefic Words on Waste}

As is now known, one major stumbling block, as perceived by the general public, to acceptance of the peaceful use of atomic energy is environmentally safe nuclear waste disposal. This subject was debated even at the first Geneva conference.

Few problems encountered in the atomic energy program have captured the interest and aroused speculation of the general public as much as the problem of radioactive waste disposal. This is, perhaps, as it should be, for the safety and welfare of both the present and the future generations may well depend on the establishment of safe and reliable disposal practices. The object, then, of waste processing is to modify the wastes in such a manner as to render them more suitable and less hazardous for ultimate or permanent confinement in some site or sites outside man's immediate environment. This may take the form of processes for separating the most hazardous isotopes from the bulk of the wastes and concentrating them in packaged form suitable for shipment and storage, or it may include processes for converting the bulk wastes to insoluble ceramics in which the radioisotopes have been "fixed" by combination with aluminosilicates. 13

\subsubsection{Chem Tech Exhibits and Papers}

Significant contributions to the success of the 1955 Geneva conference were made by Chem Tech technical papers and exhibits. Chem Tech exhibits included a mock-up of a solvent-extraction pilot plant complete with remote cell operation and manipulators. ${ }^{14}$ The conference papers collectively present many of the major Chem Tech accomplishments up to that time concerning chemical processing aspects of atomic energy. They provide simple vignettes, if you will, or glimpses into the complex and many faceted early history of the Chemical Technology Division. The Chem Tech papers presented at the conference included the following:

D. O. Campbell, "Removal of Fission Products from Stainless Steel," Paper 548.15

J. W. Landry, "High Level Sampling Devices for Radiochemical Plants," Paper 549.16

G. I. Cathers, "Radiation Damage to

Radiochemical Processing Reagents," Paper 743.17

D. L. Foster, J. E. Savolainen, and

R. G. Wymer "Nuclear Reactor Fuel Dissolution," Paper 547.18

F. R. Bruce, "The Behavior of Fission Products in Solvent Extraction Processes," Paper 719.19

F. L. Culler, "Reprocessing of Reactor Fuel and Blanket Materials by Solvent Extraction," Paper $822 .{ }^{20}$

J. R. Flanary, "A Solvent Extraction Process for the Separation of Uranium and Plutonium from Fission Products by Tributyl Phosphate," Paper 539.21

F. L. Culler, "The Processing of Uranium-Aluminum Reactor Fuel Elements," Paper 541.22

A. T. Gresky, "The Separation of ${ }^{233} \mathrm{U}$ and Thorium from Fission Products by Solvent Extraction," Paper 540.23

D. E. Ferguson, "The Processing of Aqueous Homogeneous Reactor Fuel," Paper 551.24 
Most of the Chem Tech papers (with the exception of Papers 548 and 549) were quoted in the first volume of the process chemistry series. 5 Summaries of the Campbell and Landry papers (548 and 549) and annotated abstracts of the quoted papers follow.

\section{Removal of Fission Products from Stainless}

Steel. Decontamination of equipment used for handling solutions containing fission products presents a difficult problem. Dave Campbell's paper deals with the decontamination of stainless steels, a commonly used material of construction for radiochemical process equipment.

Decontamination of large apparatus, such as that used in chemical plants for processing irradiated materials and reactor fuels, is necessary for modification of the equipment or for direct maintenance. Remote maintenance, an alternative, is generally more expensive and less flexible than direct maintenance. Successful decontamination of stainless steel type 347 using cyclic treatment with $2 M$ nitric acid followed by caustic-tartrateperoxide solutions is reported in the paper. Oxalic acid solutions were also effective. Decontamination factors (DFs) of up to $10^{4}$ were achieved. 15

High-Level Sampling Devices for Radiochemical Plants. Sampling of liquids in a radiochemical plant is necessary for process control and for accountability. Analysis of samples is the principal means for following process variables such as density, acidity, radioactivity, contamination, corrosion, viscosity, separation of phases, and presence of suspensoids or insolubles. Successful remote sampling using airlifts and jets and minimum personnel exposure to radiation is described in John Landry's paper. ${ }^{16}$

\section{Radiation Damage to Radiochemical} Processing Reagents. George Cathers' paper deals with a vitally important consideration in chemical processing of materials associated with high levels of radioactivity, that is, radiation damage to process reagents. It is obvious that knowledge of such radiation damage is necessary to design and operate chemical processing units. The abstract follows:

The use of organic reagents in radiochemical processes is limited by the destructive effects of radiation. The loss of capacity of ion exchange resins that have been irradiated is dependent on the type of resin; it has been examined for two polystyrene resins and also for a sulfonated phenolic resin. Exposure of ethylenediamine tetraacetate to more than 0.1 watt-hr $/ \mathrm{mL}$ radiation results in decreasing effectiveness of the material as a complexing agent for metallic ions. The radiation of tributyl phosphate produces hydrolytic reaction products that are deleterious in a solvent extraction process. These products lead to the retention of fission products, plutonium and uranium after the usual cycle of a solvent extraction process. The implications of this solvent breakdown in the processing of a thorium breeder blanket, after a decay of one day, is considered, together with the implications for processing the core of such a reactor by ion exchange resins. 17

The paper cites contributions of other Chem Tech scientists, including R. E. Blanco, D. E. Ferguson, I. R. Higgins, A. H. Kibbey, R. G. Mansfield, and R. P. Wischow. 17

Nuclear Reactor Fuel Dissolution. The Foster, Savolainen, and Wymer paper gives a summary of the principal dissolution methods and equipment used through 1955. The abstract follows.

The dissolution of heterogeneous nuclear reactor fuel elements is the usual first step in chemical processing to recover fissionable and fertile materials. A change of state is thus brought about from solid fuel to liquid feed solution. In this paper, chemical and engineering data are presented for dissolution systems for representative nuclear reactor fuel elements. The materials considered are uranium metal, uranium-aluminum alloy, aluminum jackets, thorium metal, and zirconium-clad uranium-zirconium alloy. Batch pot dissolution techniques may be most satisfactory for many applications. However, continuous dissolution methods with intermittent charging of metal, continuous addition of dissolvent, and continuous removal of product are of interest.

The dissolution chemistry of nuclear fuel elements is concerned with reaction rates for various fuel materials in various dissolvent systems. Nitric acid dissolution has been used for uranium, uranium-aluminum alloy and thorium. Sodium hydroxide could be considered for dissolution of aluminum jackets and uranium-aluminum alloy. Fuel elements containing zirconium can be dissolved in hydrofluoric acid.

The equipment used in dissolution includes three major units: (1) the fuel charger, (2) the 
vessel, and (3) the off-gas system. The chargers could be shielded casks capable of controlled discharge of fuel elements, or a remote crane-type unit to charge the fuel elements from buckets. Conveyor-type chargers may be used with both batch and continuous dissolvers. Dissolver vessels are of three general types-pot, column, and slab. The choice depends on the critical mass of the fuel being processed and the shape of the fuel element. Pot-type dissolvers are operated either batchwise or continuously; column and slab dissolvers are continuous-type units. The off-gas system is concerned primarily with disposal of the gaseous radioactive fission products and removal or recovery of the chemical reaction products. 18

The Behavior of Fission Products in Solvent Extraction Processes. Frank Bruce's paper states that much information exists on the behavior of fission products in solvent extraction processes for fissile and fertile materials. Such processes generally employ methylisobutyl ketone or TBP as solvents, although many solvents have been investigated (e.g., pentaether, diisopropyl ether, tertiary alcohols, dibutyl cellosolve, thionyl trifluoroacetone, dibutyl carbitol). Among the fission products, cerium, zirconium, niobium, ruthenium, and iodine tend to be extracted along with and are most difficult to separate from uranium, plutonium, and thorium. ${ }^{19}$ The abstract follows:

The variables which influence the extraction of cerium, zirconium-niobium, iodine, and ruthenium into methylisobutyl ketone and tributyl phosphate are considered. In the case of methylisobutyl ketone extraction the important variables are: solvent purity, salting agent and nitric acid concentration, and temperature. In addition to the preceding variables, uranium saturation of the solvent and tributyl phosphateconcentration influence the extraction of fission products into tributyl phosphate. 19

Reprocessing of Reactor Fuel and Blanket Materials by Solvent Extraction. Floyd Culler states that the single most important reason for chemical reprocessing of nuclear reactor fuel is to recover the fissionable materials produced by neutron capture. Solvent extraction procedures were developed to separate plutonium from natural uranium; enriched uranium from aluminum and other reactor fuel element/cladding materials; and to separate ${ }^{233} \mathrm{U}$, protactinium, and thorium. The most important features of major solvent-extraction processes were presented. The abstract follows:

This paper is a survey of liquid-liquid solvent extraction as used for the processing of irradiated reactor fuels and fertile material. Descriptions are given of the fuels for which solvent extraction processes have been developed; the times required for decay of radioactive contaminants before processing; required decontamination factors; and fission product decontamination. Solvent extraction systems are summarized and chemical processing flow sheets presented. A brief description is given of the requirements for radiochemical solvent extraction plants and the lines upon which equipment and plant may be designed. 20

The paper cites contributions of other Chem Tech scientists, including E. D. Arnold, J. R. Flanary, W. B. Lanham, A. T. Gresky, D. C. Overholt, A. C. Jealous, H. E. Goeller, W. G. Stockdale, R. W. Stoughton, S. W. Peterson, F. R. Bruce, D. O. Campbell, H. K. Jackson, and D. G. Reid. ${ }^{20}$

\section{A Solvent Extraction Process for the} Separation of Uranium and Plutonium from Fission Products by Tributyl Phosphate. Jim Flanary states that after irradiation, nuclear fuel rods contain a nearly equivalent weight of plutonium and mixed fission products that collectively represent only a small fraction of the uranium present. The abstract follows:

A continuous solvent-extraction process has been developed which uses tri- $n$-butylphosphate (TBP) as the solvent and nitric acid as the salting agent for the isolation of uranium, plutonium, and fission products from irradiated metallic uranium reactor fuel. Tributyl phosphate is less volatile and has a higher flash point than methylisobutyl ketone used in earlier processes. Nitric acid can be distilled off and reused in the process; this yields a lower waste volume than when aluminum nitrate is used as the salting agent. 21

The Processing of Uranium-Aluminum Reactor Fuel Elements. In this paper, Floyd Culler succinctly summarizes chemical processing for irradiated enriched uranium fuels. Enriched uranium fuel elements are generally stored 
underwater before chemical processing to allow for decay of fission product activity. The period of decay is usually determined by the quantity of ${ }^{237} \mathrm{U}$ produced by neutron capture from ${ }^{235} \mathrm{U}$. The ${ }^{237} \mathrm{U}$ decays with a 6.75 -d half-life to ${ }^{237} \mathrm{~Np}$. Because the ${ }^{237} \mathrm{U}$ will be present in the product uranium, it must be allowed to decay before uranium of sufficiently low background activity can be produced. The uranium product must also be sufficiently decontaminated from fission products to allow direct handling during refabrication of fuel elements. This requires gross decontamination factors on the order of $10^{8}$, hence cooling periods of 100-140 d. Because of economic value, losses of enriched uranium should not exceed $0.1 \%$. Because of the small quantity of plutonium produced from irradiation of highly enriched ${ }^{235} \mathrm{U}$ fuel, the plutonium is allowed to follow the fission-product waste streams in the chemical processes developed for such fuels. Also, contamination of the uranium product by such nonactive impurities as aluminum, iron, and sodium must not exceed several thousand parts per million. ${ }^{22}$ The abstract follows:

The recovery and decontamination of enriched uranium fuel elements of the type used in the Material Testing Reactor, in the ORNL Swimming Pool Reactor, or from any reactor which uses fuel elements of aluminum-clad uranium-aluminum alloy can be accomplished by organic solvent extraction from nitric acid solution. The unconsumed enriched $235 \mathrm{U}$ must be chemically separated from fission products, inert fuel diluents and impurities, and heavy elements resulting from neutron capture by fertile materials present in the fuel mixture and by parasitic capture of neutrons by the fuel itself. This chemical purification has been accomplished by the use of selective organic solvents such as methylisobutyl ketone (hexone) and tributyl phosphate (TBP) dissolved in an inert organic diluent such as aromatic-free kerosene. A chemical description of these two processes follows. Each process will decontaminate enriched uranium from fission products to background activity level and will separate plutonium by factors of $10^{4}$ to 106.22

\section{The Separation of ${ }^{233} U$ and Thorium from} Fission Products by Solvent Extraction. Al Gresky's paper describes the development and technological aspects of a solvent-extraction process for the chemical recovery and radioactive decontamination of ${ }^{232} \mathrm{Th},{ }^{233} \mathrm{U}$, and ${ }^{233} \mathrm{~Pa}$ from neutron-irradiated thorium. Although designed primarily for processing aluminum-clad thorium metal slugs, it may be modified for use with other reactor materials, such as thorium oxide or oxycarbonate. The process uses nitric acid as the thorium dissolution agent, tri- $n$-butyl phosphate (TBP) as the extractant, and aluminum nitrate and nitric acid as the aqueous salting agents. The ${ }^{233} \mathrm{U}$ is finally isolated by ion exchange. ${ }^{23}$

The paper cites contributions of other Chem Tech scientists, including E. D. Arnold, M. R. Bennett, W. T. McDuffee, J. E. Savolainen, R. P. Wischow, F. L. Steahly, and D. C. Overholt. ${ }^{23}$ The Processing of Aqueous Homogeneous Reactor Fuel. Don Ferguson concludes that the successful operation of the ORNL experimental homogeneous reactor demonstrated the basic feasibility of aqueous homogeneous reactors. The paper's abstract follows:

Two-region aqueous homogeneous reactors are of considerable interest for the production of economic power. A potential advantage of this type of reactor is simple, economical chemical processing. Fission products and corrosion products may be removed from the fuel solution by ion exchange or by taking advantage of the low solubility of many fission and corrosion products in the reactor fuel. Possible methods of thorium blanket processing include ion exchange, solvent extraction and precipitation. Schematic flow sheets for homogeneous reactor fuel and blanket processing are presented and the economics of the various approaches discussed. 24

The paper cites contributions of other Chem Tech scientists, including R. A. McNees, I. R. Higgins, M. E. Whatley, A. T. Gresky, W. E. Tomlin, and F. R. Bruce. ${ }^{24}$

\subsection{THE INTERIM}

The first volume $\mathrm{e}^{5}$ in the process chemistry series relied largely upon the information presented at the Geneva conference of 1955 . The second volume, ${ }^{6}$ published in 1958 , reported the progress after 1955 and also widened the scope of subjects covered. The period covered was the interim, as it were, between the first and second Geneva conferences. Much new information was included in volume 2 , for example, chapters on recovery 
processes associated with treatment of ores and feed materials for reactors, fuel cycle costs, and promising alternatives to solvent extraction. ${ }^{25}$

The following Chem Tech scientists and engineers prepared chapters for Process Chemistry, Volume 2:

K. B. Brown and C. F. Coleman, "Solvent Extraction in Ore Processing"26

O. C. Dean, "Reduction of Thorium Chloride by Alkali Metal Amalgams" 27

J. W. Ullmann, "Factors Affecting Fuel Cycle Cost"28

R. E. Blanco, "Preparation of Power Reactor Fuels for Processing by Solvent Extraction"29

E. M. Shank, "Operation of the Thorex Pilot Plant with Highly Irradiated Thorium"30

F. R. Bruce, "The Concentration and Purification of Uranium and Plutonium by Ion Exchange" 31

O. C. Dean, "Mercury Processing of Uranium and Its Alloys" 32

J. R. Flanary and G. W. Parker, "The Development of Recovery Processes for Neptunium-237"33

Annotated abstracts of the Chem Tech contributions to Volume 2 follow. Collectively, they represent significant chemical processing history.

Solvent Extraction in Ore Processing. The very intense search for uranium production with little consideration given to cost gave way to a concerted effort to build an efficient and strong industry based on efficient processing plants close to ore sources and matching steady production rates with long-term consumption rates. ${ }^{25}$

The paper of Chem Tech staff members Keith Brown and Charles Coleman summarizes significant breakthroughs in the recovery of uranium and thorium from raw materials. Nearly all uranium ores are processed by hydrometallurgical methods. The two principal methods for dissolution of the uranium from the ores involve leaching with sodium carbonate solution or with sulfuric acid. Customary solvent extraction procedures using ethers, ketones, and esters gave the best performance on aqueous feeds highly salted with nitrate and were not directly applicable to ore-leach liquors. 26

Brown and co-workers evaluated hundreds of organic compounds for ore processing purposes and found the most suitable characteristics in certain classes of alkylamines and organophosphorus compounds. This finding represented a significant technology breakthrough. The abstract of the paper follows:

The extraction and stripping properties and other essential characteristics of several uranium extraction reagents are presented, with special attention to the long chain alkylamines and alkylphosphoric and dialkylphosphoric acids. Uranium recovery processes with these reagents are described, some of which are in commercial use and others imminent, and other proposed and potential processes are noted. Recovery of the associated metals thorium and vanadium is also considered. 26

The paper cites contributions of the following Chem Tech scientists: K. A. Allen, K. B. Brown, C. F. Coleman, C. A. Blake, D. J. Crouse, A. D. Kelmers, D. J. Denis, J. G. Moore, A. D. Ryon, W. D. Arnold, R. S. Lowrie, B. B. Klima, H. M. McLeod, R. R. Wiethaup, and V. L. Saine. ${ }^{26}$

Reduction of Thorium Chloride by Alkali Metal Amalgams. Breeder reactors that use thorium metal blankets require metal's of high purity and density. This paper by Chem Tech scientist $O$. C. Dean discusses one reduction process for preparing high-quality thorium metal. The abstract follows:

A new semi-continuous, low-temperature process for producing thorium metal is described. Thorium tetrachloride is reduced with sodium amalgam to thorium metal which forms a quasi amalgam. Unreacted sodium and thorium tetrachloride are removed from the amalgam by washing with hydrochloric acid. The thorium is concentrated in the amalgam by filtration, mercury is removed in a vacuum retort and, finally, the thorium is arc melted. Laboratory studies indicate that the process will produce reactor-grade metal at a cost substantially less than the conventional process employing calcium reduction of thorium tetrafluoride. 27

This paper also cites the work of Chem Tech engineer John Chandler.

Factors Affecting Fuel Cycle Cost. In this paper by Chem Tech engineer John Ullmann, the components of overall fuel cost for nuclear reactors are analyzed and the effects of several parameters discussed. The factors include reactor variables 
(e.g., burnup, specific power, thermal efficiency, load factor, and degree of enrichment), elements of net fuel cost (e.g., fabrication, inventory, burnup, reprocessing, transportation, new fissile material, by-products, and net fuel cost), fuel cycle type (e.g., decontamination level, throwaway concept), choice of fuel element (e.g., fuel type, fabrication, diluent, cladding material, bonding material), and reprocessing variables (e.g., plant size, site, amortization, operating efficiency, waste disposal, transmutation). The paper cites contributions of the following Chem Tech scientists and engineers:

E. D. Arnold, F. L. Culler, J. O. Blomeke, W. G. Stockdale, C. E. Guthrie, J. W. Ullmann, and H. R. Zeitlin. ${ }^{28}$

Preparation of Power Reactor Fuels for Processing by Solvent Extraction. All current radiochemical solvent-extraction reprocessing systems use nitrate solutions; therefore, preparation of fuels for solvent extraction implies their conversion to nitric acid solution. Many reactor fuels have aluminum or magnesium jackets that are easily removed mechanically or by caustic solutions before solution of the uranium core in nitric acid. Newer fuel types designed for high-temperature operation use nitric acid-insoluble cladding materials (e.g., zirconium, Zircaloy-2, niobium, or stainless steel). The fuel cores of these types may contain alloys of uranium with molybdenum, niobium, zirconium and silicon, uranium oxides, or mixtures of uranium oxide with stainless steel or thorium oxide. Head-end methods for processing these newer fuels are discussed in this paper by Ray Blanco. The abstract of the paper follows:

Power reactor reprocessing problems are discussed from the viewpoint of converting heterogeneous fuels to a nitric acid solution suitable for purification by solvent extraction. Current and proposed fuels are classified into types based on reprocessing principles. Flow sheets are presented for the solution of aluminum-clad uranium or thorium fuels in nitric acid along with procedures under development for processing zirconium and stainless steel clad fuels. Methods under development include mechanical processing; solution in sulfuric, hydrofluoric or dilute hydrochloric-nitric acids; hydrochlorination; electrolytic solution; oxidation; and carburization. 29
Contributions of the following Chem Tech staff members are noted: F. L. Culler, R. E. Blanco, H. E. Goeller, C. D. Watson, J. R. Flanary, A. T. Gresky, F. G. Kitts, J. J. Perona, E. O. Nurmi, J. C. Bresee, D. L. Foster, J. E. Savolainen, and R. G. Wymer. ${ }^{29}$

Operation of the Thorex Pilot Plant with Highly Irradiated Thorium. The abstract of the paper by Chem Tech engineer E. M. Shank follows:

The Thorex solvent-extraction flow sheet was converted from a one-cycle to a multi-cycle system to increase the product decontamination when processing highly irradiated thorium. The new "co-decontamination" flow sheet provides two solvent-extraction cycles for thorium and three such cycles plus an ion-exchange step for uranium.

The Thorex Pilot Plant is mostly installed in concrete-shielded cells. It is directly maintained and remotely operated. Process equipment is unit-shielded, provisions for equipment decontamination are built in, radiochemical sampling equipment is remotely operated, and concatenated pulsed columns are used for the extraction.

The plant has been in operation for 3 years, including 17 months with the co-decontamination flow sheet. The thorium and uranium products from thorium irradiated to $4000 \mathrm{~g}$ of $233 \mathrm{U}$ per ton and decayed 400 days met radioactivity specifications. Products from material decayed 30 days contained somewhat more fission products than specifications for direct refabrication to metal fuel permit. Ionic contaminants in all products were sufficiently low for satisfactory subsequent processing. Solvent-extraction losses were higher than desired. Equipment performance was generally satisfactory. 30

Contributions of the following Chem Tech staff members are acknowledged: W. T. McDuffee, J. R. Parrott, R. H. Vaughan, R. E. Blanco, F. R. Bruce, H. G. Duggan, J. W. Landry, E. J. Frederick, A. T. Gresky, R. H. Rainey, G. S. Sadowski, J. W. Ullmann, E. M. Shank, and W. E. Unger. ${ }^{30}$

The Concentration and Purification of Uranium and Plutonium by Ion Exchange. Chem Tech scientist Frank Bruce states that chemical processes for the separation of fissionable material from fission products usually produce a dilute 
solution of the product in nitric acid that must be concentrated and further purified. Accomplishment of the concentration and purification may involve processes such as evaporation, solvent extraction, precipitation, or ion exchange. This paper discusses the use of ion exchange. The abstract follows:

Cation exchange may be used to concentrate the dilute $233 \mathrm{U}$ or plutonium products which are obtained from solvent-extraction processes. Losses of fissionable material are less than $0.01 \%$, and some separation of the products from fission and corrosion products is achieved. 31

Contributions of the following Chem Tech staff members are noted: J. R. Flanary, A. T. Gresky, I. R. Higgins, J. T. Roberts, S. H. Jury, R. E. Leuze, V. C. A. Vaughen, W. T. McDuffee, W. L. Albrecht, B. R. Olander, D. C. Overholt, F. E. Tober, and D. C. Orth. ${ }^{31}$

Mercury Processing of Uranium and Its Alloys. Chem Tech scientist O. C. Dean states that many refractory materials of interest in the construction of reactors (e.g., uranium, thorium, titanium, zirconium, niobium, rare earth metals) are reduced with difficulty, as well as with considerable expense. The loss of half the metal as scrap in the fabrication of fuel or structural elements is common. Much of the scrap is below specification and must be recycled to the refinery for purification. The method of refining metals discussed in this paper appears to be cost-effective. The abstract follows:

A process for the removal of impurities from natural and irradiated uranium by solution in and recovery from mercury is described.

Solution rates and solubilities of uranium in mercury and amalgams were determined. The extent of purification of natural uranium and decontamination factors for the higher-yield fission products were evaluated. 32

Contributions of the following Chem Tech staff members are acknowledged: R. E. Blanco, B. H. Morrison, E. Sturch, and R. G. Wymer. ${ }^{32}$

The Development of Recovery Processes for Neptunium-237. Chem Tech staff members Jim Flanary and George Parker reviewed the efforts to recover neptunium from several processes. In the first intermediate-scale effort at ORNL, $40 \mathrm{~g}$ of neptunium was recovered from a waste stream in the TBP Metal Recovery system processing irradiated natural uranium. Neptunium was also recovered from enriched uranium fuels and from residue (ash) resulting from the fluorination of uranium to produce uranium hexafluoride. The abstract of the paper follows:

Gram quantities of neptunium-237 were recovered from inradiated natural uranium, irradiated enriched uranium, and fluorination ash from depleted uranium by extraction with tributyl phosphate. The flow sheet from natural uranium is a modified Purex flow sheet, with simultaneous extraction of plutonium, uranium and neptunium(VI) and partitioning by acidity adjustment. Final concentration and purification are by ion exchange. For enriched uranium the Neptex process, which is similar to the 25-TBP process, is used. There is no plutonium present and neptunium is extracted in the tetravalent state. The process used with fluorination ash is similar to the Neptex second cycle. 33

Other Chem Tech contributors cited in the paper are as follows: F. L. Culler, H. K. Jackson, G. S. Sadowski, W. H. Lewis, W. A. Brooksbank, P. M. Lantz, and W. J. Martin. ${ }^{33}$

\subsection{SECOND GENEVA CONFERENCE, 1958}

As in the first conference, significant contributions to the success of the 1958 Geneva conference were made by Chem Tech technical exhibits and papers. Chem Tech exhibits included a motion picture on fuel reprocessing. The film opened with a view of the Hanford crane and canyon. The film also included Chem Tech Metal Recovery Plant operations during plutonium runs in which operators would dress out, go into the cells, disconnect plutonium product bottles, and move the bottles containing plutonium from the cells. This was probably the only motion picture made of the operation. ${ }^{14}$ Of the 2135 - papers submitted to the second Geneva conference held in 1958 , approximately 200 were papers concerning chemical processing aspects of atomic energy. ${ }^{34}$ Only a few papers were approved in Process Chemistry, Volume 3 . The book contained only three Chem Tech contributions, the first dealing with production of $\mathrm{UF}_{4}$, the second dealing with the recovery of $\mathrm{UF}_{6}$ from irradiated reactor fuel, and the third a review paper on process chemistry. ${ }^{7}$ 
F. R. Bruce, "Process Chemistry at the Second International Conference on the Peaceful Uses of Atomic Energy," Review Paper. ${ }^{34}$

I. R. Higgins, W. J. Neill, and L. E. McNeese, "The Excer Process-An Aqueous Method for Production of Pure Uranium Tetrafluoride from Crude Uranium Sources," Paper 506. ${ }^{35}$

G. I. Cathers et al., "Recovery of Uranium from Highly Irradiated Reactor Fuel by a Fused Salt-Fluoride Volatility Process," Paper 535.36

Although cited by Bruce, ${ }^{34}$ the following Chem Tech papers were not quoted in Process Chemistry, Volume ${ }^{7}$ but were published in the Proceedings. ${ }^{2}$

C. A. Blake, C. F. Baes, K. B. Brown,

C. F. Coleman, and J. C. White, "Solvent Extraction of Uranium and Other Metals by Acidic and Neutral Organophosphorus Compounds," Paper $1550 .{ }^{37}$

C. F. Coleman, K. B. Brown, J. G. Moore, and K. A. Allen, "Amine Salts as Solvent Extraction Reagents for Uranium and Other Metals," Paper 510.38

K. B. Brown, C. F. Coleman, D. J. Crouse, C. A. Blake, and A. D. Ryon, "Solvent Extraction Processing of Uranium and Thorium Ores," Paper 509.39

F. L. Culler and R. E. Blanco, "Dissolution and Feed Preparation for Aqueous Radiochemical Separation Processes," Paper 1930.40

F. R. Bruce, E. M. Shank, R. E. Brooksbank, J. R. Parrott, and G. S. Sadowski, "Operating Experience with Two Radiochemical Processing Pilot Plants," Paper 536. ${ }^{41}$

E. G. Struxness and J. O. Blomeke, "Multipurpose Processing and Ultimate Disposal of Radioactive Wastes," Paper 1073.42

The Chem Tech papers, summarized below, discuss selected major Chem Tech contributions to the atomic energy programs through 1958.

Process Chemistry at the Second International Conference on the Peaceful Uses of Atomic Energy. At the time of the 1958 conference, amines and dialkyl phosphates had gained wide acceptance as solvents for extraction of uranium from ore leach liquors. Their use had resulted in significant savings in both investment capital and operating cost. Solvent extraction recovery of spent reactor fuel using TBP was firmly established. Outstanding advances had been made in decreasing process waste volumes and product losses through use of waste recycle and improvement of process efficiency. ${ }^{34}$
Chem Tech scientist and reviewer Frank Bruce very perceptively concluded

Although the major research and development effort in waste disposal has centered on the handling of high activity level wastes, it becomes increasingly apparent that low and intermediate level wastes constitute an equally serious economic problem, particularly in European countries where the current United States practice of low level waste disposal to the environment is not acceptable.

Consequently, the major recent advances in low level waste treatment have been made in the European countries. 34

Chem Tech staff scientists and engineers cited in this review paper include C. A. Blake, C. F. Baes, K. B. Brown, C. F. Coleman, J. C. White, J. G. Moore, K. A. Allen, D. J. Crouse, A. D. Ryon, I. R. Higgins, W. J. Neill, L. E. McNeese, F. L. Culler, R. E. Blanco, F. R. Bruce, E. M. Shank, R. E. Brooksbank, J. R. Parrott, G. S. Sadowski, G. I. Cathers, W. H. Carr, R. B. Lindauer, R. P. Milford, M. E. Whatley, E. G. Struxness, and J. O. Blomeke. ${ }^{34}$

The Excer Process-An Aqueous Method for Production of Pure Uranium Tetrafluoride from Crude Uranium Sources. The Excer process, developed to produce pure $\mathrm{UF}_{4}$ from crude uranium sources, was studied by Chem Tech through advanced stages of engineering development. In the process, crude uranium (VI) is isolated and partially purified by ion exchange, reduced to uranium (TV), precipitated as hydrated $\mathrm{UF}_{4}$, and dehydrated to pure $\mathrm{UF}_{4}$. The Excer process requires fewer process steps than existing production methods for $\mathrm{UF}_{4}$ and is adaptable to various crude uranium sources including sulfate, nitrate, and chloride systems. The paper is authored by Chem Tech staff members I. R. Higgins, W. J. Neill, and L. E. McNeese and cites work by I. R. Higgins, J. T. Roberts, and J. A. Marinsky. 35

Recovery of Uranium from Highly Irradiated Reactor Fuel by a Fused Salt-Fluoride Volatility Process. The abstract of this paper, collectively authored by Chem Tech staff members G. I. Cathers, W. H. Carr, R. B. Lindauer, R. P. Milford, and M. E. Whatley, follows:

Uranium may be dissolved in a fused fluoride bath by hydrofluorination to tetravalent uranium and volatilized from this bath as 
uranium hexafluoride after fluorination. The hexafluoride may be purified by an absorption-desorption step using sodium fluoride. The operation of this process on a laboratory and pilot plant scale is described. ${ }^{36}$

The fused salt-fluoride volatility process appeared to hold considerable promise for recovering uranium from heterogeneous reactor fuels containing zirconium and from molten fluoride fuels. The principal advantages included small volumes of fission product waste in solid form, product as $\mathrm{UF}_{6}$ for convenient diffusion plant feed or reduction to metal or $\mathrm{UF}_{4}$, and essentially no criticality problems. Disadvantages included high temperatures and equipment corrosion. ${ }^{36}$

The ORNL Fused Salt-Fluoride Volatility Pilot Plant was constructed in Building 3019 to recover enriched uranium from irradiated Aircraft Reactor Experiment (ARE) fuel and to serve as a development facility for studying the processing of molten salt reactor fuels and zirconium-uranium metallic fuel elements. The ORNL process was unique in that it involved use of sodium fluoride for absorption and desorption of the $\mathrm{UF}_{6}$ product. Processing of $40 \mathrm{~g}$ enriched uranium ( $90 \%$ enrichment) in irradiated ARE salt produced $39.4 \mathrm{~g}$ product ( $96.92 \%$ yield), with an overall material balance of $98.91 \% .36$

This paper cites the contributions of several Chem Tech scientists and engineers, including G. I. Cathers, W. H. Carr, R. B. Lindauer, R. P. Milford, M. E. Whatley, M. R. Bennett, J. E. Bigelow, F. N. Browder, L. M. Ferris, A. E. Goldman, R. W. Horton, R. L. Jolley, R. B. Keely, J. T. Long, S. Mann, F. W. Miles, J. B. Ruch, C. L. Whitmarsh, R. G. Wymer, and R. E. Leuze. ${ }^{36}$

Solvent Extraction of Uranium and Other Metals by Acidic and Neutral Organophosphorus Compounds. Charlie Blake and co-workers systematically explored the use of organophosphorus compounds such as solvent-extraction reagents. The dialkylphosphoric acid extraction (DAPEX) process was developed during that study. This paper presents a portion of that study dealing with acidic and neutral organophosphorus reagents. The use of organophosphorus extractants is especially important in uranium raw-material processing. The reagents also extract a number of additional elements (e.g., alkali metals, alkaline earth metals, lanthanide elements, titanium, zirconium, and hafnium). This paper references several other Chem Tech scientists and engineers, including D. J. Crouse, A. D. Ryon, and W. J. Ross. 37 Amine Salts as Solvent Extraction Reagents for Uranium and Other Metals. Since 1952, the extraction properties of a wide range of amines and related organonitrogen compounds were studied at ORNL, at first principally for the recovery of uranium from ore leach liquors and later for wider application to general separations. This paper by Coleman and co-workers is a significant contribution to solvent extraction chemistry. Extraction performance was evaluated with respect to the chemical nature of the amine, molecular size and structure, acidity and basicity, concentration, and diluent. Many similarities with resin adsorption were observed. This paper references several other Chem Tech scientists and engineers, including D. J. Crouse, C. A. Blake, J. O. Denis, W. D. Arnold, R. S. Lowrie, W. J. McDowell, C. F. Baes, and A. D. Ryon. ${ }^{38}$

Solvent Extraction Processing of Uranium and Thorium Ores. This paper describes the then most representative U. S. uranium-recovery processes, which included the use of long-chain alkyl amines for extraction of uranium from sulfate leach liquors (Amex Process) and the use of organophosphorus acids, especially di(2-ethylhexyl)-phosphoric acid (Dapex Process), also for extraction of uranium from sulfuric acid leach liquors. Process flow sheets were presented and discussed with respect to chemistry, reagent costs, equipment, and the extent of commercial application. This paper references several other Chem Tech scientists and engineers, including K. A. Allen, J. O. Denis, W. D. Arnold, J. G. Moore, K. O. Johnsson, B. B. Klima, R. H. Guymon, W. T. Ward, R. R. Wiethaup, C.F. Baes, and A. D. Ryon. ${ }^{39}$

Dissolution and Feed Preparation for Aqueous Radiochemical Separation Processes. Solvent extraction was the proven and most versatile method for complete decontamination of plutonium and uranium fuels from fission products and other contaminants. The development of head-end techniques for converting zirconium- and stainless-steel-bearing fuels and homogeneous reactor fluids to nitric acid solutions suitable for solvent extraction was a major effort in Chem Tech. This Culler and Blanco paper thoroughly reviewed mechanical processes for clad fuel element and fuel assemblies (i.e., disassembly and dejacketing) and laboratory data (chemical 
dejacketing and dissolution of fuel elements) for the preparation of satisfactory aqueous feeds for solvent extraction processes. Homogeneous reactor fuel and blanket processing is also reviewed. The authors acknowledged the contributions of other Chem Tech staff, including W. D. Burch, W. E. Clark, D. E. Ferguson, L. M. Ferris, J. R. Flanary, T. A. Gens, J. H. Goode, P. A. Haas, F. G. Kitts, R. A. McNees, E. L. Nicholson, J. J. Perona, J. E. Savolainen, W. E. Unger, and C. D. Watson and cited references by D. L. Foster, R. G. Wymer, G. A. West, C. V. Chester, A. H. Kibbey, A. R. Irvine, A. C. Schafer, G. W. Parker, W. D. Bond, A. T. Gresky, and J. L. English. ${ }^{40}$

\section{Operating Experience with Two}

Radiochemical Processing Pilot Plants. This paper by Frank Bruce, Earl Shank, Bob Brooksbank, John Parrott, Sr., and George Sadowski presented the 4 and 7 years operating experience with the Metal Recovery and Thorex radiochemical processing pilot plants, respectively. The two facilities incorporated design principles derived from experience with three earlier installations that had been dismantled following completion of their intended use. In the Metal Recovery plant, various waste solutions, scrap, and miscellaneous fuel elements had been processed for the recovery of uranium, plutonium, neptunium, and americium. In the Thorex pilot plant, irradiated thorium was processed for the recovery of thorium and ${ }^{233} \mathrm{U}$. The three pilot plants that had been dismantled were the 25, Redox, and Purex plants, each of which had been operated some 5 years to obtain process chemical data for the design of larger production facilities. For example, the experience gained from the three dismantled plants was used in the design of the ICPP, and the experience gained from the Metal Recovery plant and also from the ICPP plant was used to design the Thorex pilot plant. The Metal Recovery and Thorex plants are discussed in detail. The chief way in which the design of a radiochemical processing plant differs from an ordinary plant is in the provisions that must be made to protect operating personnel from overexposure to radiation. Direct and remote maintenance, equipment reliability, decontamination, process control, and waste control are discussed relative to plant operations. The paper acknowledges contributions of Chem Tech staff, including R. E. Leuze, W. H. Lewis, W. T. McDuffee, and R. H. Rainey and cited references by F. L. Culler, A. T. Gresky, and E. D. Arnold. 41

Multipurpose Processing and Ultimate Disposal of Radioactive Wastes. In 1958 the treatment and disposal of high-level radioactive wastes were mainly in the conceptual and formative stages. There had been little treatment other than neutralization, evaporation, and storage of concentrated salt solutions in tanks. This paper by Ed Struxness of the ORNL Health Physics Division and Chem Tech engineer Tex Blomeke discussed several possibilities for ultimate disposal in geologic repositories (e.g., salt domes and deep wells). Problem areas discussed included chemical compatibility and heat dissipation. The authors acknowledge the contributions of F. L. Culler, W. J. Boegly, R. E. Blanco, W. de Laguna, F. W. Parker, L. Hemphill, I. R. Higgins, A. F. Messing, F. M. Empson, W. J. Lacey, E. E. Eastwood, O. H. Myers, and M. O. Sealand. ${ }^{42}$

\subsection{THIRD GENEVA CONFERENCE, 1964}

The theme of the third conference was Reactors and Nuclear Power. Sigvard Eklund, Director-General of the International Atomic Energy Agency in 1964, stated that the frank exchange of views that occurred at the conference on nuclear reactors and systems "should have beneficial effects on the growth of atomic energy as a source of electricity." 9

According to Glenn T. Seaborg, Chairman of the U.S. Atomic Energy Commission in 1964, many of the conference delegates viewed nuclear power as developing in three phases. The first phase had already occurred in the development of economic competitiveness of three types of reactors, namely, graphite moderated and gas cooled; heavy-water moderated and heavy-water cooled; and light-water moderated and light-water cooled. The second phase would consist of the development of advanced converter reactors, including near breeders. The third phase would consist of the development of breeder reactors, both the fast breeder using the plutonium and ${ }^{238} \mathrm{U}$ fuel cycle and the thermal breeder fueled on the thorium and ${ }^{233} \mathrm{U}$ fuel cycle. ${ }^{9}$

\subsubsection{Chem Tech Papers}

Two Chem Tech staff members, Floyd Culler and Don Ferguson, presented papers at the 1964 Geneva conference. 3 
F. L. Culler and R. E. Blanco, "Advances in Aqueous Processing of Power Reactor Fuels," Paper 249.43

D. E. Ferguson, O. C. Dean, and D. A. Douglas, "The Sol-Gel Process for the Remote Preparation and Fabrication of Recycle Fuels," Paper 237.44

The Ferguson paper was quoted in Process Chemistry, Volume 4,8 along with several detailed review papers also prepared by Chem Tech staff. A listing of the Chem Tech review papers published in Volume $4^{8}$ follows:

L. M. Ferris, "Head-End Processes for Graphite-Base and Carbide Reactor Fuels."45

C. F. Coleman, "Amine Extraction in Reprocessing." 46

R. E. Leuze and M. H. Lloyd, "Processing Methods for the Recovery of Transplutonium Elements."47

Summaries of the papers presented at the third Geneva conference and the detailed review papers follow. The papers discuss selected major Chem Tech contributions to the atomic energy programs through 1964.

Advances in Aqueous Processing of Power Reactor Fuels. This paper by Floyd Culler and Ray Blanco presents a thorough review of aqueous reprocessing methods for fuels and for the recovery of valuable radioactive materials which by 1964 had reached the stage of either pilot plant or production plant. The methods reviewed provided promise of overall processing capability of great diversity and also relative simplicity. The separation processes used organic solvent extraction and ion exchange and were based primarily on well-established processes using TBP (e.g., Purex, Thorex, TBP-25) for recovery of the fissionable and fertile materials. Inorganic adsorbents, ion-exchange resins, amines, and phosphate extractants were also used for special recovery processes (e.g., fission products, transuranium elements). Power reactor fuels generally had metal-clad ceramic core fuels (e.g., Zircaloy-2 or stainless-steel-clad $\mathrm{UO}_{2}$ or $\mathrm{ThO}_{2}-\mathrm{UO}_{2}$ ). A major effort for reprocessing power reactor fuels had been required in the development of feed dissolution and preparation methods. These head end processes included shear-leach or chop-leach followed by dissolution in boiling nitric acid; the Zirflex process in which Zircaloy jackets are dissolved in boiling $6 M \mathrm{NH}_{4} \mathrm{~F}-1 \mathrm{MNH}_{4} \mathrm{NO}_{3}$; the Sulfex process in which stainless steel jackets are dissolved in refluxing $4 \mathrm{M} \mathrm{H}_{2} \mathrm{SO}_{4}$; electrolytic dissolution; the Darex process in which stainless steel jackets are dissolved in aqua regia (thus requiring titanium equipment); combustion followed by ash dissolution (used for graphite matrix fuels). The paper summarizes major separations developments: the Purex and Thorex processes; recovery of protactinium, plutonium, and neptunium; transuranium separations; and fission product recovery. Culler and Blanco discuss safe plant operation and emphasize criticality control and secondary containment as necessary safety concerns. The paper also reviews fuel cycle costs and economies of plant scale. ${ }^{43}$

This paper references publications of many Chem Tech staff members, including L. M. Ferris, E. L. Nicholson, R. H. Rainey, J. W. Ullmann, C. D. Watson, B. C. Finney, B. A. Hannaford, G. A. West, A. H. Kibbey, J. R. Flanary, J. H. Goode, M. G. Baille, F. G. Kitts, W. E. Clark, D. E. Ferguson, J. G. Moore, W. F. Schaffer, T. A. Gens, F. G. Baird, M. J. Bradley, R. W. Horton, G. I. Cathers, R. L. Jolley, E. C. Moncrief, T. Hikido, M. E. Whatley, W. M. Woods, C. A. Blake, W. Davis, J. M. Schmitt, A. B. Meservey, R. G. Mansfield, A. T. Gresky, J. R. Oliver, J. R. Meriweather, R. E. Brooksbank, W. T. McDuffee, C. F. Coleman, F. A. Kappelmann, B. S. Weaver, W. D. Burch, E. D. Arnold, A. Chetham-Strode, W. E. Unger, B. F. Bottenfield, F. L. Hanon, R. D. Baybarz, H. B. Kinser, D. E. Horner, D. J. Crouse, K. B. Brown, J. P. Nichols, and C. E. Guthrie. 43

\section{Sol-Gel Technology in the Nuclear Reactor}

Fuel Cycle. This paper by Don Ferguson acknowledges the writing assistance of fellow Chem Tech staff members K. H. McCorkle, P. A. Haas, W. D. Bond, A. L. Lotts,

R. E. Brooksbank, L. M. Ferris, and R. G. Wymer. The paper stresses that economical nuclear power depends, in part, on developing low-cost methods for producing and recycling reactor fuels. Except for fluid fuels such as aqueous solutions or molten salts, reactor fuels and fertile materials (i.e., for breeding) are metals or ceramics. Efficiencies achieved at high temperatures and high burnups (i.e., high percentage fuel consumption before recycle) provide incentives to use ceramic fuels and fertile materials. The sol-gel process represents a technological breakthrough in the preparation of ceramic fuels and materials. Colloidal solutions (sols) and gels are important intermediates in the 
process, hence the name of the method. The paper discusses several methods to precipitate metal hydroxides, remove the anions to cause hydrolysis and sol formation, and thermally treat gel to form the desired ceramic materials. The paper discusses preparation of thoria and urania materials, with particular emphasis on the Kilorod project. The Kilorod Facility was designed, constructed, and operated at ORNL to advance the technology of the sol-gel process from a laboratory to an engineering scale. Approximately 1000 Zircaloy-clad fuel rods (hence the name "Kilorod") containing a mixture of $3 \%{ }^{233} \mathrm{UO}_{2}$ and $97 \% \mathrm{ThO}_{2}$ were prepared, and much information was obtained on radiation levels and personnel exposures encountered in fabrication of 233U-bearing fuels, as well as scale-up and engineering information applicable to the thorium fuel cycle. 44

This review cites the work of many Chem Tech staff members, including D. M. Helton, D. E. Ferguson, C. J. Hardy, C. C. Haws, J. L. Matherne, F. W. Miles, J. E. Van Cleve, E. D. Arnold, W. S. Ernst, A. L. Lotts, J. D. Sease, R. E. Brooksbank, A. R. Irvine, F. W. Davis, F. W. Miles, E. M. Shank, J. J. Varagona, J. P. Nichols, J. P. McBride, R. G. Haire, M. H. Lloyd, E. J. Kosiancic, P. A. Haas, S. D. Clinton, A. T. Kleinsteuber, S. R. Buxton, J. L. Kelly, and O. C. Dean. 44

Head-End Processes for Graphite-Base and Carbide Reactor Fuels. Graphite-base nuclear reactor fuel elements are designed primarily for use in HTGRs. The fuels are generally small particles of uranium and thorium carbides or oxides dispersed throughout a graphite matrix as the major structural component. For graphite-base fuels, two processing methods, burn-leach and grind-leach, are concluded to be most advantageous. Other methods briefly discussed include pressurized aqueous combustion, chemical disintegration, electrodisintegration, combustion-volatility, and pyrochemical processes. Unirradiated uranium, thorium, and plutonium carbides hydrolyze rapidly in water, forming hydrogen and hydrocarbons. Consequently, fuel containing carbides in massive forms (e.g., pellets, rods) would most likely be jacketed. Thus treatment processes would involve removing or penetrating the protective jackets and reacting the metal carbides with aqueous agents. This review by L. M. Ferris cites, in addition to his own, research conducted by other Chem Tech staff, including A. H. Kibbey, M. J. Bradley, R. E Blanco, G. I. Cathers, E. L. Nicholson,
J. T. Roberts, K. S. Warren, J. W. Ullmann, J. R. Flanary, J. H. Goode, H. O. Witte, V. C. A. Vaughen, C. D. Watson, R. H. Rainey, W. D. Bond, A. L. Uriarte, M. E. Whatley, G. C. Wall, P. A. Haas, J. B. Farrell, R. W. Horton, R. P. Milford, T. A. Gens, M. D. Pattengill, G. A. West, and W. F. Schaffer. 45 Amine Extraction in Reprocessing. ORNL staff member Fletcher Moore (Analytical Chemistry Division) introduced amine extraction to ORNL in 1952, and it quickly entered intensive study in the Raw Materials Group under K. B. Brown. Amine extraction soon developed into one of the major categories of solvent extraction systems. The abstract of this review paper authored by C. F. Coleman follows:

In the eighteen years since amine extraction was first reported, it has developed into one of the major categories of solvent extraction systems. Its industrial use, particularly in the hydrometallurgical processing of uranium and related metals, has both stimulated and benefitted from the commercial production of an increasing range of high molecular weight amines, especially secondary and tertiary amines. Amine extraction appears to promise special advantages in several aspects of nuclear fuel reprocessing by virtue of high extraction power, selectivity, and reagent stability. This review presents recent developments and current status in amine extraction systems as pertinent to their potential use in nuclear fuel reprocessing, including both studies of the extraction systems per se and their adaptation to particular process uses. Proposed chemical flow sheets are cited for a number of processes in and auxiliary to fuel reprocessing. Literature references are arranged so as to facilitate access to previous reviews and bibliographies and to specialized studies of the amine systems. 46

This review paper cites work of several Chem Staff scientists, including C: A. Blake, Jr., K. B. Brown, C. F. Coleman, D. E. Horner, J. G. Moore, D. J. Crouse, F. G. Seeley, D. O. Campbell, F. J. Hurst, F. A. Kappelmann, W. Davis, and J. M. Schmitt. 46

Processing Methods for the Recovery of Tränsplutonium Elements. Chem Tech staff members R. E. Leuze and M. H. Lloyd collaborated on this review paper outlining the history of TRU and transplutonium element production and detailing the process chemistry and 
engineering involved in the separation and isolation of the elements. Chem Tech personnel had a very important role in the TRU studies that have been conducted in the last several decades. The abstract of the review paper published in 1970 follows:

Within the last few years, several programs have been initiated in the United States to significantly increase the availability of the transplutonium elements. Although many process methods used for isolating small quantities of these elements are still in use, a number of special separations methods have been developed to meet the larger-scale processing requirements. Processes that have actually been used for large-scale separations of the transplutonium elements are described, and with brief descriptions of the process equipment. 47

The paper discusses the three major transplutonium element programs in the United States, namely, the AEC Transplutonium-Element Production Program, the ORNL Curium Program, and the Savannah River Laboratory pilot program to produce 3 to $4.5 \mathrm{~g}{ }^{244} \mathrm{Cm}$ for the development and demonstration of SNAP systems. ${ }^{47}$ The two ORNL and Chem Tech programs are discussed below:

- AEC Transplutonium-Element Production Program. In 1959, the AEC

Transplutonium-Element Production Program was established. Kilogram quantities of ${ }^{239} \mathrm{Pu}$ were fabricated into plutonium-aluminum alloy rods at Hanford. The rods were irradiated at moderate neutron fluxes in Savannah River reactors. The irradiated rods were processed at Savannah River to recover ${ }^{242} \mathrm{Pu}$ and to concentrate the americium and curium along with rare-earth fission products. In each of two campaigns, about $10 \mathrm{~kg}{ }^{239} \mathrm{Pu}, 1 \mathrm{~kg}{ }^{242} \mathrm{Pu}$, $300 \mathrm{~g}^{243} \mathrm{Am}$, and $300 \mathrm{~g}^{244} \mathrm{Cm}$ were produced. The ${ }^{242} \mathrm{Pu}$ in oxide form was shipped to ORNL for incorporation in HFIR targets, and the concentrates of americium, curium, and rare earths in nitric acid solution were sent to ORNL for subsequent isolation of the americium and curium. Two new facilities were constructed at ORNL for this production program: HFIR for the irradiation of ${ }^{242} \mathrm{Pu},{ }^{243} \mathrm{Am}$, and ${ }^{244} \mathrm{Cm}$ at very high neutron fluxes, and TRU (cost $\$ 8,700,000$ ), for the fabrication of HFIR targets and the processing of irradiated targets. Both facilities started operation in 1966.47

- ORNL Curium Program. The objectives of this program were to isolate gram amounts of ${ }^{242} \mathrm{Cm}$ and ${ }^{244} \mathrm{Cm}$ for use in the initial development and testing of SNAP heat sources. Processing was carried out in the Curium Recovery Facility (CRF) installed by Chem Tech in the High-Level Hot Cell Facility (Building 4507). The CRF was designed to test TRU processes at high activity levels. Curium-242 was recovered from ${ }^{241} \mathrm{AmO}_{2}-\mathrm{Al}$ cermets irradiated in the MTR and the Oak Ridge Research Reactor. Part of the Savannah River concentrate was processed to recover ${ }^{244} \mathrm{Cm}$. The CRF operations conducted by Chem Tech staff resulted in the successful isolation of about $35 \mathrm{~g}$ each of ${ }^{243} \mathrm{Am}$ and ${ }^{244} \mathrm{Cm}$ and $25 \mathrm{~g}$ of ${ }^{242} \mathrm{Cm} .{ }^{47}$

This review cites work of many Chem Tech staff members, including J. E. Bigelow, D. E. Ferguson, A. Chetham-Strode, J. R. McWherter, F. L. Culler, W. D. Burch, E. D. Arnold, L. J. King, J. L. Matherne, B. F. Bottenfield, F. L. Hannon, R. McCarter, C. A. Haws, F. L. Peishel, O. O. Yarbro, A. L. Lotts, M. K. Preston, J. D. Sease, J. E. Van Cleve, Jr., R. D. Baybarz, B. S. Weaver, R. G. Haire, C. J. Hardy, S. R. Buxton, V. C. A. Vaughen, F. A. Kappelmann, R. E. Leuze, M. H. Lloyd, R. H. Rainey, R. E. Brooksbank, W. T. McDuffee, and H. B. Kinser. ${ }^{47}$

\subsection{FOURTH GENEVA CONFERENCE, 1971}

The Fourth International Conference on the Peaceful Uses of Atomic Energy was convened in Geneva on September 6-16, 1971, under the Presidency of Glenn T. Seaborg. Over 4,000 participated in the fourth Geneva conference sponsored by the United Nations and the IAEA. The conference was somewhat broader in scope than the previous three conferences. It again proved to be an appropriate forum for exchange of information on the discoveries, projects, and problems of developed and developing nations. Three Chem Tech papers were included in the proceedings which were published in 15 volumes:

- D. E. Ferguson, C. R. Cooley, E. B. Shelton, and D. S. Webster, "Recovery of Liquid-Metal 
Fast-Breeder Reactor (MFBR) Fuels: Development of Techniques"48

- R. Salmon, J. T. Roberts, A. L. Lotts, T. N. Washburn, and W. H. McVey, "Price Forecasting and Resource Utilization for the Fuel Cycle Industry of the United States"49

- F. L. Culler, J. O. Blomeke, and W. G. Belter, "Current Developments in Long-Term Radioactive Waste Management"50

Recovery of Liquid-Metal Fast-Breeder Reactor (LMFBR) Fuels: Development of Techniques. The abstract of the Chem Tech Division Director Don Ferguson follows:

Nearly every major nuclear-fuel processing facility in existence today employs the Purex process. Its favorable features-unexcelled separation, versatility, ease of scale-up, and vast operating experience-also apply to the treatment of liquid-metal fast-breeder reactor (LMFBR) fuel and make Purex an obvious choice for use in processing this fuel. Certain modifications to the existing techniques are necessary, however, to make the process economical for LMFBR fuels. Because of the higher plutonium contents, a factor of 10 as compared with light-water reactor (LWR) fuel, there is a large economic incentive for processing at shorter decay times. This, coupled with the fact that LMFBR fuels will operate at higher power densities, $150 \mathrm{vs} 35 \mathrm{~kW} / \mathrm{kg}$ for LWR fuel, and to burn-up of the order of $80,000 \mathrm{MWd} / \mathrm{t}$, creates a serious heating problem in handling the fuel. These same factors increase the amounts of volatile fission products, such as iodine, xenon, krypton, and tritium, which must be handled and contained in the plant. A comprehensive development program is being carried out in the United States of America to solve these and other unique problems associated with the processing of LMFBR fuels. Methods are being developed for the deactivation and removal of sodium. Handling techniques are being developed to provide reliable cooling of the spent fuel elements. Two alternative head-end processes are being studied. One uses molten zinc to remove the stainless steel cladding. In the other, the fuel is chopped and the volatile fission products are removed by a new process, called voloxidation, which involves oxidation at $500^{\circ} \mathrm{C}$. Dissolution and feed preparation for the high-plutonium-content, high burn-up fuel are also being studied. Solvent extraction flow sheets to accommodate the higher plutonium and fission-product concentrations have been developed and are being tested. Both pulsed columns and centrifugal contactors are being evaluated. Methods are being developed and tested for reducing radioactive effluents, especially such volatile fission products as iodine, from the plant to near zero. 48

The paper cites several Chem Tech progress reports and Chem Tech engineers

V. C. A. Vaughen, J. G. Moore, and D. J. Crouse. 48

Price Forecasting and Resource Utilization for the Fuel Cycle Industry of the United States. In 1966, the AEC began a long-range systems analysis study to determine the optimal utilization of various types of nuclear reactors in an expanding nuclear power economy. The Fuel Cycle Task Force working group, chaired by Chem Tech Division Director Don Ferguson, was made responsible for the development of a model for the long-range projection of fuel-cycle costs. The FUELCO model was developed for this purpose by Chem Tech engineer Royes Salmon. This paper describing the model and its use in the AEC study was presented at the fourth Geneva conference. The FUELCO model typically showed individual (fuel cycle) plants earning 1 to $25 \%$ on equity. Small plants generally earned the lowest rates. Large plants coexisting with smaller competitors tended to show the highest rates of return. ${ }^{49}$

Current Developments in Long-Term Radioactive Waste Management. The abstract of the paper by ORNL Associate Director Floyd Culler and Chem Tech engineer John "Tex" Blomeke follows:

The safe disposal of radioactive wastes is possibly the most important and controlling problem in the large-scale use of nuclear energy. Radioactive wastes with very long half-lives require processing to chemically stable forms and storage in an isolated natural environment, an environment that remains protected from natural phenomena for periods of several hundreds of thousands of years. The radioactive fission products and long-lived fissile and fertile isotopes of alpha emitter, such as plutonium, set the requirements for chemical fixation, heat release, shielding, containment, shipment, and ultimate disposal. The main thrust of work in the USA radioactive-waste 
program over the past 15 years has been directed toward the development of processes for solidifying the wastes and in establishing the suitability of natural salt deposits as an ultimate repository. As a consequence of the advances made in this work, the USAEC has established the industrial requirement for conversion of all high-level liquid wastes to a solid form suitable for interim on-site storage, shipment, and disposal in a few centralized repositories.

The choices for long-term disposal or management are few. Starting in 1950 the problems of ultimate disposal were considered by various committees of the National Academy of Sciences at the request of the USAEC. Disposal in thick-bedded salt in the central part of the United States was recommended for study. A pilot project for high-level disposal was initiated by the Oak Ridge National Laboratory for the USAEC in 1963 and was satisfactorily completed in 1968. The location of this test was at Lyons, Kansas, in a portion of an old salt mine located in an extensive, 1000-ft-deep, 300-ft-thick salt layer. As a result of this demonstration and extensive supporting development, a national repository for radioactive wastes will be constructed at this site. It will serve both as an expanded demonstration project and a disposal site for radioactive wastes originating from the nuclear industry and from USAEC operations. Both plutonium-bearing wastes and fixed, canned high-level fission products will be stored, monitored, and evaluated. The initial project site will have a sufficient capacity to handle fixed high-level fission products and alpha-emitting wastes produced in the United States until near the end of this century. 50

The paper cites Chem Tech engineers John Blomeke, W. C. McClain, and R. L. Bradshaw, as well as an ORNL staff report on siting for fuel reprocessing and waste management facilities. .50

\subsection{REFERENCES}

1. Proceedings of the International Conference on the Peaceful Uses of Atomic Energy Held in Geneva, August 8-20, 1955, Volumes 1-18, New York, United Nations, 1956.

2. Proceedings of the Second United Nations International Conference on the Peaceful Uses of Atomic Energy, Held in Geneva, September 1-13, 1958, Volumes 1-33, New York, United Nations, 1958.

3. Proceedings of the Third International Conference on the Peaceful Uses of Atomic Energy, Held in Geneva, 1964, Volume 1-16, United Nations, New York, 1968.

4. Peaceful Uses of Atomic Energy, Proceedings of the Fourth International Conference, Geneva, September 6-16, 1971. Volumes 1-15, United Nations, New York and International Atomic Energy Agency, Vienna, 1972.

5. F. R. Bruce, J. M. Fletcher, H. H. Hyman, and J. J. Katz, eds., Progress in Nuclear Energy, Series III, Process Chemistry, New York, McGraw-Hill Book Co., Inc., 1956.

6. F. R. Bruce, J. M. Fletcher, and H. H. Hyman, eds., Progress in Nuclear Energy, Series III, Process Chemistry, Volume 2, New York, Pergamon Press, 1958.

7. F. R. Bruce, J. M. Fletcher, and H. H. Hyman, eds., Progress in Nuclear Energy, Series III, Process Chemistry, Volume 3, New York, Pergamon Press, 1961.

8. C. E. Stevenson, E. A. Mason, and A. T. Gresky, eds., Progress in Nuclear Energy, Series III, Process Chemistry, Volume 4, New York, Pergamon Press, 1970.

9. A. T. Gresky, "Review of Fuel Processing Technology Presented at the 1964 Geneva Conference," pp. 3-34 in Progress in Nuclear Energy, Series III, Process Chemistry, Volume 4, eds., C. E. Stevenson, E. A. Mason, and A. T. Gresky, New York, Pergamon Press, 1970.

10. "Preface," p. xi in Progress in Nuclear Energy, Series III, Process Chemistry, eds., F. R. Bruce, J. M. Fletcher, H. H. Hyman, and J. J. Katz, New York, McGraw-Hill Book Co., Inc., 1956.

11. Glenn T. Seaborg, "Foreword," p. ix in Progress in Nuclear Energy, Series III, Process Chemistry, eds., F. R. Bruce, J. M. Fletcher, H. H. Hyman, and J. J. Katz, New York, McGraw-Hill Book Co., Inc., 1956.

12. Sir Harold Hartley, "Foreword," p. vii in Progress in Nuclear Energy, Series III, Process Chemistry, eds., F. R. Bruce, J. M. Fletcher, H. H. Hyman, and J. J. Katz, New York, McGraw-Hill Book Co., Inc., 1956.

13. F. R. Bruce, T. M. Fletcher, H. H. Hyman, and J . J. Katz, eds., Progress in Nuclear Energy, 
Series III, Process Chemistry, New York, McGraw-Hill Book Co., Inc., New York, 1956.

14. Warren K. Eister, personal communication, February 28, 1992.

15. D. O. Campbell, "The Removal of Fission Products from Stainless Steel," p. 551 in Proceedings of the International Conference on the Peaceful Uses of Atomic Energy Held in Geneva, August 8-20, 1955, Volume 9, Reactor Technology and Chemical Processing, New York, United Nations, 1956.

16. J. W. Landry, "High Level Sampling Devices for Radiochemical Plants," p. 555 in Proceedings of the International Conference on the Peaceful Uses of Atomic Energy Held in Geneva, August 8-20, 1955, Volume 9. Reactor Technology and Chemical Processing, New York, United Nations, 1956.

17. G. I. Cathers, "Radiation Damage to Radiochemical Processing Reagents," pp. 68-78 in Progress in Nuclear Energy, Series III, Process Chemistry, eds., F. R. Bruce, J. M. Fletcher, H. H. Hyman, and J. J. Katz, New York, McGraw-Hill Book Co., Inc., 1956; also p. 490 in Proceedings of the International Conference on the Peaceful Uses of Atomic Energy Held in Geneva, August 8-20, 1955, Volume 7, Nuclear Chemistry and Effects of Irradiation, New York, United Nations, 1956.

18. D. L. Foster, J. E. Savolainen, and R. G. Wymer, "Nuclear Reactor Fuel Dissolution," pp. 85-96, in Progress in Nuclear Energy, Series III, Process Chemistry, eds., F. R. Bruce, J. M. Fletcher, H. H. Hyman, and J. J. Katz, New York, McGraw-Hill Book Co., Inc., 1956; also, p. 546 in Proceedings of the International Conference on the Peaceful Uses of Atomic Energy Held in Geneva, August 8-20, 1955, Volume 9, Reactor Technology and Chemical Processing, New York, United Nations, 1956.

19. F. R. Bruce, "The Behavior of Fission Products in Solvent Extraction Processes," pp. 130-146, in Progress in Nuclear Energy, Series III, Process Chemistry, eds., F. R. Bruce, J. M. Fletcher, H. H. Hyman, and J. J. Katz, New York, McGraw-Hill Book Co., Inc., 1956; also, p. 100 in Proceedings of the International Conference on the Peaceful Uses of Atomic Energy Held in Geneva, August 8-20, 1955, Volume 7, Nuclear Chemistry and
Effects of Irradiation, New York, United Nations, 1956.

20. F. L. Culler, "Reprocessing of Reactor Fuel and Blanket Materials by Solvent Extraction," pp. 172-194 in Progress in Nuclear Energy, Series III, Process Chemistry, eds., F. R. Bruce, J. M. Fletcher, H. H. Hyman, and J. J. Katz, New York, McGraw-Hill Book Co., Inc., 1956; also, p. 464 in Proceedings of the International Conference on the Peaceful Uses of Atomic Energy Held in Geneva, August 8-20, 1955, Volume 9, Reactor Technology and Chemical Processing, New York, United Nations, 1956.

21. J. R. Flanary, "A Solvent Extraction Process for the Separation of Uranium and Plutonium from Fission Products by Tributyl Phosphate," pp. 195-200 in Progress in Nuclear Energy, Series III, Process Chemistry, eds., F. R. Bruce, J. M. Fletcher, H. H. Hyman, and J. J. Katz, New York, McGraw-Hill Book Co., Inc., 1956; also, p. 528 in Proceedings of the International Conference on the Peaceful Uses of Atomic Energy Held in Geneva, August 8-20, 1955, Volume 9, Reactor Technology and Chemical Processing, New York, United Nations, 1956.

22. F. L. Culler, "The Processing of Uranium-Aluminum Reactor Fuel Elements," pp. 201-211 in Progress in Nuclear Energy, Series III, Process Chemistry, eds., F. R. Bruce, J. M. Fletcher, H. H. Hyman, and J. J. Katz, New York, McGraw-Hill Book Co., Inc., 1956; also, p. 484 in Proceedings of the International Conference on the Peaceful Uses of Atomic Energy Held in Geneva, August 8-20, 1955, Volume 9, Reactor Technology and Chemical Processing, New York, United Nations, 1956.

23. A. T. Gresky, "The Separation of ${ }^{233} U$ and Thorium from Fission Products by Solvent Extraction," pp. 212 in Progress in Nuclear Energy, Series III, Process Chemistry, eds., F. R. Bruce, J. M. Fletcher, H. H. Hyman, and J. J. Katz, New York, McGraw-Hill Book Co., Inc., 1956; also, p. 505 in Proceedings of the International Conference on the Peaceful Uses of Atomic Energy Held in Geneva, August 8-20, 1955, Volume 9, Reactor Technology and Chemical Processing, New York, United Nations, 1956. 
24. D. E. Ferguson, "The Processing of Aqueous Homogeneous Reactor Fuel," pp. 249-258 in Progress in Nuclear Energy, Series III, Process Chemistry, eds., F. R. Bruce, J. M. Fletcher, H. H. Hyman, and J. J. Katz, New York, McGraw-Hill Book Co., Inc., 1956; also, p. 514 in Proceedings of the International Conference on the Peaceful Uses of Atomic Energy Held in Geneva, August 8-20, 1955, Volume 9, Reactor Technology and Chemical Processing, New York, United Nations, 1956.

25. Editorial Preface, p. ix in Progress in Nuclear Energy, Series III, Process Chemistry, Volume 2, eds., F. R. Bruce, J. M. Fletcher, and H. H. Hyman, New York, Pergamon Press, 1958.

26. K. B. Brown and C. F. Coleman, "Solvent Extraction in Ore Processing," pp. 3-34 in Progress in Nuclear Energy, Series III, Process Chemistry, Volume 2, eds. F. R. Bruce, J. M. Fletcher, and H. H. Hyman, New York, Pergamon Press, 1958.

27. O. C. Dean, "Reduction of Thorium Chloride by Alkali Metal Amalgams," pp. 155-170 in Progress in Nuclear Energy, Series III, Process Chemistry, Volume 2, eds., F. R. Bruce, J. M. Fletcher, and H. H. Hyman, New York, Pergamon Press, 1958.

28. J. W. Ullmann, "Factors Affecting Fuel Cycle Cost," pp. 210-221 in Progress in Nuclear Energy, Series III, Process Chemistry, Volume 2, eds., F. R. Bruce, J. M. Fletcher, and H. H. Hyman, New York, Pergamon Press, 1958.

29. R. E. Blanco, "Preparation of Power Reactor Fuels for Processing by Solvent Extraction," pp. 223-246 in Progress in Nuclear Energy, Series III, Process Chemistry, Volume 2, eds., F. R. Bruce, J. M. Fletcher, and H. H. Hyman, New York, Pergamon Press, 1958.

30. E. M. Shank, "Operation of the Thorex Pilot Plant with Highly Irradiated Thorium," pp. 279-301 in Progress in Nuclear Energy, Series III, Process Chemistry, Volume 2, eds., F. R. Bruce, J. M. Fletcher, and H. H. Hyman, New York, Pergamon Press, 1958.

31. F. R. Bruce, "The Concentration and Purification of Uranium and Plutonium by Ion Exchange," pp. 363-376 in Progress in Nuclear Energy, Series III, Process Chemistry, Volume 2, eds., F. R. Bruce, J. M. Fletcher, and
H. H. Hyman, New York, Pergamon Press, 1958.

32. O. C. Dean, "Mercury Processing of Uranium and Its Alloys," pp. 412-419 in Progress in Nuclear Energy, Series III, Process Chemistry, Volume 2, eds., F. R. Bruce, J. M. Fletcher, and H. H. Hyman, New York, Pergamon Press, 1958.

33. J. R. Flanary and G. W. Parker, "The Development of Recovery Processes for Neptunium-237," pp. 501-517 in Progress in Nuclear Energy, Series III, Process Chemistry, Volume 2, eds., F. R. Bruce, J. M. Fletcher, and H. H. Hyman, New York, Pergamon Press, 1958.

34. F. R. Bruce, "Process Chemistry at the Second International Conference on the Peaceful Uses of Atomic Energy," pp. 427-469 in Progress in Nuclear Energy, Series III, Process Chemistry, Volume 3, eds., F. R. Bruce, J. M. Fletcher, and H. H. Hyman, New York, Pergamon Press, 1961.

35. I. R. Higgins, W. J. Neill, and L. E. McNeese, "The Excer Process-An Aqueous Method for Production of Pure Uranium Tetrafluoride from Crude Uranium Sources," pp. 78-85, in Progress in Nuclear Energy, Series III, Process Chemistry, Volume 3, eds.,

F. R. Bruce, J. M. Fletcher, and H. H. Hyman, New York, Pergamon Press, 1961; also, p. 473 in Proceedings of the Second United Nations International Conference on the Peaceful Uses of Atomic Energy, Held in Geneva, September I-13, 1958, Volume 4, Production of Nuclear Materials and Isotopes, New York, United Nations, 1958.

36. G. I. Cathers et al., "Recovery of Uranium from Highly Irradiated Reactor Fuel by a Fused Salt-Fluoride Volatility Process," p. 30 in Progress in Nuclear Energy, Series III, Process Chemistry, Volume 3, eds.,

F. R. Bruce, J. M. Fletcher, and H. H. Hyman, New York, Pergamon Press, 1961; also, p. 473 in Proceedings of the Second United Nations International Conference on the Peaceful Uses of Atomic Energy, Held in Geneva, September 1-13, 1958, Volume 17, Processing Irradiated Fuels and Radioactive Materials, New York, United Nations, 1958.

37. C. A. Blake, C. F. Baes, K. B. Brown, C. F. Coleman, and J. C. White, "Solvent Extraction of Uranium and Other Metals by 
Acidic and Neutral Organophosphorus Compounds," Paper 1550, pp. 289-298 in Proceedings of the Second United Nations International Conference on the Peaceful Uses of Atomic Energy, Held in Geneva, September 1-13, 1958, Volume 28, Basic Chemistry in Nuclear Energy, New York, United Nations, 1958.

38. C. F. Coleman, K. B. Brown, J. G. Moore, and K. A. Allen, "Amine Salts as Solvent Extraction Reagents for Uranium and Other Metals," Paper 510, pp. 278-288 in Proceedings of the Second United Nations International Conference on the Peaceful Uses of Atomic Energy, Held in Geneva, September 1-13, 1958, Volume 28, Basic Chemistry in Nuclear Energy, New York, United Nations, 1958.

39. K. B. Brown, C. F. Coleman, D. J. Crouse, C. A. Blake, and A. D. Ryon, "Solvent Extraction Processing of Uranium and Thorium Ores," Paper 509, pp. 472-487 in Proceedings of the Second United Nations International Conference on the Peaceful Uses of Atomic Energy, Held in Geneva, September 1-13, 1958, Volume 3, Processing of Raw Materials, New York, United Nations, 1958.

40. F. L. Culler and R. E. Blanco, "Dissolution and Feed Preparation for Aqueous Radiochemical Separation Processes," Paper 1930, pp. 259-290 in Proceedings of the Second United Nations International Conference on the Peaceful Uses of Atomic Energy, Held in Geneva, September 1-13, 1958, Volume 17, Processing Irradiated Fuels and Radioactive Materials, New York, United Nations, 1958.

41. F. R. Bruce, E. M. Shank, R. E. Brooksbank, J. R. Parrott, and G. S. Sadowski, "Operating Experience with Two Radiochemical Processing Pilot Plants," Paper 536, pp. 49-72 in Proceedings of the Second United Nations International Conference on the Peaceful Uses of Atomic Energy, Held in Geneva, September 1-13, 1958, Volume 17, Processing Irradiated Fuels and Radioactive Materials, New York, United Nations, 1958.

42. E. G. Struxness and J. O. Blomeke, "Multipurpose Processing and Ultimate Disposal of Radioactive Wastes," Paper 1073, pp. 43-55 in Proceedings of the Second United Nations International Conference on the Peaceful Uses of Atomic Energy, Held in
Geneva, September 1-13, 1958, Volume 18, Waste Treatment and Environmental Aspects of Atomic Energy, New York, United Nations, 1958.

43. F. L. Culler and R. E. Blanco, "Advances in Aqueous Processing of Power Reactor Fuel," pp. 316-327 in Proceedings of the Third International Conference on the Peaceful Uses of Atomic Energy, Held in Geneva, 1964, Volume 10, Nuclear Fuels-I. Fabrication and Reprocessing, United Nations, New York, 1968.

44. D. E. Ferguson, "Sol-Gel Technology in the Nuclear Reactor Fuel Cycle," pp. 37-78 in Progress in Nuclear Energy, Series III, Process Chemistry, Volume 4, eds., C. E. Stevenson, E. A. Mason, and A. T. Gresky New York, Pergamon Press, 1970; also, D. E. Ferguson, O. C. Dean, and D. A. Douglas, "The Sol-Gel Process for the Remote Preparation and Fabrication of Recycle Fuels," pp. 316-327 in Proceedings of the Third International Conference on the Peaceful Uses of Atomic Energy, Held in Geneva, 1964, Volume 10, Nuclear Fuels-I. Fabrication and Reprocessing, United Nations, New York, 1968.

45. L. M. Ferris, "Head-End Processes for Graphite-Base and Carbide Reactor Fuels," pp. 121-170 in Progress in Nuclear Energy, Series III, Process Chemistry, Volume 4, eds., C. E. Stevenson, E. A. Mason, and A. T. Gresky, New York, Pergamon Press, 1970.

46. C. F. Coleman, "Amine Extraction in Reprocessing," pp. 233-285 in Progress in Nuclear Energy, Series III, Process Chemistry, Volume 4, eds., C. E. Stevenson, E. A. Mason, and A. T. Gresky, New York, Pergamon Press, 1970.

47. R. E. Leuze and M. H. Lloyd, "Processing Methods for the Recovery of Transplutonium Elements," pp. 549-630 in Progress in Nuclear Energy, Series III, Process Chemistry, Volume 4, eds., C. E. Stevenson, E. A. Mason, and A. T. Gresky, New York, Pergamon Press, 1970.

48. D. E. Ferguson, C. R. Cooley, E. B. Shelton, and D. S. Webster, "Recovery of Liquid-Metal Fast-Breeder Reactor (MFBR) Fuels: Development of Techniques," pp. 395-410 (A/CONF./P/064) in Peaceful Uses of Atomic 
Energy, Proceedings of the Fourth International Conference, Geneva, September 6-16, 1971. Volume 8, Uranium and Thorium Ore Resources; Fuel Fabrication and Reprocessing, United Nations, New York and International Atomic Energy Agency, Vienna, 1972; also, pp. 2.4-1 to 2.4-32 in U.S. Papers for the Fourth United Nations International Conference on the Peaceful Uses of Atomic Energy, Geneva, Switzerland, September 6-16, 1971, Volume 1, Nuclear USA.

49. R. Salmon, J. T. Roberts, A. L. Lotts, T. N. Washburn, and W. H. McVey, "Price Forecasting and Resource Utilization for the Fuel Cycle Industry of the United States," pp. 255-230 (A/CONE./P/060) in Peaceful Uses of Atomic Energy, Proceedings of the Fourth International Conference, Geneva, September 6-16, 1971. Volume 4, Integration of Nuclear Plants in Electrical Networks; Integrated Planning of Nuclear Energy; Fuel Materials Technology, United Nations, New York, and International Atomic Energy
Agency, Vienna, 1972; also, pp. 2.2-1 to 2.2-13 in U.S. Papers for the Fourth United Nations International Conference on the Peaceful Uses of Atomic Energy, Geneva, Switzerland, September 6-16, 1971, Volume 1, Nuclear USA.

50. F. L. Culler, J. O. Blomeke, and W. G. Belter, "Current Developments in Long-Term Radioactive Waste Management," pp. 427-443 (A/Conf. 49/P/839) in Peaceful Uses of Atomic Energy, Proceedings of the Fourth International Conference, Geneva, September 6-16, 1971. Volume 11, Health Physics and Radiation Protection; Radioactive Waste Management; The Environment and Public Acceptance, United Nations, New York and International Atomic Energy Agency, Vienna, 1972; also, pp. 3.2-1 to 3.2-18 in U.S. Papers for the Fourth United Nations International Conference on the Peaceful Uses of Atomic Energy, Geneva, Switzerland, September $6-16,1971$, Volume 2, Nuclear USA. 


\section{EXPANDED AND CHANGING MISSIONS}

The work that took place at the Graphite Reactor had ramifications for many fields of science. This was the place, for example, where mammalian radiation biology in its modern sense really originated. The reactor had important implications for the development of nuclear power, both for naval submarines and for electric utilities. It had great influence, from the very beginning, on materials research, particularly the fields of neutron diffraction and radiation damage to solids. And then, of course, it was the first place where isotopes were produced for every science you can think of. ... There were other missions. The most important, I suppose, was the production and distribution of radioisotopes. Much of the work that led to unraveling the genetic code could not have been done without them. They are used in the diagnosis and treatment of cancer. They are used in agriculture to trace phosphorus in fertilizers, and in innumerable other ways. Science couldn't continue today without them. If God has a golden book and writes down what it is that Oak Ridge National Laboratory did that had the biggest influence on science, I would guess that was the production and distribution of radioisotopes.

Alvin M. Weinberg

The Graphite Reactor, 1992

During the past half century, national energy-related goals and objectives have changed. In response to these changes, the work tasks and missions of ORNL and Chem Tech have been redirected and expanded. Some of the major Chem Tech projects and programs are described in the following sections.

\subsection{SEPARATIONS DEVELOPMENT FOR RAW MATERIALS, Charles F. Coleman, David J. Crouse, and Fred J. Hurst}

In recognition of the urgent need for improvement in domestic uranium production, a Raw Materials Section under the direction of K. B. Brown (Fig. 4.1) was established in 1948 within the Y-12 Research Division, which soon became the ORNL Materials Chemistry Division. Initial emphasis was placed on improving the leaching and precipitation methods that were then being used to recover uranium from the sandstone carnotite ores located on the Colorado Plateau. Because the known domestic reserves were

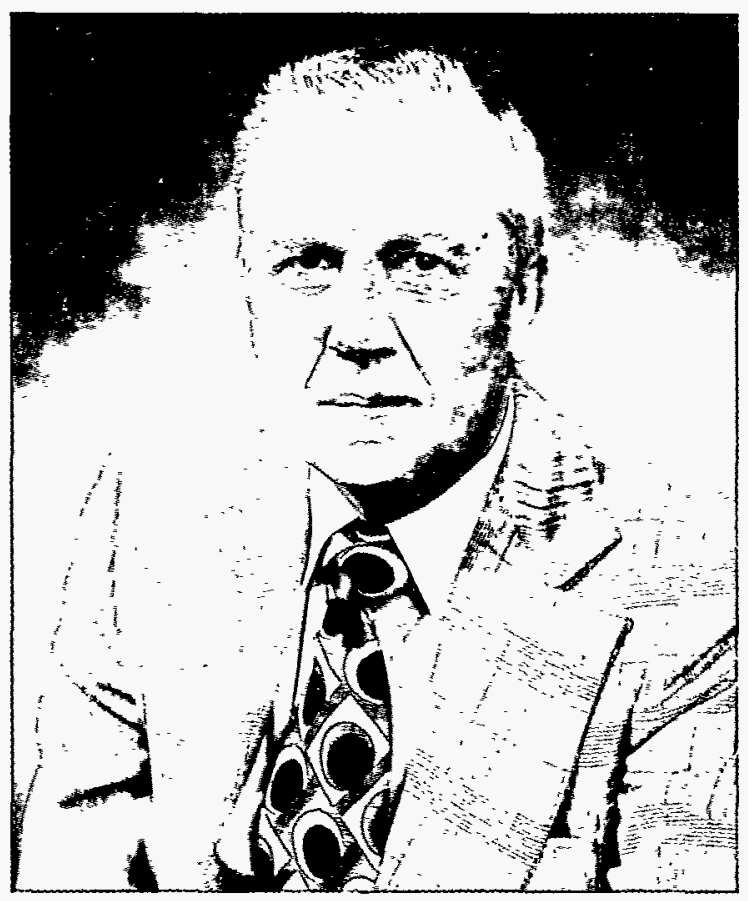

Fig. 4.1. Keith Brown, long-time leader of the separations chemistry group, was Assistant Division Director of Chem Tech in this 1978 photograph. 
extremely limited, investigations also were conducted on the recovery of uranium (and, in some cases, thorium) from a variety of low-grade sources such as phosphates, shales, lignites, granitic rocks, and monazite sands.

A limiting problem in the development of suitable recovery processes was efficient recovery of uranium from the complex process liquors. A liquid-solid ion-exchange process, already placed into operation by some other organizations, was carefully studied and evaluated. However, conviction grew that liquid-liquid extraction (solvent extraction) offered the most promise if systems could be found that would extract uranium from sulfate solutions since the extensive and growing uranium nitrate extraction systems (Sect. 3.1) could not tolerate sulfate.

A program to identify suitable extractants was initiated, and the development of separation technology soon became the principal effort of the research group. As a result of this effort, two major processes, DAPEX and AMEX, were developed. DAPEX uses a synergistic mixture of organophosphorus compounds, and AMEX uses long-chain alkyl amines to extract the uranium. These processes have been used successfully in many domestic and foreign uranium mills since the mid-1950s. Development of these processes was described at the second Geneva conference in 1958 and earned a Technical Achievement Award from Mining World and a Certificate of Merit from the American Nuclear Society.

As the Raw Materials Section grew, it was organized into specialized interacting groups: Exploratory/Descriptive Chemistry, Fundamental Chemistry, Process Development, an engineering group for scaleup studies, and, for a critical period, a synthetic organic chemistry group to synthesize potential extractants that did not yet exist.

In 1956, this separations development group was transferred to the Chemical Technology Division and became known as Chemical Development Section C. During the ensuing years, the raw materials separations technology developed in this section spread into many different areas. The special reagents and processes and the personnel skilled in the uses of those reagents and processes have been effective in many applications superficially remote from raw materials. Some of these became major projects within this section, notably the Chem Tech-Biology Division cooperative project that isolated pure tRNAs (see Sect. 4.19). Others were started and turned over to other users or were pursued jointly, including separation of transplutonium elements from rare earths in chloride or carboxylic acid solutions, recovery of uranium-neptunium-technetium from refinery wastes, recovery of uranium from sulfuric acid-fuel solution and from fluoride-fuel solution, recovery of cesium and strontium from fission-product waste solutions, and recovery of nonradioactive metals such as beryllium, cesium, and vanadium from their ores (see Sects. 2.9-2.12). One very successful program was the identification of granites as an almost unlimited supply of thorium for use in a thermal breeder system that was being studied. A considerable effort was expended on the Plowshare program to define the behavior of radionuclides in rubble cavities formed for natural gas stimulation, copper oxide leaching, and recovery of oil from shales. A study of many difficult metal separations such as $\mathrm{Zr}-\mathrm{Hf}$, Ta-Nb, and $\mathrm{Co}-\mathrm{Ni}$ was carried out using solvent extraction and ion-exchange techniques. The Co-Ni and $\mathrm{Zr}-\mathrm{Hf}$ separation techniques were later used in continuous chromatography studies. After many years of frustration, a successful process (DEPA-TOPO) was developed to recover uranium from wet-process phosphoric acid (Fig. 4.2). This process is currently being used by several companies in the United States and in several foreign countries. This development was embroiled in a bitter patent dispute which was won by ORNL and DOE and received significant attention for technology transfer. It was also selected for a prestigious Kirkpatrick Chemical Engineering Honor Award in 1979 and an IR-100 award in 1980 (Figs. 4.3 and 4.4).

Many advances in analytical methods were developed to meet the needs in separations research. In particular, a highly sensitive and versatile alpha spectrometry system (PERALS) received an IR-100 award in 1981 and is gaining increasing commercial acceptance.

While not feasible for enumeration here, it should also be noted that the open-literature publications from wide ranges of fundamental and descriptive-chemistry topics, related to and suggested by the separations studies, have been important contributions (Fig. 4.5). 


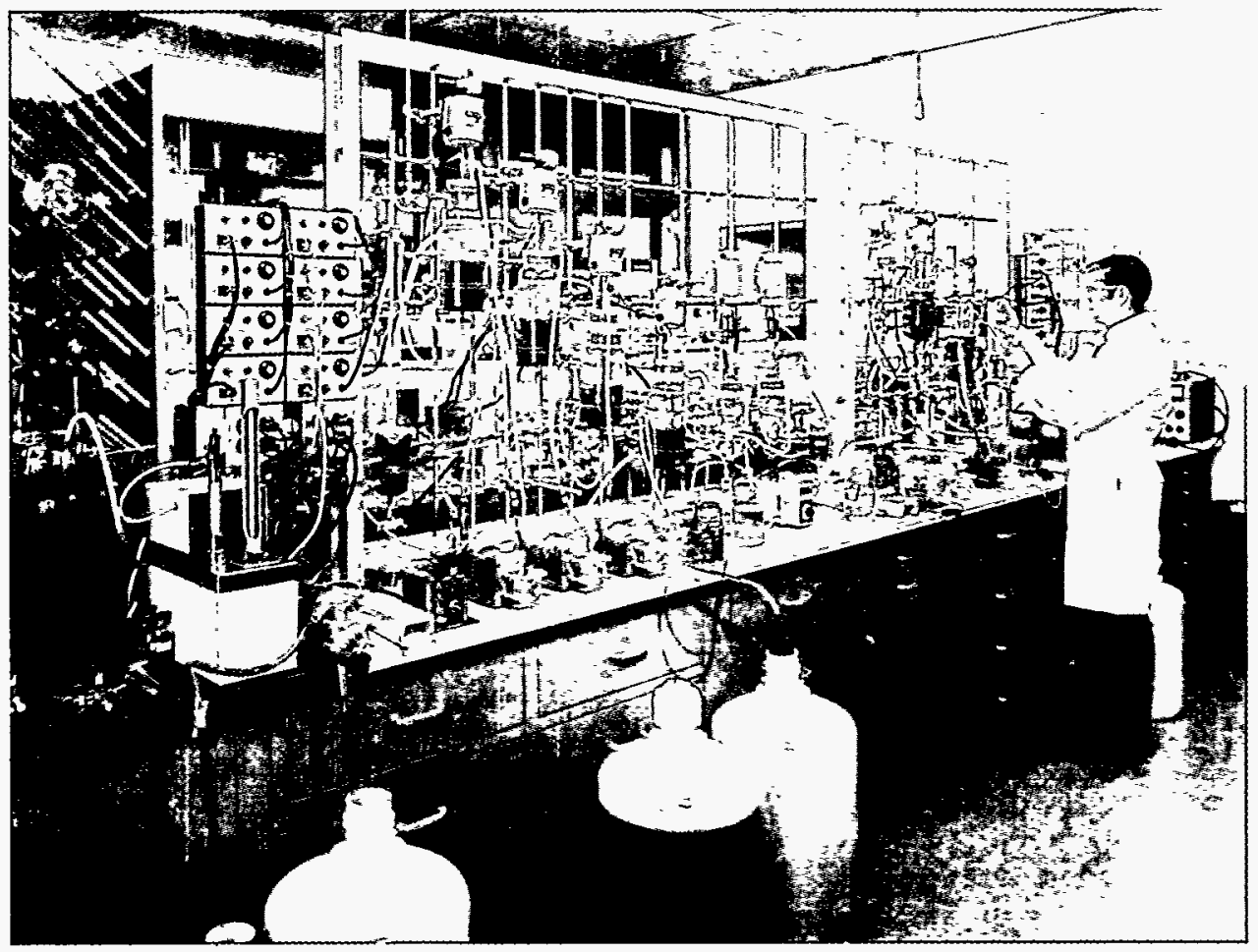

Fig. 4.2. Fred Hurst monitoring the bench-scale process for solvent extraction recovery of uranium from wet-process phosphoric acid.

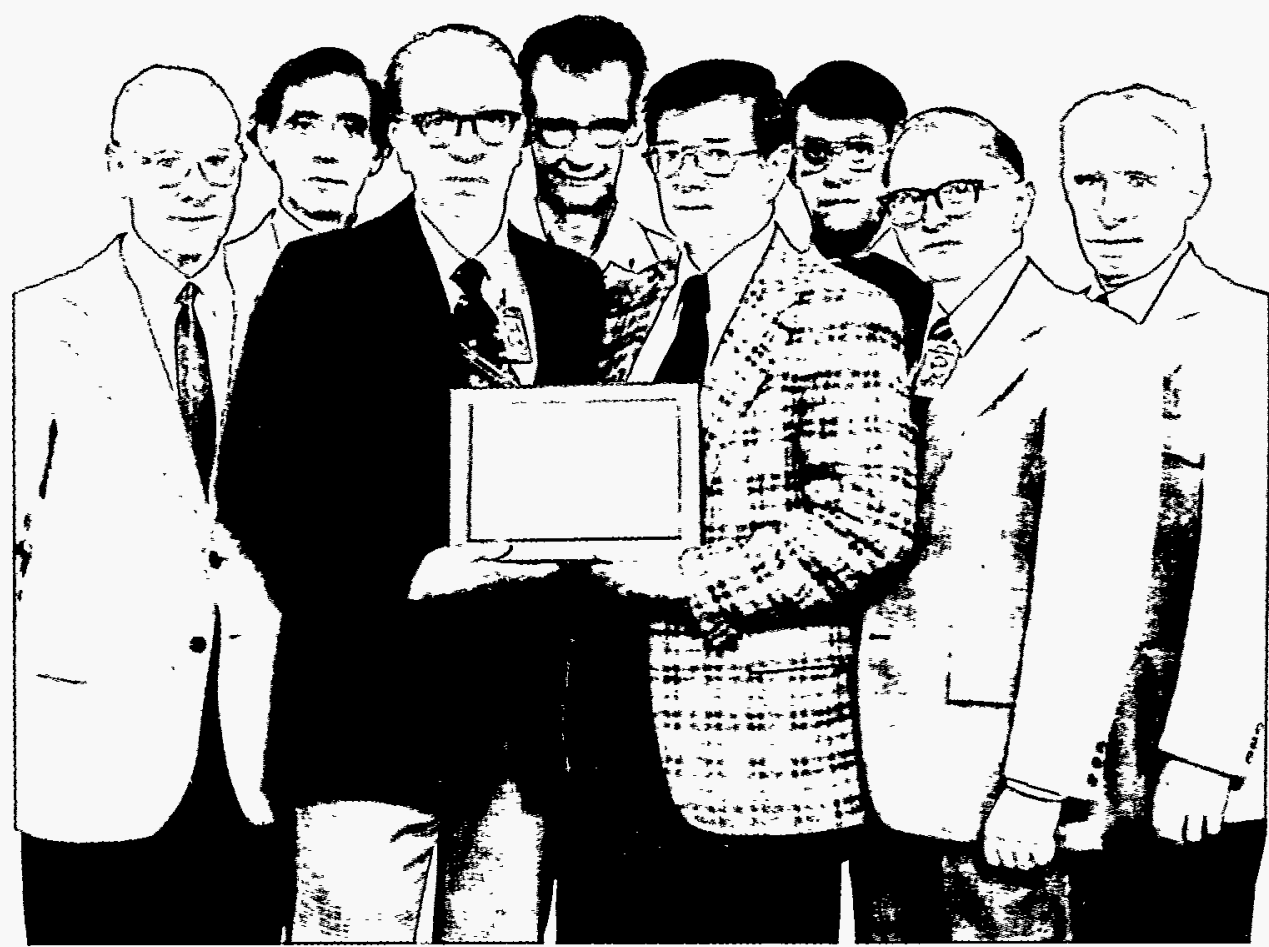

Fig. 4.3. The Chem Tech R\&D team with the 1980 Chemical Engineering Honor Award for developing a Solvent Extraction Process for Recovery of Uranium from Wet-Process Phosphoric Acid. Shown (left to right) are Charles Coleman, Iran Thomas, David Crouse, Bill Howerton, Fred Hurst, Bill Arnold, Charles Baes (Chemistry Division), and AI Ryon. 
Fig. 4.4. Fred Hurst (center) receiving the Chemical Engineering Honor Award for developing A Solvent Extraction Process for Recovery of Uranium from Wet-Process Phosphoric Acid from Calvin Cronan, Editor of Chemical Engineering (left) and Herman Postma, Director, Oak Ridge National Laboratory (right).
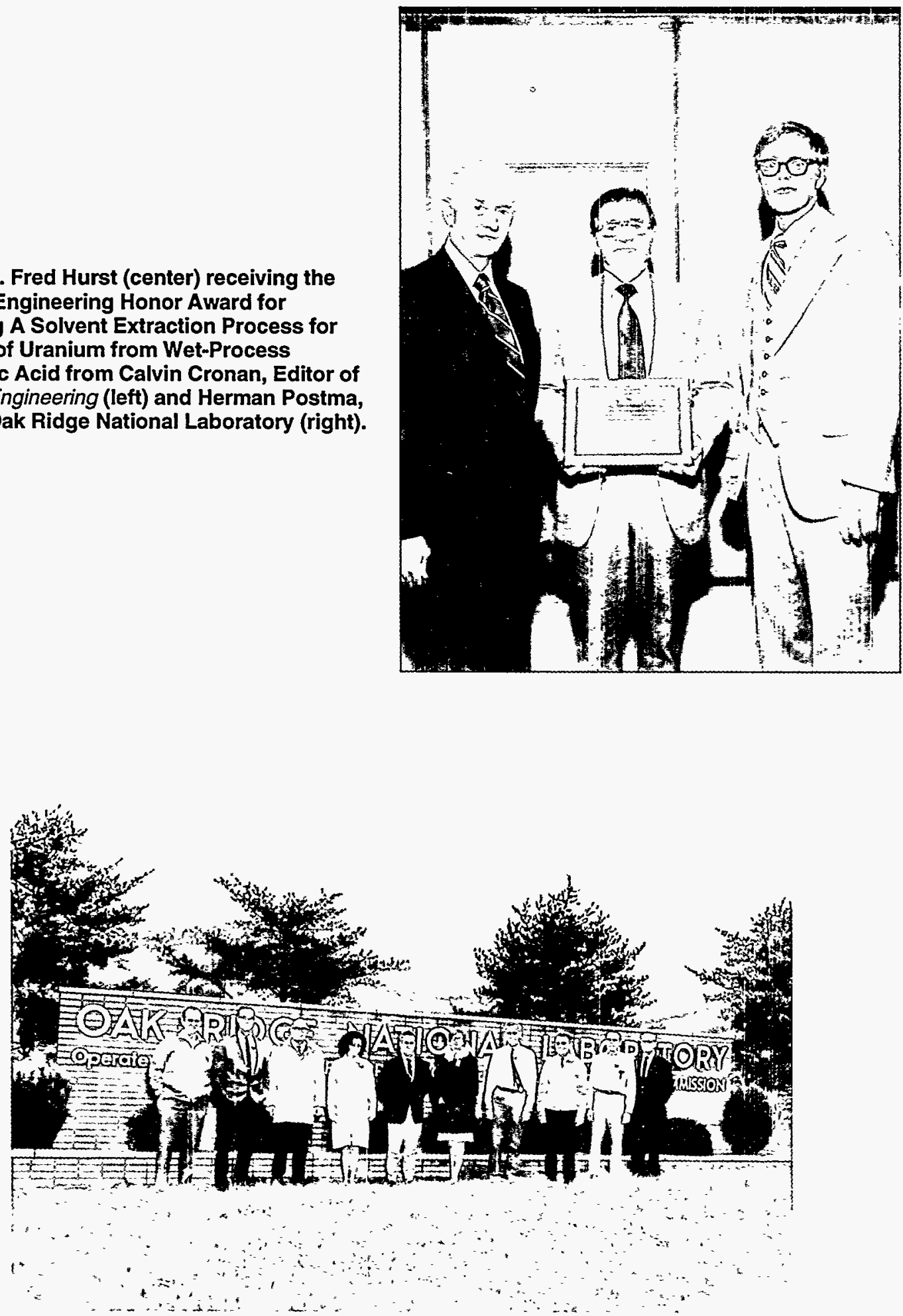

Fig. 4.5. An early 1970 s photograph of the Chemical Development Section A staff involved in fundamental studies on solvent extraction processes (left to right): P. B. Orr, Ray Wymer, Rex Leuze, Carolyn Gheen, John Fardy (guest scientist from the Australian Atomic Energy Commission), Bea Garber, Boyd Weaver, John Chilton, Richard Shoun, and Charles Coleman. 


\subsection{FUEL PROCESSING: THE SOL-GEL PROCESS, Walt Bond and Paul Haas}

\subsubsection{Early Sol-Gel R\&D}

In 1959, work was begun on a method for preparing dense fuel particles which came to be called the "sol-gel" process. The early effort was led by Don E. Ferguson (then Section Head, Chemical Development A), who was the first to recognize the advantage of sol-gel processes in regard to their adaptability to fully remote processing methods and to their potential in the manufacture of dense, homogeneous, high-strength ceramics. The initial work by Ferguson, Ken McCorkle, Chuck Schilling, O. C. Dean, and Todd Kleinsteuber quickly demonstrated the technical feasibility of the sol-gel approach to ceramics manufacture.

\subsubsection{Angular Sol-Gel Particles}

In the early 1960s, an engineering-scale demonstration project (called Kilorod) was carried out semiremotely in Bldg. 3019 in which 1000 Zircaloy-clad fuel rods were manufactured and tested. The angular fuel particles were vibratorily packed into the tibular cladding. This effort required a considerable team of chemists, chemical engineers, ceramicists, and technicians. At this point, Claude Haws, Bob Brooksbank, and Jim Snider joined the sol-gel team previously mentioned, along with John Sease and John Van Cleve from the Metals and Ceramics $(M \& C)$ Division.

This early work created considerable interest throughout the nuclear community, both nationally and internationally. The sol-gel process was revealed internationally at a conference in Rome, Italy, on June 13-15, 1961. The exhibit and the ORNL exhibit preparation team are shown in Fig. 4.6.

\subsubsection{Spherical Particles}

Concurrent with the angular particle development, Paul Haas, Todd Kleinstueber, and Sam Clinton demonstrated that spherical particles could be prepared by simply extracting water from aqueous sols of colloidal oxides. This was then followed (1962-1973) by the development of processes for preparing spherical particles of $\mathrm{ThO}_{2}$, $\mathrm{UO}_{2}, \mathrm{PuO}_{2}$, and their binary oxide combinations



Fig. 4.6. Sol-gel exhibit with ORNL research participants and exhibit preparation team. Front row (left to right): Chem Tech staff members O. C. Dean, Bob Brooksbank, Jim Snider, Paul Haas, and an unidentified engineer. Back row (left to right): Jim Bresee, Bill Groenier, Sam Clinton, Glenn Williams, unidentified engineer, Tom Gale, Pete Lotts, and an unidentified engineer. 
for high-temperature gas-cooled reactor fuels. It was also during this period that work was performed that showed that spherical, dense ceramic oxide powders could be made from nearly all elements that form highly insoluble oxides. This included the important industrial ceramic powders such as alumina, titania, and zirconia and also specialty oxides such as those of the rare earths, americium, and curium. During this period, Ray Wymer, Rex Leuze, Walt Bond, Jim Snider, Milt Lloyd, John McBride, Leon Morse, Al Ryon, Russ Baybarz, Dick Haire, Paul Haas, Fred Kitts, Karl Notz, Albert B. Meservey, Ray Buxton, and Sam Clinton were heavily involved. Examples of good-quality and poor-quality microspheres are shown in Fig. 4.7. Laboratory-scale equipment used for the resin loading process, an alternative microsphere-making process, is shown in Fig. 4.8.

\subsubsection{Fuel Particles for Light-Water and Breeder Reactors}

Work ceased on sol-gel processing in 1972 and was not resumed until 1977, when considerable

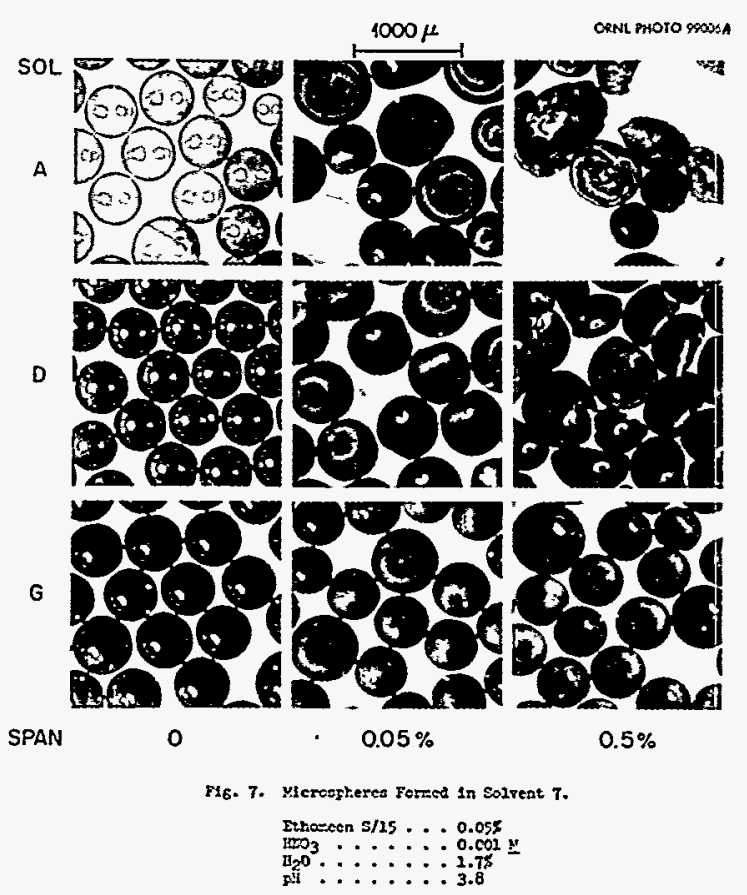

Fig. 4.7. Sol-gel microspheres. It took many tests (and failures) to determine the proper conditions to make good $\mathrm{UO}_{2}$ sol-gel microspheres. This is a very small sample of test specimens prepared by Karl Notz and Albert B. Meservey. interest arose in its potential for manufacturing spherical fuel particles for the Light-Water Reactor (LWR) and in the early 1980 s for oxide fuels for Advanced Breeder Reactors (ABR). Also, work was initiated during this period on the fixation of nuclear wastes, improving the properties and performance of ceramics in nonnuclear applications, and on improving gel properties for chromatographic separations. At the encouragement of the Exxon Company, improvements were made in the process flow sheets and equipment for LWR-grade $\mathrm{UO}_{2}$ and $\mathrm{ABR}$-grade $\mathrm{UO}_{2}-\mathrm{PuO}_{2}$ and subsequently demonstrated on the pilot plant scale $(1 \mathrm{~kg} / \mathrm{h})$ (Fig. 4.9). Incorporation of nuclear waste in zirconia-based ceramic was found feasible. Key Chem Tech players in these developments were Karl Notz, Roy Norman, Paul Haas, Milt Lloyd, Jack Collins, Vic Fowler, Sam Shell, Claude Haws, John Vavruska, Roger Spence, Al Ryon, Rex Leuze, Emory Collins, Sharon Robinson, Bruce Finney, Bill Arnold, Fletcher Daley, John Begovich, Dave Williams, and Walt Bond.

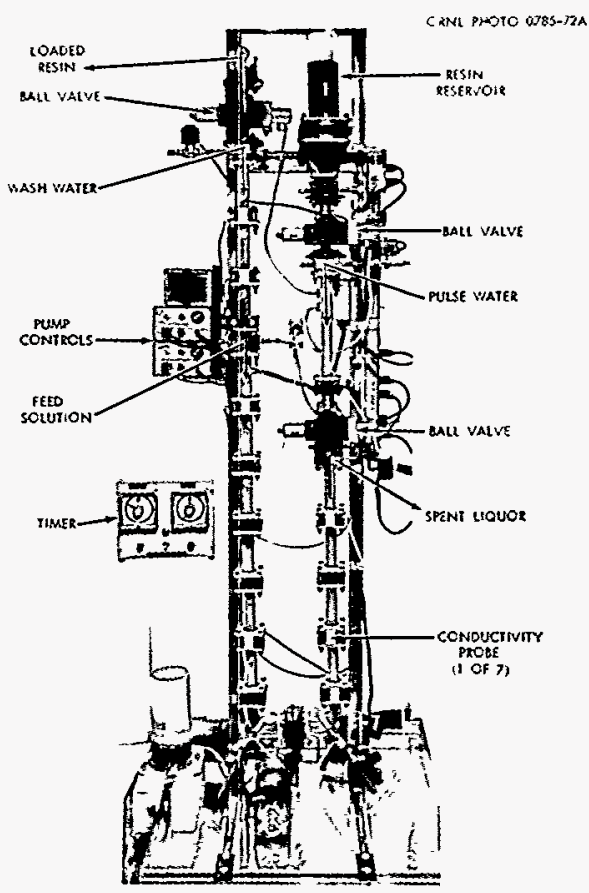

Fig. 4.8. Resin loading process. Another route developed for making $\mathrm{UO}_{2}$ microspheres is to first load uranium on spherical, weak-acid ion-exchange resin beads. This column, designed and operated by Karl Notz and Charles Greene, accomplishes the loading operation on a pulse-continuous basis. The concept is an adaptation of the Higgins column. 


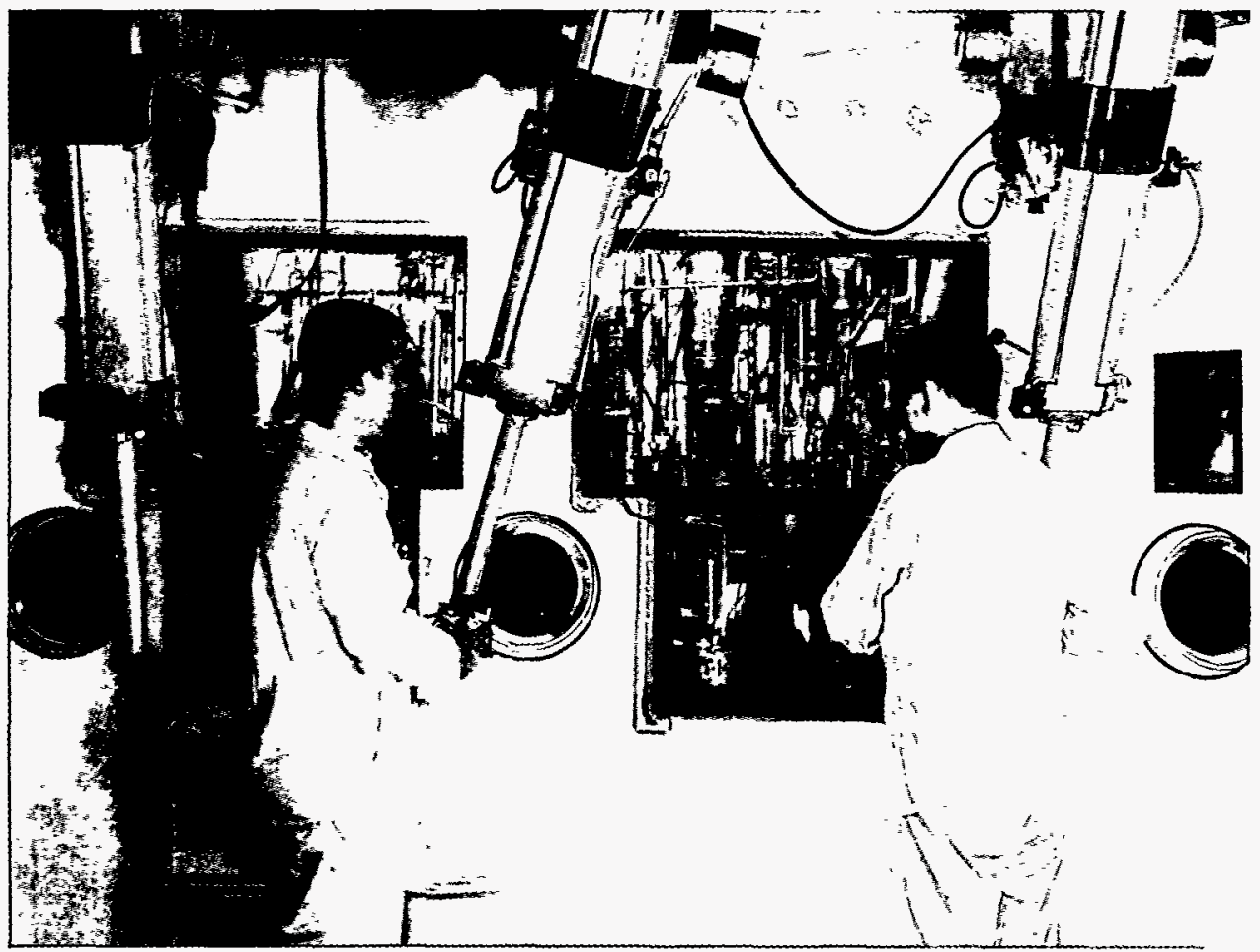

Fig. 4.9. The plutonium sol-gel pilot plant was located in a hot cell requiring that operations be conducted by glove or master-slave manipulators.

The following personnel from the ORNL Metals and Ceramics Division also made major contributions to this program: Ron Beatty, Ron Bradley, Jack Lackey, and Dave Stratton. Figure 4.10 shows Vic Fowler adjusting a prototype of the $1-\mathrm{kg} / \mathrm{h}$ sol-gel production unit.

\subsubsection{Sol-Gel-Derived Metal Oxides}

Sol-gel work on nuclear fuels and waste applications was ceased in 1985 . However, work is being continued to the present day on the applications of sol-gel processes to improve the properties of ceramic materials so that their range of applications may be extended. This work showed that tougher ceramics, better electrical surge arrestors, and superior performance can be attained in chromatographic separations using sol-gel-derived metal oxides. Major contributors to this work are Paul Haas, Jack Collins, Walt Bond, and George Davis.

\subsection{PLOWSHARE PROGRAM, Walt Bond and Bob Jolley}

In the mid-1950s, the AEC initiated studies on the peaceful applications of nuclear explosives, which came to be known as the Plowshare
Program. All types of applications were proposed for the explosives, ranging from using the blast effect to dig canals or crush mineral deposits for easy mining to utilizing the high neutron flux to produce valuable isotopes such as tritium and transuranic elements. The Chemical Technology Division became involved in the studies to develop flow sheets for the recovery of isotopes or metals from the crushed ore deposits. A necessary part of these studies was to obtain samples of the various underground nuclear detonation tests and determine the chemical species that resulted. This knowledge was then used to design chemical flow sheets. John Landry spearheaded the sampling program associated with the underground nuclear detonations. He designed the sampler system that was employed to obtain gas samples a few milliseconds after detonation and also the system for collecting solid debris. John was assisted by Baird Bottenfield in the early days of this work. Various people were involved in the determination of the "nuclear explosion chemistry" and chemical flow sheets for the recovery of isotopes or metals (such as copper) from ore bodies. Early on, the program focused on isotopes and Walt Bond, Walt Clark, Al Ryon, and Ray Wymer were involved. Floyd Culler maintained a keen personal interest in 


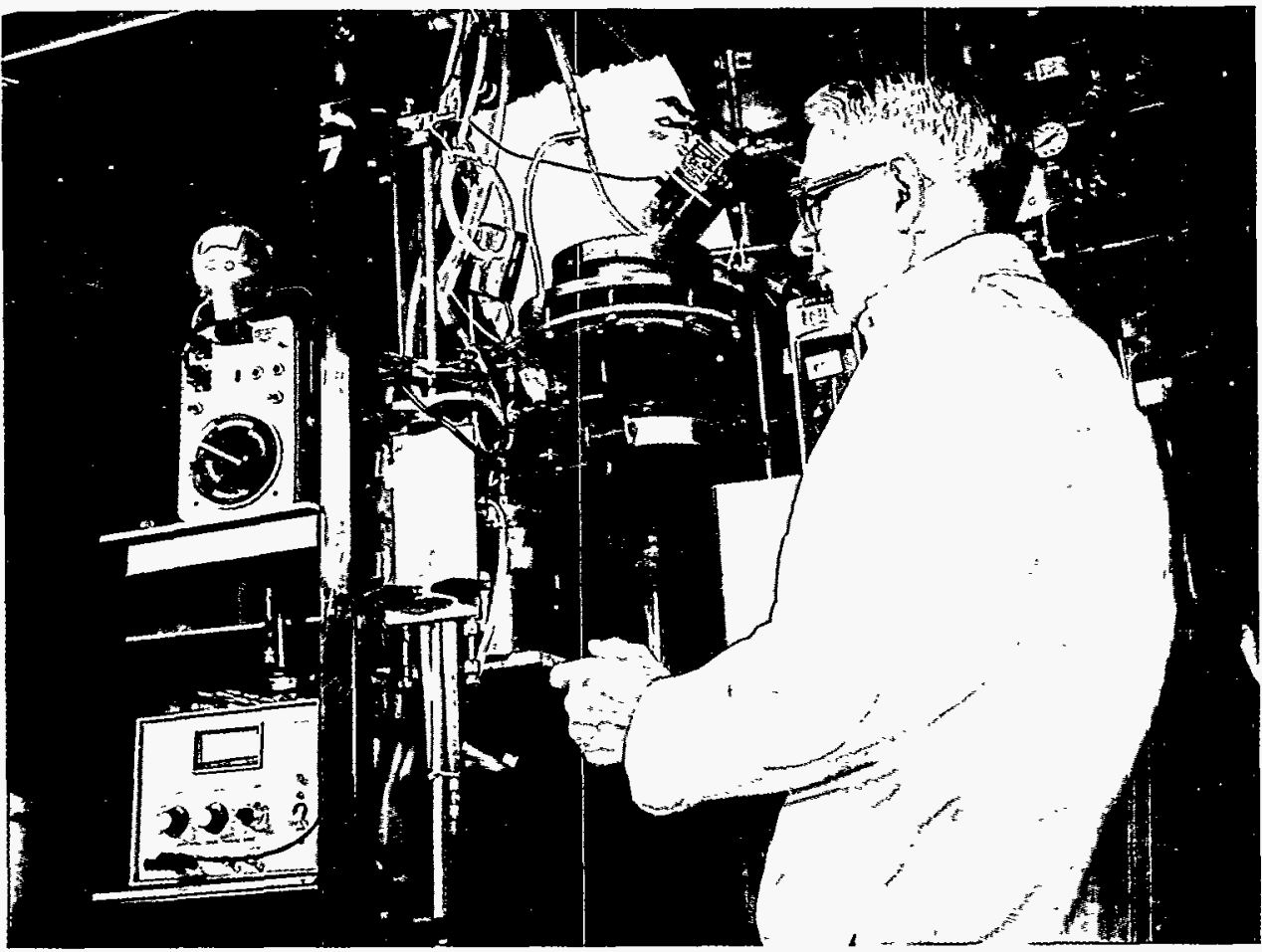

Fig. 4.10. Vic Fowler adjusts the prototype of the $1-\mathrm{kg} / \mathrm{h}$ production unit during preparation of $\mathrm{UO}_{3}$ sol-gel spheres.

the program because of (I believe) the challenging chemistry and formidable engineering problems it posed.

The person that I remember most on this program was John Landry. Figure 4.11 shows John Landry in conversation at an annual Chem Tech information meeting. John was not only ORNL's "ambassador" to the Plowshare Program, but also a character in his own right. John's mind is in the genius category, and he was interested in nearly everything going on in the universe and how it worked. This also explains how he sometimes got distracted from the main task at hand. Because of his nature to be distracted, John had a way of suddenly disappearing from the group he was traveling with. However, he always could find the group later (from a few minutes to a few hours). The following personal story illustrates the point.

John, Floyd, and I were attending a Plowshare meeting in San Francisco, and for dinner that evening, we decided to walk down to Fisherman's Wharf for seafood, along with some of the other attendees. Along the way we noticed John was missing (not unusual), so we just went on to the wharf and selected a restaurant. About 20 minutes later, John arrived at our table (we had not yet been served) and ordered his dinner. He then proceeded to describe in great detail how the drive systems for the famous San Francisco cable cars are housed, constructed, and operated. Unbeknown to us, John had noticed the cable house on our route and had talked a security guard into letting him in the cable house to see the chief engineer. The chief engineer gave him a technical tour of the cable house. John was also known for tuning up his motorcycle in his dormitory room in Oak Ridge at 1:00 a.m., which included timing by ear-I won't go into that!

Participation in the Plowshares Program ended in 1974 with experimental studies on tritium behavior during in situ recovery of oil shale and a paper describing studies of radionuclides (principally tritium as tritiated water) in copper recovery from copper ores fractured by explosives to facilitate in situ leaching. ${ }^{1}$ Examples of the breadth of the Chem Tech involvement in Plowshares follow.

\subsubsection{Tamalpais Experiment and Field Sampling Tests}

The Tamalpais underground nuclear experiment, Project Coach, Project Gnome, and CANE (for Chemical Application of Nuclear Explosives) were some of the Plowshare projects 


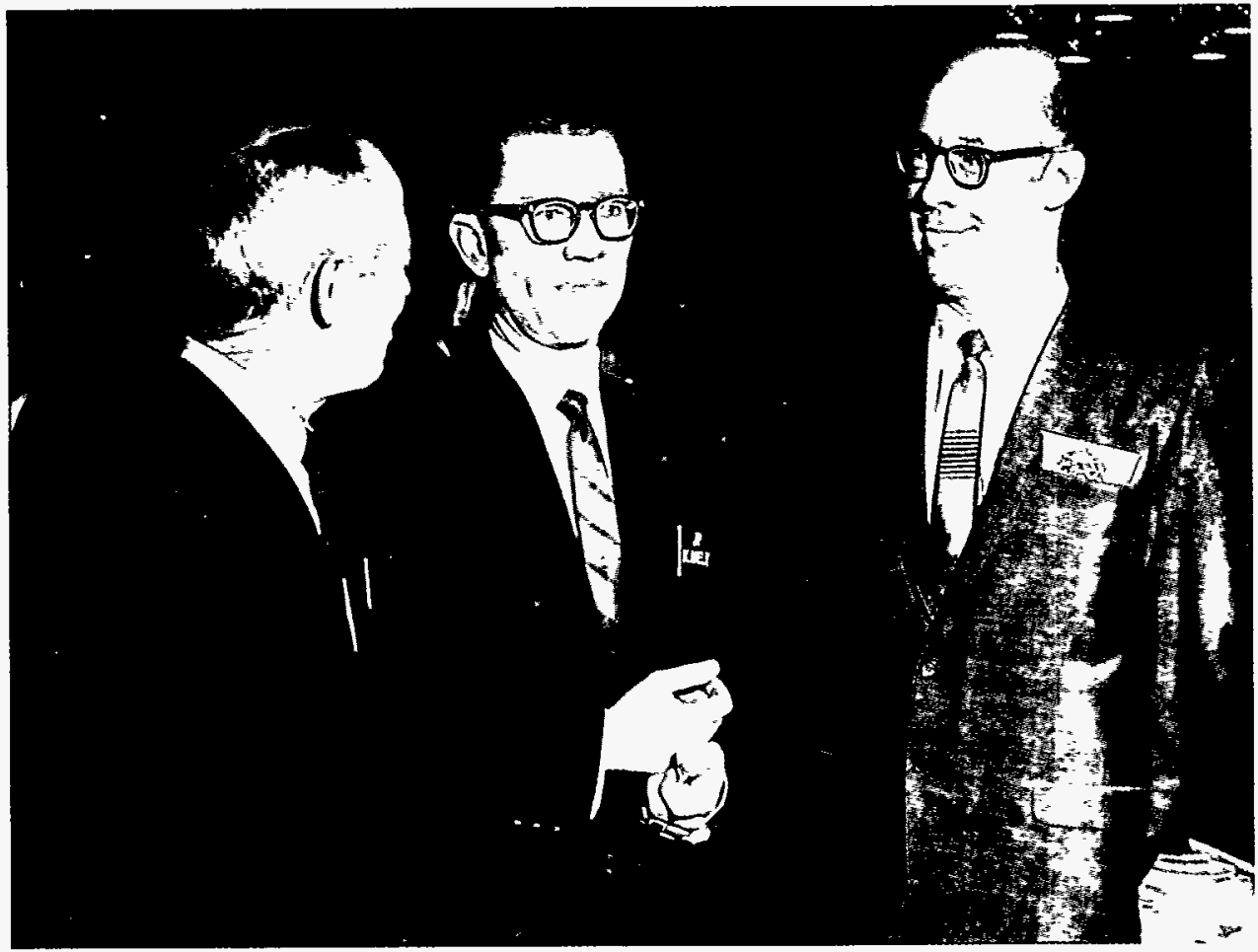

Fig. 4.11. John Landry (on right) in conversation with J. P. Blakely and another ORNL staff member at an annual Chem Tech information meeting.

for which Chem Tech staff provided technical support.

Perhaps one of the more interesting accounts of this technical support was supplied by Landry, who designed and helped install instrumentation and sampling devices for the Tamalpais project. The sampler after design was fabricated by ORNL and installed at the AEC Nevada Proving Ground. The sampling device incorporated explosion-operated valves and special features for fast removal of the samples (Figs. 4.12 and 4.13). The Tamalpais event of October 8, 1958, consisted of the explosion of an atomic device equivalent to 72 tons of TNT at a depth of $330 \mathrm{ft}$. The purpose was to investigate an isotope-producing nuclear explosion in a salt medium. Samples were to be drawn at time intervals of $0.01,0.11,1.1$, and $11 \mathrm{~s}$, and also cumulatively. Recovery of the samples and equipment was delayed for over two months. The explosive gas hazard prevented entry to the sampling room in the first two weeks following detonation. More importantly, the atomic bomb testing schedule had been accelerated to meet the October 31,1958 , ban on nuclear testing, and the effects of subsequent neighboring detonations caused additional delay. Landry stated that he "had hoped to be present for the recovery of the samples and inspection of the equipment but left the proving ground a few hours after seeing one of the succeeding events breach the mesa near the location of the sampling room."2 University of California Radiation Laboratory personnel recovered the samples in late December. A total of six large samples were collected. One of the 11-s sample vessels obtained no sample due to failure of the admission valve to fire. One 1.1-s sample was lost due to leakage during the 2-month recovery period. ${ }^{2}$

\subsubsection{Prompt Sampler Studies}

A hypervelocity jet sampler and a bubble-tapping sampler were conceptualized and tested by John Landry. The hypervelocity jet sampler was designed to recover specimens after they had been irradiated with neutrons about $1 \mathrm{~m}$ from an underground-exploded nuclear device. The sampler was designed to recover the irradiated specimen before it could be engulfed in the nuclear explosion and resulting debris. ${ }^{3}$ Copper and iron targets were jetted successfully ${ }^{4}$ and demonstrated that at least $50 \%$ of a target was formed into a jet in about $15 \mu \mathrm{s}$. The jet traveled at a velocity equal to, or faster than, the estimated velocity of a nuclear shock wave in rock. ${ }^{4}$ The non-nuclear jet tests 
ORNL-LR-DWG 46466

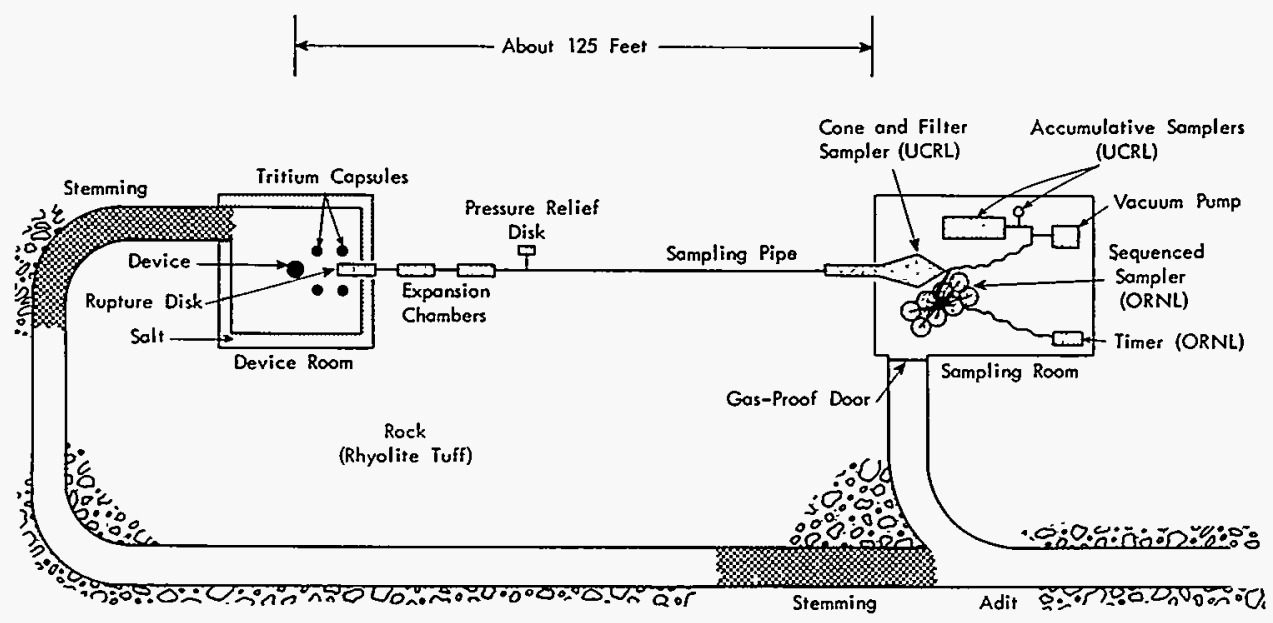

Fig. 4.12. Plan view of Tamalpais sampling arrangement. [Source: J. W. Landry, Oak Ridge National Laboratory Samples for the Tamalpais Underground Nuclear Detonation Experiment, ORNL-2881 (June 30, 1960)]

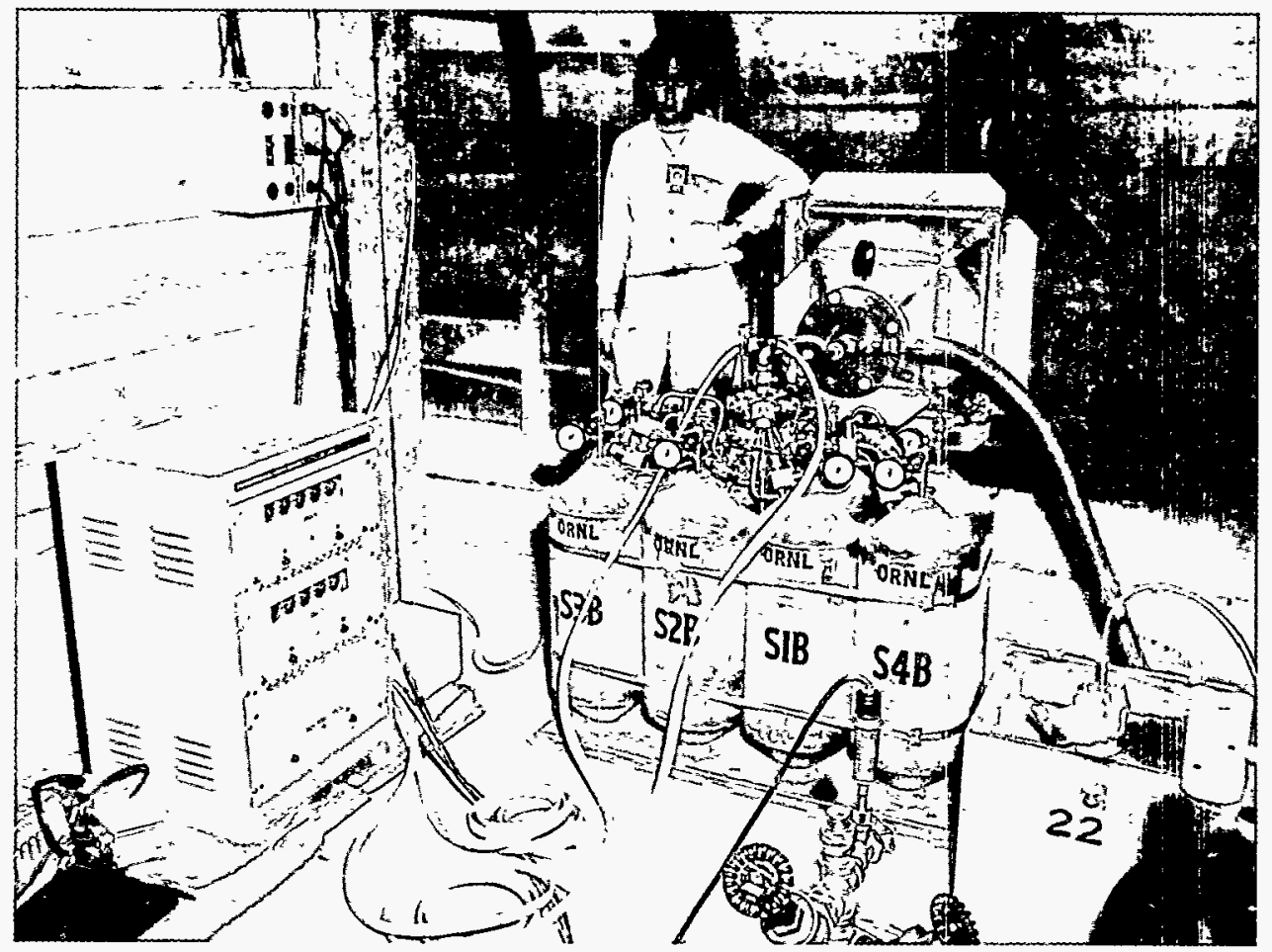

Fig. 4.13. Tamalpais sampling equipment. [Source: J. W. Landry, Oak Ridge National Laboratory Sampler for the Tamalpais Underground Nuclear Detonation Experiment, ORNL-2881 (June 30, 1960)]. 
were conducted at Frankford Arsenal, Vincentown, New Jersey, in an evacuated flight chamber $18 \mathrm{ft}$ in diameter by $55 \mathrm{ft}$ long. 5

Also, a bubble-tapping sampler was conceptualized, but not tested, to sample the gaseous and particulate explosion products from an underground nuclear explosion, providing useful knowledge about underground detonations. ${ }^{3}$

\subsubsection{Project Coach}

In Project Coach it was proposed that a 5- to 10-kiloton nuclear device designed for producing maximum nuclear fluxes be detonated underground in a bedded-salt formation near Carlsbad, New Mexico, for producing milligram or larger quantities of transcurium elements. The isotopes produced would have been dispersed in 10,000 to 35,000 tons of salt debris that would have been mined a year after detonation to allow time for fission product decay. A tentative process flow sheet was developed and tested on kilogram samples of the Project Gnome shot debris. This debris contained high concentrations of silicates and was similar in content to the debris expected from Project Coach. Flow sheet tests indicated expected transplutonium element recoveries of 80 to $95 \% .^{6}$

\subsubsection{Project Gasbuggy}

Stimulation of gas production from wells by nuclear devices was thought to be one peaceful use of nuclear explosives. ${ }^{6}$ It was proposed that Project Gasbuggy use a 10-kiloton fission device with a 10,000-Ci tritium spike to study gas stimulation and tritium-hydrogen exchange in the water and gas, as well as possible tritium contamination of the methane product. ${ }^{4}$

\subsubsection{Production of Oil from Shale}

The use of a nuclear device to crush Green River oil shale in place was proposed under the Plowshare Program. The recovery of oil from the crushed shale would involve in situ retorting. Chem Tech staff conducted bench-scale studies on radionuclide-spiked crushed shale samples. ${ }^{4}$ It was determined that tritium was the major potential contaminant of the recovered oil. Contamination was determined to be more rapid when the shale was exposed to tritiated water or tritiated hydrogen than when exposed to tritiated hydrocarbons. ${ }^{5}$

\subsubsection{Copper Ores}

The Division of Peaceful Nuclear Explosives of the AEC proposed the crushing of copper ores as a possible peaceful use of nuclear devices. The controlled explosion would be followed by in situ leaching of the shot debris to recover the product. The process flow sheet proposed by Chem Tech staff members included percolating dilute sulfuric acid down through the nuclear-broken ore to dissolve the copper, collecting the leach liquor at the bottom of the ore body and pumping it to the surface, recovering the copper concentrate from the solution by cementation on iron, and recycling the barren solution (after adding more acid) for use in the leaching step. Radiotracer studies with ${ }^{106} \mathrm{Ru}$ were conducted to determine possible ruthenium contamination of the copper product. ${ }^{7}$

\subsubsection{Magnesium Ores}

Based on discussions with the Tennessee Valley Authority and the U.S. Geological Survey, it was concluded that recovery of magnesium, and possibly nickel and chromium, from olivine deposits might be possible. The large olivine deposits contained hundreds of millions of tons of olivine $(48 \% \mathrm{MgO}){ }^{6}$

\subsection{NUCLEAR REGULATORY ASSISTANCE PROGRAMS, Ray Blanco}

In 1971, the Nuclear Regulatory Commission (NRC) requested assistance from ORNL in reviewing and supplementary construction and operating license applications for commercial nuclear power plants. This was a new field of work for Chem Tech and other personnel at ORNL. By 1972 this grew into a larger program for all nuclear installations, and I moved from Section Chief for Chemical Development to Director of NRC programs in Chem Tech.

A series of cost-benefit chemical engineering surveys were prepared to assist the NRC in defining the phrase "as low as reasonably achievable" (ALARA). This philosophic approach was of prime importance to the NRC in developing more stringent release limits for nuclear power and processing plants. The surveys determined the cost, in dollars, to reduce the amounts of radioactive materials released to the environment by adding successive treatment steps to the waste streams released to the environment. An evaluation of the 
decrease in radiation dose to the population surrounding the plants for each increment of treatment was also prepared. Graphs of the effect of added waste treatment steps on total body and thyroid dose versus annual treatment cost were developed. The abscissa of the graphs showed the dose and the ordinate the annual cost in dollars. ALARA was judged to be the area where increasing waste treatment steps and cost produced little decrease in dose. 8

The first survey served as a part of the technical basis for the environmental statement for the guidelines for limiting the releases from LWR. ${ }^{8}$ This, in turn, was the basis for the NRC to issue a revised Code of Federal Regulations, Title 10, Part 50, Appendix. This became the rule for licensing all nuclear power stations.

During the period 1972-78, similar surveys were issued on (1) reprocessing irradiated LWR fuel, (2) reprocessing irradiated HTGR fuel, (3) fabrication of LWR fuel containing uranium, (4) fabrication of LWR fuel containing plutonium, (5) milling of uranium ore, (6) fabrication of HTGR fuel, (7) conversion of yellow cake to $\mathrm{UF}_{6}$, and (8) conversion of uranium to $\mathrm{UF}_{6} \cdot 8,9$

A final paper in this series was published in Science entitled "Radiologic Impact of Airborne Effluents of Coal and Nuclear Plants."10 Coal contains up to about $43 \mathrm{ppm}$ of uranium and $48 \mathrm{ppm}$ of thorium in equilibrium with radium and other decay products. The summary from the paper states "Radiation doses from airborne effluents of model coal-fired and nuclear power plants (1000 megawatts electric) are compared. Assuming a 1 percent ash release to the atmosphere (Environmental Protection Agency regulation) and 1 part per million of uranium and 2 parts per million of thorium in the coal (approximately the U.S. average), population doses from the coal plant are typically higher than those from pressurized-water or boiling-water reactors that meet government regulations. Higher radionuclide content and ash releases are common and would result in increased doses from the coal plant." The study does not assess the impact of nonradiological pollutants or the total radiological impacts of a coal versus a nuclear economy. Of course, any ash not released in the fly ash is present in the bottom and precipitation ash and, in general, is released to holding ponds. The mere fact that coal-fired power plants release radioactive materials to the environment in the fly and bottom ash (radium is the principal contributor of dose to the surrounding population) and that coal-fired plants typically release more radioactive materials in airborne effluents than LWR power plants which meet government regulations (10 CFR Pt. 50 Appendix 1) caused considerable comment in the nuclear and coal industry and prompted a call from the EPA. However, the issue was soon forgotten. The paper received an Award of Merit from the Society for Technical Communication through the assistance of Cathy Shappert, our technical editor.

Chemical Technology collaborators for these surveys were B. C. Finney, E. J. Frederick, A. H. Kibbey, H. W. Godbee, F. G. Kitts, W. Davis, Jr., R. B. Lindauer, G. S. Ryon, J. W. Roddy, J. P. McBride, and R. E. Blanco. Environmental Sciences, Health Physics, and Metals and Ceramics Divisions províded co-authors.

\subsection{NUCLEAR ANALYSES: THE HISTORY OF THE ORIGEN COMPUTER CODE, Scott B. Ludwig}

The ORIGEN computer code, used throughout the world as the starting point for a wide variety of nuclear analyses, was created by the Engineering Coordination and Analysis Section (EC\&A) (formerly Process Design) of the Chemical Technology Division at Oak Ridge National Laboratory. ORIGEN is an acronym for "Oak Ridge Isotope GENeration." ORIGEN and ORIGEN2 have been made available to users worldwide through the Radiation Shielding Information Center (RSIC), and since the initial release of ORIGEN in 1973, about 1000 users have acquired either ORIGEN, ORIGEN2, or ORIGEN2-PC. In addition to ORIGEN and ORIGEN2, others have created their own versions of ORIGEN, including KORIGEN (Karlsruhe, Germany's version), ORIGEN-JR (Japan Research), SANDOR (Sandia Labs), and ORIGEN-S (part of SCALE package developed by ORNL's Computing and Telecommunications Division). When one mentions the name ORIGEN, Chem Tech staff may remember the original ORIGEN code created by Mike Bell in the early 1970s or may think of Allen Croff's ORIGEN2 code created in the late 1970s. Whichever version comes to mind, the creation of ORIGEN actually occurred in the 1960 s, and many staff within Chem 
Tech played an important role in the development of what is commonly called ORIGEN.

Of the thousands of computer codes created by the scientific community each year, only a few are so blessed as to take on a life of their own, to grow and mature over the years, and to endure the test of time. ORIGEN is one such code and is one of the more famous codes used in the nuclear industry, both in the United States and worldwide.

\subsubsection{Beginnings}

ORIGEN was created to predict the concentrations and radiological characteristics of individual isotopes in nuclear reactor fuel and the products (including wastes) of processing spent fuel when their initial compositions and the burnup characteristics of the reactor are known. ORIGEN requires as input a library of nuclear data containing half-lives, decay schemes, cross sections, fission yields, and disintegration energies. The ORIGEN code was first mentioned in the Chem Tech annual progress report for 1969. ${ }^{11}$ ORIGEN was the first code to deal with a large matrix $(10,000$ by 10,000$)$ encompassing over 1000 nuclides undergoing simultaneous transmutation, decay, and flow in ten separate compartments. Most neutronic codes only dealt with a handful of the most important radionuclides in a single compartment. The calculation of such a large transition matrix allowed ORIGEN to determine the concentration of actinides, fission products, and light elements within the Molten Salt Reactor Experiment (MSRE), since the concentration also determined the radioactivity and thermal power from the decay of the radioactive species. The decay heat was a controlling parameter for the design of the reactor. From this start, the ORIGEN code became an important tool in the design and analysis of reactors, reprocessing plants, shipping casks, and waste disposal facilities.

\subsubsection{The Players}

ORIGEN first came into existence in Chem Tech in the mid-1960s. Jere Nichols initiated the development of ORIGEN and was responsible for the development of the recursion technique for solution of the sparse matrix (matrix exponential method) used in ORIGEN to solve the set of first-order linear differential equations that describe the transient concentrations of radionuclides within the reactor. Jere Nichols also created the now famous ORIGEN flux parameters THERM, RES, and FAST and derived (by hand) the cross sections for the first 1000 nuclides using existing compilations of integral cross section and flux spectra and the Westcott method. The initial reactor models in ORIGEN (LWR, HTGR, LMFBR, and MSBR) were all developed (by hand) from estimates of the values of THERM, RES, and FAST and analytical solutions of the reactor physics of each type of reactor based on the assumption that the neutron flux distribution is represented by a combination of a Maxwellian, a $1 / v$, and a fission spectrum. Bill Nestor created the indexing technique used in ORIGEN to identify the non-zero terms in the matrix. Much of the decay data, cross sections, and photon yield data were developed by E. D. Arnold and Frank Soard. Mike Bell's first assignment in Chem Tech (under Jere Nichols) was ORIGEN. Mike was responsible for turning ORIGEN from an "in-house" code into the version known around the world. Mike developed the initial ORIGEN documentation and implemented the Bateman equations used for some forms of radioactive decay. Soon after ORIGEN was first released through the Radiation Shielding Information Center (RSIC), Mike Bell left ORNL for a position at the NRC. Charles W. Kee assumed the role of ORIGEN custodian. In the first in a series of "ORIGEN Newsletters" dated June 1977, Kee describes the version numbering of ORIGEN, with version 1.0 being the original Mike Bell version and 1.1 representing the version being distributed by RSIC at that time. Another version, numbered 2.0, was in use within Chem Tech's EC\&A Section and included features dealing with the chemical reprocessing of nuclear waste. Kee also mentions the existence of two other versions - one by Bill Hermann of C\&TD that employs the FIDO input method and uses a coupling code to access AMPX multigroup cross sections (precursor to ORIGEN-S) and another developed by Allen Croff of Chem Tech that uses a much more flexible problem description which allows recycling calculations and more flexibility concerning reprocessing. At this point, further development of ORIGEN appears to have ceased in favor of the Bill Hermann and Allen Croff versions, namely, ORIGEN-S and ORIGEN2. Kee was also responsible for extensive revisions to the cross-section data for light elements.

ORIGEN-S became an integral part of the SCALE system. ORIGEN2 developed a series of reactor models using more detailed reactor physics calculations. Under Allen Croff from the 
mid-1970s through the early 1980s, ORIGEN2 models for PWRs and boiling-water reactors (BWRs), CANDUs, and LMFBRs [including the Clinch River Breeder Reactor (CRBR) and the Fast Flux Test Facility (FFTF)] were developed. Croff also did extensive work updating the decay and photon libraries and determined the compositions of the fuel and structural components in the reactor, including the distribution of various impurities in each material. In this work, Croff was assisted by Mike Bjerke, Chuck Weisbin, Lester M. Petrie, and Wayne Morrison. In addition to all the work on data libraries for ORIGEN2, Croff created ORIGEN2's unique "command oriented" input structure. Using a few simple commands, the user can specify complex flow sheets undergoing a series of irradiation, decay, and reprocessing steps. Croff passed the role of ORIGEN2 "guru" to Chuck Alexander, then to Ron Ashline, and most recently to Scott Ludwig. ORIGEN2 was adapted to the IBM PC in 1986 by the late Jim Marable. In the late 1980s, ORIGEN2 code revisions and additional reactor models for LWRs were developed by John-Paul Renier and Scott Ludwig. Most recently, an ORIGEN2 version capable of working on 80386 and 80486 PCs was developed.

\subsubsection{ORIGEN-Supporting the Development of Nuclear Energy in the United States}

ORIGEN and ORIGEN2 have been used extensively to support the development of nuclear energy concepts within the United States. ORIGEN was first used to support the siting report for fuel reprocessing in 1968. ${ }^{12}$ During the 1970s and 1980s, ORIGEN or ORIGEN2 results have found their way into many major documents for DOE. ORIGEN/ORIGEN2 have also been routinely used by both license applicants and regulatory authorities to determine radiological properties. Fuel cycle areas included are reactors, spent fuel storage, transportation casks, reprocessing, fuel fabrication, and waste treatment/disposal.

\subsubsection{Bibliography}

A brief topical listing of documents that include ORIGEN/ORIGEN2 results is given below.

\section{Reactor Safety}

- "Reactor Safety Study-An Assessment of Accident Risks to U.S. Commercial Nuclear
Power Plants," Appendix VI, WASH-1900

(NUREG 75/014).

Inventory Projections

- J. O. Blomeke, C. W. Kee, and J. P. Nichols, Projections of Radioactive Wastes to Be Generated by the U.S. Nuclear Power Industry, ORNL/TM-3965 (1974).

- C. W. Alexander, C. W. Kee, A. G. Croff, and J. O. Blomeke, Projections of Spent Fuel to Be Discharged by the U.S. Nuclear Power Industry, ORNL/TM-6008 (1977).

- J. A. Klein et al., Spent Fuel and Radioactive Waste Inventories and Projections as of December 31, 1980, DOE/NE-0017 (1981) and subsequent annual updates numbered DOE/RW-0006 prepared by the ORNL Integrated Data Base Program.

- C. W. Forsberg, C. W. Alexander, and G. W. Morrison, "Integrated Data Base Projections," Trans. Am. Nucl. Soc. 41, 83 (1982).

- Characteristics of Spent Fuel, High-Level Waste, and Other Radioactive Wastes Which May Require Long-Term Isolation, DOE/RW-0184, vols. 1-6 (December 1987) and vols. 7-8 (June 1988).

Reprocessing

- Correlation of Radioactive Waste Treatment Costs and the Environmental Impact of Waste Effluents in the Nuclear Fuel CycleReprocessing Light-Water Reactor Fuel, ORNL/NUREG/TM-6 (1977).

Environmental Impacts

- Final Generic Environmental Statement on the Use of Recycle Plutonium in Mixed Oxide Fuel in Light-Water Cooled Reactors, NUREG-0002 (1976).

- Statement of Position of the United States Department of Energy in the Matter of Proposed Rulemaking on the Storage and Disposal of Nuclear Waste (Waste Confidence Rulemaking), DOE/NE-0007 (1980).

- Final Environmental Impact Statement Management of Commercially-Generated Radioactive Waste, DOE/EIS-0046F (1980).

- Technical Support of Standards for High-Level Radioactive Waste Management, Volume A-Source Term Characterization, EPA 520/4-79-007A (1977). 


\subsection{SPENT FUEL AND RADWASTE DATA BASES, Karl Notz}

Projections of future quantities of spent nuclear fuel and other radioactive wastes, along with their radiological properties, are the basis for planning future requirements regarding the handling and eventual disposal of these materials. This future planning includes systems alternatives such as spent fuel reprocessing, by-product recovery, assembly consolidation, various immobilization technologies, and also transportation and temporary storage as well as final disposal. One of the earliest applications of the ORIGEN and ORIGEN2 codes (see Sect. 4.5) was to calculate the radiological properties of spent fuels and high-level waste from commercial reprocessing. Three major reports by "Tex" Blomeke and Jere Nichols in 1973; Charlie Kee and Nichols in 1974; and Chuck Alexander, Kee, Allen Croff, and Blomeke in 1977 were milestone works in this regard. Since that time, many changes have occurred in national policy that drastically affected technological implementation, including, for example, the following:

- Commercial reprocessing has been halted in this country.

- The preferred repository geology has been changed from bedded salt to volcanic tuff (the Yucca Mountain site in Nevada, still under extreme contention).

- DOE has created a geologic disposal site for defense TRU waste [the Waste Isolation Pilot Plant (WIPP) facility near Carlsbad, New Mexico, still waiting for judicial approval to open on a test-only basis].

- Those sites currently still being used for shallow-land burial of low-level waste are in the process of being phased out (to be replaced by new sites to be developed by "compacts" of states).

- Commercial spent fuel is now being stored on-site by each utility in ever-increasing quantities.

- DOE is trying to locate a site for a centralized away-from-reactor storage site for LWR spent fuel (a Monitored Retrievable Storage facility (MRS)).

- An earlier proposal for large-scale consolidation of LWR fuel assemblies is being re-evaluated.
- Defense production reactors and defense reprocessing have been shut down.

- Start-up of the first two vitrification plants (one each for commercial and defense high-level waste) continues to be delayed.

- P/T (Partitioning/Transmutation) is, once again, under serious consideration.

One thing has remained constant, however, and that is the need to know the fundamental properties of the starting materials. DOE will eventually be directly responsible for all of the nation's spent nuclear fuel and already has jurisdiction over high-level waste, TRU waste, remedial action waste, and much of the low-level waste. The ready availability of comprehensive and self-consistent data on inventories, projections, and characteristics of these materials is clearly an essential component of all aspects of dealing with these materials. Toward this objective, the DOE has funded the creation of two major data bases, the so-called Integrated Data Base and the Characteristics Data Base. Both were conceived within the Chemical Technology Division and implemented by Chem Tech staff. Both draw extensively on data sources external to ORNL and depend strongly on cooperative interaction with other national laboratories and other DOE organizations. Both have acquired a well-deserved reputation for thoroughness and integrity of technical data. Both are highly regarded by their many users. Each is described briefly in the following paragraphs.

\subsubsection{Integraied Dała Base}

The Integrated Data Base, referred to as the IDB, provides domestic spent fuel and radioactive waste inventories, projections, and characteristics of spent fuel, high-level waste, TRU waste, low-level waste, remedial action waste, mill tailings, and mixed waste. Thus, the IDB covers all radioactive materials, which necessarily limits the level of detail. These data are assembled in a one-volume report. It was first published in its present form in 1981 and is updated annually. The latest (1991) edition is report number DOE/RW-0006, Revision 7. Along the way, a PC data base of summary data was added using a menu-driven format written in dBASE. This was one of the first significant applications of PC technology and matching data base management software within DOE. Among its many users, the IDB report is often referred-to as "the blue book" 
because of its blue cover. Development of the IDB was led by Karl Notz and Blomeke. The original IDB staff included Herschel Godbee, Lloyd Carter, Arlene Kibbey, Alexander, Bruce Finney, Charles Forsberg, and Wayne Morrison. The IDB is now under the guidance of Jerry Klein and Steve Storch.

\subsubsection{Characteristics Data Base}

The Characteristics Data Base, or CDB, covers only those materials that will, or may, be eventually disposed of in a geologic repository (such as Yucca Mountain). This includes LWR spent fuel, immobilized high-level waste, non-LWR spent fuel, and miscellaneous wastes (which are largely sealed isotope capsules and greater-than-Class-C low-level waste). These materials are characterized in extensive detail, including physical, chemical, radiological, and thermal properties, as well as inventories and projections. The CDB was first issued in 1987 and 1988 as eight volumes plus five $\mathrm{PC}$ menu-driven data bases covering LWR quantities, assemblies, hardware, and radiological properties and high-level waste. The first revision will be released in 1992 as report number DOE/RW-0184, Revision 1 , and has an additional PC data base on LWR assembly serial numbers. The $\mathrm{CDB}$ was originated under Karl Notz, and the CDB staff included Royes Salmon, Al Irvine, Tim Welch, Bill Reich, and Scott Moore (a local consultant from Automated Sciences Group) plus some dBASE programmers. A forerunner to the $\mathrm{CDB}$ was a 1985 report and a PC data base by Bill Roddy et al. on the physical and decay characteristics of LWR spent fuel.

\subsection{TRANSPORTATION STUDIES, Larry B. Shappert}

The Transportation Group in the Chemical Technology Division got its beginning in the early 1960s. At that time, drop and puncture testing had been carried out at ORNL primarily in support of $\mathrm{AEC}$ (and now $\mathrm{DOE}$ ) packaging programs. The work was initiated in 1960 by Larry Shappert to investigate the damage that would be accrued by a package if it were subject to the test requirements of the federal regulations. At that time, there was very little experimental evidence as to how packages designed to ship radioactive material would behave under the stringent regulatory requirements. Many of these activities were originally documented in different volumes of a master report, number ORNL/TM-1312. This series continued through Volume 19, which was published in 1977.

In order to carry out the drop testing of packages, a small impact pad was constructed in an area close to the X-10 steam plant in the early 1960s. Above the impact pad, a 40-ft-tall tower structure was built for use by experimenters to raise small packages to an elevation of $30 \mathrm{ft}$ above the impact pad and drop them. Testing of packages has continued and has supported the preparation of many Safety Analysis Reports on Packagings (SARPs). The SARPs were prepared by Shappert, Bart Klima, Don Box, and others, depending upon the package and its use. These and related activities ultimately led to the development of the Cask Designers Guide (ORNL-NSIC-68) in 1970 by ORNL staff and other experts in the field of packaging design.

In subsequent years, the facilities, equipment, experience base, and scoped activities have continued to expand. As packagings have gotten larger and heavier, the ORNL staff, including Box and R. D. Seagren, surveyed various locations at $\mathrm{X}-10$ with an eye to increasing the lifting capability at a fixed facility, rather than rely on dropping test pieces from a mobile crane. The Tower Shielding Facility (TSF) was found to be such a place; the towers can lift weights in excess of 25 tons and, with some modifications to the lifting system, may be increased up to 100 tons (Fig. 4.14). As a result, a large impact pad was installed at the TSF in the mid-1970s and a number of packages, some weighing up to 25 tons, were drop tested (Fig. 4.15).

In the late 1970s the Transportation Group moved into Bldg. 3019. Dave Joy and John Marshall, of Chem Tech, and Paul Johnson, of the Computing and Telecommunications Division (C\&TD), initiated work on a truck routing model and then expanded the effort to include a rail/barge routing model. These activities included the development of mapping capabilities which could be meshed with transportation routes generated by a computer and, ultimately, population density information within the continental United States (Fig. 4.16). Joy and B. Hudson developed a stochastic model of a cask- receiving facility using the GPSS code and a spent fuel logistics model that simulated the flow of waste material through DOE facilities. At about the same time, the Transportation Group became involved with Sandia National Laboratories in the design of a 


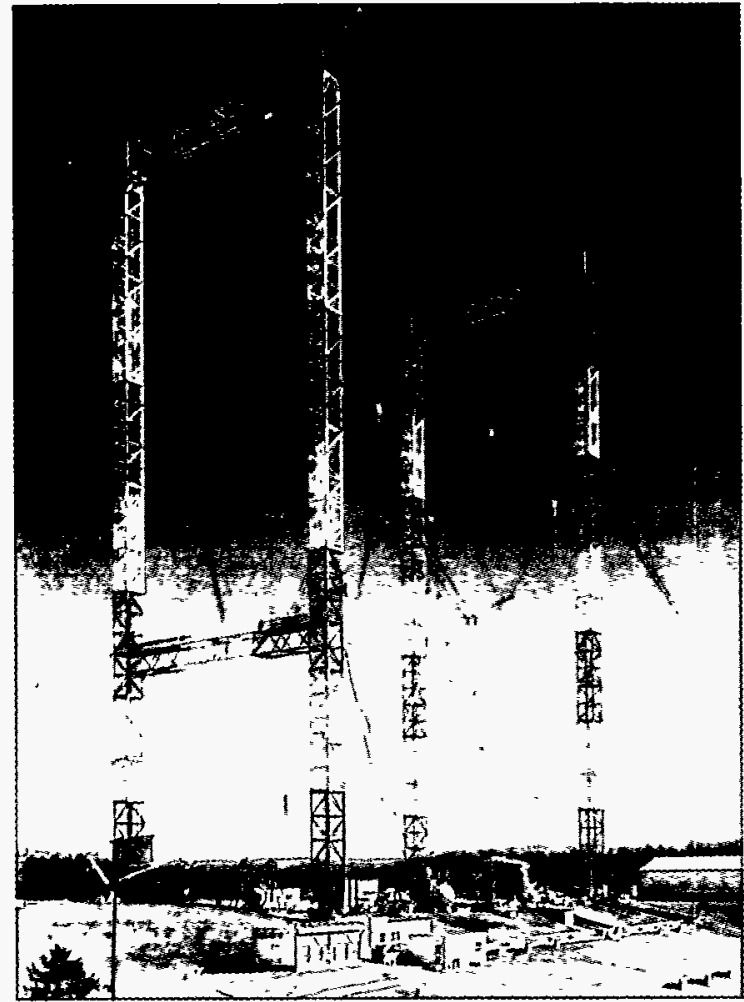

Fig. 4.14. The towers of the Tower Shielding Facility have been fitted with cables and special instrumentation for drop-testing of waste transportation casks. To facilitate testing, the concrete pad on which the casks are dropped was heavily reinforced with steel bars.

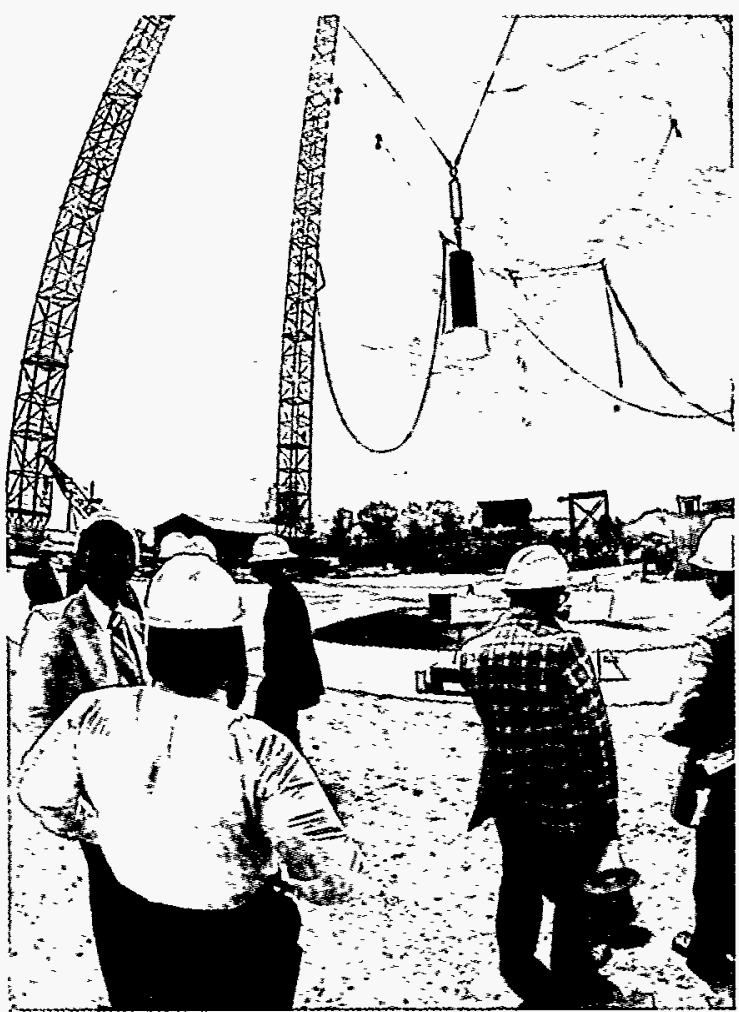

Fig. 4.15. The first in a series of drop tests conducted on a 22-ton spent-fuel shipping cask at ORNL's Tower Shielding Facility, which was normally used to suspend the Tower Shielding Reactor II. The photo was taken using a wide-angle (fish-eye) lens, which creates a distorted image of the steel towers.

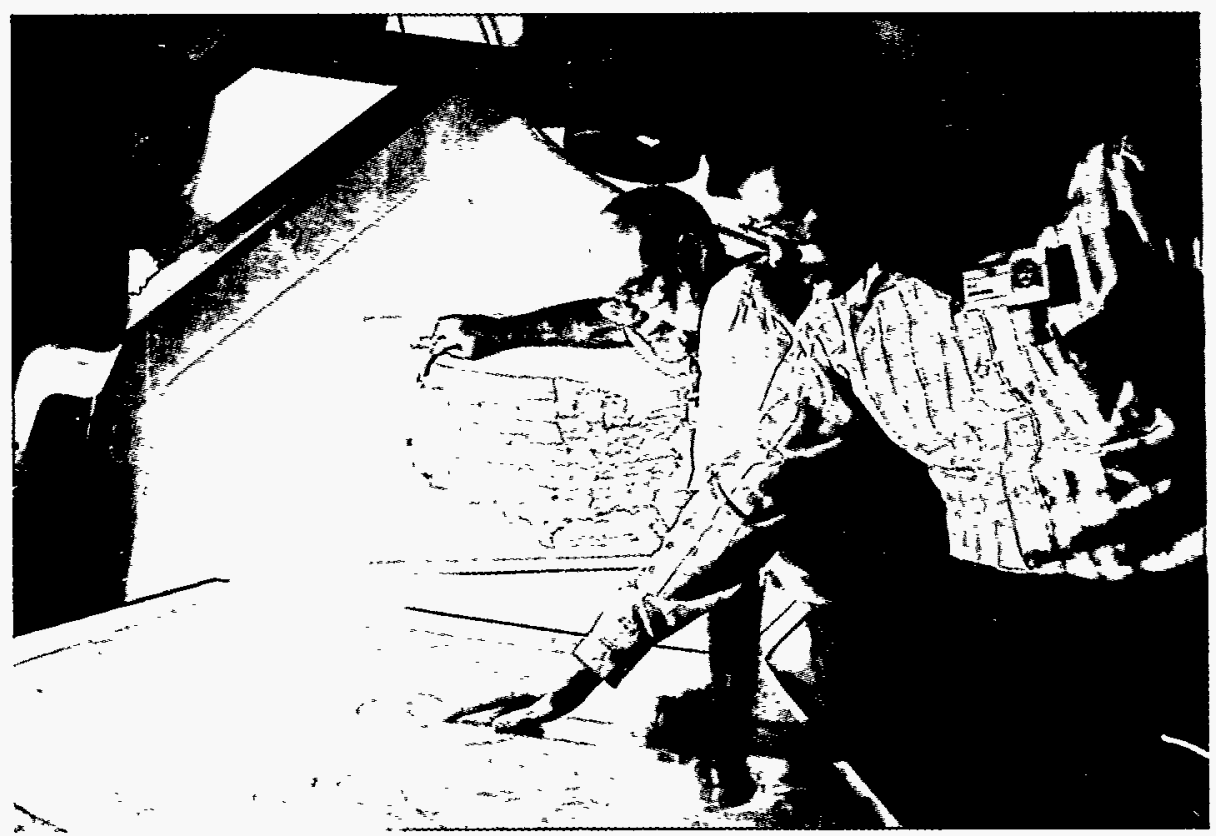

Fig. 4.16. Dave Joy and Paul Johnson studying newly created routing maps produced on the computer. 
cask for shipping CRBR fuel. That work continued until the CRBR concept was abandoned.

More recently, the Transportation Group has continued to expand both its personnel and its technical capabilities. In the mid-1980s, rapid expansion in the transportation area began, which included assisting DOE in planning and developing its system for transporting spent nuclear fuel from the nation's 122 nuclear reactors. The transportation activities in CTD were merged under R. R. Rawl, who was a key individual in promoting support of the transportation needs throughout Martin Marietta Energy Systems. A concept for a Cask Maintenance Facility was developed, the functions of transportation were delineated in detail, the transportation system was described, and numerous engineering and trade-off studies were performed. The spent nuclear fuel shipping efforts grew in the early 1990s to include institutional and economic and systems analyses, and the work in transportation expanded even further to include support in environmental health and safety, waste management, and an NRC-sponsored study for specification packages. Those who supported these efforts included Leonard Dickerson, Juan Ferrada, Ruth Gove, Vicki Green, Francis Kovac, Ron Pope, Joe Ratledge, Rick Rawl, Larry Shappert, Max Wankerl, Brad Welles, and Mimi Welch of Chem Tech; Paul Johnson of C\&TD; Glen Harrison of Energy Division; and Reid Attaway, Larry Medley, Mark Rennich, and Andy Williamson of Central Engineering.

Testing of packages continues and has been carried out for both the DOE as well as companies from the private sector. The data and information generated in the tests have been instrumental in obtaining DOE, NRC, and Department of Transportation (DOT) approvals of the package designs, meeting all necessary technical and QA requirements.

\subsubsection{Drop Test Facilities}

Test facilities were developed to test the heavy packages that are used to shield highly radioactive material.

Impact (Target) Pads. There are two drop test facilities that have been used to test packages. The smallest is the Small Test Facility (STF) that utilizes a concrete pad and has an impact surface of armor plate. This facility was modified in 1990 to provide a larger impacting surface than was available in the original pad.
The concrete and steel in the original pad weighs approximately 40 tons; its top surface is about $11 \mathrm{ft}$ by $10 \mathrm{ft}$ and has an 8 -ft-square armor plate surface imbedded in it. Recently several 6-in.-thick pieces of armor plate were added, which effectively cover the entire pad and overhang about $2 \mathrm{ft}$ in one direction. The additional armor plate is welded to the original plate and adds approximately 20 tons of weight, bringing the total weight of the pad to approximately 60 tons. However, it has a significantly larger effective mass since the bulk of the pad rests on a 3-ft-diam concrete column that was sunk into bedrock approximately $10 \mathrm{ft}$ below grade.

A much larger pad was built at the TSF. This weighs approximately 670 tons and has an armor-plate impact surface which is approximately $8 \mathrm{ft}$ wide and $20 \mathrm{ft}$ long. It was designed to accept the impact of a 100-ton cask dropped from a height of $30 \mathrm{ft}$.

\subsection{REACTOR SAFETY RESEARCH, BUILDING 4501, R. A. Lorenz}

\subsubsection{George Parker and the Manhattan Project}

The pioneer of reactor safety research in the Chem Tech Division is George Parker. While George worked for Du Pont Powder Works in Louisville, Kentucky, in 1942, he noticed that key scientists were leaving the Works without saying where they were going or why they were leaving. Another indication that something interesting was going on was that a lecturer from Purdue University commented to George that while in Knoxville he had seen several Nobel Laureates together and that he had seen the word "uranium" on a blackboard. George learned that one of the "missing" Du Pont people had been seen at the University of Chicago. Since George was looking for something more interesting to do than making gunpowder, he wrote to the University of Chicago saying that he believed that they were doing something special for the war effort and that he would like to get in on it. He immediately received a telegram asking him to come up to the university and to be prepared to stay. The first day or so after arrival consisted of a grilling from the FBI concerning how and what he knew about what was happening at the university. George told them he thought that they were involved in making a bomb. As you can imagine, George was hired on the spot; 
he came to Oak Ridge in 1943. Here he pioneered in fission product separations, which included the discovery of technetium. This work was conducted in Bldg. 706-C (now Bldg. 3026).

F. R. Bruce has told how personal decontamination was done in the early days: go home and wash the dishes. Frank claimed that the method worked well, but he did not say whether he had hands-on experience.

\subsubsection{Early Fission Product Release Tests}

G. W. Parker, G. E. Creek, and W. J. Martin began fission-product release testing in about 1955. Parker was the planner; Creek, the calculator (and often glassblower); and Martin, the equipment specialist. The earliest tests were with metal-clad research-reactor-type fuels to provide safety information for reactors such as the MTR. Uranium slug-type fuel was also tested for Hanford reactor safety studies. Uranium dioxide fuels were studied to provide LWR safety information for. TID-14844, the AEC's first reactor safety analysis. Tests were first performed with trace-irradiated fuel. In the early 1960s, "high-burnup" fuel became available; at that time, high burnup was $4 \mathrm{MWd} / \mathrm{kg} \mathrm{U}$ (now high burnup is anything $>40 \mathrm{MWd} / \mathrm{kg} \mathrm{U}$ ).

R. A. Lorenz joined Parker's group in $~ 1961$. One of the few unpleasantries associated with working in Bldg. 4501 in the late 1950s and 1960s was the odor of propylene diamine (PDA) that permeated parts of the building. This material was used earlier in the OREX process researched by Chem Tech in Bldg. 4501 (Sect. 2.4).

Parker used several methods to reach high temperatures, including the melting point of $\mathrm{UO}_{2}$ : an arc-image furnace (focused light from a carbon arc), a tungsten V-filament, and induction-heated tantalum and tungsten crucibles. Parker and Lorenz pioneered a technique using electrically heated tungsten rods inserted through the center of stacks of $\mathrm{UO}_{2}$ pellets. This method was further developed in the 1970 s by researchers at Karlsruhe, Germany, to heat bundles of 1 -m-long rods in the CORA tests, a very sophisticated and successful apparatus that is still in operation. The above work was summarized in ORNL-3981, the "Bible" of early fission product release. C. J. Barton assisted with this and other report writing.

In 1959, R. A. Lorenz was asked to design a fission product release experiment in which $\mathrm{UO}_{2}$ fuel would be heated to the melting point from fission heat in the Oak Ridge Research Reactor
(ORR). He chose to design àn irradiation facility for the test packages that would allow for installation of the package into the reactor core and adjust its position while the reactor was at full power. Dick asked for a design-draftsman to help with the project, and a young man was sent. $\mathrm{He}$ volunteered to work out the design of a piston to seal the bottom of the facility insert and to be driven by ORR core cooling water. Dick thought this to be a little ambitious (compared with a mechanically operated shutoff), but he agreed. The facility and experiment package worked flawlessly for more than 40 tests. The talented design assistant-John E. Jones-is now Director of the Engineering Technology Division.

Tests of fission-product transport behavior began in 1964 with the operation of the Containment Mockup Facility (CMF). The Containment Research Installation (CRI) was built in 1966 to provide support for the LOFT (Loss of Flow Test) program. LOFT was a LWR at Idaho Falls built especially for accident testing. Tests in the CRI showed rapid deposition of simulants $\mathrm{HI}$ and $I_{2}$ as well as fission product iodine on the walls of the vessels, slow settling of a fraction of the iodine with aerosols, slow growth of organic iodides, and a high liquid/gas iodine partition coefficient. George had good connections with the AEC in Washington. He was famous for going up there and returning with money to continue his various fission product release and behavior programs.

Two types of in-reactor fission product release and fuel behavior tests were performed in the 1960s. Lorenz and Parker ran 12 tests in the TREAT reactor to study release under rapid heatup (to $\mathrm{UO}_{2}$ melting) and cooldown. The first visiting scientist from Germany, Juergen Wilhelm, assisted with these tests. Juergen later became director of the Laboratory for Aerosol Physics and Filtration Technology (aerosol and iodine behavior) at Karlsruhe and became known by some as the "Iodine Pope." Other visiting scientists from Germany who worked in fission product studies were Heinz Buchholz, Horst Feuerstein, and Ernst Hoinkis.

M. F. Osborne joined Parker's group in 1967. LWR safety research was shifting away from fission product behavior in containments to accident-induced fuel rod rupture, cladding expansion (ballooning), and cladding embrittlement caused by oxidation of the cladding. Osborne and Parker, assisted by Bill Martin, tested 
the failure characteristics of highly irradiated Zircaloy cladding. They found slightly less expansion than with unirradiated cladding. A bundle of 25 pressurized fuel rods was heated with internal tungsten lamp heaters. The rupturing fuel rods sounded like popcorn popping.

Lorenz and Parker performed two tests with seven-rod bundles of $1-\mathrm{m}$-long fuel rods in the TREAT reactor. These tests simulated behavior during a controlled loss-of-coolant accident $\left(1200^{\circ} \mathrm{C}\right.$ maximum temperature). In addition to fission-product release information from an irradiated center rod, these tests showed that the pressurized rods ballooned and ruptured in the same way as in out-of-reactor tests. One of the fuel rods from the second bundle test was accidentally broken during post-test handling in the hot cell. This fact was used to bolster other ORNL data presented at the Emergency Core Cooling System hearings which showed that oxygen embrittlement of Zircaloy was important. When Parker and Lorenz visited Westinghouse in June 1967 to discuss a possible contract, the Westinghouse representative asked how the test fuel rods had been pressurized and sealed. Approximately two years later, the news was out that some commercial fuel rods were being pressurized with helium in order to maintain good thermal conductivity. Apparently, Westinghouse was trying to learn if ORNL had a better method for seal-welding pressurized fuel rods.

\subsubsection{The Chemical Development Section}

Most of the reactor safety research described above had been part of Reactor Chemistry Division programs. In 1973, this division was dissolved and the nuclear reactor safety research group and facilities became part of the newly formed Chemical Development Section in the Chemical Technology Division. A. P. Malinauskas was the new section chief.

Light-water reactor safety research was at a low point at this time. In 1971, Milton Shaw, Director of Reactor Development and Technology, had decreed that no further government-funded research was warranted; if additional safety information was needed, reactor vendors and utilities should pay for it. Of the Bldg. 4501 group, G. W. Parker, G. E. Creek, and even W. J. Martin were working at least part-time on environmental impact statements. M. F. Osborne was working on a gas-cooled reactor project to investigate the sorption of iodine on iron oxide.

R. A. Lorenz was working with Chem Tech's first visiting scientist from Japan, Hiroyuki Nagao, on the ignition of charcoal by decay heat from radioactive iodine. George Parker had suggested looking at $130 \mathrm{I}$ as the radioactive isotope to use instead of ${ }^{131} \mathrm{I}$ because of its shorter half-life and the possibility of generating large quantities by activation of ${ }^{129}$ I. This turned out to be feasible, and 1000-Ci amounts were generated in the HFIR for each test conducted in cell A, Bldg. 4501. It was found that heat from the oxidation of the charcoal was as important as the heat from radioactive decay, and desorption from the ignited charcoal bed was surprisingly slow, especially when the charcoal contained an excess of potassium over iodine.

In late 1973 and early 1974, G. W. Parker, assisted by G. E. Creek and somewhat by R. A. Lorenz, contributed fission product release rates and behavior to WASH-1400, the AEC report on severe reactor accidents. Back in 1961, George had contributed almost all of the needed fission product information for TID-14844, the AEC reactor safety report on which the AEC Regulatory Guides for power reactor design requirements were based. George said that most of the information he supplied was given via telephone. It is interesting to note that the "Reg-Guides" resulting from TID-14844 are still current, but Ed Beahm is reexamining iodine behavior for a probable Reg-Guide revision (Sect. 4.8.13).

\subsubsection{Restart of Fission-Product Release Testing}

After about a three-year layoff from LWR safety research, the AEC began fission product release research at ORNL in the fall of 1974. R. A. Lorenz and M. F. Osborne were assigned the task; A. P. Malinauskas was the Project Manager and Ray DiSalvo was the AEC sponsor. When M. F. Osborne went to Germany as first technical liaison for the USAEC-FRG agreement on core melt research, Jack Collins joined the project from the Isotopes Division where his experience with the chemistry of small quantities of various elements including uranium and plutonium made him a natural for this work. As part of his isotopes work, he had operated calutrons left over from the war years. Morris Osborne was on assignment in Karlsruhe, Germany, from October 1975 to 
August 1977. Technicians on this project have been S. R. Manning, R. L. Towns, O. L. Kirkland, J. R. Travis, and C. S. Webster.

This work has been funded off and on for 17 years. Work progressed along these lines: "control" tests with fission product simulant species in the absence of fuel (1975), Knudsen cell tests with cesium species (1975), "implant" tests with fission product species implanted in the pellet-clad gap space (1975), low-burnup (LBU) tests with low-burnup ( 1 to $2 \mathrm{MWd} / \mathrm{kg}$ ) fuel (1976), high-burnup (HBU) tests with high-burnup (20 to $30 \mathrm{MWd} / \mathrm{kg}$ ) fuel between 500 and $1200^{\circ} \mathrm{C}$ (1976), high-temperature (HT) tests with high-burnup fuel between 1300 and $1610^{\circ} \mathrm{C}$ (1978), and tests with BWR fuel $(\sim 10 \mathrm{MWd} / \mathrm{kg})$ between 800 and $1200^{\circ} \mathrm{C}$ (1979). Peaks of activity occurred in 1977, when seven tests were run, and in 1979, when five tests were completed.

In September 1980, more than a year after the TMI-2 accident, NRC began discussing plans for higher-temperature tests. The furnace was redesigned and the $\mathrm{HI}$ (Horizontal Induction Heated) tests were run from 1982 to 1984 $\left(1400-2000^{\circ} \mathrm{C}\right)$. Tests with Karlsruhe simulant fuel (HS Series) were run in $1984\left(2000-2425^{\circ} \mathrm{C}\right)$. A major design improvement was made in 1985 . The furnace was oriented vertically, and two additional sequentially operated fission-product collection systems were added. Six VI series tests were performed $\left(1725-2425^{\circ} \mathrm{C}\right)$ between 1985 and 1991.

The Knudsen cell work performed by Collins in 1975 and 1976 showed that the vapor pressure of both $\mathrm{CsOH}$ and $\mathrm{Cs}_{2} \mathrm{CO}_{3}$ was substantially reduced in the presence of $\mathrm{UO}_{2}$. The simulant studies (implant tests) performed by Lorenz and Collins at that time showed that the vapor pressure of both cesium and iodine were reduced by factors of 10 to 100 when $\mathrm{CsI}$ and $\mathrm{CsOH}$ were deposited on $\mathrm{UO}_{2}$ pellets inside the Zircaloy cladding.

A low point in morale came in the summer of 1976 when an abstract of a paper covering the "implant" tests was submitted for an international meeting in Norway. A Swedish reviewer commented that ORNL should be working with real irradiated fuel and not with simulants. This was taken seriously in both Washington and at ORNL, where consideration was given to withdrawing the paper or changing the authorship. The paper was well received, and the simulant (implant) work provided the foundation for the LOCA Source Term Model. It was the opinion of Chem Tech's fission-product release team that these and later radioactively traced simulant tests, dollar-for-dollar, provided ten times as much information as the expensive yet very essential tests with commercial irradiated fuel.

The LOCA Source Term Model by Lorenz, Collins, and Malinauskas was published in early 1978 after inclusion of data from the first 11 tests with high-burnup commercial fuel. The model covers the release of cesium, iodine, and fission gas from ballooned and ruptured fuel rods in the temperature range of 500 to $1200^{\circ} \mathrm{C}$. The model was confirmed by results from tests later run with high gap-inventory BWR fuel. It is still in use for low-temperature accidents such as shipping or fuel bundle handling accidents, in addition to the early stage of LWR accidents.

\subsubsection{Hearings and Investigative Support}

In early 1975 , the AEC was divided into ERDA and NRC. Funding for $\mathrm{Chem}$ Tech came from the NRC. At about this time, George Parker was called as a witness at a licensing hearing for a proposed reactor since it was known that an "intervenor" was going to claim high cesium releases from fuel shipping accidents. George testified that cesium would not be released in significant amounts at the temperatures cited. The intervenor then was called to the stand and asked what he knew about cesium. He replied that everything he knew he had learned from George Parker. The "intervenor" was dismissed from further testimony.

Also about this time there was a very serious effort to obtain NRC approval of a proposed floating off-shore nuclear plant design. George Parker and Frank Binford were assigned to evaluate the safety of the plant and decided that it was not safe enough. George said that the original floating plant design looked like a good way to spread radioactivity all along the East Coast.

\subsubsection{Response to the TMI-2 Accident}

The TMI-2 accident occurred on March 28, 1979. Preliminary fission-product release estimates released a few days after the accident showed nearly equal percentage amounts of the cesium and iodine inventories in the primary cooling water. This was exactly the behavior that the fission-product release group had seen in their experimental results: equal percentage releases of cesium and iodine, with the iodine behaving like cesium iodide. When Lorenz heard about the TMI-2 releases, he commented to Jack Collins, 
"There's our cesium iodide." This was not necessarily a correct deduction, of course, because most of the released fission products were still confined to the primary system, and all chemical forms of iodine would be there.

Babcock and Wilcox called for a meeting of specialists to discuss the accident. On April 4, Lorenz and two others from ORNL took a charter flight to Lynchburg. Lorenz presented evidence that showed that the temperature must have been above $2000^{\circ} \mathrm{C}$ for a period of time. Some "industry" representatives talked in terms of $2000^{\circ} \mathrm{F}\left(1093^{\circ} \mathrm{C}\right)$ or possibly $2800^{\circ} \mathrm{F}\left(1538^{\circ} \mathrm{C}\right)$, which were impossibly low temperatures. That evening the ORNL group had dinner with a metallurgist from B\&W. His private opinion was "I'm willing to concede the upper third of the core." He was very realistic in his estimate made only 8 days after the accident.

Extensive assistance was provided to TMI-2 by other Chem Tech members in the days and years after the accident. Floyd Culler, director of the Electric Power Research Institute (EPRI), quickly called for assistance with the highly radioactive primary system water that had escaped to the TMI-2 Auxiliary Building, a building that was not designed for containment. Bob Brooksbank formed a team with Orlan Yarbro, Jim Snider, and Frank Harrington, who immediately went to the reactor site to help with radioactive waste management projects. Snider and Harrington were involved in various engineering projects, while Yarbro analyzed the potential release of ${ }^{131} \mathrm{I}$ and methods for preventing or mitigating such a release. They found that the charcoal traps in the TMI-2 Auxiliary Building had deteriorated and arranged for replacement traps to be flown in from Hanford by the Air Force (although this didn't occur until approximately 6 weeks later). A few days after the accidents, Les King, Emory Collins, and Bill Shannon joined the on-site team. They collected and analyzed data on 131 I evolution and determined that the release was only $15 \mathrm{Ci}$, even though the reactor fuel contained $10^{7} \mathrm{Ci}$ at the time of the accident.

A few weeks later, Bob Brooksbank was selected as a member of the first Technical Advisory Group (TAG), and Chem Tech began work on designing a decontamination process for the high-activity water generated by the accident. Dave Campbell, Emory Collins, Les King, and Joe Knauer were co-developers of this process, which was first used in 1981 to decontaminate the water. A variety of other cleanup projects were performed by Joe Knauer, Walt Bond, P. B. Orr, Lew Bird, Don Box, Herschel Godbee, and Tim Scott.

Brooksbank became the first Program Manager at ORNL for TMI-2 Assistance, which included projects in Chem Tech and other ORNL divisions. He was followed by Tony Malinauskas and Emory Collins during the 1980 to 1989 period. Dave Campbell was the first appointee to the TMI-2 Technical Assistance and Advisory Group (TAAG), beginning in 1982. He was later joined by Malinauskas and Collins. The TAAG assisted with defueling and decontamination projects and devised the "quick look" examination, during which a television camera was first lowered into the core region.

Lorenz wrote a report analyzing the amount of ${ }^{85} \mathrm{Kr}$ that might be released from intact fuel rods during core removal operations. Lorenz and Jack Collins developed a model of cesium transport which showed that desorption of cesium from primary system surfaces was causing the very slow increase in cesium concentration in the primary water for up to 2 years after the accident.

\subsubsection{The President's Commission (Kemeny Commission) on the TMl-2 Accident}

President Carter appointed the Kemeny Commission to investigate the TMI-2 accident. A committee from the commission, headed by Tom Pigford, visited ORNL on June 11, 1979. Lorenz used Parker's fission-product release results obtained in the early 1960s, which showed that the fuel temperature must have been very high, probably for a long time. Volatile fission-product release estimates from TMI-2 measurements ranged around 50\%, and steam-Zircaloy reaction estimates were $\sim 60 \%$. Since the zirconium oxidation occurs at very much lower temperatures than fission-product release, Lorenz said that the best explanation for these results was that $60 \%$ of the core got very hot and $40 \%$ remained cooled. He suggested that a possible mechanism for unusually high fission-product release might be the result of reaction between zirconium cladding and the $\mathrm{UO}_{2}$ fuel. Pellet-cladding interactions had been under study at several laboratories, but only at low temperatures and only because of concern over cladding integrity. No fission-product release data had ever been obtained at high temperature with 
unoxidized Zircaloy-clad $\mathrm{UO}_{2}$. The reaction between $\mathrm{Zr}$ and $\mathrm{UO}_{2}$ came to be known as "liquefaction," but tests at ORNL in the HI and VI series showed that this reaction did not result in a significant enhancement of volatile fission-product release.

A. P. Malinauskas and D. O. Campbell worked on a committee for the President's commission to investigate the behavior of iodine during the TMI-2 accident. The committee reported that the iodine released from the fuel, if not already in the iodide form, encountered a chemically reducing environment which converted it to iodide. The iodine subsequently went into solution as iodide when it contacted water. The CRI tests by Parker, Creek, and Martin had shown a similar end point for $\mathrm{I}_{2}$ placed in oxidizing steam-air atmospheres for which liquid/gas partition coefficients of $\sim 10^{4}$ were rapidly obtained.

\subsubsection{Cesium, lodine, and Cesium lodide Before and After the TMI-2 Accident}

The Chemical Technology Division has provided most of the LWR safety study information about the chemical and physical behavior of fission product iodine. The fission-product release studies (Sect. 4.8.4) provided information about the time period of $\sim 1 \mathrm{~s}$ after releases from the fuel. The aerosol reaction/sorption studies (Sect. 4.8.14) showed significant interaction with several aerosol components that would take place at high temperature in the first minute following release. The low-temperature iodine studies (Sect. 4.8.13) evaluated the complex behavior of iodine in the containment atmosphere and water pools.

The challenge to the fission-product release group was to determine whether fission product iodine existed in volatile forms $\left(\mathrm{I}_{2}, \mathrm{HI}\right.$, or $\left.\mathrm{CH}_{3} \mathrm{I}\right)$ immediately after release from the $\mathrm{UO}_{2}$ fuel or in much less volatile forms, such as CsI. The chemical form could not be positively identified because the high radioactivity and intimate mixing with other chemical species interfered with methods such as X-ray diffraction. The question was resolved by using activated charcoal, which showed that only trivial amounts of iodine existed in the volatile form.

By 1977, the Knudsen Cell, Implant (Simulant) tests, and HBU tests had shown interesting behavior of cesium and iodine. The vapor pressures of cesium and iodine were less than expected for $\mathrm{CsOH}$ and $\mathrm{CsI}$ in the presence of fuel and cladding, there was less release of cesium than iodine at lower temperatures, and released iodine behaved much like CsI when releases were above the trace level. In late 1977, T. M. Besmann and T. B. Lindemer performed thermodynamic calculations which confirmed the observed behaviors.

By November 1978, the evidence for "release" of iodine as CsI was convincing. In a paper by Malinauskas, Lorenz, Collins, and Osborne presented at the Sixth Water Reactor Safety Research Information Meeting, they stated that "the release data obtained in the High Burnup Fuel Test Series suggests that $\mathrm{CsOH}$ and CsI were the species of cesium and iodine that were released in the steam atmosphere tests," and "in a purified helium test, the iodine was collected as CsI." The importance of these observations is that $\mathrm{CsI}$ is much less volatile than $\mathrm{I}_{2}$ or $\mathrm{CH}_{3} \mathrm{I}$.

Thermodynamic calculations consistently showed that CsI was the most stable form of iodine under most accident conditions, but convincing experimental evidence for this fact previously had been lacking.

The HT and BWR series of tests performed in 1978 and 1979 provided more evidence for the existence of fission product iodine as CsI and the absence of highly volatile forms of iodine such as $\mathrm{I}_{2}$ and $\mathrm{HI}$. For iodine releases above $1 \%$ of inventory, the amount of volatile iodine was always $<1 \%$ of the amount released. In the ORNL apparatus, collection occurred within $1 \mathrm{~s}$ of release from the fuel. Papers were presented at four national and international meetings between September and December of 1979 in which the authors explained the test results which showed that the released iodine behaved like CsI and was not in a volatile form. It was thought that iodine behavior results of the Chem Tech staff were being understood and accepted worldwide.

In July 1980, more than a year after the TMI-2 accident, A. P. Malinauskas and D. O. Campbell attended a meeting at which they were disappointed to find that most of the reactor safety community was ignoring real iodine chemistry as demonstrated by the ORNL experimental results, by thermodynamic calculations, and inferred from iodine behavior at TMI-2. They were taking the simple "conservative" approach of assuming that released fission product iodine was in the volatile form $\mathrm{I}_{2}$. W. R. Stratton (Los Alamos National 
Laboratory), who was also dissatisfied with this approach, along with Campbell and Malinauskas, wrote a letter to the NRC commissioners explaining the evidence for their belief that fission product iodine "emerged from the fuel as cesium iodide" and requested that the true iodine chemical behavior be verified and applied to NRC Regulatory Guides, accident analyses, and guidelines for emergency evacuation. The letter had a big impact. A hearing was held by the NRC, with the result being that iodine chemistry was taken more seriously.

\subsubsection{Post-TMI LWR Research}

A. P. Malinauskas continued as Chemical Development Section Head. Contrary to what was expected, there was a lull in new reactor safety research after the TMI-2 accident. This is probably because NRC concentrated its resources on analyzing the accident. In early 1980 ,

R. P. Wichner, who had been managing the HTGR studies, began building/rebuilding an LWR safety research program. The major activities and principal investigators in this program were fission product release, M. F. Osborne and R. A. Lorenz; iodine chemistry, L. M. Toth and E. C. Beahm (Fig. 4.17); Severe Accident Sequences Analysis Program (SASA), R. P. Wichner; fission product adsorption on aerosols, Roger Spence; iodine leakage from steam generator tubing, S. D. Clinton and E. C. Beahm; core-melt studies, G. W. Parker (Fig. 4.18); aerosol transport, A. L. Wright; and iodine absorption by water sprays, Mike Albert, University of Tennessee, MS thesis. In 1983 , J. R. Hightower became section head of the Chemical Development Section. He was followed by J. T. Bell in 1988 .

\subsubsection{Fission Product Release from Fuel}

In the summer of 1980, M. F. Osborne began the design of a furnace that would heat LWR fuel in steam atmospheres to temperatures as high as $2300 \mathrm{~K}$. J. R. Travis and C. S. Webster joined the project in December 1980 and began preparing the hot cells for the new apparatus and setting up computerized data recording equipment. Travis and Webster came from hot cell BIdg. 4507, where they had worked with J. H. Goode, R. G. Stacy, and V. C. A. Vaughen on head-end reprocessing studies and parametric voloxidation studies. R. A. Lorenz assisted with design of the new apparatus and with safety analyses. Jack Collins returned from TRU in 1983 specializing in chemical interpretations of the data and to perform laboratory tests using radioactively traced fission product simulants (see Fig. 4.19). Six tests (HI-1 to HI-6) were performed before the apparatus was converted to the vertical orientation in 1985. K. S. Norwood, a visiting scientist from the United Kingdom, contributed significantly to the $\mathrm{HI}$ test series (Fig. 4.20). The vertical apparatus featured higher-temperature capability $(2700 \mathrm{~K})$, improved temperature measurement, more uniform temperature along the length of the $15-\mathrm{cm}$ fuel specimen, three sequentially operated fission-product collection systems, and a hydrogen measuring system. Six tests (VI-1 to -6) have been performed to date with both steam and hydrogen atmospheres using fuel from LWR reactors with burnups up to $47 \mathrm{MWd} / \mathrm{kg} \mathrm{U}$. Fission-product release rates obtained from this program provided the data worldwide for fission-product release models.

Test VI-4 provided a surprising outcome after a difficult start. NRC and ORNL program managers required that test VI-4 be run with a steep axial temperature gradient of $\sim 400 \mathrm{~K}$ from the center to the top of the fuel specimen in order to provide an exact duplication of an in-reactor fission-product-release test run at Sandia. The ORNL experimenters maintained that such a temperature gradient makes it impossible to calculate accurate release rates as a function of temperature. Duplication of the temperature gradient required 6 months and 26 heatup tests before the proper temperature gradient and temperature calibration was obtained. Early in the actual test, the fuel specimen collapsed down into the uniform temperature zone, thus permitting the measurement of accurate release rates as a function of time and temperature. To this date, the experimenters refuse to reveal how they caused the fuel to collapse.

\subsubsection{Modeling of Fission Product Release at High Temperature}

In late 1980, the NRC instigated a high-priority project to establish the technical bases for estimating fission product behavior during LWR accidents, which resulted in the famous NUREG-0772 report. This was done to improve upon the methods used in the 1974 WASH-1400 report Reactor Safety Study. R. P. Wichner and $\mathrm{R}$. A. Lorenz wrote the section on fission product 
Fig. 4.17. Members of the Spectrophotometric Studies Group from the Chemical Development Section consult with George Begun (Chemistry Division) on a collaborative investigation in which the structure of urania and zirconia hydrous polymers is being elucidated by means of Raman spectroscopy. Mac Toth (left) and Kevin Felker are on the back row. In the front row left to right are Karen Dodson, Susan Sherrow, and George Begun. This work was supported by DOE through the Office of Basic Energy Sciences, Division of Chemical Sciences.
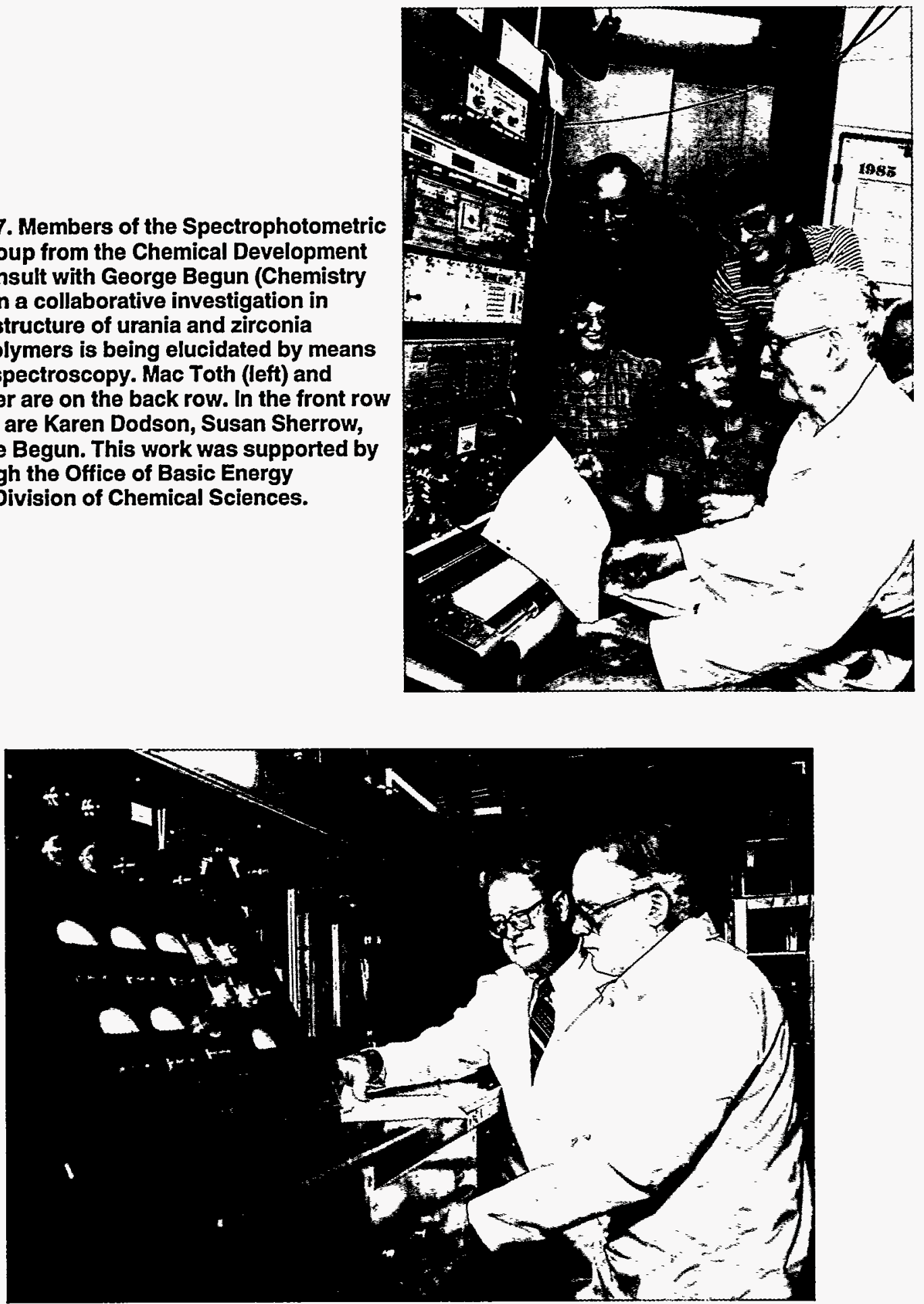

Fig. 4.18. George Parker (left) and AI Sutton are at the control panel of the Chem Tech CORE-MELT Facility checking the heating rate to be used in melting a 10-kg simulated LWR nuclear reactor core. These unique experiments allow researchers to learn about phenomena that occur during those nuclear reactor accidents in which portions of the reactor core melt. Results from these experiments helped explain findings in the damaged reactor vessel at Three Mile Island. This work was performed in Chem Tech as part of ORNL's NRC program. 


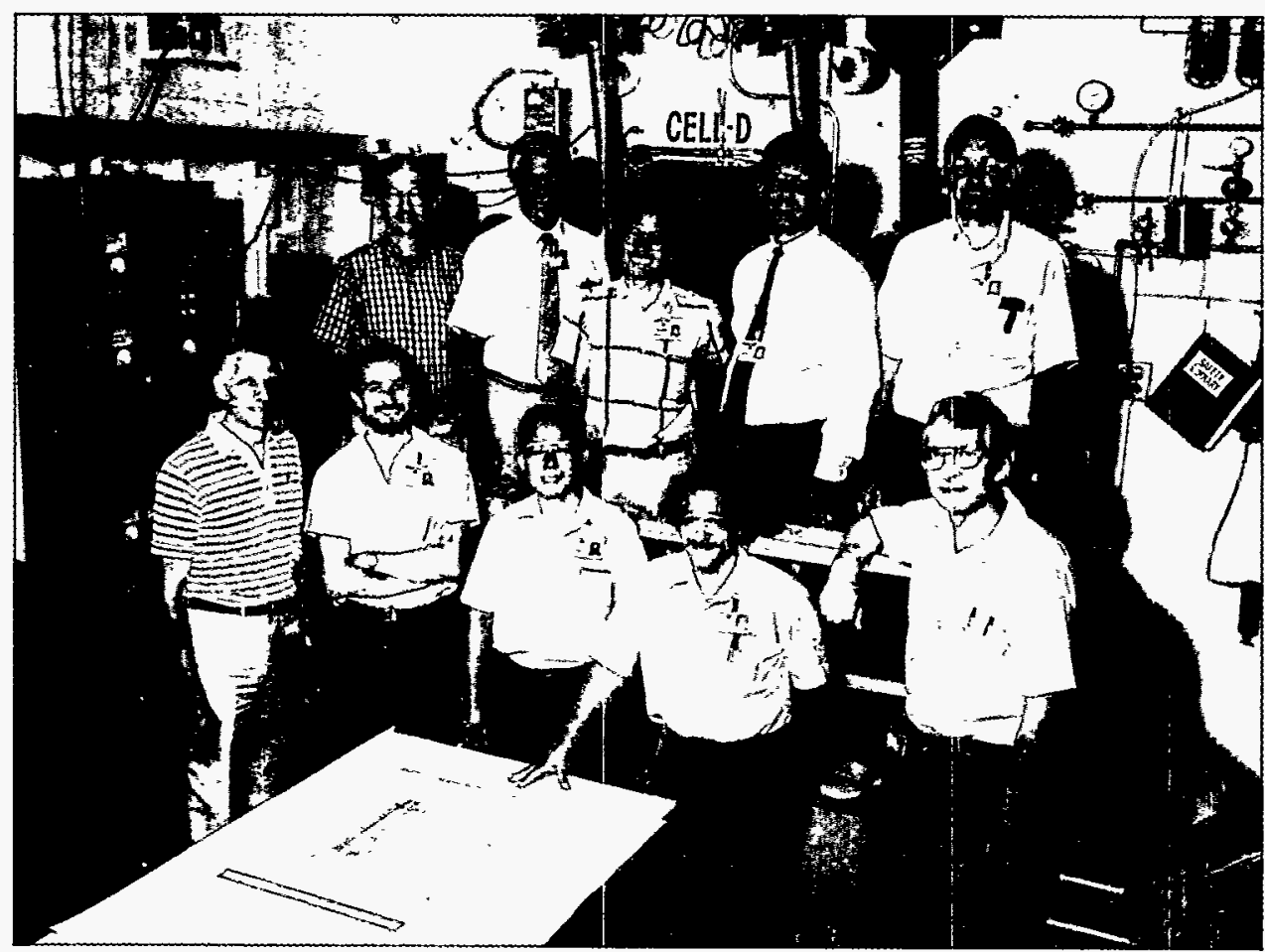

Fig. 4.19. Chem Tech members and visiting scientists in front of a hot cell used for fission product release studies. Top row (left to right): Jack Collins, Bob Hightower, Take Nakamura, Tony Wright, and Jim Travis. Bottom row (left to right): Morris Osborne, Stephen Daish, Y. -C. Tong, Charlie Webster, and Dick Lorenz.

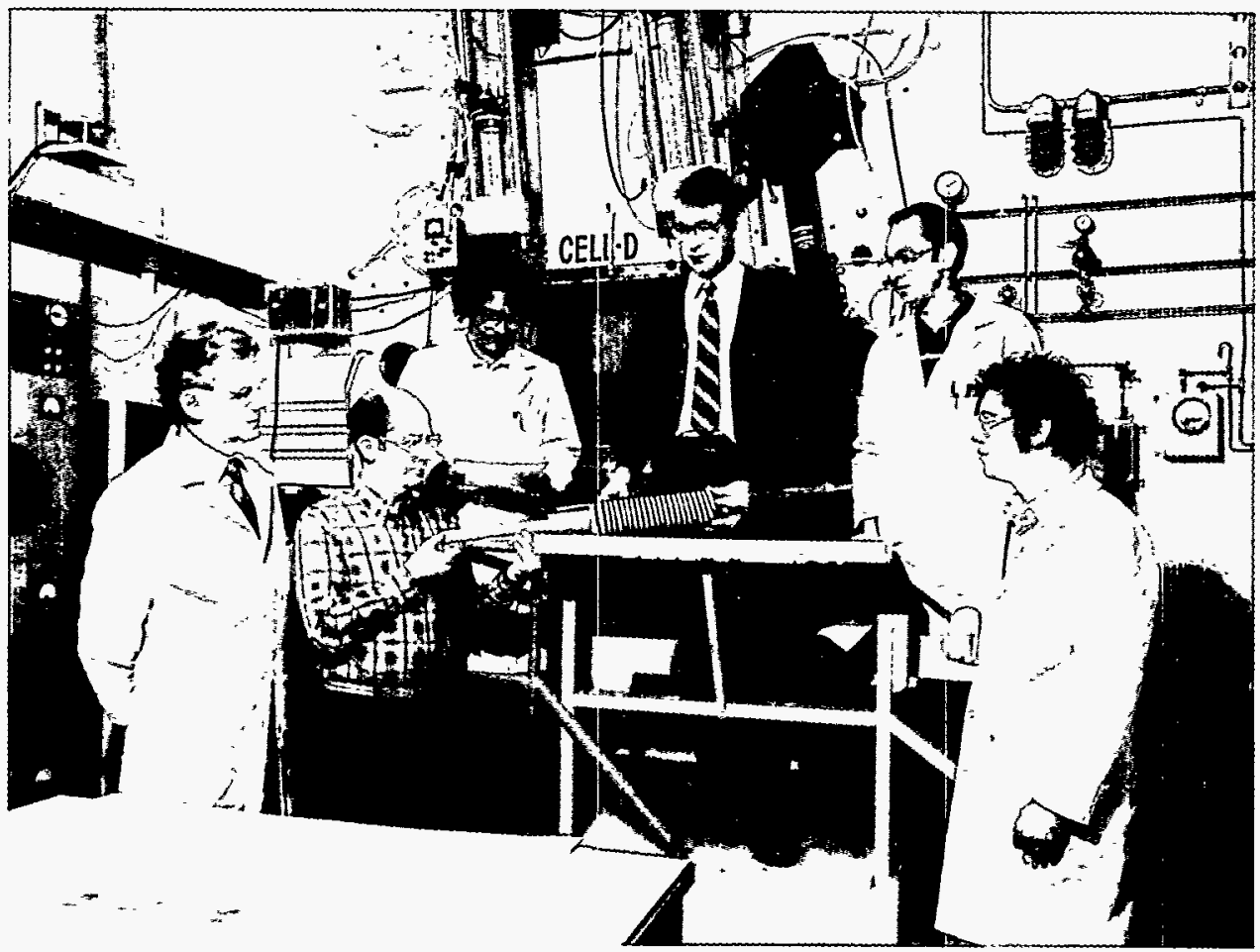

Fig. 4.20. Left to right, M. F. Osborne, J. L. Collins, C. S. Webster, R. A. Lorenz, J. R. Travis, and K. S. Norwood (United Kingdom) examine a furnace used in fission-product release tests. 
release from fuel and devised the fractional release rate model which became known as CORSOR. The model is simple and easy to use, which accounts for much of its popularity. Although not as accurate as recent, more complicated models, it continues to be used and is the basis for comparison with all other fission-product release models. J. T. Bell, L. M. Toth, D. O. Campbell, and A. P. Malinauskas assisted with the "Chemistry of Cesium and Iodine" chapter. The authors concluded that "the stability of CsI makes this compound the predominant iodine species for most conditions" in the gas phase.

In 1983, NRC asked ORNL to examine fission-product tellurium release rates. Commercial interests claimed that tellurium was released at the same rate as cesium, iodine, and fission gases, but the ORNL summary in NUREG-0772 indicated significantly lower release rates. The importance of this is that tellurium released late in the accident might actually have a better chance of escaping from containment. Lorenz, Beahm, and Wichner found that tellurium release was delayed by retention in unoxidized Zircaloy cladding but was released when the cladding became essentially completely oxidized. Jack Collins later performed tracer test C-9, which dramatically proved this to be the case.

R. A. Lorenz showed in 1985 that classical diffusion equations accounted for the time dependence of fission product release better than the CORSOR model. Takehiko Nakamura, a visiting scientist from Japan, correlated the ORNL test results using diffusion equations and developed the ORNL Diffusion Release Model. In 1991, the NRC changed the original CORSOR model to a diffusion-type model.

A. P. Malinauskas and R. A. Lorenz recently used the ORNL LOCA Source Term Model, mentioned previously, to calculate fission-product release during low-temperature shipping and fuel handling accidents. This model was also used in 1991 to determine when the first radioactivity would be released from fuel in order to know how fast reactor containment isolation valves would need to operate.

\subsubsection{Severe Accident Sequence Analysis (SASA)}

R. P. Wichner, assisted by R. A. Lorenz, W. Davis, Jr., A. L. Wright, C. F. Weber, and A. D. Mitchell, directed an investigation into fission product release, chemistry, and transport during specific reactor accidents. (Previous accident studies were much more generic in nature.) Steve Hodge's group in the Engineering Technology Division provided the time, temperature, atmosphere, and leakage rate data. The first accident studied was a station blackout (complete loss of electricity except for storage batteries) at the Browns Ferry-1 BWR. The study was a landmark in that it demonstrated the importance of individual power plant designs and the importance of iodine chemistry. All reactor safety analyses now use the SASA approach of using exact design details for the plant being studied. J. W. Nehls and E. C. Beahm worked on later SASA studies, which continued to 1985 . The work of Beahm and Weber led to the development of the TRENDS model for iodine behavior in reactor containment buildings.

\subsubsection{3 lodine Chemistry and Volatility Studies}

L. M. Toth, K. E. Dodson, and O. L. Kirkland began studying iodine chemistry in 1981 using absorption spectrophotometry at temperatures up to $150^{\circ} \mathrm{C}$. They measured the production of volatile iodine species as a function of gamma radiation and solution characteristics. Ed Beahm and Bill Shockley began the study of organic iodide formation in 1984. E. C. Beahm and C. F. Weber expanded the studies of chemistry and transport of iodine in reactor containment that was started in the SASA program. They were supported by W. E. Shockley, S. J. Wisbey (U.K. visiting scientist), and Y.-M. Wang (visiting scientist from Taiwan). Additional work was performed by M. Brown (U.K.) and T. S. Kress (Engineering Technology Division). This led to summarizing the iodine behavior work in the computer program TRENDS (Fig. 4.21).

E. C. Beahm has become the NRC's iodine behavior expert and is currently evaluating the chemical forms of iodine in containment spaces for a revision of the NRC Regulatory Guides, the safety guidelines for reactor design and siting. The TRENDS models for iodine chemical forms and other behavior in containment that have been developed by Beahm et al. include the effect of radiation on iodine in water pools, the effect of $\mathrm{pH}$, calculation of $\mathrm{pH}$, the effects of nitric acid formed in water by radiation, the effect on $\mathrm{pH}$ of $\mathrm{HCl}$ from certain decomposed plastics, and the effects of 


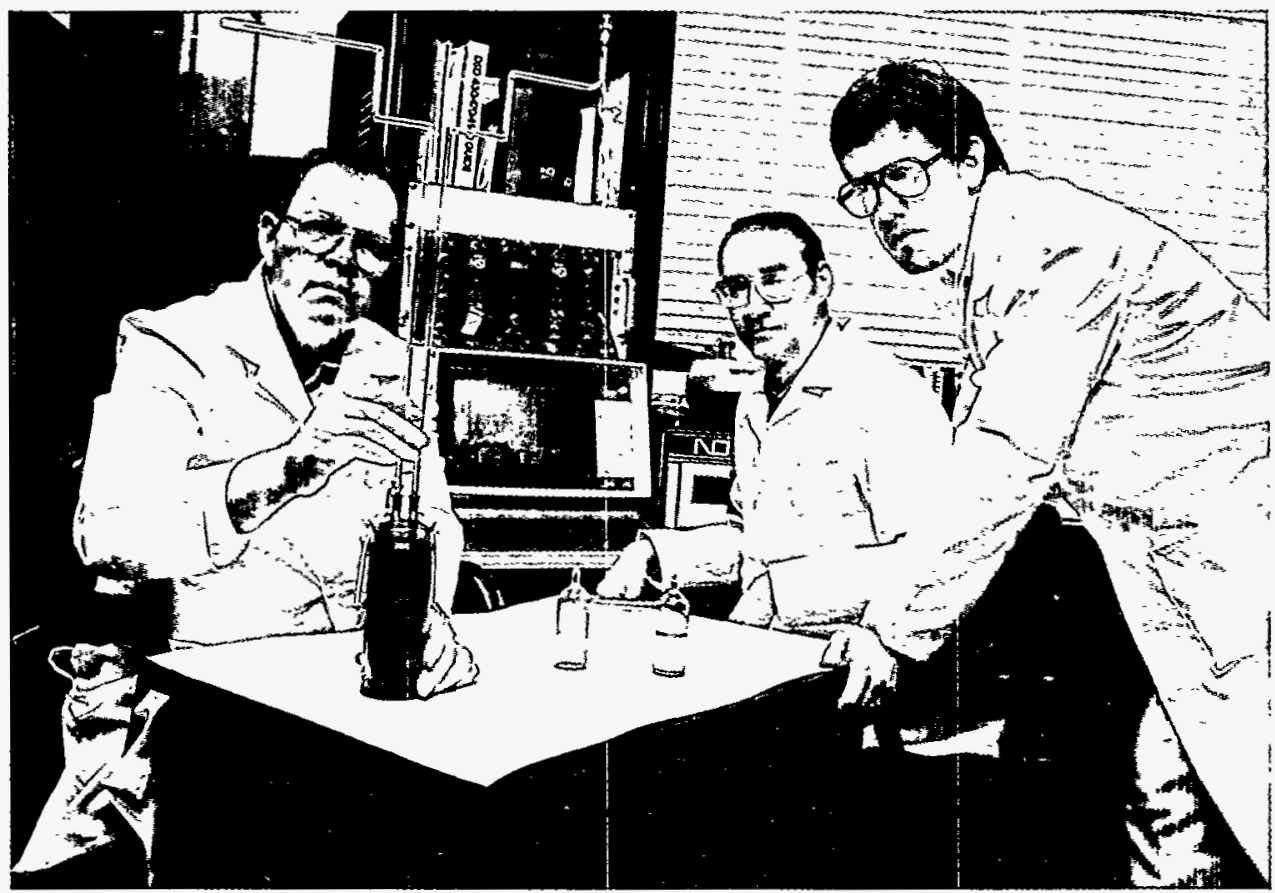

Fig. 4.21. Bill Shockley (left), Ed Beahm (center), and Simon Wisbey (guest scientist from AERE, Harwell, England) prepare an experiment to study the formation of volatile forms of fission product iodine under conditions that are predicted to occur in the containment building of a nuclear reactor that has undergone a severe accident. Because intense radiation fields would be present under such circumstances, these experiments are conducted in a ${ }^{60} \mathrm{Co}$ irradiator to study the effects of gamma irradiation. This work was performed in Chem Tech as part of ORNL's NRC program.

silver and temperature. Another iodine volatility study, "Iodine Leakage from Steam Generator Tubing," was performed by S. D. Clinton, E. C. Beahm, and W. E. Shockley (Fig. 4.22).

\subsubsection{Aerosol Studies}

G. W. Parker began aerosol studies for LMFBR safety in 1974 by forming high-concentration $\mathrm{UO}_{2}$ aerosols using a metallurgical cold hearth furnace especially designed for the purpose. Parker also used a plasma torch for aerosol generation. George, Minton Kelley, and Jim Rochelle (I\&C Division) performed another LMFBR aerosol study by developing a capacitor-discharge $\mathrm{UO}_{2}$ pellet vaporizer. One of the secrets to this very successful project was electrical preheating of the pellet, which increased the electrical conductivity for the capacitor discharge.

LWR aerosol studies were started in 1982 by A. L. Wright and W. L. Pattison. They used Parker's plasma torch method to generate LWR accident-type aerosols (Fig. 4.23). They studied both settling/plateout of high-concentration aerosols flowing at low velocity and the resuspension of deposited aerosols. They found much higher deposition velocities than predicted by the NRC's TRAP-MELT CODE.

Roger Spence and Frank Dyer (Analytical Chemistry Division) began studying the sorption and reaction of $\mathrm{CsI}$ and $\mathrm{CsOH}$ with a variety of LWR accident aerosol components. These reactions could take place in the primary system at temperatures above $500^{\circ} \mathrm{C}$. They found interesting reactions, but all the aerosol programs were terminated in late 1986 or early 1987 just as they were producing interesting and useful results.

\subsubsection{Response to the Chernobyl Reactor Accident}

The Chernobyl accident occurred April 26, 1986. R. A. Lorenz and Toshiyuki Yamashita correlated the gamma count results from several hundred air, fallout, and smear samples of radioactivity collected at locations all over the world. In combination with ORIGEN inventory estimates, they used the ${ }^{134} \mathrm{Cs} /{ }^{137} \mathrm{Cs}$ ratio to 
Fig. 4.22. Sam Clinton (left) and Cathy Simmons are preparing for an experiment that will determine the partitioning of iodine between the vapor and liquid within the environment of a simulated pressurized water reactor steam generator as it experiences a break in one of the tubes. The partitioning is being studied as a function of coolant $\mathrm{pH}$, iodine concentration, and iodine chemical form. This work was performed in Chem Tech as part of ORNL's NRC program.

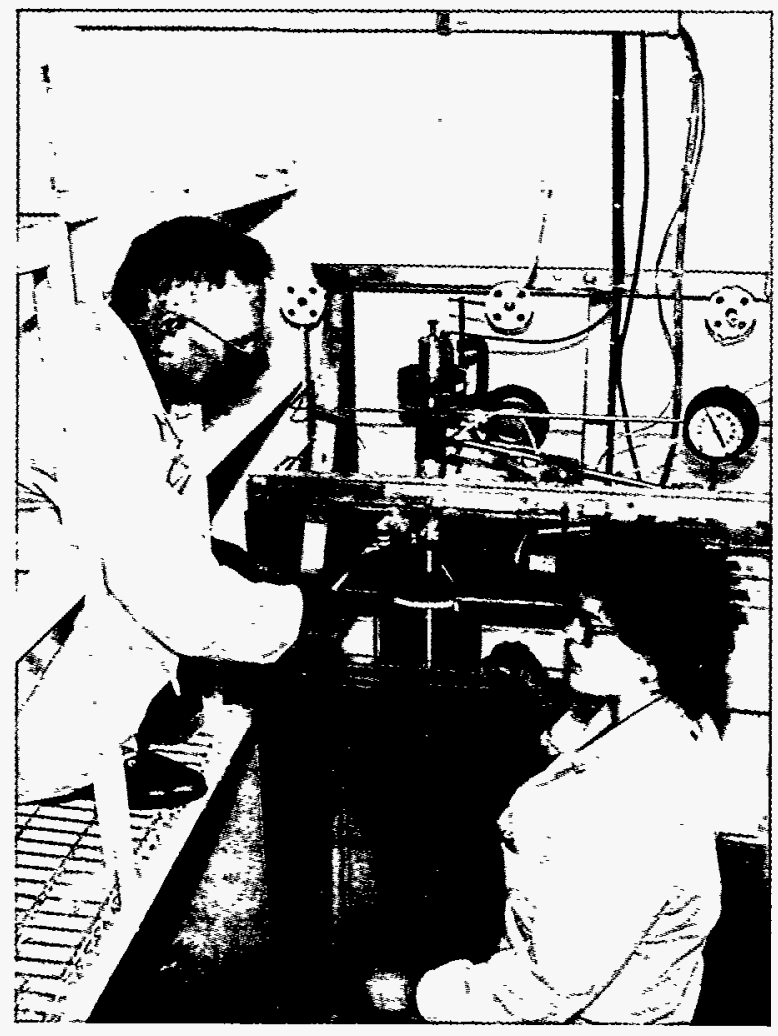

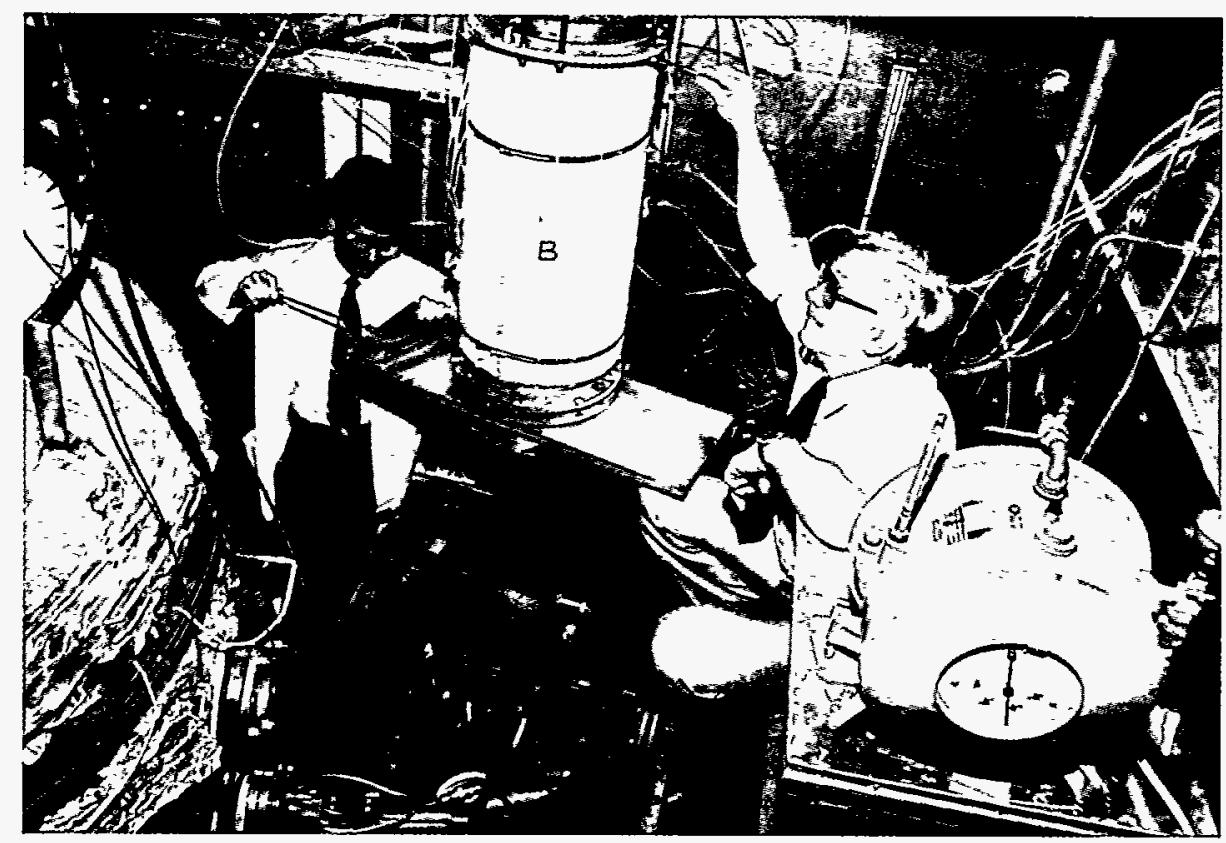

Fig. 4.23. Tony Wright (left) and Bill Pattison prepare for an aerosol transport experiment in equipment simulating the upper plenum portion of an LWR nuclear reactor vessel. These experiments are designed to determine whether the computer code TRAP-MELT accurately predicts the transport and deposition of metallic and metal oxide aerosols that would be generated during a nuclear reactor accident. This work was performed in Chem Tech as part of ORNL's NRC program. 
determine average burnup and, more importantly, the $133 \mathrm{I} / 131$ I ratio to determine the time of reactor shutdown and whether or not the reactor had been at normal power at the time of the accident. The challenge of doing this detective work was taken away about 2 weeks after the accident when the Soviets admitted to the accident and identified the reactor, the time of the accident, etc. Lorenz and Yamashita also detected increased releases of ruthenium and tellurium in material that was released 2 or 3 days after the accident, an indication that the reactor atmosphere had shifted from reducing or neutral to oxidizing. They also concluded that what appeared to be increasing releases of iodine was undoubtedly the result of the volatilization of previously deposited iodine as organic iodides.

\subsubsection{HTGR Programs, 1964-1991}

Shortly after the Peach Bottom gas-cooled reactor shutdown in November 1964, R. P. Wichner, L. Fairchild, and F. F. Dyer (Analytical Chemistry Division) entered the reactor building and gamma-scanned reactor piping and components to determine fission product distribution. They continued related work until 1979 by examining Peach Bottom samplers and graphite components for fission product behavior. Bob Wichner and others calculated tritium and ${ }^{14} \mathrm{C}$ balances for the Peach Bottom Reactor.

In the early 1970s, Bob Evans, assisted by Roy Towns, used sophisticated techniques to measure gas diffusion and permeation through various types of graphite. When a visitor arrived one day, and Roy introduced himself as Dr. Evans, he said he had to leave and turned the visitor over to his technician (the real Dr. Bob Evans). I'm sure that Bob made a good impression as the knowledgeable "technician."

Under the direction of H. J. de Nordwall, potential accidents in HTGRs were studied. E. L. Compere analyzed leakage paths from the reactor and the critical transport pathway to the human thyroid outside the reactor exclusion area and calculated potential doses to the thyroid. In an experimental project initiated by Ernst Hoinkis, a German visiting scientist, Morris Osborne studied the sorption and desorption of iodine onto/from HTGR materials, both in helium and under vacuum. In order to better simulate HTGR conditions, sorption data were obtained at much lower partial pressures of iodine, $\sim 10^{-11} \mathrm{~atm}$, than had been achieved previously. As expected, iodine sorption was shown to be proportional to iodine partial pressure and inversely proportional to surface temperature for a wide range of conditions. Maximum iodine coverages of $\sim 2 \times 10^{14}$ and $\sim 1 \times 10^{14}$ atoms $/ \mathrm{cm}^{2}$ were found for $\mathrm{Fe}_{3} \mathrm{O}_{4}$ and $\mathrm{Cr}_{2} \mathrm{O}_{3}$, respectively; graphite coverages were less by a factor of $\sim 100$. Of particular significance to reactor safety was the fact that small partial pressures of water vapor were found to enhance iodine desorption.

In later studies under Wichner, Dick Lorenz, Frank Dyer, and Roy Towns measured the sorption of iodine on graphite at higher temperatures (up to $800^{\circ} \mathrm{C}$ ) and Osborne measured the sorption of iodine (at 200 to $400^{\circ} \mathrm{C}$ ) on low-alloy steels used in HTGR steam generators. Very small amounts of surface oxide and small differences in gas chemistry were shown to strongly affect iodine sorption characteristics.

Bob Wichner and Lou Fairchild measured low-rate oxidation of graphite using a gas chromatograph to follow the oxidation rate. $\mathrm{O} . \mathrm{K}$. Tallent measured the sorptivity and diffusivity of both uranium and plutonium in graphite. Bob Fellows completed this work and analyzed the materials. Jim Wilson measured the diffusion coefficients of several fission products through graphite.

In work directed by Jim Mailen in the 1990-91 period, Sam Clinton and Randy Gibson investigated the sorption of iodine on steel at low iodine concentrations. Randy and Dick Lorenz investigated the sorption of iodine on Inconel and cesium on low-alloy steel.

T. B. Lindemer and Ray Pearson conducted research on the chemical design of HTGR fuels. One phase of their research was the "amoeba effect," the problem of fuel kernels migrating inside of the small coated fuel particles. This research led to a quantitative description of oxide and carbide fuel migration, a description that permitted a matching of fuel behavior to reactor operating characteristics. Also, they found that unirradiated fuel particles doped with synthetic fission products matched real fuel particle behavior and used them to explore the chemistry of $\mathrm{UO}_{2} / \mathrm{UC}_{2} /$ fission product mixtures typical of different burnups. This resulted in the improved chemical design of the $\mathrm{UO}_{2}-\mathrm{UC}_{2}$ fuel. Ted Besmann, Ed Beahm, Terry, and Charlie Culpepper performed Basic Energy Sciences fuẹl-related research with actinides, including uranium, 
thorium, and plutonium carbides and oxides. Terry also performed original research on the high-temperature chemistry of the urania/gadolinia system and developed a unique chemical thermodynamic model, useful for predicting the effect of lanthanide fission products on $\mathrm{UO}_{2}$.

In 1990, a cooperative effort with Metals and Ceramics Division to measure fission product release from HTGR fuels under accident conditions was begun. This project was sponsored by DOE. A graphite element furnace, capable of temperatures well above $2000^{\circ} \mathrm{C}$, was purchased, modified, and installed for remote operation in Hot Cell A of Building 4501. Morris Osborne and Jack Collins, along with Jim Travis and Charlie Webster, participated in the design, installation, and operation of this effort. The irradiated fuel specimens have included both groups of individual microspheres mounted in graphite holders and fuel particle-graphite compacts that are planned for use in the HTGR. Principal test parameters are temperature (1400 to $1800^{\circ} \mathrm{C}$ ) and time (up to $1000 \mathrm{~h})$ at temperature.

\subsection{THE STABLE ISOTOPE ENRICHMENT PROGRAM: THE EARLY YEARS, Gene Newman}

In October 1973, Floyd Culler appointed a committee to "evaluate the future strategy of the stable isotopes program at ORNL." This committee included Don Ferguson as chairman, Stan Auerbach, Gene Lamb, and Fred Maienschein. This action was prompted by concern on the part of Laboratory management that the Isotope Program, including Stable Isotopes, Radioisotopes, and the Isotope Research Materials Laboratory in the Isotopes Division, was faced with severe funding and management problems. The committee enlisted the aid of Program Planning and Analysis (PP\&A), under the direction of Bob Livingston, to provide staff support. The Chem Tech staff assigned to this project from PP\&A included John Bigelow, Gene Newman, and Colin West.

The PP\&A staff generated a report, transmitted to Culler by the committee in July 1974, entitled The Electromagnetically Separated Stable Isotopes Program at ORNL: Analysis and Recommendations. This report emphasized the benefits of the stable isotopes program to the then AEC, made note of the fact that the Laboratory gained recognition from distributing highly enriched stable isotopes to the worldwide research community, and made recommendations for implementation by both the Laboratory and the AEC to address the business aspects of the program.

In June 1975, Laboratory management dissolved the Isotopes Division and transferred the management and operation of the Stable Isotopes Program to the Chemical Technology Division, Radioisotopes Production and the Isotope Sales Office to the Operations Division, and the Isotopes Research Materials Laboratory to the Solid State Division. Chem Tech elected to create a new Stable Isotopes Section, appointed Gene Newman as section head, and nurtured the program through the perennial budget problems and changes directed toward establishing a viable business-oriented operation.

Initially the Isotope Section reported to Ray Wymer in his role as one of the two associate directors of the division. When Gene McNeese rejoined the division as the third associate director, the section was transferred to his area, and when Gene accepted another assignment at ORNL, the section once again reported to Wymer. Chem Tech reassigned activities involving the fixation of waste in concrete and borehole plugging in order to increase the $R \& D$ component of the Isotope Section at the $\mathrm{Y}-12$ site.

One of the best, and probably the last ever, isotopic enrichment of plutonium was made in the contained facility during this time. Approximately $1 \mathrm{~kg}$ of plutonium with a ${ }^{242} \mathrm{Pu}$ assay of almost 95\% was dropped off at Oak Ridge from a larger shipment on its way to Los Alamos. Joe Tracy and $H$. T. Milton reactivated the actinide facility, nursed two of the calutrons back to operational status after a stand-down of at least 5 years, and designed and built the ion sources and receivers. George Banic tweaked and tuned the high-voltage and magnet power supplies, and Bill Bell and $\mathrm{Al}$ Veach established the operational parameters. Jim Barker and Frank Scheitlin reactivated the actinide chemistry facility and did the feed preparation, product recovery, and recycle chemistry. The product recovered from running $1.6 \mathrm{~kg}$ of feed was more than $250 \mathrm{~g}$ of ${ }^{242} \mathrm{Pu}$ with an isotopic purity of $99.932 \%$. Portions of this material have been characterized and certified as mass-spectrometry standards.

One of the continuing challenges of the section was to prepare unique samples for research. Several interesting projects were accomplished, and one notable effort was the preparation of a 
$1-\mathrm{kg}$ bar of $99.9+\%$ enriched $56 \mathrm{Fe}$ for use as a neutron filter at the Brookhaven National Laboratory reactor. Purifying the material, converting it to metallic form, and then casting the bar without reintroducing any chemical contaminants sounds simple, but molten iron is almost a universal solvent. Hugh Caudill worked out a procedure that kept the impurity level to the few ppm range, and the bar was sent off to Brookhaven.

Another unique research material was prepared by Joe Paehler. The request was from the National Bureau of Standards for $10 \mu \mathrm{Ci}$ of ${ }^{229} \mathrm{Th}$ (the daughter of $233 \mathrm{U}$ ) with less than $10 \%$ activity of the other thorium isotopes. Starting with a $100-\mathrm{g}$ cow of enriched ${ }^{233} \mathrm{U}$ containing less than $18 \mathrm{ppb}$ of $232 \mathrm{U}$, Joe extracted and purified the daughter products for the National Bureau of Standards, who, in turn, characterized the sample as a standard.

The nature of the business continued to evolve from one of producing enriched isotopes of all the elements for the research community to use primarily in the measurement of nuclear properties to answering the demand generated by the nuclear medical health-care delivery field. As the pattern of demand changed from one of small quantities of all of the approximately 230 isotopes in the periodic table to one of large quantities of a very few isotopes, so did the funding and the $R \& D$ picture.

Although the budget problems were never completely solved, due mainly to the unique accounting policies associated with return of only a fraction of the isotopes sales credits to offset operating expense, the Chem Tech management did succeed in reestablishing the fact that operation of the Calutron Enrichment Program was beneficial to the research mission of the DOE and to the national nuclear medical health-care delivery sector. Furthermore, the morale of the personnel continued to improve under the leadership of the division.

In 1983, Laboratory management again reviewed the operation of the various components of the total Isotopes Program. The conclusion was that each of the activities had benefitted from the initial fragmentation and that, in the interests of unified program management, it was time to recombine the program in one division. The Operations Division was selected as the new home, and the Stable Isotope Program was transferred out of Chem Tech. The Concrete Fixation Program remained within Chem Tech but was transferred to another section, and the Isotopes Section was eliminated.

July 1988 brought another change in the stewardship of the Isotope Program. The Operations Division was eliminated, and this time the responsibility for the entire Isotope Program was transferred to Chem Tech.

\subsection{THE TRANSURANIUM ELEMENT (TRU) PROCESSING PROGRAM IN THE CHEMICAL TECHNOLOGY DIVISION, John Bigelow}

On October 27, 1957, Dr. Glenn T. Seaborg wrote to Lewis L. Strauss, then Chairman of the AEC, to stress the need for a very high flux reactor and a program to produce berkelium, californium, and einsteinium in substantial (multimilligram) quantities. This topic was then brought up at meetings of the directors of the various national laboratories, and a plan was developed whereby new facilities specifically designed for this purpose would be constructed at Oak Ridge (Fig. 4.24) and the resulting products would be allocated by the $\mathrm{AEC}$ to the participating laboratories based on the advice of a Transplutonium Program Committee.

ORNL was undoubtedly selected because of the many years of demonstrated capabilities in reactor design and development, as well as in the development of many chemical processes and the safe processing of reactor fuels and radioisotopes on the pilot-plant scale. The dedication of the transuranium research laboratories was attended by Glenn Seaborg (Fig. 4.25).

During the design and construction of the Oak Ridge facilities, two lots of ${ }^{242} \mathrm{Pu}$ feed were prepared at Savannah River by long-term irradiation of approximately $10-\mathrm{kg}$ batches of ${ }^{239} \mathrm{Pu}$, and then an extra push was given to the program by irradiating some of the $242 \mathrm{Pu}$ at Savannah River to provide feed to the processing facility before the HFIR could bring targets to maturity. Thus, initial criticality at the HFIR occurred in 1965; however, after a substantial testing program, the first targets were loaded into Cycle 3 and operated at 90 MW on August 7, 1966. The first hot processing campaign was completed in the Transuranium Processing Facility (now REDC) in November 1966 on prototype HFIR targets irradiated at Savannah River. That 


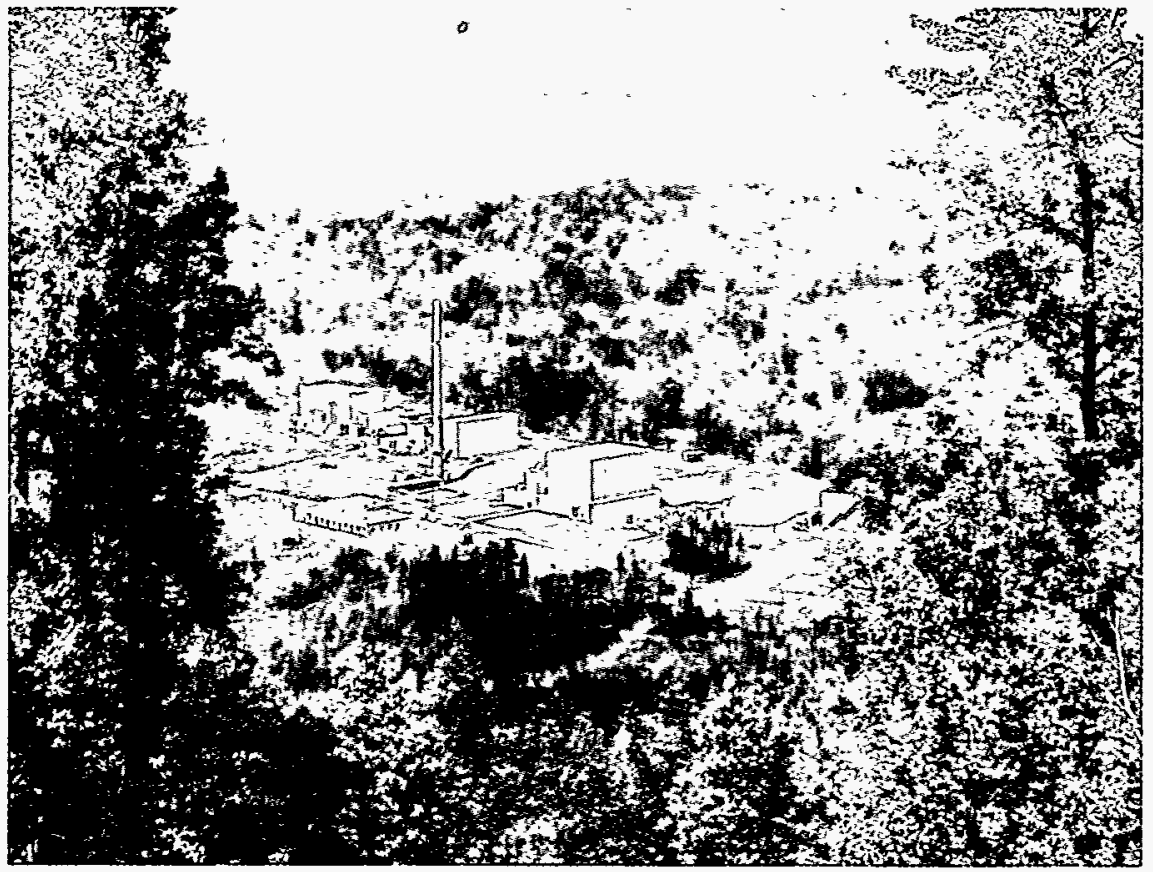

Fig. 4.24. In this photograph of the TRU Complex, the High-Flux Isotope Reactor is located in the building at the right center with the reactor's cooling tower to the far right; the Transuranium Processing Plant is located in the center behind the smokestack; the HFIR office building is located in the left foreground; and the Thorium-Uranium Fuel Cycle Development Facility is located at the extreme left.

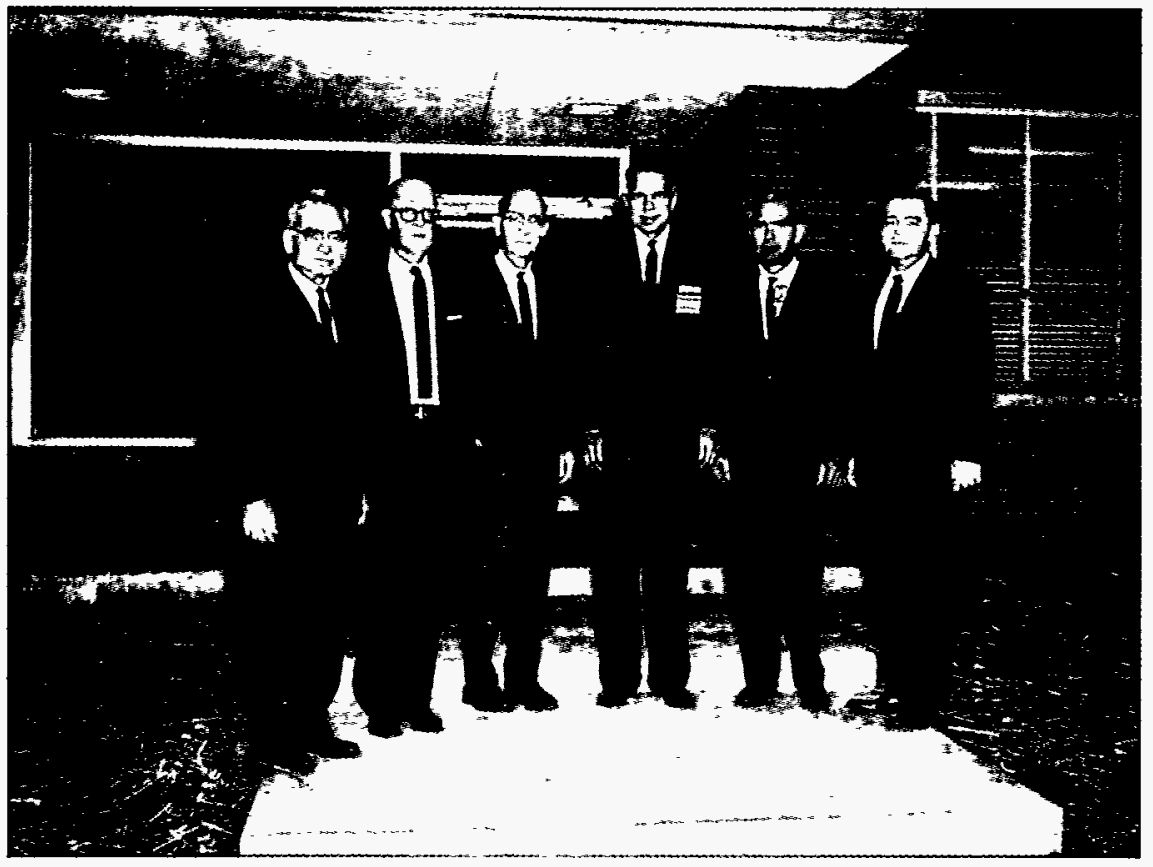

Fig. 4.25. Glenn Seaborg, discoverer of plutonium and Chairman of the Atomic Energy Commission, assisted in the dedication of the newly constructed transuranium chemistry research facilities. Pictured (left to right) are Alvin Weinberg, Director of ORNL; George E. Boyd, Associate Director of ORNL; Ellison Taylor, Director of the Chemistry Division; Chairman Seaborg; Don Ferguson, Director of the Chemical Technology Division; and Lou Keller, Manager of the TRU laboratory facility. 
campaign yielded about $180 \mathrm{~g}$ of ${ }^{252} \mathrm{Cf}$

(Fig. 4.26).

Savannah River continued to boost the National Transplutonium Element Program by producing $3 \mathrm{~kg}$ of ${ }^{244} \mathrm{Cm}$ for the Space Power Program and then embarking on a Californium-I Campaign to produce multigram quantities of ${ }^{252} \mathrm{Cf}$ for a Market Evaluation Program. As it turned out, the market for ${ }^{252} \mathrm{Cf}$ did not develop as rapidly as anticipated, the Multipurpose Processing Facility (MPPF) being built at Savannah River was never completed, and about one-third of the irradiated materials were shipped to ORNL for processing. The $720 \mathrm{mg}$ of ${ }^{252} \mathrm{Cf}$ that ORNL recovered was returned to Savannah River for the Market Evaluation Program, but eventually ORNL was allowed to include the recovered curium fraction (rich in ${ }^{246} \mathrm{Cm}$ and ${ }^{248} \mathrm{Cm}$ ) in feed to the HFIR. This advanced recycle feed allowed ORNL to reach and sustain a level of production approaching $0.5 \mathrm{~g} /$ year beginning in 1972 . It also allowed some time at the REDC to undertake other activities and some space in the HFIR target island to undertake irradiation testing activities and production of certain high-specific-activity radioisotopes.

\subsection{0.i The Early Development Years}

The chemical processes for separating and purifying the transplutonium elements had been demonstrated on the microscale by the scientists involved in the initial production and discovery of these elements and their various isotopes. These processes mostly involved ion exchange using various complexing ions to hold the materials in solution and help to differentiate between adjacent elements with nearly identical chemical properties. A group under Rex Leuze in the Chemical Development Section was assigned the responsibility for scaling up these techniques to the macro scale involving grams of curium and multimilligrams of transcurium elements. This group already had experience in handling ${ }^{233} \mathrm{U}$, ${ }^{235} \mathrm{U},{ }^{239} \mathrm{Pu}$, and ${ }^{241} \mathrm{Am}$ on the gram scale and believed that they could handle ${ }^{244} \mathrm{Cm}$ that way also, with some unit shielding in their glove boxes. Consequently, a super glove box line was designed for use in water-filled caves (there was a small concrete shielded cell to dissolve the.targets and remove the fission products). However, as the design work proceeded, it became apparent that this scheme was rather marginal. Indeed, when ${ }^{254} \mathrm{Cf}$ was first produced in a reactor and cross sections were measured, Alfred (Chet)

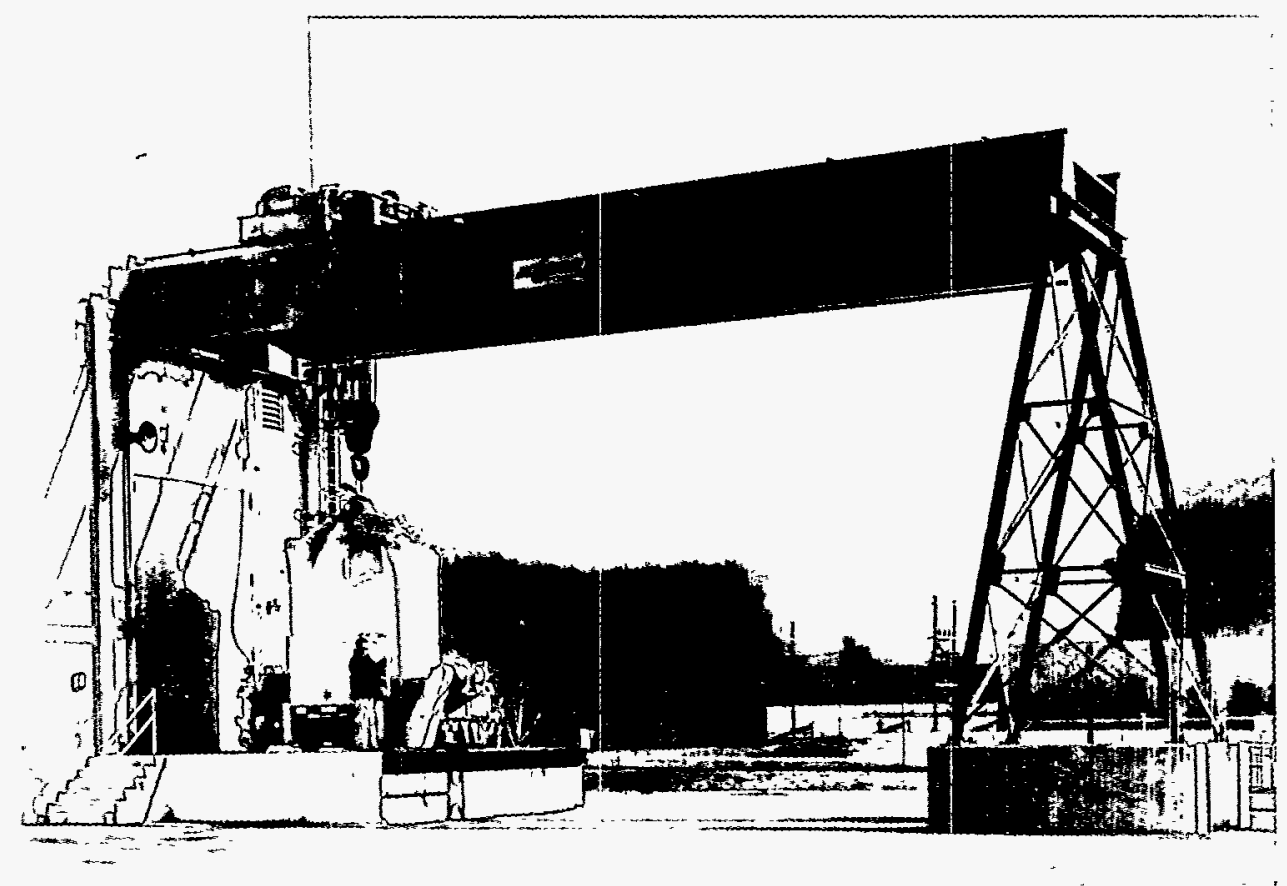

Fig. 4.26. The HFIR Target Cask and Chem Tech engineer are shown with reactor cooling towers in the background. 
Chetham-Strode, leader of the Transplutonium Group in the ORNL Chemistry Division, predicted that the neutron and gamma radiation from the ${ }^{252} \mathrm{Cf}$ produced in the HFIR would be doubled by the intense spontaneous fission rate in the ${ }^{254} \mathrm{Cf}$ that accompanied it. (Actual experience shows that at discharge about one-third as many neutrons come from the ${ }^{254} \mathrm{Cf}$ as from the ${ }^{252} \mathrm{Cf}$.) This information was the "straw" that caused a total reevaluation of the processing plans.

The result was a 12-cell, 12-laboratory version of Building 7920 that was estimated to cost $\$ 14$ million. Laboratory Director Alvin Weinberg vetoed this idea and set a ceiling of $\$ 8$ million. The Chem Tech Process Design Section team headed by Bill Unger went on a six-day week for the remainder of the summer and part of the fall to downsize the plans to the current nine-cell, eight-laboratory building. Other members of the team included Bill Burch, Orlan Yarpro, Baird Bottenfield, and John Bigelow, who had just returned from a three-year stint with the AEC. Also helping was co-op student Ben Crump.

The Process Design Section advised the Chemical Development Section (principally chemist Russ Baybarz and his technician, Chick Wiggins) to concentrate on the development of solvent extraction processes to isolate and purify the transplutonium elements. The rationale was that in ion exchange, the active site is a specific functional group bound to a polystyrene matrix. The nuclide-emitting radiation is chemically bound to that active site; thus, the radiation source is precisely located to do the most damage to the chemical structure needed to do the processing. In solvent extraction, the radiation source is dissolved in the organic phase and "theoretically" this dilutes the effect of the radiation and allows processing at a much higher radiation density. Accordingly, Baybarz developed the TRAMEX and HEPEX processes for separating the heavy elements, respectively, from the rare-earth fission products and from each other. The layout of Bldg. 7920 was based on these processes.

With the basic process established and with the advent of congressional approval of the line items for the reactor and processing plant, development work for these facilities began in earnest. The Unit Operations Section began to study designs of pulse columns that could be mounted on the new equipment racks. The Process Design Section, working with ORNL Engineering, developed a complete armory of modular equipment (e.g., pumps, valves, samplers, and filters) that could be easily mounted and dismounted from these racks using master-slave manipulators. However, along with the equipment rack concept, it was necessary to devise a series of gadgets that facilitated the entrance and removal of materials from the cell bank while maintaining positive alpha containment. These included the transfer case, the intercell conveyor system, the plastic bucket sealing system for solid-waste removal, and the concrete waste cask to accumulate plastic buckets and protect them during transfer to the burial ground.

The Chemical Development Section continued to work on the flow sheets, studying the parameters that affected the process, and providing the engineers with data to optimize the curium separation. This included a crude, small-scale batch countercurrent extraction test of the TRAMEX process at full activity level-10 W/L.

It was decided to build a test facility in the Building 4507 hot cells that, in addition to testing the processes, would provide the function of purifying some of the ${ }^{243} \mathrm{Am}$ and ${ }^{244} \mathrm{Cm}$ that had been produced at Savannah River as co-products with the ${ }^{242} \mathrm{Pu}$ destined for the initial feed to the HFIR. These materials would be the first multigram-scale distributions to the heavy-element community. However, before the Curium Recovery Facility (CRF) went into operation, a new mission developed: to back up the private operation to recover ${ }^{242} \mathrm{Cm}$ for the Space Power Program. It was necessary to upgrade the CRF to achieve a higher degree of reliable operation to support this latter mission. In fact, as the time approached, the ORNL facility became the prime recovery facility, and the Martin Company Hot Cells at Quehanna, Pennsylvania, were shut down.

The redesign and installation of the upgraded CRF equipment were under the supervision of Frank Peishel. Frank had come to ORNL as a draftsman with the Foster Wheeler Corporation architect-engineers for the ICPP. After returning to ORNL, he attended UT night school and took a year's leave of absence to complete his bachelor's degree in mechanical engineering. The CRF was Frank's first major project after becoming a professional engineer. In December 1963, the first shipment of raffinate solution was received from Savannah River and the CRF went hot. Vic Vaughen was in charge of the operation, which started out as a group within the Chemical Development Section but later was transferred to 
the Pilot Plant Section. Other personnel attached to the project included John Bigelow as data analyst, Fred Chattin, Tom McDuffee, Fred Kappelmann, and Bill Whitson as shift engineers and John Brock, Bill Lindsey, Bill Bryan, and Bill Bostic (and others) as shift technicians.

Over the next two years, several batches of ${ }^{243} \mathrm{Am}$ and ${ }^{244} \mathrm{Cm}$ were isolated and purified and distributed to various users. Then a series of irradiated ${ }^{241}$ Am slugs was processed to recover ${ }^{242} \mathrm{Cm}$ for materials compatibility studies and an environmental test of a prototype space power supply. A typical 6-g batch would generate over $700 \mathrm{~W}$ of radiation power. This stuff required very careful handling!

Besides producing useful products, the CRF served well as a pilot plant for several of the processes that were being installed in Building 7920, the Transuranium Processing Plant, or TRU as it was known in those days. The staff learned of several problems resulting from corrosion, impurities in drum-quantity reagents, and the problems of operating small mixer-settlers remotely. They also learned that high-radiation power densities did not have a significant first-order effect on solvent extraction processes, but they did cause loss of acid by radiolysis and resulted in corrosion and impurities. This information resulted in two significant design changes at TRU: Hastelloy $\mathrm{C}$, which contained molybdenum, a bad actor, was replaced by Zircaloy-2 in all process applications but was retained for use in waste tanks. Later some process vessels were upgraded again to tantalum when it was discovered that Zircaloy- 2 corroded rapidly upon coming in contact with strong $\mathrm{HCl}$ at high power densities.

During the last few campaigns to produce ${ }^{242} \mathrm{Cm}$, operational support from Building 7920 (TRU) was required to provide solution makeup and off-shift delivery services. This was necessary because some of the CRF crew had been taken away to form the nucleus of the TRU operating group. The final ${ }^{242} \mathrm{Cm}$ campaign was completed in May of 1966, at which time additional personnel moved over to TRU, leaving only a day crew for design and development.

\subsubsection{Start-up of Building 7920 (TRU)}

The organization of an operating staff for TRU began in the fall of 1965 with a formal, three-week training program commencing on October 18 ,
1965. This group was under the direction of Bill Burch, with Orlan Yarbro serving as Chief of Operations. Other personnel assigned to the project included John Bigelow, Fred Chattin, Emory Collins, Waldo Evans, Les King, Joe Matherne, and Jim Turley. John Van Cleve, from the Metals and Ceramics Division, was to be in charge of target fabrication. The operating group moved into the new facility on November 1965 and began cold checkout of equipment and calibration of tanks and flowmeters. Some of the development laboratories were placed in radioactive service in January 1966, and the first activity was introduced into the hot cells in June 1966. The first hot processing campaign was completed in November 1966 on prototype HFIR targets that had been irradiated at Savannah River. About $180 \mathrm{~g}$ of ${ }^{252} \mathrm{Cf}$ (the yardstick for heavy-element production) had been recovered in this inaugural campaign at ORNL. After final purification by Russ Baybarz, this material was distributed to Argonne National Laboratory and Savannah River Laboratory, as recommended by the Transplutonium Program Committee. Figure 4.27 shows the cell area of the Transuranium Processing Plant, and Fig. 4.28 shows operations being conducted within the cell behind a 54-in.-thick window.

In that first campaign, and indeed many that followed, the staff had to face and solve a host of problems. Some were chemical, some mechanical. Of the chemical problems, most were related to the unexpected behavior of the 92 "regular" elements. The transplutonium elements did what was expected, provided the common elements were kept under control. One exception was berkelium, but in the presence of holding reductants, it could be maintained in the $\mathrm{Bk}$ (III) state. In the mechanical arena, the same sort of situation applied. Gadgets had to be modified and some new ones invented, but the basic equipment rack concept, the equipment transfer case, and indeed the idea of total replaceability engineered into the building worked beautifully. As shakedown continued and processing of HFIR-irradiated materials began, our output increased to milligrams, tens of milligrams, and eventually hundreds of milligrams of ${ }^{252} \mathrm{Cf}$ per campaign.

While this was going on, the HFIR began having problems with the target rods. They were beginning to split open, although, fortunately, relatively small fractions of their contents were being released to the primary coolant. A very intensive effort to determine the cause ensued. 


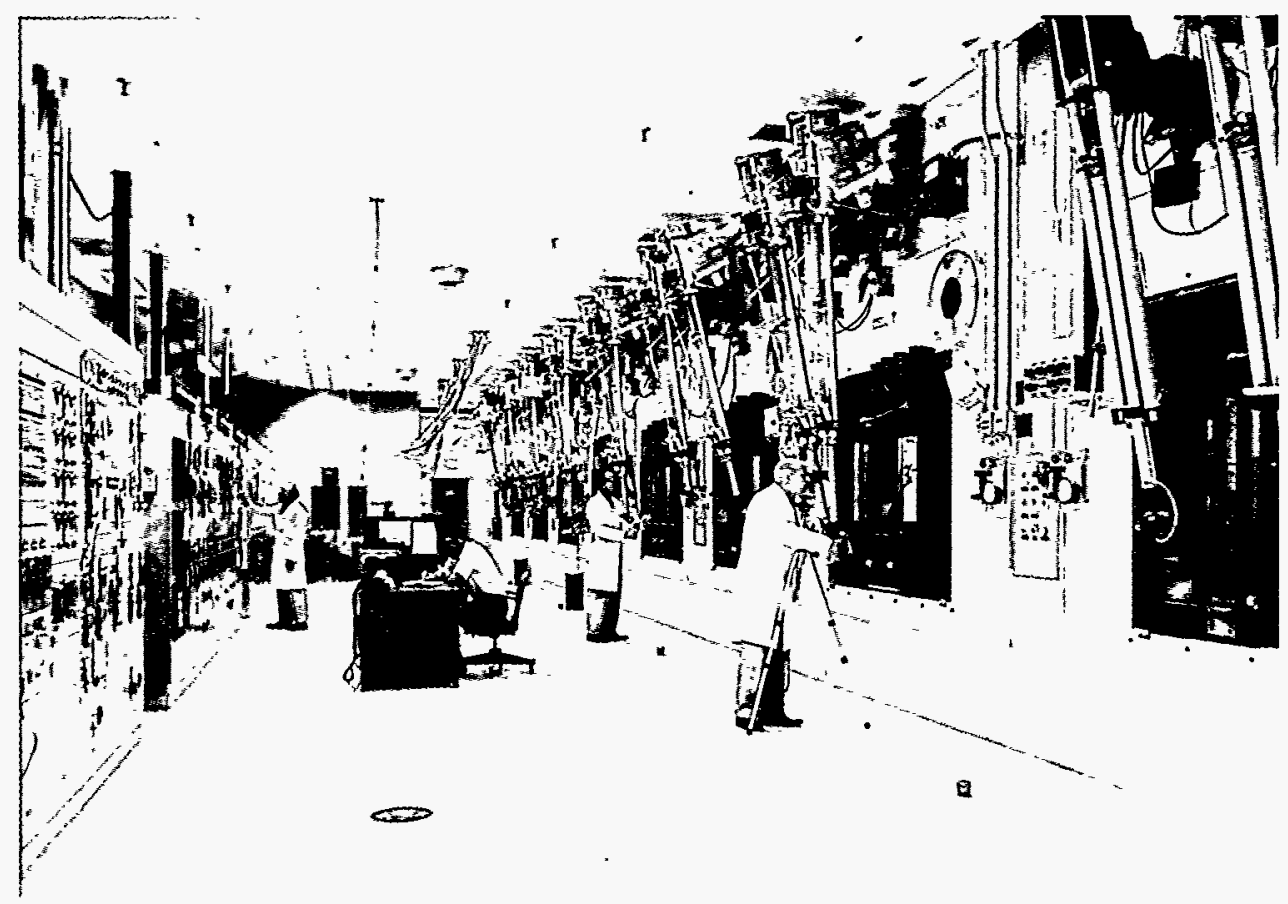

Fig. 4.27. The cell area of the Transuranium Processing Plant. The cells at the right are used in preparing target rods for irradiation and for separation of elements produced by irradiation. The panel boards at the left control the processes.

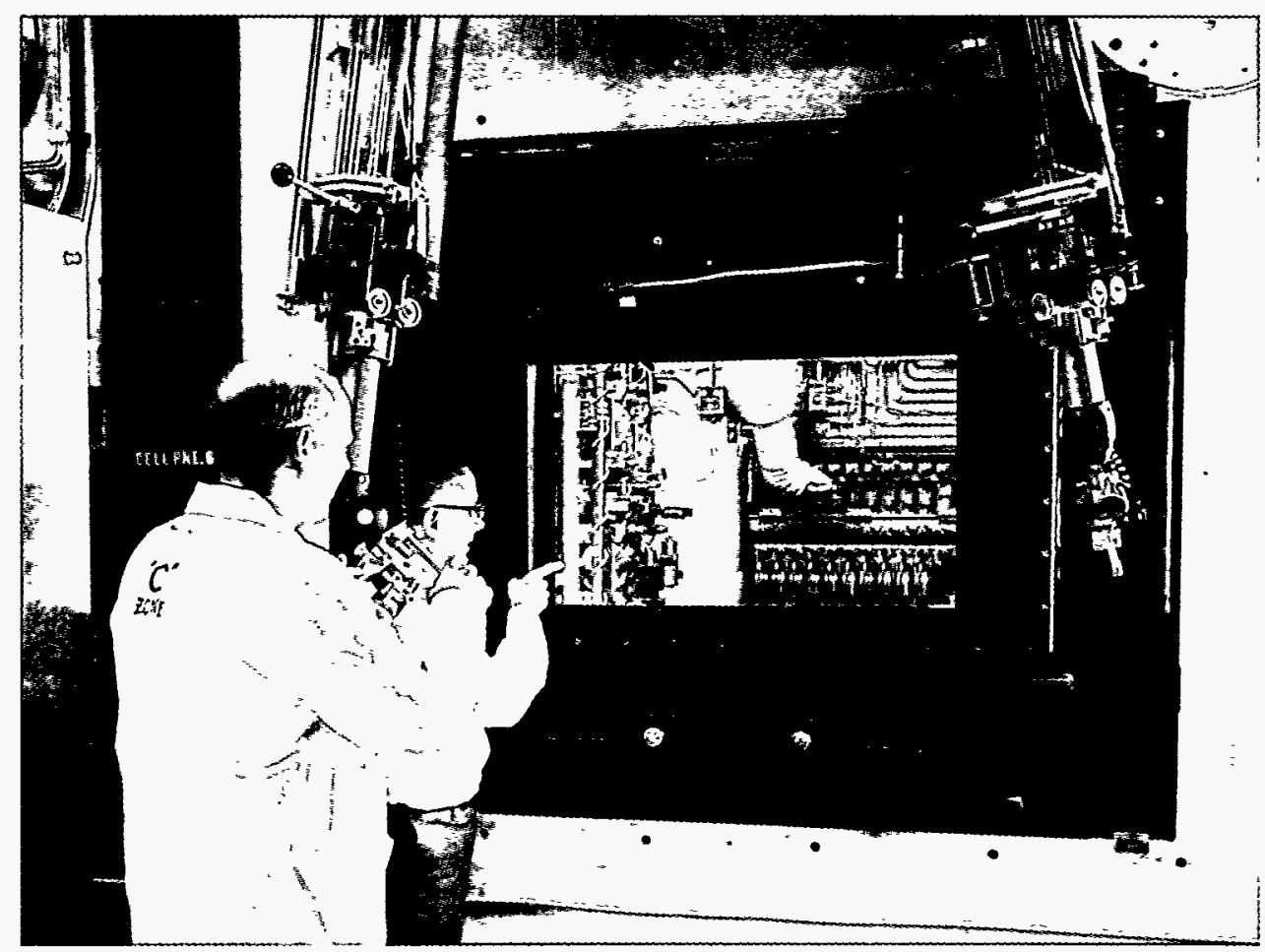

Fig. 4.28. Orlan Yarbro and a co-worker conduct cell operations with slaved manipulators behind the 54-in.-thick cell window. 
Apparently, the aluminum alloy cladding had embrittled at the very high fluence (flux multiplied by time) experienced by these targets. Seventeen had been irradiated in a high-flux demonstration run at Savannah River and then, after inspection and new shrouds at TRU, were among the first set of targets irradiated in the HFIR. By the summer of 1967 , they had received a greater neutron exposure than any other aluminum samples yet studied. New mechanisms for embrittlement were uncovered: aluminum was being transmuted to silicon, nickel (particularly ${ }^{59} \mathrm{Ni}$, itself an activation product) was undergoing an $(n, \alpha)$ reaction to produce significant amounts of helium, and the high fast-neutron flux was causing a large number of knock-on protons to end up in the outer layers of the cladding. All three of these impurities exceeded their solubility in aluminum, so they migrated to the grain boundaries, where they reduced the tensile strength and ductility of the aluminum. At the same time, the ${ }^{242} \mathrm{Pu}$ in the targets was being transmuted to ${ }^{243} \mathrm{Am},{ }^{244} \mathrm{Cm}$, and ${ }^{245} \mathrm{Cm}$, a nuclide with a very high fission-to-capture ratio. The fissioning of ${ }^{245} \mathrm{Cm}$, augmented by lesser amounts of the other heavy nuclides present, accounted for a fissioning of over $65 \%$ of the initial heavy-metal atoms present. There simply was no room for all of these fission products inside the target assembly, and since the ductility was lost, the expanding pellets split the jackets. The solution was simple: leave more space inside the pellet by pressing to only $80 \%$ density instead of the initially specified $90 \%$.

Fortunately the reactor operators and the AEC allowed the staff to continue the irradiation of the stock of $90 \%$ dense targets either till failure was detected or until the planned irradiation was reached. None showed the spectacular split that the first failures had shown, but most had a few hairline cracks when they were discharged. Of the subsequent recycle targets, only one showed cracks but no other indication that it was leaking.

In addition to solving the target failures, the staff learned to build targets containing ${ }^{244} \mathrm{Cm}$. Originally, the first batches of curium oxide microspheres were made in Bldg. 4507 by Jim Hoeschele. Based on his process parameters, an equipment rack was designed, built, and installed in TRU to carry out the process. Although the process worked, a significant recycle stream $(-30 \%)$ was generated, so Russ Baybarz and Joe Knauer of the Chemical Development Section came up with a resin-loading process that produced good oxide particles with very little rework. Dick
Haire made a suggestion on the firing cycle that improved the process more. This process has been used ever since. Research on development of plutonia microspheres was conducted in the TRU glove box facilities shown in Figs. 4.29 and 4.30.

\subsubsection{Californium-I Campaign}

The experience that Savannah River had in preparing ${ }^{242} \mathrm{Pu},{ }^{243} \mathrm{Am}$, and ${ }^{244} \mathrm{Cm}$ for the National Transplutonium Program, plus a new Curium-I and II series of irradiations to produce $3 \mathrm{~kg}$ of ${ }^{244} \mathrm{Cm}$ for the Space Nuclear Programs, suggested that they could also produce ${ }^{252} \mathrm{Cf}$ in commercial quantities at an attractive price. A Market Evaluation Program had been under way at Savannah River ever since the earliest quantities of ${ }^{252} \mathrm{Cf}$ had become available and the time seemed right to produce 2 to $3 \mathrm{~g}$ of ${ }^{252} \mathrm{Cf}$. Accordingly, they extended the Curium-II irradiation to make $4.5 \mathrm{~kg}$ of ${ }^{244} \mathrm{Cm}$ and then fabricated the excess $\mathrm{Am}-\mathrm{Cm}$ and ${ }^{242} \mathrm{Pu}$ into targets for ${ }^{252} \mathrm{Cf}$ production. Because their new MPPF was not yet in operation, they asked TRU to undertake the processing of some of the irradiated Cf-I targets. ORNL built two new shipping containers on Savannah River's account and also installed a new dissolver to handle some of the Cf-I outer housings. TRU campaigns and Cf-I campaigns were alternated, and by June 1973, $720 \mathrm{mg}$ of ${ }^{252} \mathrm{Cf}$ for Savannah River and $571 \mathrm{mg}$ for the national heavy-element research program had been recovered. As a bonus, Savannah River allowed ORNL to use the high-quality intermediates $\left({ }^{244} \mathrm{Cm},{ }^{24.6} \mathrm{Cm}\right.$, and ${ }^{248} \mathrm{Cm}$ ) recovered from the Cf-I targets to enhance the production rate in the HFIR. By then, ORNL was able to trim back the staff somewhat and maintain a production rate of about $500 \mathrm{mg}$ per year. This was sufficient for the majority of needs for the research community and for a supply to Savannah River to carry on the Market Evaluation Program. Since the needs of this program were not growing at anywhere near the rate anticipated when the Cf-I campaign was initiated, plans to complete the MPPF and process the remaining $65 \mathrm{Cf}-\mathrm{I}$ outer housings were put on indefinite hold. The 65 outer housings were eventually discharged, cropped to a length too long to fit into the Q-Ball Shipping Container, and stored in the RBOF. Perhaps these housings will be shipped to ORNL for processing someday. 


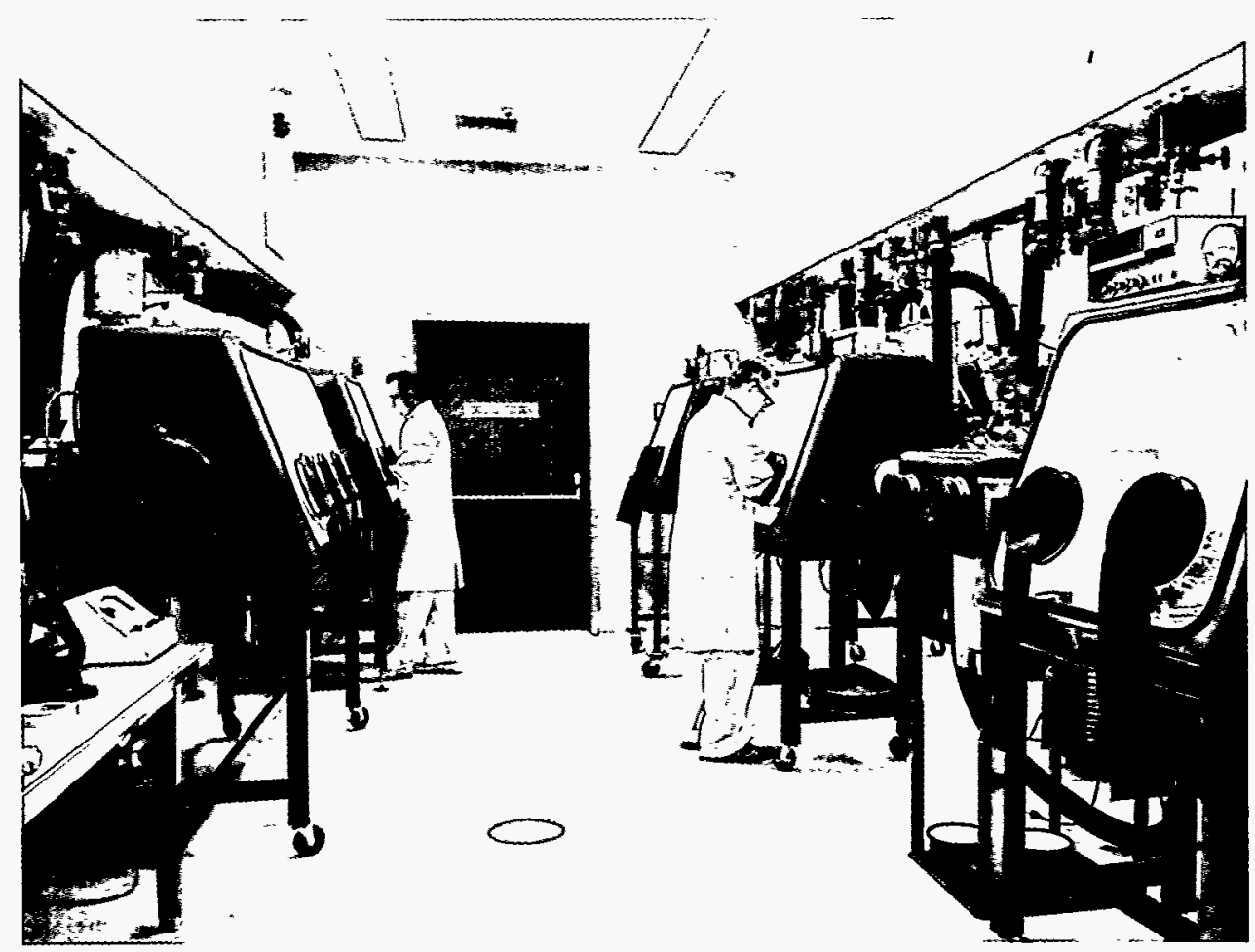

Fig. 4.29. Dick Haire (left) and O. K. Tallent researched development of plutonia microspheres in the glove box laboratory at TRU.

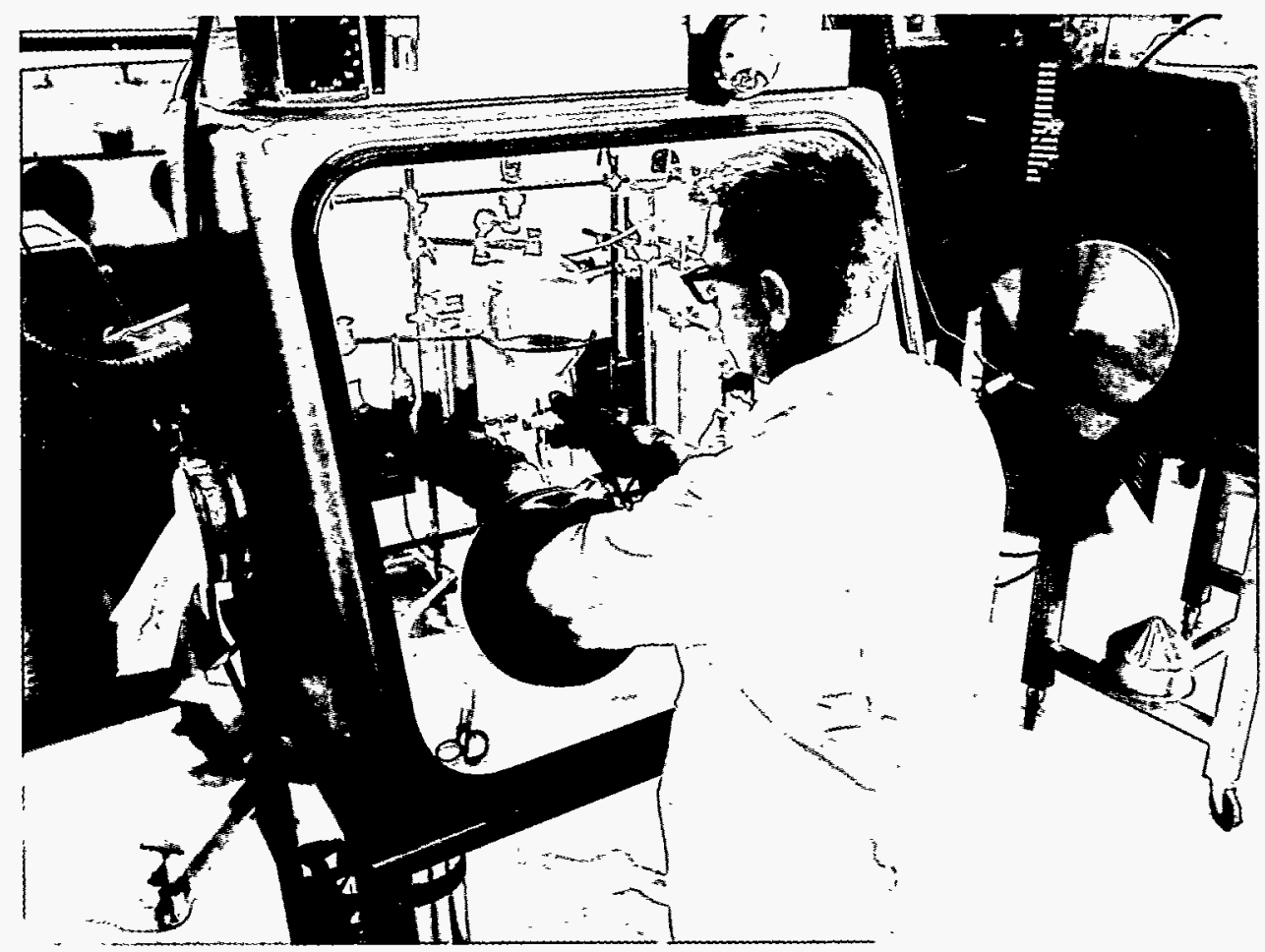

Fig. 4.30. O. K. Tallent is shown conducting a solvent extraction separation process to purify a plutonium solution for preparation of plutonium microspheres. 


\subsubsection{Maturity of the Transuranium Element Processing Program}

The years following the Cf-I campaigns were years of fruitful maturity. Bill Burch accepted another position for Union Carbide, and Les King became manager of TRU (Fig. 4.31). New equipment racks were installed that incorporated several years of operating experience. Processes underwent little change from campaign to campaign. Transplutonium Program Committee meetings became much less acrimonious because more "goodies" were available and didn't have to be fought over. Schedules could be prepared a year in advance and met within a few days. During this time, TRU established a substantial reputation as a reliable supplier of main-line isotopes ${ }^{249} \mathrm{Bk}$, ${ }^{252} \mathrm{Cf}$, ${ }^{253} \mathrm{Es}$, and ${ }^{257} \mathrm{Fm}$, as well as the secondary products ${ }^{248} \mathrm{Cm},{ }^{249} \mathrm{Cf}$, and ${ }^{254} \mathrm{Es}$. Preparation of special isotopes or special purities of standard isotopes to meet the needs of researchers was also undertaken. The details of the technology and program activities were described in a series of papers listed in Sect. 4.10.8.

This technology is available to continue a heavy-element program as long as it may be needed, provided the HFIR or Advanced Neutron Source (ANS) continues to operate and as long as the supply of makeup curium holds out.

\subsubsection{Other Spin-Offs from the Heavy-Element Program}

The CFRP funded a series of Purex flow-sheet tests in TRU to help determine the effectiveness of this process on very high-burnup fuels. Special equipment racks were installed in Cubicle 5 of Building 7920, with a set of dedicated vessels in Tank Pit 5. This special equipment was designated the Solvent Extraction Test Facility (SETF). The equipment in the cubicle included a dissolver, feed adjustment tank, feed head tanks, three each 16-stage mixer-settlers, and an anion-exchange column for plutonium purification. Various catch tanks and evaporators were in the tank pit. In a series of campaigns, several batches of LWR fuel were processed and, as it became available, small samples of oxide fuel from EBR-II and FFTF were processed, eventually working up to $100,000 \mathrm{MWd}$ /ton FFTF fuel. The tests showed that the solvent extraction flow sheet could deal with the high-burnup fuel, provided that adequate feed clarification is obtained. The SETF was closed down in 1986 because of severe funding cuts in the

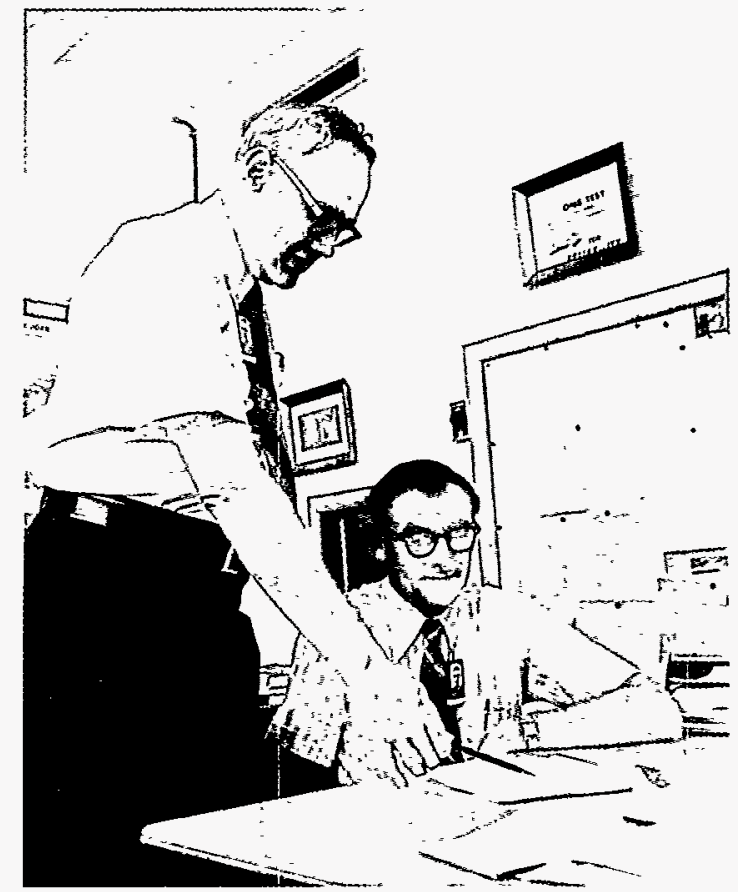

Fig. 4.31. John Bigelow (left) and Les King plan the TRU facility production in order to meet the national and international needs of scientists who use its heavy element products as research tools.

CFR Program. The equipment in the SETF was kept because it was thought that it might come in handy someday.

The LEAP (Large Einsteinium Activation Program) was more of a very special project than a program in its own right. For several years, ORNL had been considering efforts to increase the supply of ${ }^{254} \mathrm{Es}$ (typically $4 \mu \mathrm{g}$ per campaign) because this isotope was so valuable in doing research in the transactinide region. Following the National Academy Workshop in 1983, a group of four national laboratories collaborated on a proposal for a major thrust (LEAP) to increase the supply of ${ }^{254} \mathrm{Es}$ by an order of magnitude and focus the research using that isotope into four particular areas. The proposal requested funding for new instrumentation and equipment to do the research, as well as for out-of-pocket funding for the difficult production effort. The program was never funded, and preparatory work ran down when the HFIR was shut down in 1986.

The Mark-42 Processing Program is designed to recover ${ }^{243} \mathrm{Am}$ and ${ }^{244} \mathrm{Cm}$ from Savannah River-irradiated Mark-42 assemblies for use by Los Alamos National Laboratory (LANL) and Lawrence Livermore National Laboratory (LLNL). 
However, Savannah River cannot prepare the assemblies because their MPPF is not available. This program, which supplies a significant part of the REDC funding, has been in planning since 1985 and has reached the point that one segmented assembly is in the REDC hot cells and a second segmented assembly is at Pacific Northwest Laboratory (PNL) awaiting shipment to ORNL. Portions of the first assembly have been dissolved, and processing began in the spring of 1992. It will be necessary to recover the valuable ${ }^{242} \mathrm{Pu}$ also. Researchers at ORNL are hoping that some of the ${ }^{244} \mathrm{Cm}$ will be considered excess to the program and can be applied to the Transuranium Processing Program.

The Californium-252 Industrial Sales/Loan Program was transferred to ORNL in 1987 . ORNL continues this program of supplying ${ }^{252} \mathrm{Cf}$ to industry by sale and to DOE and DOD installations and contractors by loan, which was begun at Savannah River 25 years ago. ORNL furnishes the same source forms developed and furnished by Savannah River. ORNL also carries out medical and educational loans but does not, as yet, have the capability for fabricating medical sources. At the present time, there is an annual demand for about $50 \mathrm{mg}$ of ${ }^{252} \mathrm{Cf}$ for sale and about $130 \mathrm{mg}$ for all other uses. Excess ${ }^{252} \mathrm{Cf}$ (if any) is stockpiled as a "cow" for production of the ${ }^{248} \mathrm{Cm}$ daughter, a valuable research isotope.

Other radioisotopes are now being produced using (in part) REDC facilities. These include ${ }^{103} \mathrm{Pd}$ and ${ }^{63} \mathrm{Ni}$, with ${ }^{192} \mathrm{Ir}$ to be phased in shortly.

\subsubsection{The Radiochemical Engineering Development Center and Its User Community}

The Radiochemical Engineering Development Center (REDC) is comprised of two adjacent hot cell structures and ancillary facilities. It is operated around the clock by a staff of some 50 members of the Chemical Technology Division who are assisted by about 25 members of in-house support divisions-Analytical Chemistry, Plant and Equipment, Instrumentation and Controls, and Environmental and Health Protection. The principal programs carried out at the REDC are the Transuranium Element Processing Program, the Californium-252 Industrial Sales/Loan Program, and the Mark 42 Processing Program.

Transplutonium Element Processing Program. The REDC is the production, storage, and distribution center for the DOE heavy-element research program. Transplutonium element targets fabricated at the REDC and irradiated in the High Flux Isotope Reactor are returned to the REDC for processing to recover and purify all transplutonium elements from americium through fermium.

The mainline products ${ }^{243} \mathrm{Am},{ }^{244} \mathrm{Cm},{ }^{249} \mathrm{Bk}$, ${ }^{252} \mathrm{Cf}$, ${ }^{253} \mathrm{Es}$, and ${ }^{257} \mathrm{Fm}$, along with the derived products ${ }^{248} \mathrm{Cm},{ }^{249} \mathrm{Cf},{ }^{254} \mathrm{Es}$, and ${ }^{255} \mathrm{Fm}$, are routinely supplied to $6 \mathrm{DOE}$ Sites: ANL, LANL, LBL, LLNL, ORAU, and ORNL and occasionally to other laboratories in the US and overseas (4 in the past 6 years). In addition, special products can be prepared in collaboration with the researchers to suit the specific needs of their experiments.

Examples of such materials furnished in the past 6 years include ${ }^{240} \mathrm{Pu},{ }^{242} \mathrm{Cm}$, and ${ }^{250} \mathrm{Cf}$. We have also made ${ }^{24} \mathrm{Na}$ by bombarding ${ }^{27} \mathrm{Al}$ with fast neutrons from ${ }^{252} \mathrm{Cf}$. It should be noted that several of the DOE laboratories host collaborative research activities with nearby educational institutions.

Research using these transplutonium elements is conducted in the following fields:

- Nuclear Reactions and Synthesis of New Species

- Nuclear Properties of the Transplutonium Elements

- Chemical Properties in Solution of the Elements Americium through Fermium

- Spectroscopy of the Heavy Actinide Elements

- Solid-State/Magnetic Properties

- Industrial and Other Applications

- Biomedical Applications

In a number of the above areas, significant progress has been made in recent years. Among the unexpected and exciting findings and new capabilities are:

- the discovery of bimodal fission in some nuclides with $Z \geq 100$;

- the longer-than-predicted spontaneous fission half-lives in some relatively neutron-rich nuclides;

- chemical studies of Lr, element 104, and element 105 by one-atom-at-a-time techniques;

- formation of $\mathrm{Bk}(\mathrm{II})$ by pulse radiolysis of Bk(III) solutions;

- development of a technique for detecting $\mathrm{Am}^{3+}$ at a concentration level of $10^{-10} \mathrm{M}$;

- elucidation of the photophysics of $\mathrm{Bk}^{4+}$ and $\mathrm{Cm}^{4+}$. 
One of the products listed above $\left({ }^{252} \mathrm{Cf}\right)$ is a rather poor subject for research because of its intense neutron emission. However, for this same reason, the material has a great many applications as discussed in the next section. In the years since the program began, the Transplutonium Element Processing Program has provided to the Californium-252 Industrial Sales/Loan Program over $2 \mathrm{~g}$ of ${ }^{252} \mathrm{Cf}$ (out of the $\sim 8 \mathrm{~g}$ produced).

Californium-252 Industrial Sales/Loan Program. Californium-252 and ${ }^{252} \mathrm{Cf}$ neutron sources have been made available to DOE and other U.S. Government agencies since 1967 as a coproduct of the DOE heavy-element production facilities of the High Flux Isotope Reactor (HFIR) and the Radiochemical Engineering Development Center (REDC) at ORNL. A program to evaluate the market potential of ${ }^{252} \mathrm{Cf}$, based on its value as an intense neutron source, was established in 1968 at the Savannah River Site. The Market Evaluation Program continued until 1978 , when a ${ }^{252} \mathrm{Cf}$ Sales/Loan Program and a Medical/University Loan Program were instituted to continue supplying ${ }^{252} \mathrm{Cf}$ to those sectors that had found it useful. In 1987, the DOE transferred responsibility for these programs to ORNL, where they were integrated into the activities of the REDC. Special neutron source forms for medical applications will continue to be fabricated at the Savannah River Laboratory.

As of June 30, 1991, there were 102 formal loan agreements in force with 71 institutions covering 239 neutron sources containing $227.3 \mathrm{mg}$ of ${ }^{252} \mathrm{Cf}$. The 71 institutions consist of $17 \mathrm{DOE}$ units or integrated contractors, 9 U.S. Government agencies, 43 educational and medical institutions (including 1 in Japan), and 2 private research institutions that do contract research and development for various federal agencies.

In addition to the above formal loans, there were in earlier years a number of ${ }^{252} \mathrm{Cf}$ neutron sources furnished to DOE integrated contractors on a "product voucher" basis without formal loan agreements. We have identified 28 such sources containing $2.5 \mathrm{mg}$ of ${ }^{252} \mathrm{Cf}$ manufactured at ORNL and delivered to 11 different sites. Similarly, we have so far identified 34 such sources containing $32.6 \mathrm{mg}$ manufactured at SRL and delivered to 11 different sites. We have begun the process of "reclaiming" these sources where practical and requesting their return to ORNL so that they can be made available to other users under the Californium-252 Sales/Loan Program.
The 102 loan agreements are broken down as follows: 7 for medical research or treatment, 39 for classroom instruction or demonstration, and the remaining 56 for research and development and/or industrial-type applications.

DOE Production and Military Applications of ${ }^{252}$ Cf Neutron Sources. Neutron sources are on loan to 17 DOE or DOE contractor facilities and to 8 military installations. A large source has been used at Mound Laboratory for $100 \%$ nondestructive inspection of explosive fill in detonators since 1971; a replacement source for this purpose, containing $50 \mathrm{mg}$ of ${ }^{252} \mathrm{Cf}$, was shipped in October 1989. In addition, the Savarinah River production reactors require ${ }^{252} \mathrm{Cf}$ sources for startup; four 10-mg sources were furnished in 1990.

Sources have been used for neutron gauging of reactor components at the Hanford N Reactor for burnable poison content, for neutron activation analysis at Savannah River, and for assay of high-level waste glass at Westinghouse Hanford Company.

Systems designed by Los Alamos for assaying "TRU" waste require a ${ }^{252} \mathrm{Cf}$ neutron source. Such systems are in operation at Los Alamos National Laboratory, ORNL, Portsmouth Gaseous Diffusion Plant, Savannah River Site, and WINCO.

Neutron radiography of F-111 and F-15 military aircraft at McClellan Air Force Base serves as a diagnostic tool for locating areas of corrosion of the aluminum honeycomb and debonding of composites. The facility (which includes an X-ray bay as well as the neutron bay) was completed in 1988 and stocked with an initial loading of $108 \mathrm{mg}$ of ${ }^{252} \mathrm{Cf}$. After a thorough checkout of the system, routine operations began in January 1990 . The operations are going very well and the Navy has developed an interest in the procedure. They are negotiating with the Air Force to get their F-14s inspected at McClellan and are interested in acquiring a comparable facility of their own on the east coast. The first two replacement sources for McClellan AFB were delivered in October of 1990 and the second two are scheduled for January 1992.

The Naval Ocean Systems Center uses ${ }^{252} \mathrm{Cf}$ as a substitute reactor, since test reactor facilities are becoming very scarce. The neutron fields are used to expose infra-red devices to test the resistance of those devices to neutron damage. The initial loading was $190 \mathrm{mg}$ of ${ }^{252} \mathrm{Cf}$; the first $50 \mathrm{mg}$ replacement source has now been ordered. 
Medical and Health-related Applications of ${ }^{252} \mathrm{Cf}$ Neutron Sources. Neutron therapy followed by X-ray or gamma-ray therapy has been shown to be particularly effective in the treatment of advanced, hypoxic tumors of the cervix. Altogether, six hundred fifty-eight patients have been treated at the University of Kentucky Medical Center for this and other types of cancer. Survival rates have been significantly improved over that for conventional radiotherapy. Proposals have been submitted to $\mathrm{NCI}$ to fund development of boron neutron-capture therapy for malignant gliomas using a ${ }^{252} \mathrm{Cf}$ source. Sources are also being developed as an in vivo neutron activation tool for ultimate clinical use in diagnosis and monitoring of several medical conditions involving abnormal quantities of lithium, aluminum, or nitrogen.

The Food and Drug Administration has ordered $200 \mathrm{mg}$ of ${ }^{252} \mathrm{Cf}$ to be used as a neutron activation source for determining the sodium content of certain foodstuffs. This technique would allow them to simultaneously detect the presence of toxic heavy metals, such as arsenic or mercury.

Commercial Applications of ${ }^{252} \mathrm{Cf}$ Neutron

Sources. First used as a reactor startup source in $1973,{ }^{252} \mathrm{Cf}$ is currently the industry standard for this application. About $50 \%$ of ${ }^{252} \mathrm{Cf}$ is sold for this purpose. The second major use is for $100 \%$ nondestructive examination of power reactor fuel rods. This is both a quality control tool and a safeguards measure.

In some applications where reactors are not available, ${ }^{252} \mathrm{Cf}$ is used for neutron activation analysis. No other single analytical method gives as complete a profile of elemental composition. Instrument calibration, dosimetry studies, and industrial gauging also utilize about $10 \%$ of the ${ }^{252} \mathrm{Cf}$ sold. The fact that neutron fields generated by ${ }^{252} \mathrm{Cf}$ sources are now dosimetry standards is significant. $\mathrm{DOE}$ as well as civilian facilities are now setting up calibration ranges using ${ }^{252} \mathrm{Cf}$ neutron sources.

A new and exciting application is the thermal neutron analysis (TNA) technique for detecting hidden explosives in air passengers' luggage. Monitors have been installed at New York (JFK), San Francisco, Los Angeles, Miami, Gatwick and Frankfurt, while two have been installed in air freight centers in San Diego. The unit at San Francisco was unharmed by the earthquake in the fall of 1989.

Mark 42 Processing Program. The REDC has been asked to process a number $(-10)$ of
Mark 42 assemblies that were irradiated at the Savannah River Site (SRS) as part of a larger program for the Los Alamos National Laboratory. The reason for processing these assemblies at ORNL is to permit recovery of $\sim 100-\mathrm{g}$ amounts of ${ }^{243} \mathrm{Am}$ and ${ }^{244} \mathrm{Cm}$ from the irradiated targets. Facilities at SRS are not set up to accomplish this task. The recovered ${ }^{243} \mathrm{Am}$ and some of the ${ }^{244} \mathrm{Cm}$ will be shipped to Los Alamos. By using these materials for diagnostic purposes, the nuclear chemistry staffs of Los Alamos and Lawrence Livermore National Laboratories will be able to derive more information from each weapons test than would otherwise be possible.

The first of these assemblies is now at the REDC. Processing will begin upon completion of the current Transuranium Element Processing Campaign. The unused portion of the ${ }^{244} \mathrm{Cm}$ may become available for use as makeup feed for heavy element production in the HFIR, thus benefitting the Transuranium Element Processing Program.

\subsubsection{The Future of REDC}

Bob Wham took over from Les King as Manager of the REDC in March 1991. Les remained as associate section head with responsibilities for environmental, safety, and health documentation. The personnel roster has increased by about $50 \%$ to cover all responsibilities in this area. The DOE Office of Energy Research is continuing to bear these increases in cost while oversight of the operations is now under the Assistant Secretary for Nuclear Energy. The REDC is on track to meet the new requirements of DOE for excellence in operation and continues to have a mission in the preparation of radioisotopes to help meet the nation's needs, including some that are not heavy elements. It is expected the effort on the former to grow, but hopefully not at the expense of the latter.

\subsubsection{Bibliography}

The details of Chem Tech technology and transuranium processing program activities were described in the following series of papers:

J. E. Bigelow, B. L. Corbett, L. J. King, S. C. McGuire, and T. M. Sims, "Production of Transplutonium Elements in the High Flux Isotope Reactor," ACS Symposium Series No. 161, Transplutonium Elements-Production and Recovery, Ed. J. D. Navratil and W. W. Schulz, 1981. 
L. J. King, J. E. Bigelow, and E. D. Collins, "Experience in the Separation and Purification of Transplutonium Elements in the Transuranium Processing Plant at Oak Ridge National Laboratory," ACS Symposium Series No. 161, Transplutonium Elements-Production and Recovery, Ed. J. D. Navratil and W. W. Schulz, 1981.

J. E. Bigelow, E. D. Collins, and L. J. King, 'The 'Cleanex' Process: A Versatile Solvent Extraction Process for Recovery and Purification of Lanthanides, Americium, and Curium," ACS Symposium Series No. 117, Actinide Separations, Ed. J. D. Navratil and W. W. Schulz, 1980.

E. D. Collins, D. E. Benker, F. R. Chattin, P. B. Orr, and R. G. Ross, "Multigram Group Separation of Actinide and Lanthanide Elements by LiCl-Based Anion Exchange," ACS Symposium Series No. 161, Transplutonium Elements-Production and Recovery, Ed.

J. D. Navratil and W. W. Schulz, 1981.

D. E. Benker, F. R. Chattin, E. D. Collins, J. B. Knauer, P. B. Orr, R. G. Ross, and J. T. Wiggins, "Chromatographic Cation Exchange Separation of Decigram Quantities of Californium and Other Transplutonium Elements," ACS Symposium Series No. 161, Transplutonium Elements Production and Recovery, Ed. J. D. Navratil and W. W. Schulz, 1981.

F. R. Chattin, D. E. Benker, M. H. Lloyd, P. B. Orr, R. G. Ross, and J. T. Wiggins, "Preparation of Curium-Americium Oxide Microspheres by Resin-Bead Loading," ACS Symposium Series No. 161, Transplutonium Elements-Production and Recovery, Ed. J. D. Navratil and W. W. Schulz, 1981.

\subsection{FLUORIDE VOLATILITY PROCESSING, BOb Jolley, Wilson Pitt, Lloyd Youngblood, and Bob Hightower}

The purpose of the volatility program in the United States was to develop an alternative to conventional aqueous processes for recovering uranium from spent nuclear fuels. All fluoride-volatility methods used the volatility of $\mathrm{UF}_{6}$ to achieve a high degree of separation of the uranium from its fission products. Other advantages of volatility processes, compared with aqueous processes, were (1) the formation of a dry, highly concentrated waste, (2) the greater ease of processing certain refractory fuels, (3) fewer processing steps between the original fuel element and $\mathrm{UF}_{6}$, and (4) increased nuclear safety. The dependence on a physical property (i.e., volatility), rather than a chemical one, made possible the recovery of uranium for return to production channels. ${ }^{13}$ Disadvantages included the following: (1) customary engineering practices were generally oriented toward aqueous processing; (2) fluorine, hydrofluoric acid, and other chemicals used in the non-aqueous fluoride volatility process can be extremely hazardous; (3) the volatility processes frequently involved the use of high operating temperatures; and (4) high temperatures combined with extremely corrosive chemicals required the use of exotic metals and unique materials of construction.

Although studied at most national laboratories, the primary emphasis in the ORNL/Chem Tech work was on a molten-salt fluoride-volatility process for use with spent zirconium-based fuels containing highly enriched uranium. The Chem Tech process progressed through all R\&D stages from the laboratory in $4500 \mathrm{~N}$, to hot-cell-level radioactivity pilot plant in Building 4507, to unit operations studies in Building 3592, and to full-scale Fluoride Volatility Process Plant in Building 3019. The process consisted basically of three steps: (1) dissolution of the metal or oxide by hydrofluorination in molten salt $\left(\sim 500^{\circ} \mathrm{C}\right)$, (2) volatilization of the uranium as $\mathrm{UF}_{6}$ from the molten salt by fluorination, and (3) purification of the product $\mathrm{UF}_{6}$ from contaminants by adsorption and desorption from beds of $\mathrm{NaF}$ and $\mathrm{MgF}_{2}$.

Early $R \& D$. The earliest R\&D in the so-called dry fluoride process was conducted by Rex Leuze as problem leader with the assistance of a small group. Members of the group varied from time to time but included C. P. Johnston, Chuck Schilling, Bob Bennett, Brooks Graham, and A. B. Green. However, with the advent of work on Aircraft Nuclear Propulsion (ANP) and anticipated processing of the unique highly enriched fuels of the Aircraft Reactor Experiment, increased R\&D became necessary. Consequently, ORNL and Chem Tech increased the level of activity in this area. In 1954 Don Ferguson assumed the role of Problem Leader of the Volatility Studies, ANP Fuel Recovery Process and was assisted by Bob Bennett, George Cathers, and Chuck Schilling. ${ }^{14}$ In March 1955, Don Ferguson became Assistant Section Chief of the Chemical Development 
Section and George Cathers became the ANP Studies Problem Leader. ${ }^{15}$

Laboratory Bench-Scale Studies. In the mid-1950s, George Cathers became the Group Leader of the Fluoride Volatility Processing Group in the Chemical Development A Section. George was principally responsible for the chemical flowsheet development that eventually led to the pilot plant and full-scale process plant work. His R\&D group consisted initially of Bob Bennett, Bob Jolley, and Bob Duff. Bennett pioneered dissolution of uranium metals and fuel element components in molten salt, and Jolley initially studied the reaction of $\mathrm{NaF}$ with $\mathrm{UF}_{6}$.

In a 1956, Cathers and Jolley determined that $\mathrm{UF}_{6}$ could be desorbed thermally and reversibly from the unique $\mathrm{NaF}-\mathrm{UF}_{6}$ complex. Subsequently, Jolley, using plutonium tracer at the 2-ppm level, determined that $\mathrm{PuF}_{6}$ sorbs "irreversibly" on $\mathrm{NaF}$ at temperatures at which $\mathrm{UF}_{6}$ sorbs "reversibly." This led to a patent of the $\mathrm{NaF}$ volatility process for separation of $\mathrm{UF}_{6}$ from $\mathrm{PuF}_{6}$. Using mirrors and long-handled tongs, a heavily shielded bench-scale "pilot-plant" in a walk-in hood (Laboratory B-25, $4500 \mathrm{~N}$ ) was constructed to test the complete engineering flow sheet from dissolution to volatilization and isolation of the decontaminated $\mathrm{UF}_{6}$ product. The system was successfully operated by Cathers, Jolley, and Duff. Decontamination of the facility and metallurgical examination of the hydrofluorinator and fluorinator vessels provided much needed corrosion data.

With rapidly expanding responsibilities such as bench-scale studies, processing demonstrations in a walk-in hood (B-25, 4500N) and hot cell (Cell 4, 4507), and technical support for pilot plant design, the group soon expanded to include Dave Campbell, Stan Kirslis, E. C. Moncrief, Frank Soard, Calvin Shipman, and Tom Crabtree. Sidney Katz and Jim Mailen joined the volatility group in the early 1960s. Katz studied extensively the adsorption reactions of $\mathrm{UF}_{6}$ and $\mathrm{NaF}$ and expanded the adsorption studies to include the hexafluorides of several chemical elements including tellurium, tungsten, technetium, and molybdenum.

Hot Cell Pilot Plant. The bench-scale studies of the process flow sheet led to the design and successful operation of a larger scale pilot plant in Hot Cell 4, Building 4507. With the leadership of Cathers, Dave Campbell was principally responsible for the design of the remotely operated facility, and Jolley was principally responsible for the operation. Crabtree, Shipman, Soard, Bennett, Kirslis, Moncrief, and Jolley worked essentially "around the clock" during many operational runs. The remote system operated flawlessly except for one hitch in which a plugged line forced some contaminated liquid through a compressed gas line (used for remote control of valves) into the control panel outside the cell. Even Don Ferguson, Section Chief of Chem Development A, assisted in the relatively minor cleanup operation. Such hot cell work was greatly assisted by the cadre of excellently trained ORNL health physicists such as Bruce Walters, Gorman Hill, Ed Kuna, and many others. After the hot-cell pilot plant work was finished, Shipman and Jolley decontaminated and disassembled the system (blacksmithing via slave manipulators-not an easy task), first remotely, then manually. Decontamination of the cell required dressing out in several layers of protective clothing, including fully self-contained breathing apparatus and, later, gas masks. The cell was cleaned in preparation for the next activity-R\&D for separations process development in the fledgling TRU program led by Victor Vaughen.

Unit Operations Studies. The Unit Operations volatility studies increased dramatically in the late 1950s. In 1960 the group included Group Leader Bob Horton and Gene McNeese, R. J. McNamee, S. H. Stainker, Jack Beams, and F. N. McClain. ${ }^{16}$ Shortly thereafter, Bob Hightower, Bob Lowrie, Wilson Pitt, Bill Woods, Vic Fowler, Bruce Hanaford, and F. G. Kilpatrick joined the Unit Ops Group. ${ }^{17}$ Operations studies centered on (1) operation of engineering-scale molten salt dissolution, fluorination, and $\mathrm{NaF}$ sorber vessels in order to evaluate vessel designs; (2) determination of reaction rates; (3) development and testing of monitoring instrumentation and control systems; (4) evaluation of autoresistance-heated transfer lines and spray nozzles; and (5) evaluation of corrosion of test coupons and equipment under actual process conditions.

The studies of Gene McNeese and Jack Beams on sorption of $\mathrm{UF}_{6}$ by $\mathrm{NaF}$ led to the development of a mathematical model that considered the effects of temperature, concentration of $\mathrm{UF}_{6}$, gas flow rate, and $\mathrm{NaF}$ pellet characteristics. Such information proved useful in the design of the pilot plant and process flow sheet. Engineering-scale studies on the process were conducted in Building 3592 in the early sixties. Short sections of full-size zirconiumand later aluminum-clad fuel elements were dissolved in fused fluoride salts and the salt 
subsequently fluorinated. Fuel dissolution and fluorination rates were determined as well as corrosion rates on the proposed materials of construction. Proven monitoring and control concepts were also evaluated. ${ }^{17}$

Although most of the unit operations (UNOP) studies were carried out in support of the Fluoride Volatility Process (FVP) for zirconium- and aluminum-based fuels, Wilson Pitt and Vic Fowler determined the vapor liquid equilibrium of the $\mathrm{UF}_{6}$ and $\mathrm{NbF}_{5}$ system and the critical constants of $\mathrm{NbF}_{5}$. This was in support of the possible use of FVP to process the niobium-based Rover (Nuclear Rocket Prototype Reactor) fuels. Bob Hightower and Wilson Pitt also attempted to develop UV and IR photometric monitors for $\mathrm{UF}_{6}$ in fluorinator and $\mathrm{NaF}$ sorber off-gas. A major problem in that effort was the tendency for $\mathrm{UF}_{6}$ to quickly coat all window materials tested.

Process Design Activities. In the late 1950s, Bob Milford, with the assistance of W. E. Dunn, assumed responsibility for the fluoride volatility process in the Process Design Section. His group was shortly joined by John Ruch. ${ }^{18}$ Milford and Ruch were principally responsible for designing the pilot plant constructed in Building 3019.

Fluoride Volatility Process Plant, Building 3019. The first fluoride volatility pilot plant was constructed and operated between 1956 and 1958 to recover fully enriched uranium from the Aircraft Reactor Experiment (ARE) fuel. The extensive operation recovered $97.93 \%(134 \mathrm{~kg})$ uranium as $\mathrm{UF}_{6}$ product and $1.76 \%$ uranium from the $\mathrm{NaF}$ trap cleanout. No fission product activity was detected in the product. Principal operating difficulties were plugging of molten salt lines and the $\mathrm{NaF}$ beds and, also, maintenance of a gas-tight system. ${ }^{19}$

Although the principal responsible engineers were Bill Carr, F. W. Miles, Dick Keely, Sid Mann, R. G. Nichol, John Ruch, Frank Browder, C. L. Whitmarsh, and John Bigelow, many others were also involved. The magnitude of this initial pilot plant effort is evidenced by the following quotation. ${ }^{19}$

In a program of the magnitude of this one it is impossible to acknowledge the assistance of all persons who contributed. Such a program inherently requires, at various stages, the devoted efforts of a large percentage of the total number of workers at the Laboratory. However, even at the risk of inadvertently omitting acknowledgment of major contributions, the authors wish to recognize the efforts of the following: A. P. Litman, A. E. Goldman, and other members of the Metallurgy Division for continuing advice and assistance on corrosion studies and on construction and maintenance specifications; personnel at Battelle Memorial Institute for corrosion studies; W. A. Bush and other members of the Engineering and Mechanical Division for their work on design; C. L. Fox, J. B. Henry, B. E. Van.Horn, and other members of the Engineering and Mechanical Division for their work on construction and maintenance; B. Lieberman, L. H. Chase, W. J. Greter, G. P. Hinchey, and other members of the Instrumentation and Controls Division for the design and maintenance of the instrumentation; C. E. Lamb, M. J. Gaitanis, W. R. Laing, E. I. Wyatt, L. T. Corbin, and other members of the Analytical Chemistry Division for development of analytical methods, for consultation, and for the many "rush" analyses; G. J. Nessle, F. A. Doss, J. P. Blakely, R. E. Thoma, and other members of the Reactor Chemistry Division for special analytical services and for supplying fluoride salt mixtures; R. B. Lindauer, H. K. Jackson, W. H. Lewis, and F. L. Culler for over-all direction and coordination ... ; G. I. Cathers and his Chemical Development group; J. T. Long, M. E. Whatley, R. W. Horton, and other members of Unit Operations; R. P. Milford and his design group, and C. E. Guthrie for development, design, consultation, and direct pilot plant support work; J. E. Bigelow, F. N. Browder, R. B. Keely, S. Mann, F. W. Miles, R. G. Nicol, J. B. Ruch, and all the Co-op and Summer employees, technicians, and operators for the actual plant operations.

The 1960 Chem Tech organization chart (Appendix B) shows a large group responsible for the fluoride volatility process: ${ }^{16}$ Dick Lindauer (Fig. 4.32), Group Leader, Bill Carr, Problem Leader, and Sid Mann, F. W. Miles, R. G. Nichol, John Ruch, C. L. Whitmarsh, and Lloyd Youngblood. Technicians and operators were H. C. Thompson, V. R. Young, Bob Duff, J. H. Gibson, M. C. Hill, W. T. Henry, Z. R. McNutt, and A. V. Wilder. The group later included engineers Fred Kitts, Bob Lowrie, Bob Shannon, and E. C. Moncrief, technician 


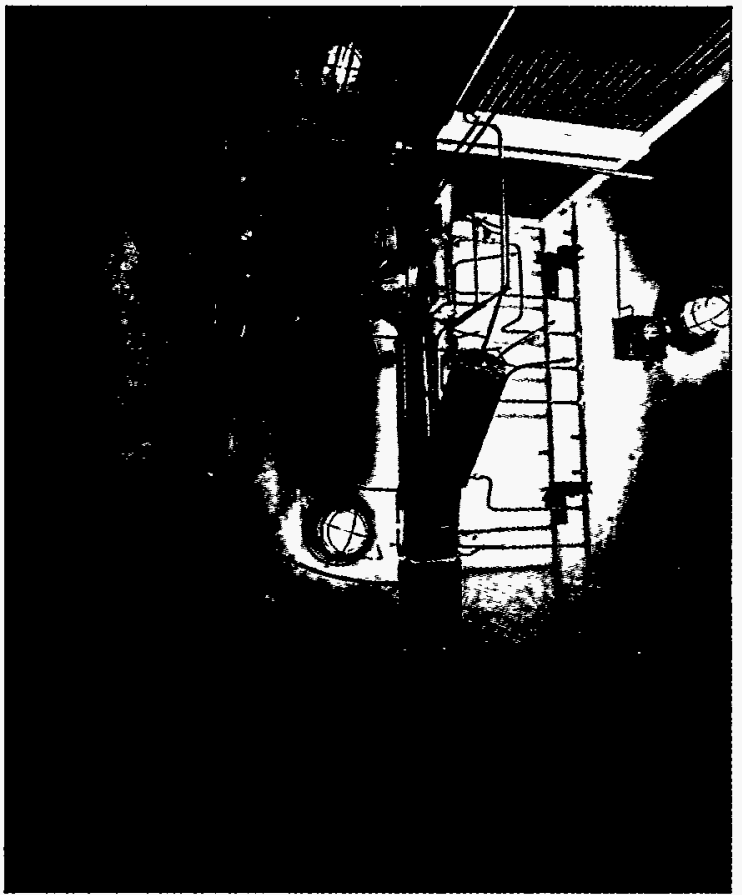

Fig. 4.32. Dick Lindauer examining the $\mathrm{UF}_{6}$ product trap for the Fluoride Volatility Process Plant (about 1975).

M. C. Hill, and operators Ed Brantley, C. W. Boatman, J. H. Brock, W. J. Bryan, H. S. Caldwell, C. H. Jones, and G. R. Thompson. ${ }^{18}$ Following the ARE fuel processing, the pilot plant was completely redesigned to permit processing of zirconium fuel of the type used in navy submarines. This involved HF dissolution of the fuel in molten salt. A magnesium fluoride trap was also added to trap the volatile fluorides of technetium and neptunium. The redesigned pilot plant was operated from about 1960 to 1964. After a series of cold runs, the pilot plant processed long-cooled Nautilus submarine fuel. Generally, one or two fuel elements were processed per run, and a run required about a week to complete.

During the operation of the 3019 fluoride volatility plant, the capability for sustained operation was demonstrated with losses of only a fraction of a percent and with excellent decontamination. Decontamination factors (DFs) were among the highest ever reported for a radiochemical process, including those for three cycles of solvent extraction. DFs ranged from $10^{6}$ to $10^{10}$ (e.g., a Zr-Nb DF greater than $5 \times 10^{10}$ was achieved in one of the runs). 13

After the campaign to process zirconium-clad fuel, the pilot plant was decontaminated and used to demonstrate the processing of aluminum-clad fuel of the type used in the LITR and ORR. Four runs were made. In the last run, an ORR fuel element was processed that had cooled for only four weeks. The processing of such short-cooled fuel represented a landmark accomplishment. DFs ranged from $10^{5}$ to $10^{8}$, with the exception of ${ }^{99} \mathrm{Mo}$ and ${ }^{125} \mathrm{Sb}$, which were 36 and 500 , respectively. Nonrecoverable uranium losses were only $0.4 \%$, but the uranium product had a high radioactivity level due to the presence of ${ }^{237}$ U. 19

The report by Bill Carr, Les King, Fred Kitts, Tom McDuffee, and F. W. Miles acknowledges the assistance of others as follows: ${ }^{20}$

R. E. Brooksbank, Chief of the Pilot Plant Section of the Chemical Technology Division, had overall responsibility for this pilot plant. R.P. Milford was responsible for coordinating the Volatility Project. Other supervisors of the Volatility Pilot Plant who made major contribution were: R. S. Lowrie, S. Mann, R. J. Shannon, and E. L. Youngblood.

Many people in other parts of the Laboratory provided aid and assistance that made the operation and maintenance of this pilot plant a success; chief among these were: G. E. Pierce and R. P. Beard of the Plant and Equipment Division, W:J. Greter of the Instrumentation and Controls Division, E. I. Wyatt and C. E. Lamb of the Analytical Chemistry Division, O. J. Smith of the Inspection Engineering Department, and C. H. Miller and W. A. McLoud of the Health Physics and Safety Division. The assistance of these, and of many other people at ORNL and at other AEC installations, is gratefully acknowledged.

We also take this opportunity to express appreciation to Martha G. Stewart for her invaluable editorial assistance.

Program Closure. The molten salt fluoride process was very successful in processing and recovering uranium from fuel. However, it was very difficult to remove the plutonium from the salt, and long fluorination times gave excessively high corrosion rates. To permit processing of plutonium-containing fuel, the molten salt equipment was removed and work was begun to install a fluidized-bed volatility system based on bench-scale work done at Argonne National Laboratory. A considerable amount of equipment 
was installed in the Building 3019 cells during the period 1965 and 1966, but the project was canceled in 1966 when it appeared that it was not economically competitive with the Purex process for uranium and plutonium recovery.

\subsection{CHEMICAL PROCESSING FOR THE MOLTEN-SALT REACTOR PROGRAM, Bob Hightower}

The ORNL molten-salt reactor program was an outgrowth of the aircraft nuclear propulsion (ANP) program to make a molten-salt reactor power plant for aircraft. The first molten-salt reactor, the ARE, was operated at ORNL in 1954 as part of the ANP program. The objective of the molten-salt reactor program was the development of nuclear breeder reactors that used fluid fuels consisting of solutions of fissile and fertile materials in suitable carrier salts. Fuel for this type of reactor would be ${ }^{233} \mathrm{UF}_{4}$ dissolved in a molten mixture (solution) of ${ }^{7} \mathrm{LiF}$ and $\mathrm{BeF}_{2}$. The fertile material would be $\mathrm{ThF}_{4}$ dissolved in the same salt or in a separate salt of similar composition. The breeder reactor concept included an on-line continuous processing plant to remove the fission product poisons and to isolate the capture product ${ }^{233} \mathrm{~Pa}$, allowing it to decay to ${ }^{233} \mathrm{U}$ outside the neutron flux. This reactor concept and the associated on-line continuous processing were rich in chemistry and chemical engineering challenges, and the Chemical Technology Division played a major role in the program from the early days.

The underlying chemical processing technology for the molten-salt reactor program had been developed in the old Reactor Chemistry Division under the leadership of Warren Grimes, Charlie Baes, Charlie Barton, and others and in the Fused Salt Fluoride Volatility Program. Extrapolations of these early developments for use in continuous processing needed for a breeder reactor were operation in 1965 of a bench-scale continuous fluorinator by Gene McNeese and development of continuous on-line measurement of $\mathrm{UF}_{6}$ in $\mathrm{F}_{2}$ streams by gas chromatography and infrared spectroscopy of Gene McNeese and Wilson Pitt in the Unit Operations Section. A concept of fluorination of salt sprays to remove uranium was tested by Jim Mailen and George Cathers in the Chemical Development B Section. The concept for converting $\mathrm{UF}_{6}$ directly to $\mathrm{UF}_{4}$ in the salt phase (fuel reconstitution) by initial formation of the intermediate $\mathrm{UF}_{5}$ and subsequent reduction by $\mathrm{H}_{2}$ was a joint development by Gene McNeese and Chuck Scott. Experiments using rapid vapor condensation were conducted by Chuck Scott and Warren Sisson to measure relative volatilities of the rare-earth fluorides in support of the design for a molten-salt distillation concept. These studies were refined and completed by Bob Hightower and Vic Fowler using small recirculating equilibrium stills operating at $1000^{\circ} \mathrm{C}$ and $0.5 \mathrm{~mm} \mathrm{Hg}$.

A major program activity through 1969 was the operation of the Molten-Salt Reactor Experiment (MSRE). The initial fuel was 0.9 mole $\%{ }^{235} \mathrm{UF}_{4}$, $5 \% \mathrm{ZrF}_{4}, 29 \% \mathrm{BeF}_{2}$, and $65 \%{ }^{7} \mathrm{LiF}$. After a period of operation with this fuel mixture, the ${ }^{235} \mathrm{UF}_{4}$ was separated and recovered and then replaced by ${ }^{233} \mathrm{UF}_{4}$. The processing plant for the removal of ${ }^{235} \mathrm{U}$ by fluorination of the reactor core and recovery of the ${ }^{235} \mathrm{U}$ by sorption on $\mathrm{NaF}$ beds was designed by Dick Lindauer of the Pilot Plant Section, who also supervised its construction, installation, and operation. The fuel loading of ${ }^{233} \mathrm{UF}_{4}$ was prepared in Building 3019 (TURF) by John Chandler, Sam E. Bolt, W. T. Bostic, B. G. DeVall, Al Farmer, Horace Wallace, J. P. Jarvis, J. Underwood, Dick Bowman, and Sid Mann. An experiment to test the separation of the rare-earth fission products by distillation was designed and built by Lloyd Carter of the Process Design Section. The experimental equipment was installed and operated at the MSRE by Bob Hightower, Hank Cochran, Bruce Hannaford, Gene McNeese, Vic Fowler, Ralph Payne, and Jack Beams, and it utilized remote condensate sampling equipment designed by Luther Pugh.

As the molten-salt reactor program matured, the chemical processing effort in the Chemical Technology Division grew substantially. Early processing developments for the molten-salt breeder reactor were guided initially by Marvin Whatley, later by Gene McNeese, and still later by Bob Hightower in the Unit Operations Section. The processing concepts and technology improved steadily, and the early flow sheets based upon fluorination and distillation were replaced by fluorination, fuel reconstitution, and molten bismuth extraction for ${ }^{233} \mathrm{~Pa}$ isolation and rare-earth removal. Flow-sheet alternatives were synthesized and analyzed by Gene McNeese and Charles Kee using sophisticated computer codes, which they developed. The definitive process design for the reference processing concept was done by Lloyd Carter and Ed Nicholson of the Process Design Section. The hydrodynamics of 
bubble columns for the fluorinator was studied and defined by Jack Watson. Concepts for frozen salt corrosion protection in fluorinators were studied by Bob Hightower, Dick Lindauer, Pete Counce, and Ralph Payne. Hank Cochran, Bruce Hannaford, and Vic Fowler constructed a facility and developed engineering experience and information on extraction from molten salt mixtures into molten bismuth using packed columns and stirred contactors; these studies were later taken over by Cliff Brown. These studies were complemented by Jack Watson's fundamental work on countercurrent flow-through packed columns of fluids with large density differences. Bill Schaffer of the Process Design Section designed and initiated fabrication of equipment made from molybdenum to test operations and reliability of equipment made from the preferred material of construction. Herman Weeren, Jerry Klein, and Cliff Brown conducted fundamental studies of mass transfer at liquid-metal interfaces to support equipment design and experimental interpretation. Don Kelmers and Bob Bennett, of the Chemical Development B Section, studied the chemistry of the conversion of $\mathrm{UF}_{6}$ to $\mathrm{UF}_{4}$, and Pete Counce designed and built engineering-scale processing equipment (gold lined) for scale-up and testing. Mike Bell studied oxide precipitation as an alternative to fluorination for uranium removal. Lloyd Youngblood, Clif Savage, and Jack Beams tested the Metal Transfer Process for extracting the rare earths into bismuth, back-extracting them into molten $\mathrm{LiCl}$, and ultimately isolating them in bismuth for disposal. The basic chemistry of these extraction processes and other alternative process concepts, including the reductive extraction chemistry of the actinides (uranium, neptunium, plutonium, americium, and californium) and the rare earths, was defined by studies headed by Les Ferris and his group in the Chemical Development B Section. This group included Fred Land, Mildred Sears, Chuck Schilling, Fred Smith, Jim Mailen, C. T. Thompson, Jack Lawrence (Australia), and Eduardo Nogueira (Spain).

The molten-salt reactor program was suspended from 1973 to 1974 and finally terminated in 1975 because of an AEC/ERDA decision to concentrate resources on LMFBR development.

\subsection{NUCLEAR WASTE PROGRAMS, Herschel Godbee and Tom Lomenick}

The Chem Tech waste treatment and disposal development program was designed to develop a comprehensive waste management system for nuclear wastes, including their final disposal, and to estimate the cost of operation. The effective, economic, safe management of radioactive effluents is a prerequisite to the natural growth of a nuclear power industry. ${ }^{21}$

In 1964 two methods were being developed in Chem Tech for the conversion of high-level radioactive wastes (HLW) to solids, the Potcal (pot calculation) and Potglass (fixation of wastes in glassy solids in a pot) processes. ${ }^{22-25}$ The calcined or glassy solids were to be contained in 88-in.-long, 24-in.-diam stainless steel "pots" (pipes), which are designed to be closed by welding prior to shipment and ultimate disposal.

Since there should be no off-gasses, future surveillance requirements during ultimate disposal were thought to be negligible. Glassy solids, rather than porous calcines, were thought to be desirable because of their higher thermal conductivity and high degree of insolubility. End products with these properties were thought to yield increased economy and safety.

Low-level radioactive wastes (LLW), such as cooling water, canal water, flood-drain water, and other low-salt-content waters, were treated to remove radionuclides prior to discharge to the environment. Chem Tech participated in the development of two general treatment methods for LLW: the scavenging-precipitation ion-exchange process ${ }^{26,27}$ and the scavenging precipitation foam separation process. ${ }^{28,29}$ An improved scavenging-precipitation ion-exchange process was successfully tested by Chem Tech, where ORNL process waste was decontaminated to less than $2 \%$ of the then-allowable permissible levels for human exposure and also reduced costs approximately $15 \% .25$

Intermediate-level radioactive waste (ILW) consisted of materials such as residues from processing LLW, evaporator concentrates, and concentrates from second and third solvent extraction cycles from processing nuclear fuels and other high-salt content wastes. Such wastes are categorized as either LLW or transuranic (TRU) waste under current definitions. Chem Tech studies 
the incorporation of such wastes in asphalt and/or concrete. 28

Chem Tech was also involved in economic analysis of HLW management and storage in ultimate disposal sites such as salt mines. ${ }^{30,31}$ The economic analyses were in addition to the collaborative R\&D with the Health Physics Division on waste-solidification systems and geologic disposal sites. ${ }^{21}$

Pot Calcination. The Chem Tech involvement in waste studies and management began at an early date (the late 1950s) with exploratory studies in calcination of HLW. Chuck Hancher and Herschel Godbee studied the pot calcination of actual Hanford waste in Building 4505. During the 1958-1959 time period, Tom Roberts, Ray Blanco, and Godbee continued waste studies in Laboratory B-13, Building $4500 \mathrm{~N}$. One of the initial problem areas was the volatility of ruthenium during waste calcination. A process was developed that used formaldehyde to reduce ruthenium $\left(\mathrm{RuO}_{4}\right)$ to a less volatile chemical form $\left(\mathrm{RuO}_{2}\right)$. Corresponding studies at Hanford used sugar instead of formaldehyde. These initial studies were conducted in stainless steel pipes 4-in. in diameter by $2 \mathrm{ft}$. At about this same time period, Hancher successfully conducted full-scale pot calcination in the high bay area of Building 4505. He controlled ruthenium by recycling the acid condensate.

Glass Formation. The waste group, soon joined by Walt Clark and George Davis, began studying use of sodium hypophosphite to reduce the volatilization of ruthenium during calcination. Subsequently, the group developed a phosphate glass process for treatment/disposal of waste. The glass process was commonly called "rising level" glass formation because the level of glass in the pots rose as the pots were filled and glass formed at $\sim 900^{\circ} \mathrm{C}$. After Curt Fitzgerald joined the group, the studies were expanded to include formation of borosilicate glasses at $\sim 900^{\circ} \mathrm{C}$. Phosphate glasses were highly and unpredictively corrosive. The corrosivity was known as the "zipper effect" in which stainless steel vessels would develop holes during the calcining/glass formation process. Dialogue was maintained with glass manufacturing firms concerning borosilicate glasses. The waste group started adding zinc oxide to the borosilicate glass to improve properties. Hanford developed a spray calcination process that produced a very fine waste oxide powder. The Chem Tech waste group developed a process that mixed this powder with a low-melting glass. The product contained the oxide powder (discontinuous phase) dispersed in the glass (continuous phase). Hanford took over the HLW glass studies after a Chem Tech management decision was made that most of the HLW problems had been solved. Hanford developed a continuous glassmaking process based on passing an electric current through the glass to generate heat for glass formation. West Valley and Savannah River are scheduled to use this technique to solidify their HLW.

FUETAP and Concrete Studies. Because concrete has considerable potential for waste treatment/disposal, the FUETAP program was initiated in 1970 by Chem Tech. The project ended about 10 years later when the Chem Tech group moved back from Y-12 to Building 3017 at ORNL. High-level waste produces an excellent ceramic, and the FUETAP group [John Moore, Gene Newman, Earl McDaniel, Marv Morgan, Les Dole (after returning from a year assignment studying waste treatment/disposal in Germany), and Mike Gilliam] conducted studies in developing such ceramics.

The FUETAP program takes its name from the phase "Formed Under Elevated Temperature and Pressure." Concretes that are formed under elevated temperature and pressure (i.e., autoclaved) are called FUETAP concretes. The accelerated curing process produces strong, durable, relatively impermeable solids. FUETAP concretes use the thermal power of radioactive waste to accelerate the curing process. Heat can also be applied externally. More than $98 \%$ of the unbound waste is driven off from the final product, and problems of radiolytic decomposition and thermal expansion become negligible. FUETAP concretes are less susceptible to weathering or degradation than normally hardened cement pastes. 32

High-Level Waste Form. The DOE appointed a committee to help determine the best waste form to select for disposal of HLW. After reviewing the several options that existed at that time, the committee recommended to DOE that borosilicate glass be selected.

Scavenging Precipitation-Ion Exchange Process. In the early 1960s, Chem Tech developed the scavenging precipitation-ion exchange process (SP-LX) to treat and remove ${ }^{90} \mathrm{Sr}$ and ${ }^{137} \mathrm{Cs}$ from large volumes of low-activity waste or process waste. ${ }^{33}$ The treatment plant, still in use, is currently managed by the Waste Operations Division. Process waste with a radioactivity level of over $40 \mathrm{dpm} / \mathrm{mL}$ is treated and stored before 
treatment in a storage pond or equalization basin. The waste goes through a precipitation step, solids settling, and an ion-exchange process. Tom Roberts suggested using Duolite CS 100 resin. Zeolite is under consideration for replacement of the resin ion exchanger. Laboratory-scale work by Roland Holcomb and Bill Shockley confirmed the feasibility of the scavenging-ion exchange process. John Holmes designed a pilot plant which was operated successfully by Bob Brooksbank.

Hydrofracture. A study for disposing of ILW (4 mCi/gal to $5 \mathrm{Ci} / \mathrm{gal}$ ) based on the oil field technique of hydraulic fracturing was initiated in 1959. Experimental injections were made with a grout mixture tagged with ${ }^{137} \mathrm{Cs}$, and core drillings with gamma-ray loggings were used to verify that the grout sheets followed the bedding planes and, also, that the fractures were essentially horizontal. Subsequent injections result in safe disposal of $1,600 \mathrm{~m}^{3}$ waste containing $11,500 \mathrm{Ci}$ total activity. Routine disposal began in 1966. A well is drilled into the geologic formation and cemented to prevent groundwater from entering the well. Water is pumped into the well under pressure and fractures the formation. The ILW wastes are then mixed with a cement-base blend of dry solids to produce a slurry that is injected into the impermeable shale formation at depths of 700 to $1000 \mathrm{ft}$. In the original grout formation, radiocesium was retained by illite clay and radiostrontium retained by cement and fly ash. ${ }^{13}$

Wally deLaguna and Tammy Tamura, then in the Health Physics Division, initiated the hydrofracture process and developed the initial grout recipe, respectively. Chem Tech staff members John Moore and Herman Weeren developed the grout formula for use in the later phases of the program. Illite clays had good cesium ion-exchange properties. However, when the source of illite clay used in the hydrofracture program was closed or shut down, Weeren discovered that pulverized Conasauga shale was even better than illite clay for sorbing cesium. However, no commercial source for large quantities of pulverized
Conasauga shale was available. Basically, the Edisonian approach was used, and many different commercially available materials were tested. Red Indian pottery clay was found to be the best commercially available substitute for illite clay.

Asphalt. In 1965, the Belgians began disposing of LLW and ILW in an asphalt waste form using a batch process (heated pot with stirrer). Asphalt processes were being studied also by the English, French, and Germans. Chem Tech initiated studies in this area, with Herschel Godbee, John Holmes, and George Davis conducting the laboratory R\&D. The Edisonian approach was again used, and the group developed and subsequently patented the use of emulsified asphalt for waste disposal in a continuous process (Fig. 4.33). The group also developed a wiped-film evaporator for use in the process but were not permitted to patent that aspect of the process. The wiped-film evaporator was tested successfully in the high bay area of Building 4505 under the direction of Ed Frederick

(Fig. 4.34). The Chem Tech group also uncovered the incompatibility of nitrates and asphalt. Their studies indicated that nitrates in the waste solutions were not compatible with the burnable asphalt mixtures and that fires, and even explosions, could result from the nitrate-asphalt mixtures with high loadings of nitrate (>10-15 wt \%). The French started using the wiped-film evaporator process developed by Chem Tech for some waste types

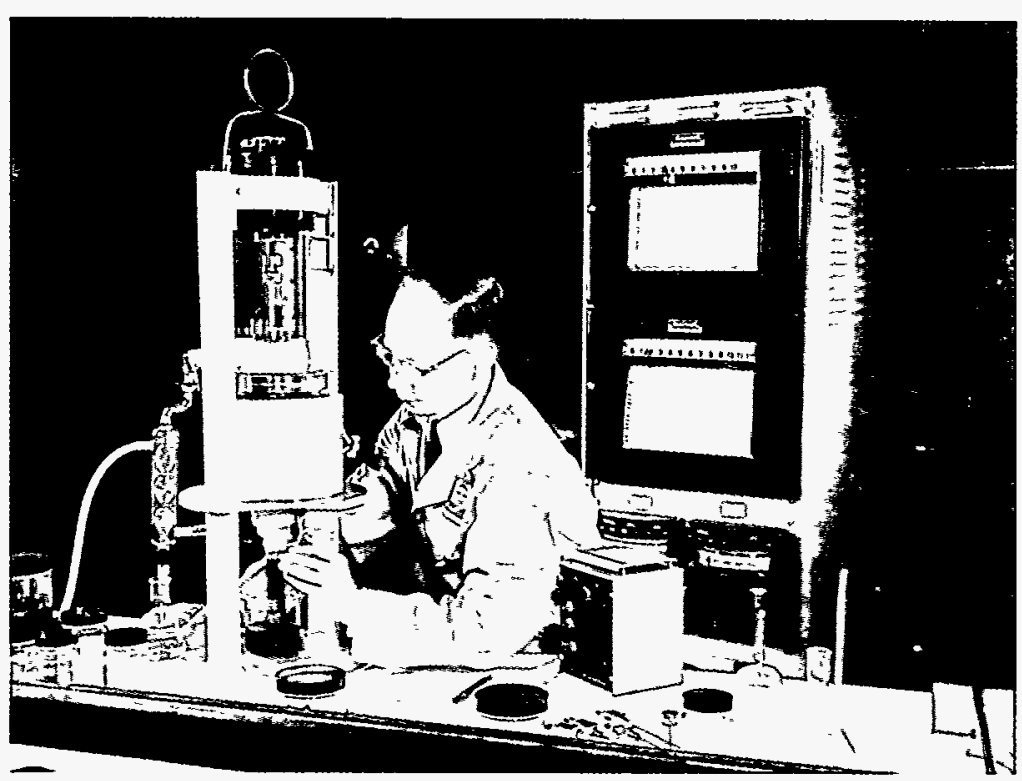

Fig. 4.33. Herschel Godbee conducting an emulsified asphalt experimental run with simulated waste. 


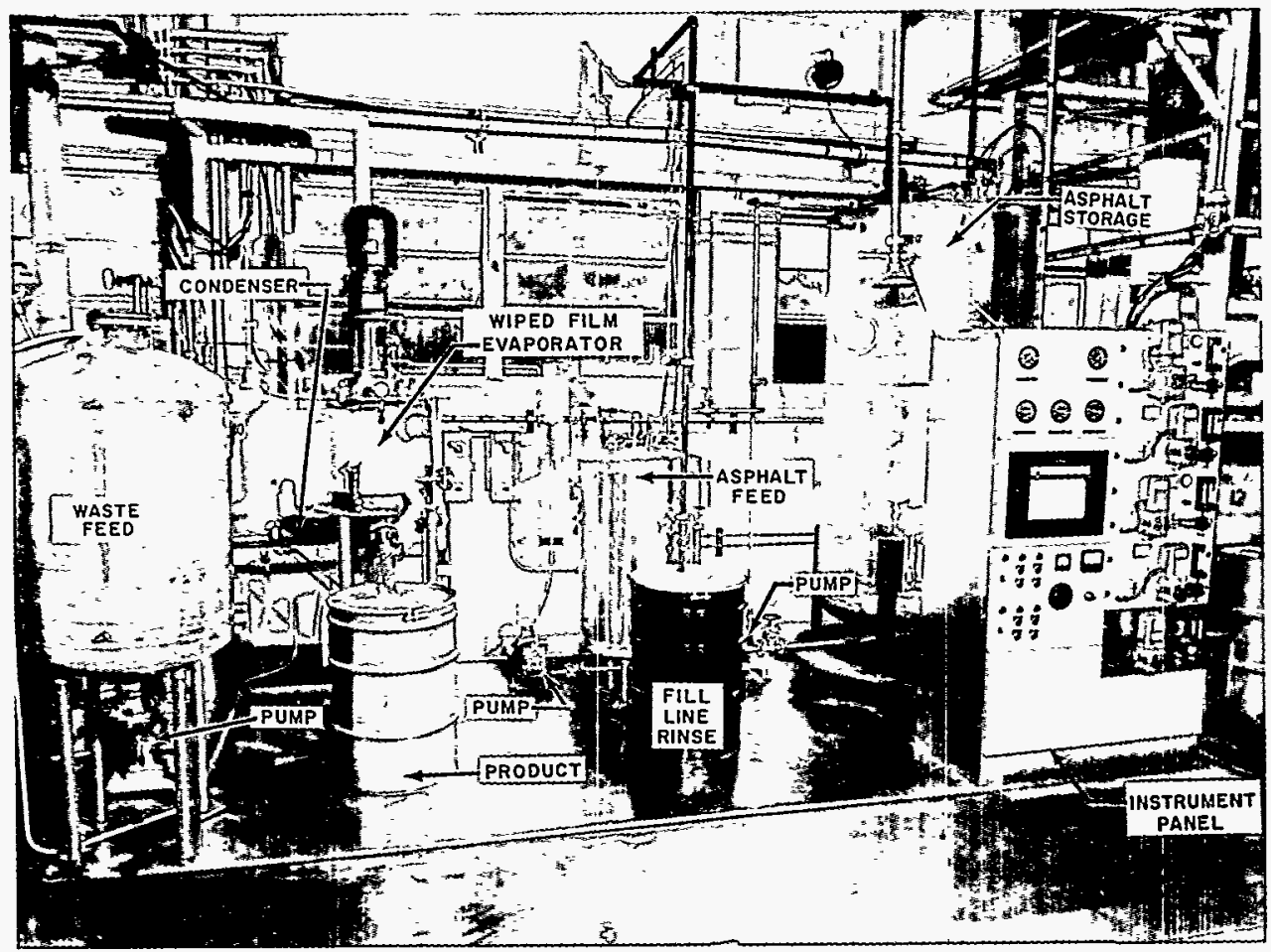

Fig. 4.34. Waste-asphalt process installation in the high-bay area showing the wiped-film evaporator equipment.

while continuing to use the screw-extruder process (continuous) which they had developed.

Disposal in Salt Domes. In the early 1970s, Chem Tech was involved in a large effort headed up by the Health Physics Division to establish a national repository for radioactive wastes in a bedded salt formation located near Lyons, Kansas. Chem Tech staff participated in almost all phases of the study but had principal responsibility in (1) conceptual design and safety analysis of the repository, (2) a survey of the sources and characteristics of TRU-contaminated solid wastes, and (3) experimental investigations concerning criteria for packages for storage of the TRU wastes. John Blomeke headed up the Chem Tech effort and was assisted by Baird Bottenfield, Frank Browder, R. S. Dillon, Ed Frederick, Frank Harrington, John Holmes, Joe Perona, and Bill Ulrich. ${ }^{34}$

Later, Bill McClain and Tom Lomenick (who transferred into Chem Tech from the Health Physics Division) were involved in the study of the feasibility of using rock salt deposits for the disposal of radioactive waste. The state of Kansas was clearly the focus of this first field investigative period, with the highly successful experimental testing during Project Salt Vault being conducted at Lyons, Kansas, followed by unsuccessful efforts to site a "demonstration" repository at the same mine used in that project, and concluded by unsuccessful additional studies to locate and evaluate other sites within the state for a similar demonstration facility. Possibly the most noteworthy realizations made during this period concerned (1) certain technical issues regarding rock salt and its dissolution by groundwater and (2) increasing interface problems between the federal and state governments.

With the successful efforts of Chem Tech and Hanford to convert liquid HLW into solids for geologic disposal, the $\mathrm{AEC}$ requested Chem Tech to conduct a demonstration test in a suitable salt formation in an effort to establish the practicality of using salt deposits for the disposal of solidified wastes. The engineering and scientific objectives of this test, which were largely carried out by McClain, Blomeke, Bottenfield, and Lomenick, included (1) the demonstration of waste-handling equipment and techniques; (2) the determination of gross effects of radiation (up to $10^{9}$ rads) on factors such as hole closure, floor uplift, and salt-pillar deformation within a temperature range of 100 to $200^{\circ} \mathrm{C}$; (3) the determination of the radiolytic production of chlorine; and (4) the collection of data on the plastic flow of salt at elevated 
temperatures. The latter information was to be used in the design of an actual disposal facility.

The Project Salt Vault demonstration was carried out in the Carey Salt Company mine located at Lyons, Kansas. Fourteen irradiated Engineering Test Reactor fuel assemblies contained in seven canisters served as the radiation sources. Individual experiments commenced in mid-1964, and testing extended until late 1967.

In view of the uncertainties identified in selecting and constructing a geologic repository at Lyons, Kansas, as well as at any of the eight supplemental study areas located in that state, the $\mathrm{AEC}$ and Chem Tech enlarged the federal waste-disposal program in March of 1972 to include investigations of rocks other than salt and alternative disposal methods. The most dramatic alternative to geologic disposal was provided by an engineering approach termed the Retrievable Surface Storage Facility (RSSF), which was pursued by Blomeke. This was to be a part of a broad program of studies and assessments to investigate alternatives for both the near- and long-term storage of high-level and alpha-contaminated wastes. Specifically, the pilot-repository program included investigations by McClain, Lomenick, and others of various formations such as bedded salt located outside Kansas, in particular, the potash mining area of the Permian Basin in southeastern New Mexico and other impermeable rock types that might be suitable for the disposal of waste.

The overall objective of this program was to identify specific locations where pilot repositories could be constructed so that in situ demonstrations could be conducted that would provide confirmatory evidence of waste-rock compatibility. In order to accomplish this objective in the time allocated, studies were to be concentrated in areas where the necessary geologic and hydrologic data were already available or could be obtained readily. Godbee determined the thermal stability of alpha-containing waste and concluded (1) combustible wastes in combustible containers should not be accepted at a repository, (2) combustible wastes sealed in noncombustible containers (e.g., DOE 17C and 17H) should be acceptable, and (3) the quantity of gases evolved during heating can be reduced substantially by adding "getters" such as $\mathrm{CaO}$ (lime). ${ }^{35}$ Other Chem Tech laboratory studies included the diffusion of ruthenium, cesium, and plutonium in salt $(\mathrm{NaCl})$. Involvement in the Lyons, Kansas, project was terminated after it was determined that the salt deposits might not provide adequate containment because they had been penetrated with numerous holes as a result of oil and gas drilling operations.

TRU Waste. Chem Tech staff members Jere Nichols and Herschel Godbee helped develop and set the disposal criteria for TRU waste. The DOE sponsor, Harvey Sole, desired to have the disposal criteria set at a TRU element concentration that produced $>1 \mathrm{nCi} / \mathrm{g}$ waste. The NRC would have accepted the limit set at $>500 \mathrm{nCi} / \mathrm{g}$. The DOE initially set the limit at $>1 \mathrm{nCi} / \mathrm{g}$. After several years, it became apparent to DOE that the limit was set much lower than necessary for protection of the public and the environment. At the request of DOE, ORNL conducted a survey that eventually resulted in the limit being set at $100 \mathrm{nCi} / \mathrm{g}$.

Leaching Tests and ANS 16.1. The characterization of phosphate, borosilicate, and dispersion glasses required the use of leaching tests. This laboratory work by Godbee and Moore led to the national development of the standardized ANS 16.1 leach test. This test was the result of a committee of $\sim 40$ people, including Oswald Anders of Dow Chemical Co., John Mendall of Westinghouse Hanford, Bob Nielsen of Idaho National Engineering Laboratory (INEL), and Ed Compere and Godbee of ORNL.

Polymers. In the 1971 Chem Tech progress report it was reported that $\mathrm{LW}$ was incorporated in polyethylene. From 19 to $32 \%$ waste solids were incorporated in low-melting polyethylene (softening point, $100^{\circ} \mathrm{C}$ ) with material balances of 95 to $100 \%$. Waste form leach rates were favorable. ${ }^{34}$ Chem Tech staff members Godbee, Fitzgerald, Davis, and Ken McCorkle patented the process for incorporating waste in polyethylene.

\subsection{WASTE MANAGEMENT TECHNOLOGY CENTER, BOb Jolley and Suman Singh}

During FY 1986, Martin Marietta Energy Systems, Inc., and DOE/ORO established a new Waste Management Technology Center (WMTC) to serve as a technology component of a comprehensive DOE/ORO waste management coordination effort referred to as the "Oak Ridge Model" (later changed to the DOE Model). The responsibility for the development and management of the WMTC was assigned to Richard Genung of Chem Tech. By April 1987, Genung, as manager, had staffed WMTC with a 


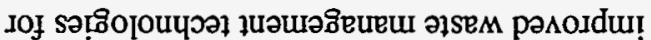

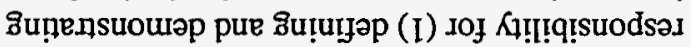

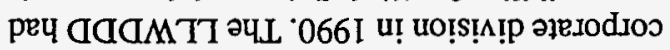

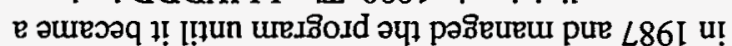

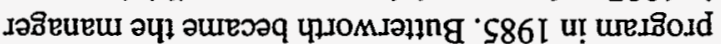

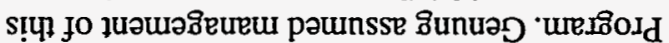

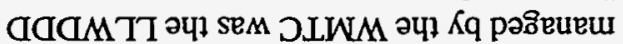

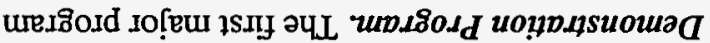

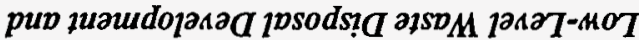
-sdousyiom [eग!uपวo]

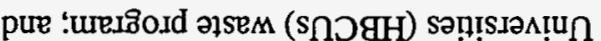

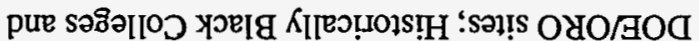

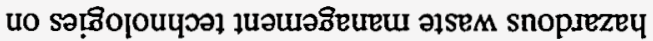

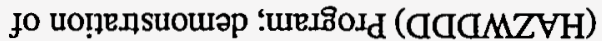

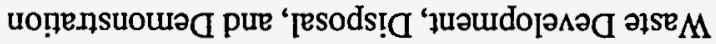

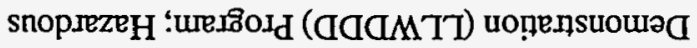

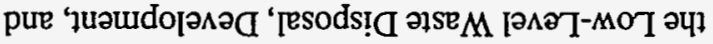

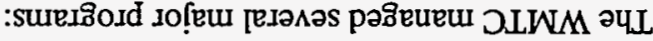

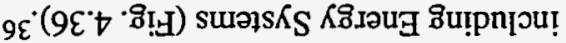

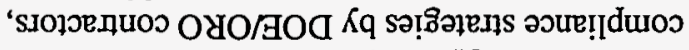
pure suoṇve [e!paurar suṭıoddns uọ̣ewroju!

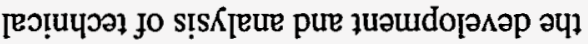

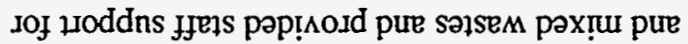

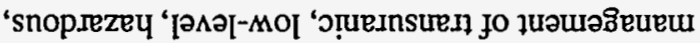

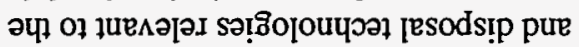

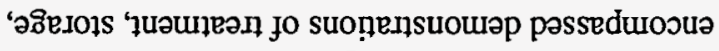

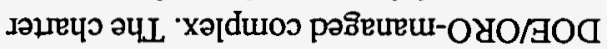

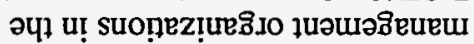

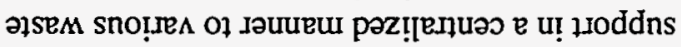

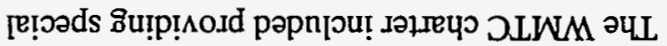
wersold

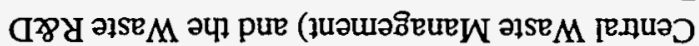

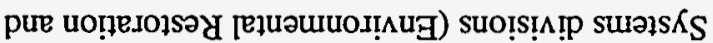

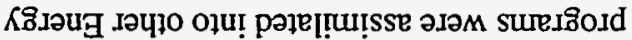

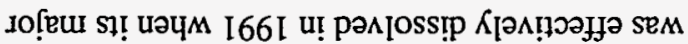

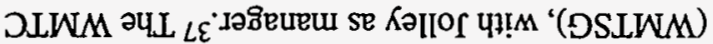

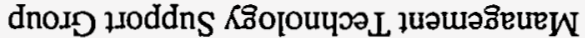

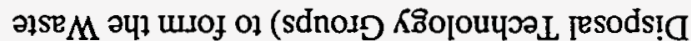

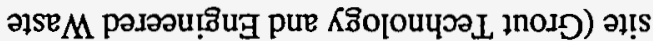

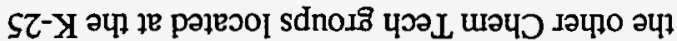

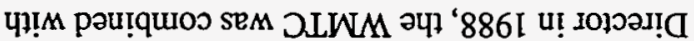

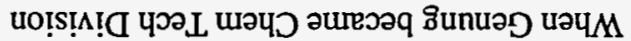

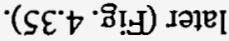

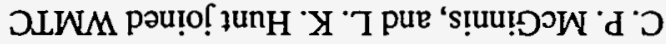

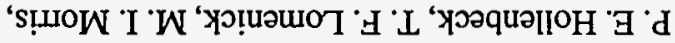

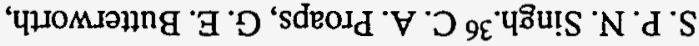

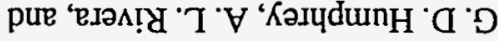

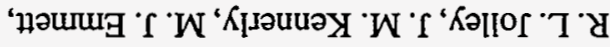

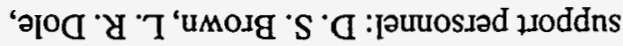

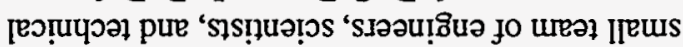

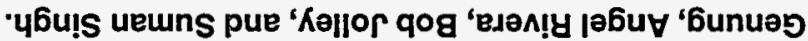

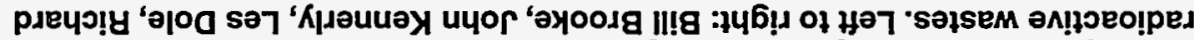

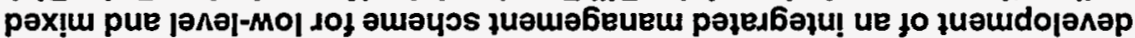

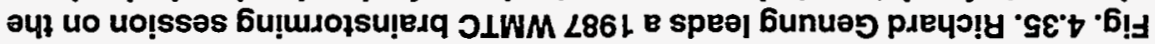

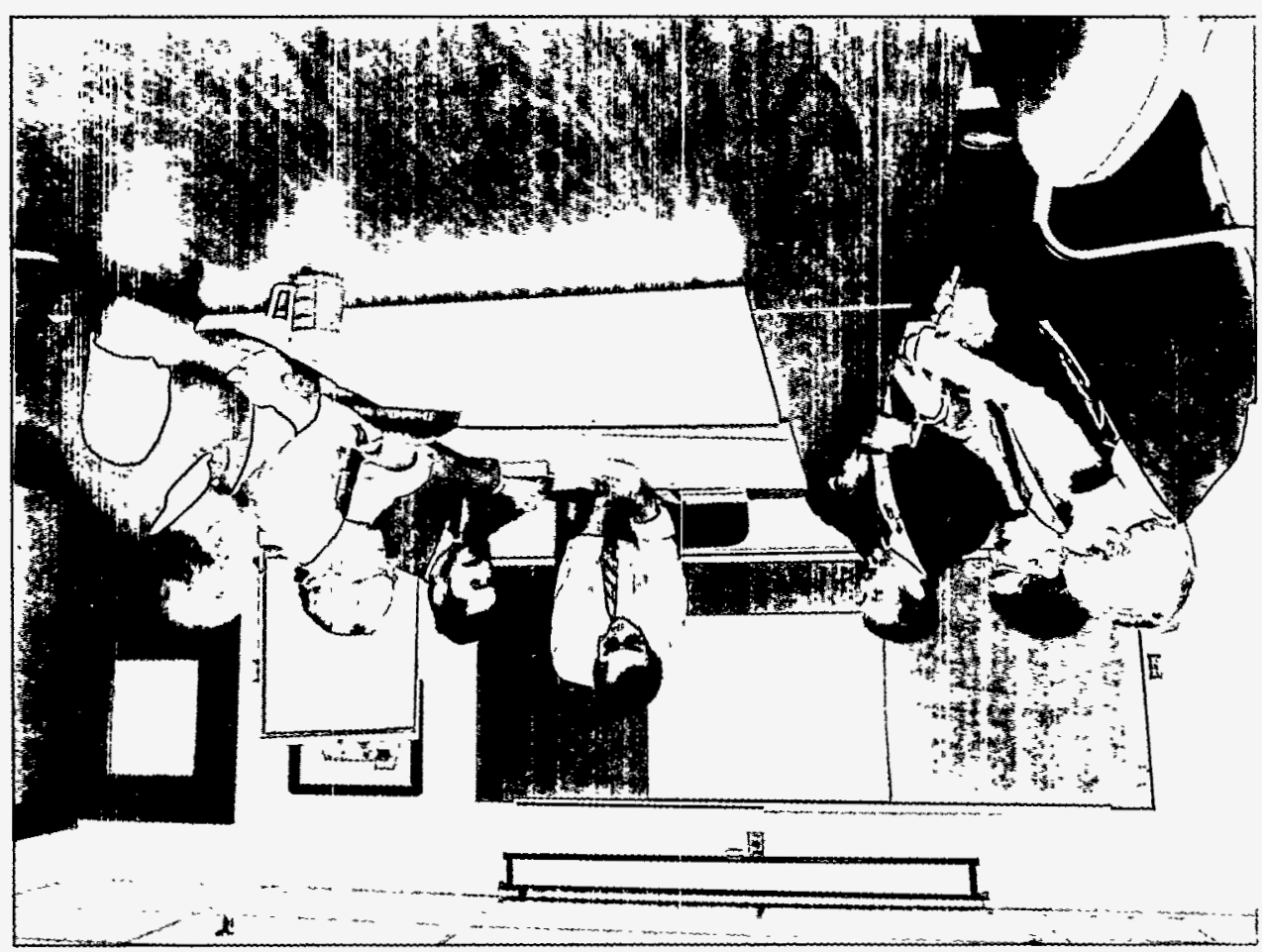




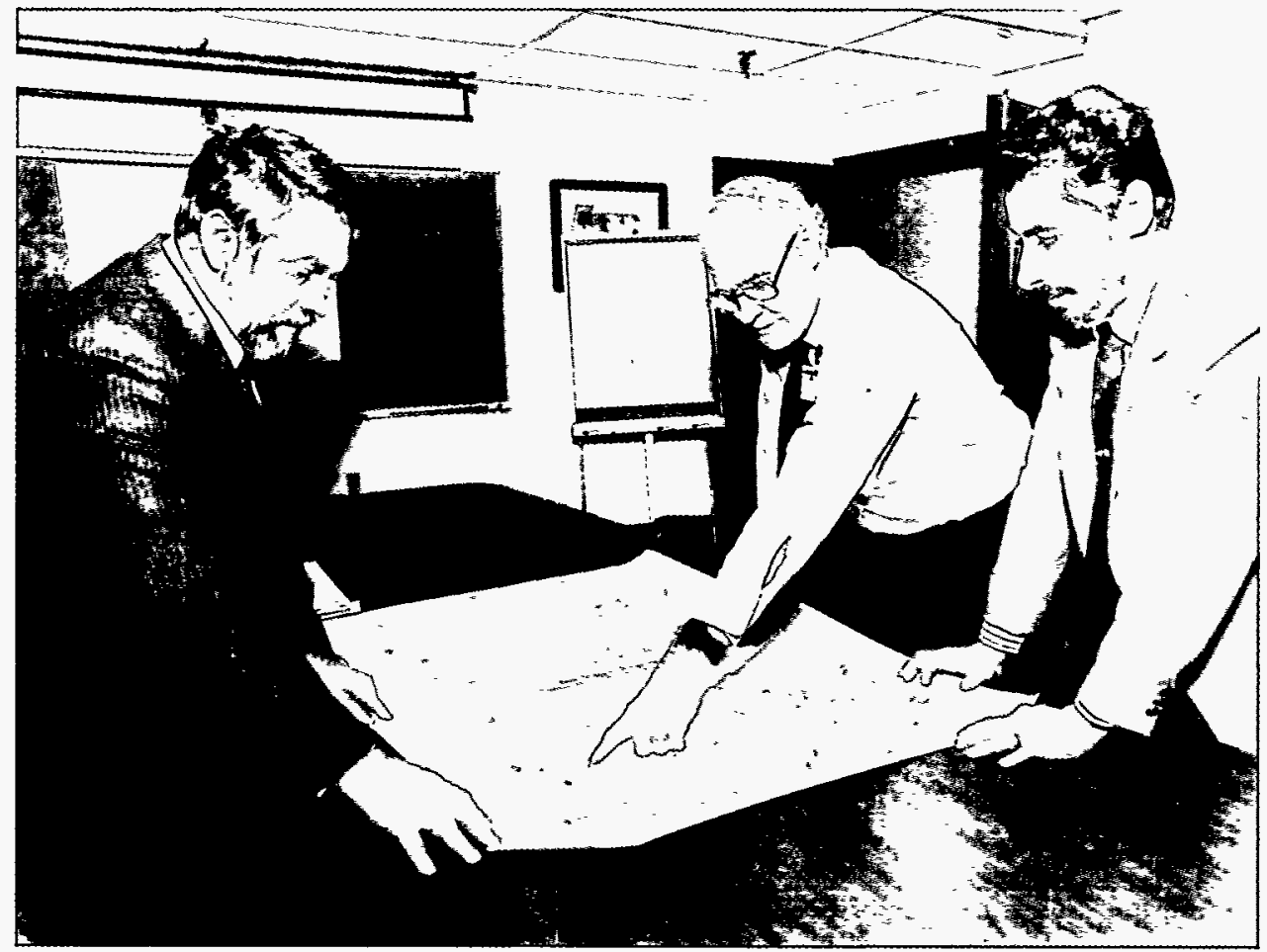

Fig. 4.36. Les Dole (left), Bob Jolley (center), and Angel Rivera discuss current DOE-managed sites.

low-level solid wastes generated within the ORO complex; (2) siting new disposal facilities to be used by plants on the Oak Ridge Reservation;

(3) coordinating the preparation of an Environmental Impact Statement for new disposal facilities on the Oak Ridge Reservation; and (4) designing and constructing large-scale disposal demonstration units within the new facilities. Several LLWDDD demonstration projects were initiated during 1986 and 1987. These included above-grade, earth-mounded disposal systems based on information exchanges with the French using their experience with similar technology, the evaluation of various waste packaging materials and technologies, and the assessment of mechanical volume reduction technologies based on super-compaction processes. All of these projects involved participants from the private sector, through competitive procurement processes, with emphasis on the selection of innovative mobile technologies for waste treatment. ${ }^{36}$

Hazardous Waste Disposal, Development, and Demonstration Program. The HAZWDDD Program managed by Phil McGinnis was initiated in late 1987 to integrate hazardous and mixed-waste treatment, storage, and disposal needs. Major responsibilities included developing an overall corporate strategy plan covering hazardous and mixed waste, including all five Energy Systems managed sites; identifying and coordinating needed development, demonstration, and technology transfer projects; and serving as a communications link among the five Energy Systems facilities, the Environmental and Safety (ESA) Organization, Central Waste Management Organization (CWMO), and WMTC. 38

Technical Demonstrations. The next major program managed by the WMTC concerned the demonstration of hazardous/mixed waste management technologies on DOE/ORO sites. John Kennerly, Suman Singh, Mike Morris, and Paul Hollenbeck were actively involved in demonstration planning, management, and execution. Demonstration projects were awarded to DOE field offices by the DOE National Hazardous Waste Remedial Action Program (HAZWRAP) and, in some cases, were also supported by the sites themselves. The WMTC identified candidate projects for DOE/ORO, assisted in presenting these candidate projects to HAZWRAP for competitive evaluation and funding, and. worked with DOE/ORO sites to manage these demonstration projects. ${ }^{36}$ The WMTC worked closely with Energy Systems sites to facilitate demonstrations. 
In 1990, demonstration management became a corporate function under the Waste R\&D Programs managed by Tony Malinauskas.

From 1986-1990, WMTC managed, coordinated, or assisted in conducting the following demonstrations. All of the projects involved participants from the private sector, through competitive procurement processes, and emphasized selection of innovative technologies for waste treatment (Fig. 4.37).

- Evaluation of Vendor, Process, and Waste Form/Packaging of Oak Ridge Reservation Waste Streams: Waste Isolation Technology Project. The

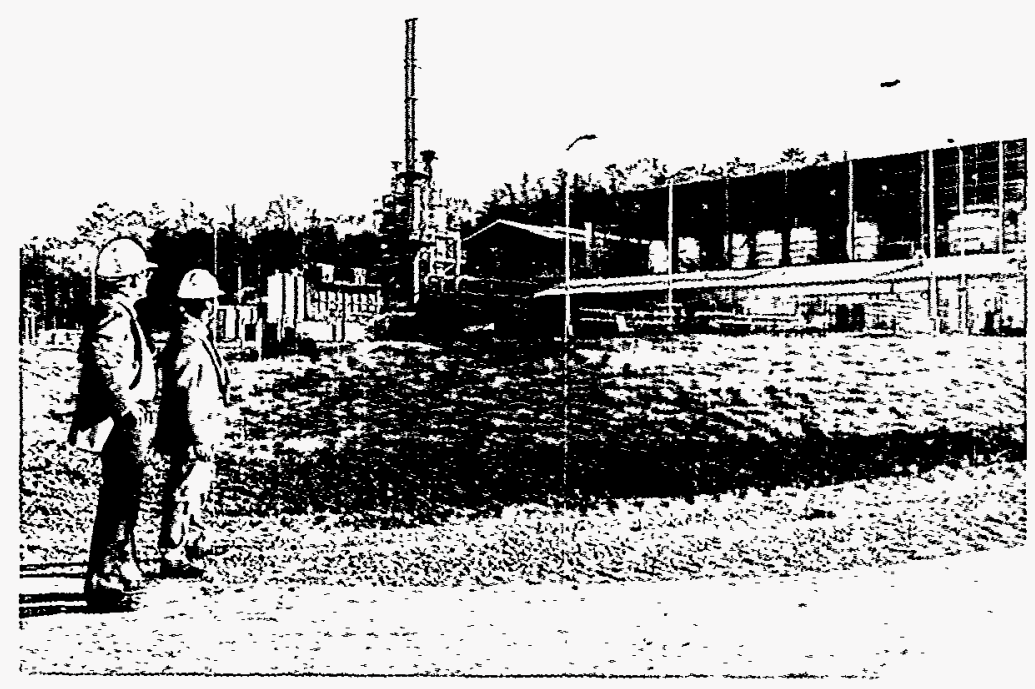

Fig. 4.37. The TSCA Incinerator located near the K-1037 office of WMTC was technically supported by Suman Singh and Angel Rivera, WMTC staff engineers. In this 1987 photograph, Bob Jolley (left) and Angel Rivera discuss Angel's support role for the incinerator. objective of this LLWDDD

demonstration managed by Mike Gilliam, Mike

Morris, and Jennifer Kasten was to evaluate the conditioning, treatment, and immobilization of selected waste streams. A major emphasis was the identification and demonstration of innovative technologies for processing four specific waste streams: $Y-12$ wastewater treatment sludge containing heavy metals and depleted uranium; ORNL wastewater-treatment water-softening sludges containing $\mathrm{Cs}, \mathrm{Sr}, \mathrm{Co}$, and trace rare earths; Y-12 metal plating sludges containing heavy metals and chlorinated phenolics; and ORNL wastewater treatment concentrates containing very high quantities of nitrates, $\mathrm{Cs}, \mathrm{Sr}$, and trace rare earths. ${ }^{38}$

- Supercompaction/Grouting of ORNL Solid Low-Level Waste Drums. The objective of this LLWDDD project was to demonstrate supercompaction and grouting of solid waste in drums after real-time radiography. The demonstration was coordinated by John Kennerly and conducted by L. C. (Red) Williams, R. W. Morrow, and R. L. Jeffers. ${ }^{38}$

- ORNL Tumulus Disposal Demonstration for Low-Level Waste. The objective of this LLWDDD project was to evaluate above-grade disposal of short-half-life radionuclides using the tumulus concept developed in France for disposal of LLW. The demonstration was coordinated by John Kennerly and managed by Dirk Van Hoesen, Sid Garland, Red Williams, and Tom Scanlan. 38

- Supercompaction of Y-12-Baled Waste. The objective of this LLWDDD demonstration was to evaluate volume reduction of previously baled solid waste using supercompaction. The demonstration was coordinated by Kennerly and Beth McDougald. 38

- Incineration of Y-12 Combustible Waste. The objective of this Y-12-sponsored demonstration was to evaluate volume reduction of $Y-12$ combustible wastes. The demonstration was conducted by a commercial vendor and coordinated by Mike Morris for Jim Bailey and Rod Kimmitt.

- Demonstration of Improved Operations Disposal at ORNL SWSA-6. The objective of this LLWDDD demonstration was to evaluate greater confinement disposal using below-grade concrete silos. The demonstration was coordinated by John Kennerly for John Van Cleve, Red Williams, and Tom Scanlan. ${ }^{38}$

- Treatment of PCB-Contaminated Soil. The objective of this Energy Systems/private sector sponsored demonstration managed by Mike Morris was to evaluate the thermal decontamination (calcination) of soils 
contaminated with uranium and PCB. This demonstration was conducted at the commercial vendor site. 38

- Y-12 Sludge Detoxification. The objective of this HAZWRAP demonstration managed by Paul Hollenbeck and John Kennerly was to evaluate the thermal treatment of Y-12 mixed waste sludges contaminated with high concentrations of phenolic materials. Detoxification of waste is defined as the removal or degradation of chemically hazardous materials. This demonstration was conducted by Chem Nuclear at the K-25 site. ${ }^{38}$

- Closure of Old Hydrofracture Surface Impoundment. The objective of this Energy Systems demonstration coordinated by Tom Lomenick and Mike Morris was to evaluate in situ processes for stabilization/fixation of impoundment residues. ${ }^{38}$

- Pyroplasma Technology for Destroying PCB-Containing Fluids (Westinghouse Pyroplasma Demonstration Project). In late February 1987, Westinghouse Plasma Systems (WPS), a subsidiary of Westinghouse Electric Corporation, sought DOE/ORO assistance to conduct a demonstration of their innovative Pyroplasma waste destruction process. Suman Singh coordinated Energy Systems support for conducting the demonstration to evaluate the high-temperature thermal destruction (Pyroplasma) of PCB-containing liquid wastes. The demonstration was conducted by WPS at the K-25 site. ${ }^{38}$

Historically Black Colleges and Universities. With support from DOE/ORO, in 1987 the WMTC also established a special program to involve staff members and graduate students from Historically Black Colleges and Universities (HBCUs) in waste management activities on the Oak Ridge Reservation. HBCUs were later to be known as the Minority Educational Institutes (MEIs). The WMTC worked with waste management organizations at ORNL, K-25, and Y-12 and with HBCU coordinators for Energy Systems and DOE/ORO to define potential problems to be addressed, identify and match HBCU staff members with Energy Systems technical project monitors, and develop contractual arrangements. ${ }^{36}$ Les Dole and later Bob Jolley coordinated the $\mathrm{HBCU}$ waste program.

Technical Workshops. The expertise available in several of the research and development organizations within Energy Systems was also used in planning and evaluating technology demonstrations, in evaluating the associated implications for the protection of human health and the environment, and in complying with regulations. These planning and evaluation exercises were supplemented by a series of technical workshops conducted by the WMTC to assist in evaluating issues and in assessing potentially useful technologies within the broad subject context. ${ }^{36}$

Workshops conducted by WMTC/WMTSG included the following:

- Leaching Test Workshop series managed by Herschel Godbee and Bob Jolley, 37,38

- Uranium-Bearing Waste Workshop managed by Tom Lomenick, 38

- RCRA/CERCLA Treatment Alternatives for Hazardous Waste workshop managed by Bob Jolley, 38

- Contaminated Soils Workshop managed by Tom Lomenick, ${ }^{37}$

- Off-Site Release Criteria Workshop managed by Suman Singh, ${ }^{37}$ and

- Alternative Treatment Technologies Workshop for Superfund Sites managed by Bob Jolley. 37

4.15 THE CEUSP PROJECT: A LARGE-SCALE CONVERSION AND SOLIDIFICATION OF HIGHLY RADIOACTIVE LIQUID WASTE, C. P. McGinnis, R. A. Jacobus, and L.. H. Bell ${ }^{39}$

The Consolidated Edison Uranium Solidification Program (CEUSP) project was a large-scale project to convert and solidify stored, highly radioactive liquid waste at ORNL. The project was made necessary because highly radioactive liquid waste had been stored for many years at ORNL in a facility where no provisions were made for the eventual chemical conversion of the solution to a form more suitable for long-term storage or disposal. ORNL's liquid radioactive waste solution resulted from a 1960's burn-up of experimental nuclear fuel consisting of mixed thorium oxide and fully enriched uranium oxide in the Consolidated Edison Indian Point I nuclear reactor in New York. The depleted experimental 
fuel was subsequently reprocessed at the Nuclear Fuel Services Plant in West Valley, New York. During reprocessing, the fuel was dissolved and passed through a Purex solvent extraction line to separate uranium from the thorium and fission products.

The reprocessed uranium solution was shipped to ORNL in late 1968 and placed in a $19,000-\mathrm{L}$ storage tank located within a stainless-steel-lined catch pit and surrounded by an additional $1 \mathrm{~m}$ of concrete shielding. The stainless steel tank was filled with ordinary borosilicate glass Raschig rings to absorb neutrons, and cadmium nitrate and gadolinium nitrate solutions were added to prevent criticality of the highly enriched solution. At storage time, the liquid waste contained $1047 \mathrm{~kg}$ of uranium as uranyl nitrate hexahydrate in $8000 \mathrm{~L}$ of nitric acid.

Immediately after reprocessing, the uranium solution was not highly radioactive and could be handled semi-remotely. However, during the years of storage at ORNL, the liquid's high concentration of ${ }^{232} \mathrm{U}$ (70-year half-life) and the resulting high concentrations of daughter decay products caused the solution to become highly radioactive. The waste contained a total estimated inventory of $20,000 \mathrm{Ci}$ by 1978 and a radiation field at the tank of more than $120 \mathrm{rad} / \mathrm{h}$. This intense radioactivity made remote handling a

necessity during the CEUSP removal, conversion, and storage processes and introduced complications in design, construction, and operation.

In 1974, a DOE Safety

Review Team visiting ORNL concluded that long-term storage of the fuel solution was unacceptable, and no uses for the material were identified. Scientists and engineers at ORNL led by John Parott, Sr., evaluated seven different disposal alternatives and eventually recommended a simple chemical and thermal decomposition and solidification process.

\subsubsection{CEUSP Process and Facility Design}

A preliminary conceptual design for the CEUSP waste processing plant was completed in 1979. The Conceptual Design Report called for a 3-year construction and fabrication schedule. An extensive process development study was conducted to determine the equipment modifications and processing conditions needed for successful process operation, including work by E. D. Collins, B. D. Patton, R. Hall, P. A. Haas, and R. J. Vedder on in situ solidification of fissile uranium, reaction of formaldehyde and nitric acid (denitration), and associated remote operations.

\subsubsection{Preoperational Testing Failure}

Construction of the CEUSP facility was completed in March 1984 (Fig. 4.38), and preoperational hydrostatic pressure testing and process shakedown were immediately done using water and then dilute acid. These initial system tests were successfully completed. Six weeks later, a second hydrostatic pressure test was done before introducing a simulated process feed material. Surprisingly, the second hydrostatic test showed the system had developed leaks. A detailed technical investigation revealed the cause to be a failure of the compression fittings used at pipeline joints.

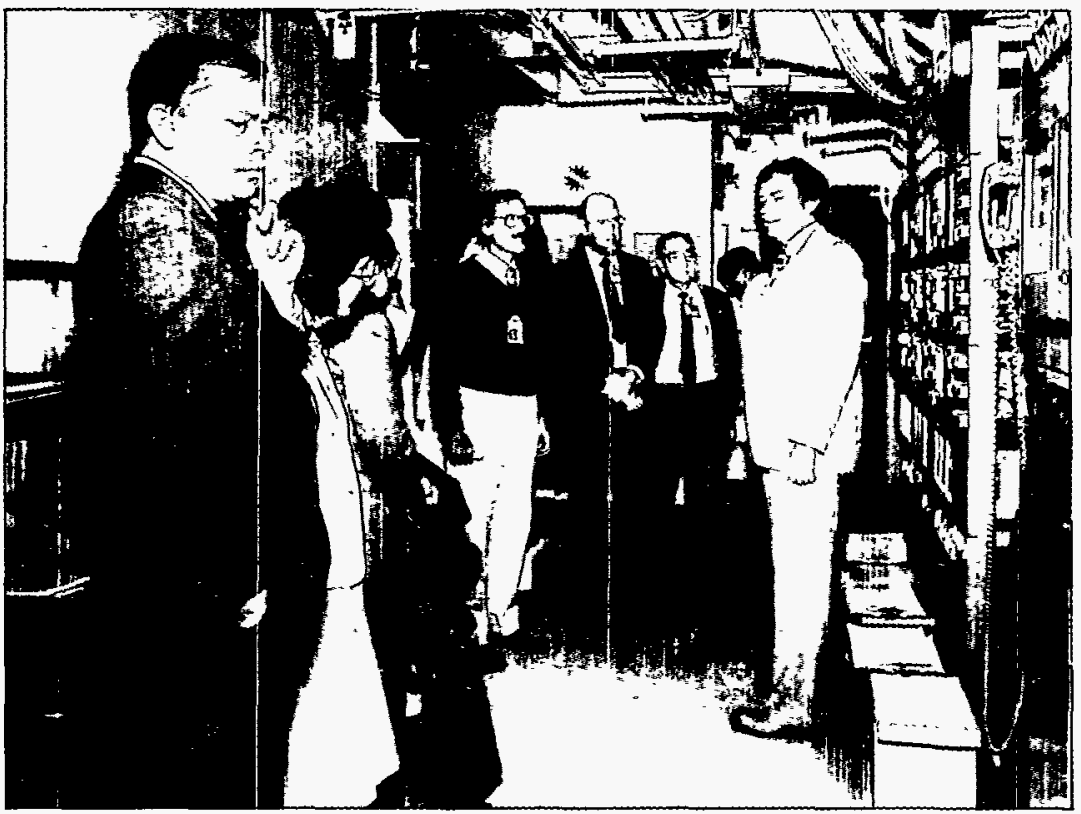

Fig. 4.38. Phil McGinnis, Program Manager (far right), and Ron Glass (far left) are shown escorting DOE visitors on a 1984 tour of the newly opened CESUP facility. Jim Cooke, DOE/ORO, and Fred Mynatt, ORNL Associate Director, are shown in the center. 


\subsubsection{CEUSP Process Operation and Results}

Actual process-line operation began in April 1985. During the initial acid destruction/ evaporation step of the CEUSP process, each 21-L batch of feed solution was heated to $>95^{\circ} \mathrm{C}$ in the evaporator before an aqueous-methanol solution containing $37 \%$ formaldehyde was added. Additional heat was added to this exothermic acid-destruction reaction to evaporate each batch to a final volume of $8 \mathrm{~L}$. Each batch of liquid from the evaporator was routed to one of three thermal denitration/solidification systems and fed directly into a can (the primary storage container) held in a small furnace. The solution was evaporated to dryness and the nitrates decomposed in situ, leaving a solid oxide cake in each can. The cans were then transferred remotely to another process area, where they were placed in secondary containment canisters and then welded shut. After sealing was completed, the materials were placed in a specially prepared shielded well for long-term storage. A "hard" (very energetic) gamma associated with the radioactive decay products of ${ }^{233} \mathrm{U}$ required special shielding and precautions. The CEUSP process successfully solidified 400 batches of highly radioactive liquid waste containing a total of $>1000 \mathrm{~kg}$ of uranium.

Surprisingly, no unanticipated downtime occurred during the entire CEUSP processing. Several planned downtimes were required to replace the waste concentrate feed pumps, which were known to have a limited service life when exposed to acidic radioactive solutions. Fortunately, no other equipment repairs or replacements were necessary. As a result, the operational phase was completed in early June 1986 , almost two months ahead of schedule. During its 13 months of operation, the CEUSP facility converted $8000 \mathrm{~L}$ of the stored radioactive liquid waste to a more stable and space-conserving solid oxide form.

Don Ferguson was the CEUSP program director. The project was managed by Phil McGinnis. Operational and management assistance was provided by R. A. Jacobus, J. M. Baker, R. D. Manthey, Jim L. Snider, Emory D. Collins, and Rex E. Leuze.

\subsection{CHEMICAL ENGINEERING RESEARCH, John Mrochek, Osman Basaran, and Tim Scott}

Chemical engineering research has, since the inception of the division in 1950, been one of the primary foci of its activities. These activities have included studies on the fundamentals of engineering science and bridging research that utilized the results of the more basic chemical research. Incorporated in these endeavors has been the innovative development of new hardware, instrumentation, and/or process concepts in order to accomplish needed programmatic goals. $R \& D$ efforts of the division have always been at the cutting edge of an established or new technology. There has always existed a relatively fine line between fundamental or basic research and applied research. In 1965, chemical engineering research was described in the division annual report as "an aggregate of studies which, while generally pertinent to the Division's applied programs, are fundamental in nature or pursue attractive new ideas. The fundamental studies usually arise from interesting effects noted during work on programs with more specific commitments." 40

Many of the activities of the division in chemical engineering research generally were focused on the fundamentals of separation methods and/or processes. In the beginning, such separations were based upon solvent extraction equipment and processes. The development of new contactors and investigations into their fundamental behavior were; of course, fair game (Figs. 4.39 and 4.40). Pioneering work on sieve-plate, pulsed columns for solvent extraction was noteworthy, as was the work on a stacked hydroclone contactor for high-speed extraction; design and development work on these new contactors continued for many years. Of interest also were fundamental studies of mass transfer, especially across two-phase interfaces associated with solvent extraction. Another important factor in the design of solvent extraction equipment, namely, the coalescence and the effect of ionizing radiation on it, was being investigated by division staff members during the period 1962-65.

The need for the production of small, uniform microspheres having particle sizes on the order of 20 led to investigations on the breakaway of droplets from a jet or nozzle in conjunction with an 


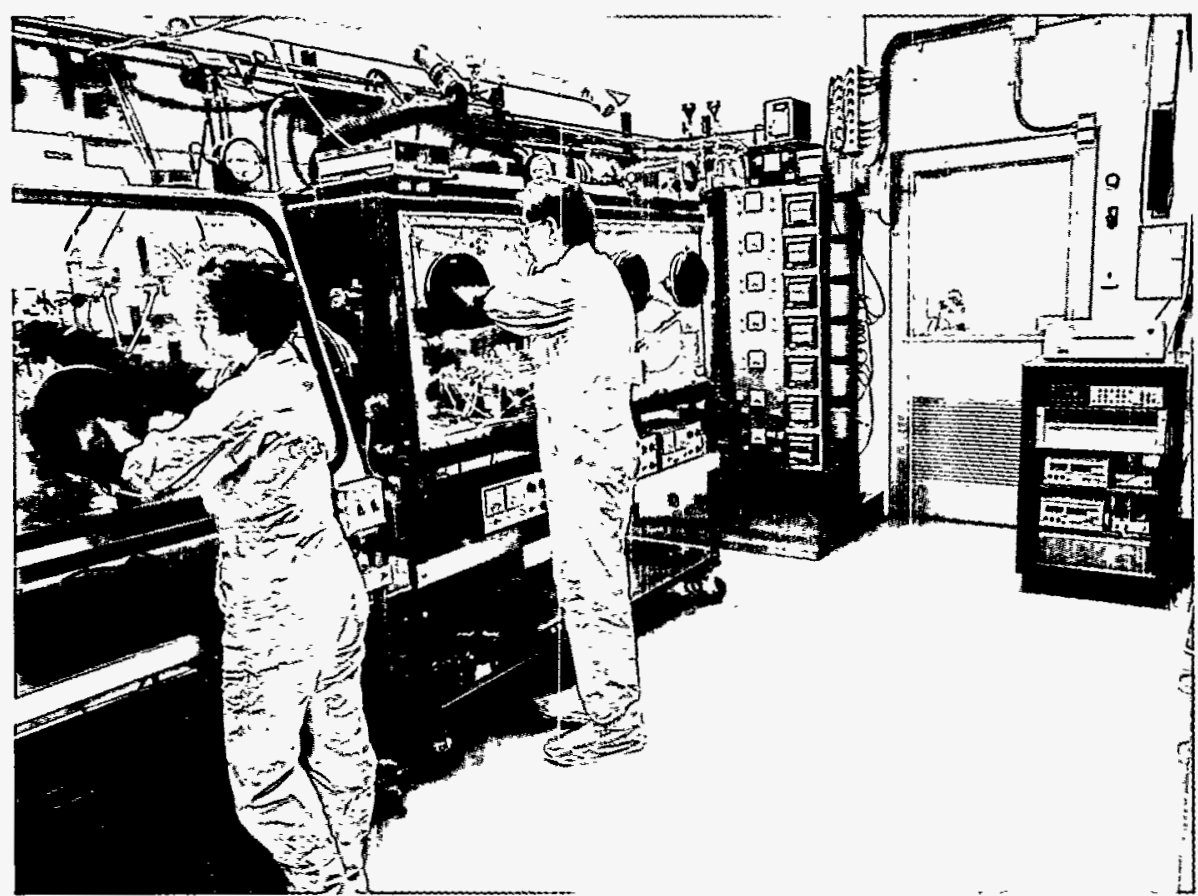

Fig. 4.39. D. F. Green (left) and George Davis work in a glove box system for plutonium flow sheet development using miniature mixer-settlers. The left glove box contains solution receivers, in-line samplers, and in-line density meters and spectrophotometers. The right glove box contains three 16-stage mixer settlers for extraction, partitioning, and stripping of plutonium and uranium. In the background are the metering systems for the feed solutions and a portion of the Hewlett-Packard data acquisition and control system.

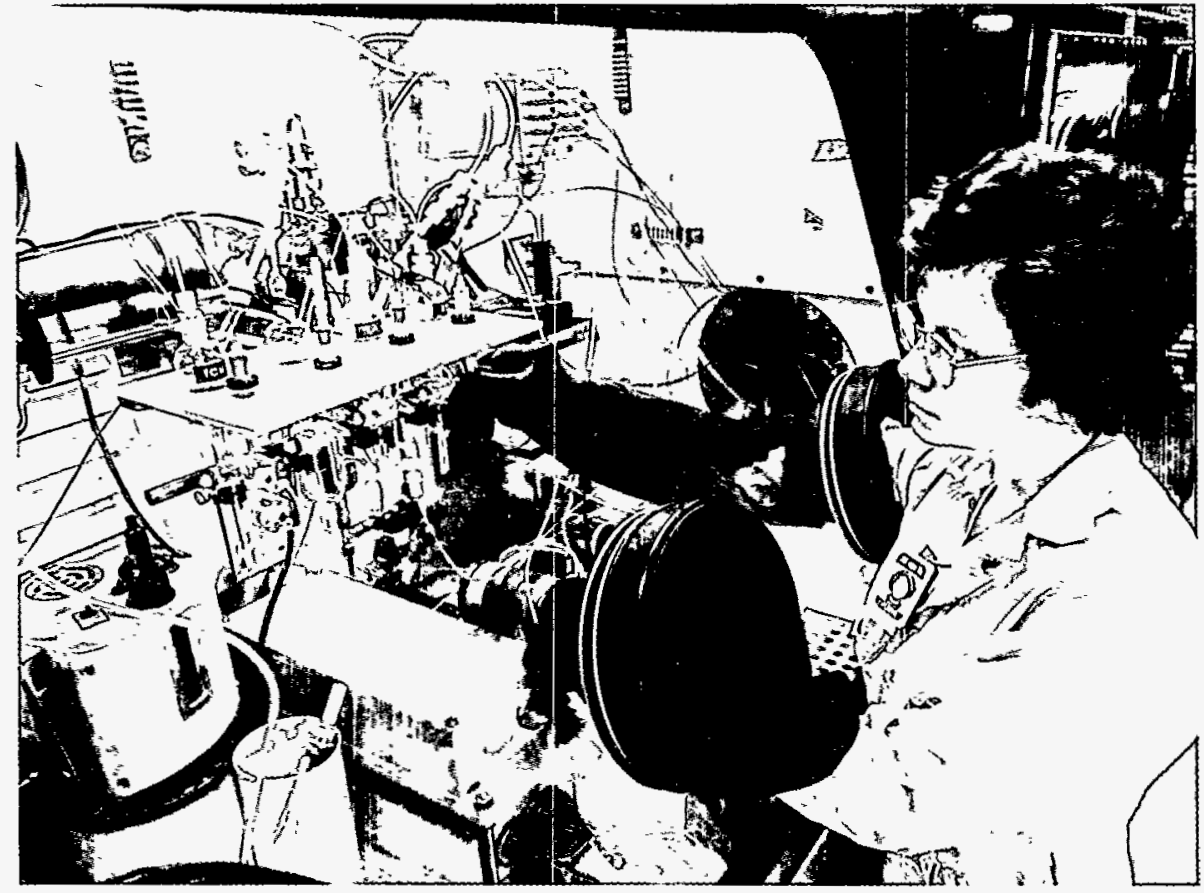

Fig. 4.40. D. F. Green is withdrawing a Vacutainer containing a 1-mL sample of the plutonium flow sheet process stream. Two remote density cells are visible in the center foreground. A miniature spectrophotometer containing a flow cell is visible in the center background. 
applied program associated with sol-gel microspheres. Nonresonant and resonant ultrasonic devices were employed to cause droplets to break away from the injection nozzle at exactly the correct time to form droplets of the desired size. This work, initiated in 1969, was a prelude to fundamental studies on the mass transfer of water from sol droplets and its effect on droplet deformation in the sol-gel process in the early 1970s. The hydrodynamics of bubble formation, dispersion, and collapse was an important fundamental investigational area associated with separations processes.

Frequently, during the 1960s and 1970s, more fundamental studies of chemical engineering problems were reported as a part of the applied programs with which they were associated. Such programs, while not enumerated here, contributed much to the fundamental knowledge associated with various separations processes.

Developments in the use of small-particle-size ion-exchange resins to improve separations were pioneered in a divisional biochemical technology program during the late 1960s. In 1971, the applicability of small resin particles in the size range of 10 to $50 \mu$ to large-scale separations processes was proposed based upon experimental and economic studies. Even though the cost of the small ion exchangers was much higher, improved separations and the downsizing of equipment enabled their utilization to be cost-effective.

About 1975, chemical engineering research programs became more oriented toward fundamental or basic science and less driven by needs in applied programs. The annual report in 1975 listed the area as "Studies in Chemical Engineering Science" instead of "Chemical Engineering Research." In conjunction with coal conversion studies, research on three-phase fluidized-bed reacting systems was initiated together with some ongoing work on tritium permeation associated with fusion reactor work. Innovative work was begun in 1975 on a new separations concept known as continuous annular chromatography. An annular chromatograph was developed which, in 1978, won a prestigious IR-100 award as one of the 100 most significant new technical products of the year (Figs. 4.41 and 4.42).

During 1977, a number of different basic research efforts, including chemical engineering research, were, for reporting purposes, combined under the title Basic Science and Technology.

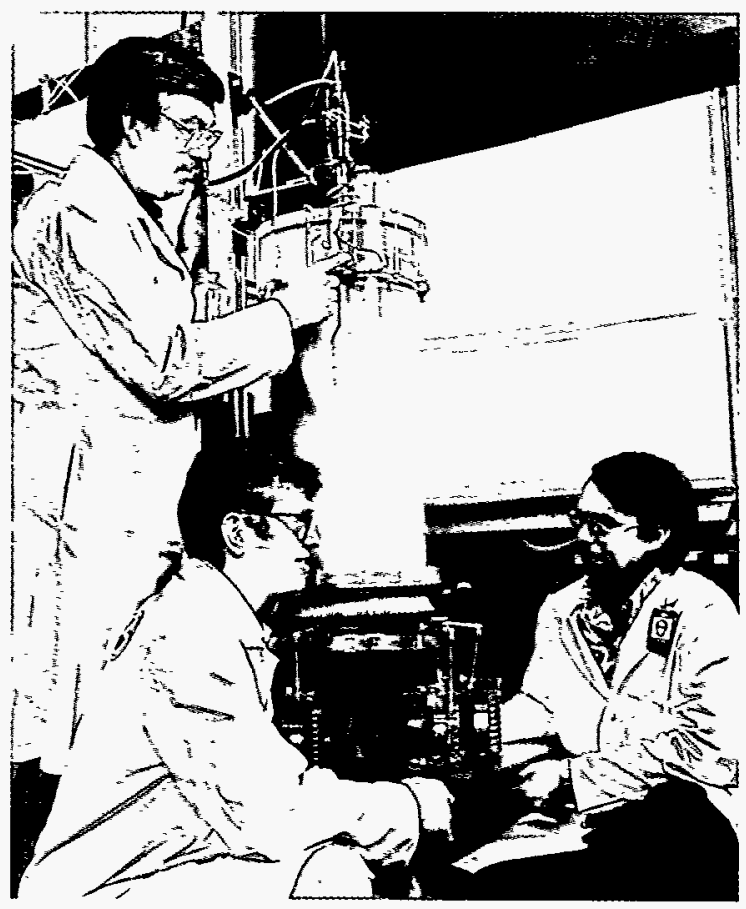

Fig. 4.41. Chem Tech development team members Warren Sisson (standing), Roger Spence (kneeling left), and Ron Canon discuss the performance of the continuous annular chromatograph for which they received the IR-100 award.

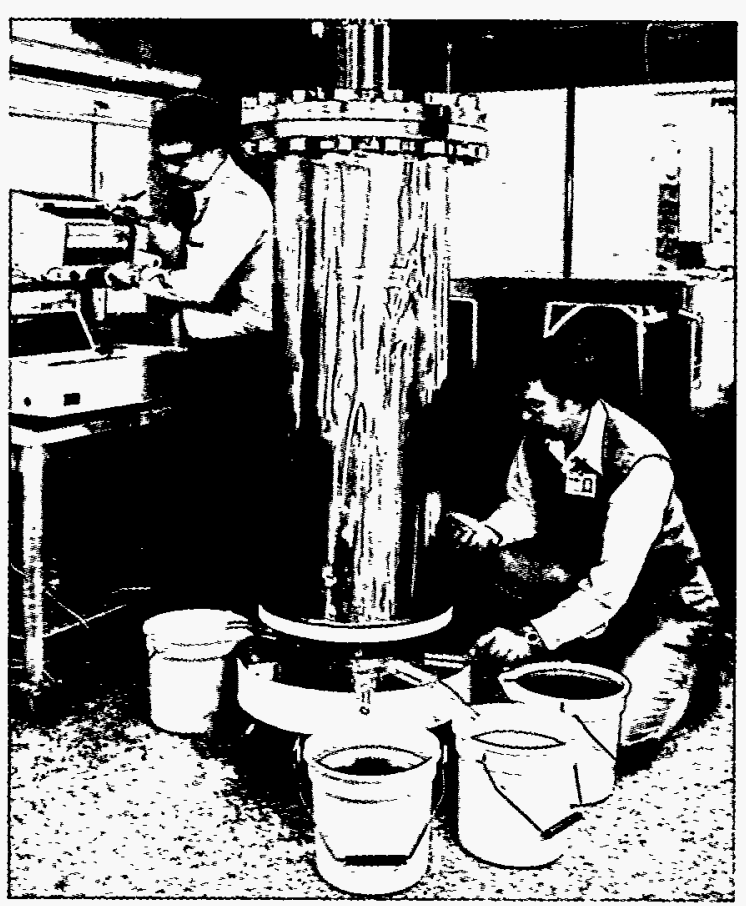

Fig. 4.42. John Begovich and Warren Sisson monitor the continuous chromatographic separation of test materials. 
Included among these were Separations Science; Resource Recovery; Interphase Transfer Kinetics; Fusion Energy Studies; Actinide Oxides, Nitrides, and Carbides; and Chemical Engineering Research. Continuous chromatography continued to be an important focus of chemical engineering research. However, because of national concerns in the overall area of energy, research associated with fossil energy conversion processes was assuming increased national importance in 1977.

Agglomeration studies of coal-derived particles in organic media began, and resource recovery employing energy-efficient processes assumed additional importance. The early 1980 s saw continued emphasis on the investigation of new engineering concepts in separation and material science areas which related to advanced energy sources, the conservation of energy, or the energy-efficient recovery of important resources. Granular electrofiltration was shown to be effective in removing small particles $(<1 \mu) \mathrm{m})$ from dilute suspensions in organic liquids in conjunction with coal conversion processes. Advanced concepts such as an absorption-fractionation process using liquid $\mathrm{CO}_{2}$ for purification of methane from advanced coal gasification processes were conceived and tested.

During the period of 1983 to 1985 , the continuous annular chromatography project was brought to a successful conclusion. Efforts to transfer the technology to industry were starting to bear fruit, with several companies building their own annular chromatographs either to solve their own problems or to commercialize the idea. Light scattering techniques were under development to measure fluid properties near the critical region of process fluids. Sorption properties were under investigation in electrically stabilized expanded beds of nonconducting granular sorbents. Also commencing were sedimentation studies on multimodal suspensions. Fundamental studies were begun on improving the efficiency of separations processes based on solvent extraction by enhancing mass transfer by causing drops to oscillate by means of a high-voltage pulsed electrical field. Basic investigations into high-temperature slagging were continued with the objective of recycling a large fraction of the nation's scrap steel, currently limited by lack of a technique for reducing its copper content.

Fundamental research in chemistry and chemical engineering within the Chemical Technology Division was supported by the Division of Chemical Sciences and the Division of Materials Sciences in the Office of Basic Energy Sciences (BES) within the Department of Energy. In 1984, most of this work was brought together in a newly formed section of the division called Energy Research Programs. A new area of research was initiated, a fundamental study of the molecular interactions between solvent and solute in supercritical solutions. The primary goal was to develop a predictive capability for use in supercritical separations employing both theoretical and experimental techniques (Fig. 4.43).

By the mid to late 1980 s, it was realized that computational capabilities in the division were lagging far behind experimental capabilities. Thus new research activities in theoretical analysis, modeling, and computational science were initiated to close this perceived gap. By the early 1990s, computational techniques, which were primarily based on finite element methods, were being

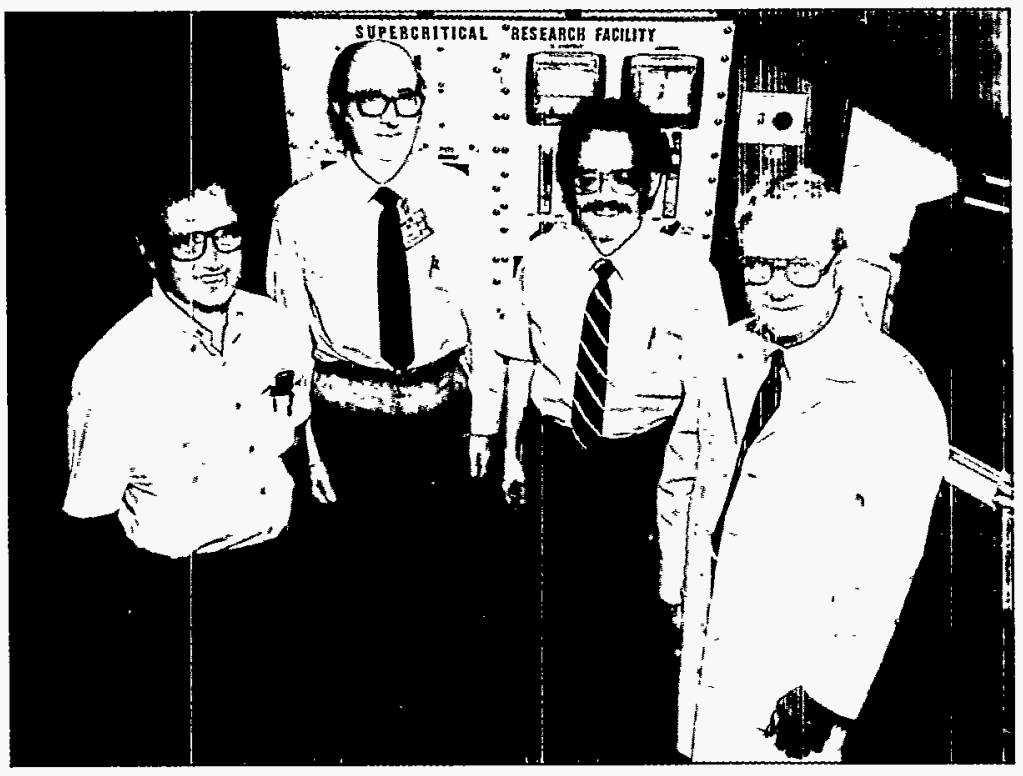

Fig. 4.43. From left to right, Charlie Byers, Jack Watson, Terry Donaldson, and Chuck Scott pose before the control panel for the supercritical research facility. 
routinely used to analyze, without approximation, oscillations of free and pendant drops, flow and mass transport to or from liquid drops, and interactions between two drops. The calculations were becoming sophisticated enough that, in a few selected instances, they provided the initial knowledge base for performing the right experiments that ultimately led to the conceptualization of improved practical designs and even patent applications. Fundamental research on separations processes continued and was combined with the new computational thrusts in an overall initiative designed to seek understanding of the principles and develop methods for studying the influence of external electric fields upon mass transport and fluid mechanics. This program, primarily concerned with droplet dispersion, coalescence, and mass transfer in two-phase systems, was to continue into the 1990s.

Continuing fundamental work in the above program during 1985-1987 resulted in the invention of a radical new concept in solvent extraction contactors, an electrically driven contactor. Two major problems which limit the use of solvent extraction in industrial applications are the efficient creation and control of mass-transfer surface area. In practice, interfacial mass-transfer surface area is usually created by a form of mechanical agitation. When attempting to maximize surface area production in an apparatus, mechanical agitation techniques tend to form polydisperse emulsions which are difficult to characterize and control in mass transfer operations. A method was required that would not only efficiently create large amounts of interfacial area for transport but also enable adequate control of phase disengagement once mass transport is completed. The use of electric fields to accomplish surface area generation and coalescence/phase separation enables multistage countercurrent solvent-extraction operations to be performed in vessels which are an order of magnitude smaller while requiring only a fraction of the operating energy of mechanical agitation. The initial patent on this new invention was granted in 1988; a subsequent patent was received in 1990 .

The development path followed by this Emulsion Phase Contactor (EPC) illustrates the unique way in which government-funded research in national laboratories should be employed for enhancement of the public welfare. This invention demonstrates conceptual development of an idea under fundamental or basic research funding by the
Chemical Sciences Division of the BES. Proof-of-principle funding to further develop the invention to a point where industry could take over was provided by the Advanced Energy Projects Division of BES. Under the impetus provided by the Technology Transfer Program, the technology has now been licensed to two industrial firms. Both firms are proceeding with the development of commercial versions of the EPC, one in petroleum, rare-earth, and specialty chemical technologies and the other in analytical and pharmaceutical applications. A commercial version is expected to be on the market in 1992.

The early 1990s saw a continuation of the programs entitled Effects of External Fields on Multiphase Systems and Interactions of Solvents, Solutes, and Surfaces. Both of these programs are, of course, deeply rooted in the fundamentals of separations processes. The former is principally concerned with improving the energetics and efficiency of solvent extraction by initiating fundamental studies on the use of electromagnetic fields to enhance multiphase separations. Experimental and theoretical thrusts are on probing transport fundamentals in field-enhanced liquid-liquid, liquid-vapor, and fluid-solid separations. The latter program is primarily concerned with developing a predictive theory for separations conducted in the supercritical region of solutes and/or solvents. Fundamental experimental and theoretical studies are aimed at understanding the striking properties of supercritical solutions in terms of the underlying fluid microstructure and molecular interactions. Basic research is focused on relating macroscopic properties of mixtures to intermolecular interactions and molecular correlation functions for the highly asymmetric systems characteristic of extraction by and adsorption from supercritical fluids.

Over the 42-year history of the Chemical Technology Division, chemical engineering research has maintained a strong interest and involvement in separations (Fig. 4.44). During the early years, there appeared to be a very close coupling of basic or fundamental research with applied problems arising in other division programs. In later years, a clear decoupling of fundamental research from applied areas seemed to occur. This was most certainly due to constraints imposed by the various funding organizations. This is not to imply that such separation was undesirable because it may have resulted in enhanced progress in the fundamental areas. The division's programs 


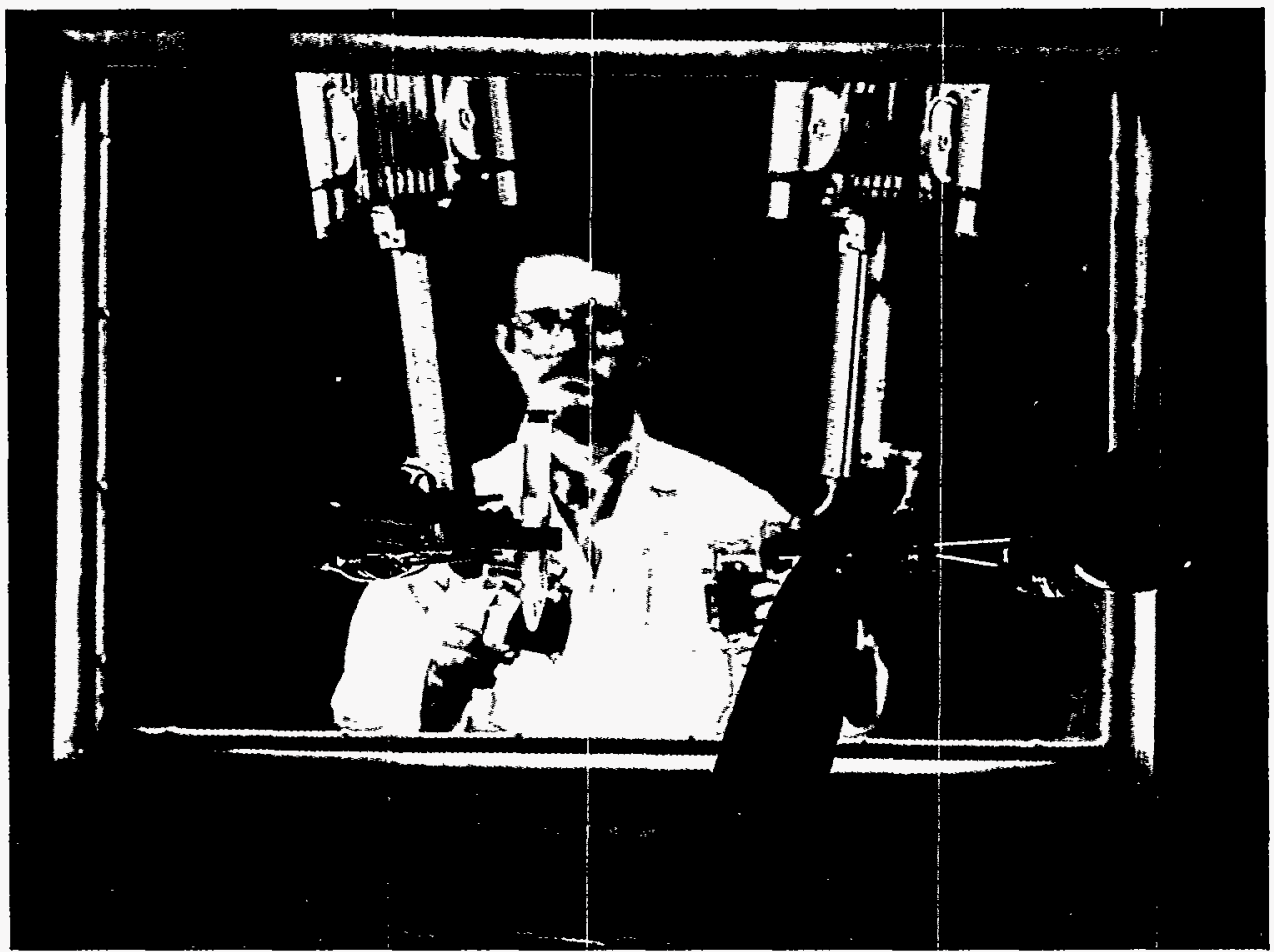

Fig. 4.44. Bob Fellows is using manipulators to prepare a solvent extraction sample for removal from the hot cell.

in chemical engineering research have usually been at the cutting edge of technology and have always served to enhance the division's image as a premier research division at the Oak Ridge National Laboratory (Fig. 4.45).

\subsection{HISTORICAL OVERVIEW OF THE CHEM TECH PILOT PLANT (BUILDING 3019), \\ J. R. Hightower and \\ R. E. Brooksbank, Sr.}

In early 1943, as part of the Manhattan Project, plans were made to build an air-cooled nuclear experimental pile, a chemical separations pilot plant, and supporting laboratories on an isolated tract known as X-10. These major installations became the prime function of the Clinton Engineer Works, now known as ORNL. Since that time, Building 3019 (formerly known as Building 205) has served as a pilot plant in the development of several radiochemical processes that have found plant-scale application in both government and commercial facilities on a worldwide basis. In addition to the process development role, the facility's operations have also produced large quantities of product materials (plutonium, uranium of all isotopes, thorium, and special isotopes) while processing highly irradiated fuel.

The programs conducted in Building 3019 during its 48 -year history have had a major impact on the government's missions. The versatility of the facility has been adequately demonstrated, indicating that the building represents a valuable asset to future government programs.

\subsubsection{Role of a Pilot Plant}

A pilot plant is one operational step in the orderly plan of chemical process development. The usual function of a pilot plant is to bring out procedures arising from the integration of all phases of the process and to obtain adequate quantitative data for the design and operation of an economical production plant. In addition to being a development facility, a pilot plant serves as a small-scale production plant, having many of the characteristics of a full-scale production plant. In general, development programs in a pilot plant should accomplish the following primary objectives: 


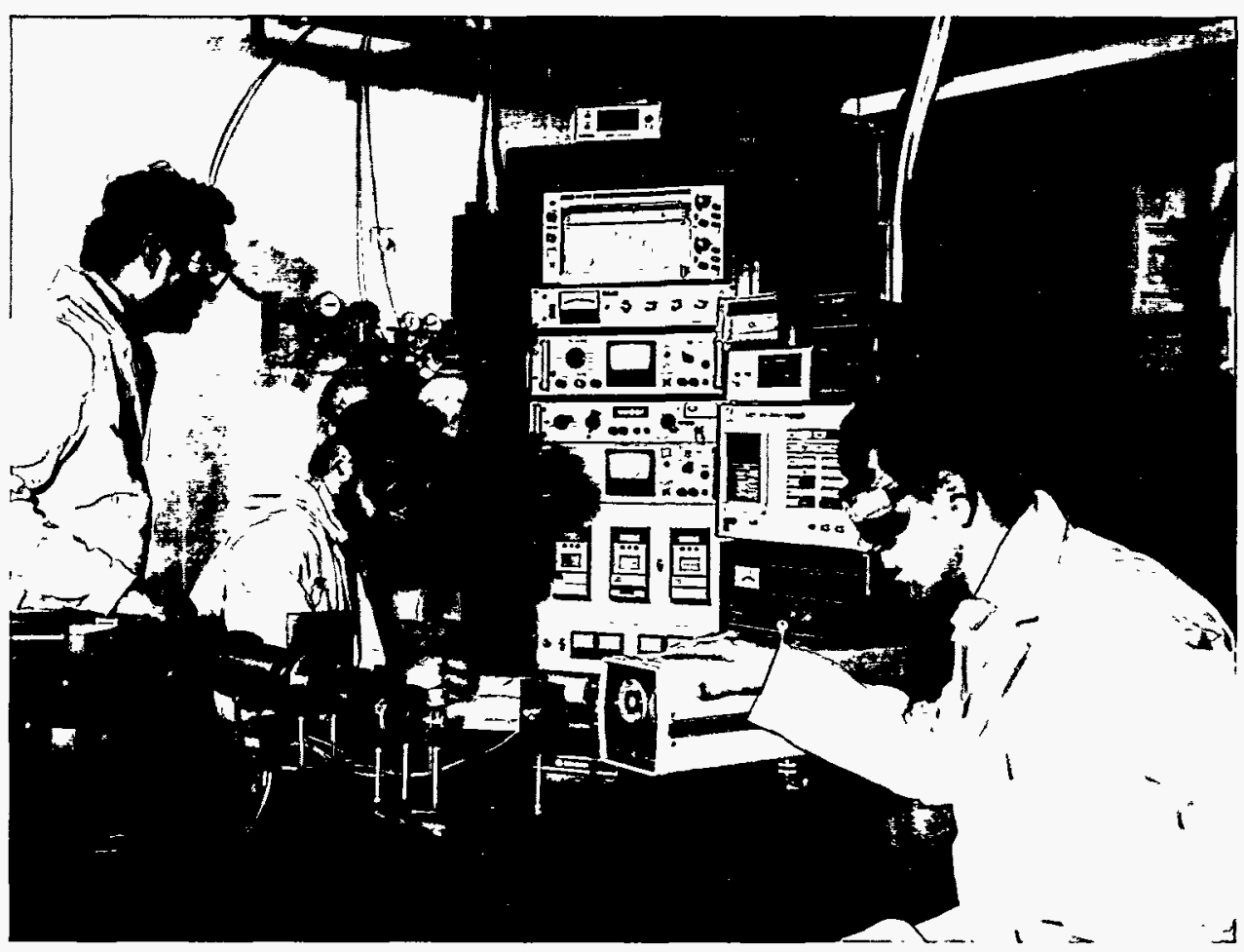

Fig. 4.45. Charlie Byers (left), Ron Brunson (center), and Dave Williams monitor the laser systems being used to study fundamental structure and properties of solutions.

1. Confirm the feasibility of the proposed process.

2. Obtain quantitative engineering data necessary for the design and operation of a production plant.

3. Provide quantities of the product for large-scale evaluation at other sites.

4. Identify chemical and engineering problems that were not recognized in smaller-scale development work.

The Chem Tech Pilot Plant achieved these objectives very successfully.

\subsubsection{Role of Building 3019 in Reprocessing Technology}

The major programs conducted within Building 3019 in support of the government's missions during the period from 1943 to 1976 (the period of formidable development) are presented in this section along with the quantities of material recovered as the result of the building's operation. These materials were recycled into other government programs as required. In addition to the efforts expended in the handling of uranium-based spent reactor fuel, the reprocessing of irradiated thorium in the United States is discussed, indicating the quantity of the ${ }^{233} \mathrm{U}$ recovered to date. This uranium isotope is currently a major concern to the operations taking place in the building because the ${ }^{233} \mathrm{U}$ isotope has unique characteristics relating to criticality, shielding, and contamination control.

The first tens-of-grams quantities of plutonium were precipitated from tons of uranium and grams of fission products in Oak Ridge in 1943, just four years after Dr. Seaborg isolated a few micrograms from an accelerator target. Between 1943 and the present time, hundreds of thousands of tons of irradiated uranium have been processed, both in defense and commercial reprocessing plants, on a worldwide basis.

Since 1942, ORNL (formally Clinton Engineer Works) has been continuously engaged in process development of the nuclear fuel cycle. The basic process techniques in which ORNL participated, along with their chronology, are listed in Table 4.1. As can be seen from this table, Building 3019 has played a major role in this development effort. The role of a pilot plant in the major development 
Table 4.1. Chronology of reprocessing experience at ORNL

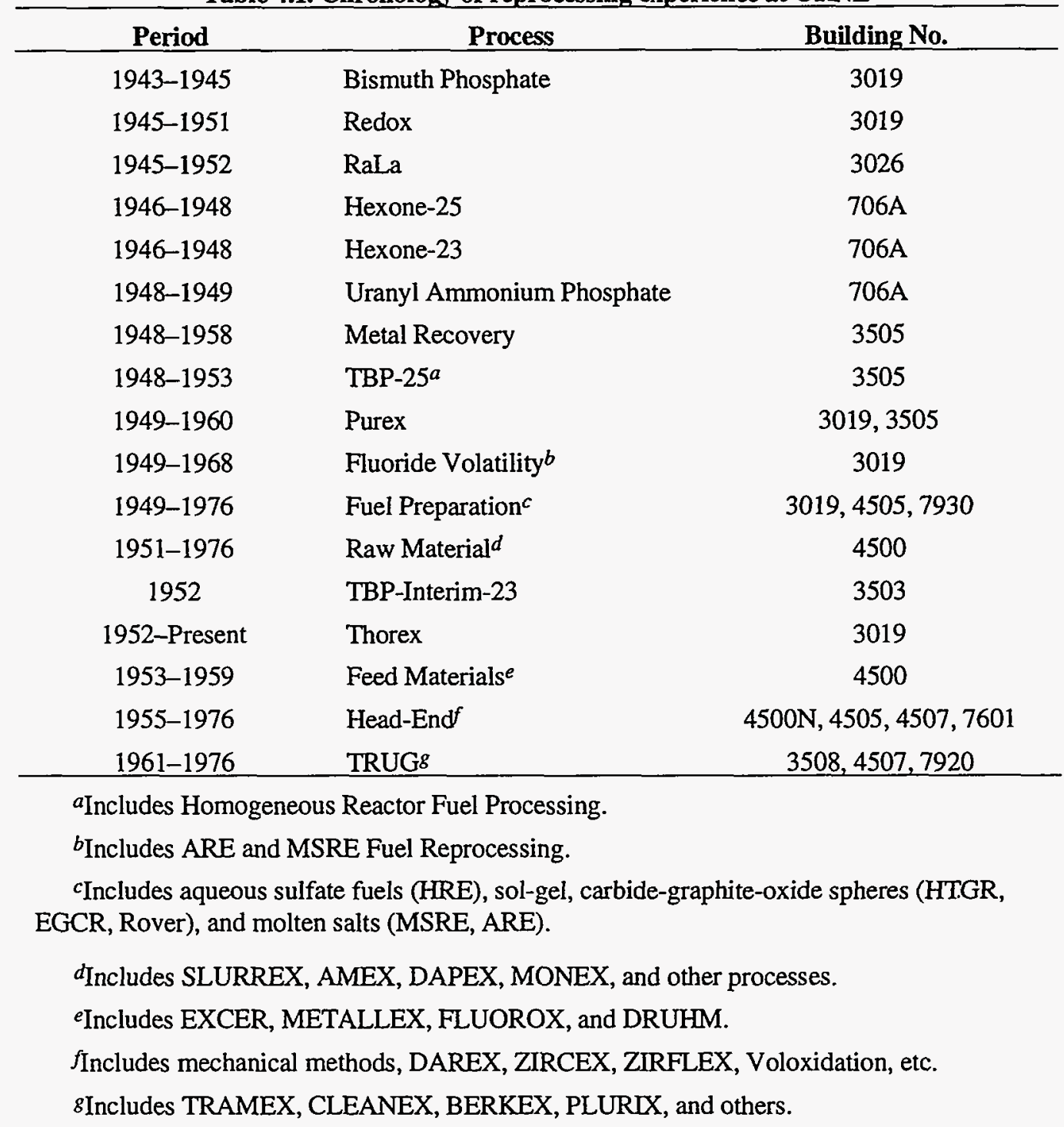

efforts undertaken in the reprocessing segment of the fuel cycle for the 1943-1976 period (the period of most development) is given in Table 4.2. The sites of full-scale plants that ultimately resulted from this development effort are also presented in this table. Major segments of reprocessing unit operations were also developed in pilot plants to formulate auxiliary processes for these large plants. Primary among these specific process development programs were the head-end operations necessary to dissolve the irradiated fuel and to remove the iodine and rare gases from the off-gas streams. Table 4.3 indicates some of the significant processes developed in this category.
For many years, ORNL and Chem Tech have been recognized worldwide as leaders in the development of reprocessing technology. In this regard, Building 3019 has played an integral part in each of the spent fuel reprocessing flow sheets used in plant-scale application within the United States (including both defense and proposed commercial facilities). Commercial firms that constructed reprocessing plants that would employ the Purex process, which was piloted in Building 3019 , included the Allied General Nuclear Services (AGNS) Plant at Barnwell, South Carolina, and the Midwest Fuel Recovery Plant (MFRP) at Morris, Illinois, operated by General Electric (GE). In the 
Table 4.2. Reprocessing experience at ORNL-separation processes

\begin{tabular}{|c|c|c|c|c|}
\hline $\begin{array}{c}\text { Development } \\
\text { dates }\end{array}$ & Process & Method & Hot pilot plant & Plant site \\
\hline $1943-1945$ & Bismuth phosphate & Precipitation for Pu only, from metal slugs & ORNL & Hanford \\
\hline $1946-1950$ & Redox & $\begin{array}{l}\text { Solvent extraction; hexone for } \mathrm{U} \text { and } \mathrm{Pu} \text { from } \\
\text { metal slugs }\end{array}$ & ORNL, Hanford, ANL & Hanford \\
\hline $1946-1950$ & Radioisotopes & $\begin{array}{l}\text { Precipitation, ion exchange, solvent extraction, } \\
\text { absorption, distillation }\end{array}$ & ORNL & $\begin{array}{l}\text { ORNL, industry, } \\
\text { Hanford }\end{array}$ \\
\hline $1946-1952$ & $\mathrm{RaLa}$ & Precipitation for barium/lanthanum & ORNL & ORNL, Idaho \\
\hline $1946-1948$ & Hexone-25 & Solvent extraction for fully enriched $\mathrm{U}-\mathrm{Al}$ alloy & ORNL & ORNL, Idaho \\
\hline $1947-1950$ & Hexone-23 & $\begin{array}{l}\text { Solvent extraction for thorium and }{ }^{233} \mathrm{U} \text { from } \\
\text { metal slugs }\end{array}$ & ORNL & ORNL \\
\hline 1948-1949 & Metal recovery & $\begin{array}{l}\text { Solvent extraction with tributyl phosphate (TBP) } \\
\text { for U slugs }\end{array}$ & ORNL (recovery of WWII U) & Hanford \\
\hline $1948-1953^{a}$ & TBP-25 & $\begin{array}{l}\text { Solvent extraction for fully enriched }{ }^{235} \mathrm{U}-\mathrm{Al} \text {; } \\
\text { homogeneous reactor fuel }\end{array}$ & ORNL & Idaho \\
\hline $1949-1960^{a}$ & Purex & Solvent extraction with TBP for $\mathrm{U}$ and $\mathrm{Pu}$ & $\begin{array}{l}\text { ORNL ( } 2 \text { plants), KAPL, } \\
\text { Hanford }\end{array}$ & $\begin{array}{l}\text { Hanford, SRS, NFS, } \\
\text { all foreign plants }\end{array}$ \\
\hline $1946^{a}$ & Pu ion exchange & Product $\mathrm{Pu},{ }^{235} \mathrm{U}$ & ORNL & \\
\hline $1949-1968$ & Fluoride & $\begin{array}{l}\mathrm{F}_{2} \text { for }{ }^{235} \mathrm{U} \text { recovery, Molten salt fuel, MSRE } \\
\text { fuel, plate fuel }\end{array}$ & ORNL, ANL & None \\
\hline 1952 & TBP-interim 23 & Solvent extraction for ${ }^{235} \mathrm{U}$ recovery only & ORNL & $\begin{array}{l}\text { NFS }^{b} \text { for Con-Ed } \\
\text { Spectral Shift, } \\
\text { Hanford, SRS }\end{array}$ \\
\hline 1955-1956 & Zirflex & Ammonium fluoride dissolution of zirconium fuel & ORNL, Idaho & Idaho, UK \\
\hline $1952-1959^{a}$ & Thorex & ${ }^{233} \mathrm{U}$ and Th recovery ( 2 versions) & ORNL & $\begin{array}{l}\text { Hanford, Savannah } \\
\text { River }\end{array}$ \\
\hline 1965-1976 & Sol-gel & $\begin{array}{l}\text { Solvent extraction and precipitation to prepare } \\
{ }^{233} \mathrm{U}\end{array}$ & ORNL & $\begin{array}{l}\text { LWBR }{ }^{233} \text { U fuel } \\
\text { demo (Bettis) }\end{array}$ \\
\hline $1961-1976^{a}$ & TRU processes & $\begin{array}{l}\text { Solvent extraction, ion exchange, precipitation for } \\
\mathrm{Am}, \mathrm{Cm}, \mathrm{Bk}, \mathrm{CF} \text {, and Es }\end{array}$ & ORNL, SRS & SRS for ${ }^{252} \mathrm{Cf}$ \\
\hline
\end{tabular}


Table 4.3. Reprocessing experience at $\mathrm{ORNL}$-head-end and dissolver off-gas processes

\begin{tabular}{|c|c|c|c|c|}
\hline $\begin{array}{c}\text { Development } \\
\text { dates }\end{array}$ & Process & Method & Hot pilot plant & Plant site \\
\hline $1943-1976^{a}$ & $\begin{array}{l}\text { Chemical dejacketing, batch } \\
\text { dissolver }\end{array}$ & Dissolution in $\mathrm{HNO}_{3}$ & All U.S. plants & All U.S. plants \\
\hline $1949-1952$ & $\mathrm{Xe}, \mathrm{Kr}$ absorption & $\begin{array}{l}\text { Removal of } \mathrm{Kr} \text { by charcoal } \\
\text { absorption; cryogenic distillation }\end{array}$ & ORNL & Idaho \\
\hline $1955-1976^{a}$ & Mechanical dejacketing & Dissolution with Magnox-clad fuel & Britain, France & Britain, France \\
\hline $1963^{b}$ & Mechanical dejacketing & $\begin{array}{l}\text { Fast reactor fuel: Hallam and SRE, } \\
\text { stainless clad metal }\end{array}$ & ORNL & None \\
\hline $1955-1976^{a}$ & Zirflex HF dissolution & Dissolution of zirconium-clad fuels & ORNL, Idaho & Idaho, Eurochemie \\
\hline $1962-1976^{a}$ & Chop-leach & Power reactor fuels & ORNL (cold) & $\begin{array}{l}\text { NFS, AGNS, Britain, } \\
\text { La Hague, Japan, } \\
\text { India }\end{array}$ \\
\hline 1965-present & Continuous dissolution & Power reactor $\mathrm{UO}_{2}$ fuels & ORNL (developing) & $\begin{array}{l}\text { None; planned for } \\
\text { LMFBR }\end{array}$ \\
\hline $1965-1976^{b}$ & Crush, burn, leach & HTGR and graphite fuels & $\begin{array}{l}\text { ORNL (hot cell); Gulf-GA } \\
\text { (cold) }\end{array}$ & $\begin{array}{l}\text { Proposed pilot plant } \\
\text { for HTGR }\end{array}$ \\
\hline $1970-1976$ & Voloxidation and tritium & $\mathrm{UO}_{2}$ to $\mathrm{U}_{3} \mathrm{O}_{8}$ for $\mathrm{Kr}, \mathrm{I}_{2}$, tritium & $\begin{array}{l}\text { ORNL (hot cell, small } \\
\text { scale) }\end{array}$ & None \\
\hline $1969-1976$ & $\begin{array}{l}\text { Selective absorption of fission } \\
\text { gases }\end{array}$ & $\begin{array}{l}\mathrm{Xe}, \mathrm{Kr}, \mathrm{CO}_{2} \text { removal with freon } \\
\text { scrubbing }\end{array}$ & $\begin{array}{l}\text { ORNL, K-25 (full-scale } \\
\text { cold) }\end{array}$ & None \\
\hline $1970-1976$ & $\begin{array}{l}\text { Iodox, } \mathrm{Ag} \text { zeolite, mercury } \\
\text { nitrate, caustic and } \mathrm{Ag}\left(\mathrm{NO}_{3}\right) \\
\text { scrubbers }\end{array}$ & Increased ${ }^{129} \mathrm{I},{ }^{131} \mathrm{I}$ retention & ORNL (hot) & $\begin{array}{l}\text { Caustic scrub in all } \\
\text { plants; others in or } \\
\text { planned }\end{array}$ \\
\hline
\end{tabular}

$a$ Widely used process.

$b$ Not for LWR fuel. 
case of the MFRP, the flow sheet selected included both solvent extraction and fluoride volatility methods. Both of these concepts were demonstrated in pilot-scale efforts in Building 3019. Exxon was proposing to build a large reprocessing plant in Oak Ridge that would also employ Purex process concepts. Purex technology has continued to evolve throughout the world and has advanced in several nations. Plants currently exist in the United Kingdom, France, Japan, China, and the Soviet Union.

Although not stressed in this document, there are the many side benefits to the government from the experience gained from the operation of Building 3019. A partial listing of these benefits is presented below:

1. The training of the Du Pont operating staff assigned to operate the Savannah River plant took place in Building 3019. During the 1952 period, 26 key operations managers were assigned to the facility to train for the production plant operation.

2. Because of the extensive Purex and Volatility experience with irradiated fuel at Building 3019 , key members of the building staff assisted the government in the training and testing of commercial reprocessing plant operators [Nuclear Fuel Services (NFS), GE, AGNS]. In essence, all of the various operators in these plants that were granted government operating licenses were examined by Building 3019 personnel at the plant site. Each of the written examinations given by examiners for all operating licenses was prepared by the Building 3019 staff.

3. Interim production quantities of plutonium, uranium (all isotopes), thorium, and various special isotopes were provided from the operations in Building 3019 and recycled.

4. A large number of technical papers and reports were prepared and presented as the direct result of the experience gained in Building 3019.

5. Because of the experience gained in the building with the handling of highly radioactive materials, personnel from the building served as consultants to the government in numerous capacities. Included in this category are (1) the recovery of weapons debris from the crash of an aircraft in Thule, Greenland; (2) the safeguards evaluation of the Tokai-Mura plant in Japan; (3) major on-site assistance to the cleanup of Three Mile Island (TMI); and

(4) other assignments too numerous to mention.

\subsubsection{Early History and Operating Philosophy Evaluation of Building 3019}

As is well known, the Oak Ridge site was selected as part of the famous Manhattan Project. Hewlett and Anderson described the construction phase of Building 205 (3019) as follows.

When the Hanford site was finally selected in January 1943, plans were made to build an air-cooled experimental pile, a chemical separations pilot plant (Building 3019 or Building 205), and supporting laboratories on the isolated tract in Bethel Valley, known as $\mathrm{X}-10$. Since the Du Pont Company was charged with both the design and construction of X-10, only a few weeks elapsed between the decision to proceed and the groundbreaking for the first building. Du Pont started the first temporary buildings February 2, 1943, and completed these and the utility installations in March 1943. At that time, sufficient data on the separations plant (Building 3019) were available to permit construction crews to initiate excavation. Two months were required to complete the foundation for the six large underground cells in which the plutonium would be separated from the uranium slugs. With concrete walls several feet thick, the cells would extend one story above ground and would be covered with mammoth concrete slabs which could be removed when replacing equipment. The first cell, linked to the pile building by an underground canal, contained a large tank in which the uranium slugs and their aluminum jackets could be dissolved. The next four cells were designed for the large stainless steel tanks, centrifuges, and piping for the successive oxidation-reduction cycles. The last cell served as a spare for storing contaminated equipment. Stretching alongside the cells was a one-story frame building used for the operating gallery and offices. By June, Du Pont had started the pouring of the cell walls. When the Bismuth Phosphate process was selected, the equipment design function was accelerated. The installation of piping and cell tankage began in September. The testing and extensive modification of process equipment required most of October, but the plant was ready to 
operate when the first slugs were discharged from the pile (December 1943). 41

Since this early beginning, numerous changes have been made to the Building 3019 pilot plant to accommodate the multitude of processes requiring demonstration. Considerable credit should be given to the original designers of the facility to permit this flexibility. Basically, the designers provided a facility and cell structure that could be tested with nonradioactive materials, demonstrate a process with irradiated fuel, collect data, decontaminate equipment to permit its removal, decontaminate the cells, and prepare for the installation of new process equipment. The successful programs accomplished in the building attest to this factor.

As with all maturing technologies, the processes conducted in Building 3019 required the facility to undergo numerous changes over the years. Demands made to improve safety, containment, criticality control, process control, safeguards, and data collection are among the requirements that have been responsible for these changes.

\subsubsection{Building 3019 Programs}

A listing of the major programs conducted in Building 3019 since it was commissioned in 1943 is presented in Table 4.4. In addition to these programs, other programs involving the development of the ion exchange of plutonium ${ }^{239} \mathrm{Pu},{ }^{238} \mathrm{Pu}$ ) were conducted in the laboratories attached to the main building cells. Analytical procedure development and analysis of the pilot plant samples for process control were accomplished in the analytical cell block on the west side of the building. During the Thorex program, a remote sample withdrawal system was developed for the process system to decrease radiation exposure to the pilot plant operators and the analytical chemists. Samples were remotely transferred from the pilot plant to the analytical cells via a shielded conveyor system located on the roof of the building. For some programs where sufficient decontamination could not be attained in the building's solvent extraction cycle, Building 3505 was used, which contained three additional cycles along with the isolation system for the plutonium product. An underground pipeline was installed between the buildings to permit the processing of certain fuels under these conditions.

A concern regarding the long-range availability of uranium as a nuclear fuel was demonstrated from 1949 to the early 1950 s, and the government turned its development efforts toward thorium. In this regard, Building 3019 has played a major and unique role. As is well known, irradiated thorium contains the isotope ${ }^{233} \mathrm{U}$, which is also a fissionable isotope. Early pilot plant programs with irradiated thorium took place in the building in the 1954-1958 period, during which time 35 tons of thorium was processed as part of the development of the Thorex and Interim-23 flow sheets. A total of $55 \mathrm{~kg}$ of ${ }^{233} \mathrm{U}$ (containing $10-40 \mathrm{ppm}^{232} \mathrm{U}$ ) was isolated from this material, which required unique storage requirements. Because of the daughter products of ${ }^{232} \mathrm{U}$ contained in the ${ }^{233} \mathrm{U}$, this material represents a serious gamma radiation hazard to personnel and requires shielding, especially when aged. As the result of the inventory of irradiated thorium in the reactors at both Hanford and Savannah River, the government wisely selected Building 3019 as the "233U National Repository" in 1962. The Purex plants at both Hanford and Savannah River modified their flow sheets to Thorex and processed a total of 870 tons of irradiated thorium during the $1964-1970$ period. The $1400 \mathrm{~kg}$ of ${ }^{233} \mathrm{U}$ isolated from these programs was sent to ORNL for storage at Building 3019. Additionally, as instructed by the government, the NFS Plant at West Valley, New York, recovered $1019 \mathrm{~kg}$ of uranium from the processing of Consolidated Edison reactor fuel. This material also found its way to the storage facilities at Building 3019. A summary of the thorium- ${ }^{233} \mathrm{U}$ processing in the United States is presented in Table 4.5.

\subsubsection{Future Plans}

Plans for the facility include the following:

- continue as the national repository and dispensing facility for ${ }^{233} \mathrm{U}$,

- provide development services to the AVLIS program for demonstration of the product conversion by modified direct denitration,

- provide radiochemical laboratories in which waste treatment studies may be performed,

- provide a test bed for demonstration of novel decontamination techniques, and

- provide secure or bonded storage of other valuable radioactive materials, as appropriate. 
Table 4.4. Building 3019 pilot plant program

\begin{tabular}{|c|c|c|c|c|c|c|c|c|c|c|}
\hline \multirow[b]{2}{*}{ Date } & \multirow[b]{2}{*}{ Program } & \multirow[b]{2}{*}{ Feed material } & \multirow[b]{2}{*}{ Process employed } & \multicolumn{4}{|c|}{ Material recovered } & \multirow[b]{2}{*}{$\begin{array}{c}\text { Irradiation level } \\
\text { (MWd/ton) }\end{array}$} & \multirow[b]{2}{*}{$\begin{array}{l}\text { Cooling } \\
\text { months }\end{array}$} & \multirow[b]{2}{*}{ Remarks and/or references } \\
\hline & & & & $\underset{(\mathbf{k g})}{\mathrm{U}}$ & $\begin{array}{c}\mathbf{P u} \\
(\mathbf{k g})\end{array}$ & $\begin{array}{l}\text { Np } \\
\text { (g) }\end{array}$ & $\begin{array}{l}\mathrm{Am} \\
(\mathrm{g})\end{array}$ & & & \\
\hline $1943-1945$ & Weapons & $X-10$ uranium slugs & Bismuth phosphate & & & & & Low & & $\begin{array}{l}\text { Recover Pu; demonstrate } \\
\text { separation process; train } \\
\text { personnel }\end{array}$ \\
\hline $1946-1948$ & Development & Enriched uranium & Redox 25 Process & & & & & Low & & $\begin{array}{l}\text { Separate and recover } \\
\text { enriched uranium }\end{array}$ \\
\hline $1950-1953$ & Purex & Uranium slugs & Purex & $\sim 7,500^{a}$ & $\sim 7$ & & & $\sim 500$ & $2-4$ & $\begin{array}{l}\text { Demonstrate Purex process; } \\
\text { recover Pu and U; train } \\
\text { personnel; provide } \\
\text { engineering data }\end{array}$ \\
\hline \multirow[t]{2}{*}{$1954-1958$} & Thorex & Thorium slugs & Thorex & $\sim 60^{b}$ & & & & $500-5,000^{c}$ & $<1-30$ & $\begin{array}{l}\text { Demonstrate Thorex } \\
\text { one-cycle, two-cycle, and } \\
\text { three-cycle process at high } \\
\text { "g/te" levels and at } \\
\text { short-decay periods }\end{array}$ \\
\hline & $\begin{array}{r}\text { High-isotopic } \\
\text { purity }{ }^{233} \mathrm{U}\end{array}$ & $\begin{array}{l}\text { Thorex short-decay } \\
\text { waste }\end{array}$ & Modified Interim-23 & $0.9^{b}$ & & & & & 12 & $\begin{array}{l}\text { Demonstrate recovery } \\
\text { process and recover }{ }^{233} \mathrm{U} \\
\text { containing }<0.5 \mathrm{ppm} 232 \mathrm{U}\end{array}$ \\
\hline \multirow[t]{6}{*}{$1958-1960$} & SCRUP-2 & NRX reactor fuel & Purex & 5,386 & 3.1 & & & $\sim 400$ & 24 & Recover high-quality Pu \\
\hline & SRPE & SRP fuel & Purex & $1.4^{d}$ & 1.5 & & & 1,000 & $\sim 12$ & Recover enriched $\mathrm{U}$ and $\mathrm{Pu}$ \\
\hline & BNL-1,2 & BNL reactor fuel & Purex & $25,000^{a}$ & 18.3 & & & $\sim 500$ & $\sim 12$ & $\begin{array}{l}\text { Recover Pu and } U ; \\
\text { 3019/3-505 complex }\end{array}$ \\
\hline & SNAP-A & SRP-U slugs & Purex & $3,071^{e}$ & 3.3 & & & $\sim 1,000$ & $\sim 6$ & $\begin{array}{l}\text { Recover } \mathrm{Pu} \text { high in } 240 \mathrm{Pu} \text {; } \\
\text { provide wastes for FP } \\
\text { recovery in } 3019 / 3505 \\
\text { complex }\end{array}$ \\
\hline & $\mathrm{H}-240$ & SRP-U slugs & Purex & $5,800^{e}$ & 7.7 & & & $\sim 800$ & 3 & $\begin{array}{l}\text { Recovery Pu high in }{ }^{240} \mathrm{Pu} \\
\text { in } 3019 / 3505 \text { complex }\end{array}$ \\
\hline & S-240 & SRP-U slugs & Purex & $5,800^{e}$ & 13.7 & & & $\sim 2,200$ & 3 & $\begin{array}{l}\text { Recover } \mathrm{Pu} \text { high in } 240 \mathrm{Pu} \text { in } \\
3019 / 3505 \text { complex }\end{array}$ \\
\hline \multirow[t]{2}{*}{$1958-1960$} & MTR-1 & $\begin{array}{l}\text { Pu-Al MTR } \\
\text { assemblies }\end{array}$ & Low TBP & & 0.5 & & & & $>6$ & $\begin{array}{l}\text { Recover high }{ }^{240} \mathrm{Pu} \\
3019 / 3505 \text { complex }\end{array}$ \\
\hline & & CP-2 reactor fuel & Purex & 4,500 & & & & Slightly & $>12$ & \\
\hline
\end{tabular}


Table 4.4 (continued)

\begin{tabular}{|c|c|c|c|c|c|c|c|c|c|c|}
\hline \multirow[b]{2}{*}{ Date } & \multirow[b]{2}{*}{ Program } & \multirow[b]{2}{*}{ Feed material } & \multirow[b]{2}{*}{ Process employed } & \multicolumn{4}{|c|}{ Material recovered } & \multirow[b]{2}{*}{$\begin{array}{c}\text { Irradiation level } \\
\text { (MWd/ton) }\end{array}$} & \multirow[b]{2}{*}{$\begin{array}{l}\text { Cooling } \\
\text { months }\end{array}$} & \multirow[b]{2}{*}{$\begin{array}{c}\text { Remarks and/or } \\
\text { references }\end{array}$} \\
\hline & & & & $\underset{(\mathrm{kg})}{\mathrm{U}}$ & $\begin{array}{c}\mathbf{P u} \\
(\mathrm{kg})\end{array}$ & $\begin{array}{l}\mathrm{Np} \\
\text { (g) }\end{array}$ & $\begin{array}{l}\text { Am } \\
(g)\end{array}$ & & & \\
\hline \multirow[t]{3}{*}{$1958-1963$} & Volatility & $\begin{array}{l}\text { ARE molten sait } \\
\text { and fuel }\end{array}$ & Volatility & $40.6^{a}$ & & & & Slightly & $>12$ & $\begin{array}{l}\text { Recover enriched } U \text {, to } \\
\text { demonstrate the volatility } \\
\text { process }\end{array}$ \\
\hline & & $\begin{array}{l}\text { Criticality } \\
\text { assembly of } \\
\text { molten salt }\end{array}$ & Volatility & $72^{a}$ & & & & Slightly & $>12$ & Provide engineering data \\
\hline & & $\mathrm{Zr}-\mathrm{U}$ fuel & Volatility & $23^{a}$ & & & & $\mathrm{BU} \sim 32 \%$ & $3-7$ & $\begin{array}{l}\text { Demonstrate the process } \\
\text { with } \mathrm{Z} \text {-clad assemblies }\end{array}$ \\
\hline $1960-1964$ & Kilorod & $\begin{array}{c}{ }^{233} \mathrm{UO}_{2}\left(\mathrm{NO}_{3}\right)_{2} \bullet \\
\mathrm{Th}\left(\mathrm{NO}_{3}\right)_{4}\end{array}$ & $\begin{array}{l}\text { U-solvent } \\
\text { extraction; } \\
\text { Th-steam } \\
\text { demonstration; } \\
\text { sol-gel } \\
\text { preparation; } \\
\text { remote fuel rod } \\
\text { fabrication }\end{array}$ & $37^{b}$ & & & & None & NA & $\begin{array}{l}\text { To fabricate } 1,100 \mathrm{SS}-\text { clad } \\
\text { fuel rods charged with } 3 \% \\
{ }^{233} \mathrm{UO}_{2}-97 \% \mathrm{ThO}_{2}\end{array}$ \\
\hline \multirow[t]{2}{*}{ 1969-1976 } & LWBR & $\begin{array}{l}233 \mathrm{UNH} \text { and } \\
{ }_{233} \mathrm{U}_{3} \mathrm{O}_{8}\end{array}$ & $\begin{array}{l}\text { Purification } \\
\text { (solvent } \\
\text { extraction, ion } \\
\text { exchange); oxide } \\
\text { conversion }\end{array}$ & $1,675^{b}$ & & & & None & NA & $\begin{array}{l}\text { To provide ceramic-grade } \\
233 \mathrm{UO}_{2} \text { of high quality for } \\
\text { fabricating LWBR fuel }\end{array}$ \\
\hline & & $\begin{array}{l}{ }^{233} \mathrm{UO}_{2}-\mathrm{ThO}_{2} \text { hard } \\
\text { scrap }\end{array}$ & $\begin{array}{l}\text { Thorex dissolution; } \\
\text { solvent } \\
\text { extraction; ion } \\
\text { exchange }\end{array}$ & $711^{b}$ & & & & None & NA & To recover ${ }^{233} \mathrm{U}$ \\
\hline
\end{tabular}

${ }^{a}$ Enriched U.

${ }^{b 233} \mathrm{U}$.

$c_{\mathrm{g} \text { mass }}{ }^{233} \mathrm{U} /$ ton $\mathrm{Th}$

${ }^{d}$ Enriched U.

eDepleted U. 
Table 4.5. Summary of thorium-233U processing in the United States

\begin{tabular}{|c|c|c|c|c|c|c|}
\hline Site & $\begin{array}{l}\text { Date } \\
\text { (year) }\end{array}$ & $\begin{array}{c}\text { Thorium } \\
\text { processed } \\
\text { (tons) }\end{array}$ & $\begin{array}{c}233 \mathrm{U} \\
\text { recovered } \\
(\mathrm{kg})\end{array}$ & $\begin{array}{l}\text { 232 U content } \\
(\mathrm{ppm} \mathrm{U})\end{array}$ & $\begin{array}{l}\text { Flow sheet } \\
\text { employed }\end{array}$ & Remarks \\
\hline \multicolumn{7}{|c|}{ Irradiated fuel processing } \\
\hline \multirow[t]{3}{*}{ ORNL } & 1954 and 1958 & 5 & 8 & $10-40$ & Interim-23 & Pilot-scale development \\
\hline & $1955-1958$ & $\underline{30}$ & $\underline{47}$ & $10-40$ & Thorex & $\begin{array}{l}\text { Pilot-scale development up to } \\
4,000 \mathrm{MWd} / \text { ton, cooled } 30 \mathrm{~d}\end{array}$ \\
\hline & Total & 35 & 55 & & & \\
\hline \multirow[t]{4}{*}{ SRP } & $1964-1965$ & 14 & 107 & 225 & Interim-23 & Th discarded \\
\hline & 1965 & 9 & 19 & 38 & Interim-23 & Th discarded \\
\hline & $1966,1968,1969$ & $\underline{193}$ & $\underline{412}$ & $6-9$ & Thorex & $\begin{array}{l}\text { Th recovered, } 1.5 M \mathrm{HNO}_{3} \text {, } \\
0.25 M \mathrm{Th}\left(\mathrm{NO}_{3}\right)_{4} \mathrm{AF}, 30 \% \mathrm{TBP}\end{array}$ \\
\hline & Total & 216 & 538 & & & \\
\hline \multirow[t]{4}{*}{ Hanford } & 1965 & 4 & & & Interim-23 & Th discarded, flow sheet test \\
\hline & 1966 & 250 & 270 & $6-10$ & Acid thorex & Th recovered, acid-deficient feed \\
\hline & 1970 & $\underline{400}$ & $\underline{589}$ & $6-10$ & Acid thorex & $\begin{array}{l}\mathrm{HNO}_{3} \text { added below } \mathrm{HA} \text { column } \\
\text { feed plate }\end{array}$ \\
\hline & Total & 654 & 859 & & & \\
\hline Nuclear Fuel & 1969 & 17 & $\begin{array}{r}1,019^{a} \\
(103)\end{array}$ & 125 & Interim-23 & $\begin{array}{l}\text { 15,800 MWd/ton, Th discarded, } \\
4.3 \mathrm{MHNO}_{3}, 112 \mathrm{~g} / \mathrm{L} \text { Th used as } \\
\text { salting agent }\end{array}$ \\
\hline \multicolumn{7}{|c|}{ Unirradiated processing } \\
\hline \multirow[t]{5}{*}{ ORNL } & 1962 & 2 & 50 & 40 & $2.5 \%$ DSBPP & $\begin{array}{l}\text { Rod fabrication, Th added to } \\
\text { process; recycled }\end{array}$ \\
\hline & $1973,1974,1975$ & 30 & 1,100 & 10 & $5.0 \%$ DSBPP-LX & Th added to process; discharged \\
\hline & 1957-continuing & 9 & 225 & $3-250$ & $2.5 \%$ DSBPP & Th added to process \\
\hline & 1957-continuing & 9 & 1,100 & $3-250$ & & \\
\hline & Total & 50 & & & & \\
\hline
\end{tabular}




\subsubsection{Bibliography}

1. H. K. Jackson, Information Required for a Pilot Plant Program, ORNL/CF-52-6-95 (July 17, 1952).

2. G. S. Sadowski, The Organization, Administration, and Operation of a Radiochemical Pilot Plant, ORNL-2132 (September 14, 1956).

3. J. T. Long, Engineering for Nuclear Fuel Reprocessing, Gordon and Breach Science Publishers, Inc., New York, March 1967.

4. R. E. Brooksbank, L. W. Cox, and A. M. Platt, "The Need for Nuclear Fuel Reprocessing Standards and Guides," ASTM Standardization News, March 1983.

5. R. G. Hewlett and D. E. Anderson, The New World, 1939/1946-Volume 1, A History of the United States Atomic Energy Commission, Pennsylvania State University Press, 1962.

6. F. L. Culler, "Information Hearings, California Commission on Energy Resources and Development," March 7, 1977.

\subsection{COAL TECHNOLOGY PROGRAM, Hank Cochran}

The United States and the rest of the industrialized world were reminded of their dependence on petroleum when in 1973 the Organization of Petroleum Exporting Countries (OPEC) cartel first exercised production constraint in order to effect dramatic increases in the world petroleum price. At that time, ORNL was the only one of the AEC laboratories to have acquired a multiprogram mission-beyond nuclear science and technology-and it was to ORNL that the AEC turned first in seeking technical solutions to the oil crisis. ORNL was asked to focus its efforts on technologies leading to increased and broadened utilization of the nation's vast coal resources; conversion of coal to liquid and gaseous fuels and cleaner and more efficient coal-fired power generation were the objectives.

The AEC gave ORNL permission to "reprogram" available monies from the AEC Applied Technology Division to bring the AEC into the coal technology field. This field had been sustained-like western culture in a few monasteries during the Dark Ages-during two decades of fiscal deprivation at a few small laboratories of the Department of Interior's Bureau of Mines. Principal among these Bureau of Mines laboratories were those at Bruceton, Pennsylvania;
Laramie, Wyoming; and Morgantown, West Virginia. Bruceton had developed a modern version of the Bergius process called Synthoil. Morgantown was conducting coal liquefaction research also. Laramie was exploring underground (or in situ) coal gasification.

At that time, Union Carbide operated ORNL for the AEC, Herman Postma was ORNL Director, Don Ferguson was Chem Tech director, and Gene McNeese, Ray Wymer, and Chuck Scott were Chem Tech associate directors.'Postma and his associate director, Murray Rosenthal, turned to Chem Tech to create the coal technology program. Interior's Office of Coal Research was at the same time negotiating with Union Carbide for a government-funded "demonstration plant" utilizing Carbide's Hydrocarbonization process for coal conversion. Chem Tech promptly assigned key personnel to initiate reviews and research in coal conversion processes.

Jere Nichols (with Royes Salmon and John Holmes) in his Engineering Coordination and Analysis Section and Bob Hightower of Gene McNeese's Unit Operations Section completed a short engineering and economic survey for Jim Bresee's (formerly from Chem Tech) Applied Technology Division in AEC. The objective was to assess technologies for conversion to coal of Ohio Valley Electric Corp's Clifty Creek Power Station. The study concluded that the application of HRI's H-Oil process to coal liquefaction ( $\mathrm{H}$-Coal) appeared technically and economically attractive. Later, Royes Salmon was tasked to initiate a major engineering evaluation of the Synthoil process. John Holmes was tasked to undertake a comparable evaluation of the Hydrocarbonization process. Mike Edwards and Bill Rodgers initiated an evaluation of solid-liquid separation technology for coal liquefaction; this was to be followed by bench-scale experimental studies by Rodgers. John Holmes, Hank Cochran, and Dave Joy initiated a review of carbonization and hydrocarbonization technologies; this was to be followed by bench-scale experimental studies by Cochran (Fig. 4.46)

In Ray Wymer's Chemical Development Section, Jim Mailen reviewed coal conversion technology. Shortly later in Scott's Experimental Engineering Section (formerly McNeese's Unit Operations Section), Hank Cochran was tasked to initiate a bench-scale experimental investigation of Hydrocarbonization; Richard Forrester, to initiate a bench-scale experimental investigation of in situ 


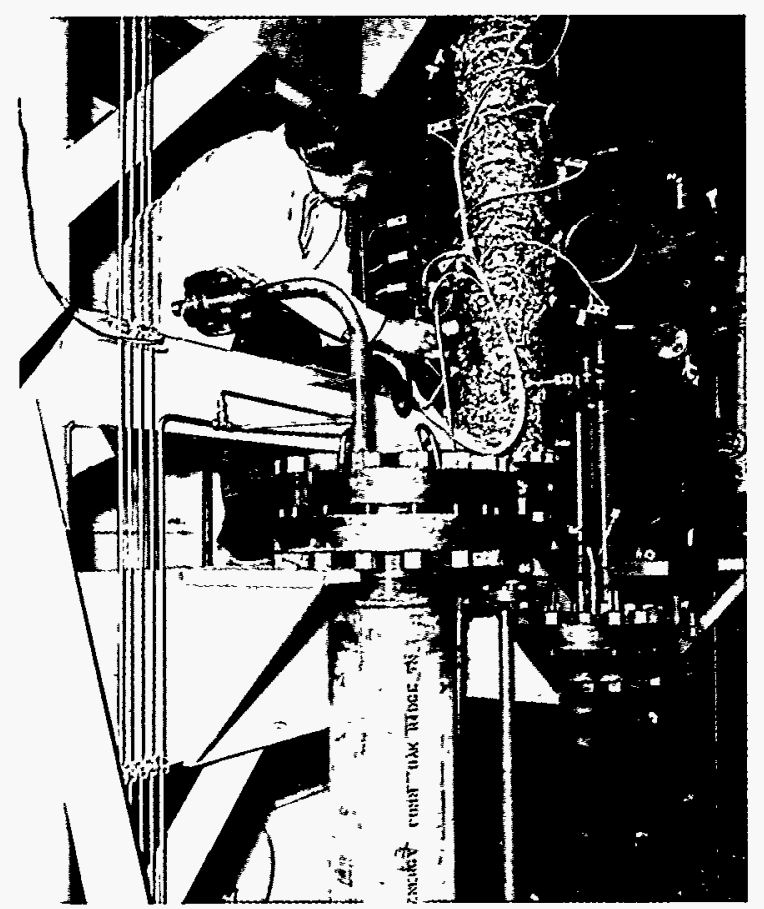

Fig. 4.46. Hank Cochran is testing the experimental hydrocarbonization reactor for leaks with a high-frequency acoustic leak detector, which moderates the supersonic noise made by the leaks into audible range.

gasification; and Bill Rodgers, to initiate a bench-scale experimental investigation of solid-liquid separation. Phil Westmoreland soon began studies of the pyrolysis of 6-in. right circular cylinders of Wyoming coal in support of in situ gasification, Fred Endelman began atmospheric pressure studies of fluidized-bed coal pyrolysis, and Rodgers started batch filtration and antisolvent deashing studies.

The creation of ERDA (Energy Research and Development Administration) brought the Bureau of Mines labs and the AEC labs together within the same organization. ORNL, operated by Union Carbide, was performing an engineering evaluation and a bench-scale experimental study of hydrocarbonization, while Carbide was designing a commercial-scale, single-train hydrocarbonization plant. With several oil companies, HRI began construction of a large-scale $\mathrm{H}$-Coal $(\mathrm{H}$ stands for the hydrogen used in the process) pilot plant in Catlettsburg, Kentucky. Smaller pilot plants employing variants of the Solvent-Refined Coal (SRC) process were operating in Wilsonville, Alabama, and Ft. Lewis, Washington, and employing different approaches to solid-liquid separation. Exxon and others began construction of a large-scale pilot plant in Baytown, Texas, employing the Exxon Donor Solvent (EDS) process. Our engineering study of the Synthoil Process concluded that (1) the fixed-bed catalytic hydrogenation reactor was technically infeasible and (2) the use of high operating pressures, residue filtration, and large hydrogen recycle requirements, together with low product value, led to very unfavorable economics. This assessment contrasted sharply with previous published studies by the Morgantown laboratory and the Pittsburgh Energy Technology Center (PETC).

On December 4, 1974, Herman Postma and about three dozen engineers and scientists from ORNL met at the Holiday Inn in Oak Ridge to celebrate the entry of ORNL into the coal conversion field. Don Ferguson and Chem Tech were commended by Postma for the proactive initiation of the Coal Technology Program. Jere Nichols had been named Director of the new Coal Technology Program in November 1974; he immediately set about to establish a fluidized-bed coal combustion program in the Engineering Technology Division and catalytic liquefaction studies in the Chemistry Division. Thus, the new coal program at ORNL became a multi-divisional effort.

In September 1977, when McNeese took over the program, it became the Fossil Energy Program, and before it was all over, dozens of Chem Tech engineers and scientists had been involved, including the following: John Begovich (gas-liquid-solid fluidized beds); Cliff Brown and Leonard Dickerson (wet-oxidation of coal conversion wastewaters and hydrocarbonization experiments) (Figs. 4.47 and 4.48); Ron Brunson (resource recovery from coal ash); Ron Canon (resource recovery from coal ash); Ron Glass and Jim Snider (a myriad of engineering studies and subcontracts); Richard Genung and Terry Donaldson (environmental control technology studies) (Fig. 4.49); Randy Gibson (experimental liquefaction studies); Jim Hewitt (solid-liquid separation experiments); Bob Hightower (a collection of bench-scale experiments); Jerry Klein, Bob Jolley, and Jennifer Brand (several wastewater treatment studies); Doug Lee (both wastewater treatment and coal liquefaction studies) (Fig. 4.50); K. H. Lin (engineering analyses); Bill Rodgers, Bob Jolley, Leonard Dickerson, and Dave McWherter (bench-scale liquefaction and chemical characterization studies); Bill Rodgers and John Mrochek (chemistry of antisolvent 


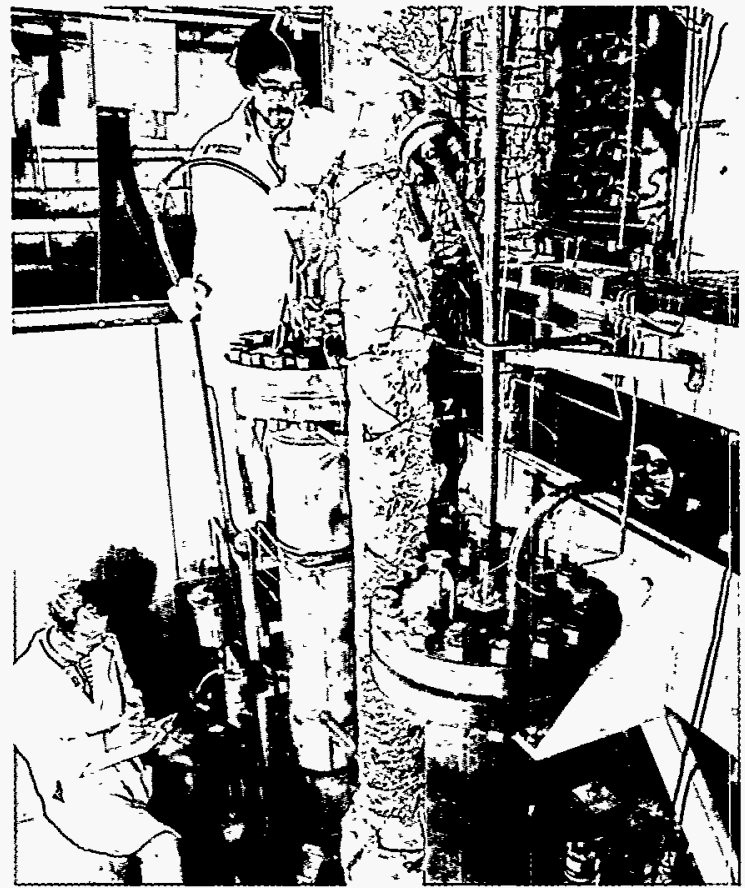

Fig. 4.47. Cliff Brown and Leonard

Dickerson record data and adjust the loading of the Chem Tech "bench-scale" coal hydrocarbonization unit in Building 2528.

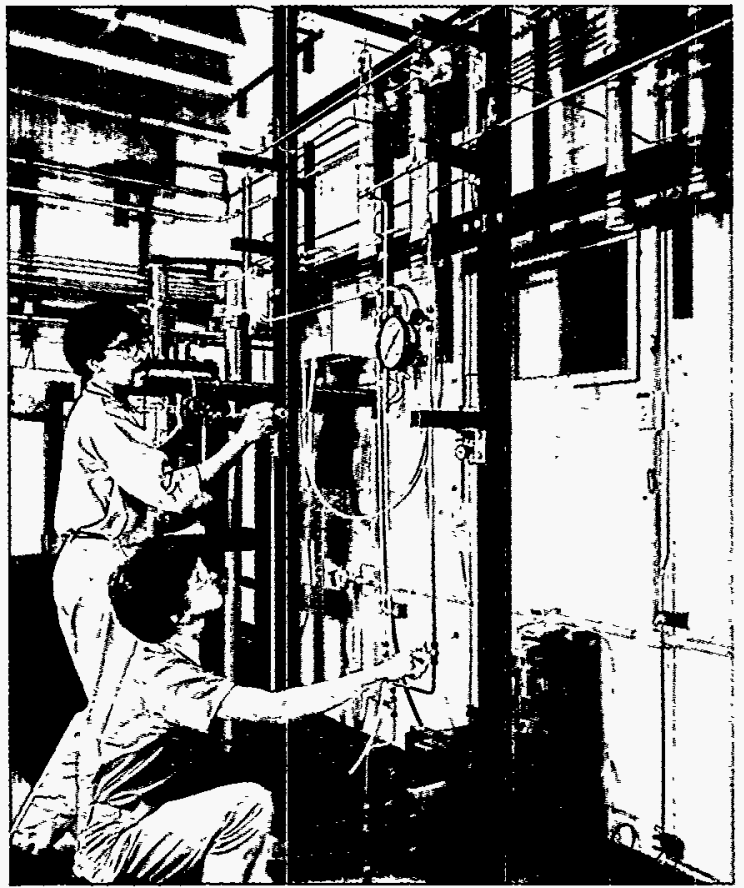

Fig. 4.48. Leonard Dickerson and another Chem Tech engineer adjust the gas flows to the coal hydrocarbonization unit.

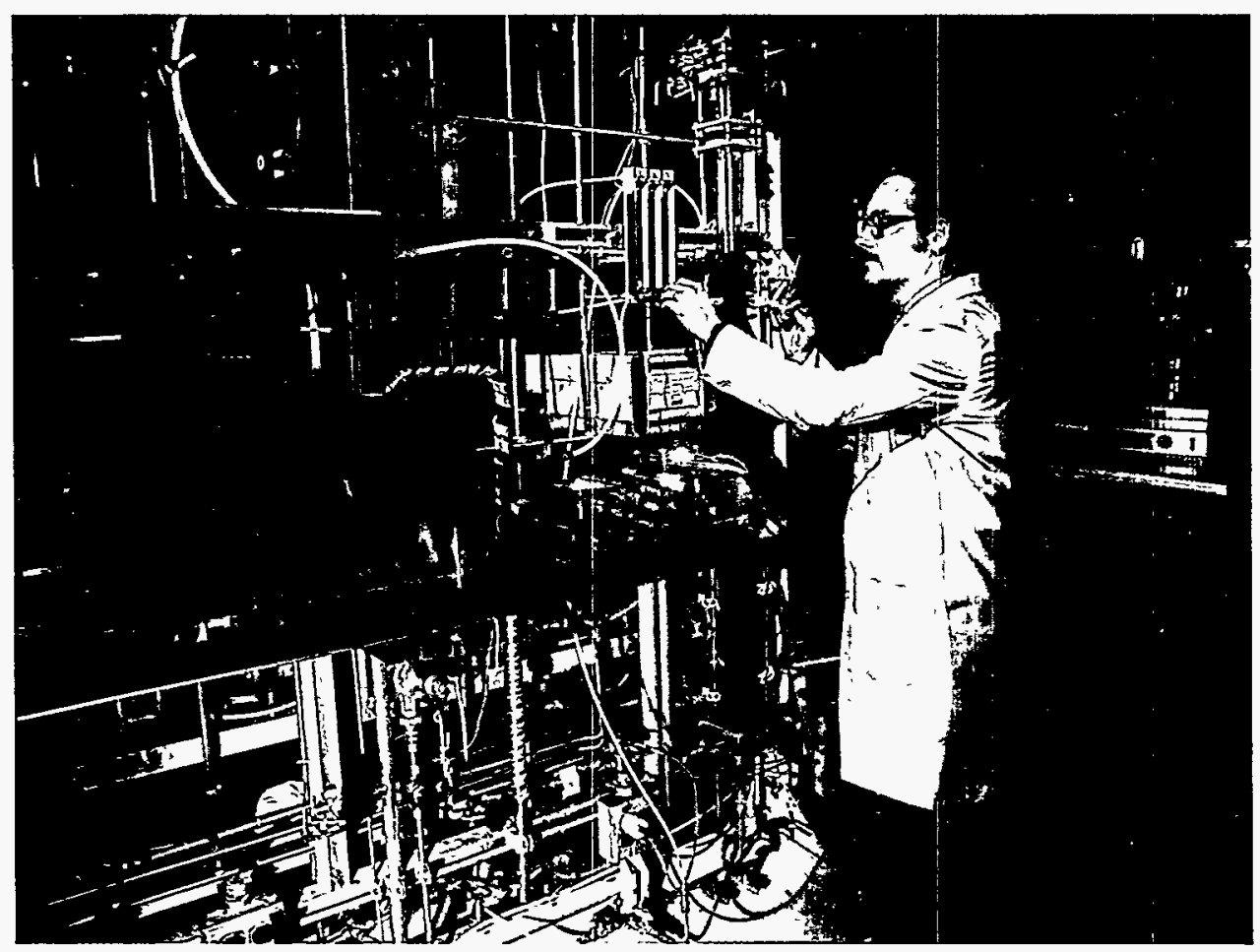

Fig. 4.49. Terry Donaldson adjusts test conditions on an experimental bioreactor used to treat coal gasification wastewater. Degradation rates for dissolved organics are substantially higher in this system than in conventional wastewater treatment systems. 


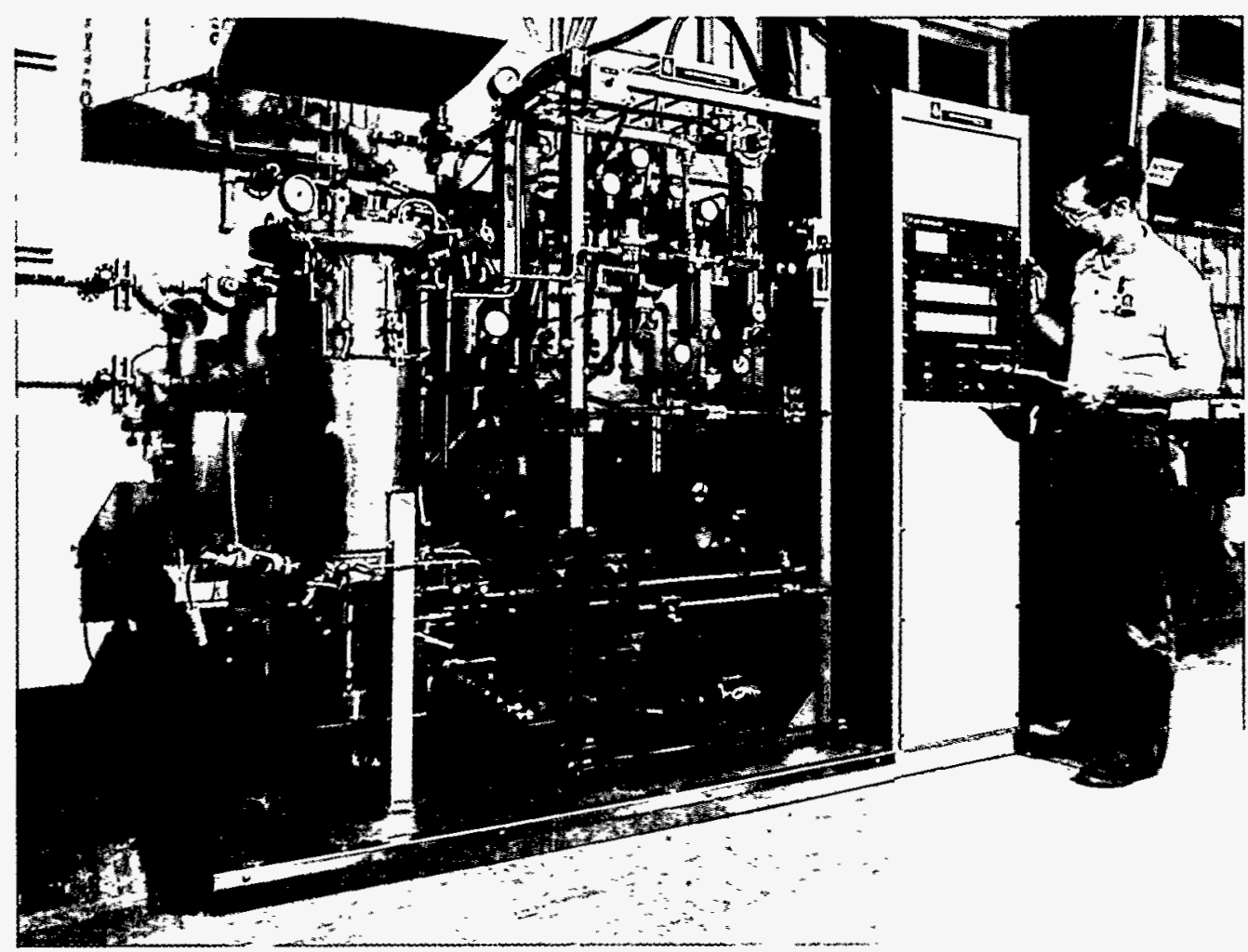

Fig. 4.50. Doug Lee monitors the Chem Tech experimental coal liquefaction unit in Building 4505.

deashing and thermal conductivity of coal liquids); Bill Rodgers and Sidney Katz (solids separations from coal liquefaction products); Royes Salmon (a member of technical and economic assessments); Terry Sams (exploratory liquefaction studies); Suman Singh (several engineering evaluations, particularly in effluent treatment technology); Suman Singh, Bob Jolley, and Leonard Dickerson (bench-scale coal desulfurization studies); Joe Walker (resource recovery from coal ash); Jack Watson (a collection of experimental studies); Bob Wham (engineering evaluations and exploratory liquefaction experiments); Jim Wilson (coal liquefaction experiments); and Lloyd Youngblood (coal liquefaction experiments). This listing omits (for brevity only) the contributions of numerous other former Chem Tech staff members. In addition, the substantial contributions to Chem Tech's program of the staff in Tom Pickel's Engineering group should not be forgotten.

In the early 1980s, interest in coal conversion processes waned with the initiation of petroleum prices being set by the market rather than by governments. From the beginning, the conservative Bureau of Mines laboratories thought of coal studies as within only their purview. There appeared to be some mistrust of the AEC laboratories which persisted through ERDA and DOE. In the end, two of the Office of Coal Research (OCR) laboratories (Bruceton and Morgantown, which had evolved through various names-PERC/MERC, PETC/METC, etc.) had taken over all of the process technology programs within the coal program from the former AEC national laboratories, including ORNL. At its peak in about 1980, the ORNL Fossil Energy Program centered around four major coal liquefaction projects, two SRC demonstration plant projects, and the two large H-Coal and EDS pilot plants managed by DOE's Oak Ridge Operations office. The program involved engineers and scientists and support personnel from at least ten ORNL divisions. Today, except for some exploratory microbial coal liquefaction studies in Chem Tech, the remnants of the Fossil Energy program are in the M\&C Division. 


\subsection{BIOTECHNOLOGY R\&D IN THE CHEMICAL TECHNOLOGY DIVISION, John Mrochek, Carl Burtis, Zane Egan, Elias Greenbaum, Bob Jolley, Jerry Strandberg, and Charles Scott}

Chem Tech has maintained a significant competence in separations science and technology throughout its history. This was the primary reason for the initiation of biotechnology R\&D in the division that occurred over 25 years ago. It all started in the winter of 1963 when Connie Chester and Don Kelmers met with Mel Stulberg of the Biology Division to discuss the possibility of large-scale production of several individual transfer ribonucleic acids (tRNAs) for use by the biomedical research community. It was proposed that current laboratory techniques for production, separation, and purification of these biochemicals be enhanced and scaled up and carried out in Chem Tech with consultation and assistance from Biology Division staff.

This new separations effort was subsequently funded by the AEC and the National Institutes of Health (NIH), and an R\&D team was then put together in Chem Tech. This included Chester and Kelmers, as well as Chuck Hancher, Herman Weeren, Zane Egan, Joe Weiss, and Ray Pearson, along with several technicians. Over the next four years, the Chem Tech staff proceeded to establish a macromolecular separations effort in which hundreds of kilograms of $E$. coli cells were grown, nucleic acids extracted, and several tRNAs were separated and purified by advanced chromatographic techniques.

Another collaborative effort was begun between the Chem Tech staff and the Molecular Anatomy (MAN) Program, also at ORNL. Dr. Norman Anderson and co-workers in the MAN Program had developed prototype systems for high-pressure liquid chromatography of ultraviolet-adsorbing and carbohydrate constituents in urine. Anderson, Director of the MAN Program, and Chem Tech staff member Don Vissers initiated the collaborative effort early in 1965. Shortly thereafter, Don left the ORNL and Chuck Scott took up this responsibility. The initial thrust of the program was the development of high-resolution separations systems based on column chromatography to separate and quantitate molecular indicators of disease. About a year later, a viable $R \& D$ program entitled the Body Fluids Analysis Program was established with support primarily from the NIH. The Chem Tech research team was headed by Scott for several years with participation first by Bob Jolley and Maurice Freeman, followed shortly thereafter by Wilson Pitt, Ken Warren, Carl Burtis, Norman Lee, Stan Dinsmore, Sidney Katz, John Mrochek, and Bill Butts (Analytical Chemistry Division). This group, in conjunction with personnel from the Instrument and Controls Division, developed a series of advanced instrumental concepts that were used for biomedical research and the clinical laboratory. A broad range of support was engendered from several of the institutes of NIH, DOE, EPA, and the National Aeronautics and Space Administration (NASA). In 1967 an annual symposium series entitled "Advanced Instrumental Concepts for the Clinical Laboratory" was initiated in cooperation with staff at the NIH. This meeting series has since been administered by the American Association for Clinical Chemistry (AACC) and is approaching its 25th year.

Spin-off from the high-resolution chromatographic separations work included application to analysis of drinking water, wastewater, and cooling water. This research was initiated by Wilson Pitt and Sidney Katz, with wastewater analysis, and applied by Bob Jolley and Jim Thompson to chlorinated wastewater and cooling water. Pioneering research coupled the use of radioactive tracers for chlorination with analysis of chlorinated products using chromatography and proved conclusively the formation of chlorinated organics during the chlorination disinfection process. In 1975 a symposium series entitled the "Environmental Impact of Water Chlorination" was initiated by Jolley. The series has continued under the sponsorship of federal agencies with the objective of documenting national and international progress in the determination of the health effects of water chlorination.

During the mid 1970s, the biotechnology staff in Chem Tech began to investigate the use of advanced biological processing concepts for the removal or degradation of various types of pollutants from aqueous effluent streams. This was the beginning of the division's bioprocessing research effort. Support for this effort was obtained from several offices within the ERDA and its successor, DOE. Chuck Scott, Chuck Hancher, and 
Wilson Pitt were the early participants, but they were later joined by Dennis Chilcote, Wes Shumate, Richard Genung, and Jerry Strandberg. Within a few years, this bioprocessing R\&D effort had expanded into investigation of many advanced bioprocessing concepts for the production of liquid and gaseous fuels and for energy-conserving environmental control technology. A broad, multidisciplinary R\&D team evolved during the late 1970s and early 1980s that included biophysicists, biochemists, microbiologists, and biochemical engineers with the addition of Eli Greenbaum, Terry Donaldson, Ed Arcuri, Jonathan Woodward, Brian Davison, and Brenda Faison.

Several bioprocesses were developed and transferred to the industrial sector, and a new symposium series entitled "Biotechnology for Fuels and Chemicals" was started. This annual international meeting series is now in its 13th year and is cosponsored by the DOE, Solar Energy Research Institute (SERI), and various industrial firms. Research efforts have included a study of biophotochemical systems, advanced methods for enzyme-catalyzed reactions, innovative bioreactor concepts, biologically oriented environmental control technology, bioprocessing concepts for fuels and chemicals from biomass, and biological processing of fossil fuels.

\subsubsection{Macromolecular Separations Program}

The Macromolecular Separations Program was a collaborative effort involving Chem Tech, the Biology Division, and the Analytical Chemistry Division during the period from about 1963 through 1973. It was directed by G. D. Novelli of the Biology Division and Don Kelmers of Chem Tech. The program was sponsored by the National Institute of General Medical Sciences and NIH. Bench-scale studies were carried out in Chemical Development Section C, and the scale-up operations were conducted in the Unit Operations Section of Chem Tech; Keith Brown was head of Chemical Development Section C. Two refrigerated laboratories ("cold rooms") were built for handling the biological materials.

At that time most of the work in the section was concerned with uranium recovery and fission product separation using solvent extraction. Based on this experience, Brown decided that one of the first things to do was grow a ton of (bacteria) cells.
(It should be noted that biochemists at the time were used to working with milligram amounts of material and usually measured ribonucleic acids in optical density units; one milligram was about twenty optical density units.) After recovering from the initial shock, Novelli became excited and enthusiastic about the program. Zane Egan, Ray Pearson, and Joe Weiss, with technician support from Perry Eubanks, Dale Heatherly, and Jim Overton, worked on the bench-scale development. Incidentally, all were trained as inorganic chemists, but they had some experience in developing separations methods. Dave Holladay, Chuck Hancher, Al Ryon, and Herman Weeren, with George Dinsmore and John Taylor, were involved in the scale-up.

The overall goals of the program were twofold: development of separations methods and engineering scale-up for the production of purified tRNAs. After a considerable development effort, several reversed-phase liquid chromatographic columns and methodologies were developed to separate individual tRNAs, ribosomal ribonucleic acids, and oligonucleotides. The most successful chromatographic packing was prepared by coating a polychlorotrifluoroethylene powder with quaternary amines. (Interestingly, a similar material was studied at Hanford for the recovery of palladium from nuclear waste solutions.) The chromatographic columns were scaled up to 2 in. in diameter by $96 \mathrm{in}$. long and 4 in. in diameter by $30 \mathrm{in}$. long to produce the first gram quantities of tRNAs.

A small spin-off company was also formed to market the chromatographic packing for a short period. During the program, the supplier of the support material discontinued manufacture of the product, and ORNL became the sole source of the material. Later, similar packings were marketed by private industry.

Sources of the RNAs were calf liver, rat liver, and various strains of $E$. coli bacteria. Half-ton batches of the bacteria were grown in a fermentor in the Biology Division at the $Y-12$ site and then harvested and brought to Building 4505, where the RNAs were recovered and separated. The RNAs were characterized by the Analytical Chemistry Division using radioactively labelled amino acids, gel electrophoresis, and nucleotide analysis. The Analytical Chemistry support was critical to the success of the project.

In related studies, other separation techniques, including solvent extraction. and gel 
chromatography, were evaluated, and the base sequences of some of the tRNAs were also determined. Many of the products were supplied to researchers in the Biology Division for studies on the structure and function of tRNAs.

Public announcement of the availability of the purified tRNAs, without charge, was made in Science and in Chemical and Engineering News in January 1970 . Requests for samples averaged one to two per day for several months. The requests were reviewed by a committee of the National Institute of General Medical Sciences, and shipments were made in accordance with their recommendations. Over 14 grams of purified specific tRNAs were produced and distributed in a total of 752 shipments to 208 scientists in the United States and 12 foreign countries, including West Germany, England, the U.S.S.R., Poland, Japan, France, Norway, and Canada. The results of the research and development program at ORNL were reported at various national and international scientific meetings and in over 40 open literature publications. Several visiting scientists from universities in the United States, as well as Australia, Italy, and the U.S.S.R., spent extended periods in our laboratories learning the separation techniques developed during this program.

\subsubsection{Body Fluids Analysis}

The genesis of the Body Fluids Analysis (BFA) Program in Chem Tech began in 1965 with a collaborative effort between Don Vissers and Norman Anderson, Director of the ORNL Molecular Anatomy Program. Initially, work from this effort was located in the Power Plant at the K-25 Site. When Vissers left ORNL, Chuck Scott assumed the responsibility for the collaborative effort, working closely with Jim Attrill (Analytical Chemistry Division). Scott established the BFA program, which was moved to Chem Tech in 1965. The initial project of the program was the development of high-resolution liquid chromatography, which was followed by development efforts in centrifugal analysis and environmental monitoring.

High-Resolution Chromatography. As a result of Chem Tech expertise in the use of ion-exchange chromatography for separation of isotopes, the first thrust of the BFA program, which was funded by the National Institute of Health General Medical Sciences (NIGMS), was the application of this technology to the separation of biological compounds, namely, the uv-absorbing constituents found in human urine. An initial breakthrough was achieved by Chuck Scott and Norman Lee with the development of an elutriation process which provided ion-exchange beads of very small and uniform particle size. The use of the small particles as a chromatographic support provided excellent resolution but required high pressure to obtain a reasonable flow rate of eluent through the column. The uniformly sized particles lowered the necessary operating pressures to a reasonable 4000-5000 psi.

Consequently, a Chem Tech development group under the direction of Chuck Scott which included Dennis Chilcote, Maurice Freeman, Bob Jolley, Guy Jones, Norman Lee, and Wilson Pitt of Chem Tech; Wayne Johnson and Lou Thacker of the Instrumentation and Controls (I\&C) Division; and Bill Walker of the Plant and Equipment (P\&E) Division developed analytical systems that were capable of operating at the high pressures dictated by the use of the small-particle, ion-exchange resins. Two types of systems were developed: a urine analyzer that was capable of separating over 140 uv-absorbing constituents from a single urine sample and a carbohydrate analyzer that would separate over 30 sugars of physiological interest. Both systems included a high-pressure sample injection valve and miniature flow-through photometer which were developed by members of this group and become prototypes for high-pressure liquid chromatography (HPLC) systems.

To identify the compounds that were separated by this new technology, a large analytical effort was launched with valuable contributions being made by Carl Burtis, Stan Dinsmore, Bob Jolley, Sid Katz, John Mrochek, and Ken Warren of Chem Tech and by Bill Butts and Bill Rainey of the Analytical Chemistry Division. In fact, this group was one of the first in the country to use the emerging technique of mass spectrometry to identify compounds from human urine. A variety of applications were also pursued by this group, and a widely quoted paper authored by John Mrochek et al. ${ }^{42}$ was one of the first to demonstrate the use of HPLC in the analysis of biogenic amines and their relationship to various types of cancer. This work engendered support from the National Cancer Institute (NCI).

Considerable interest in the biomedical community resulted from the publicity that this new technology received. Consequently, with NIGMS funding, several systems were fabricated 
and placed in research laboratories in prestigious institutions, such as the NIH and the medical schools of Duke and Johns Hopkins Universities. In addition, considerable commercial interest was also generated, which resulted in HPLC systems appearing on the marketplace, thus constituting one of the first examples of technology transfer from ORNL to the private sector. In 1971, the Body Fluids Analyzer was presented an IR-100 award as one of the most significant new technical products of the year. Subsequent application studies by Sidney Katz, Wilson Pitt, and Bob Jolley were funded by the Federal Water Pollution Control Administration [which became the Environmental Protection Agency (EPA) during the course of the Chem Tech study] and demonstrated the utility of HPLC in environmental water analysis. In 1973 Bob Jolley used the HPLC ultraviolet analyzer coupled with ${ }^{36} \mathrm{Cl}$ tracer studies to prove that chlorinated organic compounds are formed when wastewater and natural waters are chlorinated for disinfection and biofouling treatment. Also, during this period, a Body Fluids Analyzer (UV Analyzer) was fabricated by the group for the EPA Analytical Laboratory in Athens, Georgia.

Oak Ridge Conferences on Clinical Chemistry. In addition to its technical achievements, the BFA program has also had a significant impact on the practice of clinical laboratory medicine by organizing and starting a very successful conference series on advanced technology for the clinical lab. On November 30, 1967, the first conference entitled "Urinary Constituents of Low Molecular Weight" was held at ORNL. This conference was sponsored by ORNL and NIGMS. It was organized and chaired by Charles D. Scott (ORNL) and Robert Melville (NIGMS), and the proceedings from it were published in Clinical Chemistry.

This historic conference was the first of what has become an annual conference which is now known as the "Oak Ridge Conference." The basic objective of this conference series has always been to present and discuss the advanced technology and concepts that could be expected to have an impact on the practice of clinical chemistry. Consequently, the theme of these conferences has become "Tomorrow's Technology Today." Reviewing the program of past conferences indicates the successful achievement of this objective, as most of the analytical techniques and instruments that are now routinely used in clinical laboratories were presented and discussed at earlier conferences. For example, various types of high-performance chromatography, mass spectrometry, sensors, advanced analytical systems, chemometrics, advanced immunoassays, monoclonal antibodies, DNA probes, capillary electrophoresis, and robotics all were discussed at prior conferences.

A second objective and goal of this conference series has been to disseminate the information presented to a wide clinical audience in a rapid and timely manner. Consequently, the presentations that are given in early spring have all been published in peer-review journals in the same year as they were presented. With the exception of the 1969 conference, whose proceedings were published in the American Journal of Clinical Pathology, all of the previous conference proceedings have been published in Clinical Chemistry.

As mentioned previously, the early conferences had a definite Tennessee "flavor" as they were organized, sponsored, and managed by Chem Tech staff at ORNL. However, various other organizations co-sponsored and helped organize the early conferences, including NIGMS (1967-1978), the Academy of Clinical Laboratory Physicians and Scientists, AEC (1974), ERDA (1975-1977), and DOE. In 1979, the AACC joined ORNL in co-sponsoring the conferences through 1984. In 1985, the AACC assumed full sponsorship of this conference series and is currently responsible for organizing and managing them. In 1993, the conference will celebrate its 25th anniversary and will be held in Oak Ridge, its original home.

Centrifugal Analysis. The genesis of the centrifugal analysis program in the Chem Tech, again, was traceable to the division's collaborative efforts with Norman Anderson. A conference on the future instrumental needs of clinical laboratories was organized by Bob Melville of the NIGMS and held in Quail Roost, North Carolina, in 1966. Shortly thereafter, Dr. Anderson invented a new approach to automated analysis which has become known as centrifugal analysis. Basic patents were filed for and several publications appeared, beginning in 1968, which described the technology.

Basically, a centrifugal analyzer is a multicuvette spectrophotometer or spectrofluorometer in which a unique multicuvette is mounted in a modified centrifuge. By spinning the rotor, the analyzer takes advantage of the centrifugal field generated to simultaneously 
transfer and mix several aliquots of sample and reagent into their respective cuvettes. Thus, an identical starting time is established for each and all reactions and factors such as time, temperature, and reactant composition which influence each will effect all reactions simultaneously. In addition, the rotary motion of the spinning rotor is used to move the cuvettes through a stationary optical system. Thus, the contents of each cuvette in the spinning rotor can be rapidly monitored at timed intervals as low as once every 50 milliseconds. An on-line computer is used to rapidly acquire and process the data generated by a centrifugal analyzer. (Note: this rapid generating, acquiring, and processing of the data produced by a centrifugal analyzer led them to initially being called centrifugal "fast" analyzers.) The first analyzers were also known as GeMSAEC analyzers to denote that the initial funding for their development came from the National Institutes of Health's General Medical Sciences and the AEC (Fig. 4.51).

The first prototype of a centrifugal analyzer was fabricated in 1968 at K-25 under the direction of Norman Anderson, Don Hatcher, Dick Willis, and Warren Harris. In 1969, the program was moved to ORNL and Chem Tech under the direction of Chuck Scott and Carl Burtis. Over the years, several staff members worked on this project, including Bill Bostick, Richard Genung, Norman Lee, Roy Lovelace, Jim Mailen, John Mrochek, Jim Overton, Wes Schumate, Tom Tiffany, and Mel Watsky. In addition, valuable support was provided by Martin Bauer, Jim Jansen, Wayne Johnson, and Lou Thacker from the I\&C Division and by Bill Walker from the Plant and Equipment (P\&E) Division.

To demonstrate feasibility and utility, the first prototype centrifugal analyzer was placed in the clinical laboratory of the ORNL Health Division and several clinical assays were developed for it. It was then placed into routine operation where it and subsequent models were operated through 1986 (Fig. 4.52).

It became obvious immediately that centrifugal analyzers had many advantages over the currently available instruments used for clinical analyzers, and the American Instrument Co., ElectroNucleonics, Inc., and the Union Carbide Corp. were licensed to produce them commercially. The collective sales of these three companies have been over 2000 units worldwide. The analyzer received an IR-100 award in 1969 as one of the 100 most significant new technological products of the year.
In 1972, NASA funded the development of a miniaturized version of the analyzer with the expectation that it would be used as an on-board analyzer in Skylab B (Fig. 4.53). Although Skylab B was canceled for funding reasons and the analyzer therefore never flew, the development was successful, as prototype units were fabricated and used in the clinical laboratories at the Johnson Space Center, ORNL Health Division, Albert Einstein Hospital, and the NIH, with funding provided by the EPA, the Food and Drug Administration, and AEC. Additional prototypes were fabricated and used for genetic screening in the research laboratories located at the University of Michigan and the National Center for Toxicological Research.

The miniaturized version of the analyzer also generated considerable interest from the private sector, with Electro-Nucleonics, Inc., Instrumentation Laboratories, and Roche Laboratories receiving licenses to produce the units commercially. It is estimated that over 4000 of these analyzers have been sold worldwide.

With continuing funding provided by NASA, a third-generation unit was developed which featured an on-board integrated computer and portability, and in 1977, this unit received an IR-100 award. In recent years, rotors capable of processing whole blood samples and rotors useful for immunoassay have been developed. This technology has been licensed to Abaxis of Mt. View, California.

\subsubsection{Environmental and Bio-Monitoring}

As a result of active application efforts, whose goals were to expand and extend the use of the newly developed chromatographic and centrifugal technologies, the staff of the BFA program developed an interest and expertise in various types of environmental analysis. Consequently, when funding for the body fluids and centrifugal analyses was reduced or ended in the late 1970s, work continued on the development of environmental monitoring technology with funding from the DOE Office of Health and Environmental Research (OHER). A portable monitor, termed the spill spotter, and ultrasensitive bioassays to detect toxic chemical exposure were developed.

Spill Spotter. As a result of a discussion with a visitor, Wilson Pitt suggested to newly hired Chem Tech biophysicist, Don Schuresko, that it should be possible to remotely detect strongly fluorescent polycyclic aromatic hydrocarbons (PAHs). With 


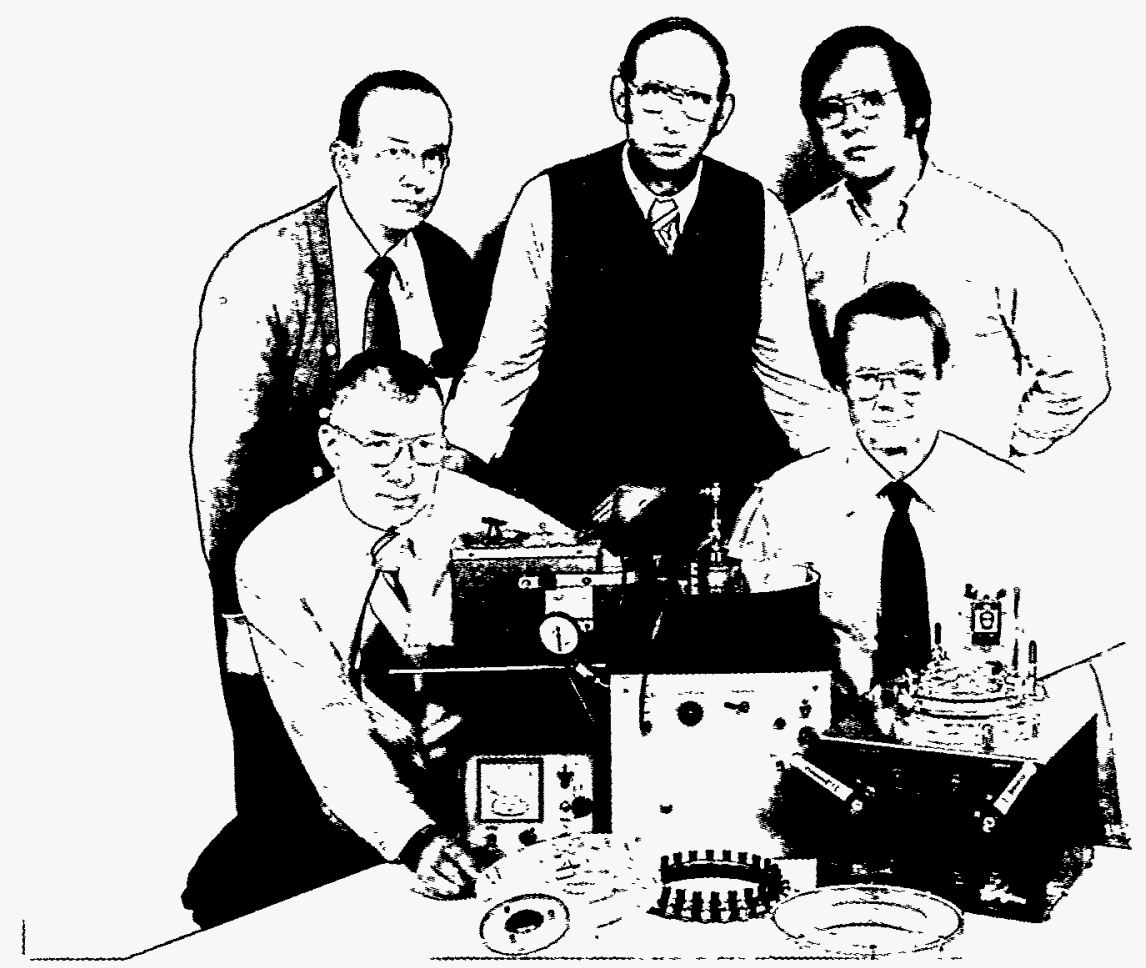

Fig. 4.51. Chem Tech development team members with early centrifugal analyzer prototype. Seated are Wayne Johnson (I\&C Division) on the left and Chuck Scott. Standing from left to right are John Mrochek, Norman Lee, and Richard Genung.

Fig. 4.52. John Mrochek (left) and Carl Burtis adjust a centrifugal analyzer for clinical chemistry analyses in the ORNL Health Division.

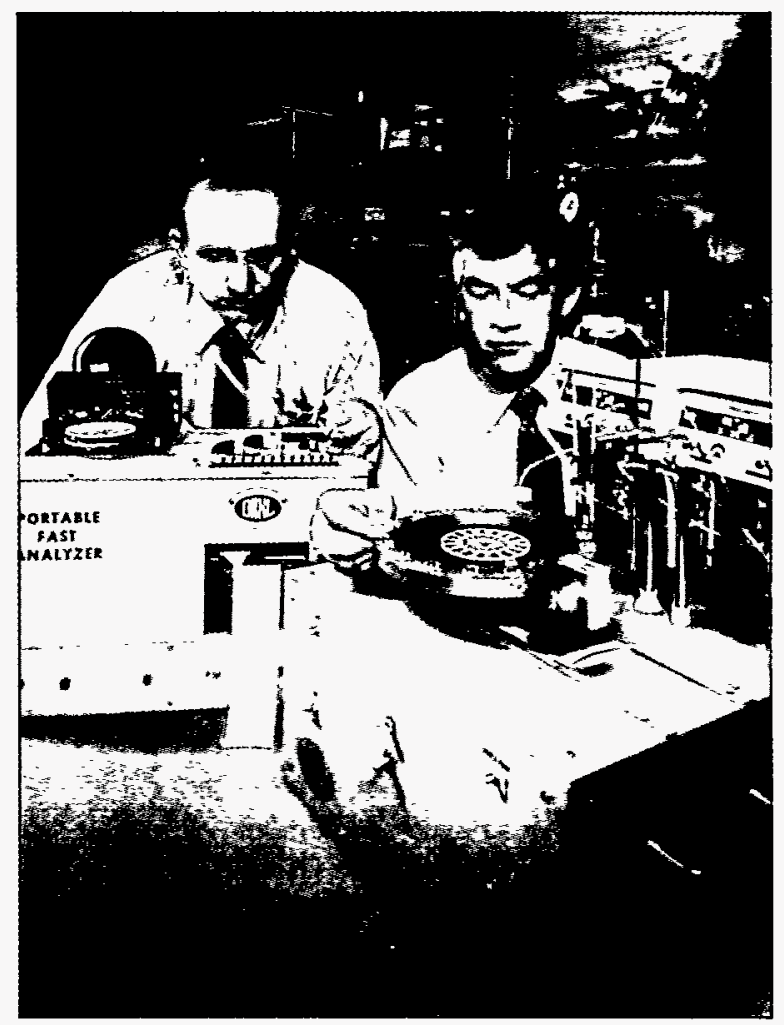




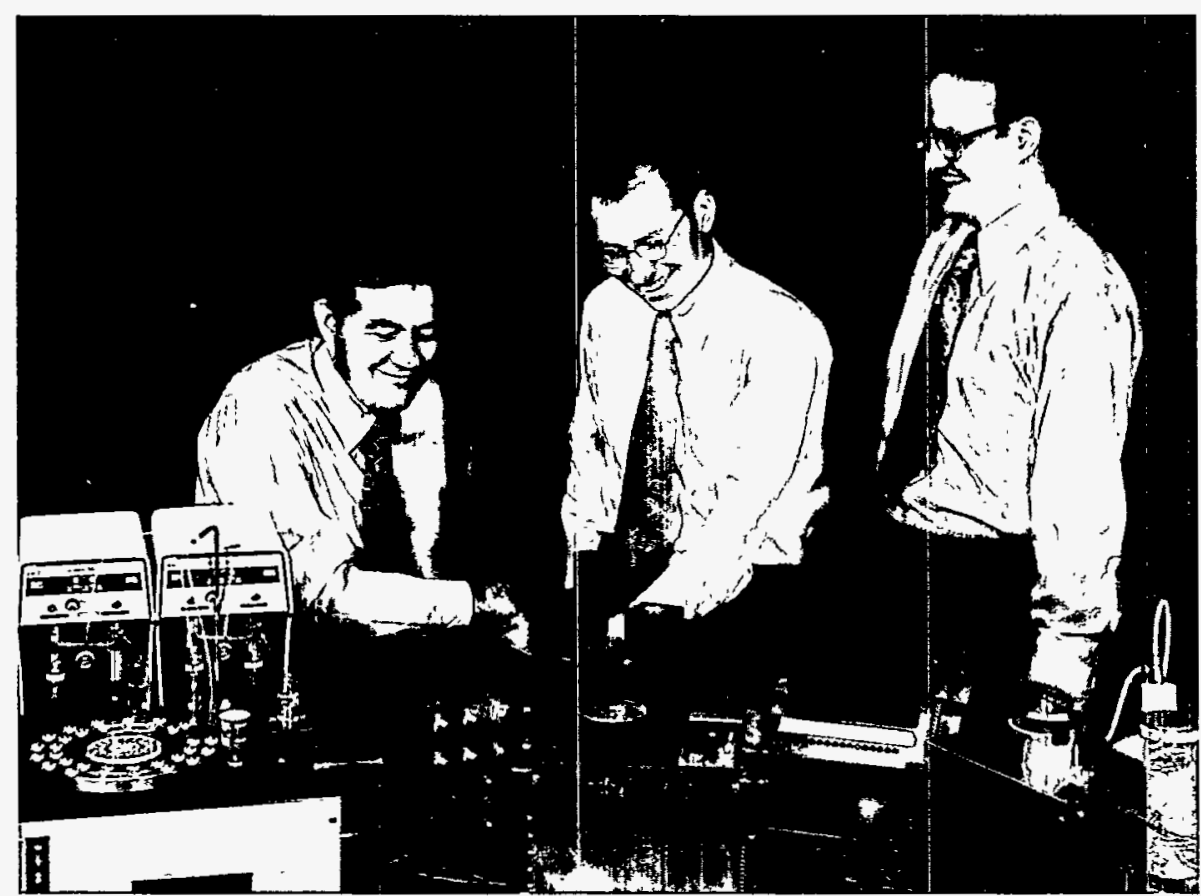

Fig. 4.53. Carl Burtis (left), Wayne Johnson (center), and Jim Mailen are pleased with the performance of the prototype miniaturized centrifugal analyzer developed for Skylab use.

Pitt's encouragement and suggestions, Schuresko worked out the basic concept. Under the guidance of Pitt and Chuck Scott, Schuresko led a multidivisional effort that resulted in the development of a portable fluorescence monitor, termed a Spill Spotter, whose purpose was to detect surface contamination by PAHs resulting from liquid spills in coal conversion plants. In addition to Pitt, Scott, and Schuresko, other Chem Tech personnel involved in its development were John Mrochek, Zane Egan, Jim Overton, Norman Lee, Guy Jones, and Carl Burtis. Technical assistance was provided by Mike Blair, Gerry Schulze, David McNeilly, Richard Hutchens, and Martin Bauer (I\&C Division), Bill Walker (P\&E Division), and Mike Holland (Biology Division).

The Spill Spotter operates by projecting an excited beam of ultraviolet (uv) light onto a surface. If PAHs are present, the emitted light resulting from their fluorescence is detected and quantified by the Spill Spotter. Prior to the development of this device, such monitoring was performed by turning off the overhead light and scanning the suspected surface with a uv ("black") light, a technique which was cumbersome, insensitive, nonspecific, and only qualitative. The
Spill Spotter offered several advantages over this monitoring technique, including: (1) capability to operate outdoors in direct sunlight or indoors in the presence of a strong background illumination,

(2) provide a quantitative measure of the fluorescing material, (3) discriminate between the fluorescence of organic and inorganic compounds, and (4) did not present a vision hazard to monitoring personnel.

Evaluation of the performance characteristics of the Spill Spotter by Chem Tech personnel demonstrated that it was capable of measuring PAH concentration at the levels where significant biohazards could occur. For example, the device was shown to have a linear dynamic range for perylene (a typical PAH) from 0.1 to $10 \mathrm{~g}$ at a distance of $50 \mathrm{~cm}$ with a lower limit of detection of $0.001 \mathrm{~g}$. Since $10 \mathrm{~g}$ doses of several PAHs are cytotoxic, it was evident that the Spill Spotter had the prerequisite sensitivity for operation for levels expected to be found in coal conversion plants. An unexpected application of the device was demonstrated when John Mrochek and Ronald H. Hill of the Ashland Synthetic Fuels, Inc. (ASFI), H-Coal Pilot Plant Project demonstrated that it was capable of detecting and quantitating skin contamination by PAHs. 
To demonstrate the monitoring utility of the Spill Spotter under field conditions, several prototypes were fabricated and tested at the SRC pilot plant in Ft. Lewis, Washington, at the coal gasifier plant in Duluth, Minnesota, and at the H-Coal Pilot Plant in Ashland, Kentucky. These field evaluations demonstrated that the Spill Spotter was capable of performing reliably in the environments for which it was developed. In 1980, the Spill Spotter received an IR-100 award as one of the most significant new technical products of the year.

Bio-Monitoring. An increasing concern about occupational and environmental exposure of personnel to toxic chemicals and potential carcinogens led a group consisting of Zane Egan, Carl Burtis, and Norman Lee in collaboration with John Kao and Mike Holland of the ORNL Biology Division and Guy Griffin of the Health and Safety Research Division to develop instrumentation and ultrasensitive bioassays for detecting exposure to such compounds. PAH compounds have been implicated as primary carcinogens in coal-derived products. These compounds are metabolized in mammals by a cytochrome P-448 enzyme system, termed the mixed function oxidase (MFO) system. Induction of this system by toxic chemicals can be measured and used as an indicator of exposure.

Consequently, a centrifugal analyzer equipped with an argon-ion laser light source was successfully used to quantify cytochrome P-448 MFO activity in mouse liver microsomes after exposing the animal to different doses of liquids derived from a coal liquefaction process. The $\mathrm{P}-448$ MFO activity was determined kinetically by measuring the rate at which the highly fluorescent compound, resorufin, was produced by conversion of 7-ethoxyresorufin substrate. The 514.5-nm laser excitation beam was directed with a fiber-optic bundle from the laser to the cuvettes of a specially designed and fabricated rotor consisting of a black, acrylic plastic center body with transparent acrylic cuvette windows. The emitted fluorescence, filtered through a 560 -nm cut-on filter, was monitored with a photomultipler tube located $90^{\circ}$ to the incident beam. A dedicated computer was used for instrument control as well as data acquisition, computation, and interpretation. A dose-response relationship was demonstrated between MFO activity and the exposure of test animals injected with various materials, including coal liquids and Aroclor mixtures. The use of a laser excitation source allowed very low MFO activities to be measured in physiologic samples. This work began in 1980 and was terminated in 1985, when funding by OHER ended.

\subsubsection{Bioprocessing}

The initial entry of Chem Tech into research and development efforts in bioprocessing research occurred in about the 1973-1974 time frame. Initial programs were in the areas of bioreactor development, particularly as applied to waste treatment technology, and more fundamental studies of photosynthetic hydrogen production. As these programs evolved and expanded, the number and diversity of the staff increased and also many new initiatives were undertaken. The program has been very dynamic, with the number and types of projects fluctuating as new ideas were rapidly assessed for their long-term potential and then further pursued or abandoned. Currently the staff includes biochemical engineers, microbiologists, a biochemist, and a biophysicist (Fig. 4.54).

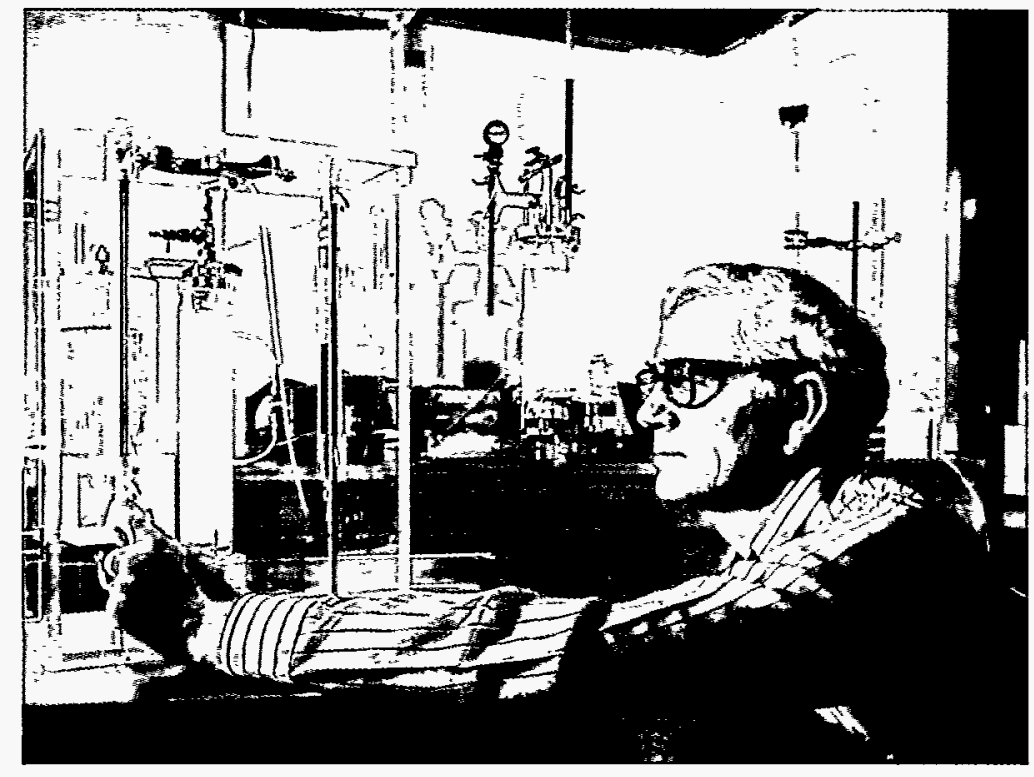

Fig. 4.54. Guy Jones adjusts the eluent flow through a chromatographic column during the separation of bioreaction products. 
Bioreactors. The use of activated sludge bioreactors employing very large tanks or ponds and lengthy retention times was a well-known bioprocessing concept in the 1970s. However, Chuck Scott, Chuck Hancher, Dave Holladay, Dennis Chilcote, and George Dinsmore pioneered the application of tapered fluidized-bed bioreactors (TFBRs) to the cleanup of aqueous effluents from coal conversion processes and the denitrification of aqueous nuclear processing waste streams. Experimental comparisons of phenolic waste degradation by continuous stirred-tank, packed-bed, and TFBRs demonstrated the volumetric efficiency advantages for the latter two technologies. Continuing developments in the application of TFBRs to bioprocessing led to an IR-100 award in 1979 for Chuck Scott, Doug Lee, and Chuck Hancher.

Photosynthetic Hydrogen. During the early 1970s, an increasing interest in a hydrogen economy where hydrogen was employed as the medium of energy transport resulted in enhanced efforts to develop alternative methods of production. Zane Egan, Perry Eubanks, and Chuck Scott initiated research efforts on a program to develop enzyme-catalyzed production of hydrogen. The initial emphasis of this BES-funded program was on determining the kinetics of hydrogen production using enzymes from Clostridia and the necessary components from plants such as spinach chloroplasts. The approach was to develop a nonliving system which was more amenable to scaleup for hydrogen production. Some interesting tales evolved from the "cultivation" of spinach on B corridor of Bldg. $4500 \mathrm{~N}$ under the watchful eyes of Egan and Eubanks.

This program and its agricultural efforts were passed on to Eli Greenbaum, a biophysicist who joined the division in 1979, coming from the Union Carbide Corporate Research Laboratory in Tarrytown, New York. Agricultural efforts were replaced by trips to the local grocery store to buy spinach as a source for chloroplasts. One of the key advances made by Eli working with Perry Eubanks was the first demonstration of simultaneous photoproduction of molecular hydrogen and oxygen in the chloroplast/ferredoxin/hydrogenase system. They also demonstrated that a simpler photosynthetic water-splitting system could be prepared by precipitating metallic platinum onto the surface of photosynthetic membranes. This work was featured on the cover of Science magazine in 1985. Another approach to this goal of hydrogen production, funded by the SERI and the Gas Research Institute (GRI), involved the use of intact microalgae for water splitting. Eli worked with Steve Blankenship, Duane Graves, Jean MacInnis, Dave McWherter, Mike Morrissey, Mark Reeves, Ginger Tevault, and Jim Thompson on these projects (Fig. 4.55).

Jonathan Woodward, a biochemist/ enzymologist, joined the division in 1980 . His work on this program has focused on the stabilization of spinach chloroplasts for the photobiological production of hydrogen (Fig. 4.56). Glenna Shields, Jim Overton, Mike Morrissey, and Norman Lee collaborated with Woodward in this work. In addition, several undergraduate students, high school teachers, and college faculty have spent between three and eight months in Woodward's laboratory between 1980 and 1992. Many of these people have had positive experiences which have aided them in achieving career goals (Figs. 4.57 and 4.58).

Biodenitrification. As mentioned previously, one of the focal points of the division's entry into the bioprocessing research area included the development of TFBRs by Scott, Hancher, Holladay, Chilcote, and Dinsmore. These reactors employed biofilms of bacteria which naturally attach to a fluidizable solid matrix (in this case, anthracite coal). One of the first attempts at application of this bioreactor design to an existing problem was the biodenitrification of nuclear processing wastewaters. Based on earlier studies by Chet Francis in the Environmental Sciences Division (ESD), who showed that certain microorganisms could metabolize the nitrate in these wastes to innocuous nitrogen gas, this process was readily adapted to the TFBR. Continuous development efforts on this bioreactor over the years led to its successful application at the Fernald facility and the Portsmouth Gaseous Diffusion Plant and, in 1989, to the startup of a pilot unit at Pacific Northwest Laboratory. Chem Tech staff were active in the design, startup, and where necessary, troubleshooting for these units. In addition to those mentioned above, several other staff members were involved at various stages in this development effort, including Terry Donaldson, Joe Walker, Hal Jennings, John Parrott, Jr., Tom Dinsmore, and Doug Lee.

Biotreatment of Wastewaters from Coal Conversion Processes. This development effort had its beginnings in the same time frame as the 


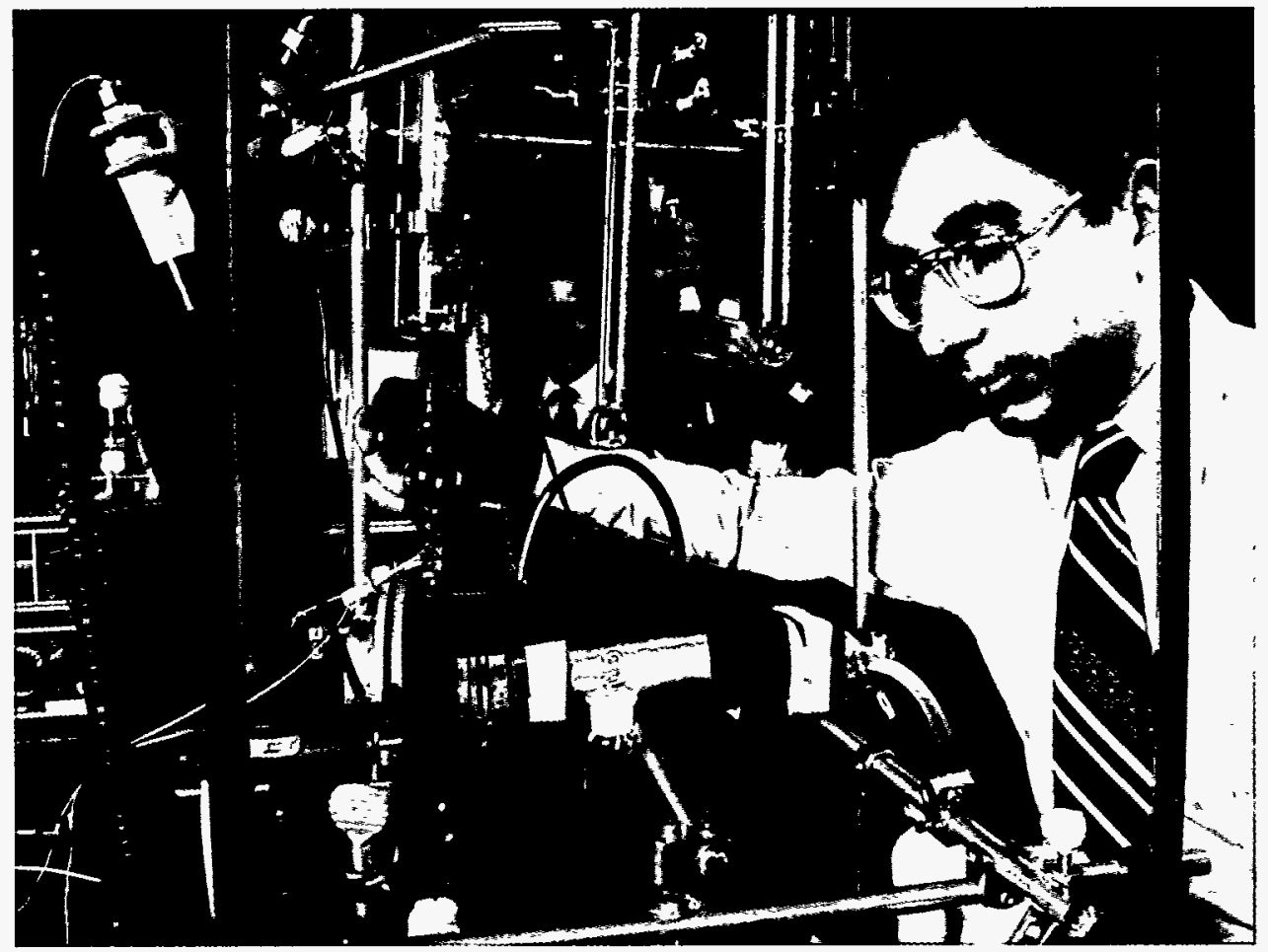

Fig. 4.55. Chem Tech researchers Elias Greenbaum in the foreground and Mark Reeves (left) with Jim Thompson in the background work in an experimental facility used to study photosynthetic splitting of water.

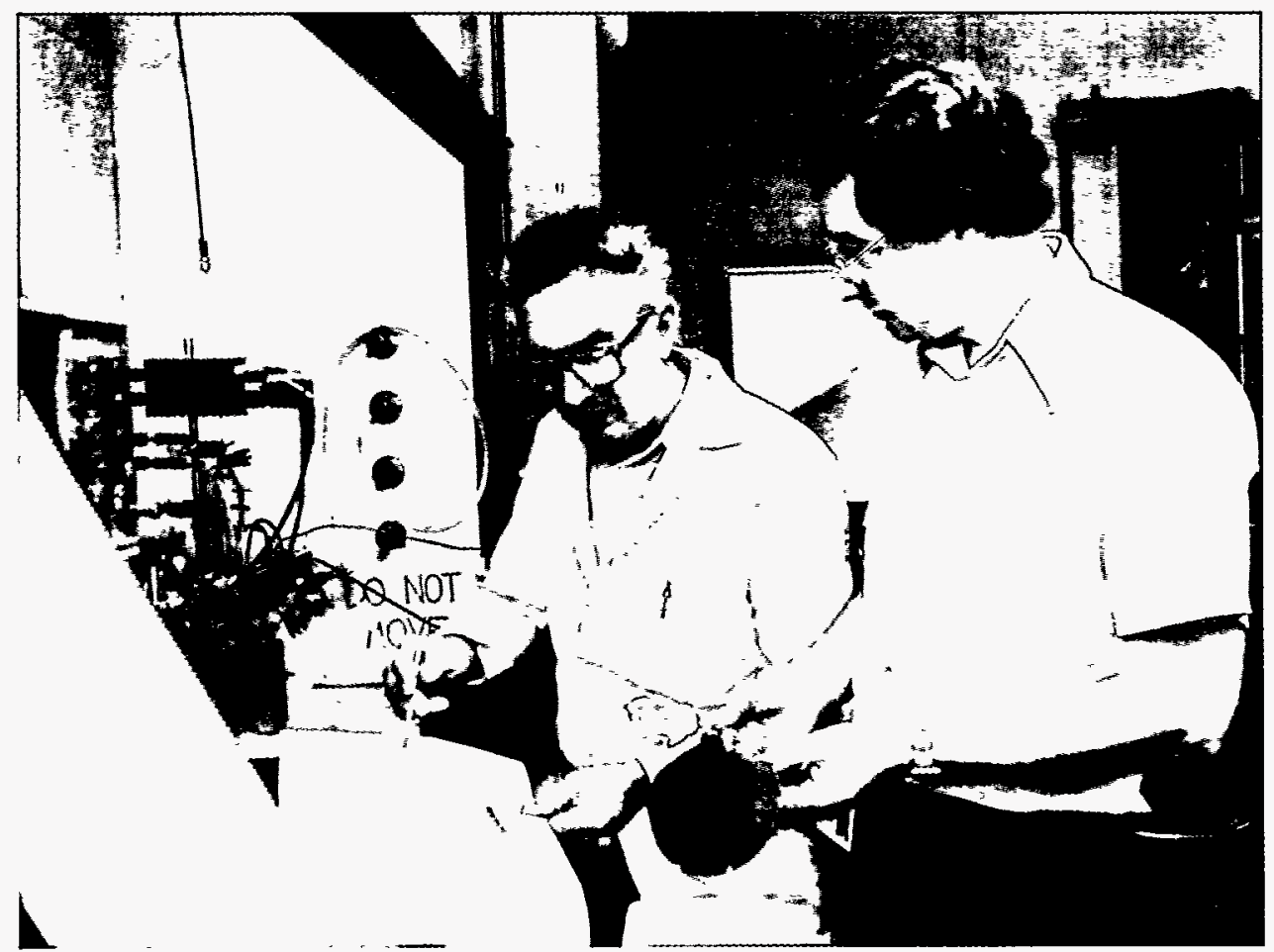

Fig. 4.56. Perry Eubanks (left) and Jonathan Woodward discuss data on the biophotolysis of water. 


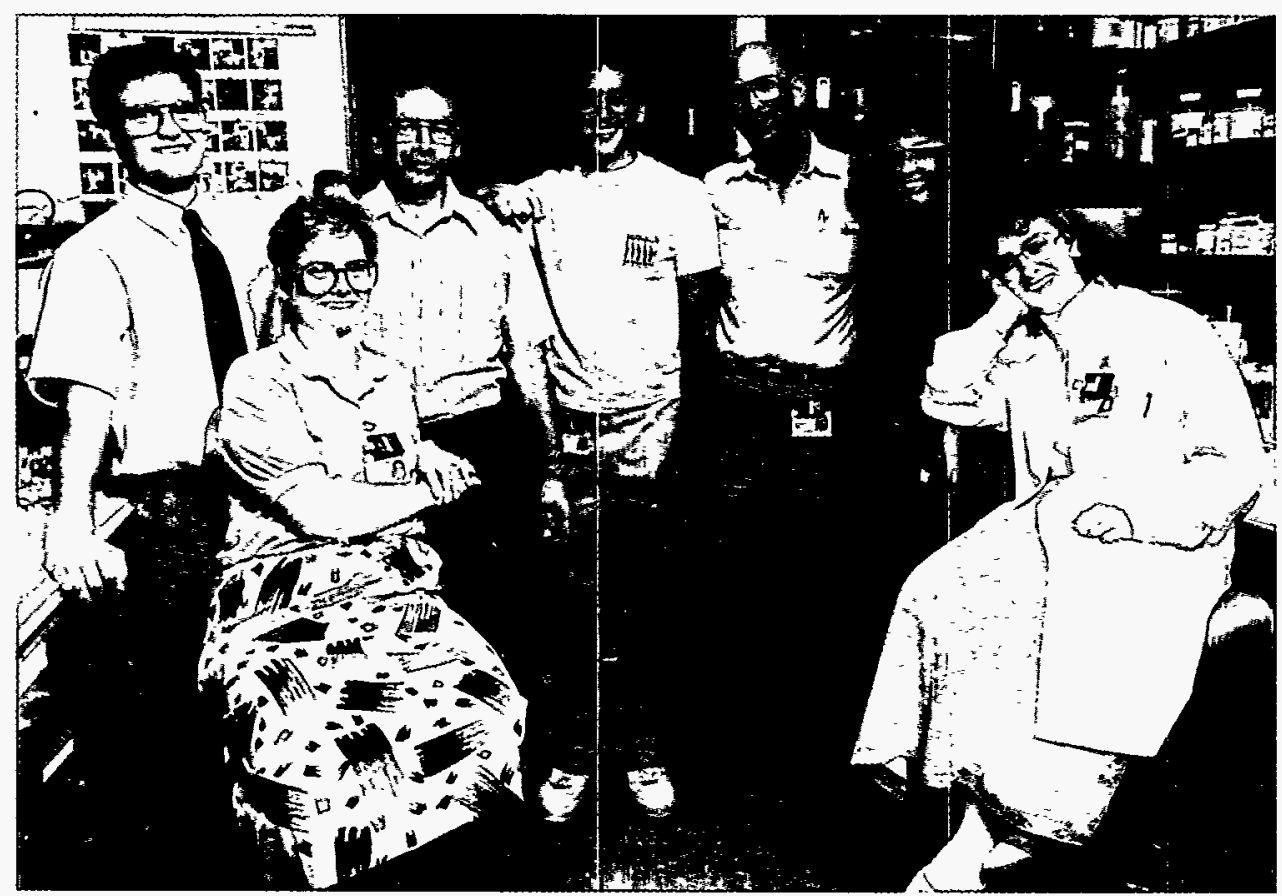

Fig. 4.57. Students and teachers under various ORAU/DOE programs working with Chem Tech scientists Norman Lee and Jonathan Woodward during the summer of 1989. From left: Steven McNair, Technology intern, Pellissippi State; Michelle Clark, Teacher Research Associate, Marquette University High School, Milwaukee, Wisconsin; Jonathan Woodward; Jeffrey Carmichael, ORSERS student, Slippery Rock University, Slippery Rock, Pennsylvania; Norman Lee; Kathy Kapps, American Chemical Society SEED student, Clinton High School, Clinton, Tennessee; Delia Truett, ORAU Summer Research Participant, Washington and Lee University.

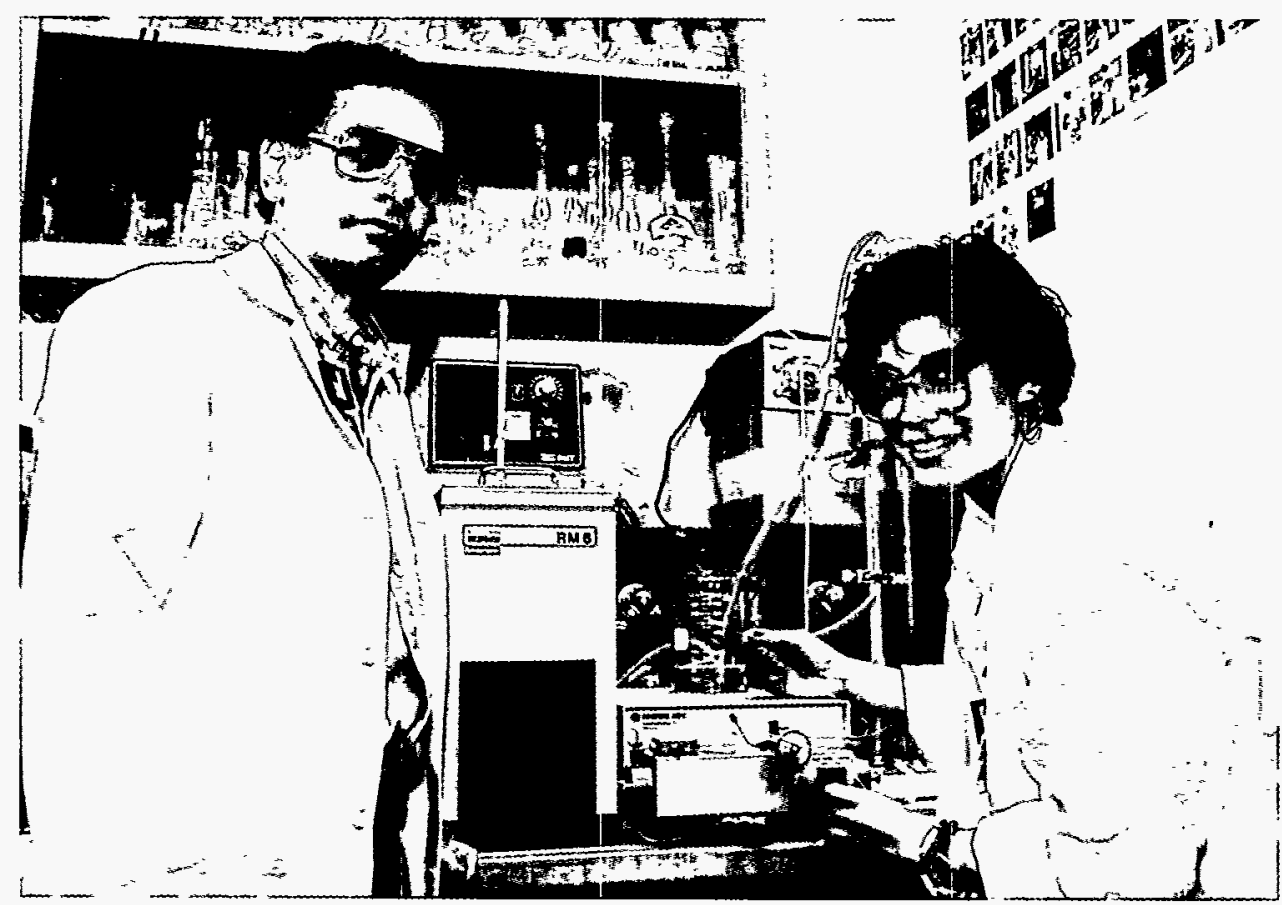

Fig. 4.58. Jonathan Woodward and SEED student Lourdes Hernandez, Central High School for the Visual Arts, Carolina, Puerto Rico, during the summer of 1991. 
biodenitrification project. It, too, was an effort to extend the application of TFBRs. The initial work was conducted by Chuck Scott, Chuck Hancher, Dave Holladay, Dennis Chilcote, and George Dinsmore and included studies on phenol degradation in both a continuous stirred-tank reactor and a TFBR. Later, Doug Lee, Chuck Hancher, and Chuck Scott began looking at the biodegradation of a number of compounds, including phenolics, in coal conversion wastewaters using the TFBR. Around 1977-1978, the commercially available culture they were using suddenly lost its ability to attach to the anthracite coal support medium. Ed Arcuri, who had recently joined the bioengineering research effort, undertook a lab study of what causes these organisms to attach to solid matrices. Ed, along with Sherry Gibson and Dave McWherter, were able to reestablish an attached film and resumed studies on phenol degradation. Around 1980, Terry Donaldson and Jerry Strandberg took over the project. Personnel at Sybron Biochemicals, who provide commercial cultures, helped to provide a relatively easy method to induce most, if not all, cultures to attach to surfaces. It involved simply supplying the organisms with cheese whey and mineral salts during the attachment phase. This procedure greatly assisted later studies of fixed-film systems. With technical assistance from Jim Hewitt, Glenna Zachary (Shields) and Mark Worden (a UT chemical engineering graduate student), the study of the biodegradation of various phenolics in coal gasification wastewater (obtained from the Morgantown Energy Technology Center) was renewed in earnest. Doug Lee returned to the project around 1985 and extended the study to include the degradation of a variety of specific organic compounds in the wastewater. A lack of sponsor interest and funding ended CTD's involvement in this development project around 1986-1987.

ANFLOW. Another significant bioreactor development that began in the mid 1970s was the ANFLOW system or "anaerobic, up-flow" bioreactor for treating organics in municipal and industrial wastewaters. Rather than a TFBR, this system employed microorganisms attached to a stationary support matrix. It has the significant advantage that a by-product of biodegradation, methane, can be recovered and reused as a fuel, thus helping reduce operating costs. Alicia Compere and Bill Griffith carried out initial bench-scale studies. Progress was rapid and in
November of 1976, in spite of record below-freezing temperatures, Chuck Hancher, Dan Million, Wilson Pitt, and George Dinsmore successfully started up the 5000-gpd pilot demonstration unit at the East End Sewage Treatment Plant in Oak Ridge. They undoubtedly recall recovering copious quantities of cow rumen contents, which served as a source of microbial inoculum for the bioreactor. This unit successfully treated raw sewage, essentially continuously, for two years, even though on two occasions "midnight" discharges from plating facilities caused month-long periods of deactivation of the Sewage Treatment Plant activated sludge. In 1981, Richard Genung, Chuck Hancher, Mike Harris, George Dinsmore, Hal Jennings, and Tom Dinsmore initiated the operation of a 50,000-gpd system at the Loves Creek Wastewater Treatment Plant in Knoxville. This technology proved quite successful and was eventually commercialized.

Biological Separation of Hydrogen Isotopes. In the mid-1970s, a U.S. Geological Survey (USGS) report claimed that a specific marine bacterium had the capability to preferentially utilize tritium as opposed to normal hydrogen. Under the intense interest and scrutiny of the sponsor (ERDA), a concerted effort was undertaken by Chuck Scott, Wes Shumate, and John Parrot, Jr., to verify this phenomenon and study its potential for removing tritium from aqueous nuclear wastes. Jerry Strandberg joined this effort in late 1976. After examining innumerable biological mechanisms capable of directly interacting with hydrogen, the somewhat frustrating conclusion was reached that biological systems (including the original USGS bacterium) tend to specifically exclude tritium from biochemical reactions when compared to the normal hydrogen isotope. From a process standpoint, this exclusion principle still offered a possible, though highly impractical, means of removing tritium from contaminated water. The project was discontinued after little more than a year's effort.

Biosorption. In the mid-1970s, existing processes for removing and concentrating radionuclides and heavy metals from waste streams were costly and relatively ineffective at low metal concentrations. Wes Shumate and Tom Dinsmore initiated studies on the use of microorganisms, which were known to be capable of accumulating certain metals, to remove uranium and strontium from nuclear processing wastewaters. The process 
was generally considered to be akin to an ion-exchange phenomenon and called "Biosorption." This effort was, like the denitrification development project, part of an overall ERDA-sponsored program for the "Removal and Separation of Radioactive Nuclides and Nitrates from Liquid Waste Streams." Around 1978, Jerry Strandberg and John Parrott, Jr., became involved in these studies. Unfortunately, in spite of ORNL's worldwide recognition for expertise in this area, there was a hiatus due to a cessation of funding for the program. Fortunately, renewed interest developed and work was resumed around $1987-88$ by Brenda Faison, Brian Davison, and Jack Watson, with a particular effort toward the use of cells immobilized in gel beads. Studies have continued and have achieved an international flavor through a project directed at the removal of uranium from contaminated waste ponds in eastern Germany.

Bioprocessing of Coal. Chemical/physical processes for converting coal to liquid and gaseous fuels require extremes of temperatures and pressures. The discovery in 1982 by researchers at the University of Hartford of a fungus that could solubilize lignite coal led to a flurry of activity around the country and within Chem Tech to further investigate this potentially important phenomenon as an alternative method of processing coal to useful fuels and chemicals. Chuck Scott, Jerry Strandberg, and Susan Lewis conducted the early studies, which led to important advances, including the extension of organisms known to solubilize coal to include other fungi and bacteria and in the understanding of the process, including a primary mechanism of coal solubilization (i.e., the action of a microbially produced organic base). Unfortunately, a primary disadvantage to the use of the microbially solubilized product is its high oxidation state. Brenda Faison and Brian Davison continued these studies in the late 1980 s, with a particular emphasis on the anaerobic microbial conversion of the oxidized product to methane. In part, because of the high oxidation state of the product, there has also been considerable interest in conversion of coal under anaerobic conditions, particularly by isolated enzymes functioning in nonpolar solvents. The products of such a conversion should be in a more reduced state and considerably more usable in terms of their fuel and chemical value. This has become the major thrust of current research by Chuck Scott and Charlene Woodward.
Enzymatic Hydrolysis of Cellulose. Jonathan Woodward joined the bioprocessing team in 1980 . He immediately initiated a program on the enzymatic conversion of cellulose to glucose, an important substrate for various fermentation processes, including ethanol production. Jonathan has maintained an active research program in this area over the years, and his work has provided several insights into the mechanism of cellulase activity. As indicated earlier, Jonathan has provided opportunities for a host of students and university faculty to conduct research at ORNL.

Anaerobic Digestion of Cellulosic Wastes. The rapid loss of available landfill space prompted an effort by Jerry Strandberg and John Parrott, Jr., in 1981 to investigate the reduction of volume of the cellulosic fraction of low-level contaminated waste by anaerobic microbial digestion. The idea was to "solubilize" the major portion of the waste and to dispose of the digested material via the hydrofracture waste disposal process. Successful bench-scale results led Doug Lee and Terry Donaldson to scale up the process to a $50-\mathrm{L}$ fermentor. A 25,000-gal digester was designed and scheduled for installation at the east end of ORNL. The unfortunate problems with the hydrofracture facility around this time led to the consideration of disposal of the digest in the grout program.

However, it was eventually decided to retain compaction and burial as the means of disposing of contaminated cellulosic wastes, and the anaerobic digestion program was discontinued.

Ethanol Production. Around 1979-1980, Ed Arcuri, Wes Shumate, Chuck Scott, and Jerry Strandberg initiated bench-scale, continuous, bioreactor studies on ethanol production. An additional twist to this development effort was the use of the bacterium Zymomonas mobilis, which has inherently better characteristics for ethanol production than the commonly used fermentation yeasts. The organism also had a propensity to naturally floc and provide its own mechanism for immobilization. A variety of bioreactor designs were investigated and substantially higher ethanol productivities were achieved by the combined use of bioreactor design and Zymomonas. Brian Davison, Jim Thompson, and Chuck Scott have continued these development efforts using more refined immobilization techniques, including entrapment in gel beads. They were also successful in establishing a cooperative venture with A. E. Staley Co., in Loudon, Tennessee. The use of gel beads as a means of cell and enzyme 
immobilization technique has proved quite successful. The scope of the work has also expanded to include bioreactor studies on acetone-butanol production and organic acid production.

Bioremediation. Chem Tech's most recent foray in biotechnology is in the area of bioremediation-the use of microorganisms not to treat waste streams, but to clean up "natural" environments such as soil and groundwater aquifers contaminated with toxic materials. The effort began with a study by Terry Donaldson, Jerry Strandberg, Phil McGinnis, and Tom Ashwood (ESD) on the efficacy of the biological remediation of a jet-fuel-contaminated site at the McChord Air Force Base in Tacoma, Washington. Subsequently, with funding from Y-12, HAZWRAP, and the ORNL director's fund, and in cooperation with members of ESD, the Oak Ridge Research Institute, and The University of Tennessee, projects were initiated on the biodegradation of PCBs, the biodegradation of mixtures of organic compounds, and the use of bioreactors employing methanotrophic bacteria to degrade trichloroethylene and other chlorinated aliphatic compounds. Terry Donaldson, Jerry Strandberg, Linda Farr, John Cosgrove, Hal Jennings, and Andrew Lucero have all been involved in the latter project in conjunction with personnel from ESD which led, in 1991, to the establishment of a demonstration bioreactor for the treatment of contaminated seep water at the $\mathrm{K}-25$ plant.

While aerobic microbial activity is effective against most of the lower chlorinated congeners of PCBs, there is little action on the higher chlorinated compounds. Mark Reeves and Betty Evans have, of late, been investigating the anaerobic microbial dechlorination of PCBs. Removal of the chlorine molecules renders the higher chlorinated congeners more susceptible to subsequent aerobic attack. A Cooperative Research and Development Agreement (CRADA) has also been established with General Electric.

Terry Donaldson, Bob Jolley, and Andrew Lucero are leading one of Chem Tech's most recent and largest efforts (in conjunction with The University of Tennessee, Oak Ridge Associated Universities, and the ORNL Environmnetal Sciences Division) directed at the remediation of diesel fuel contaminated soil on the Kwajalein Atoll in the South Pacific. Joe and Angie Walker are now temporarily located on Kwajalein, conducting activities at the site.

Bioengineering Research User's Facility. In the early 1980s, the Bioengineering Research User's Facility was established in Building 4505 under the auspices of Chuck Scott, with assistance from Terry Donaldson and Brian Davison. The purpose of this facility is to enable universities and private industry the opportunity to conduct bioengineering research at ORNL and to utilize Chem Tech's expertise and equipment.

\subsection{WATER CHLORINATION AND RELATED PROGRAMS, Bob Jolley}

\section{Formation of Chlorinated Organics During} Water Chlorination. In the 1960 s Rachel Carson's book The Silent Spring focused national attention on chlorinated organics used as pesticides and herbicides. The newly awakened environmental conscience of scientists brought into question whether toxic chlorinated organic compounds might be produced during the chlorine disinfection of drinking water and wastewater. In a major effort to answer part of that question, in 1970 Bob Jolley chlorinated several wastewater samples using ${ }^{36} \mathrm{Cl}$-tagged chlorine and separated the organic constituents from the chlorinated wastewaters using high-resolution anion exchange chromatography. Over 50 chlorine-containing organic constituents were separated from secondary wastewater samples, thus providing convincing evidence that such compounds are produced during wastewater chlorination. Follow-up studies using cooling water samples from several electric power production plants also indicated that chlorinated organics are formed during the cooling water chlorination, a common practice to prevent biofouling of heat exchangers (Fig. 4.59). At approximately the same time period, EPA researchers reported that chloroform and other trihalomethanes are produced during the chlorine disinfection of drinking waters. These collective studies led to an intense flurry of national and international research to identify chlorination by-products and to determine their toxicological properties.

Water Chlorination Conference Series. In 1975 Bob Jolley and Sidney Katz of Chem Tech, Bob Cumming of the Biology Division, and Carl Gehrs of the Environmental Science Division organized a conference, The Environmental Impact 


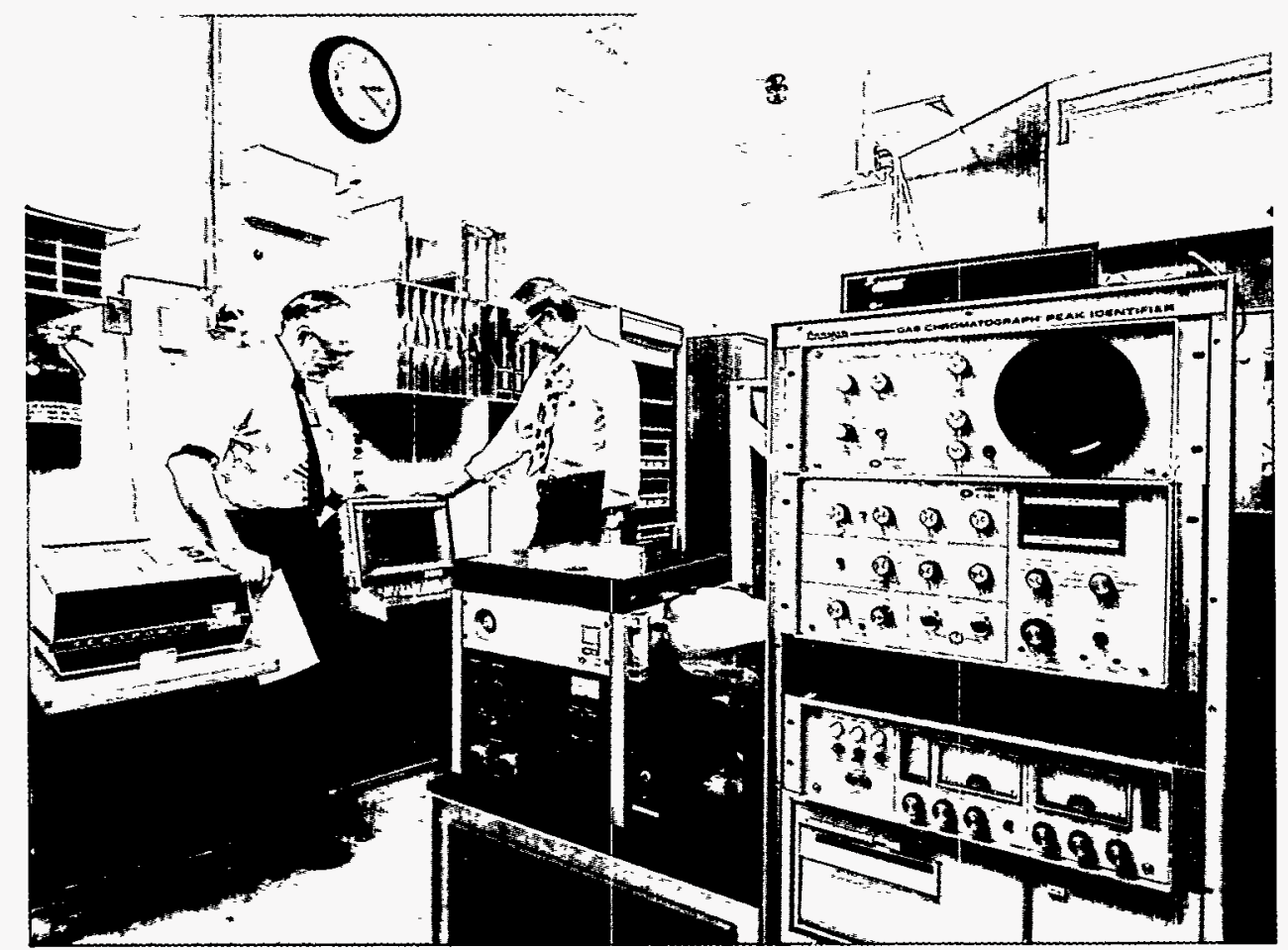

Fig. 4.59. Bob Jolley (left) and Norman Lee discuss mass spectra of constituents separated from chlorinated water samples by gas chromatography and liquid chromatography.

of Water Chlorination, held October 22-24, 1975, at ORNL. The conference was highly successful, with over 300 attendees, and resulted in publication of Water Chlorination: Environmental Impact and Health Effects, Volume 1.43 Jolley convened six conferences on the subject between 1975 and 1987, resulting in the publication of six volumes totaling over 6600 pages. ${ }^{43-48}$ The conferences and resulting books encapsulated approximately two decades of research in the area of disinfectant chemistry, engineering, and the environmental and health effects of disinfectants and disinfectant by-products. The collective volumes represent a significant national and international contribution to this important area of health and toxicology of drinking water, wastewater, and cooling water treatment.

Drinking Water and Goiter. Goiter is a common national and international disease. Untold losses to the world's reservoir of human intelligence and productivity result from goiter despite almost ubiquitous iodine prophylactic programs. ${ }^{49}$ Approximately $1 \%$ of surgical operations in the United States in the early 1980 s were reported to involve the thyroid gland (i.e., associated with goiter or goiter-related problems).$^{50}$ During the late 1970 s and early 1980 s a small collaborative program between Chem Tech and the Universities of Alabama and Mississippi explored the use of high-resolution chromatography for identification of organic constituents in a variety of drinking water sources, including wells and springs as well as public water supplies.

About one-half of the children in a certain geographical part of Cali, Columbia, developed goiter compared to $10-20 \%$ in other areas. This occurred despite a national supplementary dietary iodine program. In a classic epidemiology study conducted by Dr. Eduardo Gaitan, currently located at the University of Mississippi Medical Center, it was determined that the drinking water source for that geographical part of the city with high goiter incidence was of sedimentary geological origin and different from that for the remainder of the city. Using high-resolution chromatography for organics separation and gas chromatography/mass spectrometry for organics identification, Bob Jolley and Jim Thompson analyzed some water samples collected by Dr. Gaitan. In addition to many organic constituents, they identified resorcinol as present in the goitrogenic water. Resorcinol is a 
known potent goitrogen. ${ }^{49,51}$ The collaborative work between Dr. Gaitan and Jolley was continued in an effort to determine similar compounds in selected counties in Kentucky that have high goiter incidence. Although resorcinol was not identified in these waters, a similar compound was identified. ${ }^{49,51}$ Federal budget restraints prevented sufficient collaborative efforts to conclusively identify goitrogenic compounds in the United States water samples (Fig. 4.60).

\subsection{BRANCHING OUT-STUDIES ON AGRO-INDUSTRIAL COMPLEXES, Hal Goeller}

For the first 25 years of its existence, ORNL was renowned, pretty exclusively, for its expertise and activities in the physical and biological sciences. Looking back we all remember the 1960 s as a period of social upheaval, mainly by the baby boomers who were beginning to reach early adulthood. In those times, among other things, disillusionment was setting in against science and many of the applications of science.

It seems only natural now that ORNL should have entered into the fray - and it did-by expanding its endeavors to include the social sciences as well as its more traditional activities. At that time, this was a rather bold move. This branching out began in 1967 , when a special summer study was set up, at the urging of Alvin Weinberg and Floyd Culler, to begin examination of the many social problems which the physical sciences had long largely ignored.

The summer study ended, but the impetus led in time to the formation of ORNL's Energy Division, which included many economists, geographers, sociologists, and other social scientists who continue to examine the softer side of science. At first it was difficult for the physical and social scientists to understand, much less appreciate, each others viewpoints, but understanding did come as many scientists became generalists as well as specialists.

One of the first efforts of the 1967 summer study was the multi-disciplinary study of agro-industrial complexes using nuclear reactors to produce fresh water from seawater for irrigation agriculture and electricity for electro-intensive industries. This effort was designed to address the Eisenhower-Lilienthal plan to "make the deserts bloom" in water- and power-deficient developing nations. Some of those involved in this study included Cal Burwell, Hal Goeller, John Holmes, Jack Mrochek, John Michel, Irv Spiewak, Phil Hammond, Jim Lane, Bill Yee, Ed Mason from MIT, Perry Stout (one of the "fathers" of the green revolution) from the University of California at Davis, Clair Nader (sister of Ralph Nader), Art Squires an engineer from City College of New York, J. R. Chapman an engineer from Alcoa in Pittsburg, and M. Striplin and Glenn Blouin, engineers from TVA, Muscle Shoals, Alabama. Many members of the multi-discipline and multi-divisional study team are shown in Fig. 4.61.

At first the study was a general one, examining rough reactor designs, possible associated types of industrial chemical processes, and the most suitable crops to be grown. Later studies were directed to

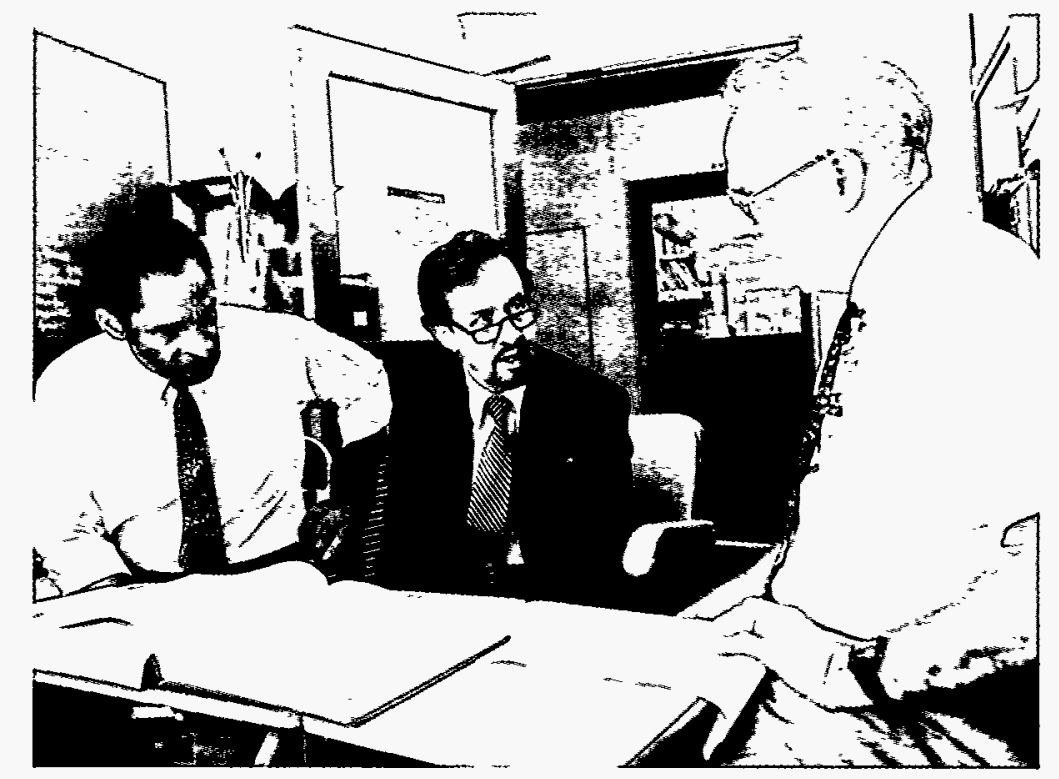

Fig. 4.60. Dr. Nathaniel Revis (left), Director of Oak Ridge Research Institute, Dr. Eduardo Gaitan (center), Chief of Endocrinology, Veterans Administration Medical Center at the University of Mississippi, and Bob Jolley discuss chemical spectra produced by analysis of drinking water samples collected by $\mathrm{Dr}$. Gaitan in geographical areas of high goiter incidence. 


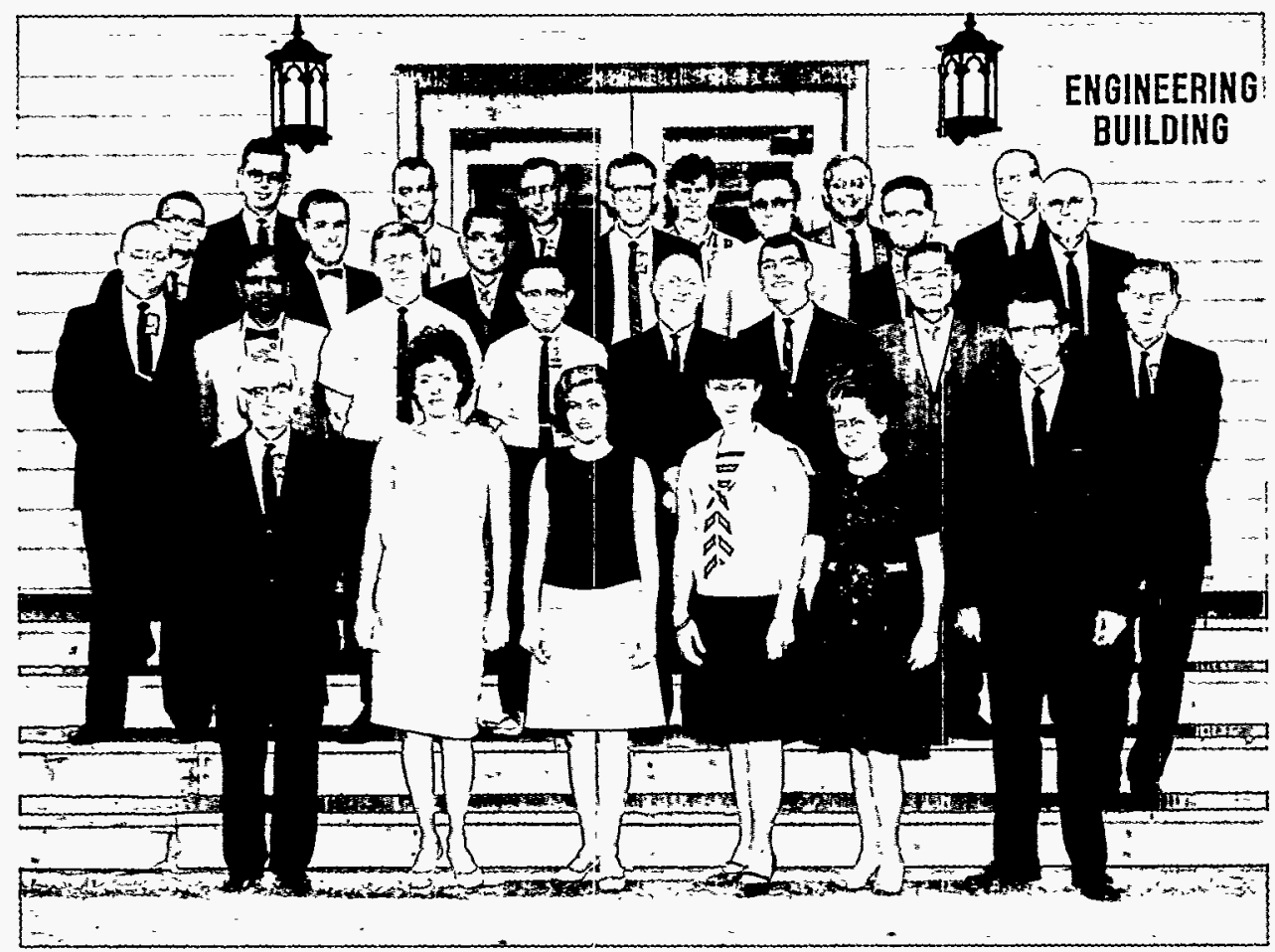

Fig. 4.61. Because of busy travel schedules and the use of a large number of consultants, not all members of the 1967 ORNL agro-industrial study team are shown. Members shown are (left to right): Front row, Alvin Weinberg, Virginia Lee, unidentified secretary, Kathy Gardner, Alice Maxwell, and Ed Mason. Second row, John Mrochek (Chem Tech), unidentified consultant, unidentified consultant, unidentified consultant, unidentified consultant, Marv Yarosh, Bill Yee (Chem Tech), and Hal Goeller (Chem Tech). Third row, John Holmes (Chem Tech), unidentified consultant, Tammy Tamura, John Michel, unidentified consultant, Ray Blanco (Chem Tech), and unidentified consultant. Back Row, unidentified consultant, Cal Burwell, Dick Philippone, unidentified Massachusetts Institute of Technology student, Floyd Culler (Chem Tech), and Gale Young.

selected countries and sites; the industrial processes were then selected to utilize local raw materials. In the case of Egypt, these proposed industrial processes included production of aluminum from domestic bauxite, phosphate-containing fertilizers from phosphate rock, and salt from seawater. Major studies were also done for India and Israel.

In addition, brief application studies were made for the Tokar Delta on the Red Sea in Sudan; the Danakil Depression in Eritria, Ethiopia; the Qattar Depression in Egypt; and the coastal desert in northern Peru. In the latter case, for example, reactors could be used for desalination of seawater or pumping water over the Andes from the Maranon River, a headwater of the Amazon located only 50 miles away.

The major studies were followed by extended trips to India and Israel in November 1967, Egypt in October 1968, and Israel in April 1969.

Discussions were held with government agencies on all trips:

During the Indian trip, visits were made to agricultural research stations, to Bakhra Dam on the Sutlej River in the Punjab, and to the Tata Chemical Works on the Arabian Sea in Gujarat, as well as to Bombay (headquarters site for the Indian AEC), New Delhi, Agra, and Chandragahr. One of the favored applications of our idea was for the powering of 30,000 tube wells to raise water from the "third great river" of India, which runs $8 \mathrm{ft}$ underground in Uttar Pradesh, in order to provide water to the area between the monsoon rains.

Discussions in Egypt were carried on mainly in Cairo and Alexandria. Visits were made to new model farms in the delta. We also toured the Mediterranean coast as far west as Mersa Matruh, Rommel's headquarters in World War II, and 
visited El Alamein, where Rommel was turned back. One problem for Egypt at the time of our visit was the fact that the High Aswan Dam produced so much electric power that no additional generating capacity would be needed for a long time.

The first trip to Israel was brief and involved; besides discussions in Tel Aviv, we traveled to Jerusalem and made a coastal trip to El Arish in the Sinai where we saw some Bedouin farming. The second Israeli trip was much more extensive-so extensive, in fact, that it is almost easier to say where we didn't go. One trip was to the south in the Negev, where we went first to Beersheba and then to Elat on the Gulf of Aqaba. There we saw desalination facilities. Then we traveled along the Jordan border to a desert farm and kabutz, where brackish water, desalinated by reverse osmosis, was used for trickle irrigation farming. Moving northward to Sedom, we visited the Dead Sea Chemical Works, which produces salt and potash. Above the Dead Sea we toured a new town that was to be the site of a magnesium plant. Traveling westward we visited an orange grove and wheat farm on the edge of the Negev, an orange processing plant, and Ashdod and Ashqelon on the Mediterranean Sea. After visiting Jaffa and Jerusalem we headed north to Nazareth and the Sea of Galilee, which supplies most of Israel's fresh water. Our trip ended with visits to Haifa, Acre, and ancient Caesarea.

Unfortunately, no solid achievements appear to have ever resulted directly from the agro-industrial studies. In retrospect, this appears to have resulted from (1) the agro-industrial complexes were based on 1 mil per $\mathrm{kWh}$ power, and that was not really feasible; and (2) there was no real chance for private or U.S. government financing of the huge costs of such projects.

\subsection{ADEQUACY OF NONRENEWABLE RESOURCES, Hal Goeller}

One problem facing domestic and world society is the long-term adequacy of nonrenewable resources. In order to initiate studies to evaluate this problem, ORNL assigned me to spend the summer of 1970 at Resources for the Future (RFF), a Washington, D.C., think tank that had devoted considerable efforts to this area since the end of World War II. During my stay there, I worked with
Joel Darmstadter under the direction of Hans Landsberg and Sam Shurr.

The arrangements proved mutually beneficial. The people at RFF are primarily economists and other social scientists who have worked closely with technical experts in the U.S. Bureau of Mines (USBM), the U.S. Geological Survey (USGS), and others but have had little in-house technical expertise. Thus, I tended to fill this void during my stay and, at the same time, came to understand many of their viewpoints.

After returning to ORNL in the fall of 1970, I continued my efforts to further understand the problems. Part of my efforts involved becoming self-taught in geology. An interesting aspect of such activity is that in approaching a new scientific discipline in this manner one tends to avoid the biases prevalent in more formal learning processes. (Witness, for example, how long it took for plate tectonics to be fully accepted by the geological community.)

In the spring of 1971, I was asked to serve on the newly formed National Academy of Science (NAS)-National Research Council (NRC) Committee for the Survey of Materials Science and Engineering, which operated under the NAS Committee on Science and Public Policy (COSPUP) and the National Materials Advisory Board (NMAB). This effort involved attending committee meetings in Washington, D.C., and Albuquerque, N.M., and providing written material for the final report.

The Limits to Growth, which provided a very dismal assessment of the long-term adequacy of nonrenewable resources, was published in 1972. We, as well as some others, have a much brighter outlook. In order to look more intensively into this problem, the U.S. government established an interagency National Commission on Materials Policy (NCMP) in early 1972 . One of their efforts involved setting up several multi-day seminars at various universities on different aspects of resource adequacy. Alvin Weinberg was asked to give the opening paper for the seminar on "Scarcity and Growth: Toward a National Materials Policy," to be held at the University of Minnesota in Minneapolis. Since he was unable to attend, he asked me to prepare and present the paper.

My paper provided a fairly optimistic appraisal of the problem and was quite well received. Later, I honored repeat requests at Ohio State, Yale, Worcester Polytechnic, and Vanderbilt universities, as well as at Monsanto Corporation in St. Louis 
and the U.S. State Department Diplomat School in Roslyn, Virginia.

Resource study activities were interrupted in 1973 and 1974 during my participation in the preparation of the World Energy Conference Survey of World Energy Resources. Returning to my earlier efforts involved two projects in 1975. In the first, Alvin Weinberg and I coauthored a paper entitled "The Age of Substitutability," which he presented at the Science Policy Forum (a British think tank) at their annual meeting in Eindhoven, The Netherlands, which I also attended. Our paper, which was published in Science in 1976, became one of the leading means of refuting the assertions of Limits to Growth. In fact, it was so well received by economists that it was republished in one economic journal as one of the salient papers of 1976.

My other effort in 1975 involved participation in a NATO study that resulted in publication of a report entitled "Use of Potentially Scarce Metals." I attended meetings in London and NATO headquarters in Brussels, Belgium, and wrote portions of the report. Unfortunately, I had to miss the final meeting in Arona on Lake Maggiore in Italy.

In 1976, I participated in an RFF Conference on National Resource Scarcity as a speaker and contributor to the book they published. My paper, entitled "The Age of Substitutability: A Scientific Appraisal of Natural Resource Adequacy," was a follow-up to the paper I presented earlier.

Floyd Culler, Dave Cope of AEC, and I participated in the 20-month study by NAS-NRC (from July 1976 to March 1978) under the Committee on Nuclear and Alternative Energy Systems. My participation involved the determination of uranium requirements for a variety of nuclear energy scenarios and its effect on uranium (and thorium) resources. We attended eight committee meetings in New York City, Washington, Denver, and San Francisco and provided extensive input for the final report.

In May 1980, I attended a Tin Substitution Meeting at RFF in Washington to participate in a review of a Penn State contract study of the same name. In June, I went to a 3-day workshop in Woods Hole, Massachusetts, as a member of the NAS-NRC-NMAB Committee on Materials Substitution Methodology and later helped write the workshop report. Later, in November 1980, I delivered a paper on resource adequacy at the Interciencia Convention in Kingston, Jamaica.
Interciencia is a Pan-American Science Organization, and the convention was attended by scientists from a variety of disciplines and countries of the western hemisphere.

In May 1981, I presented the lead-off paper for the Materials Resources and Substitution Session of the American Ceramic Society Annual Convention. Next, I participated in the NAS-NMAB committee to review USBM's R\&D activities. In addition to the Committee Meetings in Washington, we attended briefing sessions at the USBM Research Stations in Albany, Oregon; Rolla, Missouri; and Tuscaloosa, Alabama. Review and recommendation reports were prepared and given to the USBM for each of these stations. Finally, Alex Zucker and I coauthored a paper entitled "Infinite Resources: The Ultimate Strategy," which was published in Science in 1984.

\subsection{WORLD ENERGY CONFERENCE-1974 SURVEY OF ENERGY RESOURCES (1974 Enquete sur les Ressources Energetiqes), Hal Goeller}

The World Energy Conference (WEC) is an international organization based in London that concerns itself with energy matters of all sorts. In the early 1970s, it had national committees in 69 countries. The WEC holds a conference every six years (now every three years), with the host country in charge. In 1974 the conference was held in Detroit, Michigan.

For each conference the WEC updates its survey of world energy resources for presentation to conference attendees in booklet form. Until 1974 (and also thereafter) the booklets contained only a few pages of statistical material prepared by the London office based on data provided by member nations plus estimates for nonmembers.

Early in 1973 the U.S. National Committee decided, with London's approval, to finance, write, and print a much expanded survey for the Detroit Conference. They then asked the AEC to take on this task, and in turn the AEC requested ORNL to do it. ORNL readily accepted the role.

The ORNL effort was a multiphase activity for a variety of energy resources, including coal, oil, natural gas, tar sands, oil shale, nuclear fuels (uranium, thorium, and fusion fuels), hydropower, 
and other renewable resources (tidal, geothermal, solar, wind and ocean thermal gradients).

The first-phase effort involved the receipt, review, and processing of questionnaires that had been developed by others and sent out to both WEC member and nonmember nations. Ultimately, completed replies were received from 54 member nations, including 27 of their dependencies, and from 11 nonmember countries. Many replies provided data for numerous national subdivisions. All of these data were then entered into computer files for ultimate printout of a very detailed set of appendices, which finally occupied 115 pages (including introductory text). Data on the geology of fossil and nuclear fuels were also covered.

The second effort involved the writing of an appropriate text for each resource. These texts included discussions of geology, mining technology, fuel characteristics and uses, and environmental and societal problems associated with recovery and use of each resource. Summary resource tables were also provided for each resource, including data from independent sources for nonreporting countries.

Other efforts included preparation of detailed specific and general bibliographies and of world maps showing the location of resources. Finally the entire text was translated into French since the survey has traditionally been issued in bilingual form. In final form the book contained 400 pages plus eight maps.

Each attendee at the Detroit conference received a copy. In addition, President Gerald Ford, who gave opening remarks at the conference, was also presented with a copy.

Those at ORNL who contributed to the overall effort included Roger Carlsmith, Lloyd Carter, Hal Goeller, Miriam Guthrie, Frank Hammerling, and Pat Love. Ralph Perhac from UT provided geological coverage, and John Patterson from AEC Headquarters produced the nuclear resources text. I visited the WEC London office in 1986 and was informed that requests are still coming in for our book.

\subsection{HISTORY OF THE CHEM TECH REPORTS OFFICE, Martha G. Stewart}

When I came to work in the Chem Tech Reports Office in 1966, I was on loan from the Information Division (now the Publications Division). After being interviewed by Don
Ferguson, Division Director, and Ray Wymer, Head of Chemical Development Section A, I was selected to replace Howard Whetsel, Chem Tech's only editor, because he had decided to accept an assignment with the Nuclear Safety Information Center (which was located in the Y-12 area). Howard had initially said that he would train me for a month before leaving; however, as it turned out, he left after only nine working days (Fig. 4.62).

I was delighted to find that most of the Chem Tech chemists and engineers were already well versed in the tenets of grammar, punctuation, and sentence structure. The credit for this high level of training goes to Martha Gerrard, who had established the Reports Office in the early 1950 s and remained as its supervisor and sole editor for more than ten years. Her background as a former technical editor for McGraw-Hill, Inc., allowed her to have a maximum positive impact on the young technical staff members with regard to shaping and promoting their writing and organizational skills. Chem Tech owes Martha Gerrard a tremendous vote of thanks for setting and maintaining the highest publication standards during her long and valuable tenure.

I found that my career background was quite suitable for the Chem Tech programs under way at that time: 1 year of work in heavy-metals chemistry in the Y-12 Plant Laboratory, five years of work in

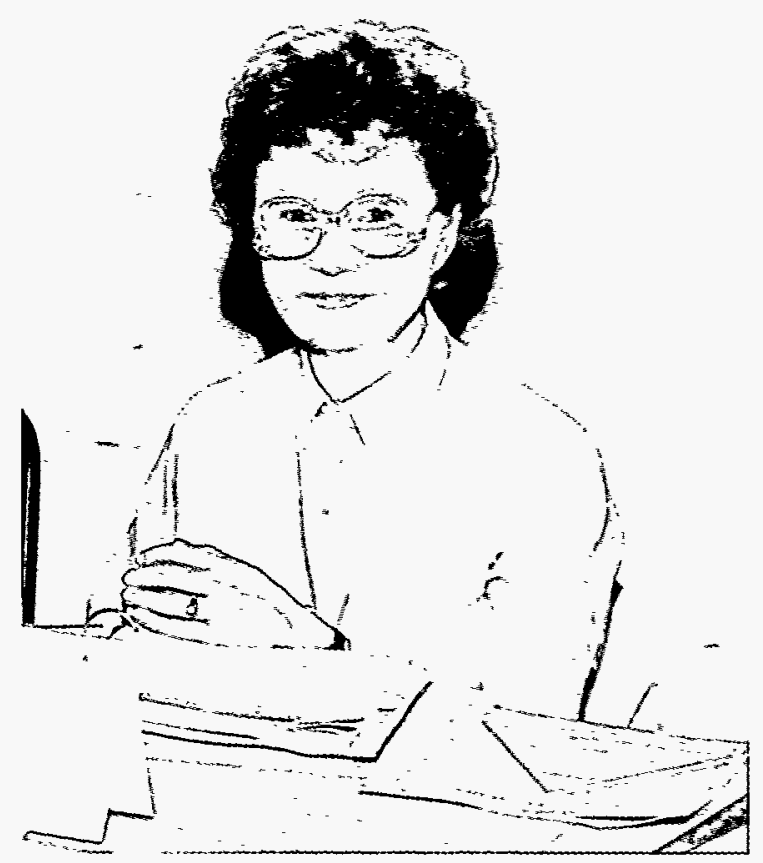

Fig. 4.62. A 1991 photograph of Martha Stewart at a seminar. 
radiochemistry and biochemistry at the Oak Ridge Institute of Nuclear Studies (now the Oak Ridge

Associated Universities), and two years of training as an editor in the Information Division. Much of my editorial work had been concerned with Biology Division materials. Fortunately, I had also had the experience of serving as the lead editor for the 1965 Chem Tech annual progress report. When I was assigned to Chem Tech Reports Office in 1966 , the division was in the throes of preparing the drafts for the 1966 annual progress report. In fact, I arrived just in time to coordinate the collection, editing, and finalization of these drafts.

At that time, the Reports Office (now called the Publications Services and Procedures Coordination Office) was located in Room B-224 in the B Attic (4500N), adjacent to the Xerox Room. There were very few resource materials, one "ancient" typewriter, one desk-and-chair combination, and one bookcase. The noise from the Xerox machine was significant-almost intolerable at times. I felt isolated and uncertain as to how to deal with the large backlog that I had inherited, but the division office personnel (Don Ferguson, Nancy Beach, and Elaine Hickman) were very helpful and the section heads made me feel very welcome.

As is the case at present, the secretaries in the various sections were responsible for report preparation. However, the mode of preparation was slow and unwieldy since it involved use of the standard IBM typewriter. Corrections, which were tedious, were made by using correction fluid, strip-on tape, or paste-ons, or by retyping entire pages. Authors traditionally wrote the first draft in longhand on yellow, lined, legal-size tablets. Then, many additional typed drafts followed, as editorial comments and suggestions from reviewers were incorporated.

All documents were prepared on photomasters (ORNL and ORNL/TM reports) or duplimats (ORNL/CF memos). Duplimats were a glossy-surface medium that had to be corrected by erasing with a special type of pencil. Thus, the preparation of reports and papers was a very time-consuming and expensive procedure.

As the years progressed, the work load of the Reports Office expanded astronomically and the editorial staff was increased accordingly: Vivian Jacobs, 1974; Cathy Shappert, 1976; Debbie Stevens, 1976; Amy Harkey, Leon Morse, and W. D. Norton, 1980; Luci Bell, 1981; Frank Scheitlin, 1983; Donna Reichle, 1984; Vicki Hinkel, 1986; Cindy Robinson, 1987;
Mary Louise Conte, 1988; and Kathryn King-Jones, 1990. Four of these editors were eventually promoted to higher-level positions and were transferred to areas of greater opportunity within the Publications Division. Two others retired, and one individual moved to a different geographical location.

During this period, the mode of report preparation also advanced significantly. Several stages of new technology and improved efficiency evolved, successively, as the following types of equipment were installed and implemented: IBM Selectric typewriter, IBM Selectric II (Correcting) typewriter, various word processing systems (MagCard, Royal's CPT, Wang, etc.), and, finally, personal computers (primarily IBM clones and WordPerfect software). Each phase, or stage, in this sequence represented a "giant step" with regard to labor and cost savings-as well as a more attractive and readable finished product.

The Publications Services and Procedures Coordination staff members have always been interested in achieving top-quality ratings for their editorial work; maintaining a high level of personnel interaction and liaison with the Records Management Department, Patent Office, Reproduction, and Central Publications services; meeting all clearance and editing deadlines with respect to papers for scientific meetings and ORNL or DOE milestones; and enhancing their capabilities commensurate with new technology. In this regard, they have won numerous Society for Technical Communication awards for journal articles, reports, and brochures; have been awarded the high honor of having the best "no-late" clearance record at ORNL (received "zero-late-clearances" award for 199.1); and have received numerous commendations for outstanding work on special projects. All in all, this group has played an integral part in the execution of the many important programs and projects carried out by Chem Tech for nearly three decades.

\subsection{A MERCIFULLY BRIEF HISTORY OF ENVIRONMENTAL CONTROL TECHNOLOGY, John Parroft, Jr.}

The core of what is now the Engineering Development Section (EDS) of the Chemical Technology Division originated in the late 1970s as the Environmental Control Technology (ECT) 
R\&D Group within the Advanced Technology Section. This group, headed by Richard Genung, drew its inspiration from and built upon the pioneering Chem Tech environmental technology efforts of Chuck Hancher's biodenitrification project and Chuck Scott's biotechnology program.

The initial projects undertaken by the ECT group included monitoring and assessment of wastewater from fossil energy plants, design and development of a mobile pilot-scale wastewater treatment system for use at fossil energy plants, bench-scale evaluations of mutanegicity and toxicity phenomena associated with proposed wastewater treatment processes at fossil energy sites, and design and development of the ANFLOW (ANaerobic upFLOW) wastewater treatment system.

Mobile Wastewater Treatment. Planning for the mobile pilot-scale wastewater treatment system, which was to play an important role in future ECT activities, began in October 1980 with the following objectives:

- Evaluate advanced wastewater treament techniques to effect zero-stream discharge or meet future discharge regulations.

- Provide scaleup data for larger conversion plants.

- Assist in solving operational problems at existing wastewater treatment facilities.

The mobile pilot plant was constructed during FY 1981 and early FY 1982 and consisted of three semi-trailer vans-two housing the process equipment and one serving as an analytical laboratory (Figs. 4.63 and 4.64). These trailers were initially deployed to the H-Coal coal gasification plant in Catlettsburg, Kentucky, in the winter of 1981-1982, manned by George Oswald, Cliff Brown, Joe Walker, Jim Hewitt, Mike Harris, Steve DeCicco, and Jack Rose. The successful completion of this mission in September 1982 led to a similar expedition in October 1983 to the Advanced Coal Liquefaction R\&D Facility in Wilsonville, Alabama. At these sites, bench-scale unit operations (granular activated carbon, ozonation, and reverse osmosis) were evaluated for treatment of the process condensate from the coal conversion processes. The trailers were then sent to Y-12 where they successfully removed mercury contamination from wastewater (by reverse osmosis and ion exchange) to a level permitting the water to be discharged.

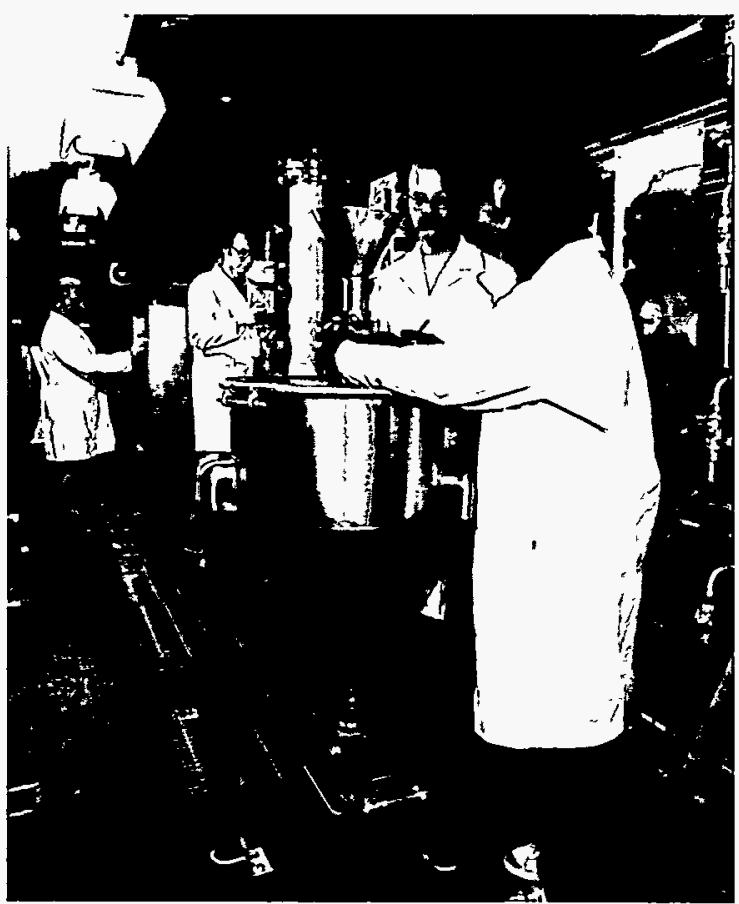

Fig. 4.63. Coal conversion wastewater treatment pilot plant operated at $\mathrm{H}$-coal and Solvent Refined Coal Pilot Plants. Left to right are Jack Rose, Joe Walker, Cliff Brown, and Mike Harris.

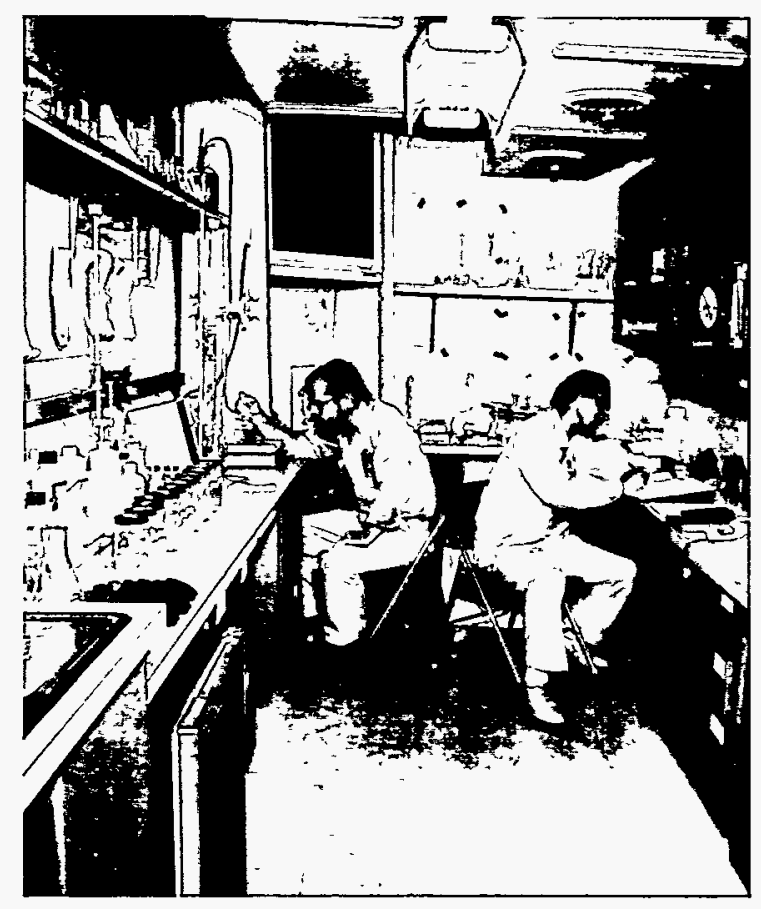

Fig. 4.64. Analytical support trailer for coal conversion wastewater treatment pilot plant, showing Chem Tech staff members Don McTaggart (left) and Jim Hewitt. 
ANFLOW Wastewater Process. The ANFLOW sewage treatment process was developed in the late 1970s using facilities in the high bay of Building 4505. A 500-gpd system was then demonstrated at the West End Treatment Plant in the city of Oak Ridge. A near-full-scale ANFLOW sewage treatment pilot plant was operated by George Dinsmore and Hal Jennings at a Knoxville wastewater treatment facility from August 1981 through the summer of 1983 (Fig. 4.65).

Growth in Wastewater Treatment Experience: Nonradiological Wastewater Treatment Plant; Process Waste Treatment Plant. After these successful wastewater treatment campaigns, the ECT group grew to encompass increased responsibilities, providing support to the entire Oak Ridge complex by conducting wastewater treatment projects for sponsors at $\mathrm{K}-25, \mathrm{Y}-12$, and ORNL. Cliff Brown became manager of the group, which by mid-1985 had become the largest group within the new Engineering Development Section. John Begovich joined the ECT group and initiated programs to provide assistance and support to the ORNL Operations Division, which was under pressure to improve the performance of ORNL wastewater treatment facilities in the face of aging equipment and increasingly stringent

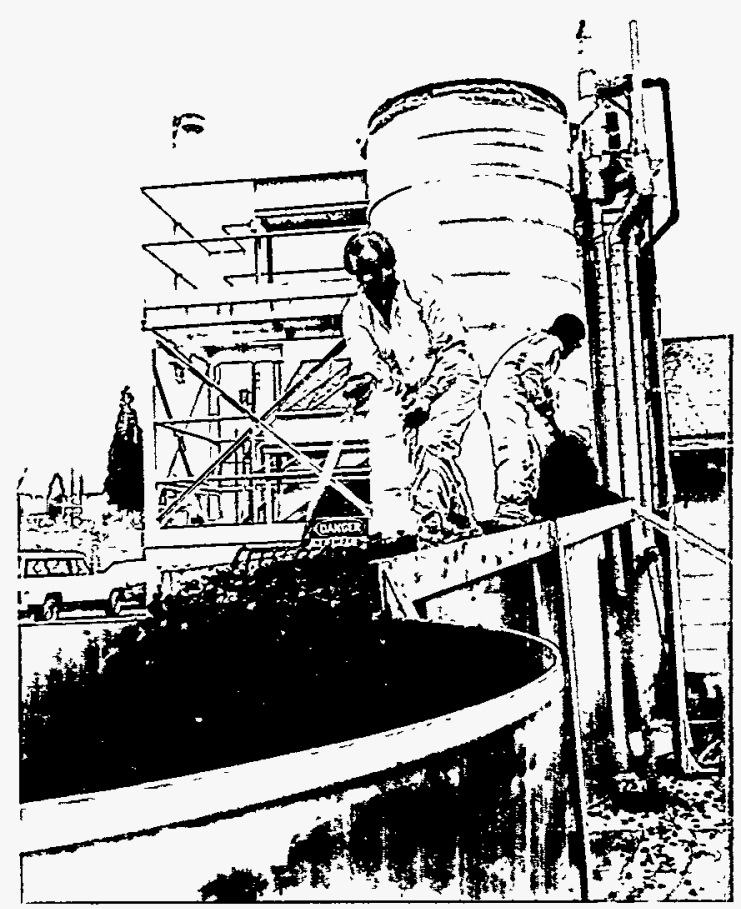

Fig. 4.65. Tom Dinsmore (left) and Hal Jennings unload support rings from the ANFLOW Pilot Plant located in Oak Ridge. environmental regulations. Operations Division support by the ECT group began when Chem Tech was asked to assess the proposed flow sheet for the new Nonradiological Wastewater Treatment Plant (NRWTP) for technical feasibility and to simulate the proposed treatment plant to provide design data for the full-scale plant. At about the same time, Operations Division requested that Chem Tech perform an evaluation of the Process Waste Treatment Plant (PWTP) to improve its efficiency and to define its relationship with the new NRWTP. To facilitate evaluations of the PWTP, an engineering-scale facility was designed and constructed to aid in the rapid solution of day-to-day operating problems at the PWTP as well as serving as a vehicle for testing new treatment concepts (Fig. 4.66). Meanwhile, experiments with new wastewater treatment technologies led to the design and operation of a zeolite column system at the PWTP. All of these projects were remarkably successful, with the

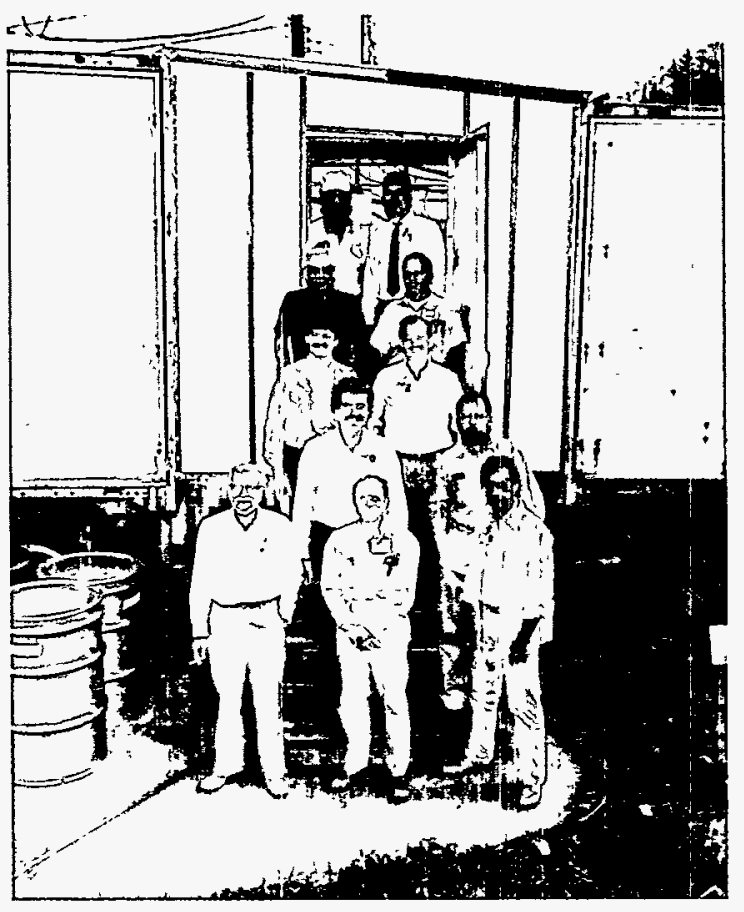

Fig. 4.66. Development team for ORNL Nonradiological Wastewater Treatment Plant. Bottom row: John Villiers-Fisher (left), George Dinsmore (center), Jim Hewitt. Second row: John Begovich (left), Don McTaggart. Third row: Brad Patton (left), Cliff Brown. Fourth row: Vic Fowler (left), Vaughn Justice (Plant and Equipment Division). Top row: Charles Kackler (left, Plant and Equipment Division), Warren Thompson (Engineering Division). 
pilot-scale zeolite columns leading to a system which is used at the PWTP today and which has become the basis for the new PWTP that will become operational in the late 1990s. The NRWTP studies led to the unit operations that were used in the actual plant, and the PWTP evaluations spawned process improvements such as the addition of the reactor/clarifier, which improved PWTP performance by decreasing LLLW generation and increasing the life of the PWTP ion-exchange resin. The success of these projects laid the groundwork for the expanded role that CTD now plays in strategic planning for Waste Management and Remedial Actions Division programs (Fig. 4.67).

AnalyticalTreatment Technology. The ECT exportable treatment technology program continued during the mid-1980s. The analytical trailer was dispatched in the fall of 1984 to the KILnGAS ${ }^{\circledR}$ rotary kiln coal gasification project in Alton, Illinois, to characterize the wastewater generated by this process. Back at ORNL, the ECT group became involved in a wide variety of endeavors, including the Fossil Energy Technology Program, which began in May 1983 under DOE sponsorship; experimental advanced treatment technologies such as the prototype wet-air oxidation system designed to remove organic constituents from wastewater; and the indirect liquefaction environmental control technology assessment project to assess the impact of designing a coal conversion plant to operate with zero aqueous discharge.

In 1986 the group, still heavily involved in support for ORNL wastewater treatment facilities, expanded its Operations Division support to include the following:

- Development and demonstration of the use of continuous automated metals monitors to characterize ORNL process waste streams (Dave DePaoli and Don McTaggart).

- Treatment of LLLW stored in the Melton Valley Storage Tanks (MVST) by filtration to remove the TRU isotopes to produce a lower-activity non-TRU waste for final disposal (Vic Fowler).

- Studies on the disposal of post-silver removal photographic wastes at the ORNL sewage treatment plant (John Parrott, Jr., and Jerry Strandberg).

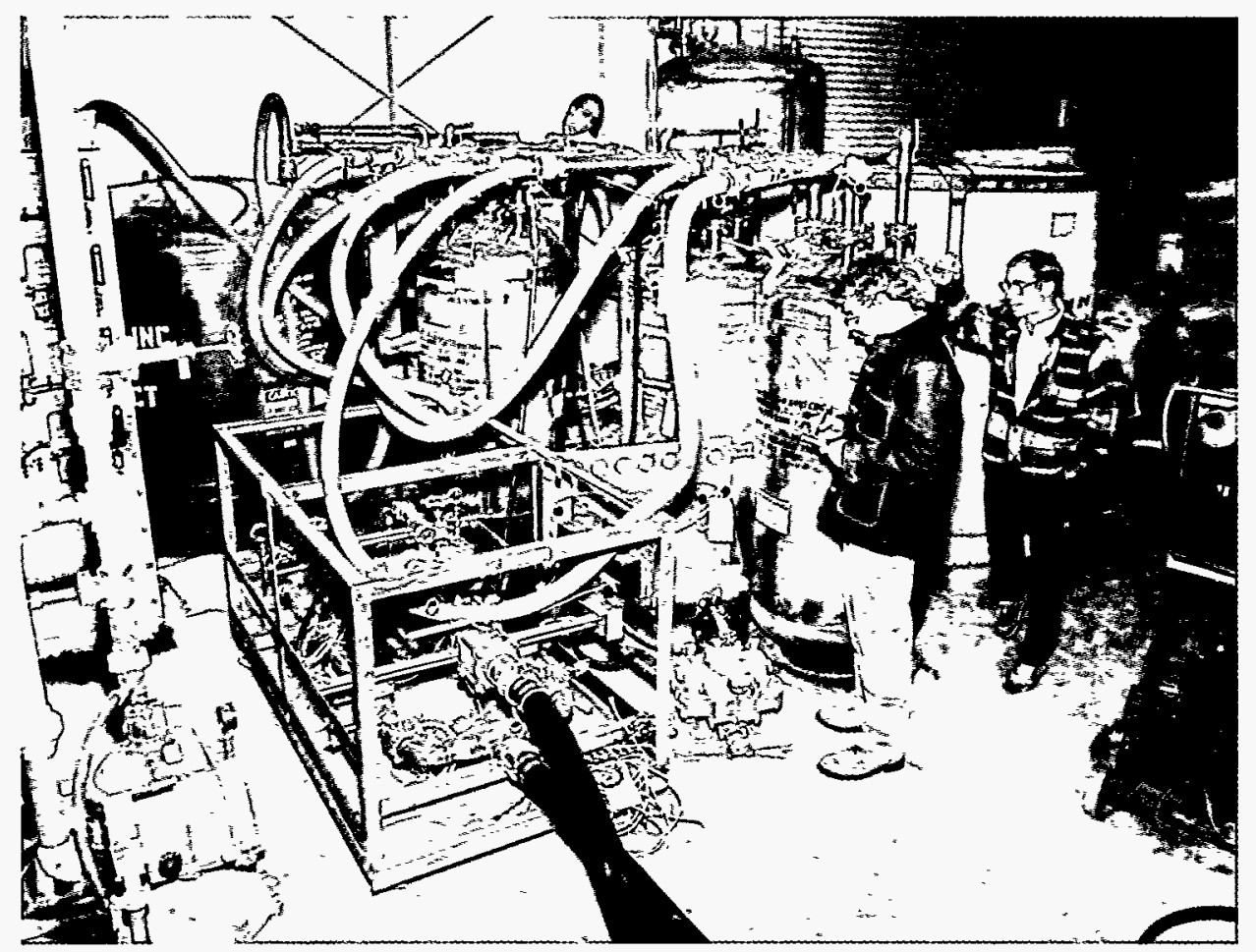

Fig. 4.67. Jim Hewitt (background), John Begovich, and Mike Morris (right) monitor emergency treatment of ORNL process wastewater using a zeolite ion-exchange treatment system. 
- Treatability studies on five new wastewater streams for discharge to the coal yard runoff treatment facility (Joe Walker, George Dinsmore, and John Parrott, Jr.).

- Laboratory-scale tests to determine the feasibility of treating ORNL-contaminated laundry wastes at the PWTP (Sharon Robinson).

Bioremediation. ECT-related activities in 1985-1986 included the ongoing bioremediation technologies being conducted by the Advanced Technology Programs Group under the direction of Terry Donaldson (Fig. 4.68). These projects included bioprocessing support to the Feed Materials Production Center at Fernald, Ohio, where a fluidized-bed biodenitrification plant was constructed based on the pilot work conducted at ORNL in the late 1970s and early 1980s and biooxidation of coal gasification wastewaters for the Morgantown Energy Technology Center. In June 1987, a project demonstrating bioremediation of PCB-contaminated soils was conducted with six lysimeters being installed at a PCB-contaminated site on the Bear Creek floodplain near Y-12. Another bioprocessing project in 1987-1988 included bench-scale biological degradation of trichloroethylene in groundwater. An additional ECT project during this time period involved conducting water quality programs through an interagency agreement with the U.S.

Environmental Protection Agency.

Changing ECT Management. In 1987 John Begovich left the ECT group (and ORNL) on an 18-month leave of absence to work on the AVLIS program at Lawrence Livermore National Laboratory. Jim Wilson and Jan Berry then came into the section, joining Sharon Robinson as group leaders, and Cliff Brown replaced Wilson Pitt as the EDS Section Head when Pitt left ORNL for a faculty position at Texas A\&M University. The four EDS groups were Work for Others Waste Technology (Wilson), Support to Operations Division (Robinson), Solid Waste Technology (Berry), and Advanced Technology Programs (Donaldson). Around the beginning of FY 1990, the Waste Soldification/Immobilization Group headed by Mike Gilliam joined the section when the Waste Management Technology Center ceased to exist.

Work for Others-Air Force. The Work for Others Waste Technology Group initially developed and demonstrated technologies to remove organic contamination from soil, obtaining

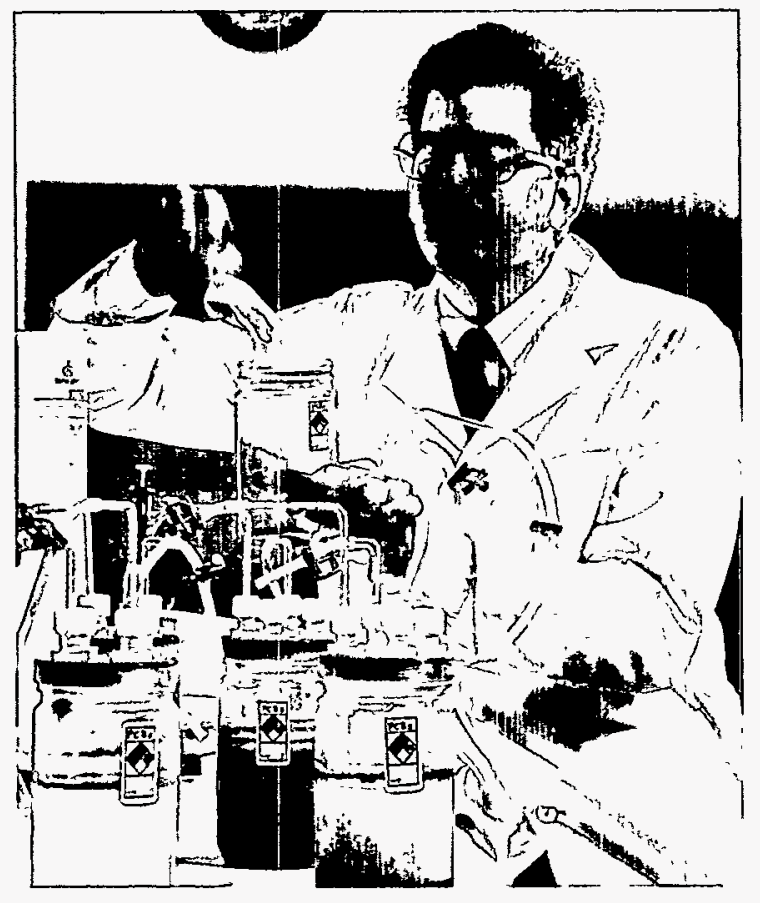

Fig. 4.68. Mark Reeves utilizes small-scale bioreactors to study PCB degradation.

contracts from the Air Force to demonstrate the ability to cleanse soil and/or groundwater contaminated with fuel spills. An air-stripping demonstration was conducted in 1987-1988 to remediate groundwater contaminated by diesel fuel at Eglin AFB near Pensacola, Florida, and a soil-venting demonstration was conducted at Hill AFB in Salt Lake City, Utah. Dave DePaoli, Hal Jennings, Andrew Lucero, and Archie Wilson were the primary investigators in these endeavors (Fig. 4.69). Other Air Force projects during this period involved environmental evaluation of fire training pits at several Air Force Bases by Tom Hylton and Joe Walker.

Work for Others-Navy. The group also conducted a hazardous waste minimization project headed by Joe Walker which demonstrated innovative wastewater treatment technologies to mimimize chromium contamination in plating shop rinsewaters from the Naval Ordnance Station in Louisville, Kentucky.

Remediation Technology. Upon the termination of the Air Force contracts, this group merged with Terry Donaldson's group and was renamed the Remediation Technology Group, with Donaldson as its leader. In 1989 this new group conducted in-lab experiments on the bioremediation of PCB-contaminated soil and in 1990 and early 1991 evaluated the performance of 


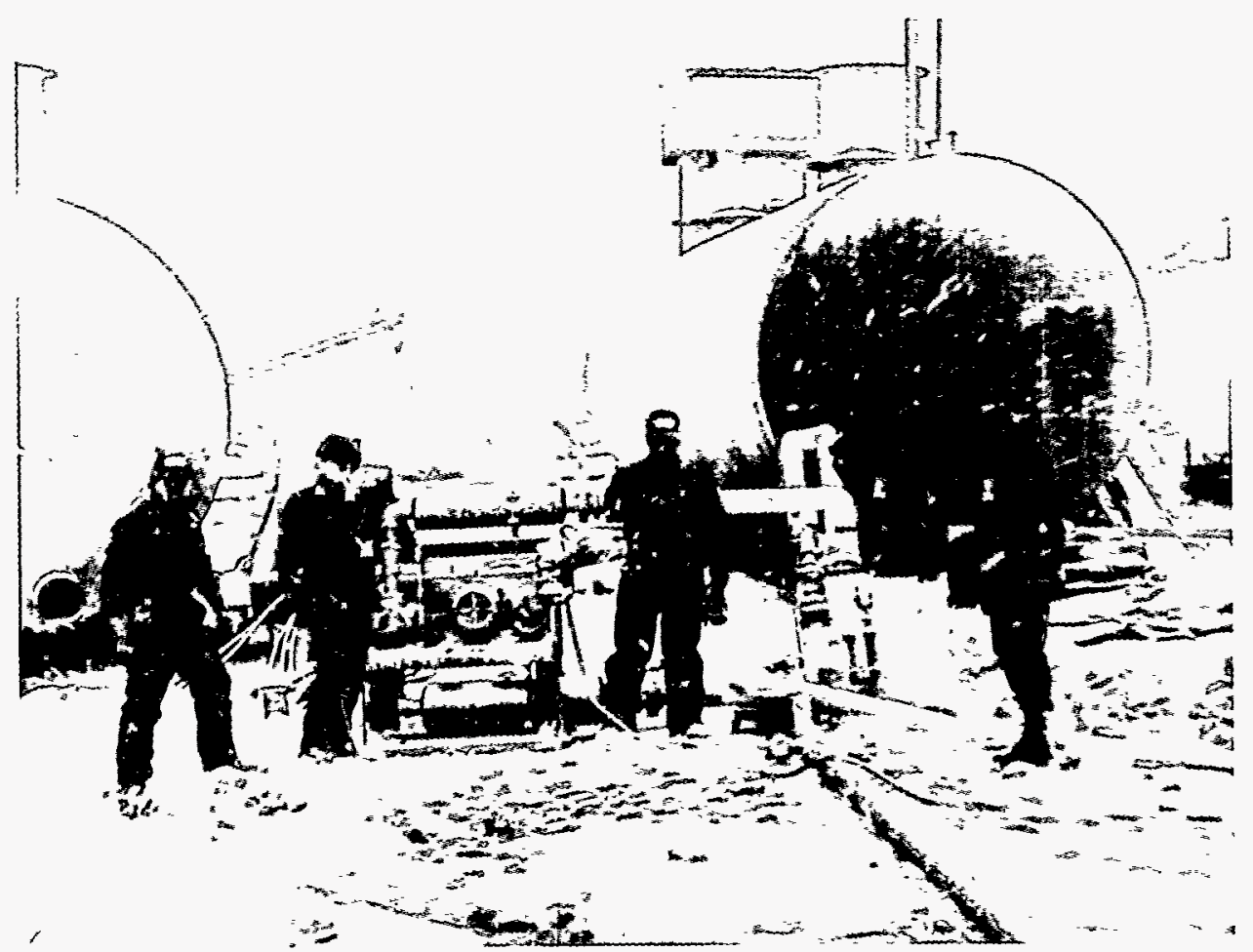

Fig. 4.69. The rigors of wintertime conductions of the soil venting demonstration at Hill Air Force Base, Utah. ORNL team members (left to right) are Hal Jennings, David DePaoli, Dan Gillespie, and Jim Wilson. U.S. Air Force Captain Ed Heyse is on the right.

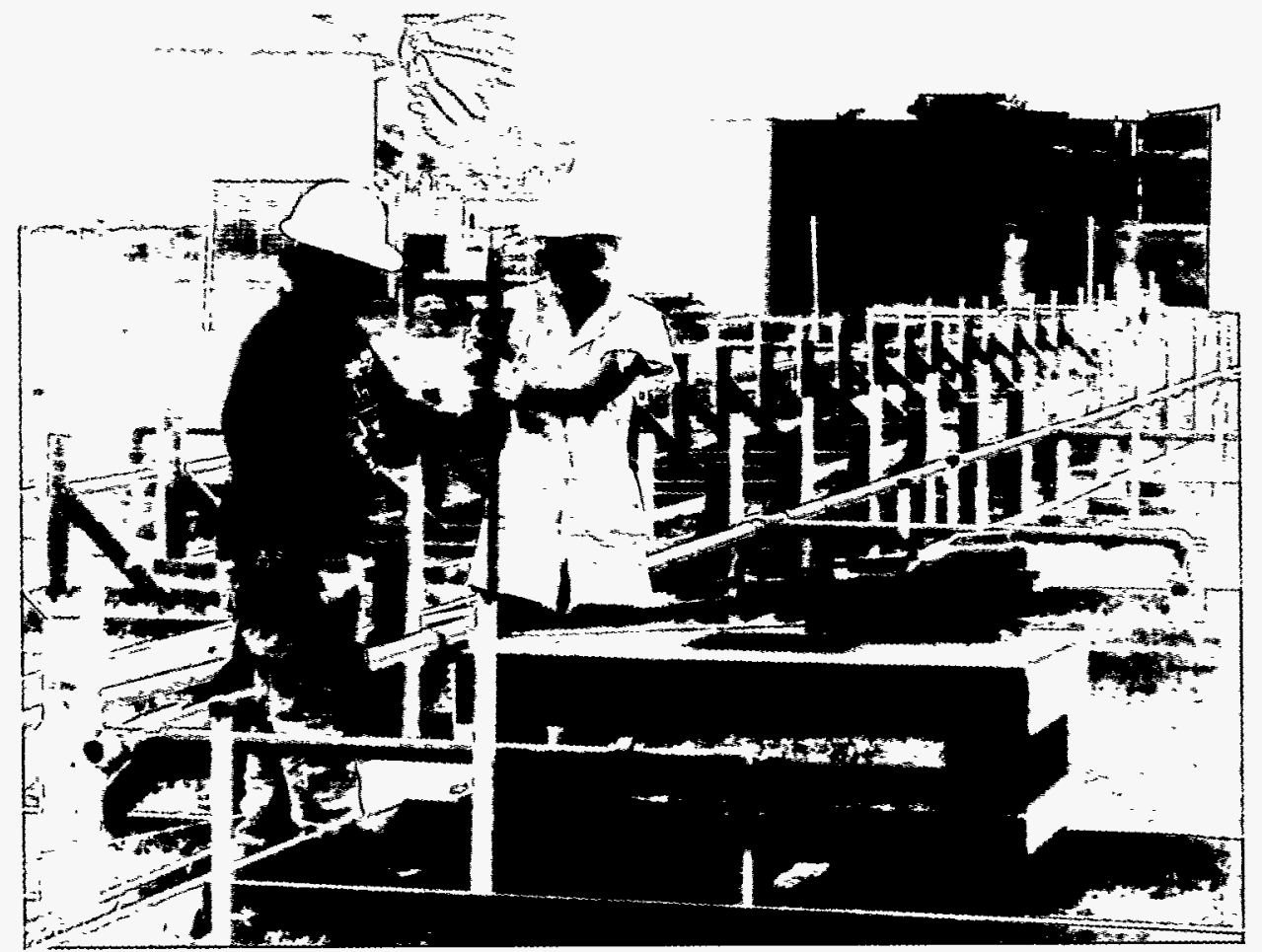

Fig. 4.70. Angie Walker (right) and Alvin Ajen (a Kwajalein Island citizen) install the multi-cell in-situ bioremediation test system on Kwajalein Island, Kwajalein Atoll, Republic of the Marshall Islands. 
a catalytic incinerator at Wurtsmith AFB, participating in a soil remediation demonstration at an old oil landfarm site at the Portsmouth Gaseous Diffusion Plant (in conjunction with ESD), and began what would be the group's farthest-reaching exportable technology demonstration when Joe and Angie Walker traveled to Kwajalein Island in the Pacific Ocean to conduct an in situ soil bioremediation project (Fig. 4.70). In late 1991, Hal Jennings and Andrew Lucero began a treatment technology demonstration much closer to home, with on-site treatment of solventcontaminated groundwater leaking from a burial ground at $\mathrm{K}-25$ using cometabolic bioreactor technology.

Waste Management Problems. The Support to Operations Division Group under Sharon Robinson quickly expanded to address all types of ORNL waste mangement problems, changing its name to the Liquid and Gaseous Treatment Technology Group. This group grew from its initial mission of providing operational support to the PWTP and NRWTP to include strategic planning and coordinating/performing applied research programs in support of ORNL waste treatment system upgrades. The assistance to Operations Division (now the Liquid and Gaseous Waste Operations Division) has been ongoing, first with John Villiers-Fisher (now retired) then Paul Taylor and Tim Kent providing answers to daily treatment plant operating problems and performing treatability studies to improve plant operations.

Low-Level Radioavtive Waste. In 1988, John Parrott, Jr., in his capacity as the Laboratory Certification Official for Liquid Waste, spearheaded development of technology-based waste acceptance criteria for all ORNL liquid waste treatment facilities and, in conjunction with other group members, developed and instituted a liquid waste certification program which encompasses training on LLLW bottling and liquid waste disposal policy in general. Also during this time period, Susan DePaoli and Angie Walker designed and implemented a comprehensive LLLW data base. In 1989, a sampling and analysis campaign to characterize ORNL LLLW was conducted to provide environmental assessment data as well as design data for Waste Handling and Packaging Plant (WHPP) and data in support of R\&D activities in developing waste management alternatives. The group used this data to perform a systems analysis in 1989 for all ORNL liquid waste treatment and collection systems. The systems analysis is currently being used to identify and prioritize LLLW system upgrades needed to meet new environmental regulations. In 1990, Sharon Robinson developed the methodology for implementing the Federal Facilities Agreement to upgrade ORNL LLLW collection and treatment facilities and developed strategies for long-term treatment of all liquid waste streams generated at ORNL. Contingency planning for LLLW management was also carried out, in which methods to decrease the volume of LLLW concentrate stored in the MVSTs were investigated. These studies are continuing, with Joe Perona working on in-tank evaporation of the stored concentrated LLLW in the MVSTs and Matt Boring concentrating on the development of a wiped-film evaporator to dewater the sludge in the MVSTs. Innovative wastewater treatment methods investigated by this group have included a continous countercurrent ion-exchange system, operated by Reggie Hall and Jim Hewitt in FY 1989, which selectively removed a preferred component (in this case strontium) from a multi-component stream which also contained calcium and magnesium. Currently in the Liquid and Gaseous Treatment Technology Group, flow sheets are being developed to treat existing LLLW, newly-generated LLLW, process wastewater, and new liquid waste streams such as those generated by environmental restoration activities. These flow sheets focus on the development of improved physical and chemical separation processes to produce small volumes of segregated waste packages for long-term disposal.

Solid Waste. The Solid Waste Technology Group began work in early 1987 in support of the proposed WHPP, performing research and development on the design of a system that would remove, treat, and solidify contaminated MVST liquid waste to prepare it for shipment to a repository in Carlsbad, New Mexico. In FY 1989, WHPP technology development continued with the creation of the WHPP Development Facility in Building 2528 to provide the engineering data needed for the design of the slurry processing systems plan to be installed at the actual WHPP. These included MVST sludge mobilization development studies to investigate methods of sludge removal from the MVSTs and conceptual designs for the evaporation by either conventional means or microwave energy of the sludge mobilized from the MVSTs. Since 1990, the expertise gained by this group in WHPP 
development has been expanded to address similar problems at K-25 and Hanford.

Waste Solidification/Immobilization. The Waste Solidification/Immobilization Group, although the last group to join the EDS, has been in existence for a long time, evolving from work starting in the early 1960s in the Waste

Management Section of the Health Physics Division in support of hydrofracture disposal of liquid waste. This effort was headed by

Dr. T. Tamura in the Health Physics Division until the responsibility was assumed by John G. Moore of the Chemical Development Section of CTD in FY 1972. Programmatically the effort was part of the Geological Isolation Program headed by Bill McClain. Initial tasks consisted of mix design for disposing of a grouted sludge via hydrofracturing and a borehole plugging program in support of sealing boreholes and mine shafts for geologic repositories.

In early CY 1976 the group became part of the newly organized Office of Waste Isolation (OWI). After several weeks, CTD management decided that the group would return to CTD since OWI was a project management organization and did not want responsibility for development efforts within their organizational structure.

In December 1976 the group moved to Building 9204-3 at Y-12, expecting very rapid growth in support of the ever-enlarging OWI and became part of the Isotopes Section headed by Gene Newman. During this period, the group tasks were hydrofracture mix development, borehole plugging, and development of a FUETAP (fixed under elevated temperature and pressure) thermally treated waste form as a candidate for high-level waste disposal.

When the Isotopes Section was transferred to the Operations Division in the late 1970s, the group was transferred to the Experimental Engineering Section of CTD and moved to Building 3017 at the $\mathrm{X}-10$ site, where they remained until moving to Building K-1006 at the K-25 site in mid-1985.

In mid-summer 1981 the first injection was made with the new Hydrofracture Facility (NHF). Support was provided for the two-year effort to dispose of all the sludge in the gunite tanks in the South Tank Farm. This effort was officially completed in FY 1984.

Grout Technologies. Beginning in FY 1982, support was provided to Rockwell Hanford Operations to provide cement-based waste form development technology for disposal of liquid wastes stored in a large number of tanks at the Hanford Reservation in southeastern Washington. This effort continues to the present, led by Earl McDaniel.

Recent projects by this group have included technical support to in situ stabilization of shallow-land burial trenches, technical support to Y-12 and K-25 in grout formulation for immobilization of mixed organic-containing wastes, hydrofracture support, ORNL pond sediment stabilization study, MVST support, and studies of polymer impregnation of cement-based waste forms in CY 1986. In 1987 through mid-1988, the group worked on a transportable grout facility, solidification of MVST supernate, and evaluation of grouts under pressure (Fig. 4.71). Fiscal year 1989 projects included grout calorimetry, grout meter development, and in situ immobilization of volatile organic compounds. From 1990 to the present, the group has focused on providing Westinghouse Hanford Company with technical support to the Hanford Grout Technology Program and with technical support for the implementation of grouting technology as a remediation option for Fernald waste.

EDS Today. The Engineering Development Section today is a viable, dynamic organization, providing real-world solutions to everyday waste

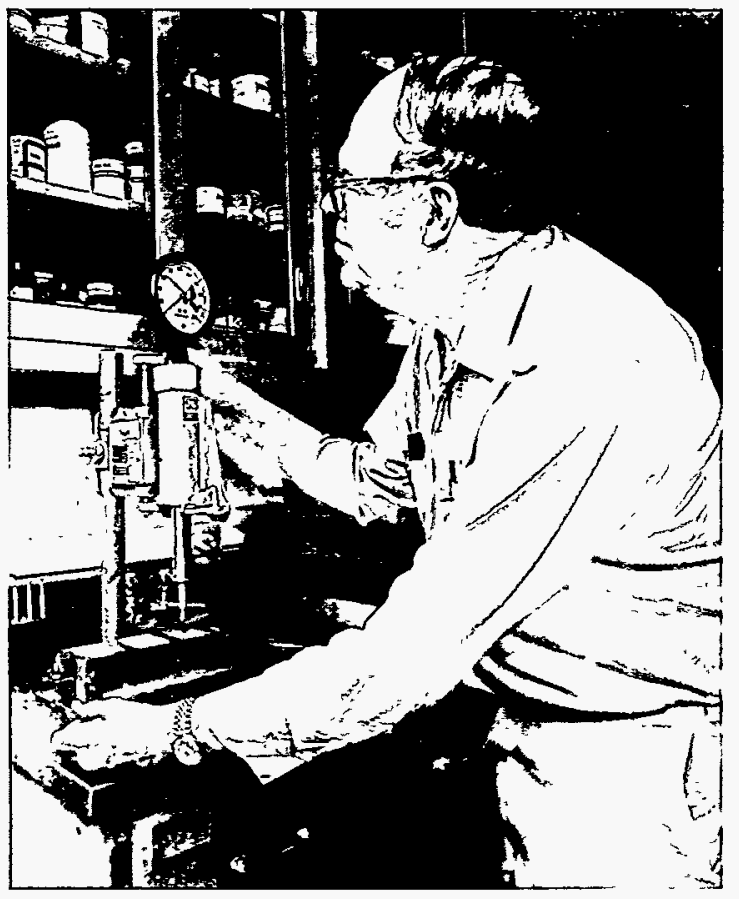

Fig. 4.71. Roy Lovelace measures penetration resistance of a grout sample. 
treatment problems while constantly striving through research to improve the environment by the application of advanced technology.

\subsection{IMPACT OF OAK RIDGE FACILITIES ON HIGHER EDUCATION, J. J. Perona}

The Oak Ridge facilities had an important influence on chemistry and chemical engineering education in the state of Tennessee. The expansion of undergraduate programs and the development of graduate-degree programs in chemistry and chemical engineering at The University of Tennessee, Knoxville (UTK), Vanderbilt, and Tennessee Technological University were strongly stimulated by the various activities and projects at Oak Ridge.

Many Chem Tech staff members were able to further their education by pursuing graduate courses on a part-time basis and, as a result, obtained masters and/or doctoral degrees. In most cases, they were able to complete the work for theses and dissertations as a part of their normal work assignments.

Through the years, too, a number of Chem Tech staff members have taught courses at The University of Tennessee, Knoxville, as adjunct professors. In addition, Chem Tech was a prime participant in the Ford Foundation program from 1963 to 1968. Tom Roberts, Marvin Whatley, and Joe Perona were the first three Chem Tech staff members to serve as part-time faculty for this program.

Perhaps the significant relationship between industry and education was best summarized by Dr. John Prados (Vice-President for Academic Affairs, Emeritus, UTK) in a paper, entitled "Chemical Engineering Education in Tennessee," that he presented at the 13th Annual WATTec Conference and Exhibition in 1986:

The coming of World War II temporarily slowed development of the fledgling chemical engineering programs at The University of Tennessee and Vanderbilt but provided a source of profound influence on both of these programs, as well as that to be developed in a few years at the Tennessee Technological University.... The Oak Ridge facilities, operated first by the Du Pont and Monsanto companies and then for many years by the Union Carbide Corporation (initially as the
Carbide and Carbon Chemicals Corporation), employed large numbers of chemical engineers in research, development, and production operations involving uranium enrichment, nuclear fuel fabrication and reprocessing, radioactive waste disposal, and a host of related areas. These activities provided:

1. A job market for significant numbers of chemical engineering graduates, including those with masters and doctoral degrees.

2. Opportunities for consulting and summer research work for chemical engineering faculty members.

3. A source of contract research support for chemical engineering faculty and graduate students.

4. A supply of well-qualified adjunct faculty. In the early 1960s, under Ford Foundation sponsorship, a number of Oak Ridge scientific and engineering staff members received regular part-time faculty appointments in appropriate departments at The University of Tennessee, including chemical engineering. One of these was Dr. J. J. Perona, who later joined the chemical engineering faculty full-time and in 1984 became the third individual to head The University of Tennessee's Chemical Engineering Department in its history.

5. A source of part-time graduate students that could take evening, early-morning, or Saturday courses on the Knoxville campus and in Oak Ridge. Some of these could carry out thesis or dissertation projects as part of their Oak Ridge employment, and a few were able to obtain leave from their employer to engage in one- to two-year periods of full-time study on the University campus.

The establishment of the Oak Ridge operations, along with the general post-War development of the U.S. chemical industry, increased the demand for chemical engineering graduates with advanced degrees: In 1949 The University of Tennessee College of Engineering proposed to the Graduate School the establishment of a Ph.D. program in chemical engineering and in metallurgy. The proposal was approved by the University's 
Board of Trustees in 1952, and in that same year, Frank S. Chance received the Ph.D. with a major in chemical engineering, the first doctoral degree in engineering conferred in the state of Tennessee. Dr. Chance was employed by the Pfizer Corporation for a number of years and is now retired. It also worth noting that the first $\mathrm{Ph}$.D. degree awarded by The University of Tennessee at the Knoxville campus in the 20th century was in chemistry in 1949 to John F. Fuzek, who had received a B.S. degree in chemical engineering from the University in 1943 and ... has recently retired from his position as a research chemist with the Tennessee Eastman Corporation in Kingsport, Tennessee.

\subsection{A BRIEF HISTORY OF THE ISOTOPE RESEARCH MATERIALS LABORATORY, Kermit B. Campbell}

I came to the Oak Ridge National Laboratory (ORNL) in January 1950 and was assigned to the Chemical Separations Department of the Operations Division, which was under the direction of Logan B. Emlet. I worked in both the Chemical Separations and the Isotope Development departments until 1955, when I was drafted into the army and served as a petroleum chemist performing analyses of petroleum products for the military facilities in Alaska.

On completion of my military service in 1957, I returned to ORNL to find that the Isotopes Division had been formed. When I was given a choice of being a member of that division or of the Operations Division, I opted to join the Isotopes Division. A new function of making target samples for particle accelerators had been conceived and funded; therefore, I joined James $\mathrm{C}$. Smith and Byron J. Massey (Group Leader) in the development of techniques applicable for target preparations.

It is appropriate to provide some definition of "target." Generally, a target is a mass of very high-purity material (usually in elemental form) on which the researcher subsequently impinges subatomic particles for the purpose of studying nuclear reactions, scattering phenomena, reaction cross sections, and many other nuclear measurements. For the target to be useful, it must be designed for a specific study and can vary from a total "thickness" of a few atoms to grams of an isotope per square centimeter. The challenge was, and continues to be, the preparation of such samples. Techniques of vacuum evaporation, high-purity metals preparation, mechanical rolling of ultrathin foils, electrodeposition of isotopes, and a myriad of other methodologies were developed for these purposes.

In 1961 the Target Preparations Group was officially formed; at that time, John Gillette was director of the Isotopes Division and Eugene Lamb was the assistant director. Direction of the group was given to Edward Kobisk, and in the next few years the scope of the target preparations function was expanded significantly. Targets of separated stable and radioactive isotopes were being prepared from materials originating from calutron operations at the Y-12 Plant and from chemical separations at ORNL.

The Target Group grew rapidly to as many as 25 individuals from a wide spectrum of scientific disciplines. In addition, many craft support people were needed to design and construct the innovative hardware required to produce the samples described above. Initially, the motivation for the Target Group was to provide local researchers (ORNL) with usable samples; however, by 1964 , samples were being prepared, by order and for sale, for studies throughout the Free World.

In 1971 ORNL sponsored and hosted an international meeting of target preparers and consumers in Gatlinburg, Tennessee. This meeting was such a success that within a year of the Gatlinburg session a new technical society, called the International Nuclear Target Development Society (INTDS), was formed. To this date, it continues to be a viable and important information-transfer medium for all countries of the world. Every other year, the INTDS holds an international conference (at least two have been sponsored and hosted by ORNL) where technical papers authored by world experts in target technology are presented on a variety of applications. E. H. Kobisk (see Fig. 4.72) was president of this organization for three years, until his retirement in 1981.

In 1975 John Gillette announced that the Isotopes Division was being disbanded and would be absorbed into various other divisions at ORNL. On July 1, 1975, the Isotope Research Materials Laboratory (IRML) was absorbed by the Solid State Division under the direction of Michael K. Wilkinson. After six years in this 


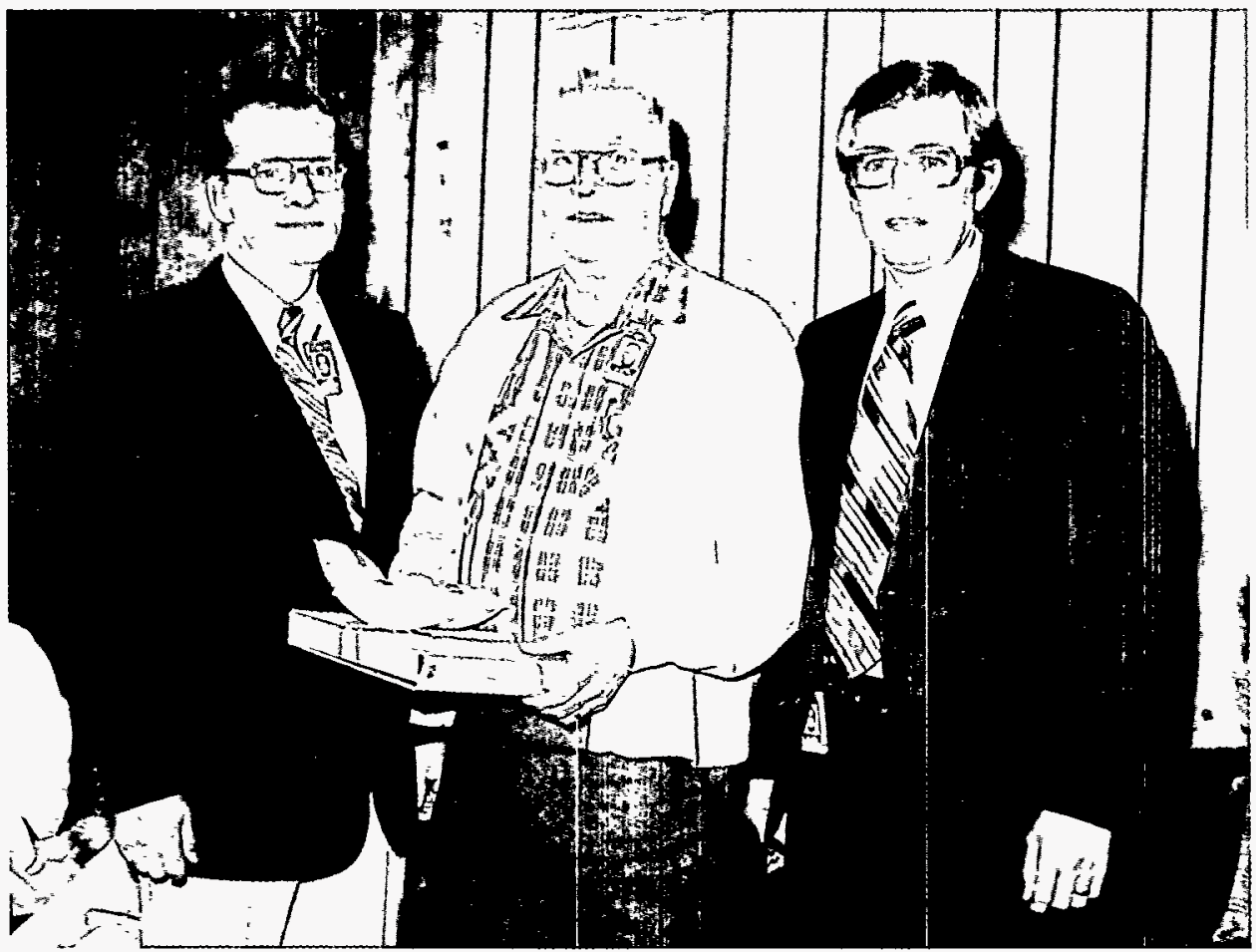

Fig. 4.72. Edward Kobisk (left) and Harold Adair (right) congratulating Bill Early on the occasion of his retirement party.

division, the group was transferred to the Operations Division under the direction of James A. Cox. Mr. Cox soon retired, and Jerry Swanks became the division director. Figure 4.73 shows former IRML staff members.

After Kobisk's retirement, Harold Adair (see Fig. 4.72) took the reins of IRML and managed the group until 1985, when he was promoted to higher management. His successor was Scott Aaron. In the spring of 1988 IRML, as part of the Operations Division, was merged with Chem Tech under Richard Genung as director. J. T. Bell was the section head responsible for IRML for about one year and was succeeded by Emory Collins. During these periods of organizational flux, Scott Aaron continued to lead the group until 1990 when IRML was essentially disbanded. Some members were transferred to the calutron operations at the Y-12 Plant (still an ORNL function), while a small group was maintained to continue target preparation on a very limited scale.

Equipment unique to IRML and stable-isotope target preparations has since been moved physically to the Y-12 Plant (Building 9204-3), and continued efforts are being made to revive this important function. Most of the radioactive operations have ceased, and the associated equipment has been dismantled with subsequent disposal. There is still a great demand for IRML products by scientists worldwide, including those in the United States.

It is interesting that many actinide metal and compound research materials were fabricated during the last 15 years of IRML operations. These included samples of uranium, plutonium, americium, curium, and californium isotopes containing microgram quantities to multigram amounts, mostly in the form of pure metals or alloys as required by the customer's specification. Much larger quantities (kilogram amounts) of many of the more abundant actinides such as ${ }^{235} \mathrm{U}$, ${ }^{238} \mathrm{U}$, and ${ }^{232} \mathrm{Th}$ were also fabricated into customer research forms. Physical forms of these metals included rolled foils, castings, and evaporated or sputtered films. One unique example. of IRML capability was the formation of promethium-doped crystals that exhibited laser activity at both 933 and $1100 \mathrm{~nm}$. (Such crystals were needed for communication experiments through seawater.)

A few of the more exotic samples produced over the years are described here. Fifty-two high-energy neutron reaction experiment (HENRE) targets were produced by the evaporation of erbium metal onto copper substrates weighing 


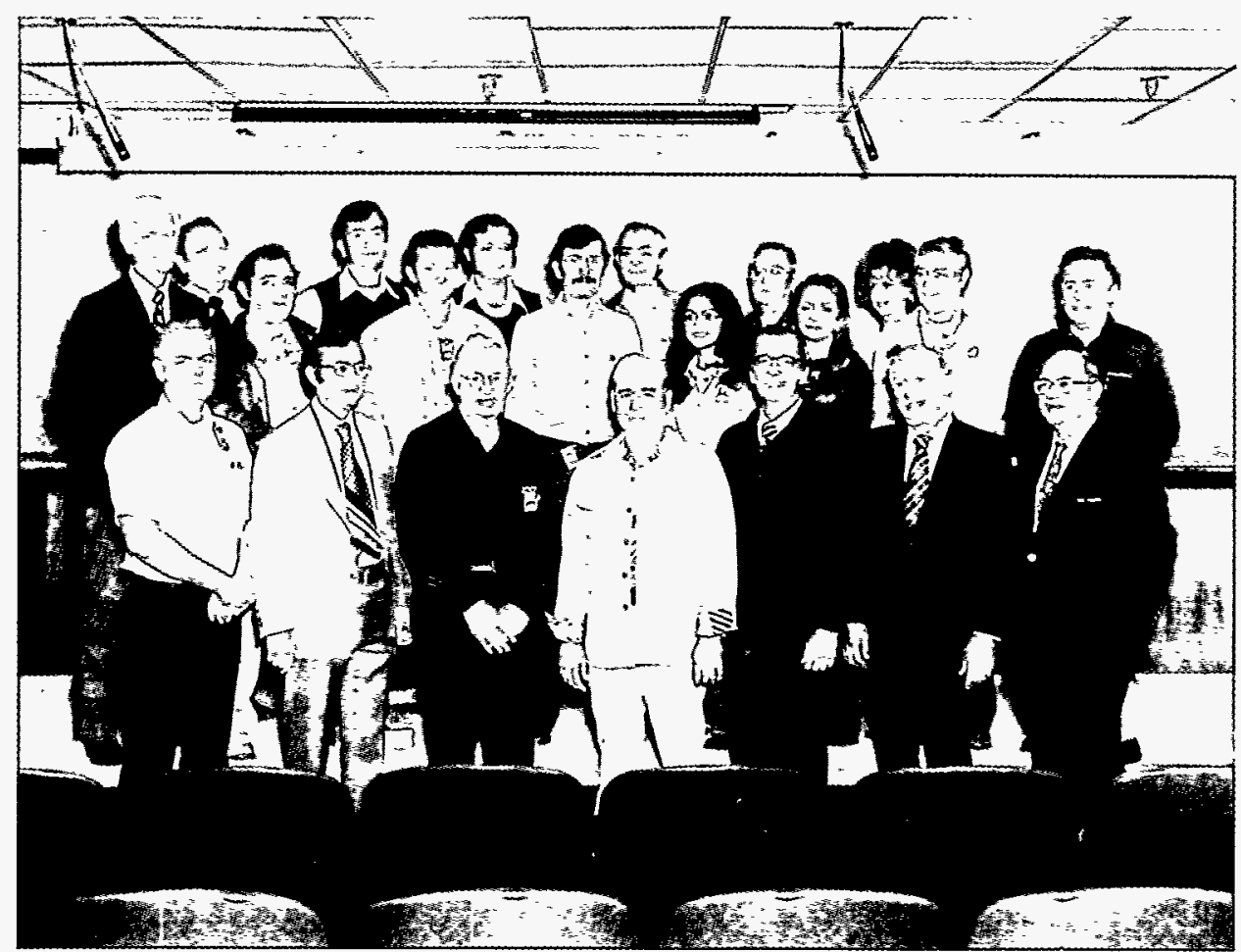

Fig. 4.73. Former members of IRML groups. Front row (left to right): H. E. Harmon, Harold Adair, Paul Kuehn, J. M. Dailey, Edward Kobisk, Mansel Ramsey, and Art Rupp. Back row (left to right): Gene Lamb, Mike Wilkinson, Bob Byrum, Jim Gibson, Tom Quinby, Dan Ramey, Scott Aaron, Bill Grisham, Joann Ramey, Bill Early, Sharon Nelson, Ann Caylor, Charlie Culpepper, and Kermit Campbell.

approximately $23 \mathrm{~kg}$ and containing water cooling channels. The erbium metal layer was subsequently "loaded" with tritium by adsorption. The target, under bombardment by accelerated deuterium ions, generated average yields of $10^{13}$ neutrons/s for a period of $4 \mathrm{~h}$ or more.

Samples were prepared for Sky Lab experiments, including those used to study self-diffusion of zinc metal in space. IRML staff members produced both the ion source material and the thin-film accelerator targets used by a German research team in 1985 for high-resolution measurements involving the synthesis of the heaviest known element, element-109. Medical research samples and other materials were produced for nonnuclear programs over the years.

Finally, one of the most significant developments was the preparation of ceramic wire fabricated to contain a wide variety of stable and/or radioactive isotopes for use in neutron dosimetry. These materials allowed physicists to map reactor core neutron flux and other reactor characteristics. The group involved in this development received an IR-100 Award in 1976.
All members of the IRML were pleased to have played a significant part in the scientific achievements of this group and in gaining its world recognition as the foremost target sample preparation source.

\subsection{JOHN M. CHANDLER, July 11, 1993}

I joined the Chem Tech Pilot Plant in September 1951 as head of the Data Section. At this time, the pilot plant personnel were completing installation and testing of the equipment for the Plutonium-uranium recovery by solvent extraction (Purex) process development tasks that followed.

Purex Pilot Plant. As you know, the Purex process has been used at Hanford, Savannah River, and throughout the world to separate, purify, and isolate uranium and plutonium from each other and from fission products generated in spent irradiated nuclear fuel.

The ORNL Pilot Plant successfully demonstrated the Purex process and, in doing so, provided valuable chemical flowsheet and equipment design information for startup of the 
Purex plants at Hanford and Savannah River. These development and demonstration runs served as a training ground for the Savannah River Plant employees who participated in the ORNL Pilot Plant operations.

H. Kirk Jackson was section chief of the pilot plant, having replaced Don Reid in that position in 1951. Under Jackson's direction, the operations were managed by Ray H. Winget, and D. O. Darby provided chemical flowsheet instructions and conditions for the pilot plant demonstrations. The final analyses of the results of these efforts are reported in the Purex Manual (classified), which was prepared by D. O. Darby and me.

Figure 4.74 shows the pilot plant personnel present in 1957. H. K. Jackson and I had transferred to Union Carbide's Colorado Uranium Milling and Mining Operations in January 1957 and were not present. The people listed are those who participated in the pilot plant demonstrations of the Purex and Thorex processes.

A measure of the success of the ORNL Pilot Plant is evidenced by the performance of the two production installations, Hanford and Savannah River.

Metal Recovery Plant. The ORNL Metal Recovery Plant was completed in 1950 and served as a large-scale (throughput, 0.5 ton metal per day) spent nuclear fuel reprocessing plant.

Ton quantities of $238 \mathrm{U}$ and kilogram quantities of ${ }^{239} \mathrm{U}$ were recovered, purified, and returned to production channels beginning in 1951 and continuing to 1960 .

Spent irradiated fuel from the Chalk River NRX Reactor, Brookhaven National Laboratory Reactor, ORNL Graphite Reactor, and Clementine Reactor (using plutonium fuel), uranium and plutonium scrap from metal reduction operations, and uranium from ORNL waste tanks were processed to recover metal values.

During one campaign, gram amounts of ${ }^{241} \mathrm{Am}$ were isolated, purified, and channeled to the Chem Tech research group. The Metal Recovery Plant was often visited by outsiders interested in large-scale operation of the Purex process. Russian and French scientists toured the plant in 1956 and were shown the techniques we used to isolated plutonium. Later, the French began producing weapons-grade plutonium.

Metal Recovery Plant personnel included W. H. Lewis, John M. Chandler, R. E. Brooksbank, J. L. Matherne, C. D. Hylton, G. D. Davis, D. E. Spangler, J. F. Lockmiller, D. G. Summers, and Vernon Mead.

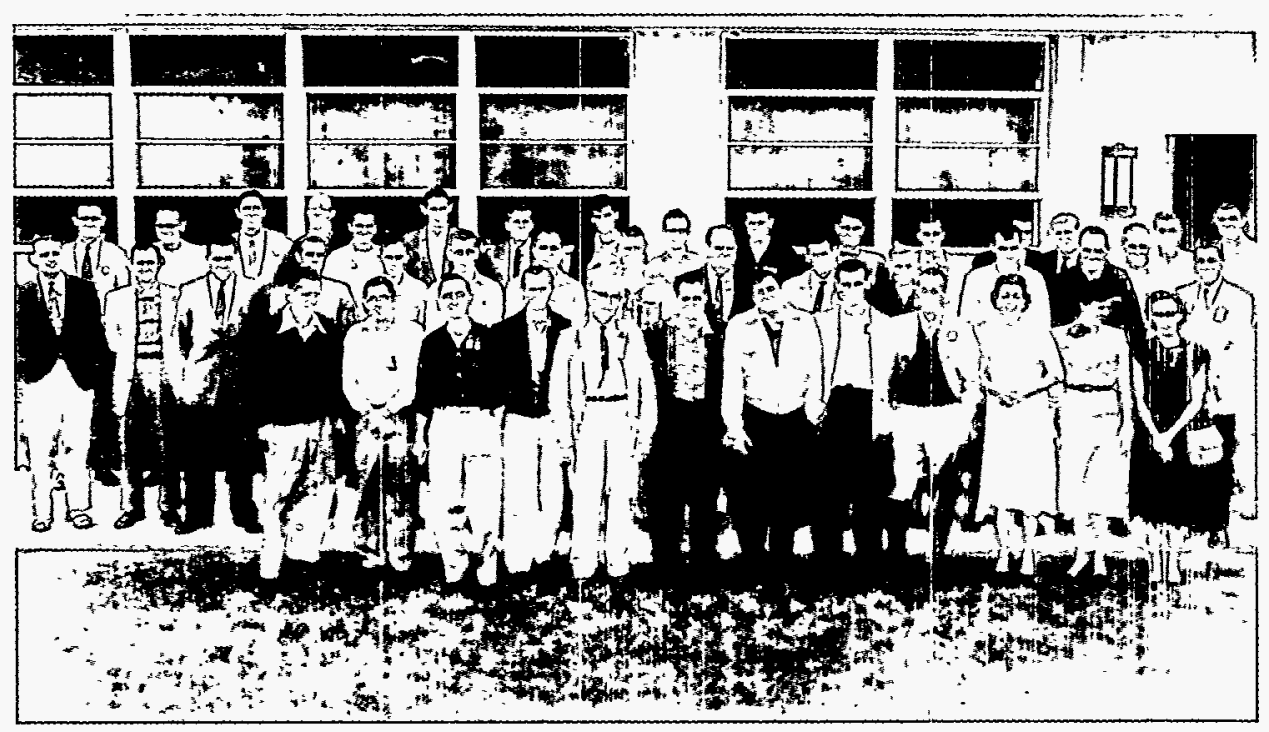

Fig. 4.74. Pilot plant personnel in 1957. 
Thorium-Uranium Recycle Facility. The Thorium-Uranium Recycle Facility (TURF), which is located in ORNL Building 7930, was constructed in the late 1960s by the Blount Construction Company using architectural drawings prepared by Giffels and Rosette under the direction of A. R. Irvine, with my help (later in 1964). Both the facility and the equipment underwent functional testing and startup in late 1960 , under the guidance of J. W. Anderson, Paul Jarvis, John M. Chandler (facility manager), and S. E. Bolt.

TURF was the focal point of the HTGR fuel cycle development and demonstration work, with collaborative efforts in solvent extraction work being conducted in the Thorium Recovery by Solvent Extraction (Thorex) Pilot Plant in Building 3019.

In 1968 TURF was equipped with a process to prepare the ${ }^{233} \mathrm{U}$ fuel for the Molten Salt Reactor Experiment (MSRE). Jim Shaffner, at the Y-12 Plant, developed a chemical flowsheet for preparing the MSRE reactor fuel, a ${ }^{233} \mathrm{UF}_{4}-\mathrm{LiF}$ eutectic mixture. The process equipment was designed by E. L. Nicholson and W. F. Shaffer. The ${ }^{233} \mathrm{U}$ oxide feedstock was obtained from the storage holes atop cell 4 in Building 3019. The ${ }^{233} \mathrm{UO}_{2}$ contained $250 \mathrm{ppm}$ of ${ }^{232} \mathrm{U}$ in the ${ }^{233} \mathrm{U}$, and a $1-1 \mathrm{~b}$ can of the oxide measured $250 \mathrm{rem} / \mathrm{h}$ at contact. This exposure dose-rate level of gamma radiation made it necessary to handle the conversion to $\mathrm{UF}_{4}-\mathrm{LiF}$ eutectic salt using the remotely operated manipulators and biological shielding provided in cell G of TURF. Thirty-three kilograms of ${ }^{233} \mathrm{U}$ were converted to the $\mathrm{UF}_{4}-\mathrm{LiF}$ salt. Most of this ${ }^{233} \mathrm{U}$ fuel remains in the MSRE reactor dump tanks (1993).

There were also other programs being carried out in Building 3019. These included:

1. Production of ${ }^{233} \mathrm{UO}_{2}$ for the Shippingport Reactor.

2. Production of $\mathrm{UO}_{2}$ from the Consolidated Edison uranyl nitrate hexahydrate stored outside Building 3019 for years. This was a ${ }^{233} \mathrm{U}_{-}{ }^{235} \mathrm{U}$ mixture that had been recovered at Nuclear Fuel Services, Inc., and shipped to ORNL. Jim Snider worked on the design, and John Parrott and co-workers worked on solvent extraction and oxide preparation in Building 3019.

3. Other requests for ${ }^{233} U$ as oxide or nitrate solution.
Liquid Metal Fast Breeder Program. The Liquid Metal Fast Breeder Program grew from a small group ( $\$ 200,000 /$ year budget) in 1974 under the direction of W. E. Unger to a full nationwide effort that relocated to the Experimental Gas-Cooled Reactor (EGCR) site east of the main ORNL campus. Eight people staffed the original group: W. E. Unger (section head), May Pepper, E. L. Nicholson, A. R. Irvine, W. G. Stockdale, J. M. Chandler (facility manager), F. L. Peishel, O. O. Yarbro, W. F. Schaffer, and D. E. Dunning. Later, W. D. Burch joined the LMRBR group as director, and the group split off from Chem Tech to become the Fuel Recycle Section of the Consolidated Fuel Reprocessing Program.

The following is a record of the events beginning in early 1974 when the abandoned (about 1964) EGCR became the birthplace of the present Robotics and Process Systems Division (previously the Fuel Recycle Division). The history of the Robotics and Process Systems Division (Fuel Recycle Division) was published in September 1992 by ORNL.

A search was made for a home for the (then) Liquid Metal Fast Breeder Reactor group of the Chem Tech Design Section. The EGCR site was selected over space in ORNL Building 4501 and space in a Y-12 building where mercury had been used in the process. The EGCR site provided, at less cost, space for expansion and space for the installation of experimental and process development equipment.

Initial and Early Operations at the EGCR Site. On July 16, 1974, a list of 24 items to be completed prior to the beneficial occupation of the site by Chem Tech was provided to Carl Fox, of the Plant and Equipment Division. This list included items such as sanitary system refurbishment and washing the building walls. The estimated cost was 300 to 500 man-hours $(\$ 37,500$ to $\$ 62,500$ ) plus $\$ 75,000$ for materials. A major portion of the cost was $\$ 25,000$ for a sanitary system drainage field. This "quick and dirty" cost was met. Craft support for refurbishing and maintenance activities was provided by the Plant and Equipment (P\&E) Division. Jim Trout and Tom Jerigan were craft foremen, and Gene Roy was area engineer.

Fourteen divisions at ORNL, as well as AEC, had eyed the EGCR site for possible occupancy at cost estimates in the millions of dollars. A neutron multiplication counter was installed in the basement of the Reactor Building in 1971 and 
operated by Ray Stoughton and Joe Halperin until about 1977.

Various groups used the EGCR site buildings for storage of items such as LMFBR (site) core samples, a waste evaporator, and liquid metals. The LME sodium heat exchanger had been in storage since 1966, and two anti-aircraft guns were stored in the fuel storage canal. Figure 4.75 shows material being stored in the Reactor Turbine Building in 1974. All these items were disposed of during site cleanup operations.

In September 1974, W. E. Unger (Chem Tech) made a formal request to $\mathrm{AEC}$ for the use of the entire 7600 site for a period of 5 years. The Reactor Service Building was shared for a short period, in 1974, with the equipment for the thermal shock-crack propagation experiment. It was soon decided that their use of methyl alcohol was not compatible with human occupancy of adjacent work areas; therefore, we gained use of the entire EGCR facility.

Soon after the initial cadre arrived and occupied a few clean, but ill-equipped, offices on the south side of the second floor of the Main Control Building (7601), a few more people from Chem Tech, including W. D. (Bill) Burch (Director), Marvin Whatley, John Blomeke, Clyde Watson,
Bradley Weil, Dick Craven, Bill Groenier, and W. F. Schaffer, joined us. John Evans and L. C. Hensley, of the ORNL Engineering Division, established a "second home" at the site to help with engineering projects. The initial LMFBR team was completed in 1976 by the addition of the "Idaho Gang," including Mel Feldman, John White, Howard Harvey, Norbert Grant, and Don Hampson. Dick Philippone served as DOE Site Representative. A drafting room was staffed by George Ford, Joe Kidd, and Al Gregory from the ORNL Engineering Division.

I do want to mention several young engineers who joined us in the late 1970s: Joe Herndon, Ben E. Lewis, R. T. Jubin, Barry Spencer, and Mike Kugan. These men gained experience and knowledge of the nuclear fuel cycle over the years. I believe that they served as the connecting link between the fuel cycle technology of the 1950s, the present, and the future, when nuclear-powered energy sources may be utilized again in the United States.

Technical accomplishment would not have been possible without the services of technicians who did the hands-on work. Again, at the risk of leaving out important people, I pay tribute to the initial staff members: W. T. (Bill) Bostic,

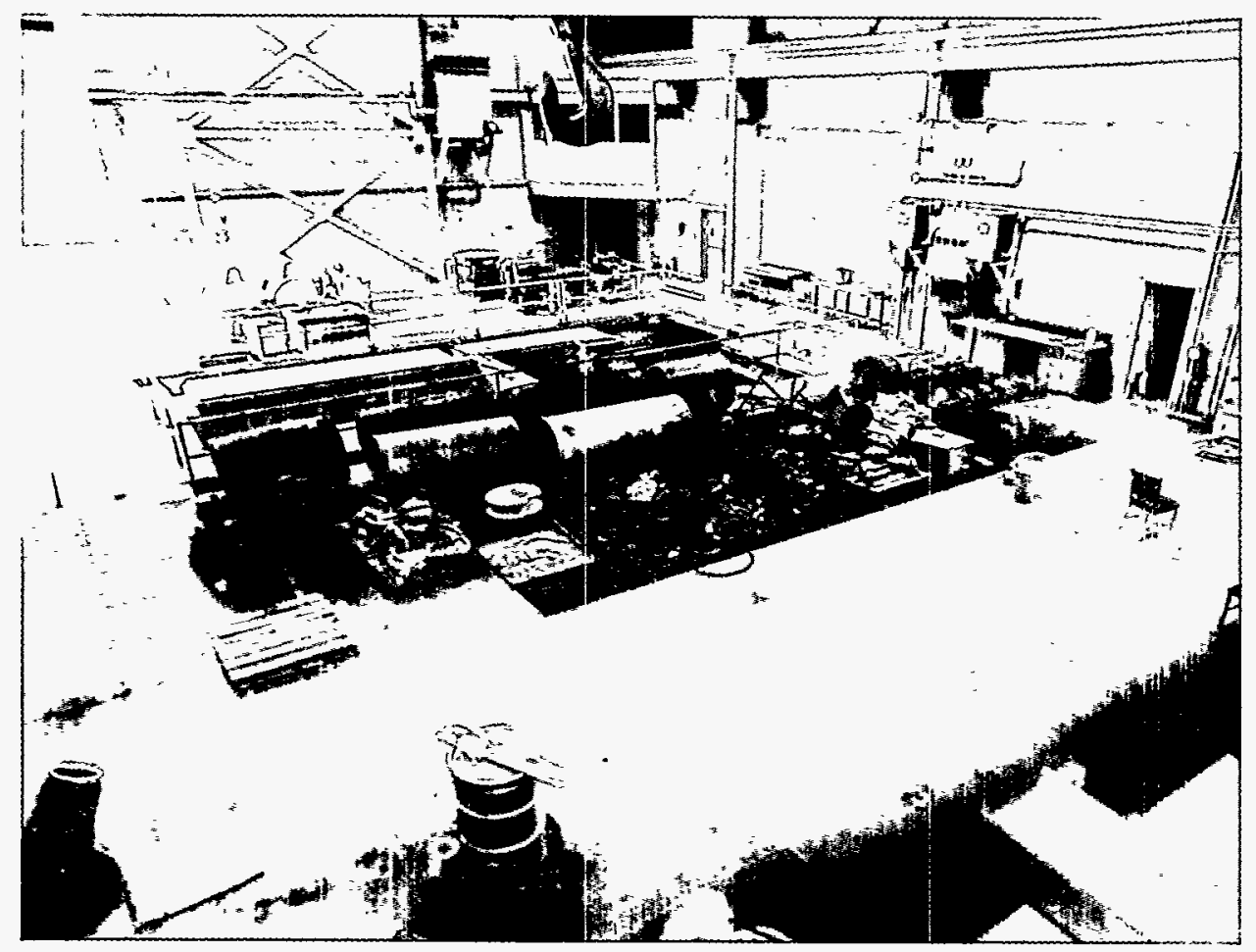

Fig. 4.75. Material stored in the Reactor Turbine Building in 1974. 
R. J. Shannon, Arnold Beets, E. R. Johns, Dan Kington, D. E. Spangler, Curtis Metz, Lee E. Thompson, J. F. Lockmiller, John Randolph, S. A. Richardson, Troy R. Trotter, Mark E. Baldwin, L. W. Byrd, and S. L. Rich.

The management activities of the Fuel Recycle Division/Robotics and Process Systems Division under Bill Burch, Sam Meacham, and Joe Herndon (1993) are covered in the history of the Robotics and Process Systems Division (Fuel Recycle Division).

If credits to important people and important projects conducted at the EGCR site between 1974 and 1980, when I departed, have unintentionally been omitted, I apologize. Some of these people and projects are mentioned in the RPSD/FRD history. They include the centrifugal contactor work; Integrated Equipment Test (IET) facility, which was conceptualized in 1976 and operated in the mid-1980s; and the Remote Control Engineering (RCE) activities, which began in 1976 under W. R. Hamel with D. E. Spangler. This RCE effort is the origin of the existing Robotics and Process Systems Division. The IET and its counterpart, the Remote Operations and Maintenance Demonstration Project (ROMD), were the outgrowth of a $\$ 16$ million line-item construction project, the Integrated Prototype Equipment Test (IPET).

The IPET (conceptualized in 1975 by W. F. Schaffer and me, with help from L. C. Hensley and John Evans, of the Engineering Division) was based on experience at the TURF, using television viewing and electromechanical manipulators to conduct in-cell operations and also from information obtained during visits to remotely viewed operations at General Motors in Detroit, Michigan, and AEC installations at Wesson, Illinois, and Idaho Falls, Idaho.

Our first operations efforts after getting some office space cleared and freeing the EGCR site from snakes, varmints, and rodents were to provide the support systems necessary to operate major research and development projects, using radioactive materials and toxic chemicals. No fission product radioactivity was allowed on site. A retention basin to collect and contain oil spills was first on the list. Process support systems such as off-gas handling, treatment, and discharge were next - followed by reagent storage tanks for caustic and demineralized water, a steam boiler, waste collection and disposal tanks and vehicles, an overhead crane system, a lunch room, an analytical laboratory, and a drafting room. Showers and convenience facilities were provided for male and female crafts and technicians.

As funding became available after the first "lean year," facility cleanup and renovation were initiated with current-year operating funds and unused operating funds remaining at the year's end in other Chem Tech projects. Miles of wire and cable trays were removed from the reactor control room area and from the massive cable-splicing network in the basement area under the control room. These areas became office space later. The areas cleared of reactor support equipment and services included: Main Control Room; Service Machine Room; Charging Machine Room; 13.8-kV Switchgear Room; Motor Control Centers 1, 2, and 3; Fuel Storage Room; the Electrical Shop; and the Turbine Building. Total expenditures for the cleanup and renovation operations between 1974 and 1980 were about $\$ 3$ million. This gave us a well-equipped development center and adequate office space.

The first piece of experimental equipment installed at the EGCR site was the 1/4-scale dissolver shown in Fig. 4.76. Later, a 200-ton Birdboro shear and support equipment and a safety enclosure were added as shown in Fig. 4.77. These items were installed in the former Reactor Turbine Building. An alligator shear installation, which was added later, is also shown.

The basement area of the Turbine Building housed massive 3-ft-diam cooling-water piping that connected pumps for bringing in water from and discharging it to Melton Hill Lake. These services and large floor trenches were home for varmints and snakes that had to be exterminated before people would work in the area.

A gantry crane was installed to provide needed headspace for lifting in the Turbine Building and preparatory to ROMD installation. This operation required raising the roof $20 \mathrm{ft}$ and is shown in Fig. 4.78. Face-lifting of the outside surfaces of the building was accomplished in 1976. Views before and after painting and cleanup are shown in Figs. 4.79 and 4.80 , respectively.

Three years time elapsed from the start of cleanup until both office space and experimental equipment installation space in the basement area were available. By that time (1980), the staff had grown to about 100 people and the Fuel Recycle Division was in full operation.

One exciting experience in effecting the move to the EGCR site was that of the connecting road 




Fig. 4.76. The $1 / 4$-scale dissolver.

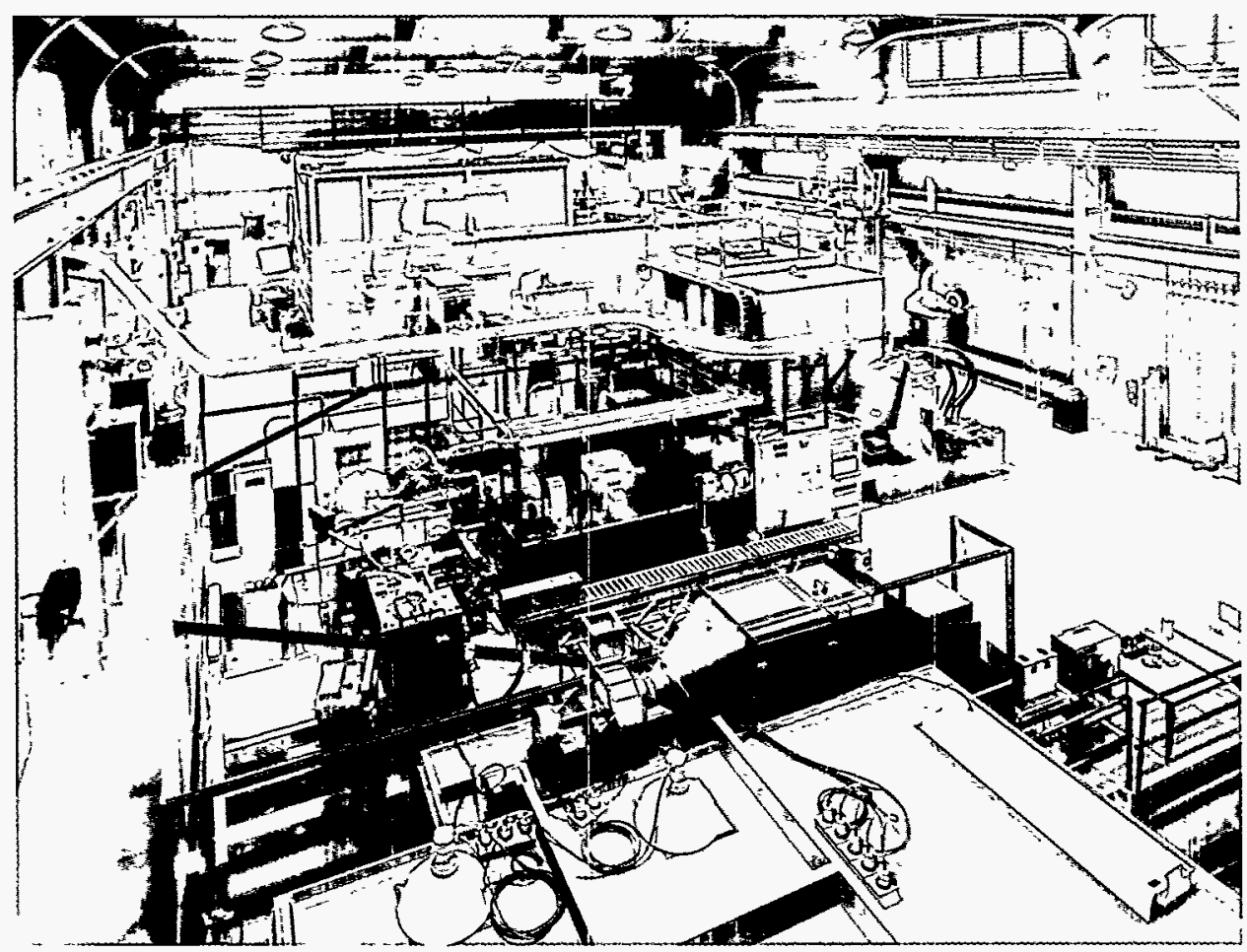

Fig. 4.77. A 200-ton Birdboro shear and support equipment shown inside a safety enclosure. 


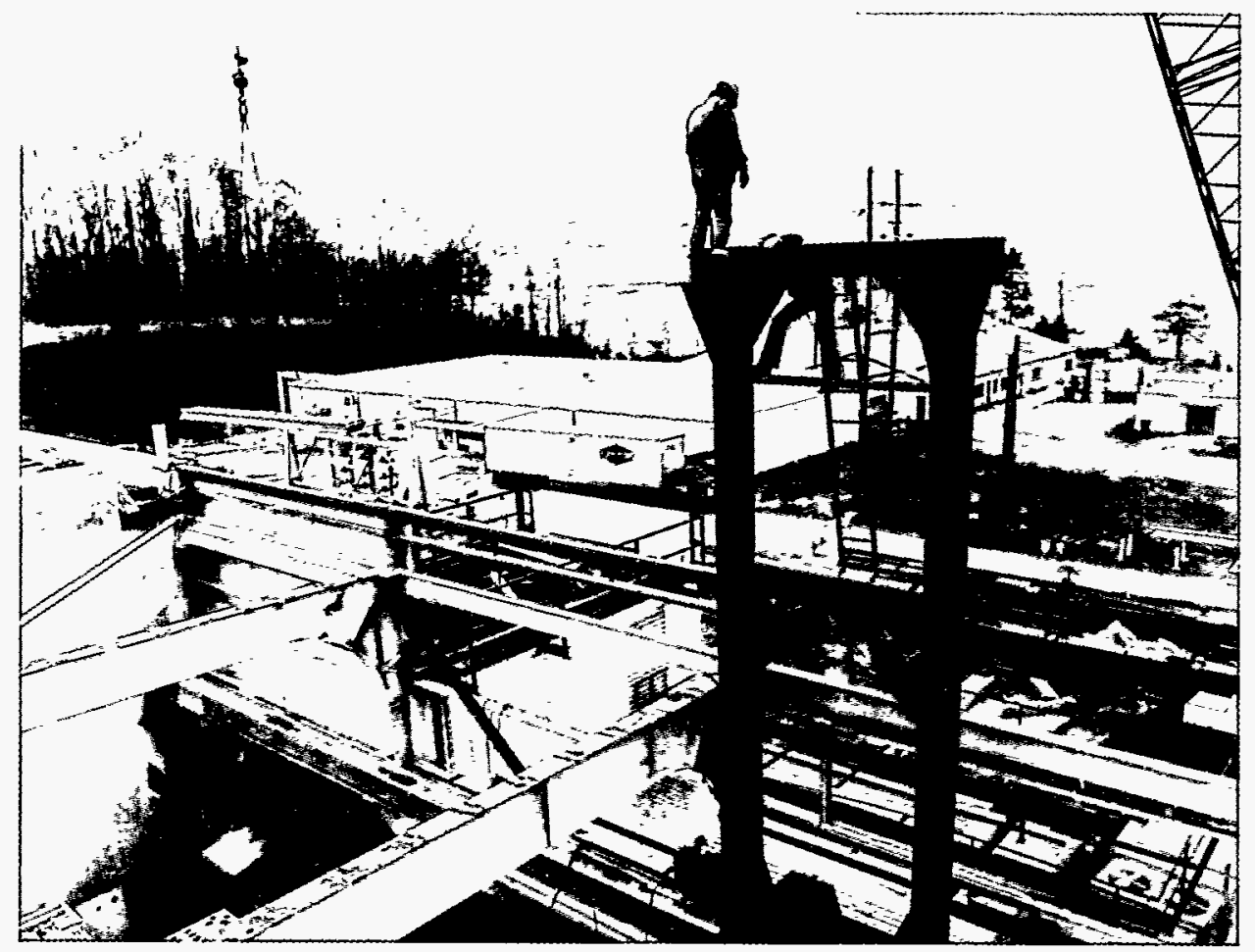

Fig. 4.78. Operation required to raise the roof of the Reactor Turbine Building $20 \mathrm{ft}$.

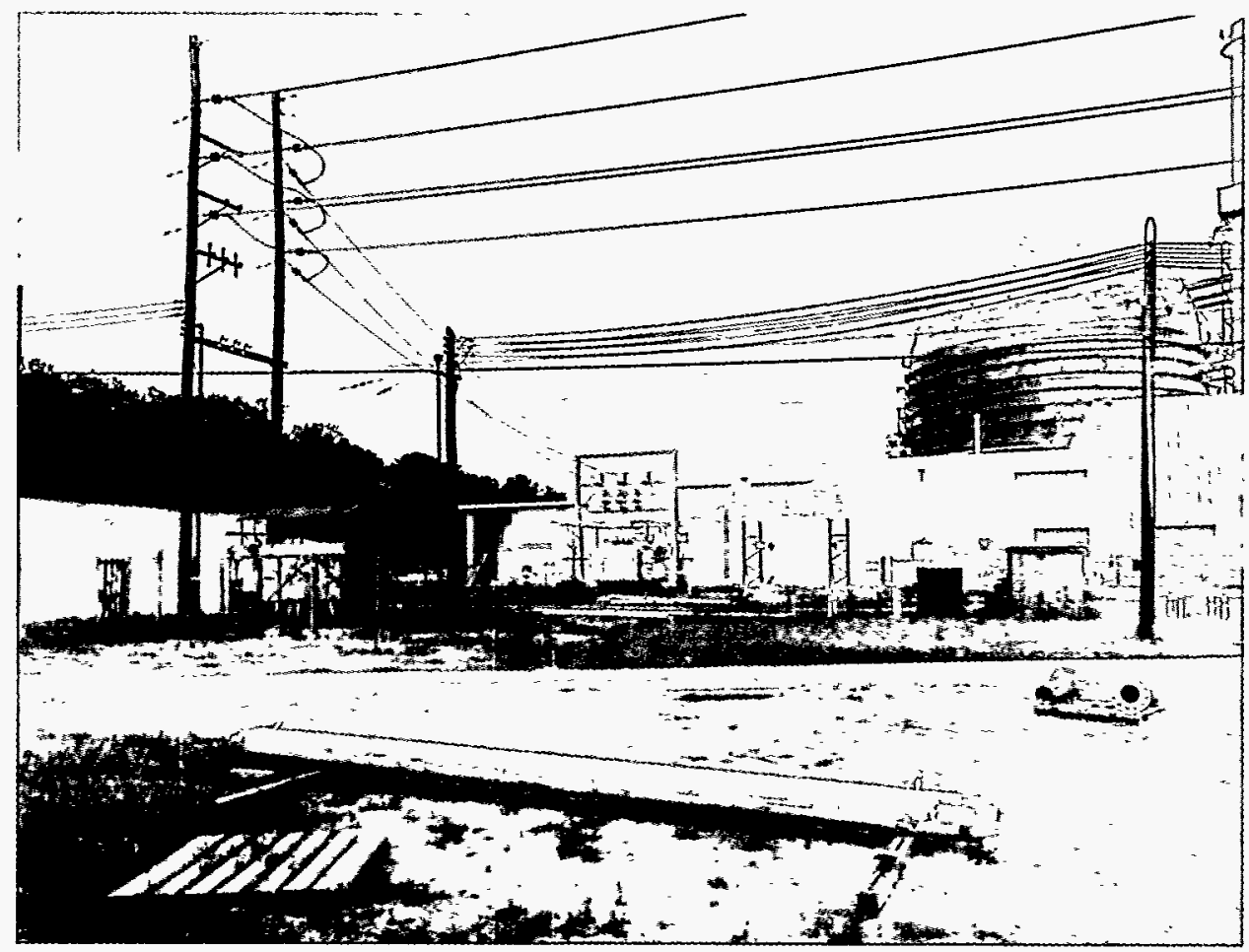

Fig. 4.79. View of Reactor Turbine Building before painting and cleanup. 


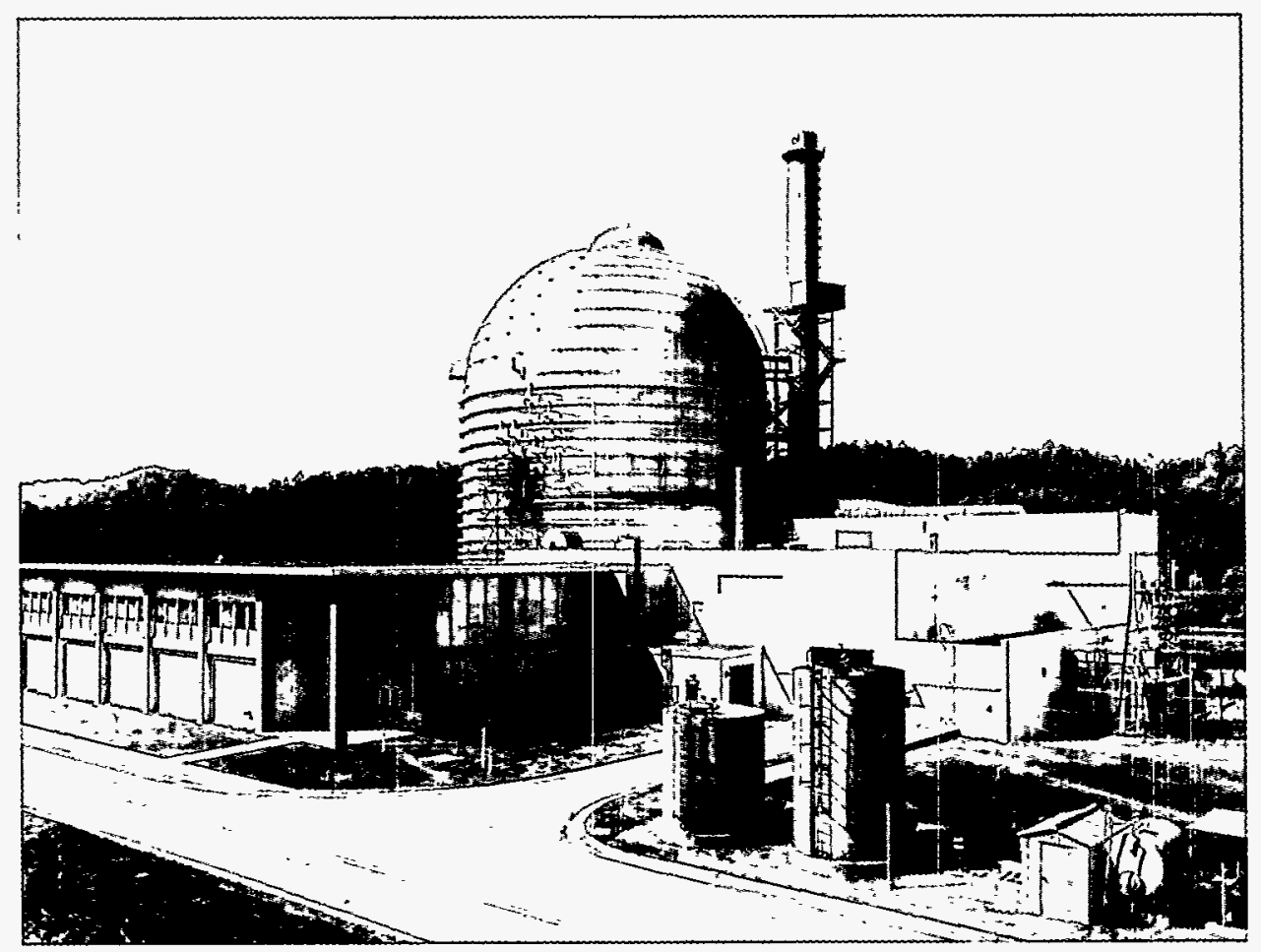

Fig. 4.80. View of Reactor Turbine Building after painting and cleanup.

named "Ramsey Boulevard" between the Melton Valley access road and the EGCR site. Carl Fox was the custodian, for P\&E Division and AEC, of the site and had received approval from Harry Segram to extend a dirt access road from Melton Valley access road to beyond a waste dump located east of the road. Fox also received permission from TVA to construct a "causeway" across a cove on Melton Hill Lake so that the maintenance access road could be extended to the EGCR site. That dirt road became known as Ramsey Boulevard. The causeway was called the John Chandler Memorial Causeway as the result of the commotion resulting from a complaint filed when a fisherman found his favorite fishing hole "dammed off." Mansel Ramsey handled the discussions with $\mathrm{AEC}$, and the maintenance access road eventually became the present scenic connecting road between ORNL proper and the EGCR site.

\subsection{REFERENCES}

1. Chemical Technology Division Annual Progress Report for Period Ending March 31, 1975, ORNL-5050.

2. J. W. Landry, Oak Ridge National Laboratory Sampler for the Tamalpais Underground
Nuclear Detonation Experiment, ORNL-2881 (June 30, 1960).

3. Chemical Technology Division Annual Progress Report for Period Ending May 31, 1964, ORNL-3627.

4. Chemical Technology Division Annual Progress Report for Period Ending May 31, 1966, ORNL-3945.

5. Chemical Technology Division Annual Progress Report for Period Ending May 31, 1967, ORNL-4145.

6. Chemical Technology Division Annual Progress Report for Period Ending May 31, 1965, ORNL-3830.

7. Chemical Technology Division Annual Progress Report for Period Ending May 31, 1970, ORNL-4572.

8. B. C. Finney, R. E. Blanco, R. C. Dahlman, G. S. Hill, F. G. Kitts, R. E. Moore, and J. P. Witherspoon, Correlation of Radioactive Waste Treatment Costs and the Environmental Impact of Waste Effluents in the Nuclear Fuel Cycle. Reprocessing Light-Water Reactor Fuel, ORNL/NUREG/TM-6 (January 1977).

9. J. P. McBride, R. E. Moore, J. P.'Witherspoon, and R. E. Blanco, Radiological Impact of 
Airborne Effluents of Coal and Nuclear Plants, ORNL-5315 (1978).

10. J. P. McBride, R. E. Moore, J. P. Witherspoon, and R. E. Blanco, "Radiological Impact of Airborne Effluents of Coal and Nuclear Plants," Science 202(4372), 1045-1050 (1978).

11. Chemical Technology Division Annual Progress Report for Period Ending May 31, 1969, ORNL-4422.

12. Siting of Fuel Reprocessing Plants and Waste Management Facilities, ORNL-4451 (July 1970).

13. Chemical Technology Division Annual Progress Report for Period Ending May 31, 1964, ORNL-3627.

14. Chemical Technology Division Semiannual Progress Report for Period Ending September 30, 1954, ORNL-1800.

15. Chemical Technology Division Semiannual Progress Report for Period Ending March 31 , 1955, ORNL-1881.

16. Chemical Technology Division Annual Progress Report for Period Ending August 31, 1960, ORNL-2993.

17. M. R. Bennett, G. I. Cathers, R. P. Milford, W. W. Pitt, Jr., and J. W. Ullmann, "Fused-Salt Fluoride-Volatility Process for Recovering Uranium from Spent Aluminum-Based Fuel Elements," I\&EC Process Design and Development, 4 (4), 387-394 (October 1965).

18. Chemical Technology Division Annual Progress Report for Period Ending May 31, 1964, ORNL-3627.

19. C. L. Whitmarsh and W. H. Carr, Fused Salt Fuel Processing in the ORNL Volatility Pilot Plant, ORNL-2918 (May 6, 1960).

20. W. H. Carr et al., Molten-Salt Fluoride Volatility Pilot Plant: Recovery of Enriched Uranium from Aluminum-Clad Fuel Elements, ORNL-4574.

21. Chemical Technology Division Annual Progress Report for Period Ending May 31, 1964, ORNL-3627.

22. J. M. Holmes et al., "Pot-Calcination Process for Converting Highly Radioactive Wastes to Solids," pp. 255-286 in Proceedings of Symposium on the Treatment and Storage of High-Level Radioactive Wastes, Vienna, October 8-13, 1962, IAEA, Vienna.

23. W. E. Clark and H. E. Godbee, "Fixation of Simulated Highly Radioactive Wastes in
Glassy Solids," pp. 411-39 in Proceedings of Symposium on the Treatment and Storage of High-Level Radioactive Wastes, Vienna, October 8-13. 1962, IAEA, Vienna.

24. C. W. Hancher et al., Engineering Studies on Pot Calcination for Ultimate Disposal of Nuclear Wastes from TBP-25, Darex, and Purex Processes, ORNL-3277 (Sept. 9, 1963).

25. R. E. Blanco et al., Status of the ORNL Potcal and Potglass Processes for the Conversion of Highly Radioactive Liquid Wastes to Solids, ORNL-TM-857 (May 8, 1964).

26. R. E. Brooksbank et al., Low-Radioactivity-Level Waste Treatment. Part II. Pilot Plant Demonstration of the Removal of Activity from Low-Level Process Waste by a Scavenging:Precipitation Ion-Exchange Process, ORNL-3349 (May 20, 1963).

27. R. R. Holcomb, Low Radioactivity-Level Waste Treatment. Part I. Laboratory Development of a Scavenging-Precipitation Ion-Exchange Process for Decontamination of Process Water Wastes, ORNL-3322 (July 10, 1963).

28. Waste Treatment and Disposal Quarterly Progress Report November 1963-January 1964, ORNL-TM-603.

29. Waste Treatment and Disposal Quarterly Progress Report May 1963-October 1963, ORNL-TM-757.

30. J. J. Perona et al., "Economic Evaluation of Tank Storage and Pot Calcination of Power-Reactor Fuel-Reprocessing Wastes," pp. 309-35 in Proceedings of Symposium on the Treatment and Storage of High-Level Radioactive Wastes, Vienna, October 8-13, 1962, IAEA, Vienna.

31. J. J. Perona et al., Comparative Costs for Final Disposal of Radioactive Solids in Concrete Vaults, Granite, and Salt Formation, ORNL-TM-664 (Oct. 23, 1963).

32. E. W. McDaniel and D. B. Delzer, "FUETAP Concrete," p. 565 in Radioactive Waste Forms for the Future, eds. W. Lutze and R. C. Ewing, Elsevier Science Publishers B.V., 1988.

33. History of Disposal of Radioactive Wastes into the Ground at Oak Ridge National Laboratory, ORNL/CF-82/202 (June 1982).

34. Chemical Technology Division Annual Progress Report for Period Ending May 31, 1971, ORNL-4682. 
35. Chemical Technology Division Annual Progress Report for Period Ending March 31, 1972, ORNL-4794.

36. Chemical Technology Division Progress Report for the Period April 1, 1985, to December 31, 1986, ORNL-6343.

37. Chemical Technology Division Progress Report for the Period July 1, 1988, to September 30 , 1989, ORNL-6596.

38. Annual Progress Report for the Period October 1, 1987, through September 30, 1988, ORNL-6557.

39. C. P. McGinnis, R. A. Jacobus, and L. H. Bell, "CESUP: A Large-Scale Conversion and Solidification of Highly Radioactive Liquid Waste," Nuclear and Chemical Waste Management 8, 115-121 (1988).

40. Chemical Technology Division Progress Report for the Period Ending May 31, 1965, ORNL-3830.

41. R. E. Brooksbank, Sr., Historical and Programmatic Overview of Building 3019 , ORNL/CF-91/298 (July 17, 1991).

42. J. E. Mrochek, W. R. Butts, W. T. Rainey, Jr., and C. A. Burtis, "Separation and Identification of Urinary Constituents by Use of a Multiple-Analytical Technique," Clin. Chem. 17, 72 (1971).

43. R. L. Jolley, Water Chlorination: Environmental Impact and Health Effects, Volume I, Ann Arbor Science Publishers, Inc., Ann Arbor, Michigan, 1978.

44. R. L. Jolley, H. Gorchev, and D. H. Hamilton, Water Chlorination: Environmental Impact and Health Effects, Volume 2, Ann Arbor Science Publishers, Inc., Ann Arbor, Michigan, 1978.
45. R. L. Jolley, W. A. Brungs, and R. B. Cumming, Water Chlorination: Environmental Impact and Health Effects, Volume 3, Ann Arbor Science Publishers, Inc., Ann Arbor, Michigan, 1980.

46. R. L. Jolley et al., Water Chlorination: Environmental Impact and Health Effects, Volume 4, Book 1 Chemistry and Water Treatment, Book 2 Environment, Health, and Risk, Ann Arbor Science Publishers, The Butterworth Group, Ann Arbor, Michigan, 1983.

47. R. L. Jolley et al., Water Chlorination: Chemistry, Environmental Impact, and Health Effects, Volume 5, Lewis Publishers, Inc., Chelsea, Michigan, 1985.

48. R. L. Jolley et al., Water Chlorination: Chemistry, Environmental Impact, and Health Effects, Volume 6, Lewis Publishers, Inc., Chelsea, Michigan, 1990.

49. E. Gaitan et al., "Goitrogens in Water," pp. 79-90 in The Thyroid Gland, Environment and Autoimmunity, ed. H. A. Drexhage et al. Elsevier Science Publishers, Biomedical Division, Amsterdam, 1990.

50. E. Gaitan, personal communication to R. L Jolley, 1985.

51. E. Gaitan et al., "The Problem of Goitrogenic Substances in the Presence of Sufficient Iodine Supplementation," pp. 76-84 in 2. Symposium interdisziplinare Probleme des Iodomangels, der Iodprophlaxe, des Iodexzesses und antithyreoidaler Substanzen, Sonderdruck, Berlin-Chemie Medizinisch-wissenschaftliche Beratung und Marktarbeit, 1989. 


\section{POTPOURRI: PERSONAL ANECDOTES, VIGNETTES, THE ST. PATRICK'S DAY DANCE, AND OTHER RECREATIONAL ACTIVITIES}

There is really a sense of satisfaction when a process we have something to do with is actually used.

David O. Campbell

Comments, 1992

Life is a theater.

Angel L. Rivera

Conversations, 1988

\subsection{MILES C. LEVERETT, SEPTEMBER 28, 1991}

One of the tasks for which I was responsible was the preparation of kilocurie quantities of carrier-free ${ }^{140} \mathrm{Ba}$. The source of the material was freshly irradiated uranium slugs, discharged from the air-cooled graphite reactor and transported immediately to Building 706D, which had been hurriedly built in a few weeks for just this purpose. Barium-140 (or, more precisely, its daughter ${ }^{140} \mathrm{La}$ ) was urgently and unexpectedly needed at Los Alamos for some weapons development tests. Barium-140 has a half-life of $12.8 \mathrm{~d}$, so it was necessary that the entire process of preparing each kilocurie batch be carried out in just a few days. The basic process was developed on a one-curie level by the Chemistry Division; it was my job to adapt the process to a three-orders-of-magnitude scaleup, develop and design the equipment, assemble and train a staff, put the plant into operation, and see that the whole thing was accomplished in the shortest possible time. An idea of the urgency that the Army attached to this project may be gained from the fact that when we needed some special alloy stainless steel, the Army

diverted a carload of it from a train which was en route to Hanford. We also had lots of "help" from the Army in other ways; they were continually asking for progress reports and doing inspections of the work. At one point, we let it be known that if they were willing to go to work as pipe fitters they would be welcome, but otherwise not.

The process involved de-canning the irradiated uranium slugs by dissolving the aluminum cans in $\mathrm{NaOH}$, dissolving the uranium in nitric acid, adding lead (as the nitrate I think), precipitating the barium and lead as the sulfates (the lead sulfate was a carrier), converting the lead and barium to a form in which the lead but not the barium would be soluble in ethyl ether, and performing an ether extraction which left the barium behind. The details of the process have become a little hazy in my mind, but the point is that we found out the hard way that the intense radiation field could cause the ether solution to solidify, thus filling our inaccessible and fragile extraction apparatus with a highly radioactive, immobile material and bringing the whole process to an untimely end. This happened several times before we found out how to avoid it-just one of the little surprises resulting from working in a new technology. 


\subsection{FRANK E. HARRINGTON, SEPTEMBER 12, 1991}

I reported to work July 8, 1946, at Clinton Laboratory managed by Monsanto Chemical Company. I was assigned to the Building 3019 (then 205) Fission Product Analysis Laboratory and conducted analytical determinations of elements such as ruthenium, zirconium, and niobium for Frank Bruce and others in the Technical Division. At that time, management believed only college-trained chemists or chemical engineers could do this type of analysis. The analytical group included Larry Corbin, Zeke Burros, Buddy Warren, and Oscar Bizzell.

I volunteered for assignment in shift operation of the first postwar pilot plant of the Technical Division to demonstrate the " 25 " process. Later the 3019 Pilot Plant was modified and expanded to demonstrate sequentially the " 25 ," Redox, Purex, and Thorex processes.

Chem Tech was started from Section T-I, Process Development, and Section VI, Pilot Plant, of the Technical Division. At that time,

Dr. M. D. Peterson was Director of the Technical Division. He was outstanding in many fields of endeavor and left to teach at Vanderbilt, then Princeton, and later Argonne. The Section VI Chief was Don G. Reid, who later went to Idaho. Reprocessing was the central mission of Section VI and became the central mission of the Chem Tech Division when the Technical Division sections became divisions. That central mission carried throughout the Laboratory and the Unit Operations and Pilot Plant Sections of Chem Tech. Prominent early in the Laboratory Section of Chem Tech were Ray Blanco, Frank Bruce, and Ray Wymer. Similarly, Unit Operations included Warren Eister, Jim Davis, Bill Unger, and Marvin Whatley. The Pilot Plant included Walt Rodger, Milt Levensen, Hal Feder, Ed Nicholson, Nelmar Rigstad, Don Reid (Reid and Rigstad went to ICPP), and Kirk Jackson. The Design Section was led by
Floyd Culler, who transferred to Clinton Labs about November 1946 from Y-12. Hal Goeller was Floyd's right-hand man.

The first Chem Tech Division Director was Frank Steahly, who left to lead Union Carbide Corporation's effort in the separation of coal processing products at South Charleston. Second was Floyd Culler. Floyd became the director at age 28 with a B.S. in chemical engineering. Floyd Culler's speeches at regular seminars were inspiring. He had the best informed division in ORNL. He also could get people to go the extra mile better than anyone I have ever known.

Working on the ICPP project was an exciting experience. The Chem Tech team assigned to conduct the ICPP work onsite in Idaho included Hal Goeller, Leader, and Bob Klotzbach, Ed Nicholson, Bill Kearsley, Al Rom, Frank Browder, John Ruch, Ed Frederick, and me. Can you imagine a Reprocessing Plant built for $\$ 30$ million? The ICPP plant was based on the 3019 Pilot Plant process and experience and was initially directly maintained. Our group plus Tex Blomeke had responsibility for initial operation of the plant (American Cyanide refused to accept responsibility until after that period). Since then the plant has had a remote head end (and more) added. It was a thrill to me to visit the plant when it was approximately 30 years old to

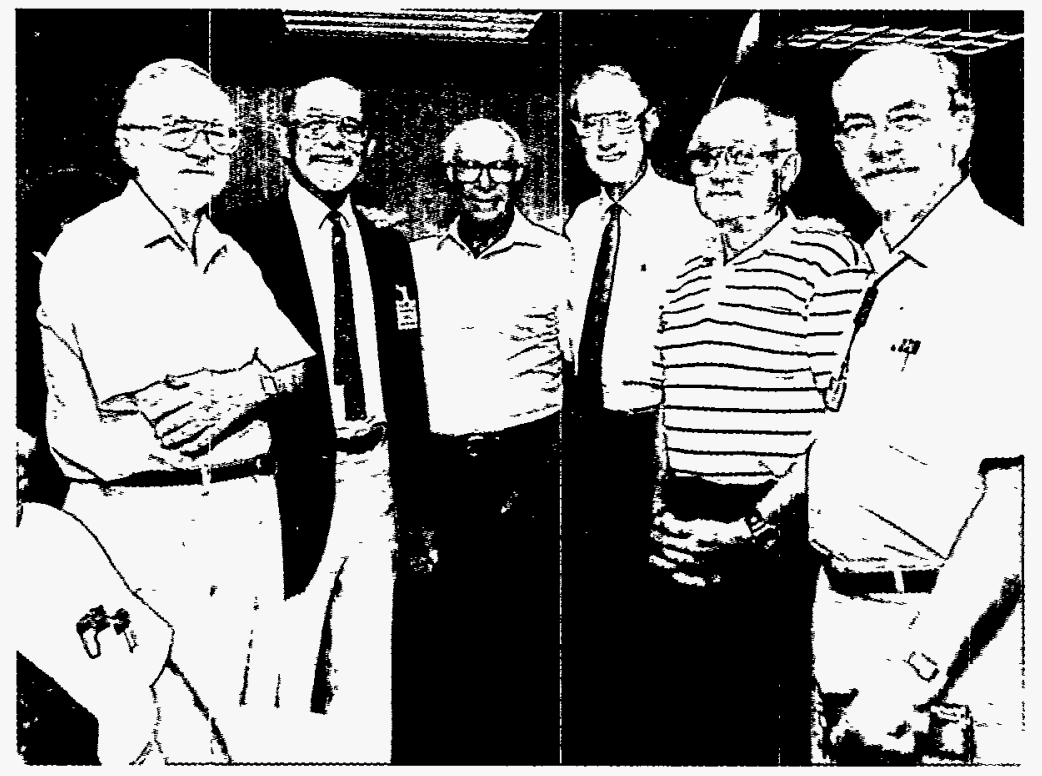

Frank Harrington (on the left) with several Chem Tech colleagues (from left to right): Karl Notz (Sect. 4.6), Al Ryon, Ray Wymer (Sect. 2.8), Claude Haws, and Paul Haas (Sect. 4.2). 
find much of original plant still operating as designed and installed.

\subsection{ED L. NICHOLSON, MAY 26, 1992}

RaLa Process. The RaLa process was run in Building 706C from 1944 through part of 1946. I was an Army GI and was involved in the design, installation, repair, and operation of the 706-C final purification part of the system. The RaLa process was then moved to Building 706D (3026D). However, the first runs in 706D were a disaster, and $706 \mathrm{C}$ was pressed back into service until the 706D system was operable.

Purex and Redox. I was discharged from the Army in 1946 and hired back into the Technical Division on March 13, 1946. After working on the last design phases of the 25 Process Pilot Plant for Building 205, I moved to the Pilot Plant Operations Group. With the able assistance of Frank Harrington, I converted the 25 Pilot Plant for Redox operations. Numerous changes were made, including facilities for filling 5-gal shipping containers (shielded) for sending the plutonium solution from the 1BP process stage to Argonne. After 2 or 3 years of Redox operation, the plant was returned to the 25 Process configuration and a few final verification runs were made using full-activity-level Hanford ${ }^{235} \mathrm{U}-\mathrm{Al}$ alloy slugs. Al Rom did that work in about 1951 to verify the ICPP system design.

All in a Day's Work. In 1946-1948, the development runs for the pilot plant 25 Hexone Process were all with natural uranium slugs from the Graphite Pile. The final confirmation runs were made about 1951 with fully enriched ${ }^{235} \mathrm{U}-\mathrm{Al}$ slugs from Hanford. I remember lifting the Hanford slugs out of the jammed slug charging funnel with long-handled tongs. All in a day's work!!!

HOPE. During the summer of 1954 or 1955 , Eugene Wigner pulled together and directed a team or "think-tank" group to try to develop innovative, very inexpensive ways to reprocess fuels. The team included Bob Charpie. Hal Goeller, Bob

Klotzbach, and I were the Chem Tech participants. Some of the "way-out" considerations included covering process equipment with sand for cheap shielding. Another was to install process equipment in a swimming pool in order to use the water for shielding. At that time the reactor fuels were enriched ${ }^{235} \mathrm{U}$ and not low enriched, as most fuels are now. Wigner wanted a project name that was indicative of being able to reduce fuel processing costs. The group considered the nature of the proposals, some of them were way-out, and came up with the name HOPE. Wigner laughed when we finally told him about our name for the project. To us HOPE stood for Hooty Owl Project Experiment, as in "crazy as a hooty owl." At the end of the summer, we had a closing celebration at either Wigner's or Charpie's home in Oak Ridge.

\subsection{BILL UNGER, APRIL 1992}

Chem Tech staff member William E. Unger participated in the design and operation of the RaLa process. His comments concerning this important process follow.

Bear in mind that some 40 years have passed, and some of the technical details have grown a bit vague. I never did find out precisely what Los Alamos did with the lanthanum that they "milked" from the ${ }^{140} \mathrm{Ba}$ that we shipped to them. In those days it was considered in bad taste to be too inquisitive beyond a "need to know," but important were the high specific activity, the hard $1.2-\mathrm{MeV}$ gamma and the short 40-h half-life. The tolerance specs on the lanthanum purity were inversely related to the half-lives of the contaminants.

The original plant (Walt Rodger gets that credit) dissolved the slugs in nitric acid after

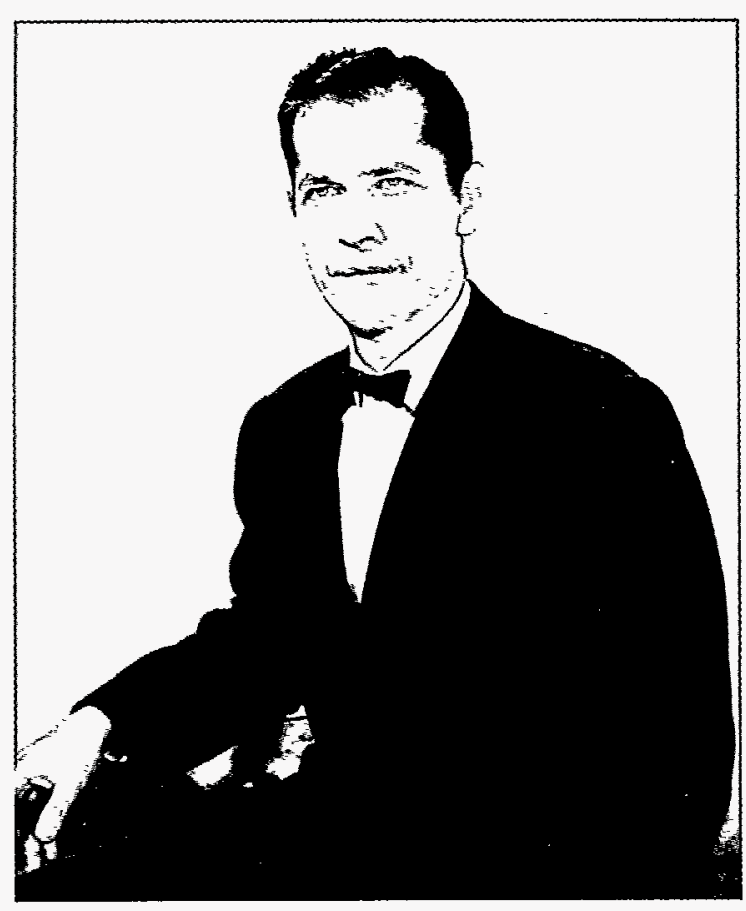

Bill Unger, 1960 
dejacketing in caustic, then a sulfate, precipitation of the barium using lead for a carrier. The lead was later removed by electroplating on a platinum screen electrode. The barium was redissolved in nitric acid and then precipitated in fuming nitric acid in which barium is uniquely insoluble, thus separating it from the contaminants by filtration in a 4-L Stange reactor. It was all a little unsophisticated, inefficient, and unreliable (the glass Stange reactor turned black from radiation), and a colorful part of every run was arguments among the operators, each taking a turn at the periscope, as to the level of the liquid in the reactor. Harris Blauer was the loudest and fortunately usually right.

The 706-D Modification Project (that title had to be lettered on every drawing and I never made that mistake again) used all of the dissolution and sulfate precipitation equipment but added new purification equipment that was located in floor pits outside the walls of the A Cell. This was to satisfy Los Alamos that the old equipment would continue to function until the new equipment was in place and operable. Stainless filters were enclosed in lead-shielded blisters in the cell wall and designed to accommodate Cellite filter aid.

Ray Blanco devised a neat ion-exchange isotope separation process which was followed by a fuming nitric acid precipitation on the eluted product stream, mainly to get rid of the iron, and a dilute nitric solution of the purified barium precipitate was drawn over into a platinum-lined 4-in. centrifuge cone and dried with hot air. The product was assayed by counting the fissions in a ${ }^{235} \mathrm{U}$ foil generated by the neutrons, moderated by a block of paraffin, that were knocked out of metallic beryllium by the $2.1-\mathrm{MeV}$ lanthanum gammas and then back-calculating to the last separation time of the fuming nitric precipitation step.

One of the frustrating operating problems was "chasing" the $\mathrm{pH}$ of the ion-exchange column feed solution. The high radiation level caused real chemical problems. Once, I recall, we lost the product and turned out the cell lights to find it. The barium was all precipitated in a glowing ring on the inside of the feed tank wall.

The equipment consisted of ion-exchange columns, a feed tank, waste tank, tantalum filter, tantalum-lined nitric precipitation tank, ancillary flow monitors (an electromagnetic device that was later patented and marketed by others), radiation monitors, and a sampler that remotely took a measured 200-lambda (microliter) sample. All equipment was compactly mounted in a rectangular frame, $2 \times 4 \times 6 \mathrm{ft}$ high, enclosed in a stainless steel shroud, and topped by a 22 -in.-deep pan through which all the instrument lines were snaked. After this module was lowered into the floor pit, the pan was filled with lead shot for shielding. The building crane had a 3-ton capacity, and the lead shot could be moved around as needed using a modified commercial vacuum sweeper. This module concept later appeared in the neodymium racks at Savannah River, and throughout the process cells in the TRU Facility.

This was a "hot" job. Some 400 pounds of slugs were received at Oak Ridge just 5 days after discharge from the Hanford reactor. The plant was designed for a nominal $2200 \mathrm{Ci}$ of ${ }^{140} \mathrm{Ba}$. But it actually shipped in one shipment $74,000 \mathrm{Ci}$ that, after the 2 days' shipment time, they could safely assume that the lanthanum daughter was in secular equilibrium with the ${ }^{140} \mathrm{Ba}$. Our assay, as I recall, was 68,000 , but Los Alamos' assay of $74,000 \mathrm{Ci}$ was probably the more accurate.

The plant was a lot "crankier" to operate than it sounds like here. It took the skill of operators like Bob Schaich to make it work. He could probably add a lot to what I have outlined here, as, of course, could Ray Blanco. Eric Wischusen would have some unbelievable stories, too.

\subsection{REX E. LEUZE, SEPTEMBER 1991 AND OCTOBER 1992}

My Exciting Trip to Oak Ridge. Monday morning June 25, 1945, I was up early so I could go from 5555 Pershing Avenue through St. Louis and across the Mississippi River to my job by 8:00 a.m. at Monsanto's Heavy Chemical Plant in Monsanto, Mlinois. When I accepted a position following graduation from Kansas State, I requested that I not be assigned to the analytical lab. However, they insisted that was the place to spend a short time to learn about all the activities at the plant. Now, more than a year later there were no prospects of ever moving from the lab.

Shortly after arriving that morning, I was called into the office and told that some of the top managers wanted to see me across the river in Monsanto's head office. Back I went with three other Monsanto employees, Page Buckley, Les Burris, and Phil Schnelle. There we were told about this important new work at a distant site. It was so secret that they couldn't describe the type of 


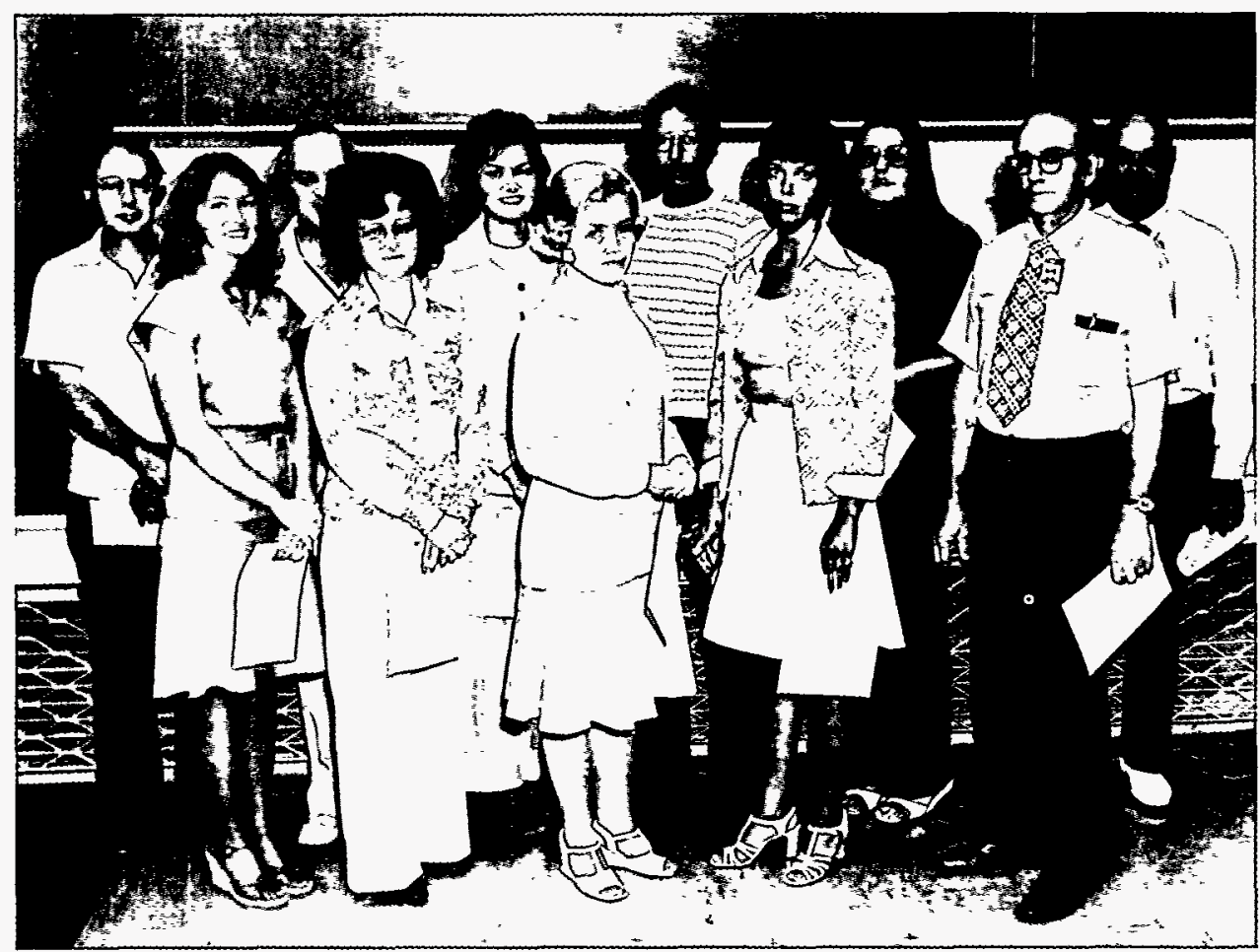

This 1977 photograph shows Rex Leuze, Pilot Plant Section Head (right front) at a Chem Tech awards ceremony with the receipients of achievement certificates. Front row (left to right): Jan Thomas, Brenda Light, Chris Flanary, Jewell Ellis, and Rex Leuze. Back row (left to right): Homer Thompson, Charles Roberts, Jane Posey, Bob Laxon, Karen Thacker, and George Ford.

work nor the location. The question was, "Are you willing to go?" My choice was easy. Here was my chance to get out of the analytical lab, so my answer was, "Yes!!" The others also agreed. The next question was, "How soon can you go?" There seemed to be such an urgency that we all said we could leave anytime. "Well, can you be ready by noon day after tomorrow?" they asked. After another brief discussion, we all agreed that we could go on that short notice.

Monday afternoon was spent packing all my belongings. I couldn't take everything with me, so several boxes were packed to be sent back home to my mother in Kansas. That evening, I walked up the street to 5630 Pershing Avenue to see if Ruth Morris (who became my wife in 1948) would mail those packages for me, since I didn't have time to go to the Post Office. She agreed to help me, so all I had left to do was to finish packing, pick up my belongings at the Lab on Tuesday, and travel to Union Station by noon on Wednesday.

Only Page Buckley had any idea where we were going. He had the train tickets for all of us and a sealed letter that wasn't to be opened until after the train left St. Louis. We were all anxious to learn where we were headed and what we would be doing. We boarded the train for Cincinnati. Soon after leaving the station, we opened the letter but didn't learn much. It said something about going to a secret government plant near Byington,

Tennessee, which was close to Knoxville. It also said that a limousine would meet us at the L\&N Station in Knoxville about 8:00 a.m. on Thursday morning.

You can't imagine how excited I was. I had never been east of Chicago, nor very far south of St. Louis. Tennessee was almost like a foreign country to me. All I knew was that it was somewhere in the Deep South, wherever that was.

The train from Cincinnati arrived in Knoxville during the night and left our pullman car in the L\&N Station. We arose early-very early -and walked up that impressive staircase to the waiting room. We didn't realize that Knoxville was on Central Standard Time (it was in 1945). But an hour after we had expected the car to arrive for us, here came Jim Rule to transport us to Clinton Laboratory. We drove out Oak Ridge Highway to 
the Clinch River and across the old Solway Bridge. There we stopped at the guard station. Since Jim Rule had passes for us, we were soon on our way again. Such dusty roads! My thought was, "Doesn't it ever rain here?" I learned about the rain a few days later when the dust turned to mud!

The first person we met at the laboratory was Larry Riordan. He gave us the standard lecture on security and on not talking about anything that went on at the lab. Soon we were ushered up the stairs into the office of Bill Thumbser. We learned that Monsanto was taking over operation of the lab effective July 1 and that Thumbser was the new lab manager. All at once he said, "I guess you know what we're doing here?" We all shook our heads and declared that we were completely in the dark. Then he said, 'We're working on an atomic bomb!!" What a shock!

A short time later, we were transported to the Guest House near Jackson Square where we resided until arrangements could be made for us to move into one of the nearby dormitories.

Later that week, after all the details required for working at the lab were completed, I was shown to my new job. I was to work with Sam Reynolds in Building 706D (now 3026D) in the analytical lab.

How exciting and thrilling it has been during the 42 plus years I had the privilege of working at ORNL. Even though there have been some difficult times, the people and experiences have been just outstanding! How glad I am that back on June 25, 1945 , I accepted the challenge of venturing into the unknown.

Outstanding Scientists. Before I retired, I collected all of my published and oral papers that I could find. One statement that I made in the Foreword of the Oral Presentations is very appropriate for the Chem Tech History. It went like this:

"Accumulating and editing this information has been a refreshing way to re-live over forty years at Oak Ridge National Laboratory. My most striking impression was the truly outstanding work by scientists like Russ Baybarz, Dave Campbell, Fred Kappelmann, Milt Lloyd, Boyd Weaver, and others as they evolved methods for the recovery of the transplutonium elements. They were able to develop processes based on scouting work with lanthanides to represent the actinides or with only tiny traces of some of the actinides. Later, when significant amounts of the transplutonium elements became available for recovery at the Transuranium
Processing Plant, these methods worked and they worked well!"

\subsection{PRE-CHEM TECH ERA: THOUGHTS FROM CLAIR W. SCHERSTEN, NOVEMBER 11, 1992"}

I have dug into the annals of not-alwaysreliable memory to try to recall some early history of Chem Tech and its precedent groups in the old Technical Division. Those were interesting and challenging days with many highly capable people and many "colorful" characters. Some were both. For many of us, lifelong friendships were forming, as we were starting our "careers" and our families.

Enough philosophizing! I will try to relate some amusing or otherwise interesting incidents or anecdotes. Thinking now of the 1946-49, pre-Chem Tech period, I have retained a lot from those early years. So much of it is not recalling specific incidents but remembering individuals and my impressions of them. Or it is recalling typical everyday happenings, relationships, or scenes. I will relate several occurrences that may be of interest.

Good Fences Make Good Neighbors. The time: circa 1948-50, when Dr. Frank Steahly was over Chemical Development in the Technical Division. The characters: Frank Steahly and Warren Eister, who was in charge of the Semi-Works. Location: the Semi-Works was a separated extension of Building 706-A (now Building 3550), located northward and at the far east end of Building 706-A. The Semi-Works was surrounded by a fence. Access to this fenced-in area was only through the Semi-Works. The situation: Eister was in Steahly's office discussing progress on a new unit. They decided to go on an inspection. (The plot thickens.) Why go all the way to and through the Semi-Works to get there when they could take a shortcut from a back door of 706-A, cross a little open ground, and climb over the low fence? Who would see them? What difference would it make? It was late afternoon and most employees had already left.

* Clair Schersten, Administrative Assistant to Floyd Culler, Director of Chem Tech, transferred in 1961 from ORNL to Union Carbide Research Division at Charleston, West Virginia. 
So the "innocent" action was taken and nobody the wiser. But an alert guard had observed them and hastened to the scene. Seeing who they were, and knowing their positions, he only admonished them. There was no gunfire! Of course, he dutifully included a report of the incident in his activity $\log$. Who should learn of this terrible deed but Larry Riordan, chief Security Officer of Oak Ridge National Laboratory! It immediately became his solemn duty and responsibility to call in the guilty parties-acting in the serious interest of national security! Chagrined, they dutifully went. They went because they knew it was a necessary exercise. In the privacy of his office, Larry charged them: "You broke security regulations! Furthermore, your irresponsible disregard for serious rules set a very bad example. Especially bad, because you hold responsible positions."

Needless to say, all of their employees soon learned of-and profited from-their supervisors' daring but costly deed. The profit, it must be said, was mostly in a good laugh and the opportunity to point fingers of shame at Steahly and Eister!

Social Life at ORNL. No doubt any Chem Tech history will not neglect the contribution of the annual St. Patrick's Day dances to the social life of ORNL. I probably have all of the printed programs from 1951-61 stashed away somewhere in boxes of mementoes moved here from Oak Ridge, many not opened since. I did run across a few in a file folder, along with a script copy from one of the famous skits.

The first Chem Tech Dance was actually on St. Patrick's Day, March 17, 1951, at the Oak Terrace in Oak Ridge. Most of the skits were authored largely by illustrious members of the Long-Range Planning Committee. I am not sure whether this responsibility was included in their job description or not. But they did pursue the task with zeal and with dedication-none of the effort ever performed on company time, of course! The primary writer was usually Al Gresky, I believe. His talented and enthusiastic co-authors were Eldon Arnold and Bob Klotzbach. Then there was a motley crew of kibitzers and volunteer collaborators of varying talents, who contributed ideas-many of them actually acceptable, some even great. Of course, the high level of success achieved in the presentation of these annual dramas was also due to the very talented actors and actresses and production crews! And we must attribute some of the successes to the illustrious
ORNL personalities, in or outside of Chem Tech, who were characterized in these plays!

Illustrious Personalities. When I first arrived in Oak Ridge and Clinton Labs in April of 1944, there was a little weekly newspaper, The Oak Leaf, that was distributed in the area. It was Oak Ridge's first newspaper. I think I got my copies at the desk of my West Village Dorm. It was edited by A. Carleton Jealous. I wondered if that was a pen name. After some time, I learned that Jealous was an engineer at Y-12 who had arrived in 1943. I think I first met him when he came to the Technical Division about 1948 and was assigned to Eister's Semi-Works. He became Assistant Section Chief in Unit Operations when Chem Tech was formed. He was one of about four Chem Tech engineers who transferred to the Union Carbide facility at Sterling Forest in New York about the mid-fifties.

In the mid-1940s there were 200 or so army personnel, mostly tech sergeants, who had degrees in science or engineering and had been pulled from their units and assigned to the Manhattan Project. They lived in barracks in the Midtown area. Some of those assigned to Chem Tech included John Blomeke, Ed Nicholson, and Joe Savolainen. I hereby offer formal apology for any omissions or false inclusions! About 1946, two other guys hired in very soon after having been discharged-Don Ferguson from the Navy and Ray Blanco from the Army.

Chem Tech. The division began with 96 personnel in February 1950. By June the Design Section, under Floyd Culler, was moved into the division, bringing the total personnel to 110 . The Pilot Plant, under D. G. (Don) Reid, was in at the first. By the late 1950 s, we reached the $280-300$ level, plus 20 to 30 on loan from other divisions.

Considering the successful contributions of Chem Tech and all its great personnel-and the more ordinary, but interesting, personnel-the historical treatise will be a boon to humanity!... Are you arranging to have it sent out in a capsule via rocket to unknown planets in outer space?

\subsection{DAVID O. CAMPBELL, JULY 17, 1992}

Unforgettable Colleagues. When I arrived at ORNL in 1953, Building 3508 was new and had just been occupied. There were several Du Pont employees developing processes and gaining experience for the Savannah River Plant, which was almost complete. Don Orth and Dave Karraker 


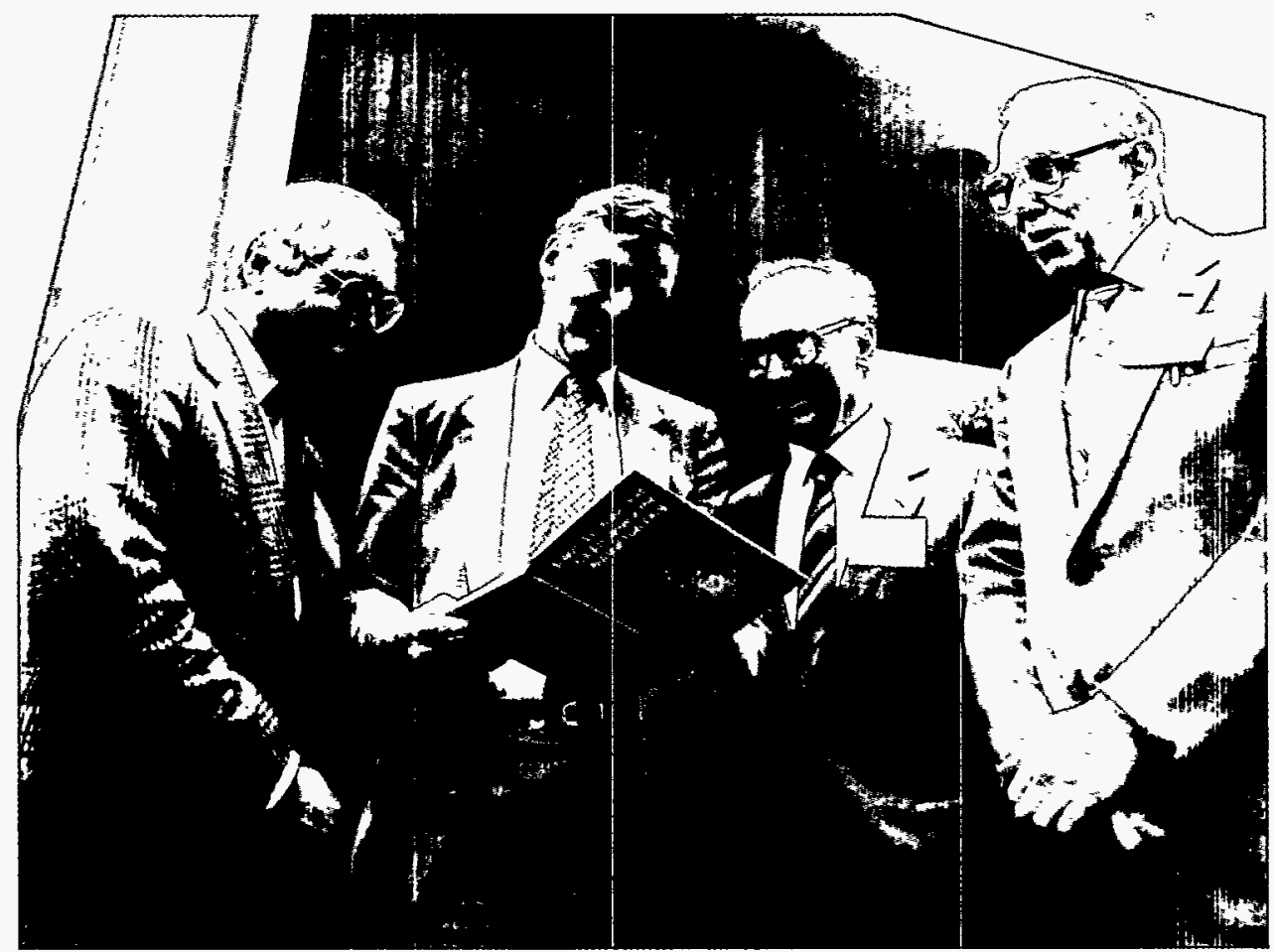

Dave Campbell (right) is shown in a 1985 visit to Harwell, United Kingdom, with (left to right) K. Ebert, Institut für Heisse Chemie Kernforschzentrum, Karlsruhe, Germany; Roy Nelson, Harwell; and L.Patarin, CEA, France.

Dave Campbell (looking up at a large pipe) in the containment building at Three Mile Island during the TAAG inspection of the reactor system (after the nuclear meltdown incident).

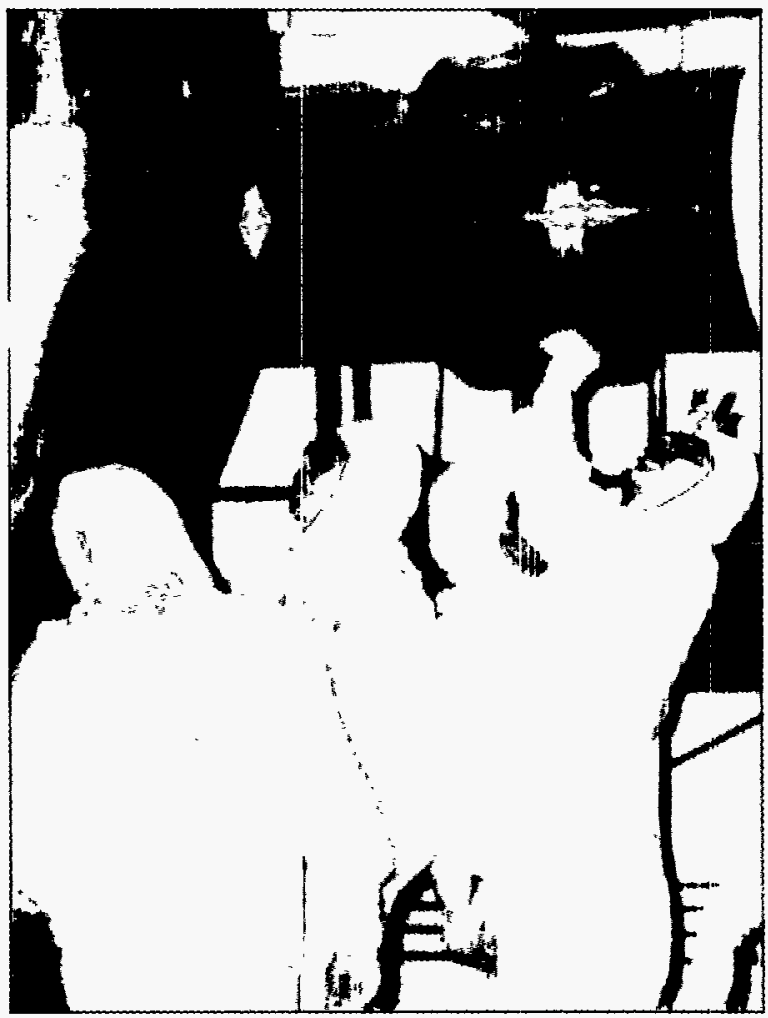


(still at Savannah River) were working on the ion-exchange process that was used at SRP for plutonium recovery, via the 3019 pilot plant. Several Du Pont people were working with John Cooper's analytical group to learn how to do the alpha analyses. The group leader was Don Overholt, about whom a book could be written. There simply are no characters in the lab anymore like he was, and they would not be tolerated if they were. Bob Rainey was there, and the technicians were Dave Hendrix, Jess Delozier, Brad Quincy, and Charlie Green. Collectively, this was the most interesting bunch of people I ever worked with.

Early Actinide Separations. My first job was equipment decontamination related to 3019 .

However, my introduction to actinide separations came in 1954. As always, the military wanted more plutonium. A program was set up at Oak Ridge to recover plutonium from some Hanford slag and crucible material. There was also about $10 \mathrm{~g}$ of americium in this material, and they wanted that also. So, the usual solvent extraction process for plutonium recovery was modified by adding an americium-recovery step, which Bob Rainey developed. All of the americium from the entire campaign was supposed to end up on a single cation-exchange column, from which it could be easily recovered. The process was carefully developed with simulants and tracers, and it looked great. They started up the plant, but after five or six days, americium started to break through the ion-exchange column. So they put on a back-up column, but it also broke through after only about five days. Before it was over, 22 columns were eluted, not just one.

\section{Lanthanum Contamination in Americium.} The real problem turned out to be that there was about $3 \mathrm{~kg}$ of lanthanum, along with the $10 \mathrm{~g}$ of americium, that they wanted. The problem was to separate americium from rare earths, and on an impossible time schedule. They wanted $1 \mathrm{~g}$ in a few months and $5 \mathrm{~g}$ in a year. This is when I was called in and told to figure out how to separate americium from lanthanum, and real fast! At that time, no one had purified more than $1 \mathrm{~g}$ of americium, and that was at Los Alamos. I called Bob Penneman at Los Alamos and Bill Crane at Livermore. The most promising method, based on their experience, was $\mathrm{HCl}$ elution from Dowex 50 resin. We started out with that and quickly decided it was a hard way to make a living. Multiple cycles and lots of rework were required. I decided to continue that method in order to meet the commitment for $1 \mathrm{~g}$ but started looking for a better process for the rest of it.

The better process turned out to be chromatographic separation with citrate and Dowex 50 resin. Better complexing agents than citrate would appear later, but, at that time, Greg Chopin had not yet published about alpha-hydroxyisobutyrate. Using this method, we were able to recover and purify the remaining $9 \mathrm{~g}$ of americium and easily met the schedule.

In view of the present state of affairs, you might be interested in how this was done. I got a 5-ft-long piece of 6-in.-diam glass pipe and put a flow distributor screen in the bottom and a stainless steel flange on each end. It made a fine column that held $18 \mathrm{~L}$ of resin. We fed it from poly bottles using a finger pump with Tygon tubing (the rotary peristaltic pump had not been invented yet); the effluent came off in a Tygon tube to a jack-leg to control interface level, and finally to a poly product bottle. All this was done in a full-length hood-no glove box - by one technician and me. The hood had sliding Plexiglas doors like a bedroom closet.

Memorable Experience. One of my memorable moments occurred during the middle of the campaign. The gamma radiation from americium was a problem, so we kept as far from the equipment as we could. During an elution, we watched the column from across the lab. In this run, just as the americium peak was coming off the column, we noted that there was no solution running into the product bottle. Closer examination revealed that the effluent tube at the bottom of the column had split, and the product was running out on the floor of the hood. Fortunately, the floor was a stainless steel pan, but it was a memorable moment to observe a nice, pink americium solution, about $10 \mathrm{~g} / \mathrm{L}$, running into the pan. Although the leak was confined to the hood, it got the adrenalin flowing!

What did we do? We put on some extra gloves, yanked the split line off the column, and stuck a new one on. Throughout this work, carried out in open hoods, neither we nor the lab outside the hoods were contaminated to any serious extent.

Pressurized Ion-Exchange Separation of Actinides. It was some 20 years later when I started pressurized ion-exchange work, which has since been used in several countries for producing and purifying the heavier actinides. In the early nuclear days, there were at least two processes developed for every task. You may know that the bismuth 
phosphate process was used for the initial plutonium production at Hanford, but you may not know that cation exchange was the back-up process. It is a good thing bismuth phosphate worked, because cation exchange gave poor decontamination. However, there was a sizable program at Oak Ridge to develop ion exchange, and later on, they did a lot of work on ion-exchange chromatography.

One of these people was a biochemist, Waldo Cohn, who eventually went back to his field and became involved with the problem of separating transfer-ribonucleic acids (t-RNAs).

Recalling his work on ion-exchange chromatography, he tried it for biochemical separations and it worked. Extreme resolution was required, and this could be achieved by using smaller resin particles. But as one moved in that direction, the flow rate decreased. The answer to that was to apply high pressure, which resulted in occasionally blowing up a column and splattering it all over the lab. Later on, better high-pressure components were developed, and Chuck Scott was instrumental in properly engineering them. It turned out that very dependable systems could be built and operated at 1000 to $1500 \mathrm{psi}$. These ion-exchange systems provided a large factor of improvement in performance-by a couple of orders of magnitude. This improvement could be taken advantage of in several different ways.

Now it turns out that these systems are admirably suited to actinide separations. It is interesting that development of this technique can be traced back to the wartime Manhattan Project work on ion exchange for separating fission products from plutonium, through biochemical separations, and finally back to actinide separations. The development for biochemical applications was driven by the need for extreme resolution. We needed good resolution, but the more practical problems were radiation damage to the resin and gas formation in the column because of radiolysis. With really high-activity actinides such as ${ }^{242} \mathrm{Cm}$ or $\mathrm{Cf}$, gas generation often limited performance.

The high-pressure systems permitted much faster elution, thus reducing radiation damage. This high pressure, in itself, eliminated the gassing problem because gases are soluble and are carried out in the effluent solution. In spite of the obvious applicability of this approach, it was surprising how much opposition was encountered to using it with highly radioactive materials. In fact, the name had to be changed to "pressurized ion exchange," although the biologists called it "high-pressure ion exchange." The term high-pressure was too much of a red flag to get through a safety analysis.

However, I did demonstrate this method, and it was adopted and has been used extensively. Those of you who work on new processes know full well that nearly everything you do will never be used in practice, no matter how brilliant your work or how useful and practical the process. That is just the way life is in our business. Very few processes are ever used at all, and the way the decision is made to choose a particular process is weird, at best. So there really is a feeling of satisfaction when a process we have something to do with is actually used.

\subsection{RAY E. BLANCO, JUNE 1, 1992}

The "Retread" Campaign. In late 1963, Floyd Culler decided his "troops" were getting "rusty and worn" and that their skills needed rejuvenation. After all, most.of them had received their degrees about 15 to 20 years earlier. Wallace Davis, Jr., was appointed professor for physical chemistry and Jere Nichols for mathematics. ORNL provided the books. We were to attend classes in the conference room on the second floor, Building 4505. The program soon became known as the "retread program." Classes met for $2 \mathrm{~h}$ once a week for 9 months. About 30 "students" signed up. The course was held twice-November 1963 to May 1964 and November 1964 to May 1965. Wallace led us through the trials of physical chemistry and Jere poured on the advanced algebra and calculus. Homework was assigned and faithfully completed, although Wally Davis said that I was remiss in some of my homework! We had a ball. Just like going back to old times. We even complained that the professors were too hard on us!

International Atomic Energy Agency (IAEA) Panel Meeting, Dubna, U.S.S.R. - 1964. I was fortunate to receive several interesting trip assignments-lucky to be in the right place at the right time. Joe Lieberman, Assistant Director for Nuclear Safety, AEC, Washington, called me at home on a Saturday to ask if I could attend an IAEA waste meeting at Dubna, U.S.S.R., as the United States representative. It was only about two weeks notice for a meeting to be held in December 1964. I said, "Sure could, if ORNL management agreed." They did agree. 


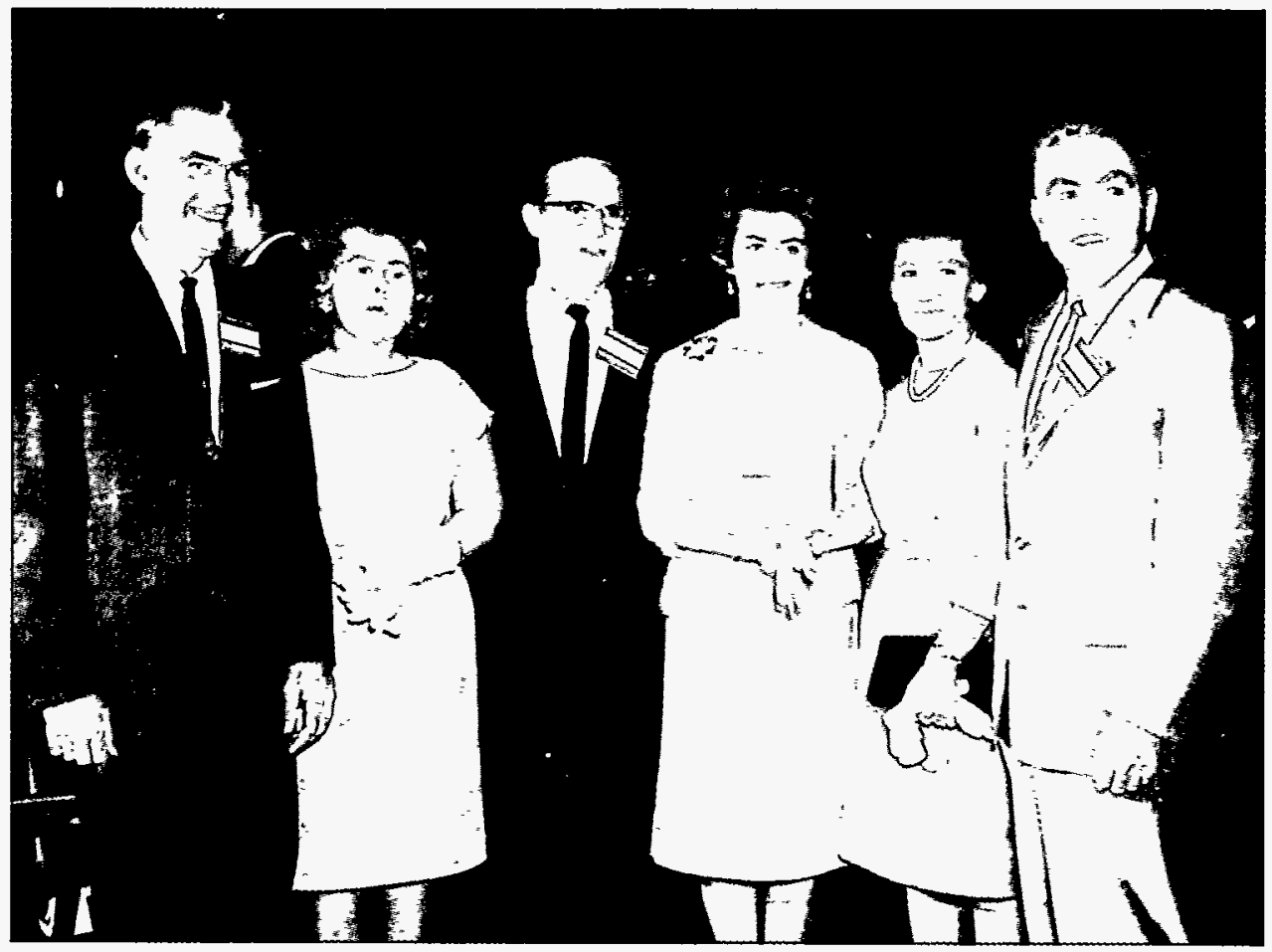

Several Chem Tech staff and guests are pictured at an early 1960 conference in Gatlinburg, Tennessee. Left to right are Don Ferguson, Wilma Ferguson, Ray Blanco, Elaine Blanco, Edna Briggs, and Beecher Briggs (Reactor Division).

Dubna was a new city (since 1944) of apartment buildings on the banks of the Volga River, about 70 miles north of Moscow. It is the main center in the U.S.S.R. for high-energy research and employed about 4000 people. Excellent meeting facilities were available here. We were given a tour of the cyclotrons and other accelerators and their thermonuclear test unit. We were free to walk around the town and take pictures, as we wished. There were many people fishing through holes in the ice on the Volga.

The emphasis of the meeting was on the exchange of information on the incorporation of low- and intermediate-level wastes in various types of concrete and the new concept of incorporation into asphalt (bitumen in Europe). The Russians and others were extremely interested in the work being done in Chem Tech by Herschel Godbee, Arlene Kibbey, and John Moore. Of particular interest were the Chem Tech results of irradiation damage to the asphalt. Results of our work reached the Russians regularly through the IAEA, where the U.S.S.R. delegates combed the literature for new information.

The principal value of the meeting to us was the opportunity to hold direct discussions with the
Russians since none of their written reports on waste treatment reached the United States. In addition to the IAEA representative, one official delegate was present from each participating country, that is, Belgium, Czechoslovakia, France, Germany, India, Japan, United Kingdom, U.S.S.R., and the United States. However, the Russians had about 20 unofficial "onlookers."

On the bus back to Moscow on the final evening, it was again one Russian and one visitor per seat. I had a Russian lady chemical engineer as my companion. We had a nice, pleasant conversation, and I didn't argue with her since she was much bigger than me! The group (a full bus) had become very friendly during the week of meetings, and there was a lot of loud shop talk-some direct and some through interpreters. The Russian leader passed down the aisle with 2 bottles of vodka, paper cups, and apples for those who wanted to celebrate the end of the meeting (the Russian lady chemical engineer did not). Soon the bus sounded like football fans going to a game-loud national songs and laughter. My lady companion sang like a valkyrie at the opera. The 70-mile, nighttime trip to Moscow over a road 
covered with ice, snow, and potholes took a long time.

Teaching at the University of São Paulo, Brazil - 1969. Professor Pedro Bento de Camargo of the Institute of Atomic Energy (IEA), São Paulo, Brazil (associated with the University of São Paulo) contacted Alvin Weinberg with a proposal for ORNL to provide postgraduate credit courses in nuclear technology. Negotiations were completed for financial backing and support from the U.S. AID, IEA, and the AEC in mid-1969. Three people were given the teaching assignment; that is, Paul Kasten and Bill Ergen, Reactor Division, were to give courses on reactor economics and reactor physics and Ray Blanco, Chem Tech Division, a course on radioactive waste management and nuclear fuel reprocessing.

The salary problem was resolved with the ORNL participants to remain on their normal salary and trip expense reimbursement. The IEA paid us their normal salary for professors in Brazilian currency, which we returned to ORNL-AEC.

I was very worried about the whole thing because Brazilians speak the Portuguese language, no textbook was available, and I didn't visualize myself as a professor. I finally rationalized that it could be no worse than a series of 50-min lectures at the annual Chem Tech Information Meeting, so I set out working to prepare all of the lectures in advance, that is, the complete text and figures (copies of slides). I planned to hand them out in advance as a textbook. I was assured that the students read and understood English reasonably well, since most of their college texts were in English. Thus, I could speak using the slides as a guide, and using the blackboard, I could get the message across. I slaved for several weeks at ORNL and at home preparing the lectures and slides. I am forever grateful to Sue Damewood for typing and Jim Farmer for drawing up the figures and slides on a rush-rush basis. It seems that permission from the AEC always arrived late for foreign visits. I expected about 17 students and prepared 25 packages of lectures.

We arrived in late September and classes started immediately. I had shipped all of my reference literature and lecture packages by air mail in advance. Disaster struck immediately!! My box of lectures, etc., were being detained in the Brazilian Customs warehouse. They claimed that the package contained pornographic material but, in reality, they were extorting ransom from the
University and Institute. Fortunately, I had brought my copy of the lectures and my slides in my personal luggage. I had to start and make the best of it for two weeks until the IEA got the shipment released. They could not reproduce the lectures from my personal copy so that I could distribute them immediately because of a lack of reproduction facilities. In the end, it all worked out very well. One of the resident professors helped grade the exam papers since the students were allowed to write in either Portuguese or English. We returned to this country in early December. The lectures were published by the IEA in 1976 and 1977 in three volumes as Radioactive Waste Management-Informacão, IEA 53-11 CPRD002.

The information I presented came from declassified literature publications which were referenced in the lectures. Many of the referenced authors were from Chem Tech and are listed as co-authors on the lecture series, including W. E. Unger, A. R. Irvine, D. J. Crocise, and C. D. Watson.

Professor Camargo asked us to prepare a preliminary survey of an Agro-Industrial Nuclear Complex for Brazil. A group in my Chem Tech Section had been active in that program at ORNL in studies on the production of fertilizer using nuclear power and developing a method for preventing scale formation on the evaporator tubes in the desalination distillation system (a patent was issued to Walt Clark, Bill Yee, and me for the latter). An initial survey was completed in cooperation with Brazilian experts on agriculture, minerals, heavy industry, and hydrology.

Northeastern Brazil is very dry and the location of a nuclear complex in that area to distill seawater (or to pump groundwater) and to produce fertilizer looked promising.

Sidelights. We stayed at a hotel in the center of São Paulo (population approximately 7 million in 1970). Our balcony overlooked eight lanes of Volkswagens moving day and night-it was like living on Times Square. Leaving Brazil proved difficult. Our visas had to be stamped for approval to depart. The officials claimed a new law had been passed in the last month saying that you had to give them one month's notice to leave. Thus, it cost each of us an extra $\$ 10$ to depart the country.

Delegation to the Institute of Nuclear Energy Research, Taiwan, 1979. In 1979, the U.S. State Department and the DOE decided to send a delegation of U.S. nuclear scientists to Taiwan as an assistance program. The U.S. had recently 
withdrawn its ambassador because of a problem with mainland China and relations were a little strained. A team was formed composed of S. Goldsmith (Fuels Development - Battelle Northwest), W. Schwartz (Quality Assurance and Control - DOE Idaho), W. Lapinski (Nuclear Reactors - Argonne National Laboratory), Ray Blanco (Waste Management - ORNL), and A. Lewis (Leader, Argonne). We spent a couple of days consulting in Taipai and the remainder of two weeks at the Nuclear Institute in the interior of Taiwan. The Institute is a smaller ORNL centered around a heavy-water-moderated, natural uranium reactor. Areas of interest to me were the countercurrent bench-scale mixer-settler solvent extraction system, research and development in waste management, and waste treatment operations for the installation. They were using a process for incorporation of low- and intermediate-level radioactive wastes into asphalt and had developed a process using a mixture of polyethylene and asphalt to increase the melting point of the product. During the tours of the facilities, I found that there was a strong rivalry between the chemical engineers doing $R \& D$ in the Engineering Research Division and those doing the actual operations in the Operating Division. On my first morning of separate meetings with these people, I had a problem! I found myself at the head of the room facing six R\&D engineers at a table to my left and seven operating engineers at a table to my right. A man from each side came to the front table and presented me with a glass of tea-one with sugar with a lotus flower floating in it and the other, plain (my "one-on-one" man was on the R\&D side). They were sort of smiling and watching to see what I would do. I drank out of both glasses immediately and the tension evaporated. We had several sessions like this where they would ask about the work at ORNL and bring up problems for discussion. At the end of the visit, the Institute management indicated that they were pleased with the efforts of the delegation. They were very gracious hosts!

Sidelights. At that time, the Republic of China (Taiwan) considered itself to be still at war with mainland China. Soldiers with rifles and bayonets were stationed at all bridges, tunnels, airport, and other strategic locations.

My "one-on-one man," Dr. Chou, spoke excellent English and had received his Ph.D. degree from the University of Louvain in Belgium using the Flemish and French languages! He and a friend took two of us to an evening theater performance about an old Chinese legend. The actors were 11- to 13-year-old children who had made their own traditional Chinese costumes and performed in the old style with slow, stilted movements. It was very beautiful and expressive! Before the performance, I noticed some empty front seats in the theater. At the last minute, they were filled when several generals and civilians marched down the aisle accompanied by two soldiers with rifles and fixed bayonets.

We were taken on a tour of the huge National Museum. Chiang Kai-shek had moved most of the beautiful treasures from China to Taiwan. They change out the displayed treasures each six months, and they have sufficient numbers to ensure that nothing is repeated over a 30 -year period.

\subsection{ROBERT L. JOLLEY, AUGUST 7, 1992}

January 2, 1956. My introduction to the strange and exotic world of fluorine, uranium hexafluoride, and molten salts occurred the day I started working in Chem Tech. I was assigned to George Cathers' fluoride volatility group (Labs A-25 and B-25 in Building 4500) and was introduced rapidly to the unique oxidative powers of fluorine via the burning leather glove demonstration; thermocouples and potentiometers; pressure gauges and "needle" control valves; using an aluminum rod as stethoscope to detect the methodical "heart beats" of the hydrogen fluoride dissolver and the fluorinator; and radiation detectors and radioactivity. To a neophyte from an organic and analytical chemistry background, it was all an exotic adventure in physical chemistrya wonderful new world to explore and learn.

Unforgettable Team. George, with a deep and practical understanding of physical and inorganic chemistry, was an excellent mentor. George's group also included Bob Bennett and Bob Duff. Both were astute experimentalists and superb craftsmen. Bennett was a master chess player and often served as the straight man for Lew Byrd, who worked in a lab close by. Regular visitors to our lab included Bill Ratledge, janitor for Corridor A, 4500, and Yankee supporter par excellence. Later, Cathers' group was joined by Dave Campbell, a genius in separations chemistry and kinetics who had recently returned from the Army; Stan Kirslis, who could have discovered the "impossible" reaction of fluorine with xenon; Tom Crabtree, a 
football referee by avocation with a heart of gold; Cal Shipman, a quiet, steady, and reliable team member; Frank Soard, thorough and competent and former baseball player; and Gene Moncrief, a young chemical engineer in training for volatility pilot plant adventures. Only years later have I realized how unique and talented the team was-a familiar refrain I am sure for most ORNL scientists and engineers, for ORNL was a meeting place for many of the nation's brightest.

\section{Joule-Thompson Effect and the Fire}

Department. I had been in Cathers' volatility group perhaps half a year. It was fall and the trees were turning-flaming golds, crimson, and reds. The grass behind Building 4500 (there was no $4500 \mathrm{~S}$ at that time) was a dead brown. George assigned me the task to dispose of the $\mathrm{ClF}_{3}$ previously used by Rex Leuze and Chuck Schilling in fluoride studies. Chlorine trifluoride, a gas at room temperature, is stored as a liquid under slight pressure. Because $\mathrm{ClF}_{3}$ is highly reactive, with properties similar to fluorine, George and I attached a 10-ft length of 0.25 -in. copper tubing to the bottle to ensure that the gas would disperse sufficiently far from 4500 and personnel.

We carried the $\mathrm{ClF}_{3}$ tank across the street behind 4500 and set it up not too far from the fence that ran between the street and the small creek behind 4500 . We aimed the tubing away from 4500 and slowly cracked the valve to release the $\mathrm{ClF}_{3}$ gas. Several minutes later we noticed what appeared to be a jet of colorless liquid shoot from the end of the tubing, arching beautifully several yards, and landing on the dry grass. Instantly, the grass caught fire. By the time we had closed the tank valve and removed it to a safe place, the fire was rapidly approaching the fence. The fire extinguisher, alertly brought by John Harris, Corridor $\mathrm{B}$ janitor, who also called the fire department, was effective except where the fire had passed through the chain length fence and appeared to be racing rapidly towards the woods.

The ORNL Fire Department soon arrived and positioned themselves for extinguishing the grass fire. When the pressure was cranked up on the tank truck, the top seal blew, and wet many of the onlookers and firemen. This was quickly corrected and the fire was extinguished.

A red-faced young chemist never forgot the Joule-Thompson effect again-that most gases, except hydrogen, cool on expansion. $\mathrm{And}^{\mathrm{ClF}_{3}}$ liquifies at $11.3^{\circ} \mathrm{C}$. The Fire Department did not forget either. For about a year, I received weekly calls and visits from the Fire Chief to ensure that I was focused on fire safety. To my knowledge, the $\mathrm{ClF}_{3}$ may still reside undisturbed and undisposed within the hallowed walls of A-25, $4500 \mathrm{~N}$.

\subsection{THE CREMATION OF JIM BRESEE'S R2-XG (A FANTASY): MARVIN WHATLEY, 1958}

The following poem indicates that renowned scientists also have lighter moments. It is included by popular demand. 
THE CREMATION OF JIM BRESEE'S R2-XG (A Fantasy)

by M. E. Whatley (about Xmas 1958) with apologies to Robert W. Service

There are strange things done for a processing run To recover reactor fuels, And the engineers' wails hold their fearful tails That would shatter your rational rules.

These fluorescent lights have seen strange sights, But the strangest they ever did see, Was the night on the brink of the awfullest stink When we process the $\mathrm{R} 2-\mathrm{XG}$.

Now the R2-XG is nine foot three with fused $\mathrm{U} O 2$ for its core plus T HO 2 in quantities true (Or perhaps just a little bit more)

Which at $5000 \mathrm{~K}$ was fired for a day

To make particles perfectly round which are quickly dispersed in a manner rehearsed And found quite philosophically sound.

This is floated in NaK and squeezed through a crack Fifteen mils by six inches or so

That produces a plate, the most stable to date, Which is clad by the method we show:

Take zirconium pure with some iron from the Ruhr And a very thin layer of gold,

Then molybdenum, tin, and a platinum fin

With a delicate film of green mold.

A mega kilo watt year it is burned, then shipped here

Where it's cooled sixty seconds or less.

"We'll process the thing in the Unit Op Wing

Without even making a mess."

So read our claim, out pride was to blame, "Just think of the prestige we'll gain.

Recover the stuff and the waste well enough, and I'll talk at Geneva again."

It was then that Bresee stated clearly his plea Not to go off half-cocked in this race.

"Some few problems involved are yet to be solved, It will take us a week at our pace."

Then the section took hold, you could tell by the cold
Quiet drive that pervaded its men,

And we wrote twelve reports of various sorts

And the coffee breaks ended at ten.

Oh the sweat that was shed, the technicians half dead

Under pressure fantastic to see.

But the group never mired, it was truly inspired

By its glorious leader, Bresee.

We'll dissolve it in salt while we whip it like malt Using $\mathrm{H} \mathrm{F}$ at one thousand $\mathrm{K}$,

Or we'll chop it in bits and grind it like grits

And bake it real solid like clay.

The reagent to sell might by day $\mathrm{H} \mathrm{CL}$,

So the volatile chlorides we'll lose,

When the reaction stops the remains will be tops,

For an Aqueous process we'll choose.

The debate then grew hot: What to use and what not Till the engineers' chins dragged the ground.

Bresee simply remarked (and the reaction sparked) "A solution will surely be found."

Like a bright gleam of light to illumine the night Where we stumbled and frequently fell, From the janitors stall "Why not just use them all? The reaction will go bent for Hell!" Thirty stories or more coming up from the floor The dissolver was built in a day:

Pulsed plates fore and aft and a super downdraft

Condenser to reflux away.

Wet, dry, hot and cold, with saws in the hold And filter to take up the fines.

The still strong of heart were now ready to start, The others were off in the mines.

Bresee gave the sign and the four-inch feed line

Gave a belch We were finally on stream.

Our handiwork ran, the reaction began

You could tell by the large cloud of steam.

There are strange things done for a processing run To recover reactor fuels

And the engineers' wails hold their fearful tails That would shatter your rational rules.

These fluorescent lights have seen strange sights, But the strangest they ever did see,

Was the night on the brink of the awfullest stink When we burned up the R2-XG. 


\subsection{CAREER OPPORTUNITIES, 1943, * George Parker}

George Parker had a hunch in early 1943. That hunch has had a lot to do with where he is in 1993 as a researcher in ORNL's Chemical Technology Division.

During the early, nervous years of World War II, the former University of Tennessee graduate student had taken a munitions industry job at the Indiana Ordnance Works.

Du Pont then operated Indiana Ordnance, and shortly after Parker joined Du Pont the company began to transfer employees. "It was all very secretive," Parker said. "Nobody knew or would say where they were going or what they were going to do."

Meanwhile, Parker had also enrolled in a night class taught by a Purdue University engineering professor, who returned from a trip to the University of Tennessee with an interesting story for the class. "He said that he had just come from Knoxville where he visited UT's engineering and physics departments, and he was amazed to see four Nobel laureates in one group!" (Parker now speculates that the four were probably Arthur Compton, Harold Urey, Ernest Lawrence, and Sam Allison.)

Parker's professor then told of a project getting under way close to nearby Clinton that might be connected to the plethora of brilliant scientists present at the school. In fact, someone at UT had put a note on a blackboard that said, "What's going on at the Clinton site?"

"The professor said that there were all kinds of wild guesses listed under it, such as chemical warfare," Parker related, but one speculation was noted as "uranium energy," and it clicked with the young chemist.

Parker recalled an article in Physical Review that announced that German scientists had fissioned uranium by exposing it to neutrons, yielding a very high energy content.

"I immediately associated it with the blackboard guess," Parker said.

At that time the selective service was inducting eligible young men at a rapid rate, and Parker's draft board in his hometown of Johnson City, Tennessee, suggested that if he intended to

*Appeared as an article written by W. H. Cabage in Lab Notes, No. 26 (January 1993).

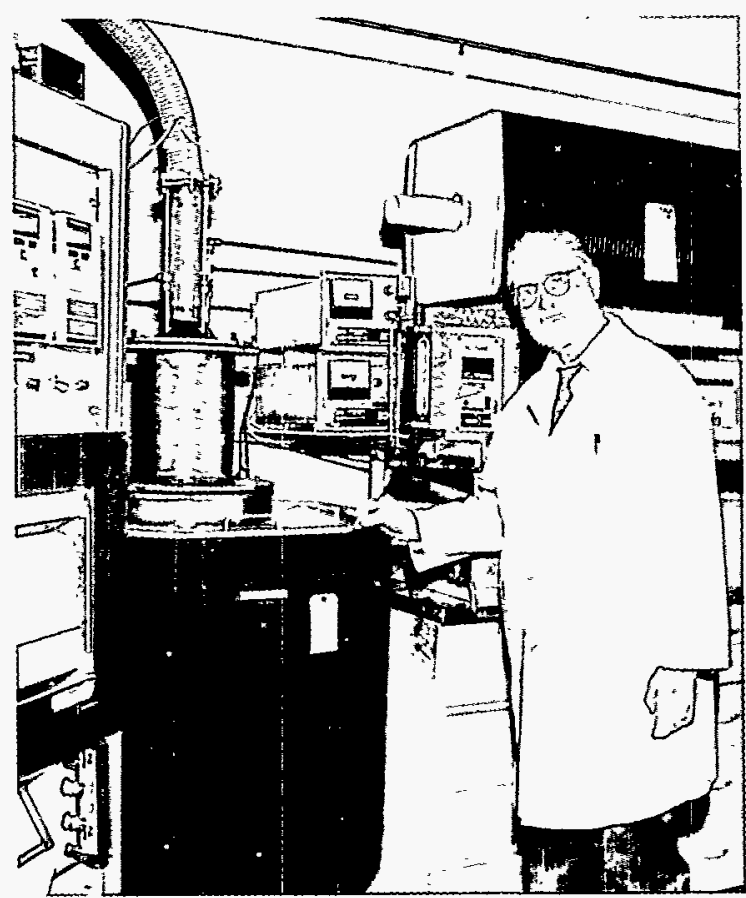

George Parker's canny observations on the purpose of a big wartime project in his home state of Tennessee led to a 50-year career at Oak Ridge National Laboratory.

continue his new career uninterrupted, he should seek employment that was more vital to the war effort.

"I had a draft board at home in Johnson City who kept pretty good track of me and what I was doing, and they suggested I should find a more strategic job. One day a friend told me that he had seen so-and-so at the University of Chicago who was temporarily assigned there."

"That gave me an idea to write a letter to the University of Chicago registrar that I had reason to believe there was an important defense effort being conducted at the school, and I would like to be in on it. After about the third day I got a telegram that said simply 'come up for an interview prepared to stay."

Parker resigned from the ordnance plant, packed his few belongings, and left for Chicago. Once at Chicago, Parker met with people from the "Metallurgical Project Laboratory" and was interviewed by gentlemen who he later discovered were FBI and military intelligence agents. "They were extremely interested in what I knew." Parker told them how he had put his hunch together from the professor's reports and the journal article. He was told that his guesses were wrong but that they 
had a job for him, anyway, in the biochemistry group isolating trace quantities of fission products from uranium nitrate taken from the St. Louis cyclotron's shielding. The day after he started work he was told that, in truth, the agents were actually amazed at the accuracy of his speculations.

Parker was assigned to a laboratory next to the university's Stagg Field squash court, the site of the graphite pile of the first nuclear reactor. A slightly romanticized painting depicts the famous pile and the scientists who developed and operated it standing on the squash court's balcony. Parker's first uranium extraction lab was in a locker room adjacent to the balcony. "I could walk out and look at the pile any time," Parker said.

The pile by then had been shut down and a better one was being built, as Parker had suspected, near Knoxville. In October 1943 Parker was transferred to the barren East Tennessee site called Clinton Laboratories.

"I took a train from Chicago, checked into the laboratory's personnel office in the L\&N station, and was instructed to get a bus to Oak Ridge and obtain quarters in the guest house."

"After a bus ride down Highway 62, they checked our papers at Elza Gate and let us in. I asked the bus driver to indicate where the guest house was. Suddenly the bus driver stopped and said 'this is where you get out.' I got out and immediately sank in mud almost up to my knees."

"People who were knowledgeable wore high boots," Parker said.

Conditions at Oak Ridge were spartan, but eventually Parker, after experiencing the shady politics of waiting lists (he kept slipping down them), was able to obtain housing for himself and his new bride. Entertainment was available in
Knoxville, which, since there were no cars, involved a journey on "atrocious buses." Transportation to the reactor site was via "cattle car," a converted car carrier equipped with a woodstove heater.

The Parkers became friends with several noted scientists. They babysat for the Arthur Comptons. Parker said he also knew Enirico Fermi, Harold Urey, and Edward Teller informally, along with Leo Szilard, Robert Oppenheimer, and General Leslie Groves, who once came through with a quartet of four-star generals in tow. 
Such visits were not uncommon. Preparations for an anticipated visit by President Roosevelt, which never happened, included making sure all corridors were clear enough for a wheelchair to pass.

Parker also came to know several "strange and wonderful" individuals, including a foreign fellow who bathed in the quarters' community shower in his skivvies, then wrung them out and dressed. A mechanical wizard from Knoxville named Arthur Tripp once fashioned a radial engine out of tin cans.

Another fellow always wore a topcoat and a felt hat, even in summer. One day he failed to show up for work-he had disappeared. His mother demanded to know where her son was, but officials had no clue. Parker said the man's job was very ill-defined: although he was a scientist, no one knew exactly what he did. Parker never did find out what had happened to him.

There was no open discussion then about the Laboratory's mission, although Parker said that he was aware that $\mathrm{Y}-12$ was enriching ${ }^{235} \mathrm{U}$ and that the Graphite Reactor was a pilot plant for plutonium separation. An extremely important issue was neutron yield, Parker related, and it became apparent that plutonium would make a better bomb than uranium.

"I saw some of the first milligrams of plutonium that were separated at the Graphite Reactor. There was a microchemist from Berkeley, Louis Werner, who even though he was a microchemist was one of the biggest men I ever knew, about seven feet tall. One day he asked me to look at a small amount of blue-green liquid under a microscope. It was the first visible quantity of plutonium made in the Oak Ridge reactor, and from that tiny amount they made a lot of extremely important measurements."

Parker's work during the war was in the separation of radioactive materials for biological damage safety studies. "Our efforts were the basis for the radioisotope industry," Parker said. "All of our early work was with ${ }^{14} \mathrm{C},{ }^{131} \mathrm{I},{ }^{32} \mathrm{P}$, and ${ }^{35} \mathrm{~S}$, biologically important isotopes that were generated in the Graphite Reactor and separated in the old 706-C hot lab (now Building 3026)."

His first actual knowledge of the atom bomb came in July 1945, when he saw a report that a test bomb had been successfully fired in Alamogordo, New Mexico. At that point an in-house controversy had blossomed over the use of the atom bomb, Parker said. "Many well-informed individuals were against it."
However, almost half a century later, Parker sat in his office, which is computerless and stacked with reports and documents, and described his learning of the use of the atom bomb and the resulting end of the war as his best day at the Lab.

"The darkest day may be yet to come," he said, "but I've been lucky. I've had experimental work continuously."

Not a bad career just for putting two and two together.

\subsection{CHARLES F. COLEMAN, MARCH 31,1993*}

Extraction of uranium and thorium from geological materials (e.g., granite, sands, shale) is one of the most remarkable achievements of ORNL and Chemical Technology Division research and development. This work received international acclaim, and many of the extractants developed or studied by the group were used not only for commercial extraction process, but also found application in nuclear fuel reprocessing. Some of the unique accomplishments of the R\&D team responsible for developing the separations chemistry were described in Sect. 4.1. That modest writeup provides a brief history of the R\&D team. This anecdotal section includes some additional photographs of some Chem Tech personnel and visiting international scientists (Figs. 5.1-5.3).

\subsection{MY MANHATTAN PROJECT EXPERIENCE, IRWIN R. HIGGINS}

I started on the Manhattan Project on May 10, 1943. One incentive in recording an historical account is that I got in early and can relate some "firsts." Another reason is because it was so incredibly interesting to be part of this highly secret and unusual endeavor.

I came from a potato farm in northern Maine, far removed from the industrial world. I was interested in chemistry, but took biochemistry instead, at the University of Maine because it was related to farming. Pearl Harbor Day was on Sunday, December 7, 1941, and I was a senior just 6 months from graduation. The next day, December 8 , I received my first $1 \mathrm{~A}$ card to go into the Army. The Dean of the College of Agriculture wrote a letter to the Draft Board asking if I might

\footnotetext{
*Prepared by Robert L. Jolley.
} 


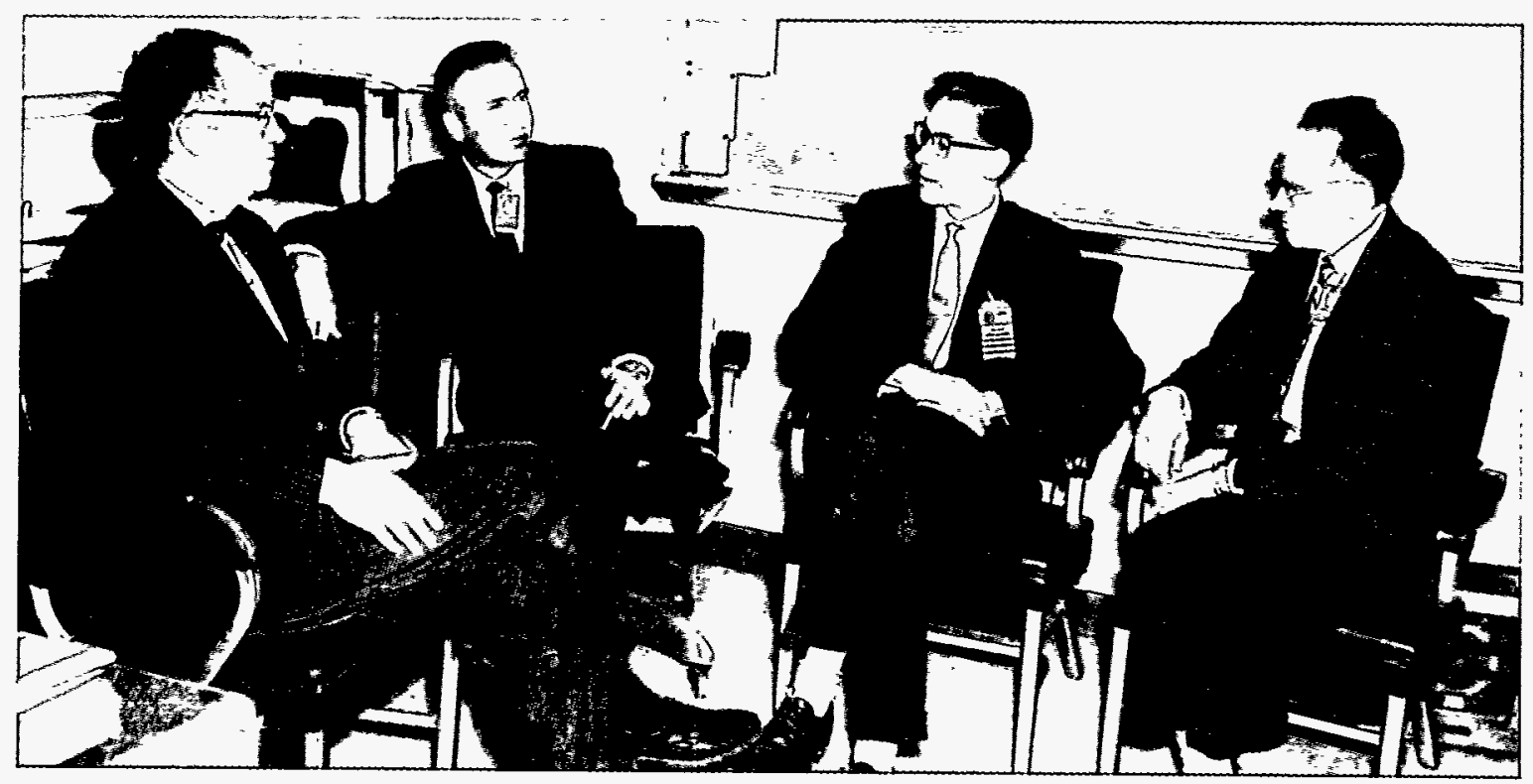

Fig. 5.1. Jim Hardy of the Atomic Energy Research Establishment (AERE), Harwell, England, was a visiting scientist in Chem Tech on a 1-year assignment to study separations chemistry. This April 23, 1963, photograph shows (left to right) Charles Blake, Keith Brown, Jim Hardy, and Charles Coleman.

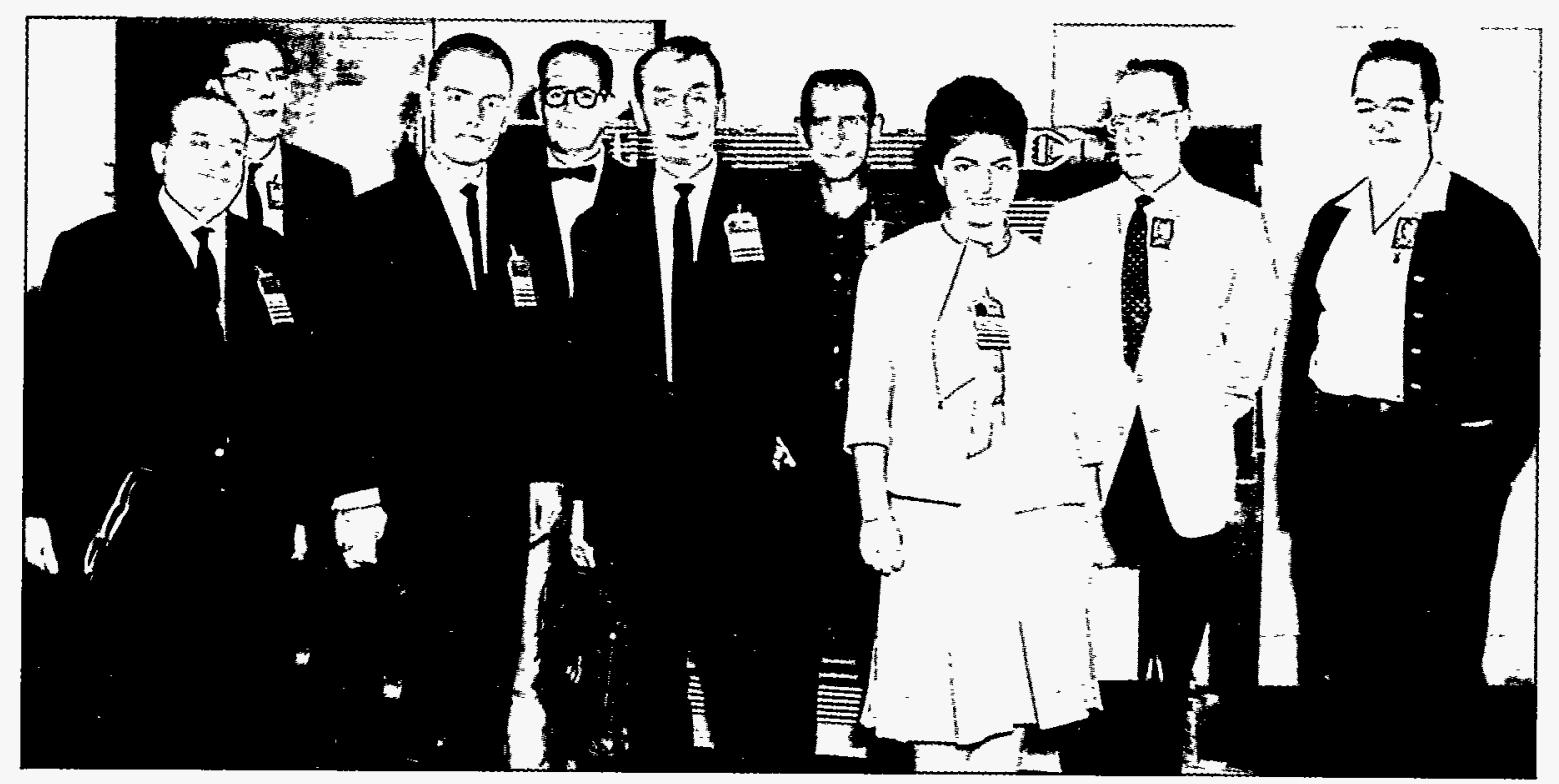

Fig. 5.2. International scientists visited the Chemical Technnology Division for discussions of extraction and separations chemistry in the fledging nuclear fuel reprocessing area. This October 19, 1962, photograph shows (left to right): Andre Grieneisen, in charge of plutonium purification by solvent extraction, Direction Industrielle, Montrouge (Seine), France; Hal E. Goeller, Chem Tech; Claude Bernard, Chemical Engineering, Saint-Gorbain Nucleaire, Courbevoie (Seine), France; Clyde D. Watson, Chem Tech; Andre Bathellier, in charge of plutonium purification by solvent extraction, Centre d'Etudes Nucleaires, Fontenay-aux-Roses (Seine), France; AI D. Ryon, Chem Tech; Michele Journet, Service Control Department, Saint-Gobain Nucleaire; Charles F. Coleman, Chem Tech; and W. (Bill) F. Schaffer, Chem Tech. 


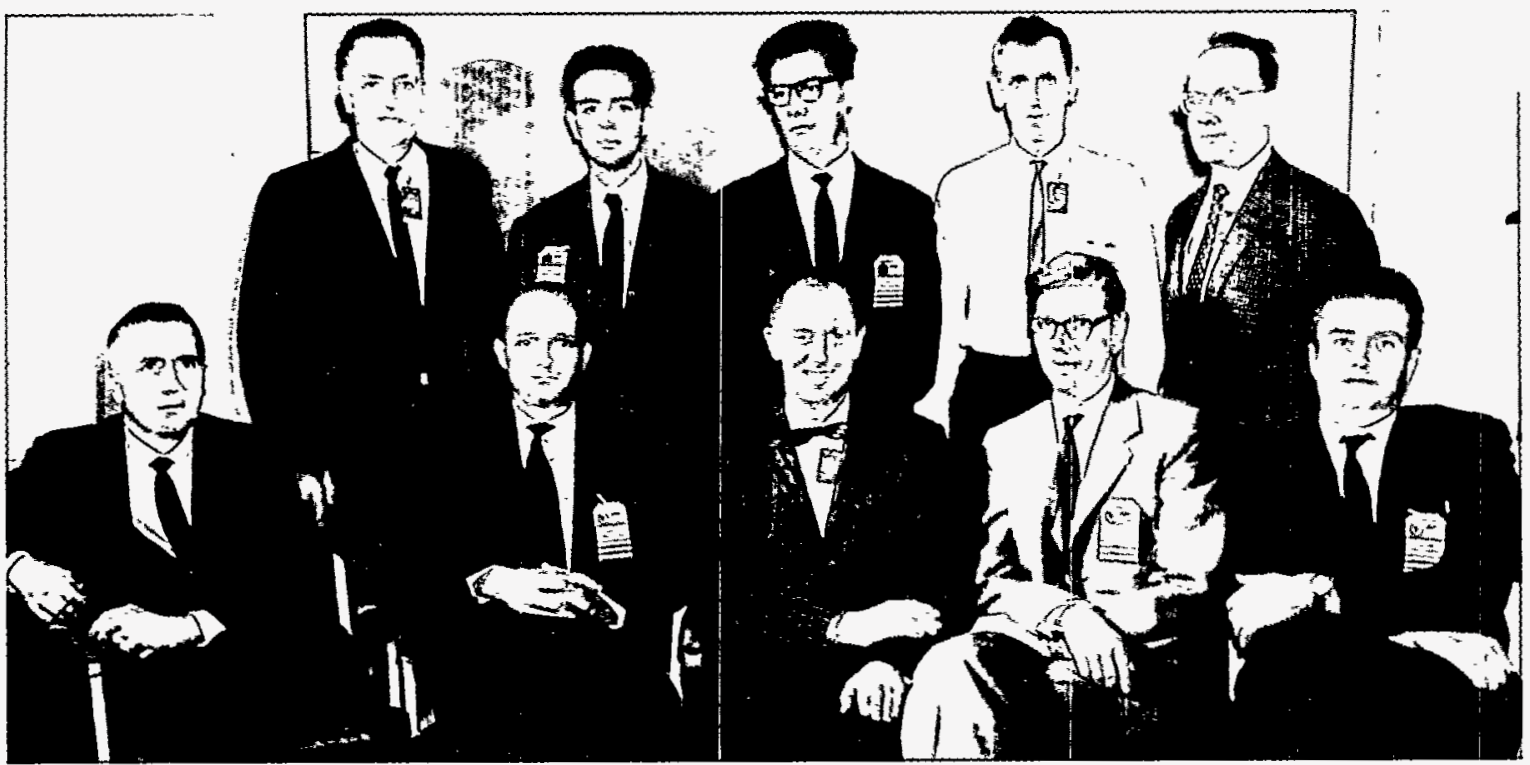

Fig. 5.3. International scientists visited the Chemical Technology Division for discussions of extraction and separations chemistry in the fledgling nuclear fuel reprocessing area. This October 30 , 1962, photograph shows seated (left to right): Keith B. Brown, Chem Tech; A. S. Kertes, Hebrew University of Jerusalem, Israel; Charles A. Blake, Chem Tech; Erik Axel Strandell, AB Atomenergi, Stockholm, Sweden; and Giacomo Calleri, CNEN, Rome, Italy. Standing (left to right): Dave Crouse, Chem Tech; G. Scibona, CNEN; F. Baroncelli, CNEN; Boyd Weaver, Chem Tech; and Charles F. Coleman, Chem Tech.

be deferred 6 months in order to graduate. I never inquired why he should write such a letter, but Dean Deering was well acquainted with my father. I didn't think about it at the time, but maybe I had political pull. I never asked my dad or mother, and they never said a word.

That extra 6 months gave me a little time to think. I was healthy and strong with no responsibilities. Since boys with families and jobs were being drafted into the army, it wasn't hard to figure out that my presence would soon be required there, too, and I had resigned myself to that.

But I underestimated my mother, who had requested a miracle. How could a farm boy expert in picking potatoes and milking cows evade the army and be chosen to process nuclear fuels? The 6-mon reprieve was nearly over when Professor Pedlow casually said, "Why don't you try for a job?" I responded how futile that would be. He answered, "I think you ought to try it." That total conversation took about $10 \mathrm{~s}$.

I had never been near a chemical plant and went to the library, where I dug out the names and addresses of ten chemical companies. My letter of application was handwritten and a bit crude. Du Pont, which was the only company that replied, asked me to come to Wilmington, Delaware, for an interview. I went home for one day after graduation with my second $1 \mathrm{~A}$ card in my pocket. Dad drove me over to Caribou to talk to my Draft Board. I asked if it made sense to try for this job and showed them my letter from Du Pont.

What a foolish question! They informed me that I was on the top of their list and started to throw my letter in the wastebasket. I retrieved my letter, Dad gave me $\$ 70$, and I jumped on a train headed for Wilmington. The interview was with a huge man behind a desk who didn't even shake hands. He had my letter in his hand and asked three questions:

1. What is biochemistry?

2. Have you had quantitative analysis?

3. Would you be willing to go to Alabama?

With a choice of Germany, Japan, or Alabama, I decided to give Alabama a try. What I didn't know was that Du Pont had been assigned the job of managing the project for producing plutonium - no small undertaking. Du Pont asked the government not to put all the boys in the Army; after all, they needed a few. I called it a miracle to get caught in that narrow slot. The Draft Board never gave up. I got $1 \mathrm{~A}$ cards every 6 mon and 
sometimes every 3 mon. Years later, I met a member of the Draft Board on the streets of Presque Isle. He said, "What on earth did you do? You were the only boy in the county that we couldn't get our hands on."

On June 4, 1942, I started work in a TNT plant in Childersburg, Alabama. This work-my first paid job-was quite mild compared with farming. I kept trying to tell myself that I was doing something worthwhile for the war effort. I didn't have the slightest hint of what was coming up. After nearly a year, I was told to report to the University of Chicago on May 10, 1943. The first thing I had to do was to sign a statement declaring that if I revealed anything, the penalty would be (1) a $\$ 10,000$ fine, (2) life imprisonment, or (3) death. It seemed a little extreme to me, but I decided this might be standard procedure in wartime.

The scope of the job was revealed to us in small groups of five or six at a time. A big man behind a desk held up a piece of uranium metal about 1 in. wide and $4 \mathrm{in}$. long and said, "We are going to make a bomb." We don't know how big it will be, or even if it will explode. It might blow up a whole city, or even a whole state."

By that time I could feel the hair on the back of my neck sticking straight out. There is no way to describe how fascinating and exciting the next few years were. It was like being transferred to a new world. My first thoughts were that we had a serious war to fight and these crazy scientists were wasting effort and resources on the most unlikely thing that could ever happen.

The fission reaction and the method of making plutonium were written down for us that first day. Natural uranium is $99.3 \%{ }^{238} \mathrm{U}$ and $0.7 \%{ }^{235} \mathrm{U}$. Only ${ }^{235} \mathrm{U}$ will fission, but ${ }^{238} \mathrm{U}$ will pick up a neutron $(n)$ and form plutonium, and ${ }^{239} \mathrm{Pu}$ will also fission.

$$
\begin{aligned}
& { }^{235} \mathrm{U}+n \rightarrow \text { Fission Products }+2.3 n+\text { Energy } \\
& { }^{238} \mathrm{U}+n \rightarrow{ }^{239} \mathrm{U}\left(\mathrm{T}_{1 / 2}=23 \mathrm{~s}\right) \rightarrow \\
& { }^{239} \mathrm{~Np}\left(\mathrm{~T}_{1 / 2}=2.3 \mathrm{~d}\right) \rightarrow \\
& { }^{239} \mathrm{Pu}\left(\mathrm{T}_{1 / 2}=\text { many years }\right)
\end{aligned}
$$

Our job was to chemically separate plutonium from highly radioactive fission products (FPs). Our leader was Arthur Compton, a Nobel prize winner in physics. This fission reaction was discovered by two Germans, Hahn and Strassmann. It was pointed out that the Germans might be ahead of us.
Methods of separating ${ }^{235} \mathrm{U}$ from ${ }^{238} \mathrm{U}$ were being pursued by other groups. But isotope separations are extremely difficult as compared with chemical separations. In addition, the separation of plutonium, uranium, and FPs had to be done with a dangerous level of radioactivity far in excess of anything ever encountered before. All operations had to be performed behind thick concrete walls. The chemistry of plutonium was not even known.

At Chicago, three different processing methods were being considered. It was known that $\mathrm{UF}_{6}$ was a gas and, therefore, might be distilled away from the FPs. It was also known that uranium salts were soluble in nonaqueous solvents, such as ethyl ether, with expectations that FPs would stay in the aqueous phase. It was found the plutonium would selectively coprecipitate in certain insoluble compounds. This carrier-precipitation method was a final choice.

I came to Oak Ridge in August 1943. The Clinton Reactor started up in November of that year. The first experiment to prove the "chain reaction" was performed in the West Stands of the football field at the University of Chicago. I wasn't there until much later, when they were still sweeping up graphite.

At Clinton Laboratories (now ORNL) we worked in the "Semi-works," on the end of Building 706-A. That was a well-designed building for pilot work. All of the floors sloped toward the drains. One end contained four shielded cells with 2-ft-thick, 20-ft-high concrete walls with exhaust fans in the top. When I first walked into that building, there was a motor-generator set and a large 8 -in. by 10 -ft-long carbon electrode. That equipment was purchased before the decision was made to abandon the fluoride volatility process.

My boss, Lu Perry, taught me how to weld. My assignment was to set the tanks, agitators, centrifuges, etc., in these four cells and install the connective piping. The first cell was for the dissolver to put the uranium, plutonium, and FPs in solution. By going through several precipitation steps, the plutonium was isolated from the uranium and high levels of radioactivity.

The first material delivered to us was in the form of $1-\mathrm{cm}$ cubes of uranium metal that had been used as targets in all the cyclotrons in the United States. After months of bombardment, the radioactivity was so low that all we had to do was wear gloves. This material was pushed into the dissolver. Next we dissolved the fuel elements from the Chicago Test Reactor, which were bare 
uranium cylinders about $2 \times 3$ in. Although this reactor had only been operated a few moments to prove the chain reaction, the fuel elements were so "hot" that we had to use a 10-ft length of 1/4-in. pipe with a vacuum cup on the end. Each slug was picked up and shoved into the dissolver. Next we picked up one slug from the Clinton Reactor, which had only been running a short time. I had the honor of going after it because I was the only one in the crew with a truck driver's license. This $1 \times 4$ in. hot slug was carried in a lead-shielded container. The radioactivity was so high that we used a 20 -ft-long wooden pole with a clamp on the end. This was very quickly shoved into the dissolver.

Each of these batches went through our precipitation, purification, and concentration steps. After one cycle of this operation, the crude slurry was collected in a 5-gal glass jug and transferred to the laboratory up the hallway. Isadore Perlman and $\mathrm{Lu}$ Werner went through the final isolation steps. After a few days, Lu came down the hallway and said, "Would you like to see what you have been doing?" In a small glass tube was a piece of green $\mathrm{PuF}_{4}$ about the size and shape of an exposed pencil lead. That was probably the greatest quantity of plutonium that ever existed up to that time.

We continued to operate the Semi-works until the main processing plant, next to the reactor, started operating. We finished off with $1 \mathrm{~g}$ of plutonium being added to our system. With the first operating nuclear reactor in the world, new discoveries were being made almost daily. C. D. Coryell, from MIT, was isolating individual fission products, measuring their energies and half-lives, and tying together parents and daughters. For a period of time, we had meetings in the Central Theater (with guards at the doors, of course), where Coryell kept us informed about these discoveries. Among other things two new elements, technetium and promethium, were produced.

In August 1944, some of us were transferred to the Hanford Site near Richland, Washington, where we operated a similar, but more sophisticated, Semi-works - one "hot" and one "cold." We arrived at Hanford during the last stages of the construction. Cement arrived in open box cars. Sand and gravel were scooped up from the desert. A big pipeline came from the Columbia River. The raw materials were all thrown together to make the 5 -ft-thick concrete walls for the processing plant. We checked the heel of liquid left in every tank and centrifuge in the processing plant before it was all closed up, never to be entered again.

The town of Richland was at the junction of the Columbia and Yakima rivers. Irrigated farms and orchards were abandoned. We gorged ourselves on peaches, apples, plums, cherries, and asparagus.

Du Pont was good enough to send most of us back to Wilmington, Delaware, with several choices of where we would like to work in their peacetime plants. I thought this might be an opportunity to get into some area of biochemistry. When asked where I got my degree, I was informed that the biochemistry course at the University of Maine was not worth $10 \phi$ and I should forget it. What I had learned in the last 3 years with Du Pont was of far greater value. That flushed my college education "down the drain" in a hurry, but I knew the reply was correct.

I was sent to the Grasselli plant in Linden, New Jersey, where I worked on two agricultural chemicals, DDT and 2,4-D. That plant, which produced bulk chemicals such as $\mathrm{HCl}, \mathrm{H}_{2} \mathrm{SO}_{4}$, $\mathrm{Na}_{2} \mathrm{SO}_{4}, \mathrm{Na}_{3} \mathrm{PO}_{4}$, alum, glass, $\mathrm{BaCl}_{2}$, and $\mathrm{SnCl}_{2}$, was a real antique. Shiny stainless steel was absent; wooden tanks were common. It was an interesting and worthwhile experience, but the crowded New York area didn't feel much like home to me. Clarence Keirnan and I were the only ones there who had transferred from the Manhattan Project. When the bomb went off in August 1945, the war ended and we were suddenly big heroes-at least for a few days.

I frequently saw Ted Arehart, who worked in a nearby Du Pont plant. When he said he was going back to Oak Ridge, that was the cue I was looking for. M. D. Peterson hired me in May 1946, and I was back in the Semi-works that I had left two years earlier. I worked in that same room for Du Pont, Monsanto, and Union Carbide.

The plutonium project was over, and now there was great excitement about the development of nuclear power. Part of that project involved nuclear fuel processing, and my first assignment was the ion-exchange separation of uranium and FPs. I looked at ion-exchange separations as an opportunity to reinforce my biochemistry since they are related to biological reactions. My supervisor, Gil Monet, left me in a few months. I had never worked without supervision before, and it took me about a year to realize that I was supposed to design and plan things myself. I entered this new world when someone asked me when I was going to write up all the things I had 
been doing. I was quite surprised since I hadn't had the slightest intention of writing anything; however, I realized I was very fortunate to have more or less accidentally landed at ORNL. There were new and extremely interesting technologies and great opportunities. I was working in the midst of some of the greatest scientists in the world. Rapid discoveries and advancements were being made in the field of ion exchange. Very early, John Swartout worked on selective plutonium extraction on the old phenolic cation-exchange resins. Fundamental and original work was being done by George Boyd, Kurt Kraus, Fred Nelson, and others. We were observing the ion-exchange behavior of each of the radionuclides produced from the fission reaction.

I claim to be among the first to work on radioactive waste. While I had no dedication to this problem, ion exchange was an effective way to extract $99.99999 \%$ of ${ }^{137} \mathrm{Cs}$ or ${ }^{90} \mathrm{Sr}$ from water. ORNL was researching many different types of nuclear reactors: a molten salt reactor for aircraft propulsion, materials test reactors, and a homogeneous liquid fuel reactor. Art Rupp was directing a radioisotope separation plant that supplied the industrial, medical, and academic world with radiotracers. We were encouraged to visit seminars of all the different ongoing studies. We attended an elementary nuclear physics course taught by Dr. Soodak. It was common for us to have stacks of technical reports on our desks in the morning. We could choose to read only the title, if uninterested, or to study each report in more detail.

A large and new biological group was starting up, largely because we now had radiotracers to follow life processes. I attended some of the seminars to see if I wanted to make a transfer. I still couldn't disconnect myself from a potato farm in Maine. My father never asked me to come back and help, but he had said once that it was a shame for a man to be sitting at a desk when he could be rolling a barrel of potatoes up a plank. I asked my older brother if it made sense to come back to the farm. His reply was, "Don't you know when you are well off?" But I was always haunted by my biochemistry degree in the College of Agriculture and the fact that I was making believe that I was an engineer. I was just enjoying this sideline avocation with the thought that I would someday get serious and return to farming.

A most interesting assignment was the extraction of FPs from 1-d-cooled $\mathrm{UO}_{2} \mathrm{SO}_{4}$ Homogeneous Reactor fuel. Cation exchange worked well for the selective extraction of uranium, but the radiation was so intense that the effect on the resin was unknown. Two questions had to answered:

1. How much radiation can ion-exchange resin receive and still be effective?

2. How can the cycle of loading the resin and then quickly taking it off be speeded up?

The answer to the first question led to exposing resin to very high levels of radiation, and I may have been among the first to do that (ORNL-1425). Finding an answer to the second question became the incentive to develop a continuous countercurrent device (ORNL-1418).

The conceptualization of this particular continuous countercurrent ion-exchange (CCIX) device in September 1951 changed the whole direction of my life. I knew it was novel and useful because Clark Center and Clarence Larson came down to my laboratory and congratulated me.

One of the earliest studies made using the CCIX involved lithium isotope separation, ${ }^{6} \mathrm{Li}$ from ${ }^{7} \mathrm{Li}$ (1953). We set up a CCIX unit and ran it for two weeks on a 24-h/d basis at total reflux. A $10^{7}$ separation of sodium and lithium was made in $3 \mathrm{ft}$ of height with a separation factor of 3 . Bill Bauman, of the Dow Chemical Company, said that was probably the highest degree of separation ever attained by using a column that short and a separation factor that low, in any mass transfer operation.

A new method of ion-exchange extraction of uranium from unfiltered leach, called Resin-In-Pulp (RIP), was introduced in Colorado. We proved that we could do this with added efficiency and had a pilot plant in Grand Junction extracting $99.8 \%$ of the uranium from an $8 \%$ pulp on a $16-t / d$ ore scale. This unit was transferred to the Y-12 Plant and, under John Googin's direction, processed all the bomb-liner scrap in the United States over a 3-year period. This RIP capability was an expectation of our "foot in the door" for getting into the mining business.

Cesium-137 has an unusual affinity for phenolic resin in alkaline solution. We did considerable study for its extraction from strong $\mathrm{NaNO}_{3}$ neutralized wastes, with the objective of making ${ }^{137} \mathrm{Cs}$ radiation sources. Interest in this system is still alive. Considerable work was also done on our ion-exchange and electrolytic process for going from "yellow-cake" to high-purity $\mathrm{UF}_{4}$. 
This process, called EXCER, was first scaled up for the Japanese.

Very early after its conception, the CCIX system was adapted by Hanford personnel for plutonium purification and concentration.

The amusing part of all this was that the AEC Patent Department declared that the CCIX device was not patentable, even though ORNL was doing so much with it. The basis was that there were about ten other patents on other continuous ion-exchange devices. So they gave the patent to me. On my own, with the able help of the Dow Chemical Company, I did receive a patent in 1957. With prodding from $M$. D. Peterson, a group of us formed the Chemical Separations Corporation in 1955. Our objective was to apply CCIX for whatever advantage it would offer to industry in general, and not only for nuclear application. M. D. Peterson, Tom Roberts, Chuck Hancher, and I were the original stockholders.

Tom Roberts came in at an opportune time. He was a chemical engineer whose doctoral thesis was on ion exchange. I was a "hit-or-miss" type of chemist. He taught me how to measure distribution coefficients, HTUs, etc., and how to use them. Tom was a perfectionist and sometimes became exasperated at how slow the biochemist was converting to a chemical engineer. But I owe everything to him, because I would never have made it without his teaching. Tom started the idea of writing a book on "Continuous Ion Exchange Process Development"; however, he accepted a position with the International Atomic Energy Commission in Austria and died early at age 51. After some struggle, I turned out the book in a crude form, but it very much lacked his input.

In the mid-1950s, ORNL was going through a "declassification" conversion. U.S. companies and foreign visitors were pouring through the Laboratory, picking up bits of new technology. It became standard procedure to drop by and see this new CCIX device, which became known as the Higgins contactor. ORNL had not only provided a tremendous boost in the early proof and development of this machine, but hundreds of potential applications were suggested by the visitors. This may have been ORNL's first technology spinoff.

The CCIX system is still viable. Many applications, including those in water, waste, fertilizer, special chemicals, and the hydrometallurgical treatment of ores, have been in operation for over 25 years.

\subsection{HISTORY OF THE CHEMICAL TECHNOLOGY DIVISION SAINT PATRICK'S DAY DANCE, KAYE JOHNSON}

From the very beginning, the staff of the Chemical Technology Division has always "worked hard." As a reward for their endeavors, they decided long ago that they should also "play hard," and what better theme for celebrations than St. Patrick, the patron saint of engineers. Approximately a year after the formation of the Chemical Technology Division, a celebration was planned for Saturday, March 17, 1951. Thus the first Chem Tech St. Patrick's Day Dance was held. The place was the Oak Terrace Ballroom in Oak Ridge, Tennessee. The music was provided by a ten-person orchestra conducted by Bill Dexter. The dance chairman was Johnny W. Clark. His subcommittee chairpersons were Ruth Pennington, decorations; Clyde Watson, entertainment; and Taylor Napier, tickets. One of the highlights of the evening was a group called the Spark Plugs, who evidently functioned successfully without a leader. The Spark Plugs included such notable characters as Frank Rogers, Garrett Parker, Ed Johns, Al Gresky, Bob Klotzbach, Bill Unger, George Sadowski, Jim Lockmiller, Virginia Malone, Cathleen Foster, and Frances Bray. The evening festivities began at nine and lasted until one. In addition to the orchestra, entertainment provided by division staff members included songs, dances, Irish music, door prizes, a quartet contest, and what was to become the traditional skit. The first skit was written by Don Ferguson, presented by Don Ferguson and Company, and lasted 8 minutes. Obvious by omission in the historical records is any description or photographs of the skit. However, it must have made quite an impression on the attendees because there has been some type skit every year for the past 42 years. Ticket sales were strictly limited to 300; in the true Chem Tech tradition, 301 tickets were sold, at a cost of $\$ 1.00$ each plus a $\$ 0.20$ entertainment tax.

Historic records show that many successful managers were strong participants in the annual St. Patrick's Day Dance activities. On August 11, 1953 , F. L. Culler was authorized to sign checks written on the Chem Tech Dance checking account. In 1953 he became the division director (Fig. 5.4). For many years after he left the division, he would 
Fig. 5.5. The ballet team featured in the Ballet Grotesque or The Dance of the Fairies are (left to right) Bob Milford, Bill Burch, Taylor Napier, Kyle Stooksbury, Dick Lindauer, Chuck Guthrie, Hal Goeller, Ray Blanco, Jack Ullmann, and John Landry.
Fig. 5.6. Bill Burch performs in the first ballet recital at the St. Patrick's Day Dance.
Fig. 5.7. Paul Haydon (left) as a cigarette girl with Larry Shappert as Peter Gum in The Scissor-Frantics skit. In the background is Tom Roberts as a checkroom attendant.
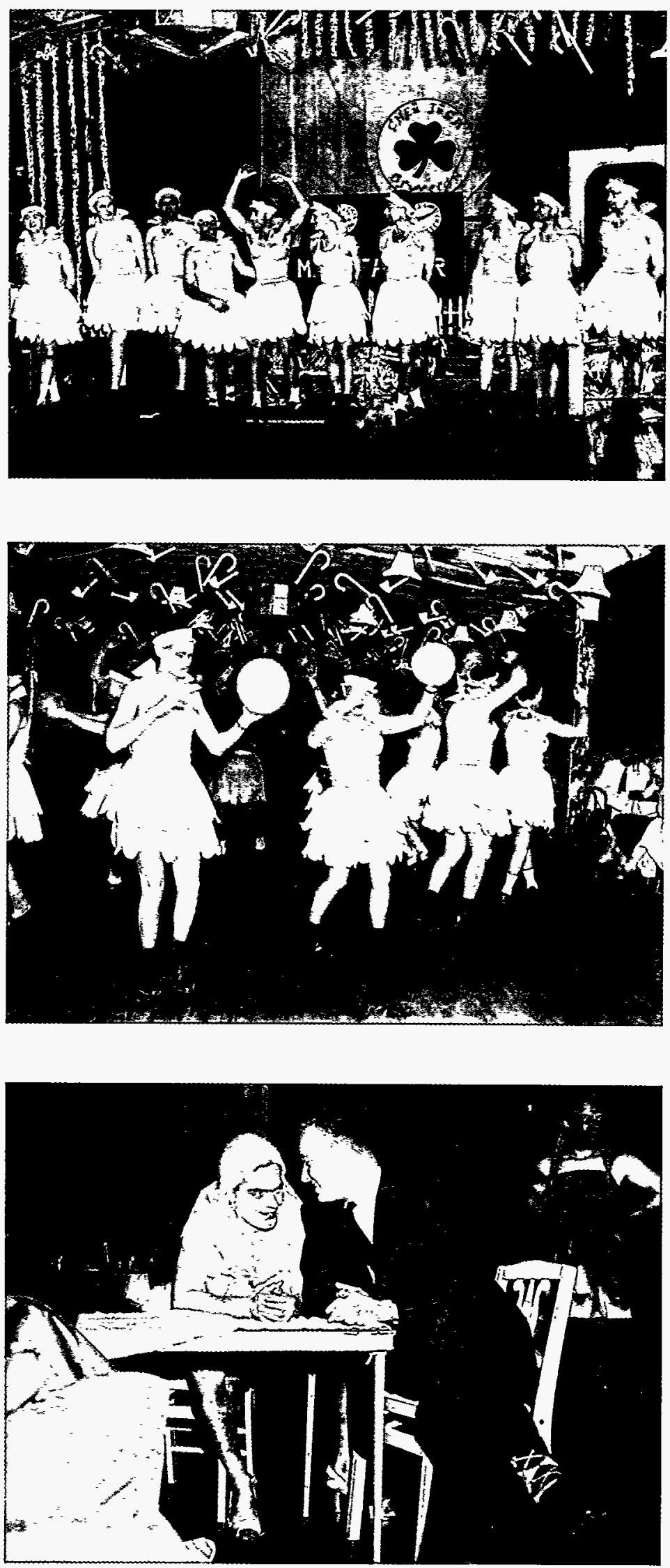
RSVP his plans to attend the dance by telegram. Sadly, the records for 1952, 1953, and 1954 do not contain any descriptive materials about the skit. However, we do know that in 1954 the production company changed its name to the Atomic Thespians.

Other notable researchers and scientists made their debut in the 1957 production of Oak Ridge Revisited. Scene IV, entitled "Ballet Grotesque or The Dance of the Fairies," featured Ray Blanco, Bill Burch, Hal Goeller, Chuck Guthrie, John Landry, Dick Lindauer, Taylor Napier, Bob Milford, Kyle Stooksbury, and Jack Ullmann (Fig. 5.5). Bill Burch, later to become Director of the Fuel Recycle Division, performed in his first ballet recital in Fig. 5.6.

In 1959 coaches were chartered and the dance was held at the Beaver Brook Country Club in Knoxville. WCTD, the division's "Thru Channels" Station, presented The Scissor-Frantics, starring Larry Shappert as Peter Gum, with Paul Haydon and Tom Roberts as the cigarette and checkroom girls (Fig. 5.7). Larry Shappert was not seen or heard of again until 1962, at which time he served as chairman of the dance committee.

The decade of the sixties brought America protesters to the Vietnam War, long-haired hippies, and Woodstock. It brought Chem Tech
Brenda Light, Janice Shannon, Jimmy T. Bell, and Martha Stewart. The following is a list of the dance skits developed and presented during that decade:

$\begin{array}{ll}1960 & \text { Beauty and the Beasts } \\ 1961 & \text { Please Mr. Collar } \\ 1962 & \text { The KKK, Kollar's Kemical Kollege } \\ 1963 & \text { The Wonderful World of Collar } \\ 1964 & \text { School Daze } \\ 1965 & \text { Coldfinger } \\ 1966 & \text { A Night on CTD TV } \\ 1967 & \text { A Happening } \\ 1968 & \text { Do You Remember } \\ 1969 & \text { CTD Laugh-in or Misinformation } \\ & \text { Session of 1969 }\end{array}$

It is hard to overlook the talent that Les King, Chairman of the 1962 Program Committee, discovered that year. First, there was Alice McWilliams in her famous fishnets (Fig. 5.8). Next, was Fred Kitts and Vic Fowler in their bold horizontal-stripe motif (Fig. 5.9). Last, but not least, was John Bigelow in his virgin cells attire (Fig. 5.10).

As the Chem Tech Division grew in number of employees, patents, discoveries, publications, and technical expertise, the one thing that remained unchanged over the decades was the acting ability

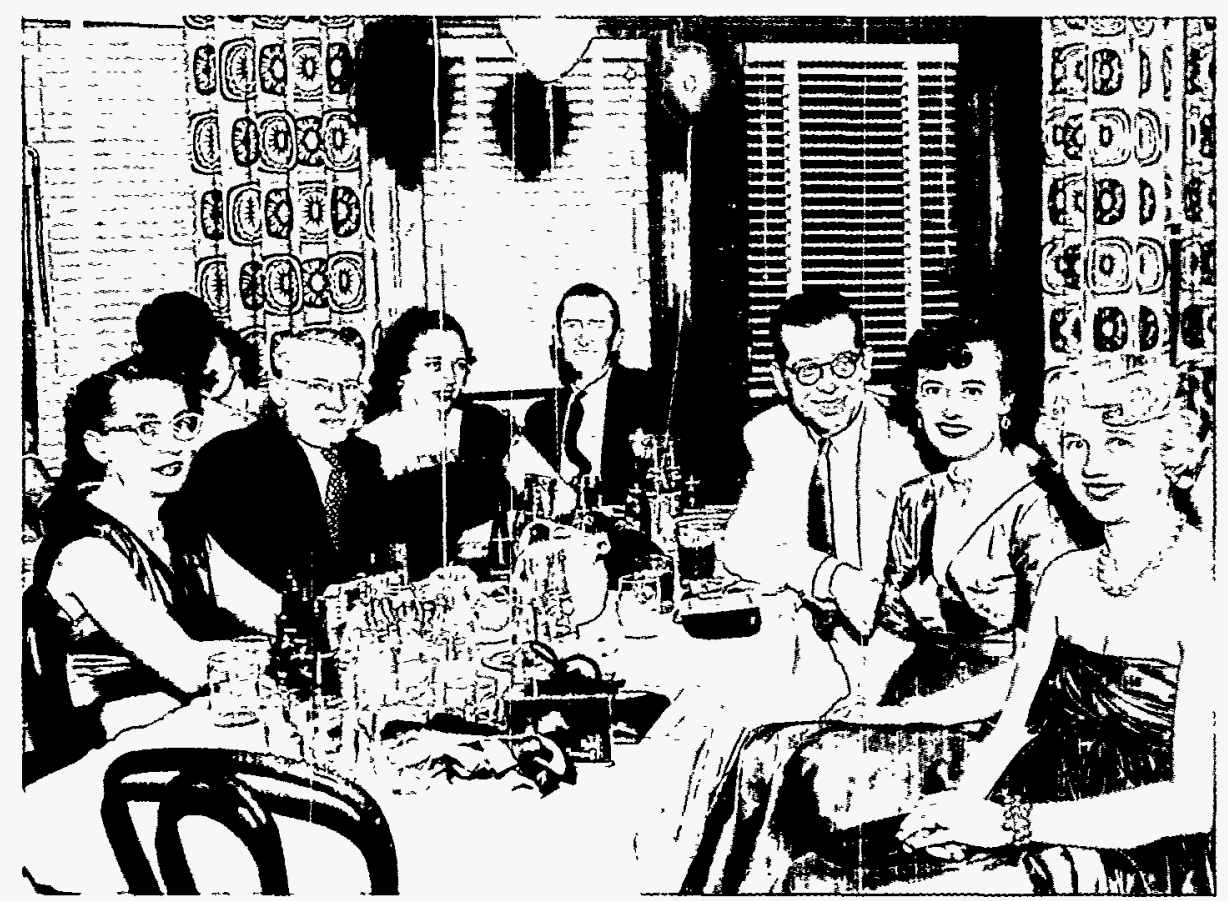

Fig. 5.4. Floyd Culler with Chem Tech guests at an early St. Patrick's Day Dance. Left to right are as follows: unidentified, Edgar J. Murphy, Lib Corbin, Larry Corbin, Culler, Della Culler, and Delores Browder. 


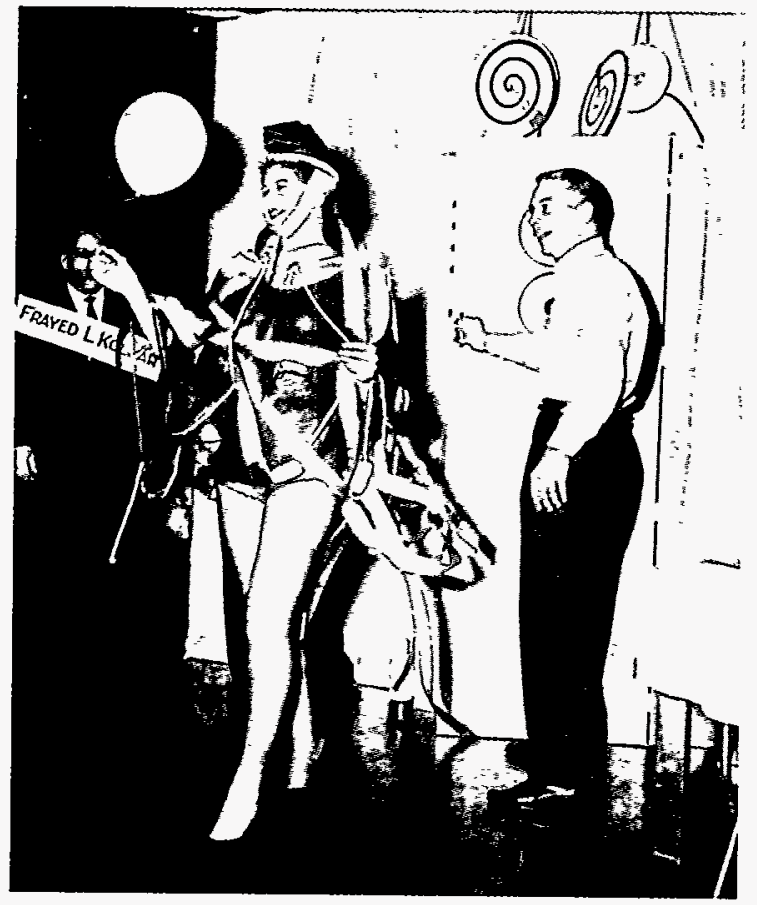

Fig. 5.8. Alice McWilliams in her famous fishnets with Bruce Finney as Frayed L. Kollar and Vic Fowler as the doorman.

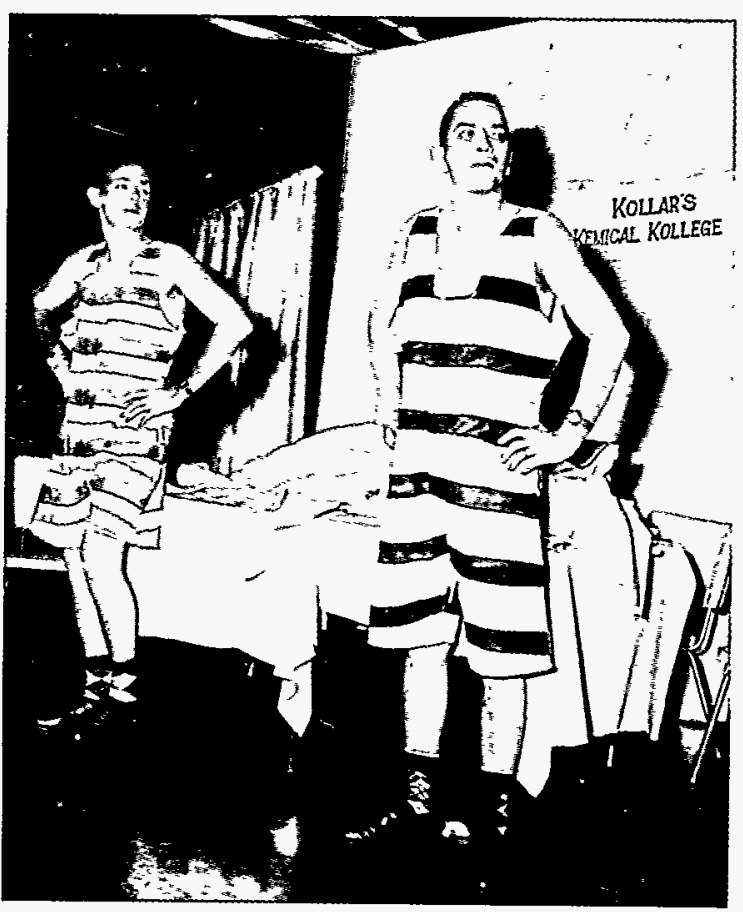

Fig. 5.9. Fred Kitts (left) and Vic Fowler as inmates in Kollar's Kemical Kollege.

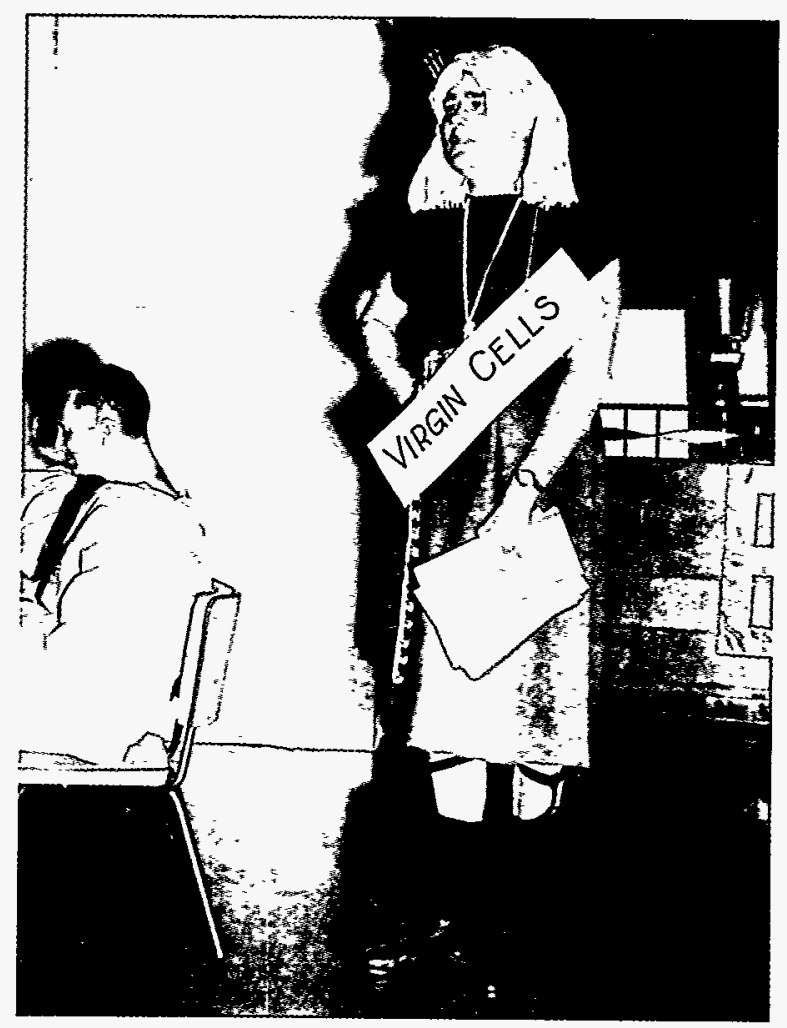

Fig. 5.10. John Bigelow as Virgin Cells with Bob Rainey in the background in the 1962 Kollar's Kemical Kollege skit. 
of the St. Patty's Day Dance casts and the caliber of the skits that were written.

The dance activities of the seventies were equal to previous years' events in every possible way. In 1971, the archives show that " 203 people attended the social hour and consumed 2.0 gallons of unspiked punch, 10.3 gallons of spiked punch, and 16 pounds of potato chips and peanuts." The skit that year, one of the dance's earliest musicals, was entitled The Devil Made Us Do It, starring Eldon Arnold, George Dinsmore, and

Steve Goldberg. The original score was provided by John Holmes. The words to one of the songs sung in this production have proven to be ageless. Sung to the tune of "America, The Beautiful," the words are as follows:

Oh beautiful for smoggy skies,

Insecticided grain,

For strip mines, mountains, majesty

Above the asphalt plain.

America! America!

Man sheds his wastes on thee,

And hides the pines

With billboard signs

From sea to oily sea.

The Happy Hippy Flowerpot Dance Company, who also made their appearance that year, consisted of Linda Knauer, Donna Fitzgerald, Nancy Pope, Linda Loveday, Les Hubbard, Mike Hartsell, Bob Oliver, and Kyle Stooksbury.

Remarkably, only two Chem Tech St. Patrick's Day Dance skits have gone down in infamy at ORNL. The first was M. Hartman, M. Hartman, which premiered Friday, March 18, 1977, in the Social Hall of St. George's Greek Orthodox Church in Knoxville, Tennessee. The idea was to produce the first (and, to date, final) full-length (25-min) feature movie. The subject of the movie was a parody on lab activities. The cast consisted of Ron Glass, Ray Barker, Mike Gilliam, Jan Talbot, John Parrott, Jr., Brad Weil, Bill Eldridge, Tom Dinsmore, John Younghanse, the remaining Chem Tech section heads, and the CTD associate directors. Rex Leuze only agreed to appear in the production because he was told that the last scene was to be a pie fight among the section heads, and Rex wanted to throw a pie in Chuck Scott's face. Chuck Scott did not show up for the filming. The movie cost $\$ 165$, which included the developing of 20 rolls of film. The reason the film is legendary is because the pie fight was filmed in Building 4505 Conference Room and the janitorial crew was not pleased with having to clean up the mess. As a result, an official ORNL announcement was issued that effective immediately film crews were not allowed on the site without official permission. Postscript: Jim Snider won the door prize that year, a magnum of New York State champagne.

The second infamous skit was Martina Marietta and the Seven Benefits, presented in 1984. In true Chem Tech tradition, this production was quite topical and timely in that it tried to capture all the concerns about the potential change in company benefits as a result of the Department of Energy changing its Oak Ridge Operations contractor from the Union Carbide Corporation, Nuclear Division, to Martin Marietta Energy Systems, Inc. The cast consisted of Beverly Sweeden in the title role and the seven benefits played by Suman Singh, Becky Hamley, Debbie Weaver, Karen Pannell, Donna Snow, Martha Dawson, and Mary Ann Neal, with Millicent Drake, Otis Scates, Phil McGinnis, Ray Wymer, and Bob Hightower. The production was narrated by John Parrott and directed by Jonathan Woodward and Bob Wham. All preparations, plans, rehearsals, and costume preparations were going well when suddenly, 2 days before the dance, an official complaint was registered with the ORNL Affirmative Action Coordinator. Ray Wymer, the division director at the time, was called and told to take down all posters and pictures advertising the dance. It seems that someone in another division felt that the women in the production were being exploited. And so, after 33 consecutive years of presenting a skit, the division officially scored poorly with the theatrical critics. The offensive picture is presented here for an objective opinion (Fig. 5.11).

We believe the Chemical Technology Division Annual Saint Patrick's Day Dance is, by far, the longest running social activity of any division at ORNL. In 1992 the division celebrated the 43rd annual event. A skit entitled Weekday at Begovich's proved beyond the shadow of a doubt that theatrical talent in the division has been maintained and that very little, if anything, has been lost in the tradition of skit writing. The purpose of the first and all subsequent skits was to allow the staff an opportunity to poke fun at the management of the division. This concept was the forerunner of what is know today as stress management. 


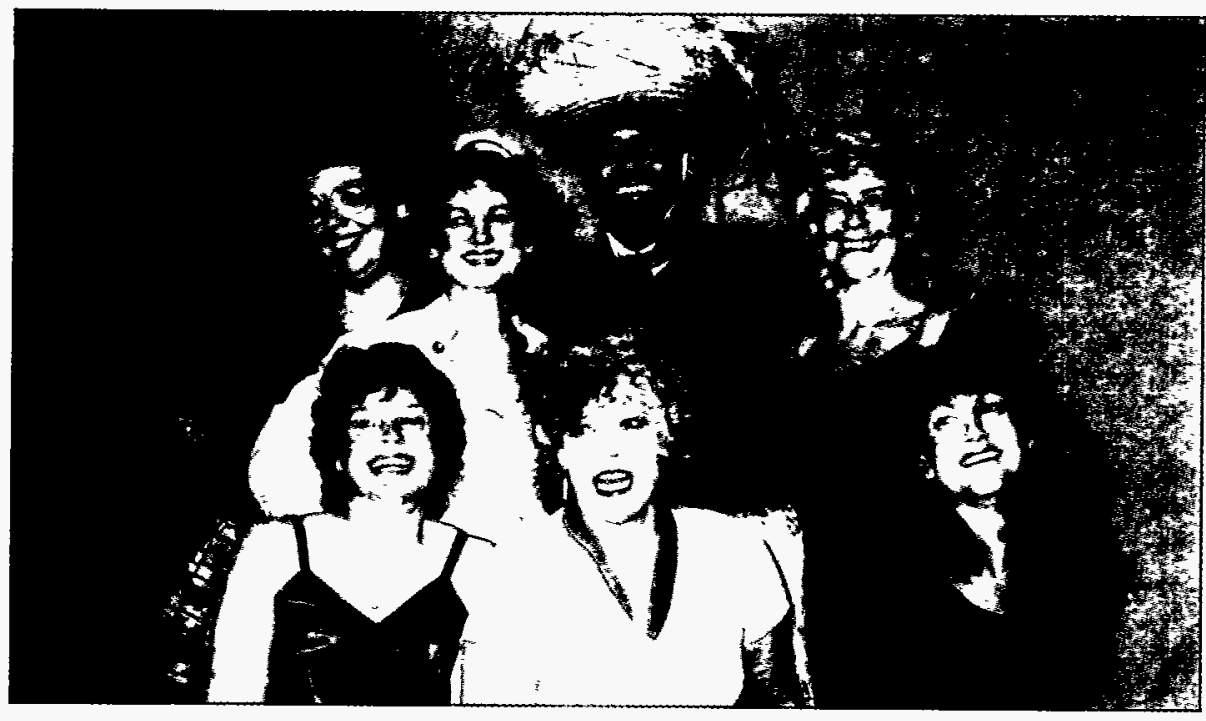

Fig. 5.11. Clockwise from center are Suman Singh, Mary Ann Neal, Donna Snow, Beverly Sweeden, Becky Hamley, Martha Dawson, and Karen Pannell as actors in the 1984 Martina Marietta and the Seven Benefits skit.

\subsection{OTHER RECREATIONAL ACTIVITIES}

Over the years, Chem Tech personnel participated in every, recreational opportunity made available to ORNL employees. Although a thorough search of ORNL News items was not attempted, several examples follow.

Bowling. Many Chem Techers were avid bowlers. Figure 5.12 shows Bill Burch receiving an award for bowling a perfect game.

Softball. Both fast pitch and, later, slow pitch softball teams were sponsored by Chem Tech. A 1955 fast pitch team is shown in Fig. 5.13. A slow pitch Chem Tech Pilot Plant team was fielded in the late 1960s, as shown in Fig. 5.14.

White water. During the mid-1960s, several Chem Techers participated in white water activities sponsored by the Carbide Canoe Club. An especially favorite float was the 10-mile trip on the Emory River from Nemo Bridge near Wartburg, Tennessee, to Oakdale after heavy rains. John Landry and Arnold Lyle are shown in Fig. 5.15 amidst the roaring white waters of the Emory River on a July 17,1967 , float trip following a heavy rain in the Cumberland Plateau. The summer of 1967 had frequent heavy rains, and Arnold and John are shown on an August 5, 1967, Emory River float in Fig. 5.16. The end product or conclusion of that float is shown in Fig. 5.17.

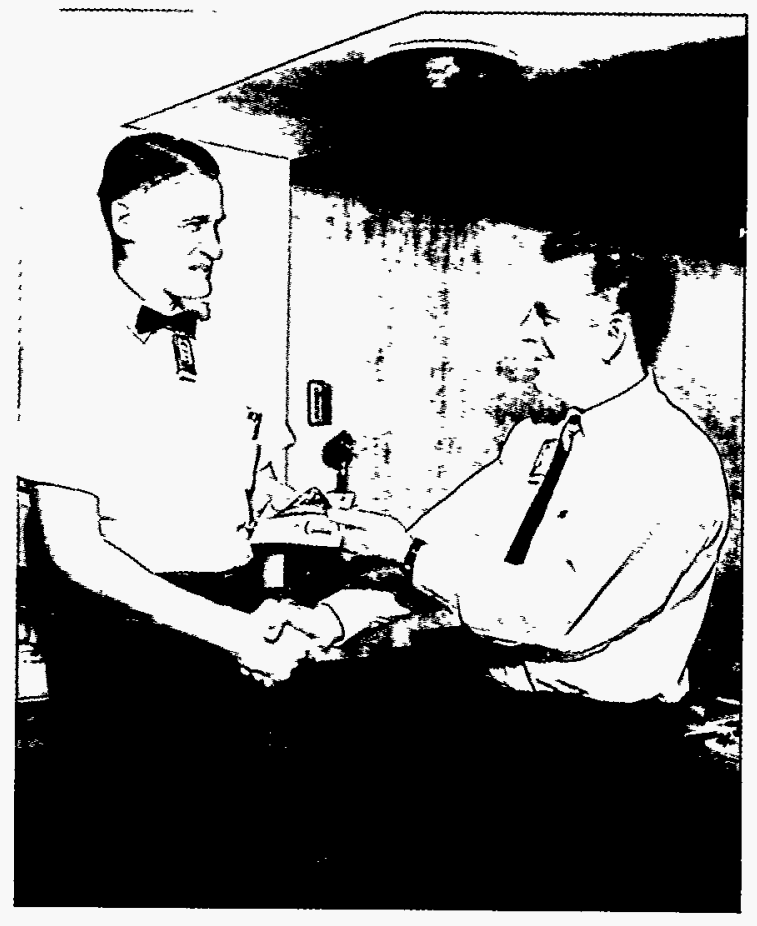

Fig. 5.12. Bill Burch (left) receiving a bowling award from the ORNL Recreation Department manager.

Bob Jolley is shown running a rapid solo on the July 17 Emory River run in Fig. 5.18 and with his son Richard on the August 5 Emory River Run (Fig. 5.19). 
Fig. 5.13. The 1955 Chem Tech fast pitch softball team members were, front row, left to right, Marvin Whatley, unidentified, Vic Fowler, and John Parrott, Sr.; Back row, left to right, unidentified, unidentified, unidentified, Sam Clinton, Pete Newman, Milt Lietzke, Arky Vaughn, and Bob Blair.

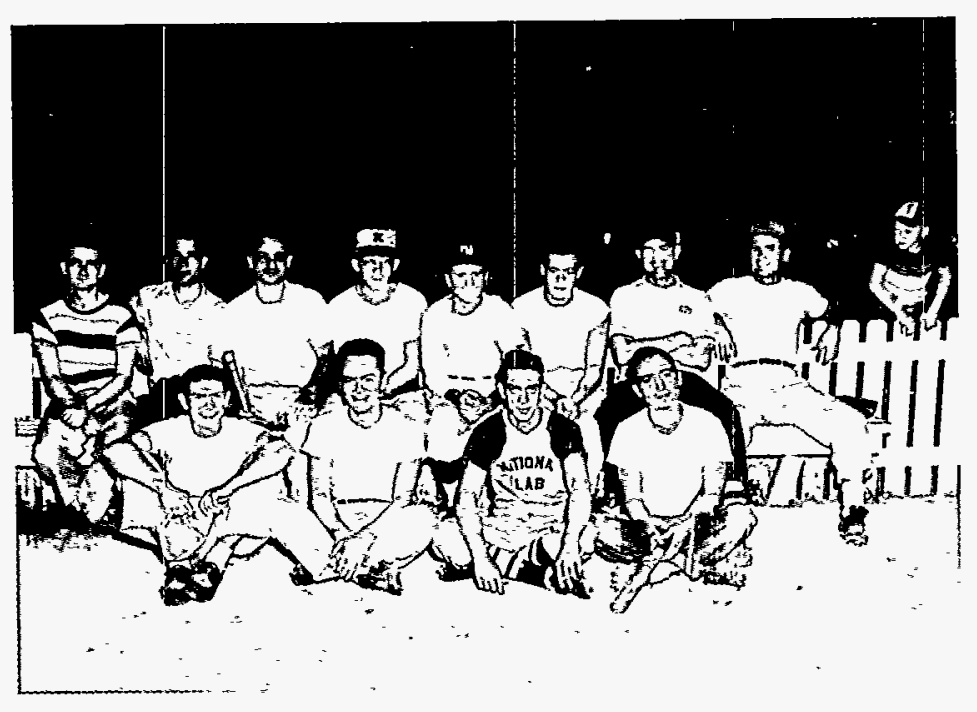

Fig. 5.14. The Chem Tech Pilot Plant slow pitch team, approximately 1967 , members were, first row, left to right, Fred Chattin, Jerry West, and Joe Tinley (I\&C Division); second row, left to right, unidentified, Sam Shell, Fred Kitts, Bill Lindsey (team manager), Ron Cooper, Bob Shannon, and unidentified; back row, left to right, Jerry Beeler (P\&E Division), Rob Waters (K-25), Ray Cooper (Health Physics Division), Don Taylor, Ray Bolden (P\&E Division), unidentified, Bill Stines (M\&C Division).

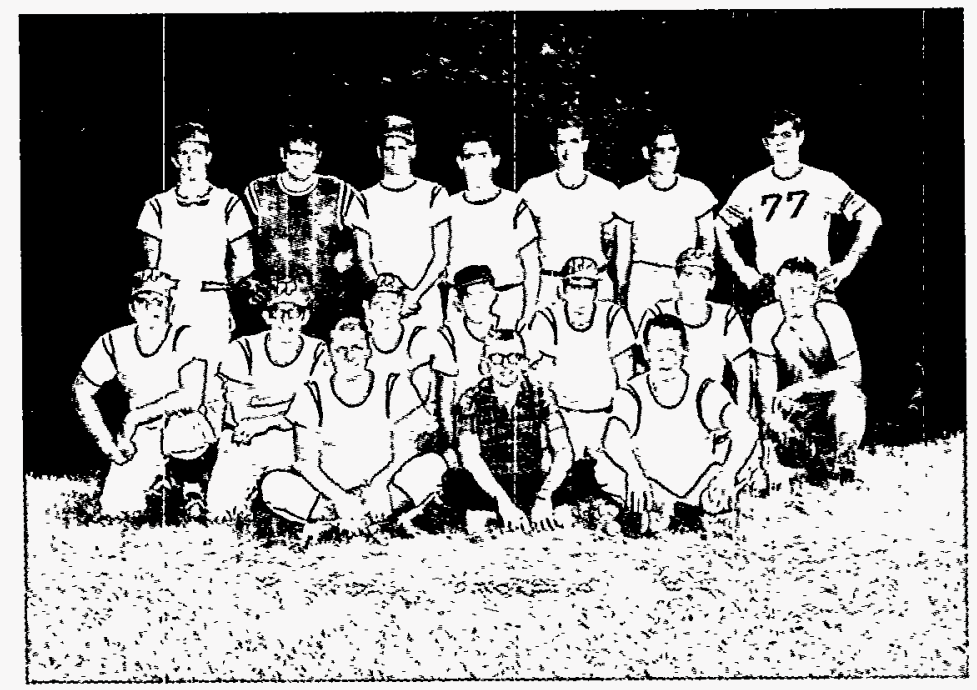

Fig. 5.15. John Landry (left) and Arnold Lyle approach a monstrous standing wave on the July 17, 1967, Emory River float trip.

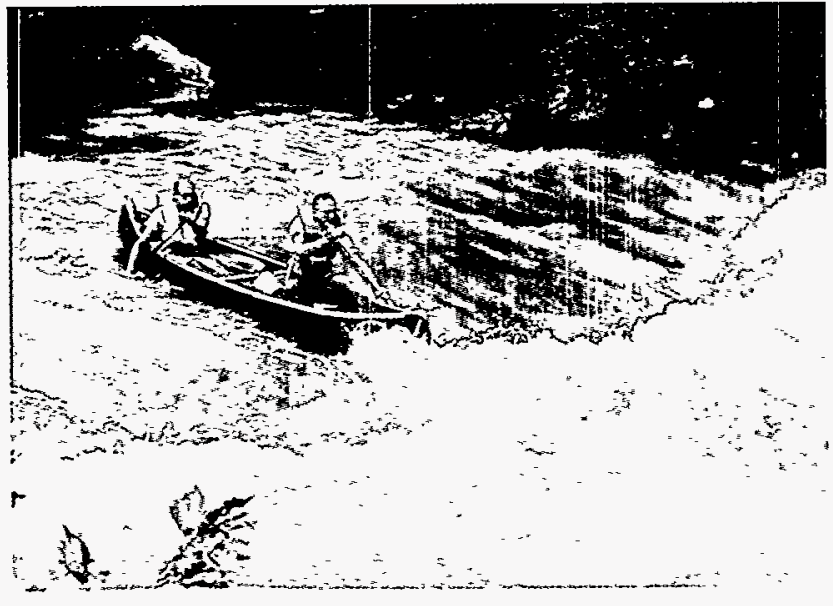




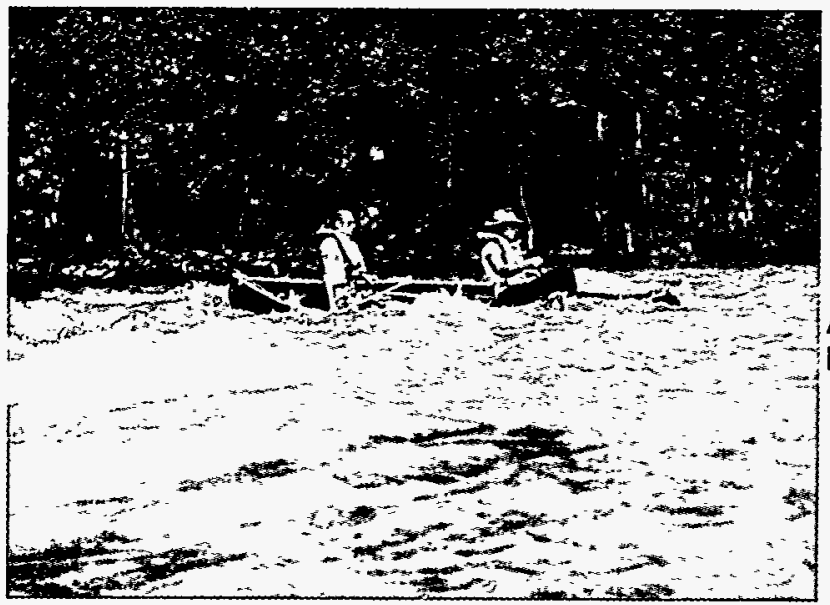

Fig. 5.16. John Landry (left) and Arnold Lyle on the August 5, 1967, Emory River float.
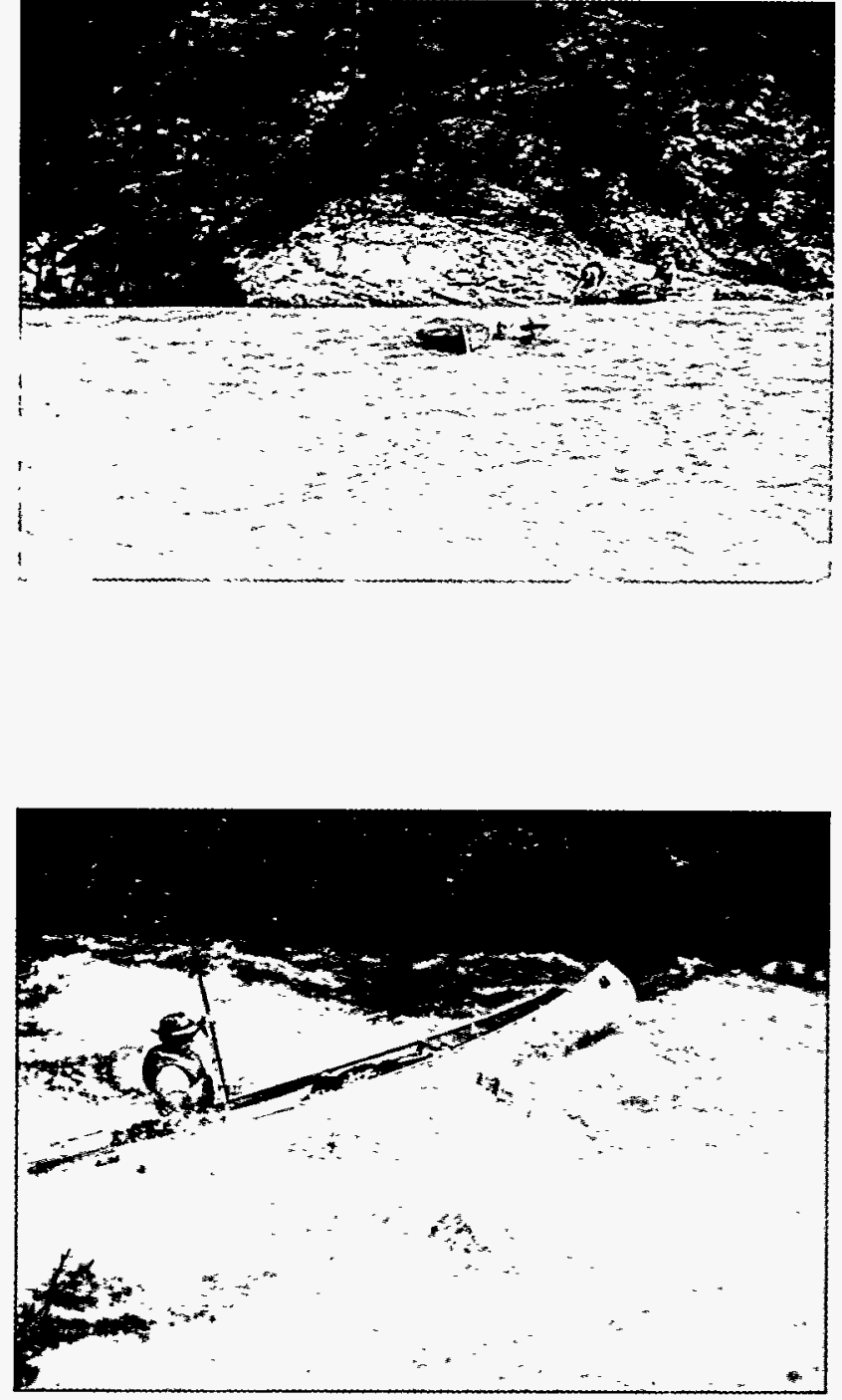

Fig. 5.17. John Landry and Arnold Lyle (still with hat) are shown with capsized canoe. Such a conclusion following a large rapid was often encountered.
Fig. 5.18. Bob Jolley ran the 10-mile float solo on the July 17, 1967, Emory River float and encountered some heavy white water. 


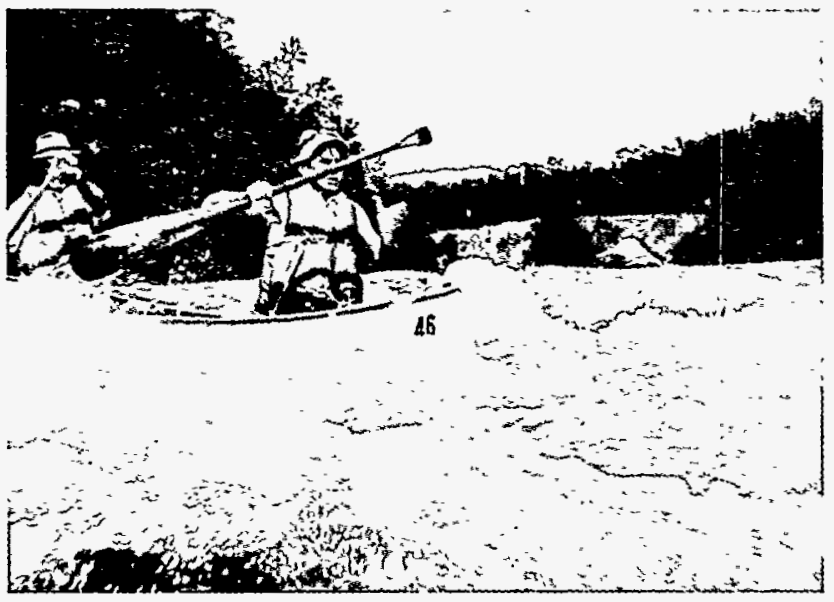

Fig. 5.19. Bob Jolley and son Richard Jolley negotiate a rapid on the August 5, 1967, Emory River float trip.

\subsection{THE 25,000-GALLON DEMONSTRATION, July 27, 1994, Joe Perona}

"It was bound to happen, sooner or later," they said, feeding frogs to the alligators living in the crater, watery and dank, where once stood the 25,000-gallon tank.

The order had come from HQ to Trivelpiece, to Fulkerson, then to McNeese, to Robinson, who said to the Section, "Upon us rests the coming election."

"The Republicans say the waste money was frittered away on research and the country is littered with mixed waste galore, and they are strongly

hint'n

that the blame lies squarely on President Clinton."

"So HQ has decided, in a blizzard of memos that the answer lies in the mother of demos, a demonstration to appease the taxpayers, the chamber of commerce and other naysayers."

"What waste shall we treat?" Robinson to McNeese, to Fulkerson, then to Trivelpiece, to DOE Headquarters in their marble hall the answer came back, "Well, of course, all."

All? you mean strontium and cesium, colbalt and technicium, mercury and PCB's,

uranium and VOC's?

Those and the rest, the reply was emphatic, the result will not be problematic, future DOE funding requires success, so show us how you'll treat this mess.

The section agreed regardless of rank, that only 25,000-gallon tank, had sufficient capacity despite all the dangers,

of mixing wastes and reagents, like ion exchangers.

Ferrocyanide for cesium, plenty of resorcinol

Savannah River resin, too many others to recall,

Mersorb for mercury, and what about the PCB's?

Thomas' solvated electrons, and whatever else you please.

The chemicals were carried to the platform over the tank

The aroma was impressive, some even thought it stank.

Three days it took to load them in, topped off with liquid ammonia,

Thomas said, "Sweden is too close, I'll watch from Estonia."

Tommy Hylton said to Cummins, "We'll mix it with the jet,

Youngblood will give the signal when the observers are all set."

The visitors from Washington had invited the reporters,

EDS folks were not too pleased, but had to follow orders,

Politicians on the platform, waving to the crowd, when the tank began to rumble, at first not too loud, then a little tremor started and a potential field detected,

flashes of blue light were seen, solvated electrons were suspected.

Cummins threw the diesel switch while Hylton studied graphs,

"It'll mix in 13 minutes," he said, and then ... Lloyd laughed,

because a bolt of lightning had struck the tank in half a second, 
"that no doubt will mix it up," Lloyd said, "much faster than we reckoned."

And melted a hole in the northeast head, from which hot gases flashed,

"looks like a saturn rocket" Cummins said, just as he dashed,

then the tank lifted off majestically and accelerated south as it disappeared over Melton Hill, Lloyd said, "Well, shut my mouth."

The tank was never seen again, and Headquarters was delighted,

"I wasn't so sure," Robinson said, "when the tank first ignited,

but the waste is gone forevermore, and best of all, just remember,

not a single permit was required, we'll do it again in September." 


\section{APPENDICES: THE CURTAIN REMAINS OPEN}


, 
APPENDIX A

A.1 ORGANIZATION CHART FOR THE METALLURGICAL
PROJECT, UNIVERSITY OF CHICAGO, JANUARY 23, 1943

A.2 ORGANIZATION CHART FOR THE TECHNICAL DIVISION, OAK RIDGE NATIONAL LABORATORY, 1948 
$\because 4$ 
APPENDIX A.1

ORGANIZATION CHART FOR THE METALLURGICAL PROJECT, UNIVERSITY OF CHICAGO, JANUARY 23, 1943

ORNL DWG 92A-658

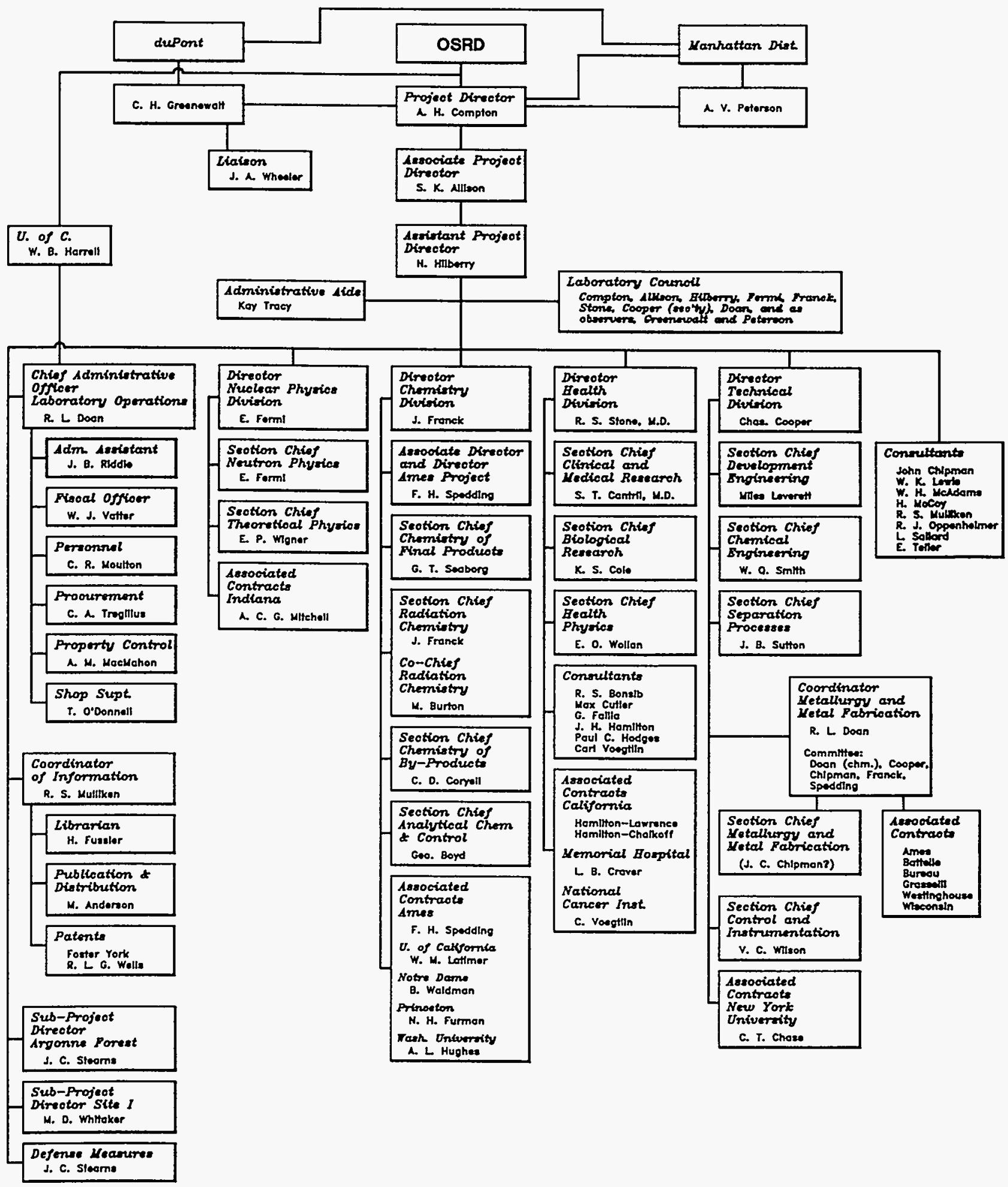





\section{APPENDIX A.2 \\ ORGANIZATION CHART FOR THE TECHNICAL DIVISION, OAK RIDGE NATIONAL LABORATORY, 1948*}

M. C. Leverett-Director

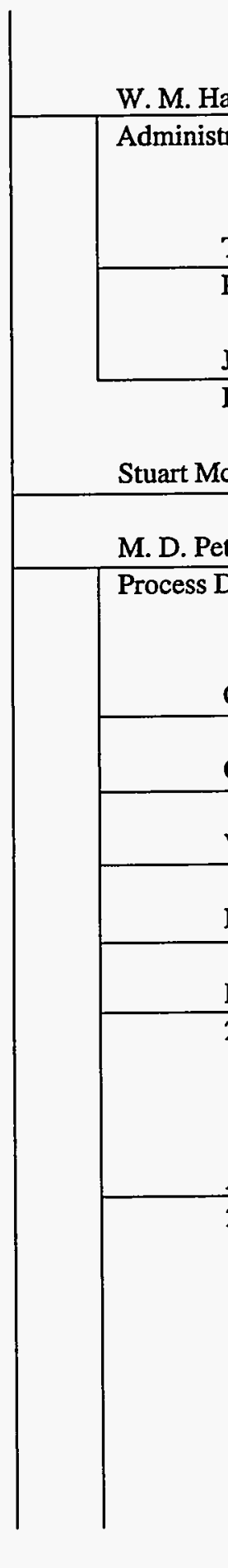

Ethel Tuttle, Sec.

Louise Bond, Sec.

Eleanor Pippin, Sec.

Evelyn Gilliland, Clerk.

Jane Snow, clerk.

Eunice Greenway, Sec.

Projects \& Safety

J. R. Whitlock, Administration Assistant

Procurement

Virgil Reynolds, Clerk June Hale, Clerk

Jean Kuna, Sec.

Marie Wolfe, Sec. Agnes Hair, Typist Ann Leinart, Sec.

C. W. Schersten, Assistant to Chief

C. D. Watson, Assistant to Chief

W. K. Eister, Assistant to Chief - Semi-Works

F. L. Steahly, Assistant Chief - Laboratory and Plant Assistant

D. E. Ferguson, R. E. Leuze, Group Leaders

J. L. Bamberg, Tech. 23 Extraction

G. C. Balock, Tech.

R. C. Lovelace, Tech.

(J. W. Gost) (C. V. Ellison)

H. F. Soard, Tech.

A. C. Jealous, F. R. Bruce, Group Leaders

R. O. Chambers, Tech. 25 Extraction

G. B. Dinsmore, Tech.

J. E. Farmer, Tech.

F. N. Browder

J. O. Davis

G. R. Guinn, Tech.

E. O. Nurmi

Guy Jones, Tech.

G. A. West

W. H. Luster, Tech.

W. A. Horne - Shift Supervisor

F. L. Rogers, Tech.

W. E. Shockley, Tech.

C. D. Hylton - Shift Supervisor

J. W. Smith, Tech.

*This organization chart for the Technical Division was supplied through the courtesy of Dr. Miles Leverette, Director of the Technical Division, 1943-1948. 
F. R. Bruce, Group Leader, 25 Extraction

R. E. Blanco

Arlene Kibbey

W. B. Lanham

L. P. Morse

A. T. Gresky-Special Assignment

M. R. Poston, F. N. Browder, Group Leader

Solvents

F. L. Steahly

D. C. Overholt

T. C. Runion

W. K. Eister

I. R. Higgins

J. B. Ruch

C. D. Watson

G. A. West

R. B. Briggs. Chief, Section T-II Engineering Development

S. B. Beall, Leader - Control Elements Group

T. H. Mauney

J. Reed, Leader - Corrosion Group

O. Sisman, Leader - Pile Irradiation

Engineering Assistant Group

R. Van Winkle, Leader - Scale Formation and Water Treatment Group

C. D. Bopp

J. B. Chrisney

W. B. Allred, Leader - Strength of Materials Group

H. C. Savage

W. H. Stromquist - Special Problem

C. E. Clifford - Special Problem

C. P. Coughlen
A. Johnson, Janitress

C. A. Clark, Tech.

L. A. Byrd, Tech.

W. B. Howerton, Tech.

Vannesse Orr, Tech.

E. R. Johns, Tech.

D. Q. White, Tech.

B. I. Bailey, Tech.

Gladys Howser, Tech.

J. M. DeLozier, Tech.

V. L. Fowler, Tech.

R. B. Quincy, Tech.

T. D. Napier, Tech.

Thelma Sutton, Sec.

A. L. Davis, Tech.

J. J. Hairston, Tech.

W. Kirkland, Tech.

J. L. Stepp, Tech.

R. L. Towers, Tech.

C. M. Burchell, Tech.

W. B. Krick, Tech.

R. Smith, Tech.

G. H. Johnstone, Tech. 
(B. W. Kinyon)-Research Shops Coordinator

J. R. Huffman, Chief, Section T-III - Process Design

Mary Dougher, Sec.

C. F. West, Jr. - Administrative Assistant

D. Nicoll, Assistant Chief

C. E. Winters, Associate Section Chief
A. D. Mackintosh

J. A. Lane, Associate Section Chief

R. M. Jones, Joint Leader, Group A

C. W. Day, Draftsman

Pile Proper

N. E. Hill

R. C. Allerbe, Draftsman

A. S. Ludlow, Draftsman

D. Nicoll

H. W. Watts. Draftsman

S. Scott, Jr.

(C. A. Roberts), Draftsman (Sue Eatherly), Clerk

J. T. Weills, Joint Leader, Group A, Pile Proper

W. S. Farmer

W. G. Stockdale

G. Hovorka, Leader, Group B - Pile Buildings

F. C. McCullough, Leader, Group C - External Systems

W. R. Gall, Leader, Group D - Pile Mockup

D. J. Mallon

J. R. McWherter

R. A. Long

W. E. Unger

F. C. Zapp

F. L. Culler, Leader, Group E - 1200 - 1300 Areas

G. Hanson

H. E. Goeller

R. L. Klotzbach

R. P. Milford 
J. A. Kyger, Chief, Section IV

Engineering Materials

W. L. Cockrell, Assistant Chief

F. A. Kocur - Individual Assignment

C. D. Smith, Leader, Group A

G. M. Adamson

H. Wallace

F. W. Drosten, Leader, Group B

J. T. Howe

D. A. Lawson

V. L. McKinney

F. Kerze, Leader, Group C

G. M. Carlton

J. E. Cunningham

W. H. Wilson

J. L. English, Leader Group D

A. R. Olsen

S. H. Wheeler

T. Rockwell, Leader, Group E

F. J. Roehrenbeck

(J. H. Erwin)

R. N. Lyon, Chief, Section V - Engineering Research

D. G. Reid, Chief Supervisor, Acting Chief

Section VI - Pilot Plant

H. M. Feder, Assistant Chief Supervisor

H. K. Jackson

M. Levenson, Assistant Chief Supervisor
Ruby Bullard, Sec.

Susan Comish, Sec.

F. Blackshere, Tech.

C. F. Cutcher, Tech.

J. H. Day, Tech.

J. N. Hix, Tech.

C. C. Cooley, Tech.

R. N. Tench, Tech.

(Harry Seaman), Machinist

C. C. Hurtt, Tech.

Jeanne Doran, Sec.

R. F. Benson, Operator

H. S. Caldwell, Operator

H. G. Chambers, Operator

G. Davis, Operator

L. L. Fairchild, Operator

C. A. Gifford, Operator 


\begin{tabular}{|cl}
\hline K. K. Kennedy, Senior Supervisor & F. M. Grizzell, Operator \\
& J. H. Groover, Operator \\
W. H. Carr & W. Jenings, Operator \\
& C. H. Jones, Operator \\
& \\
E. L. Nicholson, Senior Supervisor & J. Land, Operator \\
& W. E. Ledbetter, Operator \\
G. Sadowski & J. F. Lockmiller, Operator \\
& T. R. McLellon, Operator \\
& J. R. Ogle, Operator \\
N. J. Rigstad, Senior Supervisor & R. P. Purkey, Operator \\
& M. Richardson, Operator \\
B. B. Harrington & H. E. Sexton, Operator \\
& \\
A. M. Rom, Senior Supervisor & E. E. Shields, Operator \\
& B. J. Stradder, Operator \\
E. M. Shank & G. Tipton, Operator \\
& H. C. Thompson, Operator \\
& J. T. Wiggins, Operator
\end{tabular}

(W. P. Bigler - Argonne)

Hired: $\quad$ Monthly - Nurmi

Weekly - Bond

Teminated: $\quad$ Monthly - Bigler, Bornwasser, Burris, DeHaan, Ward

Weekly - Allen (January) Caraglin

Transferred In: Leinard from Purchasing Department (Weekly)

Personnel on loan to the Technical Division from other departments as shown in parenthesis.

Monthly (Technical)

Weekly (Non-technical)
2-4-48

105

87

192
3-1-48

101

88

189 


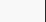


APPENDIX B

ORGANIZATION CHARTS FOR THE CHEMICAL TECHNOLOGY DIVISION

B.1 ORGANIZATION CHART FOR 1950

B.2 ORGANIZATION CHART FOR 1960

B.3 ORGANIZATION CHART FOR 1970

B.4 ORGANIZATION CHART FOR 1981

B.5 ORGANIZATION CHART FOR 1987

B.6 ORGANIZATION CHART FOR 1991

B.7 ORGANIZATION CHART FOR 1994 



\title{
APPENDIX B.1
}

\section{ORGANIZATION CHART FOR THE CHEMICAL TECHNOLOGY DIVISION, JUNE 1, 1950*}

\author{
F. L. Steahly, Director \\ W. K. Eister, Special Assignment \\ C. W. Schersten, Assistant to Director \\ F. R. Bruce, Section Chief - Laboratory \\ F. L. Culler, Section Chief - Process Design \\ J. O. Davis, Section Chief - Unit Operations \\ D. G. Reid, Section Chief - Pilot Plants
}

\section{PERSONNEL DISTRIBUTION}

$\begin{array}{lll}\text { Monthly Weekly } \quad \text { Hourly } & \text { Total }\end{array}$

\begin{tabular}{|c|c|c|c|c|}
\hline Admimistration & 2 & 4 & 0 & 6 \\
\hline Laboratory & 16 & 16 & 4 & 34 \\
\hline Process Design & 13 & 1 & 0 & 14 \\
\hline Unit Operations & 8 & 13 & 0 & 21 \\
\hline Pilot Plants & 13 & 2 & 18 & 33 \\
\hline TOTALS: $\quad(6-1-50)$ & 52 & 36 & 22 & 110 \\
\hline$(2-20-50)$ & 41 & 33 & 22 & 96 \\
\hline
\end{tabular}

CHANGED SINCE FEBRUARY 20

Monthly

R. B. Lindauer

J. W. Ullmann

F. N. Browder

F. L. Culler

H. E. Goeller

R. J. Klotzbach

R. G. Mansfield

F. C. McCullough

R. P. Milford

W. G. Stockdale

W. E. Unger

R. H. Vaughn
Weekly

Hourly
Hired:

Transferred in:

$$
\begin{aligned}
& \text { Mary Pemberton } \\
& \text { J. C. Suddath } \\
& \text { Virginia Wells }
\end{aligned}
$$

Lucille Kuykendall

Terminated:

W. H. Luster

Source: Chemical Technology Division Progress Report for Quarter Ending May 31, 1950, ed. W. K. Eister, ORNL 763. 
F. L. Steahly, Director

W. K. Eister, Special Assignment

C. W. Schersten, Assistant to Director

F. R. Bruce, Section Chief - Laboratory

T. C. Runion, Problem Leader - Metal Recovery

C. V. Ellison

R. G. Mansfield

C. E. Schilling

W. B. Lanham, Problem Leader-Purex

D. O. Darby

G. A. Eaton

J. R. Flanary

R. E. Leuze, Problem Leader - Dry Fluoride

C. P. Johnston

R. E. Blanco, Problem Leader - RaLa

A. H. Kibbey

D. C. Overholt, Problem Leader - Isolation

D. E. Ferguson

W. E. Tomlin

L. E. Morse, Problem Leader

Homogeneous Reactor

F. L. Culler, Section Chief - Process Design

W. E. Unger, Project Engineer - RaLa

L. Brewer \#

J. B. Ruch

R. H. Vaughn

E. Wischhusen \#
June Parrott, Sec.

Agnes Hair, Sec.

Virginia Wells, Sec.

J. W. Clark, Tech.

A. Johnson, Janitress

Mary Pemberton, Sec.

J. L. Bamberg, Tech.

V. L. Fowler, Tech.

H. F. Soard, Tech.

L. A. Byrd, Tech.

E. R. Johns, Tech.

W. B. Howerton, Tech.

C. F. Keck, Tech.

H. S. Caldwell, Opr.

C. H. Jones, Opr.

H. B. Graham, Tech.

A. B. Green, Tech.

G. C. Blalock, Tech.

S. E. Farmer, Tech.

J. M. Delozier, Tech.

R. B. Quincy, Tech.

J. F. Land, Opr.

R. C. Lovelace, Tech.

Lucille Kuykendall, Typist

Draftsman

R. L. Berry \#

R. V. Foltz \# 


\begin{tabular}{|l} 
F. N. Browder - Liquid Waste \\
H. E. Goeller - "25" \\
\hline R. J. Koltzbach - "25" \\
\hline F. C. McCullough - Cost Analysis \\
R. P. Milford - Metal Recovery \\
E. L. Nicholson - " 25 " \\
A. M. Rom - "25" \\
E. C. Stewart - Metal Recovery \\
W. G. Stockdale - Gaseous Waste
\end{tabular}

\# On loan from Engineering.

J. O. Davis, Section Chief Unit Operations

A. C. Jealous," Assistant Chief

T. A. Arehart ${ }^{1}$ - Evaporation

M. R. Bennett

I. R. Higgins ${ }^{2}$ - Ion Exchange

H. O. Weeren

A. C. Jealous ${ }^{* 3}$ - Solvent Extraction

W. L. Carter ${ }^{x}$

F. P. Pike \#

C. D. Watson - Equipment Development

J. C. Suddath

G. A. West

E. O. Nurmi, Shift Coordinator - Metal Recovery

F. Mills
Ruth Pennington, Sec. C. J. Shipman, Tech.

D. B. Masters, Tech. W. E. Shockley, Tech.

P. O. Payne, Tech.
G. B. Dinsmore, Tech.

G. R. Guinn, Tech. G. Jones, Tech. T. D. Napier, Tech.

F. L. Roger, Tech.

J. C. Rose, Tech. 
D. G. Reid, Section Chief - Pilot Plants

H. K. Jackson, * Associate Chief

H. K. Jackson," Program Leader-Purex

\section{F. E. Harrington}

J. W. Landry

W. H. Lewis

N. J. Rigstad, Problem Leader, CR Separations

G. S. Sadowski, Assistant Leader
A. T. Gresky
C. D. Hylton
R. B. Lindauer
J. W. Ullmann
R. H. Winget

Phyllis Groover, Sec.

R. B. Walters, Draftsman

R. F. Benson, Operator

J. H. Groover, Operator W. Jennings, Operator W. E. Ledbetter, Operator J. F. Lockmiller, Operator T. R. McLellan, Operator R. E. Purkey, Operator H. L. Sexton. Operator E. E. Shields, Operator R. C. Shipwash, Operator D. E. Spangler, Operator B. J. Strader, Operator D. G. Summers, Operator H. R. Thomas, Operator H. C. Thompson, Operator J. T. Wiggins, Operator

A. M. Rom, Coordinator - "25" Process Data

E. M. Shank, Problem Leader

G. D. Davis, Operator Waste Processor

1 - responsible for Purex in this Section

2 - responsible for RaLa in this Section

3 - responsible for Metal Recovery in this Section

\# - Research Participant

* - dual capacity

$\mathrm{x}$ - on loan from Engineering 


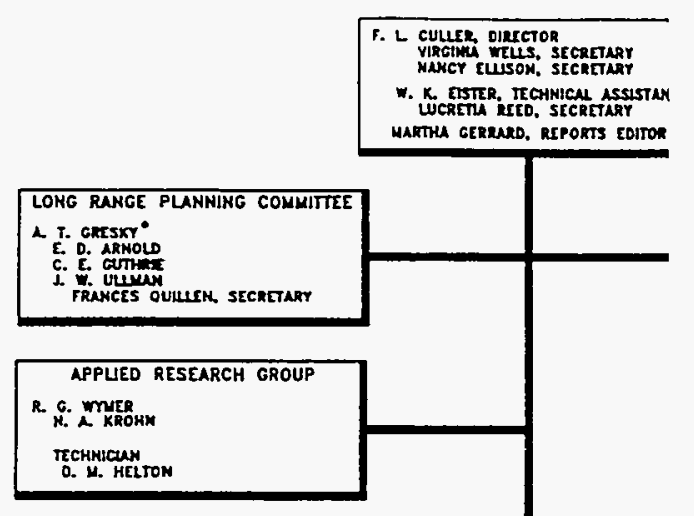

\section{CHEMICAL OEVELOPMENT SECTION o. C. FERCUSON, SECTION CHIE JOAMME MAYES, SECRETARY C. F. KeCK. TE CKNICUN \\ SURFACE CHEMISTRY \\ C. H. STCOY. GROUP IIADER H. F. HOtuies
F. H. SWreto TECHMICLAN
H. r. SOARD \\ THORIUH OXIDE STUDIES \\ J. P. WGBXIDC, GROUP LEADER \\ TECHMicuns \\ w. L PATASOK}

ALPHA-ACTIVE MATERIALS PROCESSING

R. E. LEUzE, GROUP LEADER

R. o. gAYeARz. Proglem leader.

M. H. LLOYO

TECHMICIANS

R. L. HICKEY TALENT

EQUIPMENT DECONTAMINATION

A. B. MESERVYY problem Leaden

TECHRICLAN

D. H. MEWLAN

FLUORIDE VOLATILITY PROCESSING

C. 1. CATHERS. GROUP LEADER

p. L. JOLLTY, PROBLEN LEAOER.

O. O. CAMPBELL PROBLEN IEADER.

4. R. MERAETT

TECHHICINSS

T. E. CRATRER

FLUORIDE VOLATILITY PROCESSING

o. C. DEAN, GROUP teadeR

k. T. KLINSTEU McCoRkis

TECHNICLAN

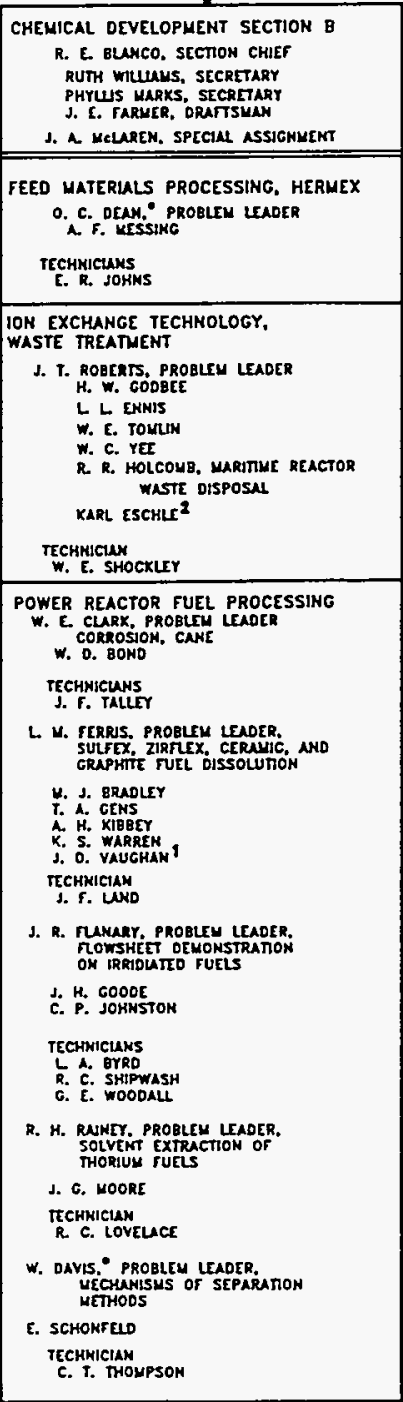

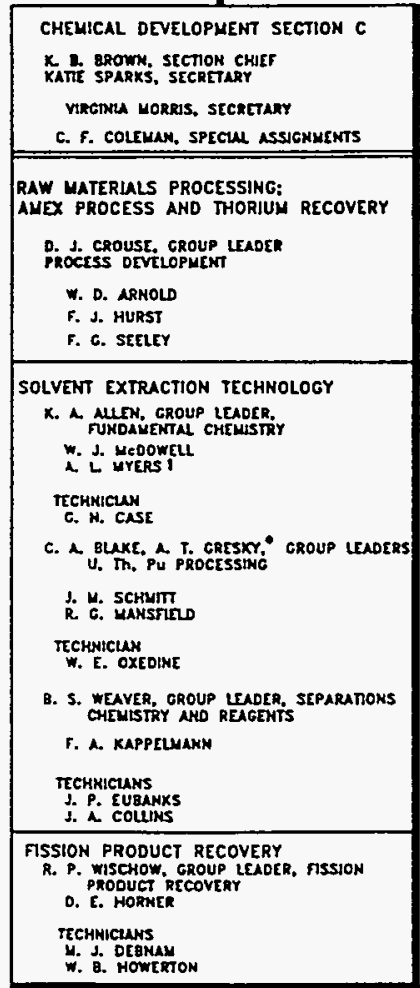

TOTAL PERSONHEL

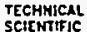

SOMIXISTRATIVE NDD CERICA

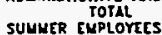

; DUAL CAPACITY

FOREIGN RESEARCH PARTICIPANT

EMPLOYEE OF RADIATION APPLICATIONS. INC. 4 CONSULTANT, U. $T$. 
CHEWICAL OEVTLORMENT SECHON A

*. c. mute stcios chacr

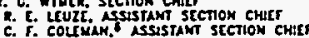

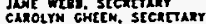

Techenseus: c. F. keck

sol-cel stuores

J. P. Menkipe. Group Lader

W. $L$. Vorst

TECHALCAN: S. S. TALIST

ruta crels stuotrs

7. O. Hong. crour lenote

A.

TreHMicuns: c. W. GRerges

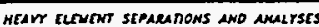

o. O. caspazu. prozlon caota

strekenows enowsint arscuech

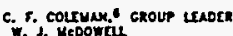

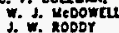

tecriccuns: 8. W. cest

mant aruent stracenow

“. K. Loro: cookgoutor

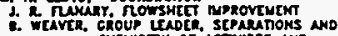

CHIMLSRY

TECHXTCUN: a. R. SHOUM

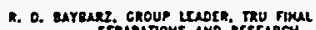

f. a xuprewaMn

Tenverens:

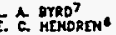

i. H. Hitery

H. H. WOrO Croup LeOE. TRU proctss

5. 2. cuxpon

e. e. Tume

тенк:cuks: s.t. A. Mecoss

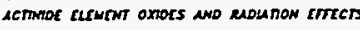

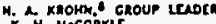

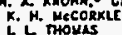

Techicus: D. R. nermast

ACMNOE RLECMT SMECRROPHONONTTR

H. A knohm." GRoup thoter

Techmicur: O. M. netsor

MOchINen scearanows

a. O. Keugres. croul Lenoth

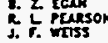

Trenicuss: w. E. enturss"

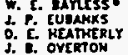

ooor nutos exurses

c. D. scort. Cin

surtsis

c.

5. XAl2

i. seinorfelos

x. S. WAREYMG

TECHAICUNS; S. R. OANSHOREs

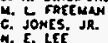

\begin{tabular}{|c|}
\hline 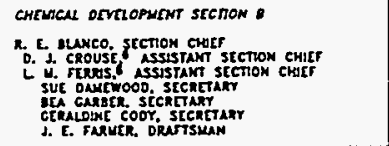 \\
\hline 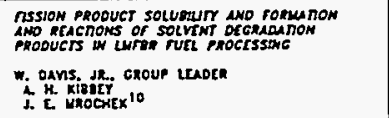 \\
\hline 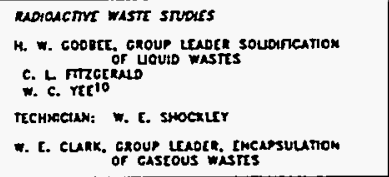 \\
\hline 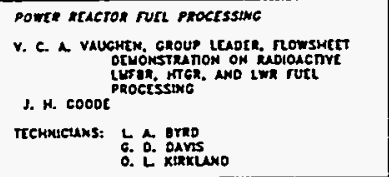 \\
\hline 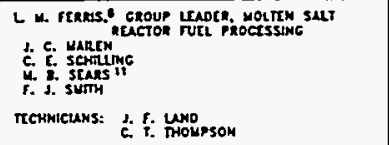 \\
\hline 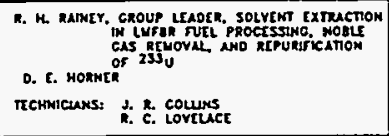 \\
\hline 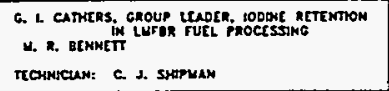 \\
\hline 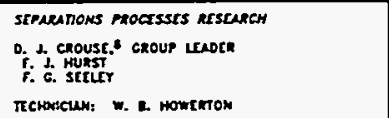 \\
\hline 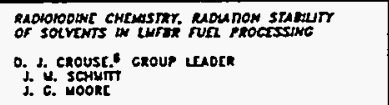 \\
\hline 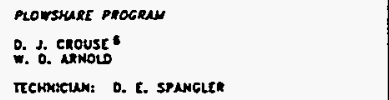 \\
\hline
\end{tabular}

unt oereanons stcrion

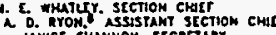

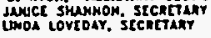

sur cras stuors amo monus Unu

P. A Hus croup Ladel

c. c. Thants. $\mathrm{cos}$

i. i. Long 12

TtChoucuns: R. D. ARTHUf

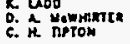

wot TRN SAlt Procrssine

L. E. HeHEESE. GEOUP LEAOCA

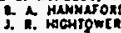

c. 4. xiry

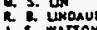

t. 2 tounson

Terenicuns: د. scums

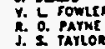

alocksmeces screanons

a. O. Hrow: cenour thotn

c. W. Howerga

TCMmicuns: c. 2. Ounswont

nowne enactor fust proctssoms

c. O. WATSOH, EROUP LADOL

a. 0. contow

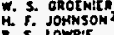

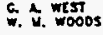

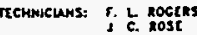

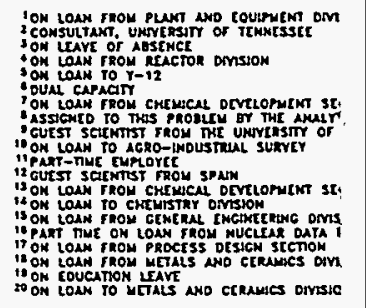

Source: Chemical Technology Division Annual Progress Report for Period Ending May 31, 1970, ORNL-4572. 


\begin{tabular}{|c|c|}
\hline \multirow{2}{*}{ 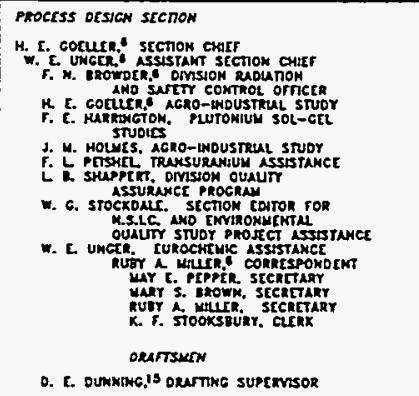 } & 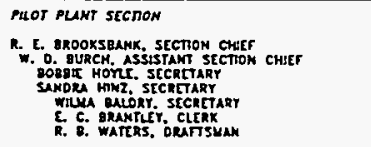 \\
\hline & \multirow{3}{*}{ 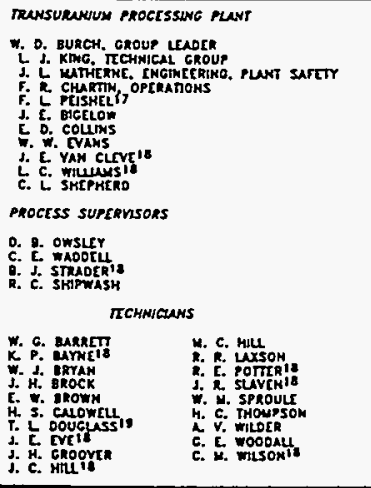 } \\
\hline 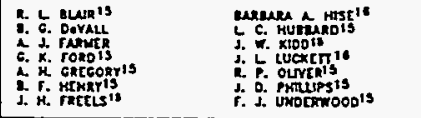 & \\
\hline \multirow{2}{*}{ 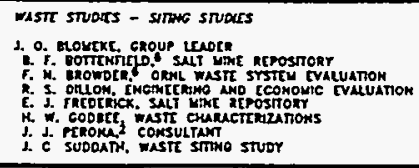 } & \\
\hline & \multirow{3}{*}{ 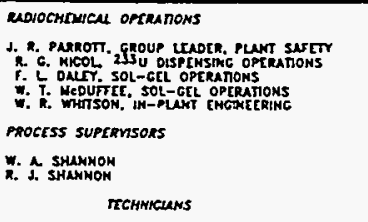 } \\
\hline 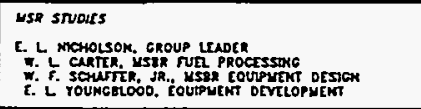 & \\
\hline \multirow{2}{*}{ 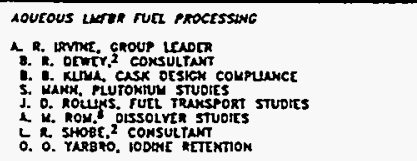 } & \\
\hline & 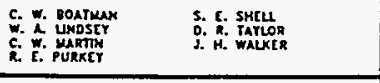 \\
\hline \multirow{3}{*}{ 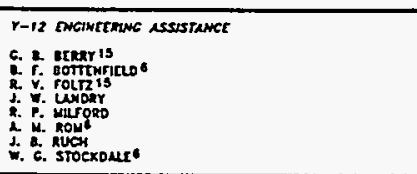 } & 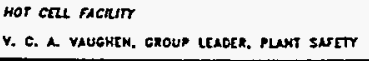 \\
\hline & 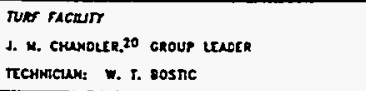 \\
\hline & \multirow{3}{*}{ 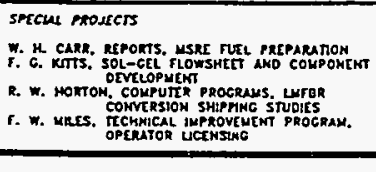 } \\
\hline 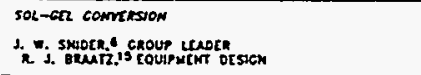 & \\
\hline 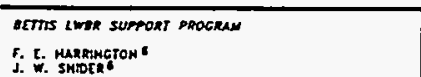 & \\
\hline
\end{tabular}




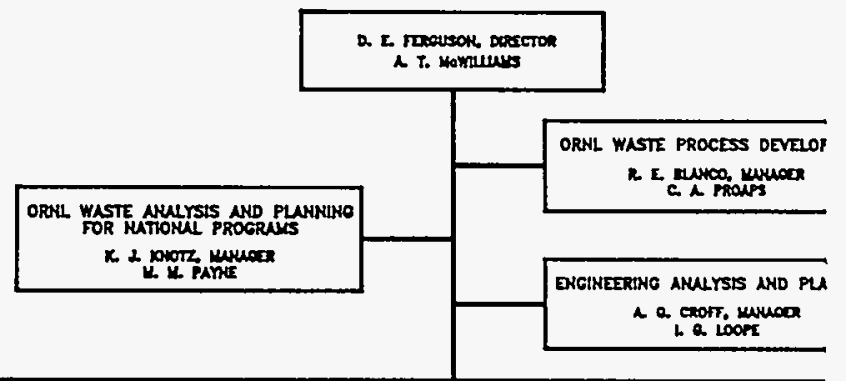

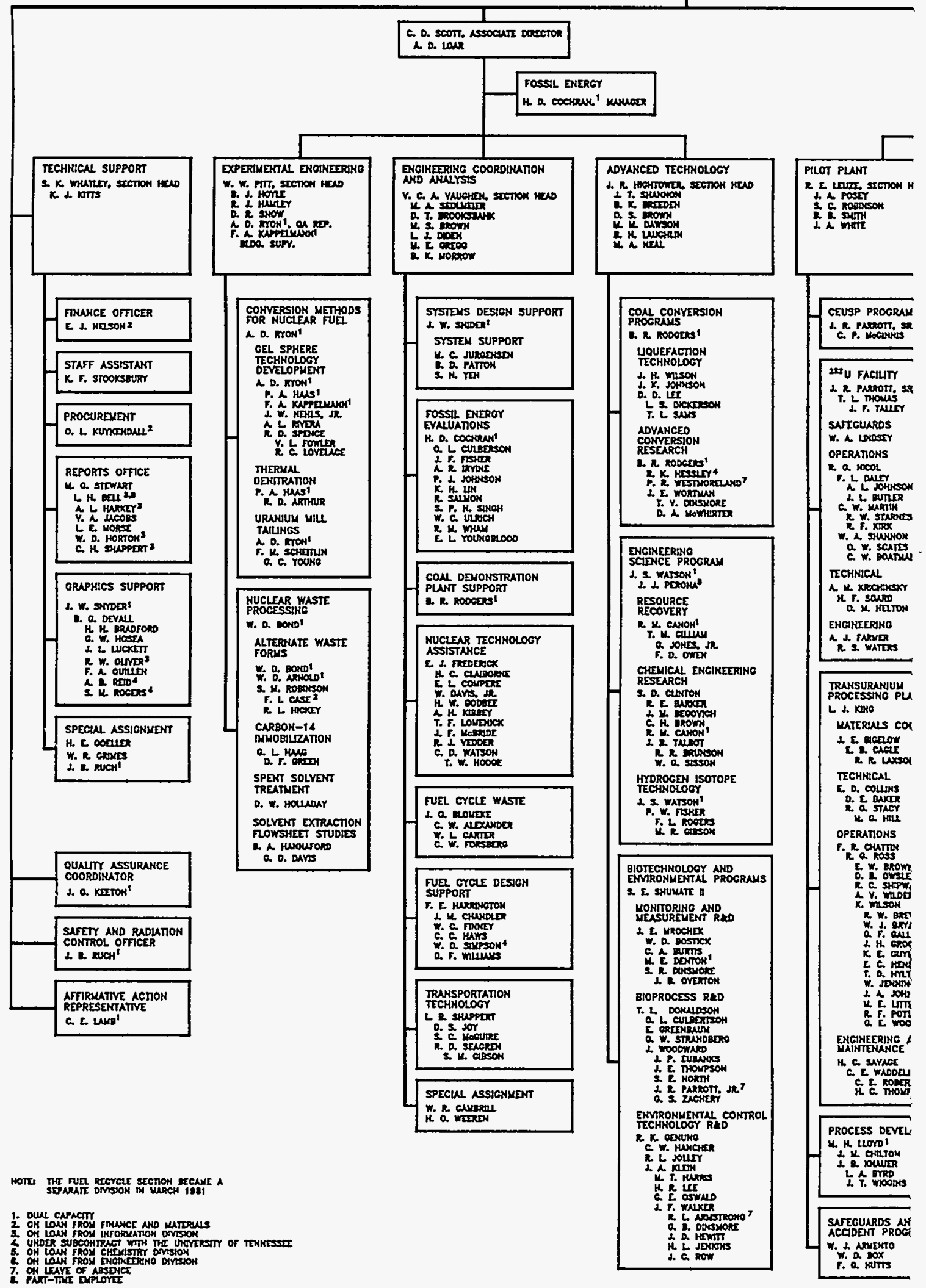


APPENDIX B.4

ORGANIZATION CHART FOR JULY 1, 1981

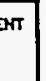

mec

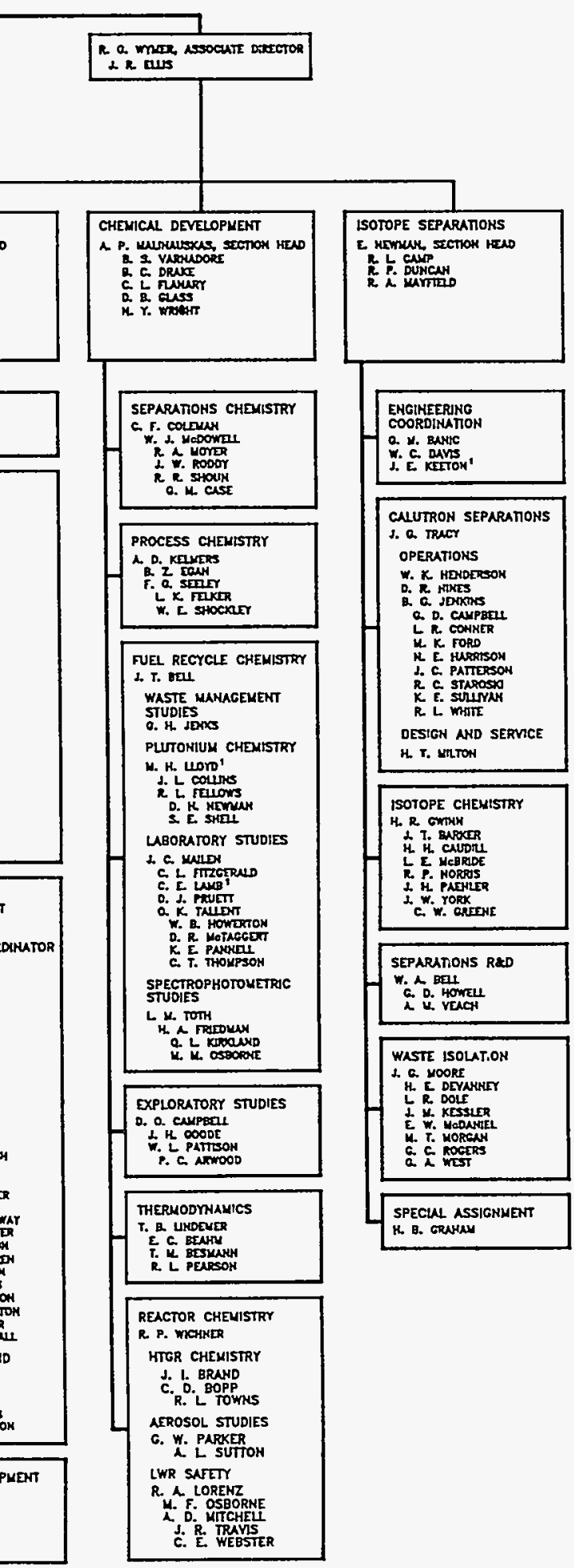



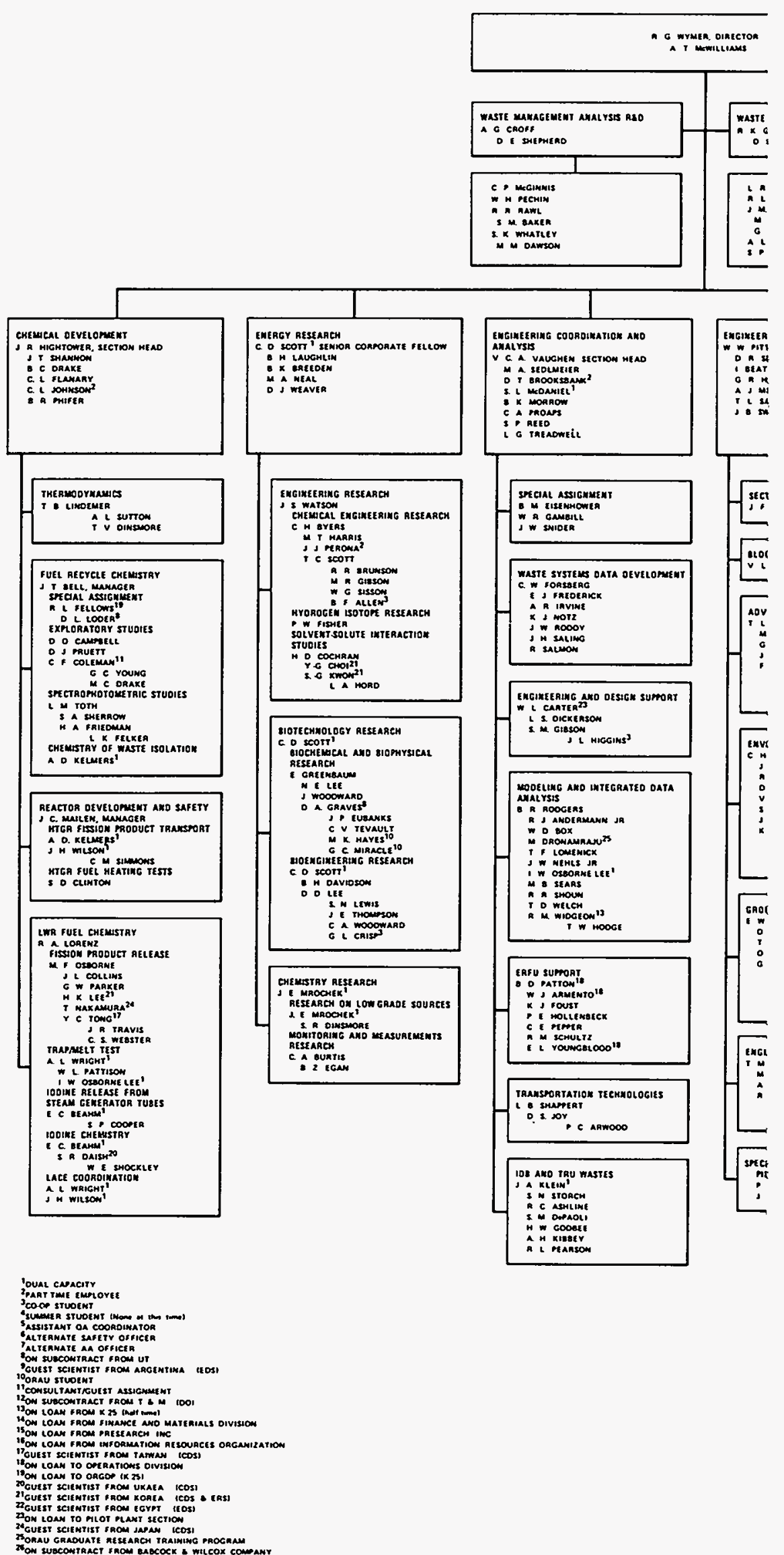


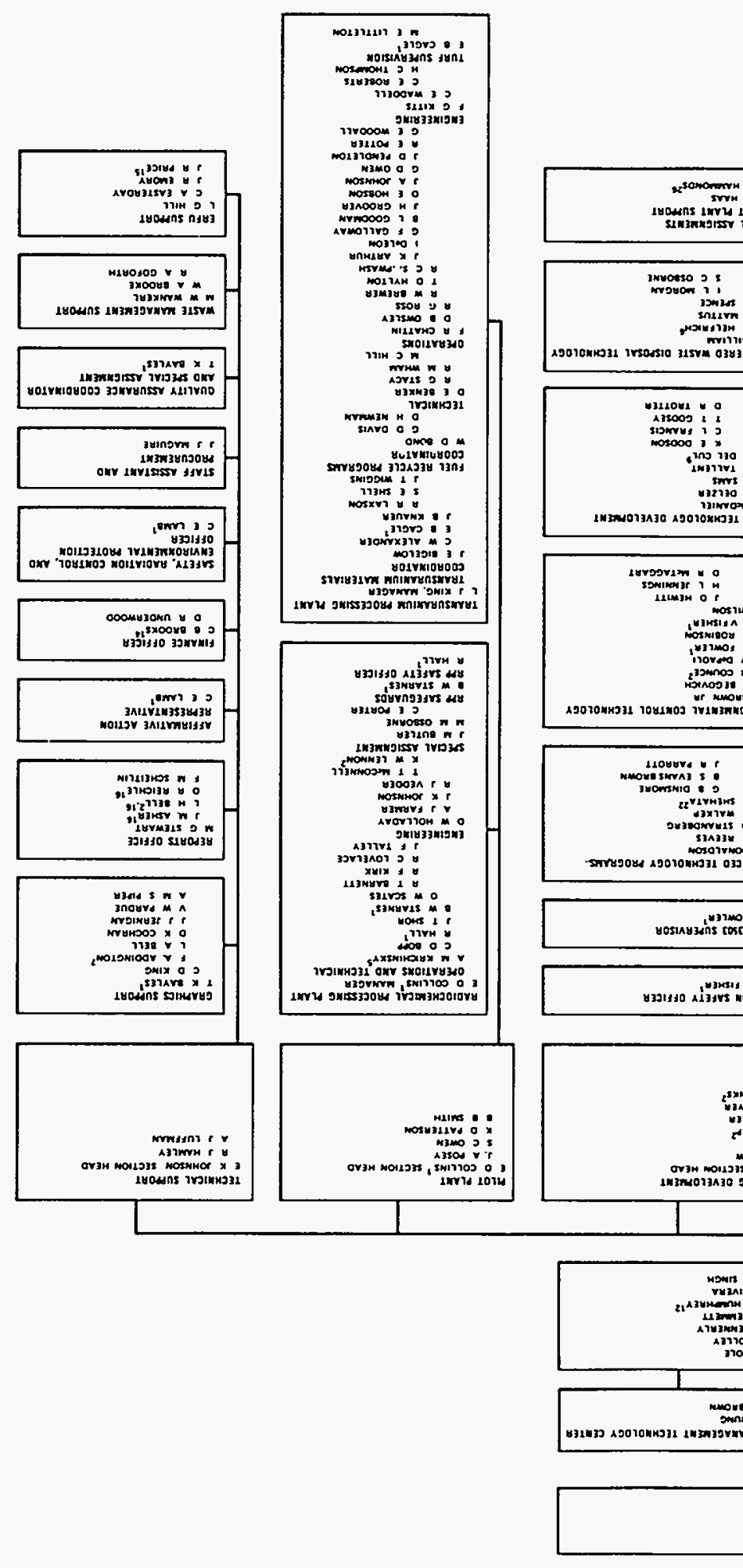




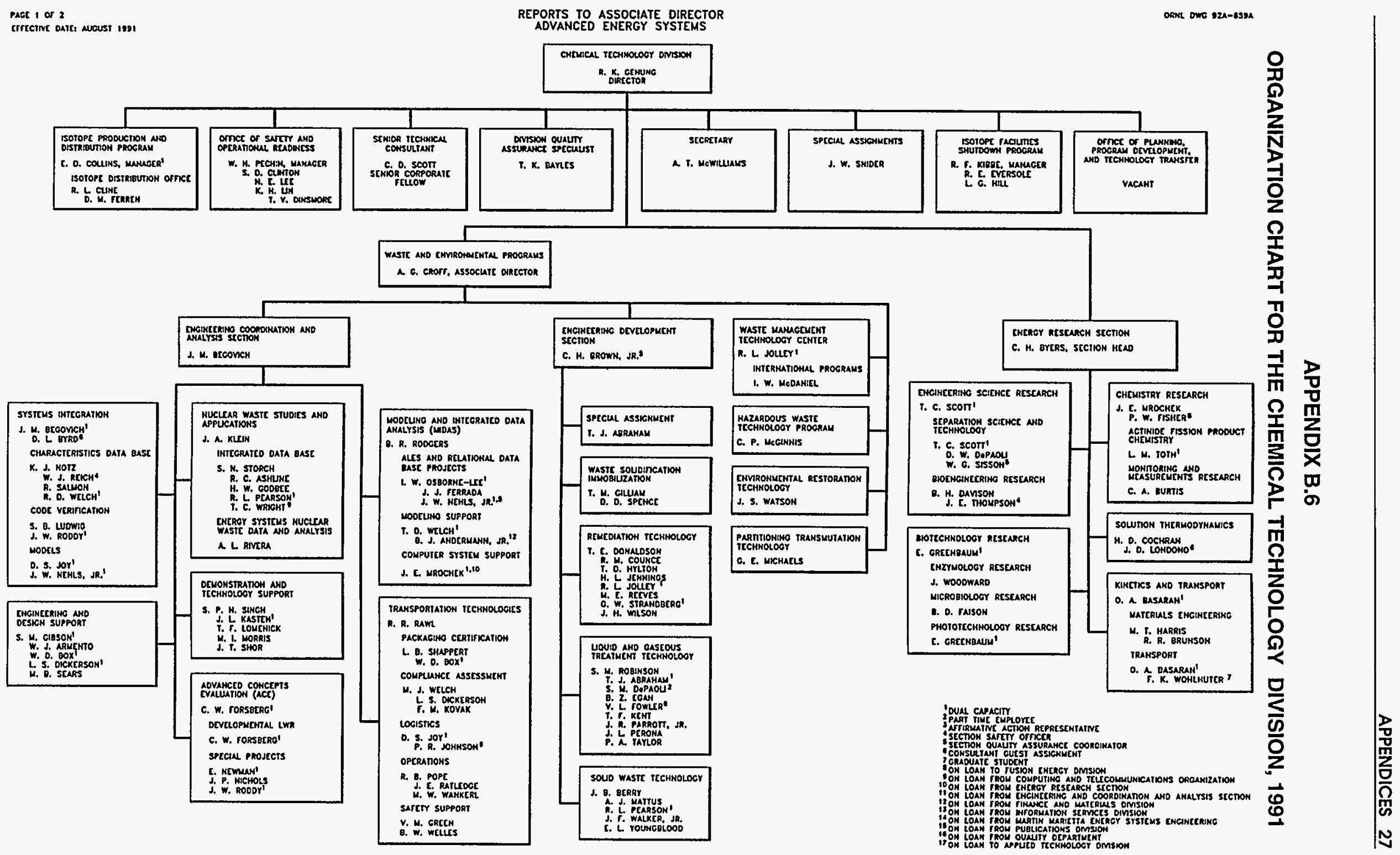




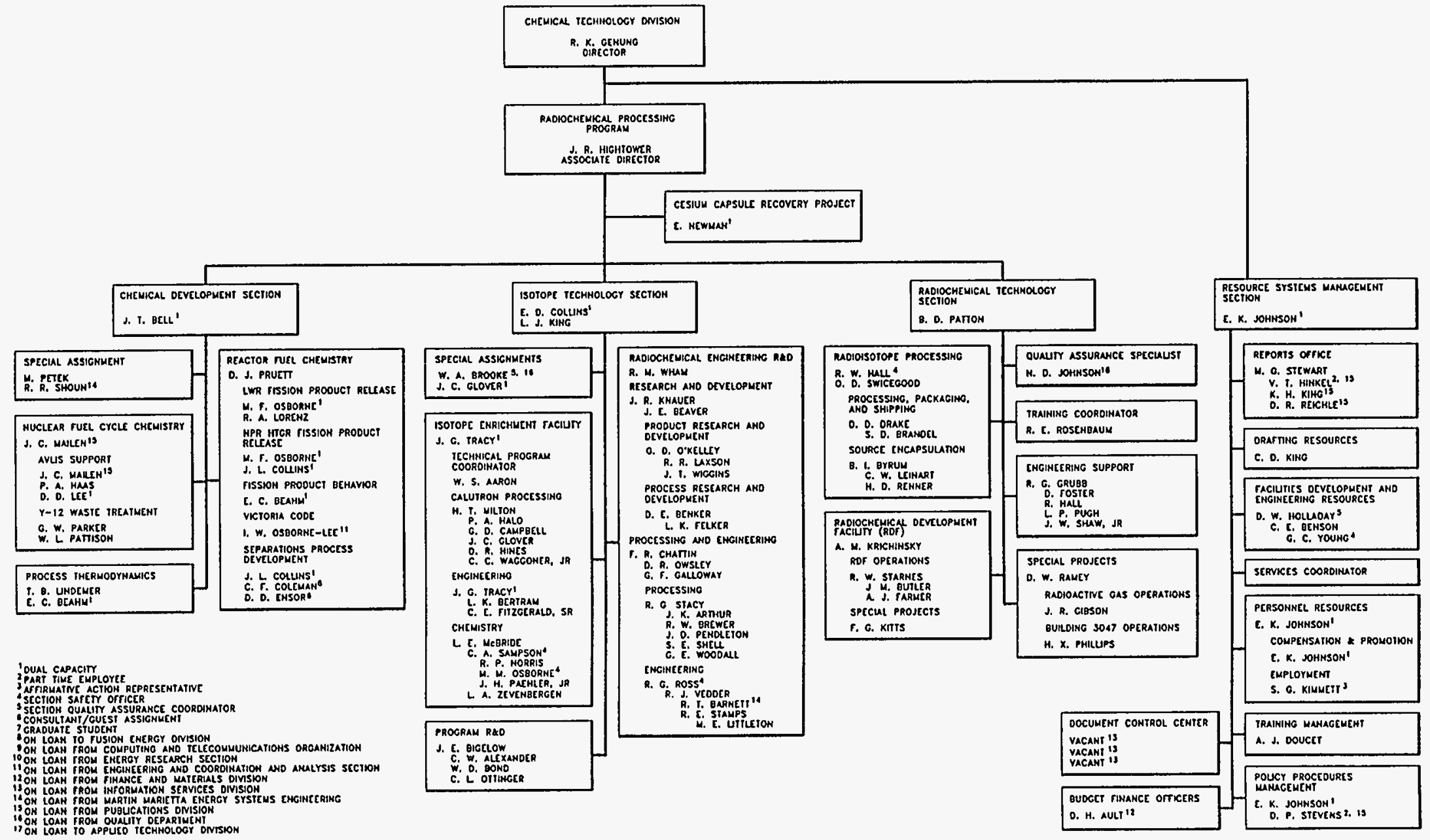




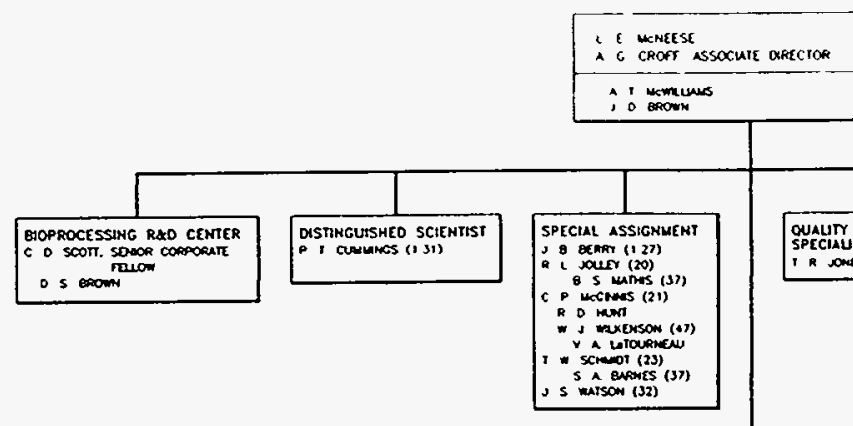

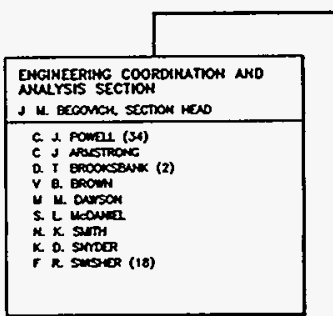

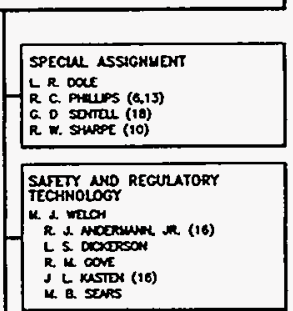

\begin{tabular}{|c|}
\hline 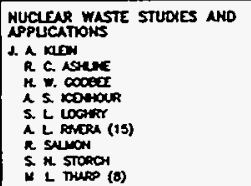 \\
\hline
\end{tabular}

\begin{tabular}{|c|}
\hline 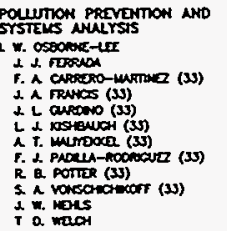 \\
\hline
\end{tabular}

TRAMSPORTATION TECHMOLOGLES

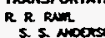

S. s. noonson
$x .5 .0005$

P. E Donson (8)

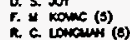

a. poen wus

i. E. PATLPC

L. W. Wund

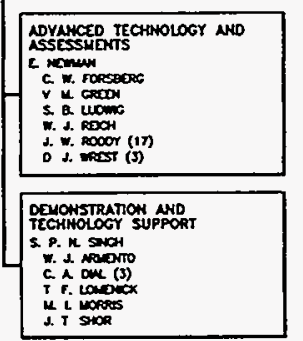

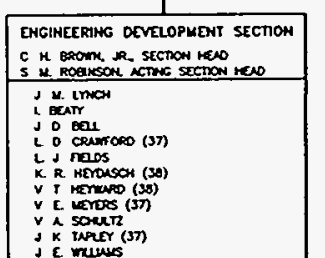

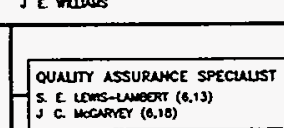

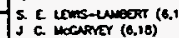

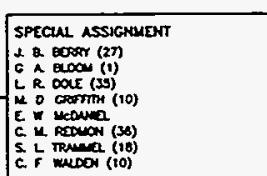

WASTE OSPOSA TECHNOLOCT

$T<$ cerve

c.

R. D spowe

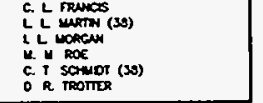

REYCOUNON TECHNOLOCY

i. L oonweson

P. A gionus (1)

v. p. cuser

c. 4.

is weron

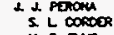

L. E. Rores (18)

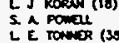

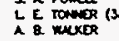

WAST IEATINT

T. E. KOT

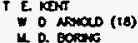

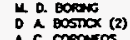

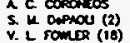

V. L L romor (18)

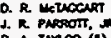

P. A tumpa (3)

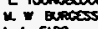

c. R. Remon (30)

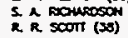

\section{MOUSTRAN RESOURCE
CONSERVATON}

\section{$x R$ Muty}

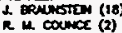

r.

it a. mrow

a.

C. I ven

R. A avars (18)

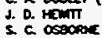
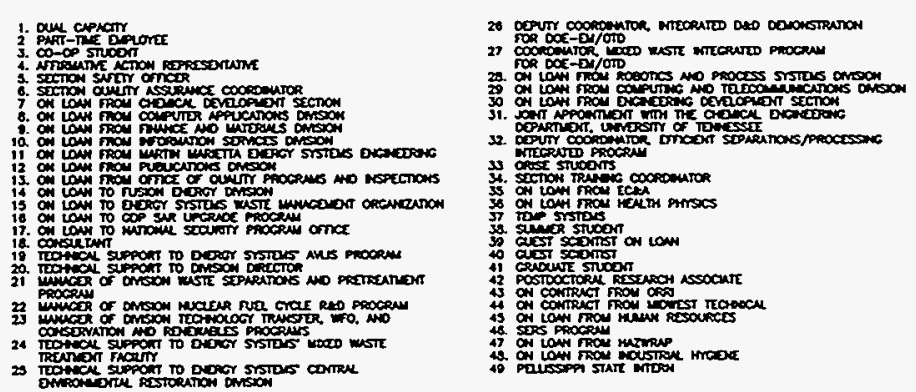

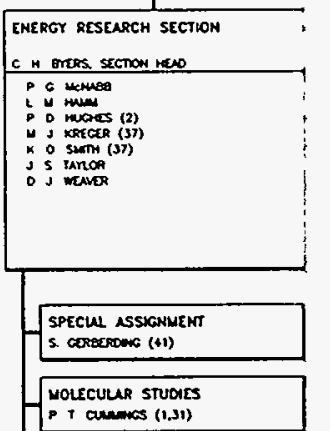

ENCANEERING SCIENCE RESEARCH

ic scoms sctor

S.

i.

se nnowersow

a. 5 men

S5 p cooper

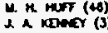

a in ume (4)

a. sonsters (100)

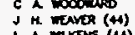

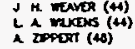

BOTECHNOLOCY RESERCM

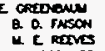

S. L entarcters

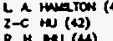

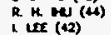

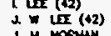

c sitivet

CHEMISTRY RESEARCH

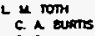

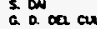

0
0
0

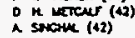

SOUUTON THERMOORHWWCS

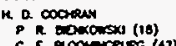

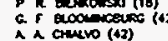

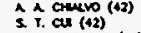

S. S Spesco (18)

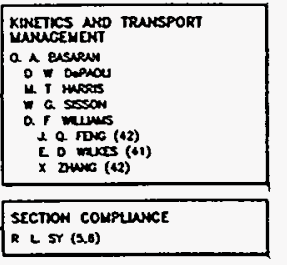

$R<5(2.0)$

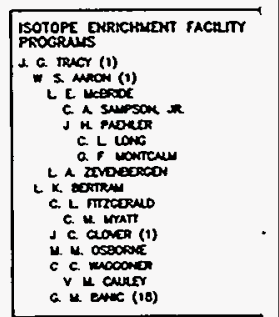




\section{APPENDIX C}

\section{C.1 A COMPILATION OF CHEM TECH LEADERS}

\section{C.2 EVOLUTION OF CHEM TECH PROGRAMS}

C.3 AN ENUMERATION OF CHEM TECH FACILITIES 


\section{APPENDIX C.1 \\ A COMPILATION OF CHEM TECH LEADERS}

Many of the technical accomplishments of Chem Tech during the past four decades have been achieved because of the effective use of collective groups or research teams. This fact is a tribute not only to the research teams and individual members, but also to the technical knowledge and good management skills of the Chem Tech leaders. This was specifically recognized by Dr. Herman Postma, Director of ORNL from 1974 to 1989 , who stated "Chem Tech managed to develop some of the very best people that ORNL ever had in terms of what they did in science, engineering, and management ... and they exported these people throughout the laboratory." The following listing of Chem Tech leaders was developed from examination of technical progress reports, organization charts, and Chem Tech records.

\section{Division Directors}

$\begin{array}{ll}\text { F. L. Steahly } & 1950-1953 \\ \text { F. L Culler } & 1953-1965 \\ \text { D. E. Ferguson } & 1965-1983 \\ \text { R. G. Wymer } & 1983-1988 \\ \text { R. K. Genung } & 1988-1994 \\ \text { A. G. Croff (Acting) } & 1994\end{array}$

\section{Assistant/Associate Directors}
F. R. Bruce
1954-1959
D. E. Ferguson
1963-1964
J. C. Bresee
1963-1964
K. B. Brown
1967-1976
R. G. Wymer
1973-1983
C. D. Scott
1976-1984
L. E. McNeese
$1977-1978$
J. R. Hightower
1988-1993
A. G. Croff
1988-present

\section{Long-Range Planning Committee}

In 1953, soon after he became Director of Chem Tech, Floyd Culler initiated the Long-Range Planning Committee. The purpose of the committee was to determine and evaluate future needs in the atomic energy area and to help prepare or guide Chem Tech to assume major programmatic roles in fulfilling or resolving those needs. The committee functioned well in that capacity. It was discontinued in 1974.
R. J. Klotzbach (Chair 1953-1955)
1953-1955
E. D. Arnold
$1953-1971$
D. E. Ferguson
1953-1955
A. T. Gresky (Chair 1956-1965) 1953-1965
A. C. Jealous
1955-1956
C. E. Guthrie
1956-1967
J. W. Ullmann
1956-1967
W. B. Albrecht
1958-1960
J. P. Hammond
1958-1959
J. T. Roberts (Chair 1966-1968)
1961-1973
P. B. Camargo
1965
R. Salmon
1966-1973
O. L. Culberson
1967-1973
S. C. Jacobs
1968-1970 


$\begin{array}{ll}\text { J. P. Nichols (Chair 1969-1973) } & 1969-1973 \\ \text { M. J. Bell } & 1969-1970 \\ \text { H. F. Soard } & 1969-1973 \\ \text { D. S. Joy } & 1970-1973 \\ \text { F. G. Welfare } & 1970-1971 \\ \text { V. A. DeCarlo } & 1971-1973 \\ \text { R. D. Cheverton } & 1972-1973 \\ \text { H. C. Claiborne } & 1972-1973 \\ \text { W. Davis, Jr. } & 1972-1973 \\ \text { M. E. LaVerne } & 1972-1973 \\ \text { K. H. Lin } & 1972-1973\end{array}$

\section{Pilot Plant Section Heads}

The name of the Pilot Plant Section was changed to Process Development in 1987 and to the current name, Isotope Technology, in 1990.
D. G. Reid
$1950-1951$
H. K. Jackson
$1951-1957$
R. B. Lindauer
$1957-1960$
J. C. Bresee
1960-1963
R. E. Brooksbank
$1963-1979$
R. E. Leuze
1979-1987
E. D. Collins
1987-present

\section{Process Design Section Heads}

In 1973, the name of the Process Design Section was changed to Engineering Coordination and Analysis Section.
F. L. Culler
1950-1953
H. E. Goeller
1953-1973
J. P. Nichols
1973-1975
D. E. Ferguson
1975-1977 (Acting)
R. W. Glass
1977-1982
V.C. A. Vaughen
1982-1989
J. M. Begovich
1989-present

\section{Laboratory Section Heads}

In 1954, the name of the Laboratory Section was changed to Chemical Development Section. In 1955, the Chemical Development Section was split into two sections, Section A and Section B.

F. R. Bruce

1950-1955

\subsection{Chemical Development A Section Heads}

In 1973, Chemical Development Section A became Chemical Development.

D. E. Ferguson

R. G. Wymer

A. P. Malinauskas

J. R. Hightower

J. T. Bell
1955-1963

1963-1973

1973-1983

1983-1988

1988-present 


\subsection{Chemical Development B Section Heads}

In 1974, the Chemical Development B Section was dissolved, with most personnel joining the Chemistry Division.
R. E. Blanco
$1955-1972$
C. D. Scott
$1972-1973$
L. M. Ferris
1973-1974

\subsection{Chemical Development C Section Head}

In 1948, the Raw Materials Section, under the direction of K. B. Brown, was established within the Y-12 Research Division. This division became the ORNL Materials Chemistry Division. In 1956, the Raw Materials Section became Chemical Development Section C of the Chemical Technology Division. The Section was dissolved in 1967, with personnel joining Sections A and B.
K. B. Brown
1956-1967

\section{Unit Operations Section Heads}

Originally titled the Semi-Works Section, the section name was soon changed to Unit Operations. The section name was changed again in 1973 to Experimental Engineering. In 1976, the section was split to form the Advanced Technology and Experimental Engineering Sections, and the former, in 1984, became the Energy Research Section.
J. O. Davis
$1950-1952$
W. K. Eister
$1952-1956$
J. C. Bresee
$1956-1960$
M. E. Whatley
1960-1973

\section{Experimental Engineering Section}
C. D. Scott
1973-1976
R. E. Leuze
1976-1979
W. W. Pitt
1979-1989
C. H. Brown
1989-present

\section{Advanced Technology Section}

J.R. Hightower

1976-1984

10. Energy Research Section
C. D. Scott
1984-1990
C. H. Byers
1990-present

\section{Isotope Separations Section}

The Isotope Separations Section was created in June of 1975 and existed until 1983, when it was functionally transferred to the Operations Division of ORNL. In 1988, the Operations Division was eliminated and the entire Isotope Program was transferred to Chem Tech and became the Isotope Section. In 1990, the section became known as Radiochemical Technology.
E. Newman
1975-1983
B. D. Patton
1988-present 


\section{Fuel Recycle Section}

This section enjoyed only a brief history within the division, being formed in 1977 and then becoming a new ORNL division in 1981.

W. D. Burch

$1977-1981$

\section{Technical Support Section}

In 1981, a new section called Technical Support was created. It combined in one section all of the rather diverse support functions needed within a large and complex organization, which the division had become. The name of the section was changed to Resource Systems Management Section in 1988.

S. K. Whatley

1981-1984

E. K. Johnson

1984-present

\section{Reference for Appendix C.1}

1. Herman Postma, personal communication, August 30, 1991. 


\section{APPENDIX C.2 \\ EVOLUTION OF CHEM TECH PROGRAMS}

The programmatic efforts of this large and complex organization known as the Chemical Technology Division have, of necessity, been many and varied over its 42-year history. The following are program titles drawn from annual reports of the division at five-year intervals. They illustrate an evolving, changing, and vibrant organization.

1950

First Filtered Exhaust Gas Systems - precipitators, glass wool, asbestos

Enriched Uranium-Fission Process (Hexone)

Purex Process

RaLa Process (with Isotopes Division)

Redox Process

Thorex Process

Tri-Butyl Phosphate (TBP) Metal Recovery Process (U + Pu)

Dry Fluoride Process

OREX

First High-Level-Waste Disposal Evaporator (with Operations Division)

Fuel Dissolution Processes with Xe-Kr Recovery for ICPP

Installation of Stainless Steel and High-Level-Waste Tanks

\section{5}

Training of Foreign Scientists (France, Sweden, Germany, India, Belgium, Japan)

Thorex Process

Recovery of Uranium from Wartime Wastes (Metal Recovery Project)

Homogeneous Reactor (HR) Studies

HOPE Project

Slurex Process for Weldon Springs

Metallex Process

Pilot Plant for Organic (EDTH)-Mercury Amalgam Process for ${ }^{6} \mathrm{Li}$

Fluorox Process

Monex Process

Excer Process

Manhattan Process (Dissolution of Zr Fuel)

Initiation of TRU - Californium Recovery Program

Establishment of Long-Range Planning Group for Power Fuels

1960

Head-End (Chop Leach) and Solvent Extraction Processing for Power Fuel Power Reactor Fuel Processing Pilot Plant

Uranium Ore Recovery for U.S. Ores (with Materials Chemistry Division)

- Di-2-Ethylhexyl Phosphoric Acid Process

- Ion Exchange

- Amine Processes

Fused Salt-Fluoride Volatility Process

Production of Multi-Kg Quantities of ${ }^{233} \mathrm{U}$ (Thorex Pilot Plant)

Molten Salt Reactor (MSR) Fuel Processing

Homogeneous Reactor Program (HRP) 
- HRP Fuel Processing

- HRP Thoria Blanket Development

Waste Treatment and Disposal

- Operation of Salt-Bed High-Level Waste Test with Health Physics

Fuel Cycle Development

Amex Process

Transuranium (TRU) Studies

- Construction of TRU Facility

Fission Product Recovery

Solvent Extraction Technology

Extraction Reagent Performance

Ion Exchange Technology

Chemical Applications of Nuclear Explosions

Processing of Gas-Cooled Reactor Fuel

1965

Equipment Development for Remote Processing of Power Fuels

Power Reactor Fuel Processing

Fluoride Volatility Processing

Waste Treatment and Disposal

TRU Element Processing and Recycle (with Metals \& Ceramics Division)

Development of Thorium Fuel Cycle

Sol-Gel Process for the Thorium Fuel Cycle

- Graphite-Coated Spheres (with Metals \& Ceramics Division)

Sol-Gel Process for the Uranium Refueling Cycle

Separations Chemistry Research

Recovery of Fission Products by Solvent Extraction

Mechanisms of Separations Processes

Chemical Applications of Nuclear Explosions

Preparation and Properties of Actinide-Element Oxides

MSR Processing

Biochemical Processes

Metallex Processes for Thorium and Uranium

Processing of Graphite Gas-Cooled Reactor Fuel

Production of Hydrocarbons from Metal Carbides

Studies of Radiolytic Hydrogen Production

Ion Exchange Process for Reduction of Radioisotopes from Low-Level Waste

(Plant in ORNL Tank Farm)

1970

Combustion and Leaching of Graphite-Uranium Rocket Fuel

MSR Processing by Fluoride Volatility Processing

Development of Aqueous Processes for Fast Reactor Fuels

Development of Methods for Reprocessing High-Temperature Gas-Cooled Reactor (HTGR) Fuels

Waste Treatment and Disposal

TRU Element Processing

Studies of Actinide Burning for High-Level Waste

Development of the Thorium Fuel Cycle

${ }^{238} \mathrm{Pu}$ Studies for Proliferation Protection

Sol-Gel Processes for the Uranium Fuel Cycle

Conversion Studies in the Liquid-Metal Fast Breeder Reactor (LMFBR) Fuel Cycle 
Preparation of ${ }^{233} \mathrm{UO}_{2}$ for Light-Water Breeder Reactors (LWBR)

Separations Chemistry Research

Chemical Applications of Nuclear Explosives

Biochemical Technology

- Zonal Gradient Centrifuge (with Biology Division)

Preparation and Properties of Actinide Oxides

Nuclear-Powered Agro-Industrial Complexes

1975

Development of Aqueous Processes for LMFBR Fuels

HTGR Fuel Recycle Development Program

${ }^{14} \mathrm{CO}_{2}$ Removal

MSR Program

Waste Management

TRU Element Processing

Separations Chemistry Research

Biomedical Technology

- Centrifugal Fast Analyzer

- High-Resolution Chromatography

Environmental Studies

Biochemical Engineering

Coal Technology

Controlled Thermonuclear Program

Purification of Multigram Quantities of t-RNA (with Biology Division)

Nuclear Regulatory Assistance

Iodine Studies

Actinide Oxides, Nitrides, and Carbides

Resin Loading Process for Making Microspheres

1980

Consolidated Fuel Reprocessing Program (CFRP)

HTGR Studies

Nuclear Waste Management

Cement and Concrete Technology

Partitioning and Transmutation

FUSRAP Stabilization Technology Development

Fossil Energy-Coal Conversion Process Development

Continuous Chromatography-Annular Chromatograph

Sol-Gel Studies for Non-Nuclear Applications

Integrated Data Base (IDB) of Radiological Data

Three Mile Island Support 
1985

CFRP, Fuel Recycle Section of CTD became ORNL Division in 1981

Fast Flux Test Facility

Waste Immobilization Technologies

Support of New Hydrofracture Facility

Development of Pumpable Grouts for Hanford

Integrated Data Base (IDB) of Radiological Data

Characteristics Data Base (CDB) of Spent Fuel and High-Level Waste

Environmental Control Technology

Basic Energy Science Research

Multi-Phase Studies in External Fields

Solvent-Solute Interactions in Separations with Supercritical Solvents

Kinetics of Nucleation and Growth of Microcrystalline Systems

Biophotolysis and Enzyme Kinetics

Biotechnology Programs

- Advanced Bioreactor Systems and Microbial Immobilization

- Development of Bioprocessing Systems for Wastewater Treatment

- Development of Bioanalytical Techniques for Monitoring Physiologic Effects of Environmental Pollutants

TRU Processing

NRC Programs

Fission Product Release

Core Melt

Iodine

Consolidated Edison Uranium Solidification (CEUSP)

Miscellaneous Programs

- Fusion Energy

- Three-Mile Island Support

- FUSRAP

- Molten Salt Reactor Decommissioning

- Process Monitoring for Coal Conversion

1990

Radiochemical Processing Programs

- Fission Product Transport Studies

- Process Development for AVLIS Feed Material

- Chemistry of Radioactive Waste Isolation

- High-Temperature Thermodynamics

- Chemical Development for Waste Treatment

- Transuranium Elements for Research

- ${ }^{252} \mathrm{Cf}$ Neutron Sources

- Enrichment of Stable Isotopes

- Isotope Production and Distribution

- ${ }^{85} \mathrm{Kr}$ Loading and Shipping

Waste Management and Environmental Programs

- Waste Management Technology Center

- Waste R\&D Program Management

- Environmental Restoration

- Guidance Manual for Technology Demonstrations

Engineering Coordination and Analysis Programs

- Developmental Light-Water Reactors 
- Partitioning-Transmutation Concepts

- Modeling and Integrated Data Analysis

- Expert System for Liquid Low-Level Waste

- Aerosol Models for VICTORIA

- Decontamination of Concrete

- Integrated Data Base

- National Profile on Commercially Generated Mixed Waste

- Performance Assessment of Solid Waste Storage Area (SWSA) 6

- Office of Civilian Radiactive Waste Management (OCRWM) Transportation Operations

- Groundwater Treatment Demonstrations

- Control of Metal Emissions from Mixed-Waste Incinerators

- Removal of Toxic Metals from Contaminated Scrap

Engineering Development Programs

- Stack and Vent Survey

- Hazardous and Mixed-Waste Separation

- Sanitary Landfill Analysis

- Bioremediation of Polychlorinated Biphenyls (PCBs)

- Bioremediation of Trichloroethylene (TCE)-Contaminated Groundwater

- Destruction of PCBs in Mixed Wastes

- Bioremediation Demonstration on Kwajalein Island

- Soil Remediation Demonstration at Portsmouth Gaseous Diffusion Plant

- Evaluation of Catalytic Incineration

- Ultrahigh-Pressure Water Cleaning Demonstration

- Waste Stabilization and Treatability Studies-Fernald

- Process Waste-Water Treatment Studies

- In-Tank Evaporation

- Low-Level Liquid Waste Treatment

- Development of High-Temperature Membranes for Gas Separation

- Federal Facilities Agreement Program Management

Energy Research Programs

- Chemical Kinetics of Enzyme-Catalyzed Reactions

- Development of Bioelectronic Components and Biomaterials

- Fundamental Investigations of Superconductivity

- Multicomponent Separations by Continuous Chromatography

- Fundamental Studies of Homogeneous Nucleation and Particle Growth

- Chemical and Physical Principles in Multiphase Separations

- The Emulsion-Phase Contactor

- Chemistry of Actinides and Fission Products

- Bioprocessing for Energy Applications

- Advanced Bioreactor Concepts

- Bioconversion of Coal

- Isotope Separations from Dilute, Supercritical Solutions 



\section{APPENDIX C.3}

\section{AN ENUMERATION OF CHEM TECH FACILITIES}

From the beginning, the work of Chem Tech and predecessor groups has taken place in many different areas and buildings. Table C.3.1 presents some interesting information concerning major buildings significantly involved in Chem Tech's work and mission. Aerial views (about 1960 and 1965) of Oak Ridge National Laboratory with Chem Tech facilities identified are shown in Figs. C.3.1 and C.3.2.

Table C.3.1. Selected Chemical Technology Division facilities completion and cost information

\begin{tabular}{|c|c|c|c|c|}
\hline $\begin{array}{c}\text { Year } \\
\text { completed }\end{array}$ & Building No. ${ }^{a}$ & Title & $\begin{array}{l}\text { iginal cost } \\
(\$ K)\end{array}$ & Figure \\
\hline 1943 & $3019(205)$ & Separations Bldg. & 681 & C.3.3-C.3.5 \\
\hline 1943 & $3550(706-A)$ & Chemistry Lab. & 804 & C. 3.6, C. 3.7 \\
\hline 1948 & 3503(706-HD,-HB) & $\begin{array}{l}\text { High-Radiation- } \\
\text { Level Chem. Lab. }\end{array}$ & 566 & C.3.8 \\
\hline 1951 & 3019 & Addition to Sep. Bldg. & 706 & \\
\hline 1951 & 3505 & Metal Recovery Plant & 487 & C.3.9 \\
\hline 1951 & 3508 & High Alpha Lab. & 313 & C. 3.10 \\
\hline 1951 & $4500 \mathrm{~N}$ & Central Research Bldg. ${ }^{b}$ & 4966 & C.3.11 \\
\hline 1951 & $4501 / 5$ & $\begin{array}{l}\text { High-Level } \\
\text { Radiochemical Lab. }{ }^{b}\end{array}$ & 3070 & C. 3.12 \\
\hline 1952 & 3592 & $\begin{array}{l}\text { Unit Operation } \\
\text { Volatility Lab. }\end{array}$ & 34 & \\
\hline 1958 & 4507 & $\begin{array}{l}\text { High-Radiation-Level } \\
\text { Chemical Development Lab. }\end{array}$ & 281 & \\
\hline 1962 & $4500 \mathrm{~S}$ & $\begin{array}{l}\text { Central Research Bldg. } \\
\text { Add. } b\end{array}$ & 7495 & \\
\hline 1965 & 7920 & $\begin{array}{l}\text { Transuranium Processing } \\
\text { Plant }\end{array}$ & 8000 & C. 3.13 \\
\hline
\end{tabular}

$a$ Where applicable, former building designations are presented within the parentheses.

${ }^{b}$ Shared with other ORNL divisions and tenants.

Principal Source: W. E. Thompson, History of the Oak Ridge National Laboratory 1943-1963, ORNL Central File Number 63-8-75 (Aug. 23, 1963). 


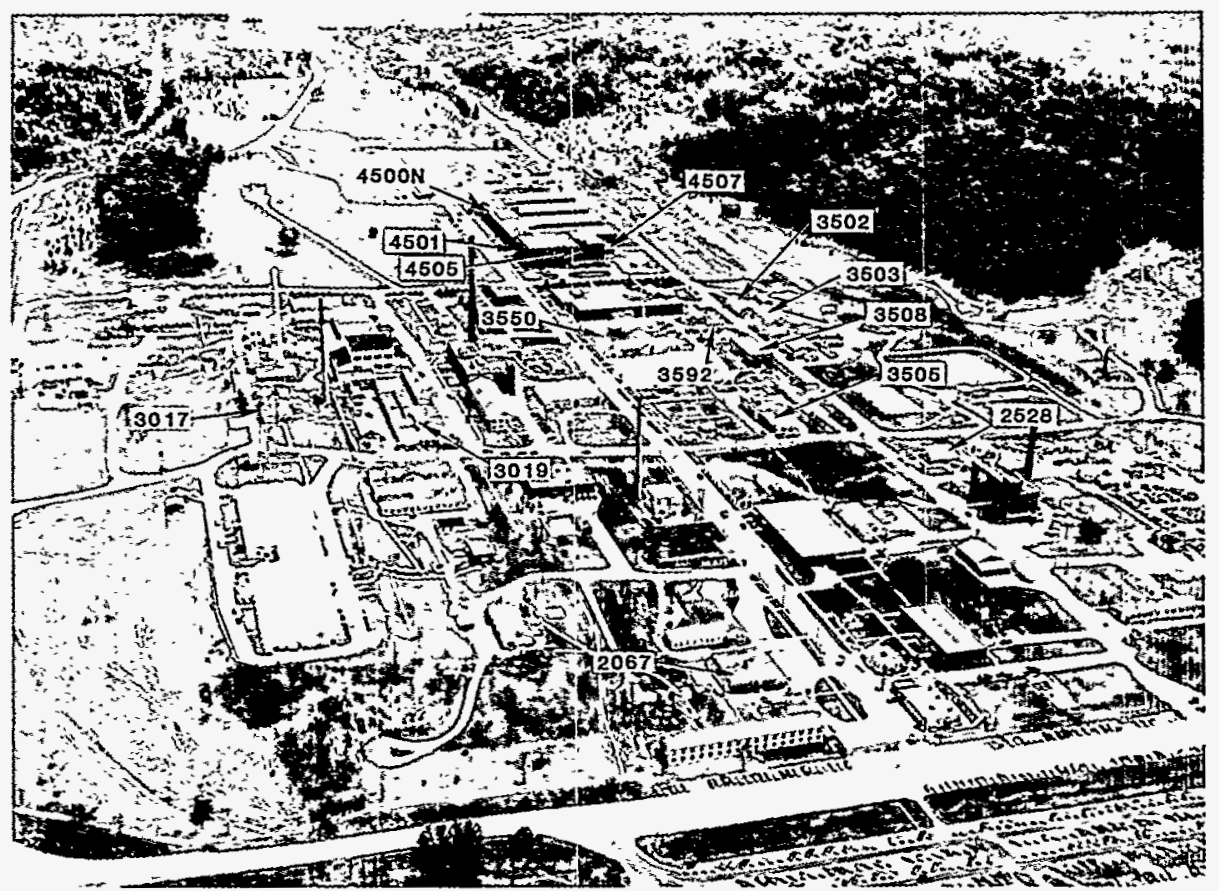

Fig. C.3.1. An aerial view (about 1960) of Oak Ridge National Laboratory, $X-10$ site, looking eastward. Chem tech facilities are identified.

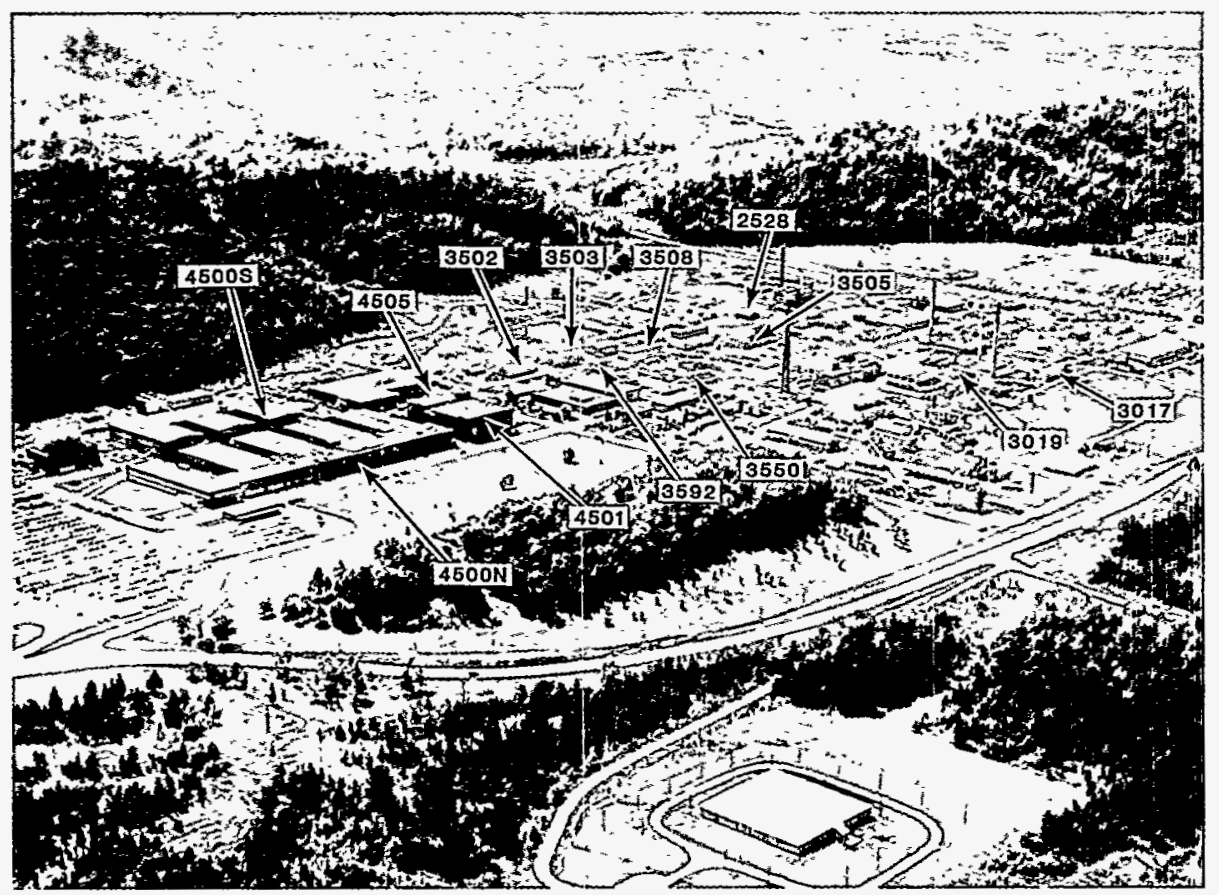

Fig. C.3.2. An aerial view (about 1965) of Oak Ridge National Laboratory, X-10 site, looking approximately south-southwest. Chem tech facilities are identified. 


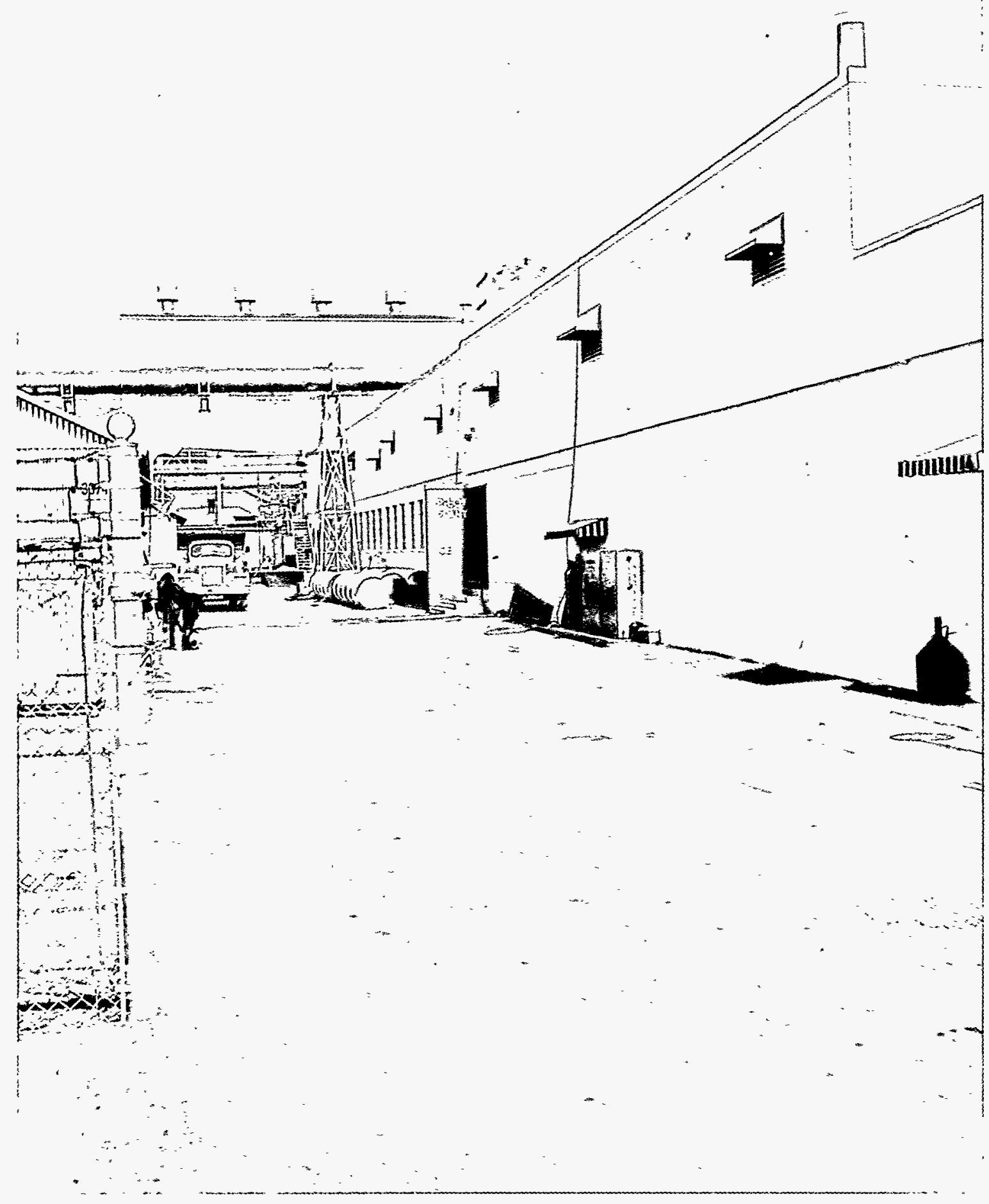

Fig. C.3.3. North side of Building 3019 showing Graphite Reactor in background. See also Figs. 1.1-1.3, 2.1, and 2.2. 


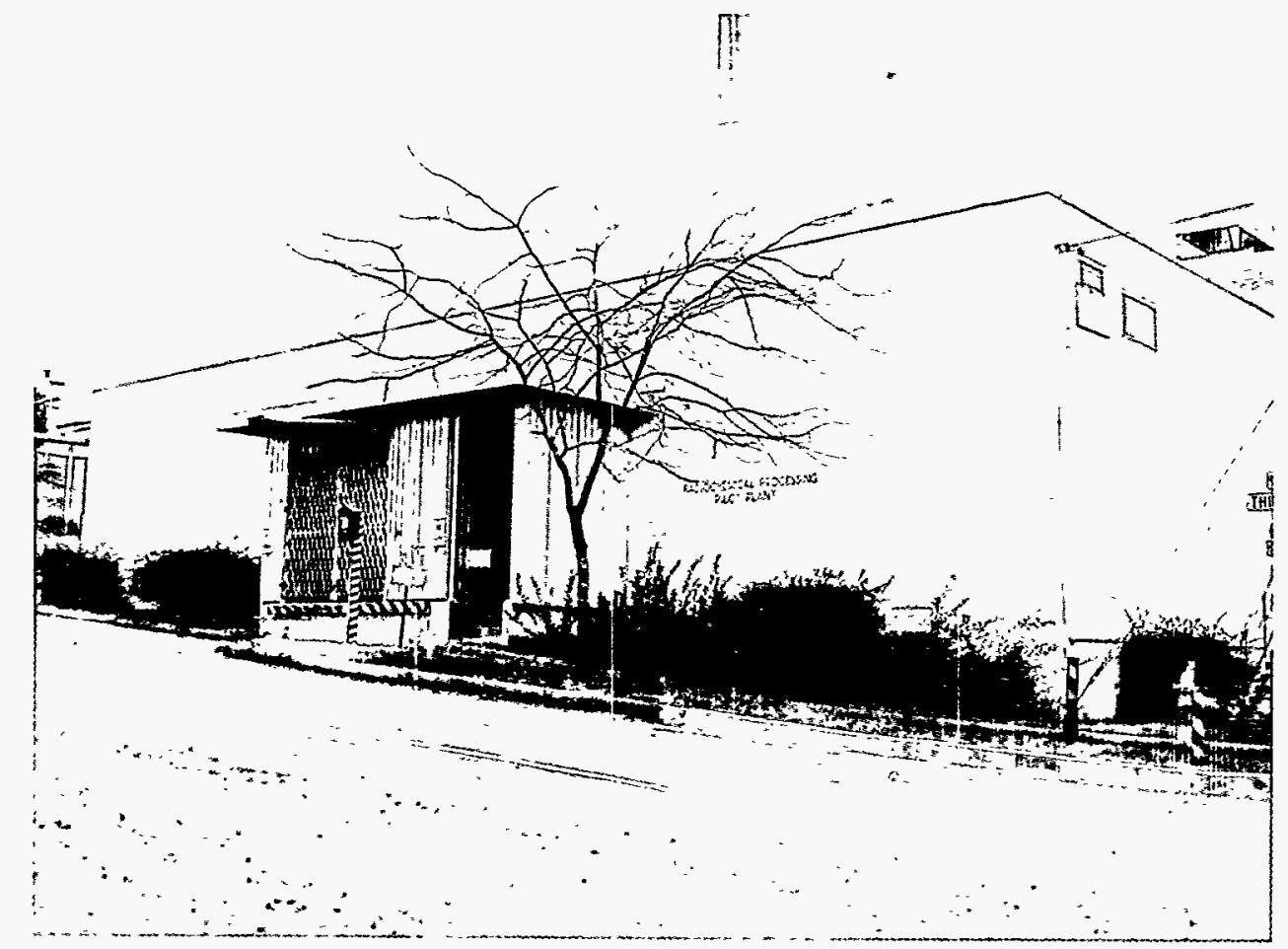

Fig. C.3.4. West end of Building 3019.

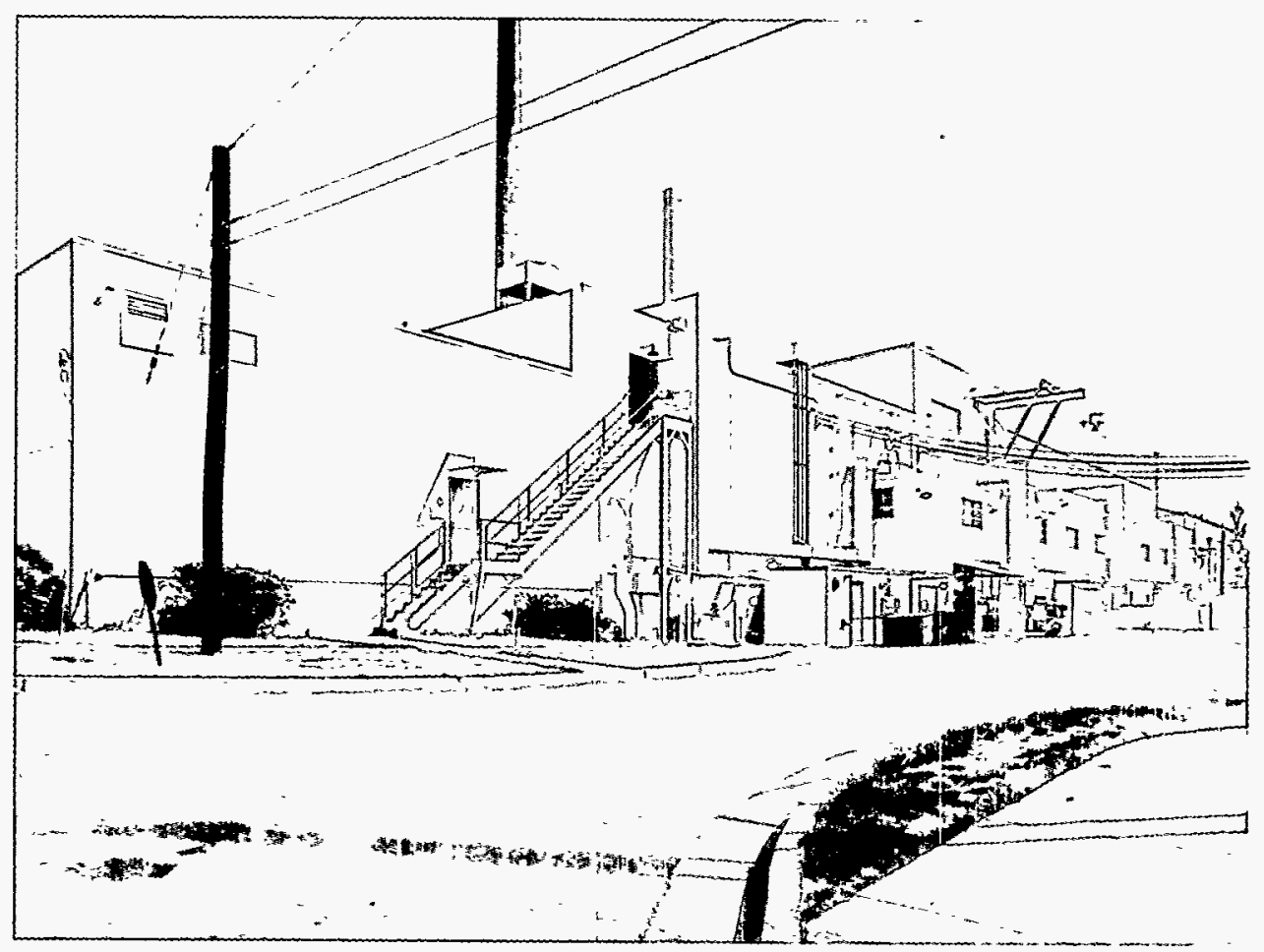

Fig. C.3.5. South side of Building 3019 showing the Graphite Reactor to the extreme right. 


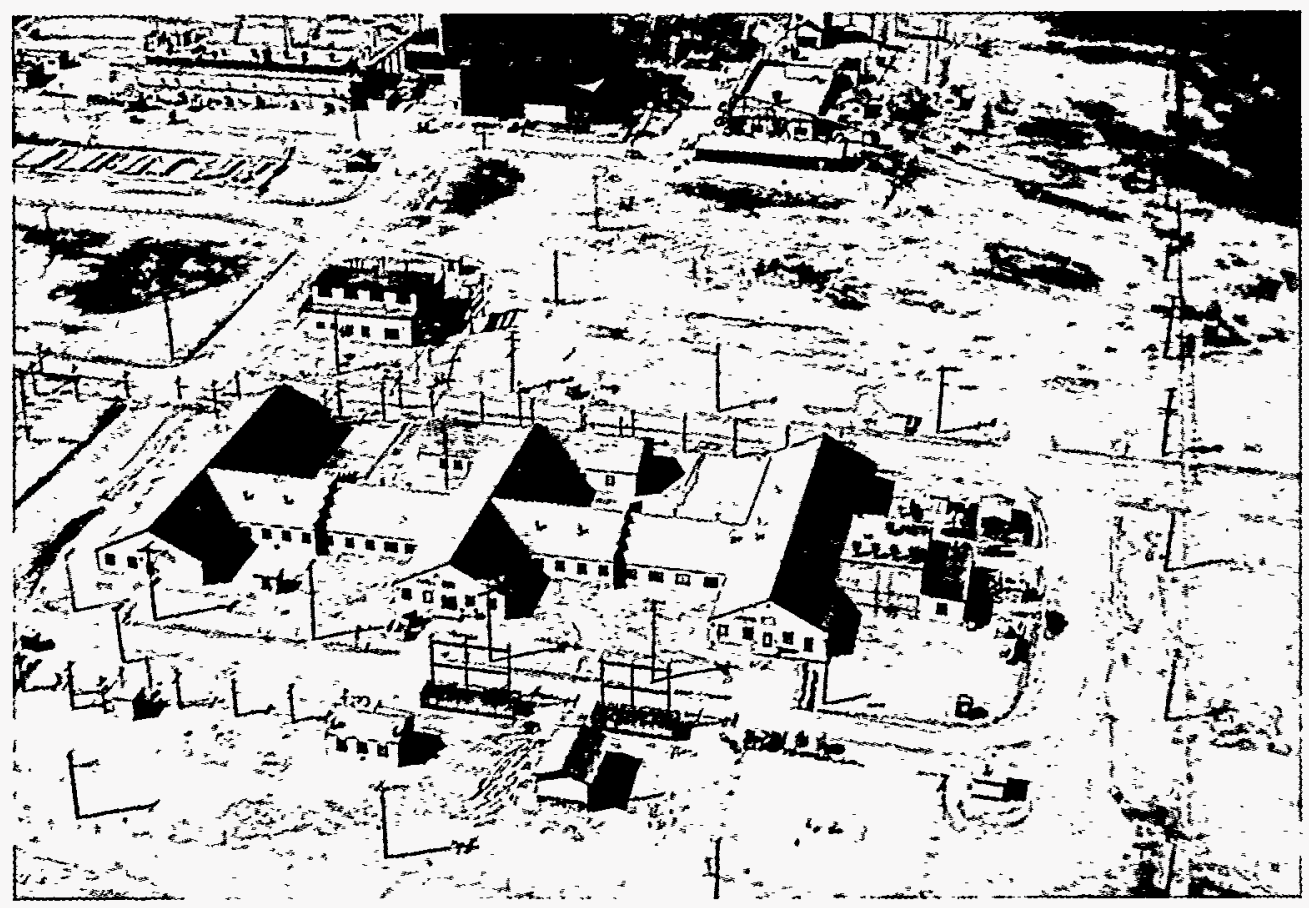

Fig. C.3.6. Aerial view of Main Laboratory, Building 706-A, looking northward at the Clinton Engineer Works in March 1944. The heavily shielded construction at the extreme right of the building was used for high-level radioactive experimentation. That portion was razed during the 1960s. Building 706-A is now designated Building 3550.

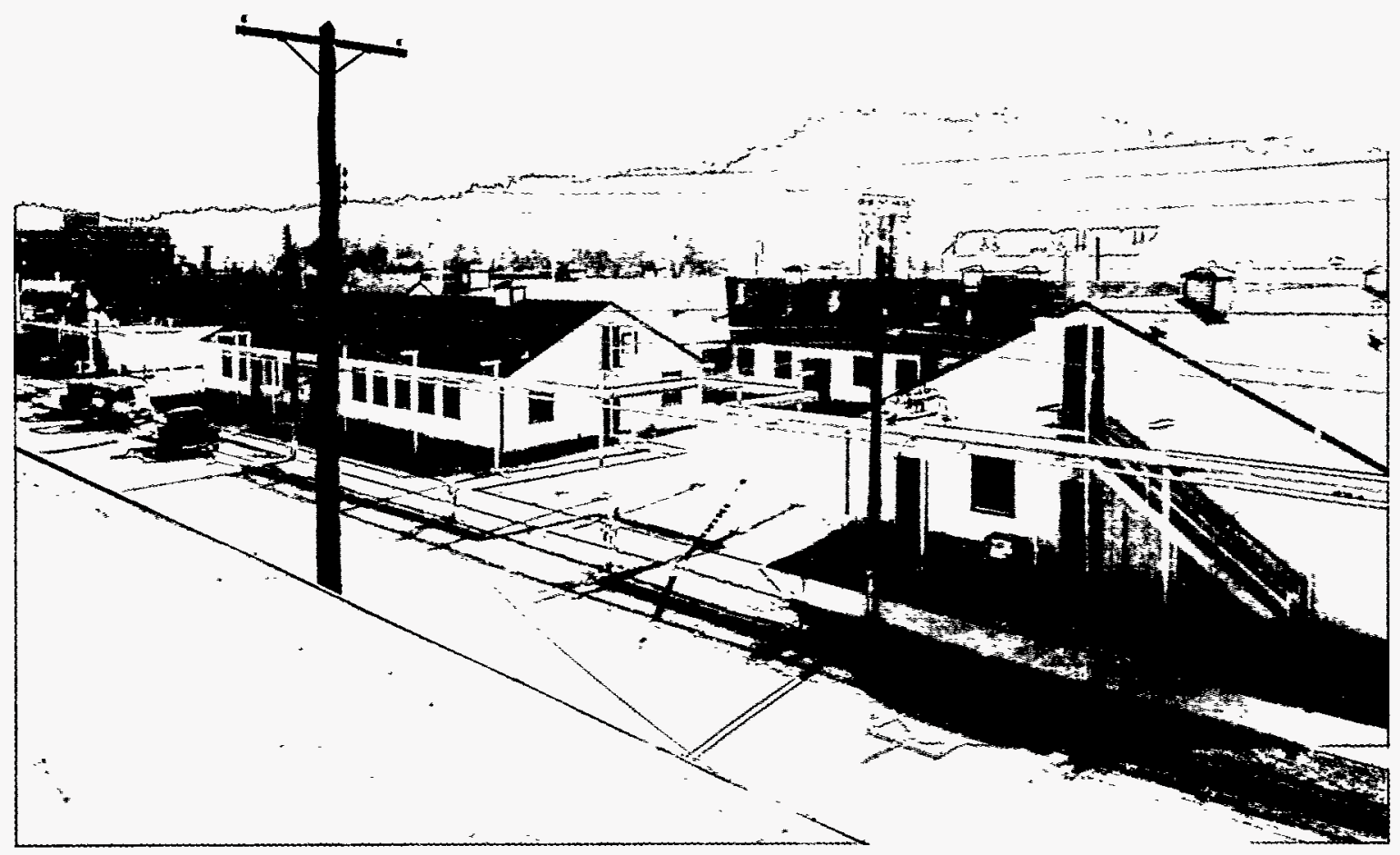

Fig. C.3.7. Building 3550 about 1965 looking southeast. Building 3503 is in the background. 


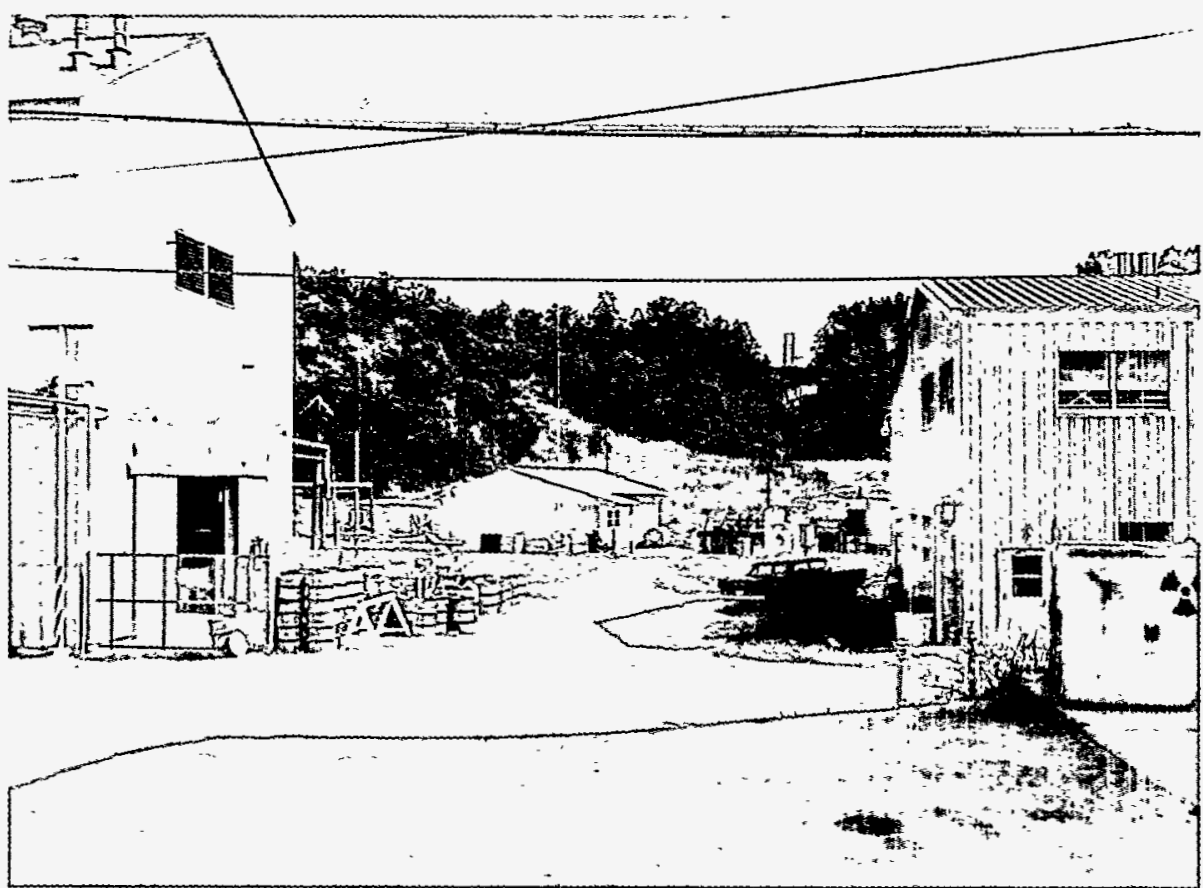

Fig. C.3.8. Part of Building 3503 is shown on the left in this photograph taken about 1960. A Health Physics facility, Building 3504, is on the right. See also Fig. C.3.7.

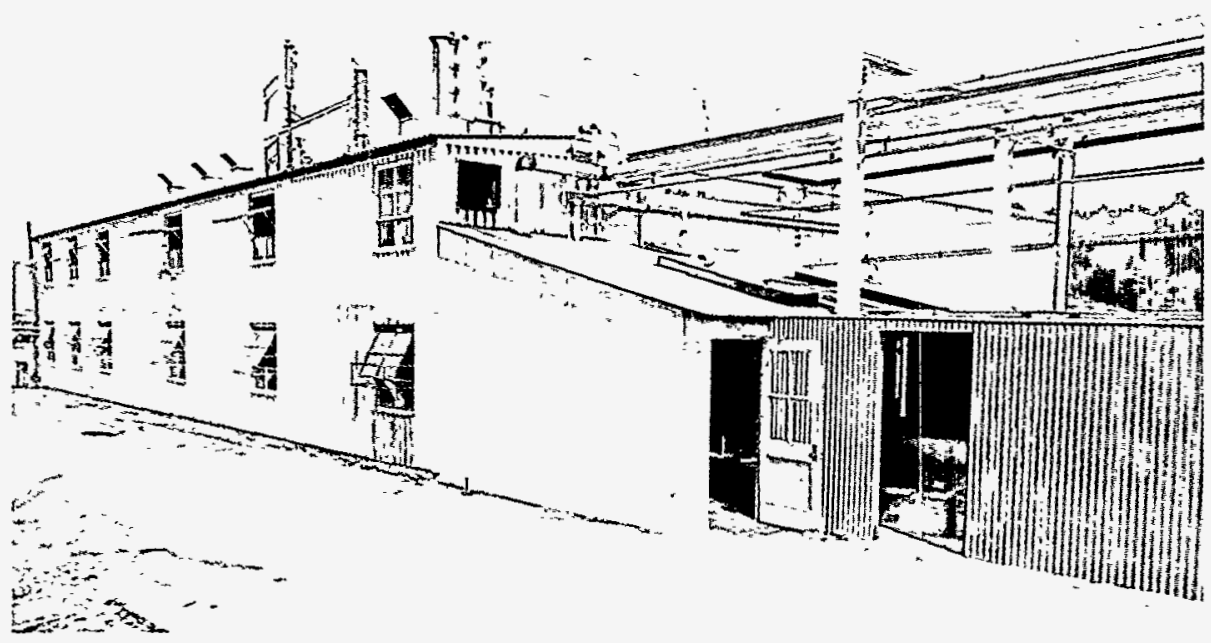

Fig. C.3.9. Building 3505, Metal Recovery Plant. 


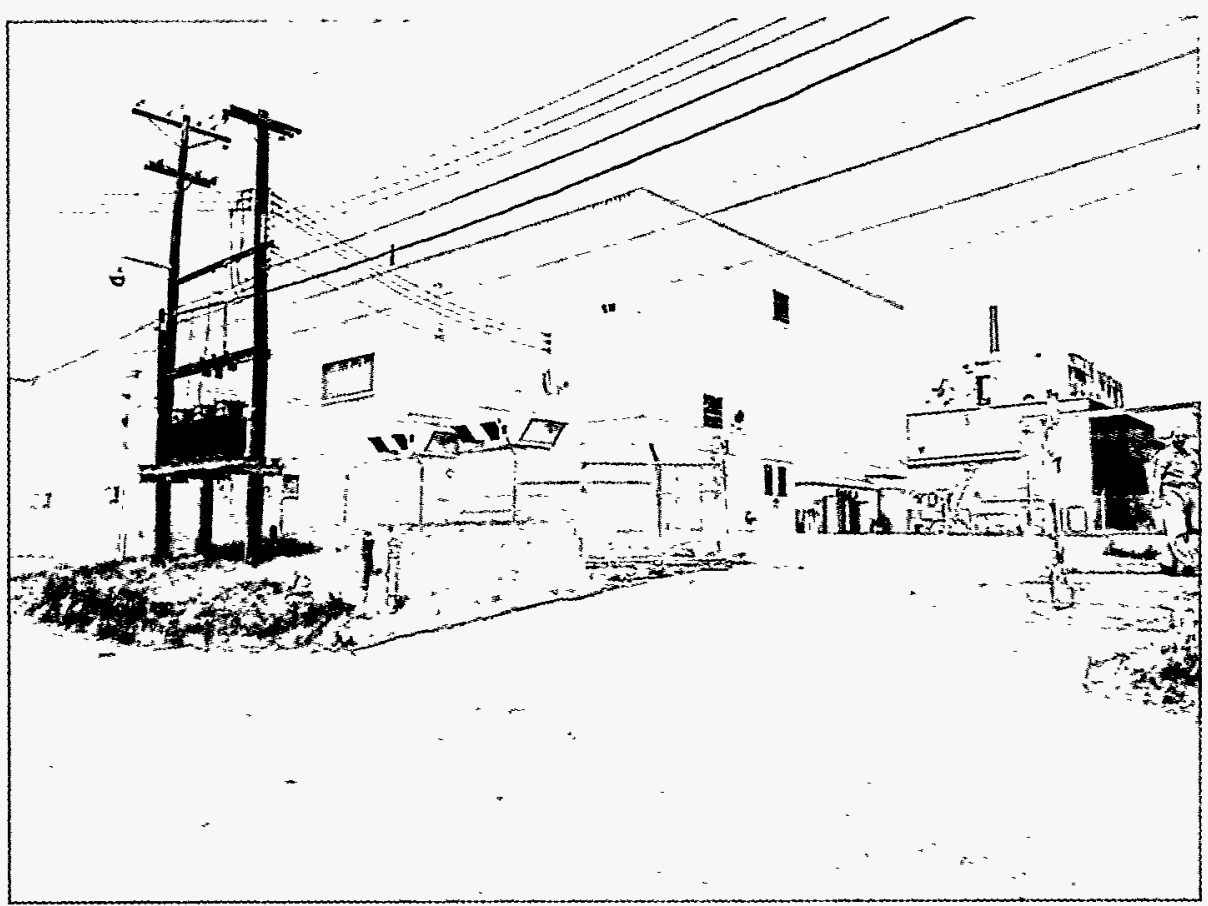

Fig. C.3.10. Building 3508, High Alpha Laboratory.

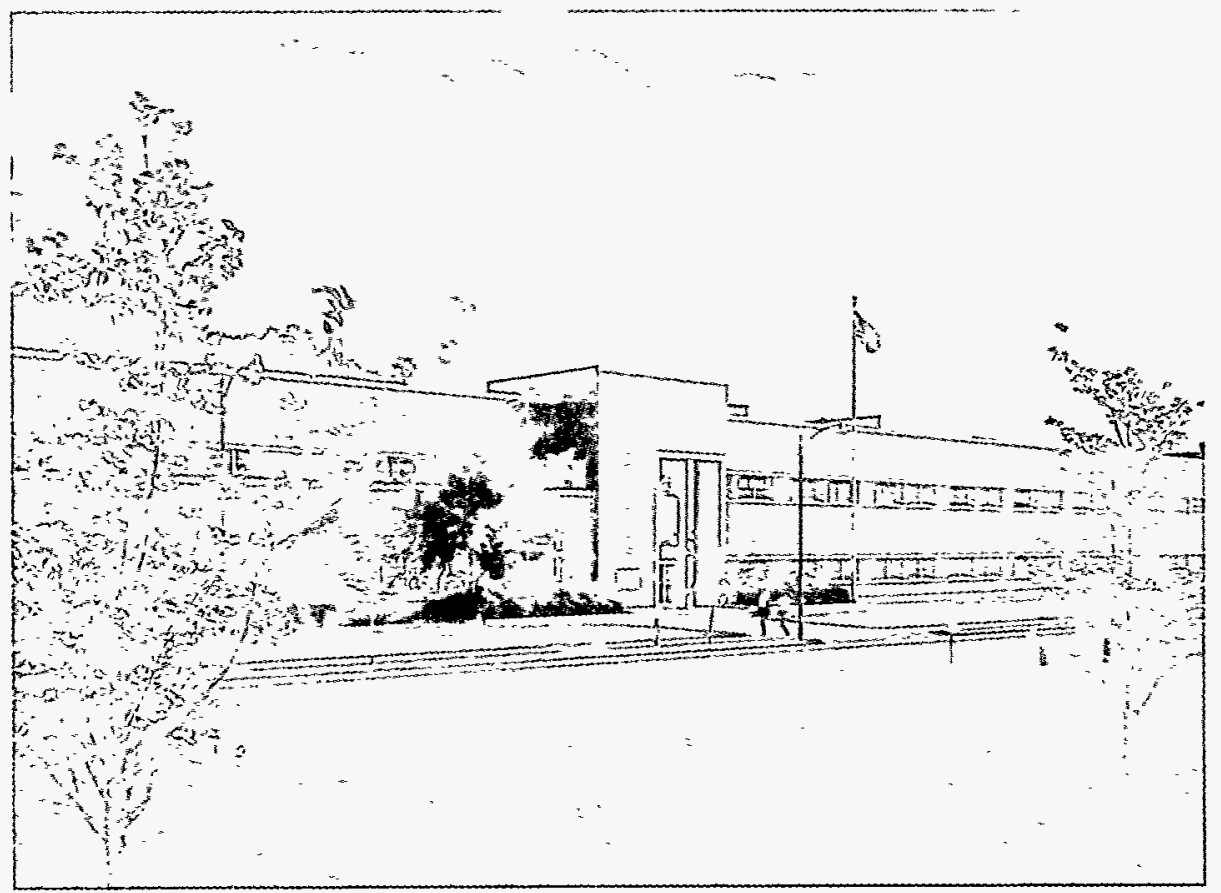

Fig. C.3.11. Building 4500N, Central Research Building. 


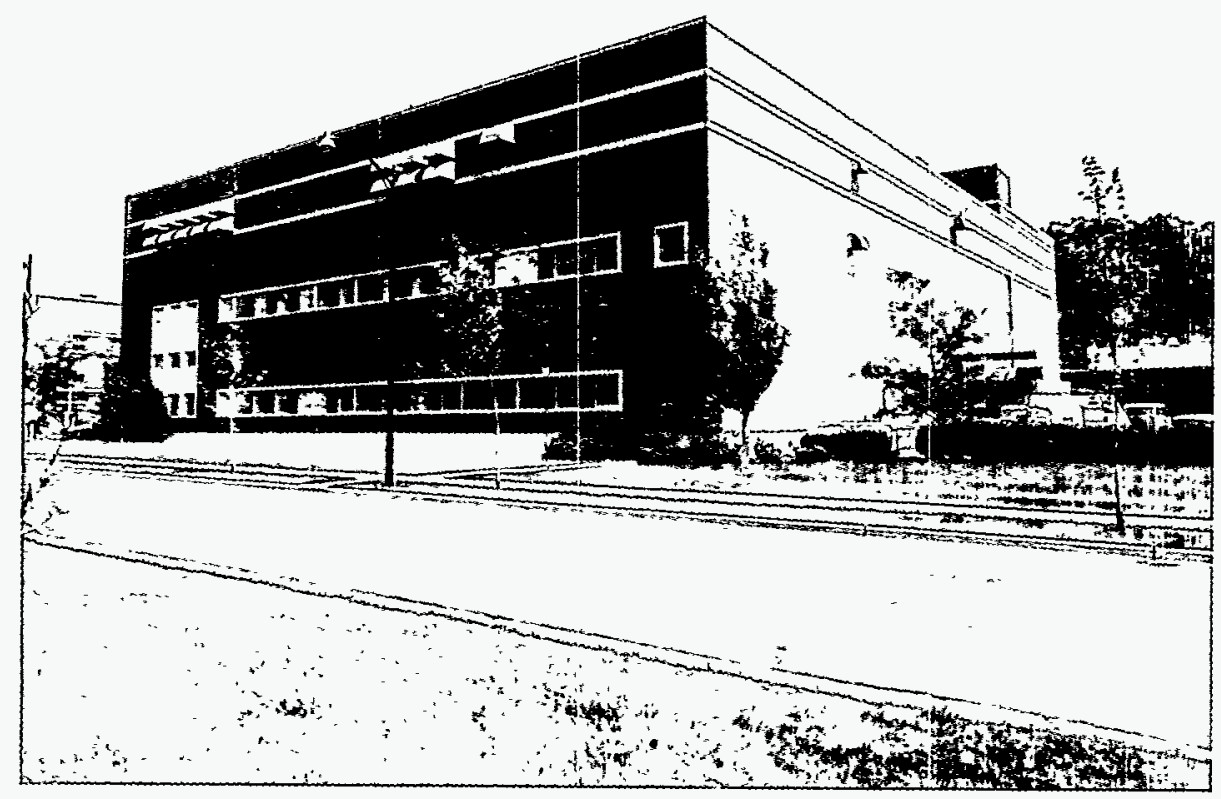

Fig. C.3.12. Building 4501/5, High-Level Radiochemical Laboratory.

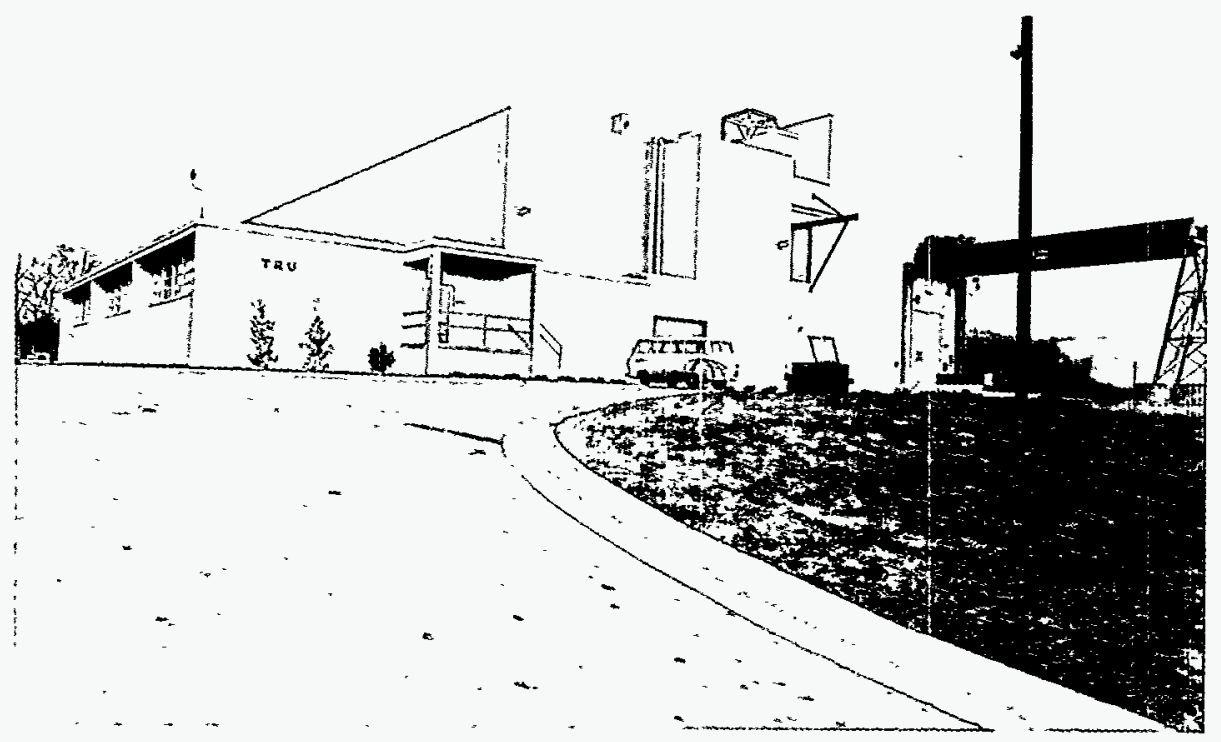

Fig. C.3.13. Building 7920, Transuranium Processing Plant. 


\section{APPENDIX D}

HONORS AND AWARDS RECEIVED BY CHEMICAL TECHNOLOGY DIVISION PERSONNEL 


\section{LIST OF ACRONYMS FOR APPENDIX D}

AAAS
AACC
AAES
AAWA
ACerS
AChS
AIC
AIChE
ANS
APS
ASCET
ASES
ASME
CEUSP
DOE
ISES
NAE
NRC
NSF
PSI
STC
STC/ETC
SWE
TSPE
UCC

American Association for the Advancement of Science American Association for Clinical Chemistry

American Association of Engineering Societies

American Water Works Association

American Ceramic Society

American Chemical Society

American Institute of Chemists

American Institute of Chemical Engineers

American Nuclear Society

American Physical Society

American Society of Certified Engineering Technicians

American Solar Energy Society

American Society of Mechanical Engineers

Consolidated Edison Uranium Solidification Program

United States Department of Energy

International Solar Energy Society

National Academy of Engineering

National Research Council

National Science Foundation

Professional Secretaries International

Society for Technical Communication

Society for Technical Communication, East Tennessee Chapter

Society of Women Engineers

Tennessee Society of Professional Engineers

Union Carbide Corporation

\footnotetext{
"Society for Technical Communication award ranking: first place, Distinction; second place, Excellence; third place, Merit; fourth place, Achievement.
} 
Table D.1. Honors and Awards received by Chemnical Technology Division personnel

\begin{tabular}{|c|c|c|}
\hline Name & Award & Sponsor \\
\hline \multirow[t]{3}{*}{ Beahm, Edward C. } & Best Paper Award (2) & $\begin{array}{l}\text { ANS, Materials Science and } \\
\text { Technology Division }\end{array}$ \\
\hline & $\begin{array}{l}\text { Significant Implications } \\
\text { for Energy Technology }\end{array}$ & $\begin{array}{l}\text { DOE, Materials Science } \\
\text { Research Competition }\end{array}$ \\
\hline & $\begin{array}{l}\text { Materials Science Research } \\
\text { Competition Award }\end{array}$ & DOE \\
\hline \multirow[t]{2}{*}{ Begovich, John } & IR-100 Award & Research and Development \\
\hline & Publications Award & Energy Systems \\
\hline Bell, Jimmy T. & Silver Acorn Award & Energy Systems \\
\hline Berry, Jan B. & Waste Minimization Award & DOE \\
\hline \multirow[t]{3}{*}{ Besmann, Theodore M. } & $\begin{array}{l}\text { Materials Science Research } \\
\text { Competition Award }\end{array}$ & DOE \\
\hline & $\begin{array}{l}\text { Best Paper Award for } \\
\text { Nuclear Division }\end{array}$ & ACerS \\
\hline & $\begin{array}{l}\text { Membership Chairman, } \\
\text { Program and National Public } \\
\text { Information Committees }\end{array}$ & ACerS \\
\hline \multirow[t]{2}{*}{ Bigelow, John E. } & Best Paper Award & $\begin{array}{l}\text { ANS, Remote Systems } \\
\text { Technology Division }\end{array}$ \\
\hline & Community Service Award & UCC \\
\hline \multirow[t]{3}{*}{ Blanco, Raymond E. } & Alumni Achievement Award & North Dakota State University \\
\hline & Fellow & ANS \\
\hline & Chairman & $\begin{array}{l}\text { ANS, Nuclear Fuel } \\
\text { Recycle Division }\end{array}$ \\
\hline Blomeke, John & $\begin{array}{l}\text { Outstanding Work in Chemical } \\
\text { Technology in Fuel Recycle }\end{array}$ & ANS \\
\hline \multirow[t]{2}{*}{ Bond, Walter D. } & Award of Excellence & STC/ETC \\
\hline & IR-100 Award & $\begin{array}{l}\text { Industrial Research and } \\
\text { Development }\end{array}$ \\
\hline Bopp, C. Daniel & Fellow & AIC \\
\hline Box, W. Donald & Silver Acorn Award & Energy Systems \\
\hline \multirow[t]{2}{*}{ Brooksbank, Donna T. } & Award of Excellence (2) & STC/ETC \\
\hline & Award of Achievement & $\begin{array}{l}\text { STC, International Technical } \\
\text { Publications Competition }\end{array}$ \\
\hline Brooksbank, Robert E. & Professional Engineering License & TSPE \\
\hline Brown, Deborah S. & Certified Professional Secretary & PSI \\
\hline Brown, Janet D. & Certified Professional Secretary & PSI \\
\hline
\end{tabular}


Table D.1 (continued)

\begin{tabular}{|c|c|c|}
\hline Name & Award & Sponsor \\
\hline \multirow[t]{4}{*}{ Brown, Keith B. } & Technical Achievement Award & Mining World \\
\hline & Certificate of Merit & ANS \\
\hline & $\begin{array}{l}\text { Kirkpatrick Chemical } \\
\text { Engineering Achievement Award }\end{array}$ & Chemical Engineering \\
\hline & 1984 Citation Classics Award (2) & $\begin{array}{l}\text { Citation Index Physical, } \\
\text { Chemical and Earth Sciences; } \\
\text { Engineering,Technology and } \\
\text { Applied Sciences }\end{array}$ \\
\hline Brunson, Ron R. & Award 1990 & STC/ETC \\
\hline \multirow[t]{5}{*}{ Burtis, Carl A. } & $\begin{array}{l}\text { President, Board of Directors, } \\
\text { and National Lectureship Award }\end{array}$ & $\mathrm{AACC}$ \\
\hline & Award of Distinction & STC/ETC \\
\hline & Award of Distinction & $\begin{array}{l}\text { STC, International Technical } \\
\text { Publications Competition }\end{array}$ \\
\hline & Silver Acorn Award & Energy Systems \\
\hline & IR-100 Award & $\begin{array}{l}\text { Industrial Research and } \\
\text { Development }\end{array}$ \\
\hline \multirow[t]{3}{*}{ Campbell, David O. } & $\begin{array}{l}\text { Advancements in Nuclear } \\
\text { Technology (2) }\end{array}$ & ANS \\
\hline & Silver Acorn Award & Energy Systems \\
\hline & $\begin{array}{l}\text { Glenn T. Seaborg Award for } \\
\text { Actinide Separations }\end{array}$ & $\begin{array}{l}\text { Advisory Board; Actinide } \\
\text { Separations Conference }\end{array}$ \\
\hline Case, Gerry N. & IR-100 Award & $\begin{array}{l}\text { Industrial Research and } \\
\text { Development }\end{array}$ \\
\hline Clinton, Sam D. & Silver Acorn Award & Energy Systems \\
\hline Cochran, Henry D. & Silver Acorn Award & Energy Sysytems \\
\hline \multirow[t]{3}{*}{ Coleman, Charles F. } & $\begin{array}{l}\text { Kirkpatrick Chemical } \\
\text { Engineering Achievement Award }\end{array}$ & Chemical Engineering \\
\hline & Silver Acorn Award & Energy Systems \\
\hline & 1984 Citation Classics Award (2) & $\begin{array}{l}\text { Citation Index Physical, } \\
\text { Chemical and Earth Sciences; } \\
\text { Engineering, Technology and } \\
\text { Applied Sciences }\end{array}$ \\
\hline Collins, Emory D. & Chairman & $\begin{array}{l}\text { AIChE, Knoxville-Oak Ridge } \\
\text { Chapter }\end{array}$ \\
\hline \multirow[t]{2}{*}{ Collins, J. L. } & Literary Award for 1987 and 1988 & $\begin{array}{l}\text { Materials Science and } \\
\text { Technology }\end{array}$ \\
\hline & Silver Acorn Award & Energy Systems \\
\hline
\end{tabular}


Table D.1 (continued)

\begin{tabular}{|c|c|c|}
\hline Name & Award & Sponsor \\
\hline \multirow[t]{4}{*}{ Collins, J. L. } & $\begin{array}{l}\text { Awards of Distinction and } \\
\text { Achievement }\end{array}$ & STC/ETC \\
\hline & 1989 Technical Achievement (Team) & Energy Systems \\
\hline & 1990 Special Achievement Award & Energy Systems \\
\hline & $\begin{array}{l}1991 \text { President's Award for } \\
\text { Performance Improvement }\end{array}$ & Energy Systems \\
\hline \multirow[t]{3}{*}{ Crouse, D. J. } & IR-100 Award & $\begin{array}{l}\text { Industrial Research and } \\
\text { Development }\end{array}$ \\
\hline & $\begin{array}{l}\text { Kirkpatrick Chemical } \\
\text { Engineering Achievement Award }\end{array}$ & Chemical Engineering \\
\hline & 1984 Citation Classics Award (2) & $\begin{array}{l}\text { Citation Index Physical, } \\
\text { Chemical and Earth Sciences; } \\
\text { Engineering, Technology and } \\
\text { Applied Sciences }\end{array}$ \\
\hline \multirow[t]{2}{*}{ Culberson, Oran L. } & Fellow & AIChE \\
\hline & Silver Acorn Award & Energy Systems \\
\hline Davis, Wallace R. & Fellow & AAAS \\
\hline Dawson, Martha M. & Certified Professional Secretary & PSI \\
\hline Dinsmore, S. R. & Silver Acorn Award & Energy Systems \\
\hline Dodson, Karen E. & Silver Acorn Award & Energy Systems \\
\hline Egan, B. Z. & $\begin{array}{l}\text { Awards of Distinction (2), } \\
\text { Excellence, and Achievement }\end{array}$ & STC/ETC \\
\hline Emmett, Mary J. & Certified Professional Secretary & PSI \\
\hline Felker, Leslie K. & Award of Achievement & STC/ETC \\
\hline \multirow[t]{4}{*}{ Ferguson, Don E. } & $\begin{array}{l}\text { Fellow, Board of Directors, } \\
\text { and Award for Outstanding Work } \\
\text { in Chemical Technology in } \\
\text { Fuel Recycle }\end{array}$ & ANS \\
\hline & Award of Excellence & STC/ETC \\
\hline & $\begin{array}{l}\text { 25th Anniversary Exceptional } \\
\text { Service Award }\end{array}$ & ANS \\
\hline & Engineer of Distinction & Tennessee Technological Univ. \\
\hline \multirow[t]{2}{*}{ Forsberg, Charles W. } & Award of Achievement & $\begin{array}{l}\text { STC, International Technical } \\
\text { Publications Competition }\end{array}$ \\
\hline & Award of Excellence (2) & STC/ETC \\
\hline \multirow[t]{2}{*}{ Frederick, Edward J. } & Certificate of Appreciation & DOE \\
\hline & Silver Acorn Award & Energy Systems \\
\hline
\end{tabular}


Table D.1 (continued)

\begin{tabular}{|c|c|c|}
\hline Name & Award & Sponsor \\
\hline Friedman, Horace A. & Silver Acorn Award & Energy Systems \\
\hline \multirow[t]{2}{*}{ Gambill, Wallace R. } & $\begin{array}{l}\text { Editorial Excellence } \\
\text { Award of Merit }\end{array}$ & Chemical Engineering \\
\hline & Silver Acorn Award & Energy Systems \\
\hline Genung, Richard K. & IR-100 Award & $\begin{array}{l}\text { Industrial Research and } \\
\text { Development }\end{array}$ \\
\hline Gibson, S. M. & Newsletter Editor & $\begin{array}{l}\text { AIChE, Nuclear Engineering } \\
\text { Division }\end{array}$ \\
\hline \multirow[t]{4}{*}{ Godbee, Herschel W. } & Certificate of Appreciation & DOE \\
\hline & Silver Acorn Award & Energy Systems \\
\hline & M. Sacid (Sarge) Ozker Award & ASME \\
\hline & $\begin{array}{l}\text { Chairman, Standards Working } \\
\text { Group } 16.6\end{array}$ & ANS \\
\hline Graves, D. A. & Award of Distinction & STC/ETC \\
\hline \multirow[t]{13}{*}{ Greenbaum, Elias } & Chairman & $\begin{array}{l}\text { ASES, Biotechnology and } \\
\text { Chemical Sciences Division }\end{array}$ \\
\hline & $\begin{array}{l}\text { Delegate, U.N. Conference on New } \\
\text { and Renewable Sources of Energy, } \\
\text { Nairobi, Kenya }\end{array}$ & ISES \\
\hline & $\begin{array}{l}\text { Awards of Distinction, Excellence, } \\
\text { Merit (2), and Achievement (2) }\end{array}$ & STC/ETC \\
\hline & Award of Achievement & $\begin{array}{l}\text { STC, International Technical } \\
\text { Publications Competition }\end{array}$ \\
\hline & Fellow & APS \\
\hline & Secretary-Treasurer & APS, Division of Biological Physics \\
\hline & $\begin{array}{l}\text { Delegate. U.S.-Japan Seminar on } \\
\text { Artificial Photosynthesis, } \\
\text { Okazaki, Japan }\end{array}$ & NSF \\
\hline & $\begin{array}{l}\text { Grant. U.S.-Japan Program of } \\
\text { Cooperation in Photoconversion } \\
\text { and Photosynthesis }\end{array}$ & NSF \\
\hline & Silver Acorn Award & Energy Systems \\
\hline & Significant Event Award & Energy Systems \\
\hline & Technical Achievement Award & Energy Systems \\
\hline & Fellow & AAAS \\
\hline & Chairman & $\begin{array}{l}\text { APS, Division of Biological } \\
\text { Physics }\end{array}$ \\
\hline
\end{tabular}


Table D.1 (continued)

\begin{tabular}{|c|c|c|}
\hline Name & Award & Sponsor \\
\hline \multirow[t]{2}{*}{ Greenbaum, Elias } & $\begin{array}{l}\text { Associate Editor, } \\
\text { Biophysical Journal }\end{array}$ & Biophysical Society \\
\hline & $\begin{array}{l}\text { Co-Chairman, U.S.-Israel } \\
\text { Bi-national Workshop on } \\
\text { Photosynthesis and Energy } \\
\text { Related Biological Science }\end{array}$ & $\begin{array}{l}\text { DOE and Israel Ministry } \\
\text { of Science and Technology }\end{array}$ \\
\hline Grimes, Warren R. & $\begin{array}{l}\text { Fellow, 25th Anniversary } \\
\text { Exceptional Service Award } \\
\text { and Outstanding Contributions } \\
\text { in the Field of Reactor Chemistry }\end{array}$ & ANS \\
\hline \multirow[t]{5}{*}{ Haas, P. A. } & 1990 Award of Distinction & STC/ETC \\
\hline & IR-100 Award & $\begin{array}{l}\text { Industrial Research and } \\
\text { Development }\end{array}$ \\
\hline & Fellow & AIChE \\
\hline & Golden Acorn Award & Energy Systems \\
\hline & Inventor Award & Energy Systems \\
\hline \multirow[t]{2}{*}{ Harrington, Francis E. } & IR-100 Award & $\begin{array}{l}\text { Industrial Research and } \\
\text { Development }\end{array}$ \\
\hline & Silver Acorn Award & Energy Systems \\
\hline Haws, Claude C. & IR-100 Award & $\begin{array}{l}\text { Industrial Research and } \\
\text { Development }\end{array}$ \\
\hline \multirow[t]{2}{*}{ Hightower, J. R. } & $\begin{array}{l}\text { Outstanding Advisory } \\
\text { Committee Member }\end{array}$ & $\begin{array}{l}\text { Pellissippi State Technical } \\
\text { Community College }\end{array}$ \\
\hline & Engineer of the Year & $\begin{array}{l}\text { AIChE, Knoxville-Oak Ridge } \\
\text { Chapter }\end{array}$ \\
\hline Holladay, David W. & Silver Acorn Award & Energy Systems \\
\hline Horton, Robert W. & Professional Engineering License & TSPE \\
\hline \multirow[t]{2}{*}{ Hurst, F. J. } & IR-100 Award & $\begin{array}{l}\text { Industrial Research and } \\
\text { Development }\end{array}$ \\
\hline & $\begin{array}{l}\text { Kirkpatrick Chemical Engineering } \\
\text { Achievement Award }\end{array}$ & Chemical Engineering \\
\hline Irvine, Alvin R. & Silver Acorn Award & Energy Systems \\
\hline \multirow[t]{4}{*}{ Jolley, Robert L. } & Distinguished Alumni Award & Friends University, Kansas \\
\hline & $\begin{array}{l}\text { Chairman, Vice-Chairman, } \\
\text { Secretary, and Program Chairman }\end{array}$ & $\begin{array}{l}\text { AChS, Division of } \\
\text { Environmental Chemistry }\end{array}$ \\
\hline & 1986 Distinguished Service Award & $\begin{array}{l}\text { AChS, Division of } \\
\text { Environmental Chemistry }\end{array}$ \\
\hline & Councilor & AChS \\
\hline
\end{tabular}


Table D.1 (continued)

\begin{tabular}{|c|c|c|}
\hline Name & Award & Sponsor \\
\hline \multirow[t]{6}{*}{ Jolley, Robert L. } & Member & $\begin{array}{l}\text { AChS, Committees on } \\
\text { Environmental Improvement } \\
\text { and Meetings and Expositions }\end{array}$ \\
\hline & Community Service Award & UCC \\
\hline & Silver Acorn Award & Energy Systems \\
\hline & $\begin{array}{l}\text { Awards of Distinction (2), } \\
\text { Achievement, and Merit }\end{array}$ & STC/ETC \\
\hline & Award of Distinction, Books & $\begin{array}{l}\text { STC, International Technical } \\
\text { Publications Competition }\end{array}$ \\
\hline & Member & $\begin{array}{l}\text { AAWA, Health Effects } \\
\text { Research Committee }\end{array}$ \\
\hline Joy, Dave S. & Silver Acorn Award & Energy Systems \\
\hline \multirow[t]{2}{*}{ Kappelmann, Frederick A. } & IR-100 Award & $\begin{array}{l}\text { Industrial Research and } \\
\text { Development }\end{array}$ \\
\hline & Silver Acorn Award & Energy Systems \\
\hline \multirow[t]{2}{*}{ Kelmers, A. Donald } & Award of Achievement & STC/ETC \\
\hline & Silver Acorn Award & Energy Systems \\
\hline King, Lester J. & Professional Engineering License & TSPE \\
\hline King, Vaneeta $M$. & Certified Professional Secretary & PSI \\
\hline Knight, John R. & Best Paper Award & $\begin{array}{l}\text { ANS, Nuclear Criticality } \\
\text { Safety Division }\end{array}$ \\
\hline Lee, Douglas D. & IR-100 Award & $\begin{array}{l}\text { Industrial Research and } \\
\text { Development }\end{array}$ \\
\hline \multirow[t]{5}{*}{ Lee, Norman E. } & Silver Acorn Award & Energy Systems \\
\hline & $\begin{array}{l}\text { Awards of Distinction (2), } \\
\text { Merit, and Achievement }\end{array}$ & STC/ETC \\
\hline & Award of Distinction & $\begin{array}{l}\text { STC, International Technical } \\
\text { Publications Competition }\end{array}$ \\
\hline & Award for Technical Support & Energy Systems \\
\hline & Fellow & AIC \\
\hline \multirow[t]{3}{*}{ Leuze, Rex E. } & Fellow & AIC \\
\hline & IR-100 Award & $\begin{array}{l}\text { Industrial Research and } \\
\text { Development }\end{array}$ \\
\hline & Silver Acorn Award & Energy Systems \\
\hline Lewis, Barbara A. & $\begin{array}{l}\text { Margaret Oakley Dayhoff } \\
\text { Memorial Award }\end{array}$ & Biophysical Society \\
\hline Lewis, Susan E. & Publications Award & Energy Systems \\
\hline
\end{tabular}


Table D.1 (continued)

\begin{tabular}{|c|c|c|}
\hline Name & Award & Sponsor \\
\hline Light, Brenda B. & Certified Professional Secretary & PSI \\
\hline \multirow[t]{4}{*}{ Lindemer, Terrence B. } & Fellow & ACerS \\
\hline & $\begin{array}{l}\text { Chairman, Vice-Chairman, } \\
\text { Trustee, and Best Paper Award }\end{array}$ & ACerS, Nuclear Division \\
\hline & Publications Award & Energy Systems \\
\hline & Silver Acorn Award & Energy Systems \\
\hline \multirow[t]{2}{*}{ Lloyd, Milton $\mathrm{H}$. } & IR-100 Award & $\begin{array}{l}\text { Industrial Research and } \\
\text { Development }\end{array}$ \\
\hline & Silver Acorn Award & Energy Systems \\
\hline \multirow[t]{5}{*}{ Lorenz, R. A. } & Technical Achievement (Cont.) & Energy Systems \\
\hline & 1989 Technical Achievement (Team) & Energy Systems \\
\hline & $\begin{array}{l}\text { Assistance to President's } \\
\text { Commission (TMI-2) }\end{array}$ & DOE \\
\hline & Award of Distinction & STC/ETC \\
\hline & Literary Award for 1987 and 1988 & ANS, Material Science Division \\
\hline Lowrie, Robert S. & Silver Acorn Award & Energy Systems \\
\hline Lynch, Judy M. & Certified Professional Secretary & PSI \\
\hline \multirow[t]{2}{*}{ Mailen, J. C. } & Fellow & AIChE \\
\hline & Golden Acorn Award & Energy Systems \\
\hline \multirow[t]{2}{*}{ Malinauskas, Anthony P. } & $\begin{array}{l}\text { Special Award, Advancements in } \\
\text { Nuclear Technology }\end{array}$ & ANS \\
\hline & $\begin{array}{l}\text { Ernest O. Lawrence } \\
\text { Memorial Award }\end{array}$ & DOE \\
\hline McBride, J. P. & $\begin{array}{l}\text { Award of Excellence (2) } \\
\text { Award of Excellence }\end{array}$ & $\begin{array}{l}\text { STC/ETC } \\
\text { STC, International Technical } \\
\text { Publications Competition }\end{array}$ \\
\hline \multirow[t]{2}{*}{ McDaniel, Earl W. } & $\begin{array}{l}\text { First Prize. Optical Microscopy, } \\
\text { Unique Techniques }\end{array}$ & ACerS, Ceramographic Exhibit \\
\hline & $\begin{array}{l}\text { Awards of Excellence (2) } \\
\text { and Achievement }\end{array}$ & STC/ETC \\
\hline McDowell, William J. & IR-100 Award & Industrial Research and Development \\
\hline \multirow[t]{4}{*}{ McGinnis, C. Phil } & Certified Professional Engineer & TSPE \\
\hline & Editor & AIChE, Nuclear Engineering Division \\
\hline & Chairman and Engineer of the Year & AIChE, Knoxville-Oak Ridge Chapter \\
\hline & $\begin{array}{l}\text { Award of Achievement, } \\
\text { CEUSP Operation }\end{array}$ & Energy Systems \\
\hline
\end{tabular}


Table D.1 (continued)

\begin{tabular}{|c|c|c|}
\hline Name & Award & Sponsor \\
\hline \multirow[t]{2}{*}{ McGinnis, C. Phil } & Operational Performance Award & Energy Systems \\
\hline & Awards of Distinction and Merit & STC/ETC \\
\hline McTaggart, Donald R. & Silver Acorn Award & Energy Systems \\
\hline Moore, John G. & 1984 Citation Classics Award (2) & $\begin{array}{l}\text { Citation Index Physical, } \\
\text { Chemical, and Earth Sciences; } \\
\text { Engineering, Technology } \\
\text { and Applied Sciences }\end{array}$ \\
\hline \multirow[t]{3}{*}{ Mrochek, John E. } & IR-100 Award (2) & $\begin{array}{l}\text { Industrial Research and } \\
\text { Development }\end{array}$ \\
\hline & Silver Acorn Award & Energy Systems \\
\hline & Inventor Award & Energy Systems \\
\hline \multirow[t]{2}{*}{ Notz, Karl J. } & IR-100 Award & $\begin{array}{l}\text { Industrial Research and } \\
\text { Development }\end{array}$ \\
\hline & Silver Acorn Award & Energy Systems \\
\hline \multirow[t]{4}{*}{ Osborne, M. F. } & Literary Award for 1987 and 1988 & Materials Science \& Technology \\
\hline & 1989 Technical Achievement (Team) & Energy Systems \\
\hline & $\begin{array}{l}\text { Awards for Distinction } \\
\text { and Achievement }\end{array}$ & STC/ETC \\
\hline & $\begin{array}{l}\text { President's Award, Performance } \\
\text { Improvement Project }\end{array}$ & Energy Systems \\
\hline \multirow[t]{3}{*}{ Osborne-Lee, Irvin W. } & Executive Board Member & $\begin{array}{l}\text { National Organization } \\
\text { of Black Chemists and } \\
\text { Chemical Engineers }\end{array}$ \\
\hline & Chairman & $\begin{array}{l}\text { AIChE, Minority Affairs } \\
\text { Committee }\end{array}$ \\
\hline & Chairman & $\begin{array}{l}\text { AIChE, Committee for New } \\
\text { Technology and Development }\end{array}$ \\
\hline Owen, Sue C. & Certified Professional Secretary & PSI \\
\hline Parrott, John R. & Professional Engineering License & TSPE \\
\hline Pattison, William L. & Silver Acorn Award & Energy Systems \\
\hline Pearson, Ray L. & Publications Award & Energy Systems \\
\hline Peishel, Frank L. & Professional Engineering License & TSPE \\
\hline \multirow[t]{2}{*}{ Perona, Joseph J. } & Chairman & $\begin{array}{l}\text { AIChE, Energy Transport } \\
\text { Research Committee }\end{array}$ \\
\hline & Fellow & $\mathrm{AIChE}$ \\
\hline
\end{tabular}


Table D.1 (continued)

\begin{tabular}{|c|c|c|}
\hline Name & Award & Sponsor \\
\hline \multirow[t]{4}{*}{ Pitt, W. W., Jr. } & IR-100 Award (2) & $\begin{array}{l}\text { Industrial Research and } \\
\text { Development }\end{array}$ \\
\hline & Silver Acorn Award & Energy Systems \\
\hline & Fellow & $\mathrm{AIChE}$ \\
\hline & Professional Engineering License & TSPE \\
\hline \multirow[t]{2}{*}{ Pruett, David J. } & Chairman & $\begin{array}{l}\text { ACS, Nuclear Chemistry and } \\
\text { Technology Division }\end{array}$ \\
\hline & Silver Acorn Award & Energy Systems \\
\hline Reeves, M. E. & Award of Distinction & $\begin{array}{l}\text { STC, } 1990 \text { Technical } \\
\text { Publications Competition }\end{array}$ \\
\hline \multirow[t]{3}{*}{ Robinson, S. M. } & Young Engineer of the Year & TSPE \\
\hline & Director of Executive Committee & $\begin{array}{l}\text { Tau Beta Pi, Great Smoky } \\
\text { Mountains Alumni Chapter }\end{array}$ \\
\hline & $\begin{array}{l}\text { Outstanding Young Woman } \\
\text { of America for } 1988\end{array}$ & $\begin{array}{l}\text { Outstanding Young Women } \\
\text { of America }\end{array}$ \\
\hline Roddy, J. William & Award of Excellence (2) & STC/ETC \\
\hline \multirow[t]{3}{*}{ Rodgers, B. R. } & $\begin{array}{l}\text { Chairman, Director, } \\
\text { Program Chairman }\end{array}$ & $\begin{array}{l}\text { AIChE, Fuels and } \\
\text { Petrochemicals Division }\end{array}$ \\
\hline & Director & AIChE \\
\hline & Silver Acorn Award & Energy Systems \\
\hline Ross, Robert G. & Silver Acorn Award & Energy Systems \\
\hline \multirow[t]{2}{*}{ Ryon, Allen D. } & $\begin{array}{l}\text { Kirkpatrick Chemical Engineering } \\
\text { Achievement Award }\end{array}$ & Chemical Engineering \\
\hline & IR-100 Award & $\begin{array}{l}\text { Industrial Research and } \\
\text { Development }\end{array}$ \\
\hline Salmon, Royes & Silver Acorn Award & Energy Systems \\
\hline \multirow[t]{2}{*}{ Scheitlin, F. M. } & Award of Distinction & $\begin{array}{l}\text { STC, } 1990 \text { International } \\
\text { Technical Publications } \\
\text { Competition }\end{array}$ \\
\hline & Silver Acorn Award & Energy Systems \\
\hline \multirow[t]{3}{*}{ Scott, C. D. } & Award of Distinction & $\begin{array}{l}\text { STC, } 1990 \text { International } \\
\text { Technical Publications } \\
\text { Competition }\end{array}$ \\
\hline & IR-100 Award (4) & $\begin{array}{l}\text { Industrial Research and } \\
\text { Development }\end{array}$ \\
\hline & $\begin{array}{l}\text { Outstanding Engineering } \\
\text { Alumnus Award }\end{array}$ & The University of Tennessee \\
\hline
\end{tabular}


Table D.1 (continued)

\begin{tabular}{|c|c|c|}
\hline Name & Award & Sponsor \\
\hline \multirow[t]{17}{*}{ Scott, C. D. } & Senior Corporate Fellow & Energy Systems \\
\hline & Engineer of the Year & $\begin{array}{l}\text { AIChE, Knoxville-Oak Ridge } \\
\text { Chapter }\end{array}$ \\
\hline & Fellow & $\mathrm{AIChE}$ \\
\hline & $\begin{array}{l}\text { Ernest O. Lawrence } \\
\text { Memorial Award }\end{array}$ & DOE \\
\hline & Outstanding Contribution Award & AACC \\
\hline & $\begin{array}{l}\text { National Award for Advanced } \\
\text { Analytical Concepts }\end{array}$ & AACC \\
\hline & Award of Excellence & STC/ETC \\
\hline & Corporate Fellow & $\mathrm{UCC}$ \\
\hline & Silver Acorn Award & Energy Systems \\
\hline & $\begin{array}{l}\text { Member of Advisory Committee } \\
\text { and Committee of Fundamental } \\
\text { Research for Emerging and Critical } \\
\text { Engineering Systems }\end{array}$ & NSF \\
\hline & Golden Acorn Award & Energy Systems \\
\hline & Member & NAE \\
\hline & Inventor of the Year & Energy Systems \\
\hline & Publications Award & Energy Systems \\
\hline & Director & $\mathrm{AIChE}$ \\
\hline & Fellow & AAAS \\
\hline & $\begin{array}{l}\text { Missouri Honor Award for } \\
\text { Distinguished Service in Engineering }\end{array}$ & University of Missouri \\
\hline \multirow[t]{2}{*}{ Scott, T. C. } & Award of Achievement & STC/ETC \\
\hline & Award of Distinction & $\begin{array}{l}\text { STC, } 1990 \text { International } \\
\text { Technical Publications } \\
\text { Competition }\end{array}$ \\
\hline Seeley, F. G. & Silver Acorn Award & Energy Systems \\
\hline Shell, S. E. & Silver Acorn Award & Energy Systems \\
\hline Shepherd, Deborah E. & Certified Professional Secretary & PSI \\
\hline \multirow[t]{2}{*}{ Shockley, William E. } & Technician of the Year & ASCET \\
\hline & Silver Acorn Award & Energy Systems \\
\hline Shor, Joel T. & Silver Acorn Award & Energy Systems \\
\hline Singh, S. P. N. & Silver Acorn Award & Energy Systems \\
\hline
\end{tabular}


Table D.1 (continued)

\begin{tabular}{|c|c|c|}
\hline Name & Award & Sponsor \\
\hline Sisson, Warren G. & IR-100 Award & $\begin{array}{l}\text { Industrial Research and } \\
\text { Development }\end{array}$ \\
\hline \multirow[t]{2}{*}{ Spence, Roger D. } & IR-100 Award (2) & $\begin{array}{l}\text { Industrial Research and } \\
\text { Development }\end{array}$ \\
\hline & Award of Achievement & STC/ETC \\
\hline Stewart, Carol E. & Certified Professional Secretary & PSI \\
\hline \multirow[t]{5}{*}{ Stewart, Martha G. } & Award of Distinction & STC/ETC \\
\hline & Award of Excellence (2) & STC/ETC \\
\hline & Award of Merit (2) & STC/ETC \\
\hline & Award of Achievement (2) & STC/ETC \\
\hline & Award of Achievement (2) & $\begin{array}{l}\text { STC, International Technical } \\
\text { Publications Competition }\end{array}$ \\
\hline Strandberg, Gerald W. & Publications Award & Energy Systems \\
\hline Tallent, O. K. & Silver Acorn Award & Energy Systems \\
\hline Toth, L. M & Silver Acorn Award & Energy Systems \\
\hline Villiers-Fisher, John F. & Golden Acorn Award & Energy Systems \\
\hline \multirow[t]{2}{*}{ Watson, Jack S. } & Member & $\begin{array}{l}\text { AIChE, National Research } \\
\text { Committee }\end{array}$ \\
\hline & Silver Acorn Award & Energy Systems \\
\hline Weaver, Deborah J. & Certified Professional Secretary & PSI \\
\hline \multirow[t]{2}{*}{ Weeren, Herman O. } & $\begin{array}{l}\text { First Prize. Optical Microscopy, } \\
\text { Unique Techniques }\end{array}$ & ACerS, Ceramographic Exhibit \\
\hline & Award of Excellence & STC/ETC \\
\hline Wham, R. M. & Secretary, Treasurer, Director & $\begin{array}{l}\text { AlChE, Knoxville-Oak Ridge } \\
\text { Chapter }\end{array}$ \\
\hline \multirow[t]{4}{*}{ Whatley, Susan K. } & $\begin{array}{l}\text { President, Vice-President, and } \\
\text { Distinguished New Engineers Award }\end{array}$ & SWE \\
\hline & Women of Achievement Award & The University of Tennessee \\
\hline & Member & $\begin{array}{l}\text { AAES, Management Committee, } \\
\text { Engineering Affairs Council }\end{array}$ \\
\hline & Governor & AAES \\
\hline Woodward, C. A. & Award of Distinction & $\begin{array}{l}\text { STC, } 1990 \text { International } \\
\text { Technical Publications } \\
\text { Competition }\end{array}$ \\
\hline
\end{tabular}


Table D.1 (continued)

\begin{tabular}{|c|c|c|}
\hline Name & Award & Sponsor \\
\hline \multirow[t]{4}{*}{ Woodward, Jonathan } & Librarian & $\begin{array}{l}\text { AChS, Division of Microbial } \\
\text { and Biochemical Technology }\end{array}$ \\
\hline & Award of Merit & STC/ETC \\
\hline & Significant Event Award & Energy Systems \\
\hline & Advisory Editor & $\begin{array}{l}\text { Journal of Biomass, Energy } \\
\text { Society of China }\end{array}$ \\
\hline \multirow[t]{7}{*}{ Wymer, Raymond G. } & Fellow & AIC \\
\hline & $\begin{array}{l}\text { Fellow and Award for } \\
\text { Outstanding Work in Chemical } \\
\text { Technology in Fuel Recycle }\end{array}$ & ANS \\
\hline & President & $\begin{array}{l}\text { AIC, Tennessee Institute of } \\
\text { Chemists }\end{array}$ \\
\hline & Member & $\begin{array}{l}\text { NRC, Subcommittee on } \\
\text { Nuclear and Radiochemistry }\end{array}$ \\
\hline & $\begin{array}{l}\text { Awards of Excellence (2) } \\
\text { and Achievement }\end{array}$ & STC/ETC \\
\hline & Silver Acorn Award & Energy Systems \\
\hline & Robert E. Wilson Award & AIChE, Tennessee Chapter \\
\hline
\end{tabular}


Table D.2. IR-100 Awards ${ }^{a}$

\begin{tabular}{cll}
\hline Date & \multicolumn{1}{c}{ Technical Achievement } & \multicolumn{1}{c}{ Inventors } \\
\hline 1971 & ORNL Ultraviolet Analyzer & $\begin{array}{l}\text { C. D. Scott, N. G. Anderson, W. W. Pitt, Jr., and } \\
\text { W. F. Johnson }\end{array}$ \\
1977 & Portable Centrifugal Fast Analyzer & $\begin{array}{l}\text { C. D. Scott, J. E. Mrocheck, R. K. Genung, } \\
\text { W. F. Johnson, M. L. Bauer, C. A. Burtis, and }\end{array}$ \\
& & D. G. Lakomy \\
1978 & Pressurized Continuous Annular & C. D. Scott, R. M. Canon, W. G. Sisson, and \\
1979 & Chromatograph (CAC) & R. D. Spence \\
1979 & Tapered Fluidized-Bed Bioreactor & C. D. Scott, D. D. Lee, and C. W. Hancher \\
1980 & Fabrication Process & Team of engineers and scientists in the Chemical \\
& Portable Fluorescence Spotter & Technology and Metals and Ceramics Divisions \\
1980 & DEPA-TOPO Processed Uranium & D. D. Schuresko, G. K. Schulze, R. G. Phillips, J. \\
1981 & Perals Spectrometer & E. Mrocheck, M. S. Blair, W. A. Walker, \\
198 & Metal Oxide Varistor (ORNL SG-2) & Fred J. Hurst and David J. Crouse
\end{tabular}

aThe IR-100 award, sponsored by the magazine Industrial Research and Development, is a prestigious award for significant technical product achievement. Each year, the 100 most significant technical products are selected and given this award. The Chemical Technology Division has won nine of these awards. 


\section{APPENDIX E}

\section{PATENTS RECEIVED BY CHEMICAL TECHNOLOGY DIVISION} PERSONNEL (1950-1991) 

Table E.1. Patents Received by Chemical Technology Division Personnel (1950-1991)

\begin{tabular}{|c|c|c|c|}
\hline Year & Patent No. & Patentee & Subject \\
\hline 1951 & $2,546,933$ & $\begin{array}{l}\text { Steahly, F. L. } \\
\text { Stoughton, R. W. } \\
\text { Schuler, F. R. }\end{array}$ & Method of Dissolving Thorium Values \\
\hline 1957 & $2,815,322$ & Higgins, I. R. & $\begin{array}{l}\text { Counter-Current Liquid-Solid Mass } \\
\text { Transfer Method and Apparatus }\end{array}$ \\
\hline \multirow[t]{6}{*}{1958} & $2,849,283$ & $\begin{array}{l}\text { Stoughton, R. W. } \\
\text { Steahly, F. L. }\end{array}$ & Separation of Uranyl Nitrate by Extraction \\
\hline & $2,852,419$ & $\begin{array}{l}\text { Peterson, M. D. } \\
\text { Overholt, D. C. } \\
\text { Acken, M. F. }\end{array}$ & $\begin{array}{l}\text { Process of Decontaminating Material } \\
\text { Contaminated with Radioactivity }\end{array}$ \\
\hline & $2,859,094$ & $\begin{array}{l}\text { Schmitt, J. M. } \\
\text { Blake, C. A., Jr. } \\
\text { Brown, K. B. } \\
\text { Coleman, C. F. }\end{array}$ & $\begin{array}{l}\text { Uranium Extraction Process using } \\
\text { Synergistic Reagents }\end{array}$ \\
\hline & $2,863,718$ & $\begin{array}{l}\text { Overholt, D. C. } \\
\text { Tober, F. W. }\end{array}$ & $\begin{array}{l}\text { Plutonium Concentration and } \\
\text { Decontamination Method }\end{array}$ \\
\hline & $2,864,668$ & $\begin{array}{l}\text { Baldwin, W. H. } \\
\text { Higgins, C. E. }\end{array}$ & Uranium Extraction Process \\
\hline & $2,865,737$ & $\begin{array}{l}\text { Blanco, R. E. } \\
\text { Morrison, B. H. }\end{array}$ & Method of Purifying Uranium Metal \\
\hline \multirow[t]{5}{*}{1959} & $2,877,131$ & $\begin{array}{l}\text { Overholt, D. C. } \\
\text { Peterson, M. D. }\end{array}$ & $\begin{array}{l}\text { Method and Coating Composition for } \\
\text { Protecting and Decontaminating Surfaces }\end{array}$ \\
\hline & $2,877,250$ & $\begin{array}{l}\text { Brown, K. B. } \\
\text { Crouse, D. J., Jr. } \\
\text { Moore, J. G. }\end{array}$ & Recovery of Uranium Values \\
\hline & $2,895,798$ & Blanco, R. E. & Barium Recovery Process \\
\hline & $2,909,406$ & $\begin{array}{l}\text { Meservey, A. B. } \\
\text { Rainey, R. H. } \\
\text { to Ruthenium }\end{array}$ & $\begin{array}{l}\text { Process for Decontaminating Thorium } \\
\text { and Uranium with Respect }\end{array}$ \\
\hline & $2,917,406$ & McBride, J. P. & $\begin{array}{l}\text { Method of Increasing the Dispersibility } \\
\text { of Slurry Particles }\end{array}$ \\
\hline \multirow[t]{3}{*}{1960} & $2,931,706$ & $\begin{array}{l}\text { Gresky, A. T. } \\
\text { Nurmi, E. O. } \\
\text { Foster, D. L. } \\
\text { Wischow, R. P. } \\
\text { Savolainen, J. E. }\end{array}$ & Preparation of Dibasic Aluminum Nitrate \\
\hline & $2,937,925$ & $\begin{array}{l}\text { Blake, C. A., Jr. } \\
\text { Brown, K. B. } \\
\text { Horner, D. E. }\end{array}$ & $\begin{array}{l}\text { Solvent Extraction Process for } \\
\text { Uranium from Chloride Solutions }\end{array}$ \\
\hline & $2,945,740$ & Gresky, A. T. & Ruthenium Decontamination Method \\
\hline
\end{tabular}


Table E.1 (continued)

\begin{tabular}{|c|c|c|c|}
\hline Year & Patent No. & Patentee & Subject \\
\hline \multirow[t]{8}{*}{1961} & $2,968,183$ & $\begin{array}{l}\text { Hannaford, B. A. } \\
\text { Rosenberg, R. } \\
\text { Segaser, C. L. } \\
\text { Terry, C. L. }\end{array}$ & Sampling System \\
\hline & $2,981,643$ & Baybarz, R. D. & $\begin{array}{l}\text { Process for Descaling and Decontaminating } \\
\text { Metals }\end{array}$ \\
\hline & $2,990,244$ & $\begin{array}{l}\text { Brown, K. B. } \\
\text { Crouse, D. J., Jr. }\end{array}$ & $\begin{array}{l}\text { Extraction of Thorium and Uranium } \\
\text { Values from Acid Leach Liquors }\end{array}$ \\
\hline & $2,992,249$ & $\begin{array}{l}\text { Boyd, G. E. } \\
\text { Russel, E. R. } \\
\text { Taylor, M. D. }\end{array}$ & $\begin{array}{l}\text { Ion Exchange Adsorption Process for } \\
\text { Plutonium Separation }\end{array}$ \\
\hline & $2,992,886$ & Gens, T. A. & $\begin{array}{l}\text { Method for Dissolving Zirconium-Uranium } \\
\text { Compositions }\end{array}$ \\
\hline & $3,009,062$ & $\begin{array}{l}\text { Brooksbank, W. A.,Jr. } \\
\text { Leddicotte, G. W. } \\
\text { Strain, J. E. } \\
\text { Hendon, H. H., Jr. }\end{array}$ & Absorption Analyzer \\
\hline & $3,009,768$ & $\begin{array}{l}\text { Adams, J. B. } \\
\text { Bresee, J. C. } \\
\text { Ferris, L. M. } \\
\text { Scott, C. D. }\end{array}$ & $\begin{array}{l}\text { Continuous Process for Preparing Uranium } \\
\text { Hexafluoride from Uranium Tetrafluoride } \\
\text { and Oxygen }\end{array}$ \\
\hline & $3,023,085$ & McBride, J. P. & Method of Combining Hydrogen and Oxygen \\
\hline 1962 & $3,035,895$ & $\begin{array}{l}\text { McCorkle, K. H. } \\
\text { Kleinsteuber, A. T. } \\
\text { Schilling, C. E. } \\
\text { Dean, O. C. }\end{array}$ & $\begin{array}{l}\text { Preparation of High-Density, Compactible } \\
\text { Thorium Oxide Particles }\end{array}$ \\
\hline \multirow[t]{7}{*}{1962} & $3,039,847$ & $\begin{array}{l}\text { Campbell, D. O. } \\
\text { Cathers, G. I. }\end{array}$ & $\begin{array}{l}\text { Separation of Metal Values from Nuclear } \\
\text { Reactor Poison }\end{array}$ \\
\hline & $3,043,653$ & Gens, T. A. & $\begin{array}{l}\text { Recovery of Uranium from Zirconium- } \\
\text { Uranium Nuclear Fuels }\end{array}$ \\
\hline & $3,048,474$ & Morse, L. E. & $\begin{array}{l}\text { Catalytic Recombination of Radiolytic } \\
\text { Gases in Thorium Oxide Slurries }\end{array}$ \\
\hline & $3,049,400$ & $\begin{array}{l}\text { Rainey, R. H. } \\
\text { Moore, J. G. }\end{array}$ & $\begin{array}{l}\text { Solvent Extraction Process for } \\
\text { the Separation of Uranium and Thorium } \\
\text { from Protactinium and Fission Products }\end{array}$ \\
\hline & $3,052,361$ & $\begin{array}{l}\text { Whatley, M. E. } \\
\text { Woods, W. M. }\end{array}$ & Liquid Cyclone Contactor \\
\hline & $3,052,513$ & Crouse, D. J., Jr. & $\begin{array}{l}\text { Stripping of Uranium from Organic } \\
\text { Extractants }\end{array}$ \\
\hline & $3,065,044$ & $\begin{array}{l}\text { Blanco, R. E. } \\
\text { Higgins, I. R. }\end{array}$ & $\begin{array}{l}\text { Recovery of Aluminum from Fission } \\
\text { Products }\end{array}$ \\
\hline
\end{tabular}


Table E.1 (continued)

\begin{tabular}{|c|c|c|c|}
\hline Year & Patent No. & Patentee & Subject \\
\hline \multirow[t]{5}{*}{1963} & $3,079,225$ & $\begin{array}{l}\text { Baybarz, R. D. } \\
\text { Lloyd, M. H. }\end{array}$ & $\begin{array}{l}\text { Process for Separating Americium and } \\
\text { Curium from Rare Earth Elements }\end{array}$ \\
\hline & $3,086,926$ & $\begin{array}{l}\text { Helton, D. M. } \\
\text { Savolainen, J. E. }\end{array}$ & Method of Dissolving Refractory Alloys \\
\hline & $3,101,058$ & $\begin{array}{l}\text { Carr, W. H., Jr. } \\
\text { Dobyns, E. R. }\end{array}$ & Diaphragm Pumping System \\
\hline & $3,105,052$ & Haws, C. C., Jr. & Preparation of Refractory Oxide Microspheres \\
\hline & $3,116,106$ & $\begin{array}{l}\text { McNees, R. A., Jr. } \\
\text { Taylor, A. J. }\end{array}$ & $\begin{array}{l}\text { Preparation of High-Density Thorium Oxide } \\
\text { Spheres }\end{array}$ \\
\hline \multirow[t]{3}{*}{1964} & $3,117,372$ & $\begin{array}{l}\text { McNees, R. A. } \\
\text { Potter, R. A. }\end{array}$ & $\begin{array}{l}\text { Stabilized Rare Earth Oxides for a Control } \\
\text { Rod and Method of Preparation }\end{array}$ \\
\hline & $3,120,493$ & $\begin{array}{l}\text { Clark, W. E. } \\
\text { Godbee, H. W. }\end{array}$ & $\begin{array}{l}\text { Suppression of Ruthenium Volatilization in } \\
\text { Evaporation and Calcination of Radioactive } \\
\text { Waste Solutions }\end{array}$ \\
\hline & $3,122,414$ & $\begin{array}{l}\text { Horner, D. E. } \\
\text { Wischow, R. P. }\end{array}$ & $\begin{array}{l}\text { Process for Recovery of Strontium Values } \\
\text { from Fission Product Waste Solutions }\end{array}$ \\
\hline 1964 & $3,148,941$ & Gens, T. A. & $\begin{array}{l}\text { Dissolution of Uranium-Molybdenum } \\
\text { Reactor Fuel Elements }\end{array}$ \\
\hline \multirow[t]{8}{*}{1965} & $3,171,815$ & $\begin{array}{l}\text { Kelly, J. L. } \\
\text { Dean, O. C. } \\
\text { Ferguson, D. E. }\end{array}$ & $\begin{array}{l}\text { Method for Preparation of Thorium Dicarbide } \\
\text { and Thorium-Uranium Dicarbide Particles }\end{array}$ \\
\hline & $3,178,258$ & $\begin{array}{l}\text { Cathers, G. I. } \\
\text { Jolley, R. L. }\end{array}$ & $\begin{array}{l}\text { Separation of Plutonium Hexafluoride from } \\
\text { Uranium Hexafluoride by Selective Sorption }\end{array}$ \\
\hline & $3,179,503$ & $\begin{array}{l}\text { Horner, D. E. } \\
\text { Crouse, D. J., Jr. } \\
\text { Brown, K. B. }\end{array}$ & $\begin{array}{l}\text { Extraction of Cesium from Aqueous Solutions } \\
\text { Using Phenols }\end{array}$ \\
\hline & $3,202,475$ & Gens, T. A. & $\begin{array}{l}\text { Method for Collecting Zirconium } \\
\text { Tetrachloride }\end{array}$ \\
\hline & $3,211,526$ & Crouse, D. J., Jr. & $\begin{array}{l}\text { Recovery of Sulfuric Acid from an Aqueous } \\
\text { Solution Containing Metal Values by } \\
\text { Extraction with Tertiary Amines }\end{array}$ \\
\hline & $3,218,123$ & $\begin{array}{l}\text { Davis, W., Jr. } \\
\text { Yee, W. C. }\end{array}$ & $\begin{array}{l}\text { Recovery of Strontium Values from Sulfate- } \\
\text { Containing Waste Solutions }\end{array}$ \\
\hline & $3,219,408$ & $\begin{array}{l}\text { Bradley, M. J. } \\
\text { Ferris, L. M. }\end{array}$ & $\begin{array}{l}\text { Chemical Disintegration and Recovery of } \\
\text { Uranium from Sintered Graphite-Uranium } \\
\text { Compacts }\end{array}$ \\
\hline & $3,222,289$ & $\begin{array}{l}\text { Clark, W. E. } \\
\text { Gens, T. A. }\end{array}$ & $\begin{array}{l}\text { Dissolution of Zirconium in Titanium } \\
\text { Equipment }\end{array}$ \\
\hline
\end{tabular}


Table E.1 (continued)

\begin{tabular}{|c|c|c|c|}
\hline Year & Patent No. & Patentee & Subject \\
\hline \multirow[t]{13}{*}{1966} & $3,228,886$ & Lloyd, M. H. & $\begin{array}{l}\text { Method of Preparing Compactible Thorium } \\
\text { Oxide-Plutonium Oxide Particles }\end{array}$ \\
\hline & $3,230,036$ & $\begin{array}{l}\text { Kappelmann, F. A. } \\
\text { Weaver, B. S. }\end{array}$ & $\begin{array}{l}\text { Method for Separating Americium and } \\
\text { Curium from the Lanthanide Rare Earths } \\
\text { and Yttrium }\end{array}$ \\
\hline & $3,238,014$ & Gens, T. A. & $\begin{array}{l}\text { Recovery of Uranium and Plutonium Values } \\
\text { from Aqueous Solutions of Ammonium } \\
\text { Fluoride }\end{array}$ \\
\hline & $3,243,257$ & Coleman, C. F. & $\begin{array}{l}\text { Recovery of Uranium and Zirconium from } \\
\text { Aqueous Fluoride Solutions }\end{array}$ \\
\hline & $3,262,760$ & $\begin{array}{l}\text { McCorkle, K. H. } \\
\text { Morse, L. E. } \\
\text { Schilling, C. E. }\end{array}$ & $\begin{array}{l}\text { Method of Preparing High-Density } \\
\text { Compactible Uranium Dioxide Particles }\end{array}$ \\
\hline & $3,265,627$ & $\begin{array}{l}\text { Clark, W. E. } \\
\text { Fitzgerald, C. L. } \\
\text { Davis, G. D. }\end{array}$ & $\begin{array}{l}\text { Addition of Lithium Values in Conversion of } \\
\text { Fission-Product Wastes to a Glass-Like Solid } \\
\text { for Disposal }\end{array}$ \\
\hline & $3,273,973$ & $\begin{array}{l}\text { Bennett, M. R. } \\
\text { Ullmann, J. W. } \\
\text { Thoma, R. E., Jr. }\end{array}$ & $\begin{array}{l}\text { Method for Processing Aluminum-Containing } \\
\text { Nuclear Fuels }\end{array}$ \\
\hline & $3,275,422$ & $\begin{array}{l}\text { Cathers, G. I. } \\
\text { Mailen, J. C. }\end{array}$ & Continuous-Gas-Phase Volatility Process \\
\hline & $3,276,850$ & Rainey, R. H. & $\begin{array}{l}\text { Method of Selectively Reducing Plutonium } \\
\text { Values }\end{array}$ \\
\hline & $3,278,278$ & $\begin{array}{l}\text { Flanary, J. R. } \\
\text { Goode, J. H. } \\
\text { Wall, G. C. }\end{array}$ & Pyrohydrolysis of Carbide-Type Nuclear Fuels \\
\hline & $3,278,387$ & $\begin{array}{l}\text { McNeese, L. E. } \\
\text { Scott, C. D. }\end{array}$ & Fuel Recycle System in a Molten Salt Reactor \\
\hline & $3,288,717$ & Morse, L. E. & Method for Preparation of Urania Sols \\
\hline & $3,290,122$ & $\begin{array}{l}\text { Clinton, S. D. } \\
\text { Haas, P. A. } \\
\text { Hirth, L. J. } \\
\text { Kleinsteuber, A. T. }\end{array}$ & $\begin{array}{l}\text { Process for Preparing Oxide Gel } \\
\text { Microspheres from Sols }\end{array}$ \\
\hline \multirow[t]{3}{*}{1967} & $3,298,957$ & Gens, T. A. & $\begin{array}{l}\text { Method for Dissolving Zirconium and } \\
\text { Forming Stabilized Alkaline Solutions Thereof }\end{array}$ \\
\hline & $3,298,961$ & $\begin{array}{l}\text { Davis, G. D. } \\
\text { Frederick, E. J. } \\
\text { Godbee, H. W. } \\
\text { Holmes, J. M. }\end{array}$ & $\begin{array}{l}\text { Concentration and Containment of } \\
\text { Radioactivity from Radioactive Waste } \\
\text { Solutions in Asphalt }\end{array}$ \\
\hline & $3,300,852$ & DeBruin, H. J. & $\begin{array}{l}\text { Method for Bonding Beryllium Oxide } \\
\text { to Graphite }\end{array}$ \\
\hline
\end{tabular}


Table E.1 (continued)

\begin{tabular}{|c|c|c|c|}
\hline Year & Patent No. & Patentee & Subject \\
\hline \multirow[t]{10}{*}{1967} & $3,303,004$ & $\begin{array}{l}\text { Cathers, G. I. } \\
\text { Bennett, M. R. }\end{array}$ & $\begin{array}{l}\text { Method for Dissolving Stainless Steel } \\
\text { Members }\end{array}$ \\
\hline & $3,310,386$ & Lloyd, M. H. & $\begin{array}{l}\text { Preparation of Plutonium Oxide Sol and } \\
\text { Calcined Microspheres }\end{array}$ \\
\hline & $3,312,526$ & $\begin{array}{l}\text { Hanson, C. K. } \\
\text { Horton, R. M. } \\
\text { Wadsworth, M. E. }\end{array}$ & $\begin{array}{l}\text { Method and Catalyst for Combining Hydrogen } \\
\text { and Oxygen in Thorium Oxide Slurries }\end{array}$ \\
\hline & $3,320,179$ & Gens, T. A. & $\begin{array}{l}\text { Openly Porous Refractory Nuclear Fuel } \\
\text { Microspheres and Method of Preparation }\end{array}$ \\
\hline & $3,328,132$ & $\begin{array}{l}\text { Bennett, M. R. } \\
\text { Cathers, G. I. }\end{array}$ & $\begin{array}{l}\text { Method of Separating } \mathrm{UF}_{6} \text { from Bromine } \\
\text { Fluorides }\end{array}$ \\
\hline & $3,331,898$ & $\begin{array}{l}\text { Haas, P. A. } \\
\text { Clinton, S. D. }\end{array}$ & $\begin{array}{l}\text { Method for Preparing Metal Oxide } \\
\text { Microspheres }\end{array}$ \\
\hline & $3,335,095$ & Moore, J. G. & $\begin{array}{l}\text { Preparation of Actinide Sols by Amine } \\
\text { Extraction }\end{array}$ \\
\hline & $3,352,950$ & $\begin{array}{l}\text { Helton, D. M. } \\
\text { Wymer, R. G. }\end{array}$ & $\begin{array}{l}\text { Electrical Potential Method for Dispersion } \\
\text { of Metal Oxide Microspheres }\end{array}$ \\
\hline & $3,356,776$ & $\begin{array}{l}\text { Meservey, A. B. } \\
\text { Sease, J. D. } \\
\text { Fitts, R. B. }\end{array}$ & $\begin{array}{l}\text { Method of Fabricating Ceramic Nuclear Fuel } \\
\text { Product }\end{array}$ \\
\hline & $3,359,064$ & $\begin{array}{l}\text { Crouse, D. J., Jr. } \\
\text { Seeley, F. G. }\end{array}$ & $\begin{array}{l}\text { Process for Separating Beryllium Values } \\
\text { from Aqueous Solutions }\end{array}$ \\
\hline \multirow[t]{4}{*}{1968} & $3,361,676$ & $\begin{array}{l}\text { McBride, J. P. } \\
\text { Pattison, W. L. }\end{array}$ & $\begin{array}{l}\text { Urania Sol Forming Method in the Presence } \\
\text { of Formic Acid and a Palladium-on-Thoria } \\
\text { Catalyst }\end{array}$ \\
\hline & $3,362,791$ & Ryon, A. D. & $\begin{array}{l}\text { Apparatus for Separation of Immiscible Liquid } \\
\text { Pairs Including Remote Interface Control }\end{array}$ \\
\hline & $3,367,881$ & Morse, L. E. & $\begin{array}{l}\text { Extraction Method for Preparing } \mathrm{UO}_{2} \\
\text { Microspheres }\end{array}$ \\
\hline & $3,374,157$ & Box, W. D. & $\begin{array}{l}\text { Electrolyte for the Electrodeposition of } \\
\text { Technetium }\end{array}$ \\
\hline \multirow[t]{3}{*}{1969} & $3,451,790$ & $\begin{array}{l}\text { Katz, S. } \\
\text { Cathers, G. I. }\end{array}$ & $\begin{array}{l}\text { Method of Separating Neptunium and } \\
\text { Uranium Values }\end{array}$ \\
\hline & $3,461,076$ & $\begin{array}{l}\text { Lloyd, M. H. } \\
\text { Haire, R. G. }\end{array}$ & Process for Preparing Plutonia Aquasols \\
\hline & $3,463,738$ & $\begin{array}{l}\text { Fitzgerald, C. L. } \\
\text { Godbee, H. W. }\end{array}$ & $\begin{array}{l}\text { Conversion and Containment of Radioactive } \\
\text { Organic Liquids into Solid Form }\end{array}$ \\
\hline
\end{tabular}

McCorkle, K. H., Jr. 
Table E.1 (continued)

\begin{tabular}{|c|c|c|c|}
\hline Year & Patent No. & Patentee & Subject \\
\hline \multirow[t]{2}{*}{1969} & $3,463,814$ & $\begin{array}{l}\text { Blanco, R. E. } \\
\text { Clark, W. E. } \\
\text { Yee, W. C. }\end{array}$ & $\begin{array}{l}\text { Chemical Cycle for Evaporative Water } \\
\text { Desalination Plant }\end{array}$ \\
\hline & $3,472,633$ & $\begin{array}{l}\text { McNeese, L. E. } \\
\text { Watson, J. S. } \\
\text { Whatley, M. E. }\end{array}$ & $\begin{array}{l}\text { Liquid-Liquid Removal of Protactinium from } \\
\text { Spent Molten Salt Mixtures Containing } \\
\text { Uranium Tetrafluoride }\end{array}$ \\
\hline \multirow[t]{2}{*}{1970} & $3,513,101$ & Meservey, A. B. & $\begin{array}{l}\text { Preparation of Stable Sols of Thoria-Uranium } \\
\text { Trioxide }\end{array}$ \\
\hline & $3,518,063$ & $\begin{array}{l}\text { Seeley, F. G. } \\
\text { Crouse, D. J., Jr. }\end{array}$ & $\begin{array}{l}\text { Purification of Beryllium by Liquid-Liquid } \\
\text { Extraction }\end{array}$ \\
\hline \multirow[t]{8}{*}{1971} & $3,575,875$ & $\begin{array}{l}\text { Pattison, W. L. } \\
\text { McBride, J. P. }\end{array}$ & $\begin{array}{l}\text { Method for Preparing Uranium-Containing } \\
\text { Aquasols Employing a Platinum Oxide } \\
\text { Catalyst }\end{array}$ \\
\hline & $3,577,485$ & $\begin{array}{l}\text { Beatty, R. L. } \\
\text { Leitnaker, J. M. } \\
\text { Notz, K. J., Jr. }\end{array}$ & $\begin{array}{l}\text { Method for Preparation of Carbonitride Nuclear } \\
\text { Fuel Materials }\end{array}$ \\
\hline & $3,580,705$ & $\begin{array}{l}\text { Coleman, C. F. } \\
\text { Weaver, B. S. }\end{array}$ & $\begin{array}{l}\text { Selective Stripping of Plutonium from Organic } \\
\text { Extracts }\end{array}$ \\
\hline & $3,600,323$ & Tallent, O. K. & $\begin{array}{l}\text { Method for Preparing Stable Urania-Plutonia } \\
\text { Sols }\end{array}$ \\
\hline & $3,617,585$ & $\begin{array}{l}\text { Haas, P. A. } \\
\text { Clinton, S. D. }\end{array}$ & $\begin{array}{l}\text { Method for Preparing Oxide Gel Microspheres } \\
\text { from Sols }\end{array}$ \\
\hline & $3,627,479$ & Yee, W. C. & $\begin{array}{l}\text { Chemical-Electro-Chemical Cycle for } \\
\text { Desalination of Water }\end{array}$ \\
\hline & $3,629,133$ & $\begin{array}{l}\text { McBride, J. P. } \\
\text { McCorkle, K. H. } \\
\text { Pattison, W. L. }\end{array}$ & $\begin{array}{l}\text { Production of Predominantly Crystalline Sols } \\
\text { or Urania }\end{array}$ \\
\hline & $3,629,138$ & Thomas, I. L. & $\begin{array}{l}\text { Method for Exchanging Counterions in } \\
\text { Actinide Oxide Sols }\end{array}$ \\
\hline \multirow[t]{6}{*}{1972} & $3,640,888$ & $\begin{array}{l}\text { Baybarz, R. D. } \\
\text { Peterson, J. R. }\end{array}$ & $\begin{array}{l}\text { Californium-252 Neutron Source and Method } \\
\text { of Making Same }\end{array}$ \\
\hline & $3,672,846$ & $\begin{array}{l}\text { McNeese, L. E. } \\
\text { Ferguson, D. E. }\end{array}$ & $\begin{array}{l}\text { Method for Reprocessing Spent Molten Salt } \\
\text { Reactor Fuels }\end{array}$ \\
\hline & $3,675,746$ & Irvine, A. R. & Impact Energy Absorber \\
\hline & $3,677,719$ & Whatley, M. E. & $\begin{array}{l}\text { Method for Reprocessing Molten Fluoride } \\
\text { Salt Reactor Fuels }\end{array}$ \\
\hline & $3,683,975$ & $\begin{array}{l}\text { Harrington, F. E. } \\
\text { Sease, J. D. }\end{array}$ & $\begin{array}{l}\text { Method of Vibratory Loading Nuclear Fuel } \\
\text { Elements }\end{array}$ \\
\hline & $3,716,616$ & Lin, K. H. & $\begin{array}{l}\text { Process for Decontamination of Neutron- } \\
\text { Irradiated Beryllium }\end{array}$ \\
\hline
\end{tabular}


Table E.1 (continued)

\begin{tabular}{|c|c|c|c|}
\hline Year & Patent No. & Patentee & Subject \\
\hline 1972 & $3,708,392$ & Campbell, D. O. & $\begin{array}{l}\text { Isotope Enrichment Process for Lanthanide } \\
\text { and Actinide Elements }\end{array}$ \\
\hline \multirow[t]{16}{*}{1973} & $3,711,591$ & $\begin{array}{l}\text { Hurst, F. J. } \\
\text { Crouse, D. J. }\end{array}$ & $\begin{array}{l}\text { Reductive Stripping Process for the Recovery } \\
\text { of Uranium from Wet-Process Phosphoric Acid }\end{array}$ \\
\hline & $3,714,056$ & Tallent, O. K. & $\begin{array}{l}\text { Method for Preparing Stable Urania-Plutonia } \\
\text { Sols }\end{array}$ \\
\hline & $3,714,322$ & $\begin{array}{l}\text { Bell, M. J. } \\
\text { Whatley, M. E. }\end{array}$ & Method for Preparing High Purity ${ }^{233}$ Uranium \\
\hline & $3,715,317$ & $\begin{array}{l}\text { Lloyd, M. H. } \\
\text { Tallent, O. K. } \\
\text { Leuze, R. E. }\end{array}$ & $\begin{array}{l}\text { Solvent Extraction Process for Producing } \\
\text { Low-Nitrate and Large-Crystal-Size } \mathrm{PuO}_{2} \text { Sols }\end{array}$ \\
\hline & $3,717,582$ & $\begin{array}{l}\text { Bradley, R. A. } \\
\text { Lindemer, T. B. }\end{array}$ & $\begin{array}{l}\text { Method for Reducing the Oxygen in Certain } \\
\text { Actinide Oxides to Less than Stoichiometric } \\
\text { Levels }\end{array}$ \\
\hline & $3,725,293$ & Haas, P. A. & $\begin{array}{l}\text { Conversion of Fuel-Metal Nitrate Solutions } \\
\text { to Oxides }\end{array}$ \\
\hline & $3,735,736$ & $\begin{array}{l}\text { Yee, W. C. } \\
\text { Stout, P. R. }\end{array}$ & $\begin{array}{l}\text { Method for Growing Edible Aquatic Animals } \\
\text { on a Large Scale }\end{array}$ \\
\hline & $3,742,720$ & $\begin{array}{l}\text { Ferguson, D. E. } \\
\text { Haas, P. A. } \\
\text { Leuze, R. E. }\end{array}$ & $\begin{array}{l}\text { Quantitative Recovery of Krypton from Gas } \\
\text { Mixtures Mainly Comprising Carbon Dioxide }\end{array}$ \\
\hline & $3,744,975$ & Mailen, J. C. & Rotor for Multistation Photometric Analyzer \\
\hline & $3,752,876$ & $\begin{array}{l}\text { Cathers, G. I. } \\
\text { Shockley, W. E. }\end{array}$ & $\begin{array}{l}\text { Removal of Organic and Inorganic Iodine } \\
\text { from a Gaseous Atmosphere }\end{array}$ \\
\hline & $3,758,670$ & $\begin{array}{l}\text { McBride, J. P. } \\
\text { McCorkle, K. H. } \\
\text { Pattison, W. L. }\end{array}$ & Production of Predominantly Crystalline Sols \\
\hline & $3,761,564$ & $\begin{array}{l}\text { Mailen, J. C. } \\
\text { Ferris, L. M. }\end{array}$ & Separation of Californium from Other Actinides \\
\hline & $3,763,292$ & $\begin{array}{l}\text { Stradley, J. G. } \\
\text { Sease, J. D. }\end{array}$ & $\begin{array}{l}\text { Manufacture of Bonded-Particle Nuclear Fuel } \\
\text { Composites }\end{array}$ \\
\hline & $3,763,374$ & $\begin{array}{l}\text { Tiffany, T. O. } \\
\text { Mailen, J. C. } \\
\text { Thacker, L. H. }\end{array}$ & Dynamic Multistation Photometer-Fluorometer \\
\hline & $3,764,552$ & $\begin{array}{l}\text { Godbee, H. W. } \\
\text { Lovelace, R. C. }\end{array}$ & $\begin{array}{l}\text { Method for Storing Radioactive Combustible } \\
\text { Waste }\end{array}$ \\
\hline & $3,778,348$ & $\begin{array}{l}\text { Harrington, F. E. } \\
\text { Sease, J. D. }\end{array}$ & $\begin{array}{l}\text { Nuclear Fuel Element with Axially Aligned } \\
\text { Fuel Pellets and Fuel Microspheres Therein }\end{array}$ \\
\hline
\end{tabular}


Table E.1 (continued)

\begin{tabular}{|c|c|c|c|}
\hline Year & Patent No. & Patentee & Subject \\
\hline \multirow[t]{17}{*}{1974} & $3,785,161$ & $\begin{array}{l}\text { Singh, S. P. N. } \\
\text { Hart, W. C. }\end{array}$ & $\begin{array}{l}\text { Separation of Components of Vaporous } \\
\text { Fluids }\end{array}$ \\
\hline & $3,792,154$ & $\begin{array}{l}\text { Cathers, G. I. } \\
\text { Shipman, C. J. }\end{array}$ & Removal of Iodine from Nitric Acid Solutions \\
\hline & $3,793,433$ & $\begin{array}{l}\text { Seeley, F. G. } \\
\text { Baldwin, W. H. }\end{array}$ & $\begin{array}{l}\text { Extraction of Lithium from Neutral Brines } \\
\text { Using a Beta Diketone and Trioctylphosphine } \\
\text { Oxide }\end{array}$ \\
\hline & $3,794,715$ & Lloyd, M. H. & $\begin{array}{l}\text { Solvent Extraction Process for Producing } \\
\text { Low-Nitrate and Large-Crystal-Size } \mathrm{PuO}_{2} \text { Sols }\end{array}$ \\
\hline & $3,795,451$ & Mailen, J. C. & Rotor for Fast Analyzer of Rotary Cuvette Type \\
\hline & $3,798,123$ & Lindemer, T. B. & $\begin{array}{l}\text { Nuclear Fuel for High-Temperature Gas- } \\
\text { Cooled Reactors }\end{array}$ \\
\hline & $3,798,459$ & $\begin{array}{l}\text { Anderson, N. G. } \\
\text { Burtis, C. A. } \\
\text { Johnson, W. F. } \\
\text { Mailen, J. C. } \\
\text { Scott, C. D. }\end{array}$ & $\begin{array}{l}\text { Compact Dynamic Multistation Photometer } \\
\text { Utilizing Disposable Cuvette Rotor }\end{array}$ \\
\hline & $3,800,023$ & Haas, P. A. & $\begin{array}{l}\text { Loading a Cation Exchange Resin with Uranyl } \\
\text { Ions }\end{array}$ \\
\hline & $3,800,161$ & $\begin{array}{l}\text { Scott, C. D. } \\
\text { Collins, E. L. }\end{array}$ & $\begin{array}{l}\text { Portable Dynamic Multistation Photometer- } \\
\text { Fluorometer }\end{array}$ \\
\hline & $3,803,295$ & $\begin{array}{l}\text { Cathers, G. I. } \\
\text { Shipman, C. J. }\end{array}$ & Method for Removing Iodine from Nitric Acid \\
\hline & $3,804,533$ & Scott, C. D. & $\begin{array}{l}\text { Rotor for Fluorometric Measurements in } \\
\text { Rotary Fast Analyzer }\end{array}$ \\
\hline & $3,806,581$ & $\begin{array}{l}\text { Grimes, W. R. } \\
\text { Shaffer, J. H. } \\
\text { Doss, F. A. }\end{array}$ & $\begin{array}{l}\text { Removal of Fluoride from Chloride or } \\
\text { Bromide Melts }\end{array}$ \\
\hline & $3,821,356$ & Baldwin, W. H. & Production of High Purity Halides \\
\hline & $3,825,649$ & $\begin{array}{l}\text { Gresky, A. T. } \\
\text { McDuffee, W. T., Jr. } \\
\text { Wischow, R. P. } \\
\text { Savolainen, J. B. }\end{array}$ & $\begin{array}{l}\text { Process for Separation of Protactinium, } \\
\text { Thorium and Uranium from Neutron-Irradiated } \\
\text { Thorium }\end{array}$ \\
\hline & $3,827,989$ & Scott, C. D. & Impregnated Chemical Separation Particles \\
\hline & $3,835,214$ & $\begin{array}{l}\text { Hurst, F. J. } \\
\text { Crouse, D. J., Jr. }\end{array}$ & $\begin{array}{l}\text { Oxidative Stripping Process for the Recovery of } \\
\text { Uranium from Wet-Process Phosphoric Acid }\end{array}$ \\
\hline & $3,835,040$ & $\begin{array}{l}\text { Mahlman, H. A. } \\
\text { Sisson, W. G. }\end{array}$ & Cross-Flow Filtration Process \\
\hline
\end{tabular}


Table E.1 (continued)

\begin{tabular}{|c|c|c|c|}
\hline Year & Patent No. & Patentee & Subject \\
\hline \multirow[t]{6}{*}{1974} & $3,835,122$ & $\begin{array}{l}\text { Parkinson, W. W., Jr. } \\
\text { Kelly, M. J. } \\
\text { Sturm, B. J. } \\
\text { Martin, W. J. }\end{array}$ & $\begin{array}{l}\text { Novel Polystyrene Product Having Rapid Post- } \\
\text { Irradiation Decay of Conductivity and Process } \\
\text { of Making Same }\end{array}$ \\
\hline & $3,847,550$ & $\begin{array}{l}\text { Scott, C. D. } \\
\text { Pitt, W. W., Jr. }\end{array}$ & Differential Chromatographic Method \\
\hline & $3,851,179$ & Irvine, A. R. & Shipping Cask Neutron and Heat Shield \\
\hline & $3,852,407$ & $\begin{array}{l}\text { Schmitt, J. M. } \\
\text { Crouse, D. J., Jr. } \\
\text { Howerton, W. B. }\end{array}$ & $\begin{array}{l}\text { Method for Removing Alkyl Iodides from Air } \\
\text { by Mercuric Nitrate Solution }\end{array}$ \\
\hline & $3,853,979$ & $\begin{array}{l}\text { McNeese, L. E. } \\
\text { Ferris, L. M. } \\
\text { Smith, F. J. }\end{array}$ & $\begin{array}{l}\text { Method for Removing Rare Earths from Spent } \\
\text { Molten Metallic Fluoride Salt Mixtures }\end{array}$ \\
\hline & $3,854,508$ & $\begin{array}{l}\text { Burtis, C. A. } \\
\text { Johnson, W. F. } \\
\text { Walker, W. A. }\end{array}$ & Automated Sample-Reagent Loader \\
\hline \multirow[t]{10}{*}{1975} & $3,860,691$ & Gens, T. A. & Actinide Mononitride Microspheres and Process \\
\hline & $3,864,089$ & $\begin{array}{l}\text { Mailen, J. C. } \\
\text { Tiffany, T. O. } \\
\text { Scott, C. D. } \\
\text { Pitt, W. W., Jr. } \\
\text { Johnson, W. F. }\end{array}$ & $\begin{array}{l}\text { Multiple-Sample Rotor Assembly for Blood } \\
\text { Fraction Preparation }\end{array}$ \\
\hline & $3,878,041$ & $\begin{array}{l}\text { Leitnaker, J. M. } \\
\text { Lindemer, T. B. }\end{array}$ & $\begin{array}{l}\text { Oxynitride Fuel Kernel for Gas-Cooled } \\
\text { Reactor Fuel Particles }\end{array}$ \\
\hline & $3,880,619$ & $\begin{array}{l}\text { Richardson, D. M. } \\
\text { Bamberger, C. E. }\end{array}$ & Solid Sorbent for Trapping Iodine \\
\hline & $3,890,101$ & $\begin{array}{l}\text { Tiffany, T. O. } \\
\text { Walker, W. A. } \\
\text { Johnson, W. F. }\end{array}$ & $\begin{array}{l}\text { Collection Ring for Use in Multiple-Sample } \\
\text { Blood Fractionation Centrifugal Rotors }\end{array}$ \\
\hline & $3,899,296$ & $\begin{array}{l}\text { Mailen, J. C. } \\
\text { Johnson, W. F. }\end{array}$ & $\begin{array}{l}\text { Whole Blood Analysis Rotor for a Multistation } \\
\text { Dynamic Photometer }\end{array}$ \\
\hline & $3,901,658$ & $\begin{array}{l}\text { Burtis, C. A. } \\
\text { Johnson, W. F. }\end{array}$ & $\begin{array}{l}\text { Whole Blood Analysis Rotor Assembly Having } \\
\text { Removable Cellular Sedimentation Bowl }\end{array}$ \\
\hline & $3,908,123$ & $\begin{array}{l}\text { Veach, A. M. } \\
\text { Bell, W. A., Jr. }\end{array}$ & Extraction Electrode Geometry for a Calutron \\
\hline & $3,914,388$ & $\begin{array}{l}\text { Cathers, G. I. } \\
\text { Shipman, C. J. }\end{array}$ & $\begin{array}{l}\text { Volatilization of Iodine from Nitric Acid Using } \\
\text { Peroxide }\end{array}$ \\
\hline & $3,919,406$ & $\begin{array}{l}\text { Grimes, W. R. } \\
\text { Bamberger, C. E. }\end{array}$ & Thermochemical Production of Hydrogen \\
\hline
\end{tabular}


Table E.1 (continued)

\begin{tabular}{|c|c|c|c|}
\hline Year & Patent No. & Patentee & Subject \\
\hline \multirow[t]{3}{*}{1975} & $3,920,577$ & $\begin{array}{l}\text { Godbee, H. W. } \\
\text { Cathers, G. I. } \\
\text { Blanco, R. E. }\end{array}$ & $\begin{array}{l}\text { Iodine Retention During Evaporative Volume } \\
\text { Reduction }\end{array}$ \\
\hline & $3,927,192$ & $\begin{array}{l}\text { Bamberger, C. E. } \\
\text { Richardson, D. M. }\end{array}$ & $\begin{array}{l}\text { Chemical Cycle for Thermochemical } \\
\text { Production of Hydrogen from Water }\end{array}$ \\
\hline & $3,929,979$ & $\begin{array}{l}\text { Bamberger, C. E. } \\
\text { Richardson, D. M. } \\
\text { Grimes, W. R. }\end{array}$ & Process-for Generating Hydrogen \\
\hline \multirow[t]{3}{*}{1976} & $3,969,218$ & Scott, C. D. & Elution Electrophoresis \\
\hline & $3,979,498$ & Campbell, D. O. & $\begin{array}{l}\text { Recovery of Cesium and Palladium from } \\
\text { Nuclear Reactor Fuel Processing Waste }\end{array}$ \\
\hline & $3,995,009$ & Notz, K. J., Jr. & $\begin{array}{l}\text { Process for Loading Weak-Acid Ion Exchange } \\
\text { Resin with Uranium }\end{array}$ \\
\hline \multirow[t]{9}{*}{1977} & $4,004,993$ & $\begin{array}{l}\text { Horner, D. E. } \\
\text { Mailen, J. D. } \\
\text { Posey, F. A. }\end{array}$ & $\begin{array}{l}\text { Electrolytic Trapping of Iodine from Process } \\
\text { Gas Streams }\end{array}$ \\
\hline & $4,005,178$ & $\begin{array}{l}\text { Bennett, M. R. } \\
\text { Bamberger, C. E. } \\
\text { Kelmers, A. D. }\end{array}$ & $\begin{array}{l}\text { Method for Converting } \mathrm{UF}_{5} \text { to } \mathrm{UF}_{4} \text { in a Molten } \\
\text { Fluoride Salt }\end{array}$ \\
\hline & $4,012,209$ & $\begin{array}{l}\text { Coleman, C. F. } \\
\text { McDowell, W. J. }\end{array}$ & Liquid Film Target Impingement Scrubber \\
\hline & $4,017,417$ & $\begin{array}{l}\text { Clark, W. E. } \\
\text { Thompson, C. T. }\end{array}$ & Immobilization of lodine in Concrete \\
\hline & $4,025,602$ & $\begin{array}{l}\text { Campbell, D. O. } \\
\text { Buxton, S. R. }\end{array}$ & $\begin{array}{l}\text { Recovery of Transplutonium Elements from } \\
\text { Nuclear Reactor Waste }\end{array}$ \\
\hline & $4,032,407$ & $\begin{array}{l}\text { Scott, C. D. } \\
\text { Hancher, C. W. }\end{array}$ & Tapered Bed Bioreactor \\
\hline & $4,035,156$ & Shumate, S. E., II & Filter Type Rotor for Multistation Photometer \\
\hline & $4,046,690$ & $\begin{array}{l}\text { Rodgers, B. R. } \\
\text { Edwards, M. S. }\end{array}$ & $\begin{array}{l}\text { Filtering Coal-Derived Oil Through a Filter } \\
\text { Media Precoated with Particles Partially } \\
\text { Solubilized by Said Oil }\end{array}$ \\
\hline & $4,051,202$ & Arnold, W. D., Jr. & $\begin{array}{l}\text { Method for Separating Mono-and-Di- } \\
\text { Octylphenyl Phosphoric Acid Esters }\end{array}$ \\
\hline \multirow[t]{2}{*}{1978} & $4,069,293$ & Tallent, O. K. & Method for Dissolving Plutonium Dioxide \\
\hline & $4,070,438$ & $\begin{array}{l}\text { Notz, K. J. } \\
\text { Rainey, R. H. } \\
\text { Greene, C. W. } \\
\text { Shockley, W. E. }\end{array}$ & Method for Loading Resin Beds \\
\hline
\end{tabular}


Table E.1 (continued)

\begin{tabular}{|c|c|c|c|}
\hline Year & Patent No. & Patentee & Subject \\
\hline \multirow[t]{3}{*}{1978} & $4,077,838$ & $\begin{array}{l}\text { Beatty, R. L. } \\
\text { Lindemer, T. B. } \\
\text { Long, E. L., Jr. }\end{array}$ & Pyrolytic Carbon-Coated Nuclear Fuel \\
\hline & $4,083,242$ & Cochran, H. D., Jr. & $\begin{array}{l}\text { Method of Measuring the Mass Flow Rate of } \\
\text { a Substance Entering a Cocurrent Fluid Stream }\end{array}$ \\
\hline & $4,131,527$ & $\begin{array}{l}\text { Friedman, H. A. } \\
\text { Toth, L. M. } \\
\text { Bell, J. T. }\end{array}$ & $\begin{array}{l}\text { Method for Selectively Reducing Plutonium } \\
\text { Values by a Photochemical Process }\end{array}$ \\
\hline \multirow[t]{3}{*}{1979} & $4,132,639$ & $\begin{array}{l}\text { Katz, S. } \\
\text { Rodgers, B. R. }\end{array}$ & $\begin{array}{l}\text { Method for Improving the Sedimentation and } \\
\text { Filterability of Coal-Derived Liquids Compact } \\
\text { Gate Valve }\end{array}$ \\
\hline & $4,134,960$ & $\begin{array}{l}\text { Vondra, B. L. } \\
\text { Tallent, O. K. } \\
\text { Mailen, J. C. }\end{array}$ & $\begin{array}{l}\text { Method for Dissolving Plutonium Oxide with } \\
\text { HI and Separating Plutonium }\end{array}$ \\
\hline & $4,162,298$ & $\begin{array}{l}\text { Holladay, D. W. } \\
\text { Haag, G. L. }\end{array}$ & $\begin{array}{l}\text { Method of Immobilizing Carbon Dioxide from } \\
\text { Gas Streams }\end{array}$ \\
\hline \multirow[t]{2}{*}{1980} & $4,200,801$ & Schuresko, D. D. & $\begin{array}{l}\text { Portable Spotter for Fluorescent Contaminants } \\
\text { on Surfaces }\end{array}$ \\
\hline & $4,225,455$ & Haas, P. A. & $\begin{array}{l}\text { Process for Decomposing Nitrates in Aqueous } \\
\text { Solution }\end{array}$ \\
\hline \multirow[t]{4}{*}{1981} & $4,252,777$ & $\begin{array}{l}\text { Seeley, F. G. } \\
\text { McDowell, W. J. }\end{array}$ & $\begin{array}{l}\text { Recovery of Aluminum and Other Metal Values } \\
\text { from Fly Ash }\end{array}$ \\
\hline & $4,254,088$ & $\begin{array}{l}\text { Seeley, F. G. } \\
\text { McDowell, W. J. }\end{array}$ & $\begin{array}{l}\text { Salt-Soda Sinter Process for Recovering } \\
\text { Aluminum from Fly Ash }\end{array}$ \\
\hline & $4,263,406$ & $\begin{array}{l}\text { Bostick, W. D. } \\
\text { Denton, M. S. } \\
\text { Dinsmore, S. R. }\end{array}$ & $\begin{array}{l}\text { Apparatus for Continuously Referenced } \\
\text { Analysis of Reactive Components in Solution }\end{array}$ \\
\hline & $4,290,967$ & $\begin{array}{l}\text { Campbell, D. O. } \\
\text { Buxton, S. R. }\end{array}$ & $\begin{array}{l}\text { Process for Recovery of Palladium from Nuclear } \\
\text { Fuel Reprocessing Wastes }\end{array}$ \\
\hline \multirow[t]{4}{*}{1982} & $4,316,776$ & $\begin{array}{l}\text { Arwood, P. C. } \\
\text { Bell, J. T. } \\
\text { Mailen, J. C. } \\
\text { Tallent, O. K. }\end{array}$ & $\begin{array}{l}\text { Method of Removing Pu(IV) Polymer from } \\
\text { Nuclear Fuel Reclaiming Liquid }\end{array}$ \\
\hline & $4,336,044$ & $\begin{array}{l}\text { Barker, R. E. } \\
\text { Ryon, A. D. } \\
\text { Scott, C. D. }\end{array}$ & $\begin{array}{l}\text { Process for Separating Coal Synthesized } \\
\text { Methane from Unreacted Intermediate and } \\
\text { Contaminant Gases }\end{array}$ \\
\hline & $4,339,309$ & $\begin{array}{l}\text { Howerton, W. B. } \\
\text { Pruett, D. J. }\end{array}$ & $\begin{array}{l}\text { Method for Removing Fluoride Contamination } \\
\text { from Nitric Acid }\end{array}$ \\
\hline & $4,343,478$ & $\begin{array}{l}\text { Morgan, J. G. } \\
\text { Rennich, M. J. } \\
\text { Whatley, M. E. }\end{array}$ & Face Seal Assembly Rotating Drum \\
\hline
\end{tabular}


Table E.1 (continued)

\begin{tabular}{|c|c|c|c|}
\hline Year & Patent No. & Patentee & Subject \\
\hline \multirow[t]{2}{*}{1982} & $4,357,420$ & $\begin{array}{l}\text { Bostick, W. D. } \\
\text { Denton, M. S. } \\
\text { Dinsmore, S. R. }\end{array}$ & $\begin{array}{l}\text { Bioluminescence Methods for Enzymatic } \\
\text { Determinations }\end{array}$ \\
\hline & $4,358,426$ & $\begin{array}{l}\text { Crouse, D. J., Jr. } \\
\text { Mailen, J. C. } \\
\text { Tallent, O. K. }\end{array}$ & $\begin{array}{l}\text { Method for Cleaning Solution Used in Nuclear } \\
\text { Fuel Reprocessing }\end{array}$ \\
\hline \multirow[t]{7}{*}{1983} & $4,376,792$ & $\begin{array}{l}\text { Angelini, P. } \\
\text { Lackey, W. J., Jr. } \\
\text { Stinton, D. P. } \\
\text { Blanco, R. E. } \\
\text { Bond, W. D. } \\
\text { Arnold, W. D., Jr. }\end{array}$ & $\begin{array}{l}\text { Method for Primary Containment of Cesium } \\
\text { Wastes }\end{array}$ \\
\hline & $4,382,885$ & Haas, P. A. & Method for Producing Nuclear Fuel \\
\hline & $4,394,269$ & $\begin{array}{l}\text { Mailen, J. C. } \\
\text { Pannell, K. E. } \\
\text { Tallent, O. K. }\end{array}$ & $\begin{array}{l}\text { Method for Cleaning Solution Used in Nuclear } \\
\text { Fuel Reprocessing }\end{array}$ \\
\hline & $4,397,778$ & Lloyd, M. H. & $\begin{array}{l}\text { Coprocessed Nuclear Fuels Containing (U,Pu) } \\
\text { Values as Oxides, Carbides or Carbonitrides }\end{array}$ \\
\hline & $4,409,157$ & $\begin{array}{l}\text { Haas, P. A. } \\
\text { Stines, W. B. }\end{array}$ & $\begin{array}{l}\text { Method for Improved Decomposition of Metal } \\
\text { Nitrate Solutions }\end{array}$ \\
\hline & $4,413,058$ & $\begin{array}{l}\text { Donaldson, T. L. } \\
\text { Arcuri, D. J. }\end{array}$ & $\begin{array}{l}\text { Continuous Production of Ethanol by Use of } \\
\text { Flocculent Zymomonas Mobilis }\end{array}$ \\
\hline & $4,415,536$ & $\begin{array}{l}\text { Haas, P. A. } \\
\text { Ryon, A. D. }\end{array}$ & $\begin{array}{l}\text { Apparatus for Contacting Particulate Material } \\
\text { with Processing Liquid }\end{array}$ \\
\hline \multirow[t]{7}{*}{1984} & $4,431,609$ & Scheitlin, F. M. & $\begin{array}{l}\text { Removal of Radium from Acidic Solutions } \\
\text { Containing Same by Adsorption on Coal } \\
\text { Fly Ash }\end{array}$ \\
\hline & $4,432,945$ & $\begin{array}{l}\text { Hurst, F. J. } \\
\text { Brown, G. M. } \\
\text { Posey, F. A. }\end{array}$ & $\begin{array}{l}\text { Removing Oxygen from a Solvent Extractant } \\
\text { in a Uranium Recovery Process }\end{array}$ \\
\hline & $4,442,211$ & Greenbaum, E. & $\begin{array}{l}\text { Method for Producing Hydrogen and Oxygen } \\
\text { by Use of Algae }\end{array}$ \\
\hline & $4,443,413$ & $\begin{array}{l}\text { McTaggart, D. R. } \\
\text { Pruett, D. J. }\end{array}$ & $\begin{array}{l}\text { Separation of Uranium from Technetium in } \\
\text { Recovery of Spent Nuclear Fuel }\end{array}$ \\
\hline & $4,446,105$ & $\begin{array}{l}\text { Dinsmore, S. R. } \\
\text { Mrochek, J. E. }\end{array}$ & $\begin{array}{l}\text { System for Analyzing Coal Liquefaction } \\
\text { Products }\end{array}$ \\
\hline & $4,459,245$ & $\begin{array}{l}\text { Haas, P. A. } \\
\text { Ryon, A. D. } \\
\text { Vavruska, J. S. }\end{array}$ & $\begin{array}{l}\text { Method and Apparatus for Controlled Size } \\
\text { Distribution of Gel Microspheres Formed From } \\
\text { Aqueous Dispersions }\end{array}$ \\
\hline & RE.31,686 & $\begin{array}{l}\text { Hurst, F. J. } \\
\text { Crouse, D. J., Jr. }\end{array}$ & $\begin{array}{l}\text { Reductive Stripping Process for the Recovery } \\
\text { of Uranium from Wet-Process Phosphoric Acid }\end{array}$ \\
\hline
\end{tabular}


Table E.1 (continued)

\begin{tabular}{|c|c|c|c|}
\hline Year & Patent No. & Patentee & Subject \\
\hline 1984 & $4,476,105$ & Greenbaum, E. & Process for Photosynthetically Splitting Water \\
\hline \multirow[t]{5}{*}{1985} & $4,459,338$ & $\begin{array}{l}\text { Angelini, P. } \\
\text { DeVore, C. } \\
\text { Lackey, W. J., Jr. } \\
\text { Blanco, R. E. } \\
\text { Stinton, D. P. }\end{array}$ & $\begin{array}{l}\text { Method for Deposition of Silicon Carbide } \\
\text { Layers on Substrates and Product }\end{array}$ \\
\hline & $4,500,493$ & Hurst, F. J. & $\begin{array}{l}\text { Reductive Stripping Process for Uranium } \\
\text { Recovery from Organic Extracts }\end{array}$ \\
\hline & $4,502,987$ & $\begin{array}{l}\text { Lloyd, M. H. } \\
\text { Collins, J. L. } \\
\text { Shell, S. E. }\end{array}$ & $\begin{array}{l}\text { Method of Controlling Crystallite Size in } \\
\text { Nuclear-Reactor Fuels }\end{array}$ \\
\hline & $4,509,856$ & Lee, N. E. & Rotor for Centrifugal Fast Analyzers \\
\hline & $4,528,165$ & Friedman, H. A. & $\begin{array}{l}\text { Separation of Uranium from Technetium } \\
\text { in Recovery of Spent Nuclear Fuel }\end{array}$ \\
\hline 1986 & $4,562,748$ & $\begin{array}{l}\text { Mrochek, J. E. } \\
\text { Dinsmore, S. R. } \\
\text { Chandler, E. W. }\end{array}$ & $\begin{array}{l}\text { Disc Valve for Sampling Erosive Process } \\
\text { Streams }\end{array}$ \\
\hline \multirow[t]{5}{*}{1987} & $4,657,646$ & Greenbaum, E. & $\begin{array}{l}\text { Method of Producing Metallized Chloroplasts } \\
\text { and Use Thereof in the Photochemical } \\
\text { Production of Hydrogen and Oxygen }\end{array}$ \\
\hline & $4,663,093$ & $\begin{array}{l}\text { Haas, P. A. } \\
\text { Fowler, V. L. } \\
\text { Lloyd, M. H. }\end{array}$ & $\begin{array}{l}\text { Preparation of Nuclear Fuel Spheres by } \\
\text { Flotation-Internal Gelation }\end{array}$ \\
\hline & $4,666,654$ & Forsberg, C. W. & $\begin{array}{l}\text { Boiling Water Neutronic Reactor Incorporating } \\
\text { a Process Inherent Safety Design }\end{array}$ \\
\hline & $4,683,042$ & Scott, C. D. & $\begin{array}{l}\text { Method and Apparatus for Continuous Annular } \\
\text { Electrochromatography }\end{array}$ \\
\hline & $4,740,472$ & $\begin{array}{l}\text { Burtis, C. A. } \\
\text { Johnson, W. F. } \\
\text { Walker, W. A. }\end{array}$ & $\begin{array}{l}\text { Method and Apparatus for Automated Processing } \\
\text { and Aliquoting of Whole Blood Samples for } \\
\text { Analysis in a Centrifugal Fast Analyzer }\end{array}$ \\
\hline \multirow[t]{2}{*}{1988} & $4,767,929$ & $\begin{array}{l}\text { Scott, T. C. } \\
\text { Wham, R. M. }\end{array}$ & $\begin{array}{l}\text { Surface Area Generation and Droplet Size } \\
\text { Control in Solvent Extraction Systems Utilizing } \\
\text { High Intensity Electric Fields }\end{array}$ \\
\hline & $4,789,436$ & Greenbaum, E. & $\begin{array}{l}\text { Method and Apparatus for Nondestructive } \\
\text { In Vivo Measurement of Photosynthesis }\end{array}$ \\
\hline \multirow[t]{3}{*}{1989} & $4,800,183$ & Quinby, T. C. & Method for Producing Refractory Nitrides \\
\hline & $4,835,106$ & $\begin{array}{l}\text { Johnson, W. F. } \\
\text { Burtis, C. A. } \\
\text { Walker, W. A. }\end{array}$ & $\begin{array}{l}\text { Rotor for Processing Liquids Using Movable } \\
\text { Capillary Tubes }\end{array}$ \\
\hline & $4,840,904$ & Woodward, J. & $\begin{array}{l}\text { Recovery and Reuse of Cellulase Catalyst in } \\
\text { an Enzymatic Cellulose Hydrolysis Process }\end{array}$ \\
\hline
\end{tabular}


Table E.1 (continued)

\begin{tabular}{|c|c|c|c|}
\hline Year & Patent No. & Patentee & Subject \\
\hline \multirow[t]{5}{*}{1989} & $4,846,964$ & $\begin{array}{l}\text { Scott, C. D. } \\
\text { Strandberg, G. W. }\end{array}$ & $\begin{array}{l}\text { Fluidized-Bed Bioreactor Process for the } \\
\text { Microbial Solubilization of Coal }\end{array}$ \\
\hline & $4,847,205$ & $\begin{array}{l}\text { Burtis, C. A. } \\
\text { Johnson, W. F. }\end{array}$ & $\begin{array}{l}\text { Device and Method for Automated Separation } \\
\text { of a Sample of Whole Blood into Aliquots }\end{array}$ \\
\hline & SIR H659 & Haas, P. A. & $\begin{array}{l}\text { Process for Electrolytically Preparing Uranium } \\
\text { Metal }\end{array}$ \\
\hline & SIR H660 & $\begin{array}{l}\text { Tallent, O. K. } \\
\text { Dodson, K.E. } \\
\text { McDaniel, E. W. }\end{array}$ & $\begin{array}{l}\text { Method and Composition for Immobilization } \\
\text { of Waste in Cement-Based Materials }\end{array}$ \\
\hline & $4,941,959$ & Scott, T. C. & Magnetic/Electric Field Solvent Extraction \\
\hline \multirow[t]{6}{*}{1990} & $4,914,024$ & $\begin{array}{l}\text { Strandberg, G. W. } \\
\text { Lewis, S. N. }\end{array}$ & Microbial Solubilization of Coal \\
\hline & $4,916,092$ & $\begin{array}{l}\text { Tiegs, T. N. } \\
\text { Lindemer, T. B. }\end{array}$ & $\begin{array}{l}\text { Ceramic Composites Reinforced with Modified } \\
\text { Silicon Carbide Whiskers }\end{array}$ \\
\hline & SIR H800 & $\begin{array}{l}\text { Beahm, E. C. } \\
\text { Shockley, W. E. }\end{array}$ & $\begin{array}{l}\text { Method for Gettering Organic, Inorganic, and } \\
\text { Elemental Iodine in Aqueous Solutions }\end{array}$ \\
\hline & $4,941,959$ & Scott, T. C. & $\begin{array}{l}\text { Electric Field-Driven, Magnetically Stabilized } \\
\text { Ferro-Emulsion Phase Contactor }\end{array}$ \\
\hline & SIR H857 & Haas, P. A. & $\begin{array}{l}\text { Electrolytic Process for Preparing Uranium } \\
\text { Metal }\end{array}$ \\
\hline & $4,978,647$ & $\begin{array}{l}\text { Scott, C. D. } \\
\text { Woodward, C. A. } \\
\text { Byers, C. H. }\end{array}$ & Gel Bead Composition for Metal Adsorption \\
\hline \multirow[t]{3}{*}{1991} & $4,994,416$ & $\begin{array}{l}\text { Tiegs, T. N. } \\
\text { Lindemer, T. B. }\end{array}$ & $\begin{array}{l}\text { Ceramic Composites Reinforced with Modified } \\
\text { Silicon Carbide Whiskers and Method for } \\
\text { Modifying the Whiskers }\end{array}$ \\
\hline & $4,995,985$ & $\begin{array}{l}\text { Scott, C. D. } \\
\text { Woodward, C. A. } \\
\text { Byers, C. H. }\end{array}$ & Gel Bead Composition for Metal Adsorption \\
\hline & $5,100,781$ & Greenbaum, E. & $\begin{array}{l}\text { Measurement of Gas Production by Algal } \\
\text { Clones }\end{array}$ \\
\hline
\end{tabular}




\section{CONTRIBUTORS INDEX}

Basaran, Osmond 4-59

Bell, L. H. 4-57

Bigelow, John 4-32

Blanco, Ray 2-18, 4-11, 5-10

Bond, Walt 4-5, 4-7

Brooksbank, Sr., R. E. 4-64

Bruce, Frank 1-22

Burtis, Carl 4-78

Campbell, David O. 5-7

Campbell, Kermit B. 4-107

Chandler, John M. 4-109

Cochran, Hank 4-74

Coleman, Charles F. 5-18, 4-1

Crouse, David J. 4-1

Culler, Floyd 2-10

Egan, Zane 4-78

Eister, Warren 2-5

Godbee, Herschel 4-49

Goeller, Hal 2-23, 4-93, 4-95, 4-96

Greenbaum, Elias 4-78
Haas, Paul 4-5

Harrington, Frank E. 5-2

Higgins, Irwin R. 5-20

Hightower, Bob 4-44, 4-48, 4-64

Hurst, Fred J. 4-1

Jacobus, R. A. 4-57

Johnson, Kaye 5-29

Jolley, Bob 4-7, 4-44, 4-53, 4-78, 4-91, 5-13

Leuze, Rex E. 5-4

Leverett, Miles C. 1-16, 5-1

Lomenick, Tom 4-49

Lorenz, R. A. 4-18

Ludwig, Scott B. 4-12

McCullough, F.C. 2-38

McGinnis, C. P. 4-57

Mrochek, John 4-59, 4-78

Newman, Gene 4-31

Nicholson, Ed L. 5-3
Notz, Karl 4-15

Parker, George 5-16

Parrott, Jr., John 4-98

Perona, J. J. 4-106, 5-32

Pitt, Wilson 4-44

Postma, Herman 1-19

Schersten, Clair W. 5-6

Scott, Tim 4-59

Scott, Charles 4-78

Shappert, Larry B. 4-16

Singh, Suman 4-53

Stewart, Martha G. 4-97

Strandberg, Jerry 4-78

Thompson, William E. 1-13

Trauger, Donald 1-21

Unger, Bill 5-3

Weinberg, Alvin 1-18

Whatley, Marvin 5-14

Youngblood, Lloyd 4-44 
The following index does not include the subjects uranium and plutonium because they appear on essentially every page in Sections 1 through 5 . The appendices have not been indexed because the names of individuals may be readily determined.

A

A Happening 5-25

A Night on CTD TV 5-25

A. E. Staley Co. $4-90$

Aaron, Scott 4-108, 4-109

Academy of Clinical Laboratory

Physicians and Scientists 4-81

Accident testing 4-19

Acid thorex 4-73

Acid-Deficient Redox Process 2-7

Acken, M. F. $1-12$

Actinide 4-44, 4-108

Actinide Separations 5-9, 5-10

Activated sludge 4-86

Activation product 4-38

Adair, Harold 4-108, 4-109

Adsorption 1-3, 2-4, 3-10

Advanced Breeder Reactors 4-6

Advisory Committee on Uranium 1-2

Aerosol transport 4-24

Agro-industrial complexes 3-1, 4-93

Aiken, South Carolina 2-4

Air Force 4-42, 4-102

Airborne effluents 4-12

Aircraft Nuclear Propulsion (ANP) program 1-9, 2-33, 4-44, 4-48

Aircraft Reactor Experiment (ARE) fuel $2-26,2-33,3-10,4-44$, 4-46, 4-72

Ajen, Alvin 4-103

Aken, Marshall 2-7

Alabama 1-16

Alamogordo, New Mexico 5-18

ALARA 4-10

Albert Einstein Hospital 4-82

Albert, Mike 4-24

Albrecht, W. L. 3-8

Alcoa 4-93

Alexander, Chuck 4-14, 4-15, 4-16

Allen, K. A. 3-6, 3-9, 3-10

Allied Chemical Corporation $2-4$

Allied General Nuclear Services

(AGNS) Plant 2-5, 4-66, 4-69

Allsion, Sam 5-16
Alton, Illinois $4-101$

Aluminum nitrate 2-4, 2-8

Aluminum-24 4-41

Aluminum-clad fuel 1-6. 2-19, 3-7, 4-38, 4-45

American Association for Clinical Chemistry 4-81

American Cyanamid Corporation $x i x, 2-24,5-2$

American Instrument Co. 4-82

Americium 2-30, 2-31, 2-37, 3-14, 4-34, 4-35, 4-36, 4-38, 4-40, $4-41,4-43,4-44,4-48,4-67$, 4-110, 5-9

Ames, Iowa 1-10, 1-12

Ames Laboratory 2-8

Amex process 2-28, 2-37, 3-10, 4-2, 4-66

Amine extraction 3-13

Anaerobic, up-flow (ANFLOW) 4-89, 4-99, 4-100

Analog computer 2-36

Analytical Chemistry Division $1-13,2-10,2-12,2-16,2-37$, 3-13, 4-28, 4-30, 4-41, 4-46, 4-47, 4-78, 4-79

Andermann, Ralph 1-24

Anders, Oswald 4-53

Anderson, D. E. 4-69, 4-74

Anderson, J. W. 4-111

Anderson, Norm 2-16, 4-78, 4-80, 4-81, 4-82

Annapolis Center for Environmental Quality 2-18

Annex to 703-A 2-1, 2-2

Annular chromatograph 4-61

Antimony 4-47

Antisolvent deashing studies 4-75

Apple, R. S. 1-12

Aquafluor process 2-5

Aqueous homogeneous reactor 2-15

Architect-engineers(AEs) 2-11

Arco, Idaho 2-23, 2-29

Arcuri, Ed 4-79, 4-89, 4-90

ARE Fuel Aqueous Processing 2-34

ARE Fuel Volatility Process Study 2-34
Area $200 \quad$ 1-17

Arehart, Ted 2-6, 2-9, 5-22

Argonne, Illinois 1-10, 1-22

Argonne metal 1-12

Argonne National Laboratory 1-9, $1-18,2-4,2-5,2-20,2-30$, 2-37, 4-36, 4-41, 4-47

Armento, Joe 1-24

Army Specialized Training Program 1-17

Arnold, Bill xi, 3-6, 3-10, 3-11, 3-12, 3-13, 3-14, 4-3, 4-6

Arnold, Eldon 2-14, 2-36, 3-4, 3-5, 3-7, 4-13, 5-7, 5-25

Ashin, Jean 1-12

Ashland, Kentucky 4-85

Ashland Synthetic Fuels, Inc. 4-84

Ashline, Ron 4-14

Ashwood, Tom 4-91

Asphalt 4-51, 5-11

Atlanta, Georgia xxii

Atlantic Richfield Company $2-4$

Atomic bomb xiii, 1-1, 1-13, 4-9

Atomic energy ix, xiii, xiii, $1-1$, 1-9, 3-1

Atomic Energy Commission $x i$, $1-9,1-16,1-18,2-9,2-15$, 2-21, 2-24, 2-27, 2-32, 2-37, 3-11, 3-14, 3-16, 4-9, 4-31, 4-32, 4-33, 4-35, 4-52, 4-53, 4-74, 4-75, 4-78, 4-81, 4-96, 4-97, 4-112, 4-113

Atomic Research Institutes 2-21

Atoms for Peace conferences 2-15

Attaway, Reid 4-18

Attrill, Jim 4-80

Auerbach, Stan 4-31

Ault, Donna 1-25

Australia 2-20

AVLIS program 4-70, 4-102

Awards 1-26

B

Babcock and Wilcox 4-22

Baes, C. F. 3-9, 3-10, 4-3, 4-48

Bailey, Jim 4-56 
Bailey, P. D. 1-23

Baille, M. G. 3-12

Baird, F. G. 3-12

Baker, J. M. 4-59

Bakhra Dam 4-94

Baldwin, Mark E. 4-113

Ballet Grotesque or The Dance of the Fairies 5-24, 5-26

Banic, George 4-31

Barium xiii, 1-3, 1-13, 1-17, 2-1, 2-19, 2-29, 4-67, 5-1, 5-3

Barker, Jim 4-31

Barker, Ray 5-28

Barnett, R. T. 1-23

Barnwell, South Carolina 2-5, 4-66

Barton, C. J. 4-19, 4-48

Basaran, Osman 1-24, 4-59

Battelle Memorial Institute 4-46

Bauer, Martin 4-82, 4-84

Bauman, Bill 5-23

Baybarz, Russ 2-27, 3-12, 3-14, 4-6, 4-35, 4-36, 4-38, 5-6

Bayles, Tom 1-25

Baytown, Texas 4-75

Beach, Nancy 4-98

Beahm, Ed 4-20, 4-24, 4-27, 4-30

Beall, Sam 1-17, 2-17

Beams, Jack 4-45, 4-48, 4-49

Beard, R. P. 4-47

Beatty, Ron 4-7

Beaty, I. 1-25

Beauchamp, Ed 1-13, 2-9

Beauty and the Beasts 5-25

Beaver Brook Country Club 5-24

Beaver, J. E. 1-23

Bechtel 2-14, 2-23, 2-29

Beeler, Jerry 5-30

Beer brewery 1-12

Beets, Amold 4-113

Begovich, John 1-24, 4-6, 4-61, 4-75, 4-100, 4-101, 4-102

Begun, George 4-25

Belgian Congo 2-15, 2-20

Belgium 2-5, 2-15, 2-16, 2-20, 5-11

Bell, Bill 4-31

Bell, Jimmy 1-24, 4-24, 4-27, 5-24

Bell, L. H. 4-57, 4-98, 4-118

Bell, Mike 4-13, 4-49

Belter, Walter 2-21, 3-15

Benedict, Manson 2-8

Benker, D. E. 4-44

Bennett, M. R. 3-5, 3-10, 4-44, $4-45,4-49,4-117,5-13$

Benson, Ed 1-25

Berkelium 4-32, 4-36, 4-40, 4-41, 4-67

Berkex process 2-28, 4-66
Bernard, Claude 5-19

Berry, Jan 4-102

Besmann, T. M. 4-23, 4-30

Bethel Valley Road 1-15, 4-69

Bigelow, J. E. xi, 1-23, 2-27, 3-10, 3-14, 4-31, 4-32, 4-35, 4-36, $4-43,4-44,4-46,5-25,5-27$

Bigler, Bill 1-17

Bimodal fission 4-41

Binford, Frank 4-21

Biodenitrification 4-86, 4-89

Bioengineering 1-19, 1-21

Biology Division 1-12, 2-16, 2-18, 4-2, 4-78, 4-79, 4-84, 4-85, 4-91, 4-98

Biomedical Applications 4-41

Biophotochemical Systems 4-79

Bioreactors 4-86, 4-91

Bioremediation 4-91, 4-102

Biotechnology xiii, 2-16, 2-27, 4-78, 4-85, 4-89, 4-102

Bird, Lew 4-22

Bismuth phosphate precipitation $1-3,1-6,1-22,2-4,2-6,2-28$, $4-66,4-67,4-69,4-71,5-9$

Bizzell, Oscar 5-2

Bjerke, Mike 4-14

Blair, Bob 5-29

Blair, Mike 4-84

Blake, C. A. 3-6, 3-9, 3-10, 3-12, 3-13, 5-18, 5-19

Blakely, J. P. 4-9, 4-46

Blanco, Ray xi, xiii, 2-18, 2-21, 2-22, 2-24, 2-38, 3-3, 3-6, 3-7, 3-8, 3-9, 3-10, 3-11, 3-12, 3-13, 4-10, 4-11, 4-50, 4-94, 4-116, 4-117, 5-2, 5-4, 5-7, $5-10,5-12,5-13,5-24,5-26$

Blankinship, Steve 1-24, 4-86

Blauer, Harris 1-14, 5-4

Blomeke, John 1-13, 2-6, 2-29, 2-36, 3-7, 3-9, 3-11, 3-15, 3-16, 4-14, 4-15, 4-16, 4-52, 4-53, 4-112, 5-2, 5-7

Blouin, Glenn 4-93

Blount Construction Company 4-111

BNL reactor fuel 4-71

Boatman, Allen 1-24, 4-47

Body fluids analysis $1-21,4-78$, 4-80, 4-81

Boeder, Imgrad 1-12

Boegly, W. J. 3-11

Bohlman, Ed 1-14

Boiling-Water Reactors (BWRs) 4-14

Bolden, Ray 5-30
Bolt, Sam E. 4-48, 4-111

Bond, Walt xi, 2-27, 3-11, 3-12, $3-13,4-5,4-6,4-7,4-22$

Borehole plugging 4-31, 4-105

Boring, Matt 4-104

Borosilicate glass 4-50

Borst, Lyle 1-12

Bostic, Bill 4-36, 4-48, 4-112

Bostick, Bill 4-82

Bottenfield, B. F. 3-12, 3-14, 4-35, 4-52

Bowling 5-29

Bowman, Dick 4-48

Box, Don 1-24, 4-16, 4-22

Boyd, Dave 2-38

Boyd, George 1-11, 1-12, 4-33, 5-22

Bradley, M. J. 3-12, 3-13

Bradley, Ron 4-7

Bradshaw, R. L. 3-16

Brand, Jennifer 4-75

Brantley, Ed 4-47

Bray, Frances 5-24

Breeden, Brenda xi, 1-25

Breeder reactor concept 1-6, 2-15, 3-11, 4-48

Bresee, J. C. 3-7, 4-74, 5-14, 5-15

Breshneva, Madame 2-21

Briggs, Lyman J. 1-2

Briggs, R. B. 1-10, 1-17

Bright, Robin 1-24

British reports 1-2

Brock, John 4-36. 4-47

Brooke, W. A. 1-23, 4-54

Brookhaven National Laboratory 2-30, 2-31, 4-32, 4-110

Brooksbank, Bob xi, 3-8, 3-9, 3-11, 3-12, 3-13, 3-14, 4-5, 4-22, 4-47, 4-51, 4-64, 4-74, 4-110, 4-117

Brooksbank, Donna 1-24

Browder, Frank 2-24, 3-10, 4-46, 4-52, 5-2

Browder, Mrs. 5-25

Brown, D. S. 4-54

Brown, Jr., C. H. 1-25, 4-49, 4-75, 4-76, 4-99, 4-100, 4-102

Brown, K. B. 2-14, 3-6, 3-9, 3-12, 3-13, 4-1 , 4-79, 5-18, 5-19

Brown, M. 4-27

Brown, Vanessa 1-24

Browns Ferry 4-27

Bruce, Frank xi, xiii, 1-10, 1-13, $1-14,1-22,2-5,2-7,2-8,2-9$, 2-16, 2-19, 2-20, 2-24, 3-1, $3-2,3-4,3-6,3-7,3-9,3-11$, $4-19,5-2$ 
Bruceton, Pennsylvania 4-74

Brungs, W. A. 4-118

Brunson, Ron 1-24, 4-65, 4-75

Bryan, Bill 4-36, 4-47

Buchholz, Heinz 4-19

Buckley, Page 5-4, 5-5

Buford, Cheryl xi

Building $2051-3,1-7,1-18,2-1$, $2-2,2-4,2-28,2-38,4-64$, 4-69, 5-3

Building 2067 2-1, 2-2

Building 3017 2-2, 4-50, 4-105

Building 3019 (Pilot Plant) 1-3, 2-1, 2-2, 2-4, 2-28, 2-29, 2-31, 2-38, 4-16, 4-44, 4-46, 4-47, 4-48, 4-64, 4-65, 4-69, 4-70, 5-2, 5-9

Building $30262-38,4-19,5-3,5-6$, 5-18

Building 3502 2-1, 2-2

Building 3503 2-1, 2-2

Building 3505 (Metal Recovery Plant) 1-10, 2-1, 2-2, 2-30, 2-34

Building 3508 (High Alpha Laboratory) 2-1, 2-2, 2-34, 2-37, 5-7

Building 3550 2-1, 2-2, 2-24, 2-29, $2-31,2-38,5-6$

Building 3592 2-35, 4-45

Building 4500N 2-35, 5-13

Building $45012-24$

Building 4505 2-24, 4-50, 4-51, $4-79,5-10,5-28$

Building 4507 (hot cells) 2-35, 2-37, 3-14, 4-35, 4-38, 4-45

Building 704 D 2-19

Building 706-A 1-5, 2-1, 2-2, 2-29, 2-38

Building 706-C 2-38, 4-19

Building 706-HB 2-1, 2-2

Building 706-HD 2-1, 2-2

Building 706A Semi-works 2-31, 2-38, 5-6

Building 706C 2-29, 2-38, 5-3, 5-18

Building 706D 1-17, 5-1, 5-3, 5-4, 5-6

Building 7601 4-112

Building 7920 4-35, 4-36

Building 7930 4-111

Building 9204-3 4-105

Building 9212 2-12

Building K-1006 4-105

Burch, Bill 2-17, 2-27, 3-11, 3-12, 3-14, 4-35, 4-36, 4-40, 4-111, $4-112,4-113,5-24,5-26,5-29$
Bureau of Mines 4-74, 4-75, 4-77, 4-95

Burgess, M. W. 1-25

Burn-leach 3-13

Burnable poisons 2-3

Burner technology 2-35, 4-68

Burning rocks 2-16, 3-1

Burns, R. H. 2-22

Burris, Les 5-4

Burros, Zeke 5-2

Burtis, Carl xi, 4-78, 4-80, 4-82, $4-83,4-84,4-85,4-118$

Burwell, Cal 4-93, 4-94

Bush, Vannevar 1-2, 1-14

Bush, W. A. 4-46

Butler, J. M. 1-25

Butterworth, G. E. 4-54

Butts, Bill 4-78, 4-80, 4-118

Buxton, S. R. 3-13, 3-14, 4-6

Byers, Charles 1-24, 4-62, 4-65

Byington, Tennessee 1-16, 5-5

Byrd, L. W. 4-113, 5-13

Byrum, B. L. 1-25, 4-109

C

Caldwell, H. S. 4-47

Cali, Columbia 4-92

Californium 2-9, 4-32, 4-34, 4-35, 4-36, 4-38, 4-40, 4-41, 4-42, 4-43, 4-44, 4-49, 4-67

Californium-252 Industrial Sales/Loan Program 4-41, 4-42

Californium-252, medical use $4-43$

Callahan, Dixon 2-12

Calleri, Giacomo 5-19

Calutrons 2-12, 4-31, 4-32, 4-107, 4-108

Camp, Rita 1-25

Campbell, D. O xi, xiii, 2-27, 3-2, $3-3,3-4,4-22,4-23,4-27$, $4-45,5-1,5-6,5-7,5-8,5-13$

Campbell, Kermit xi, 4-107, 4-109

Campbell, S. G. 2-36, 3-13

Can do attitude 1-22

Canal water 4-49

Cancer therapy 2-23

CANDUs 4-14

Canon, Ron 2-27, 4-61, 4-75

Carbide Canoe Club 5-29

Carbide Reactor Fuels 3-12, 3-13

Carbohydrate analyzer 4-80

Carbon-14 xxiv, 2-38

Carbonization 4-74

Carlsbad, New Mexico 4-10, 4-15

Carlsmith, Roger 4-97
Carmichael, Jeffrey 4-88

Carnegie Foundation 1-2

Carr, W. H. 3-9, 3-10, 4-46, 4-47, 4-117

Carrier-precipitation method 5-20

Carter, Lloyd 4-16, 4-48, 4-97

Cask Designers Guide 4-16

Cask Maintenance Facility 4-18

Catalytic Construction 2-14, 2-37

Cathers, G. I. 2-20, 2-35, 3-2, 3-3, 3-9, 3-10, 3-12, 3-13, 4-44, $4-45,4-46,4-48,4-117,5-13$

Cation Exchange 4-44

Catlettsburg, Kentucky 4-75, 4-99

Caudill, Hugh 4-31

Caylor, Ann 4-109

Cellulose hydrolysis $4-90$

Cement-based waste forms 4-105

Center, Clark 5-23

Centrifugal analyzer 4-81

Centriguge separations 1-2

Ceramic powders 4-5

Cesium 4-50, 5-23

Cesium iodide 4-22

Chalk River 2-1, 2-30, 2-31

Chambers, Pots 2-8

Chance, Frank S. 4-107

Chandler, John xi, 3-6, 4-48, 4-109, 4-110, 4-111

Chapman, J. R. 4-93

Characteristics Data Base 4-15, 4-16

Charleston, West Virginia 5-6

Charpie, Bob 2-32, 2-36, 5-3

Chase, Bill 1-24

Chase, L. H. 4-46

Chattin, F. R. 1-23, 4-36, 4-44, 5-30

Checkprints 2-14

Chem Nuclear Inc. 4-57

Chem Tech dance 2-17

Chem Tech exhibits 3-2

Chem Tech Reports Office 4-97

Chemical Application of Nuclear Explosives 4-8

Chemical Development Section 2-20, 2-24, 4-10, 4-20, 4-24, 4-34, 4-35, 4-38, 4-44, 4-74, 4-105

Chemical Development Section A $x x i, x x i i, 4-5,4-45,4-97$

Chemical Development Section B 2-24, 4-48, 4-49

Chemical Development Section C 4-2, 4-79

Chemical engineering $1-17,1-18$, $1-19,1-21,2-1,4-59$ 
Chemical Engineering Section 1-12

Chemical processing ix, 1-17, $1-22,2-10,2-23,3-1,4-62$

Chemical separation columns $1-21$

Chemical separations pilot plant (see Pilot Plant) 1-4, 1-16

Chemical Separations Corporation 5-23

Chemical Technology Division, Acting Director xxiv

Chemical Technology Division, Director $x i x, x x, x x i, x x i i, x x i i i$

Chemical Technology Division, establishment 1-9

Chemical Technology group 2-13

Chemistry Division 1-11,1-12, $1-13,1-17,2-5,2-10,4-25$, $4-35,5-1$

Chernobyl accident 4-28

Cherry picker 2-7

Chester, C. V. 3-11, 4-78

Chetham-Strode, A. 3-12, 3-14, 4-34

Chevy Chase, Maryland 2-7

Chicago 1-12, 2-6, 5-5, 5-17, 5-21

Chicago Museum of Science and Industry 2-8

Chicago Pile (reactor) $1-14,5-21$

Chilcote, Dennis 4-79, 4-80, 4-86, 4-89

Childersburg, Alabama 5-20

Chilton, John 2-27, 4-4

China 2-5, 4-69

Chlorinated wastewaters 4-91

Chlorine trifluoride 2-26, 2-35

Chop-leach 4-68

Chopin, Greg 5-9

Cincinnati, Ohio 5-5

City College of New York 4-93

Clark, John W. 5-24

Clark, Michelle 4-88

Clark, W. E. 3-11, 3-12, 4-7, 4-50, 4-117, 5-12

Cleanex process 2-28, 4-44, 4-66

Clementine Reactor 2-30, 4-110

Clifty Creek Power Station 4-74

Clinch River 1-15, 5-6

Clinch River Breeder Reactor 4-14, 4-18

Clinical Chemistry conferences 4-81

Clinton Engineering Works xiii, $\mathrm{xx}, 1-1,1-3,1-4,1-13,1-14$, $1-15,1-16,2-2,4-64$

Clinton High School 4-88

Clinton, President 5-32
Clinton Laboratories ix, xiii, xix, $x x i, 1-3,1-4,1-5,1-6,1-9$, $1-11,1-12,1-13,1-15,1-16$, $1-17,1-18,1-22,2-6,2-31$, 5-2, 5-17, 5-21

Clinton National Laboratory $1-5$, $1-9$

Clinton Pile (reactor) 1-14, 1-15, 5-20

Clinton, Sam 1-25, 3-13, 4-5, 4-6, 4-24, 4-28, 4-29, 5-29

Clinton, Tennessee 1-10,1-12, 1-13, 4-88

Clure, T. D. 1-25

Coal bioprocessing 4-90

Coal conversion processes $1-20$, 4-74, 4-77, 4-86, 4-90, 5-2

Coal conversion wastewater 4-89, 4-99, 4-102

Coal desulfurization studies 4-77

Coal gasification 4-74, 4-85

Coal Technology Program 4-74

Coal yard runoff 4-102

Coal-derived particles 4-62

Coal-fired power plants 4-12

Cobalt-60 2-23

Cochran, Danny 1-25

Cochran, Hank xi, 1-24, 4-48, 4-49, 4-74, 4-75

Cohn, Waldo 1-12, 1-13, 2-16, 5-10

Cold-war period 1-21

Cole, Tom 2-8

Coleman, Charles xi, 3-6, 3-6, 3-9, 3-12, 3-13, 4-1, 4-3, 4-4, 5-18, 5-19

COLEX process 2-9, 2-20, 2-24

Collins, E. D. xi, 1-23, 4-22, 4-23, 4-36, 4-44, 4-58, 4-59, 4-108

Collins, Jack 1-24, 4-6, 4-7, 4-20, 4-22, 4-24, 4-26, 4-27, 4-31

Colorado Plateau 4-1

Columbia River 1-13, 5-22

Columbia University $1-2,1-10$, 1-14

Cometabolic bioreactor technology 4-104

Commercial reprocessing 4-15

Commercial spent fuel 4-15

Commonwealth Edison 2-34

Compacts 4-15

Compere, Alicia 4-89

Compere, E. L. 4-30, 4-53

Compton, Arthur 1-2, 1-10, 1-12, $1-14,2-39,2-39,5-16,5-21$

Computing and Telecommunications Division 4-13, 4-16
Conant, James 1-2

Conasauga shale 4-51

Concrete Fixation Program 4-32

Concrete Studies 4-50

Conference proceedings 3-1

Conner, L. R. 1-25

Consolidated Edison 2-34, 4-70, 4-111

Consolidated Edison Indian Point I nuclear reactor 4-57

Consolidated Edison Uranium Solidification Program (CEUSP) 4-57

Consolidated Fuel Reprocessing Program 4-111

Containment Mockup Facility 4-19

Conte, Mary Louise 4-98

Continuing Education 2-16, 2-17

Continuous ion-exchange 2-9, 4-61, 5-23, 5-24

Control rods 2-3

Conway, I. A. 1-25

Cooke, Jim 4-58

Cooley, C. R. 3-14

Cooling water 4-49, 4-78, 4-91, 4-92

Cooper, Charles M. 1-3

Cooper, D. S. $1-25$

Cooper, John 5-9

Cooper, Ray 5-30

Cooper, Ron 5-30

Cooper, Stan 1-24

Cooper, Vance 2-7

Cope, Dave 4-96

Copeland, Brian 1-25

Copper nitrate 2-12

Corbett, B. L. 4-43

Corbin, L. T. 4-46, 5-2, 5-25

Corbin, Lib 5-25

Core-melt studies 4-24

Corps of Engineers 1-13

Corrosion studies 3-5, 4-46

Coryell, C. D. 1-11, 1-12, 5-22

Cosgrove, John 1-24, 4-91

Cotter, L. J. 1-23

Counce, Pete 4-49

Cox, Jim 2-22, 4-108

Cox, L. W. 4-74

Crabtree, Tom 4-45, 5-13

CRADA 4-91

Crane, Bill 5-9

Craven, Dick 4-112

Creek, G. E. 4-19, 4-20, 4-23

Criticality 1-14, 2-9, 2-12, 2-13

Crito 1-1

Crocan, Calvin 4-4 
Croff, Allen xxiv, 1-25, 4-13, 4-14, 4-15

Crouse, Dave xi, 3-6, 3-9, 3-10, 3-12, 3-13, 3-15, 4-1, 4-3, 5-12, 5-19

Crump, Ben 4-35

Crush process $4-68$

CTD Laugh-in or Misinformation Session of 1969 5-25

Culler, Floyd xi, xiii, xx, 1-10, $1-18,1-22,2-1,2-5,2-9.2-10$, 2-20, 2-21, 2-24, 2-27, 3-2, 3-4, 3-7, 3-8, 3-9, 3-10, 3-11, 3-12, 3-14, 3-15, 4-7, 4-22, 4-31, 4-46, 4-74, 4-93, 4-94, 4-96, 5-2, 5-6, 5-7, 5-10, 5-25

Culler, Mrs. 5-25

Culler's College 2-16

Culpepper, Charlie 4-30, 4-109

Cultural exchange program 2-21

Cumming, Bob 4-91, 4-118

Cummins, R. L. 1-25, 5-32

Curium 2-37, 3-14, 4-34, 4-35, $4-36,4-38,4-40,4-41,4-43$, 4-44, 4-67

CURIUM Recovery Facility (CRF) 3-14, 4-35

Cyclotron 1-6, 2-6

Czechoslovakia 5-11

D

Dahlman, R. C. 4-116

Dailey, J. M. 4-109

Daish, Stephen 4-26

Daley, Fletcher 4-6

Damewood, Sue 5-12

DAPEX process 2-28, 2-37, 3-10, 4-2, 4-66

Darby, D. O. 4-110

Darex Process 2-28, 2-34, 3-12, 4-66

Darmstadter, Joel 4-95

Davidson, Debbie 1-24

Davies, Harrison 1-12

Davis, D. O. 1-10

Davis, F. W. 3-13

Davis, George 4-7, 4-50, 4-51, 4-53, 4-60, 4-110

Davis, Jim 2-5, 5-2

Davis, Larry $x i$

Davis, W. 3-12, 3-13, 4-11, 4-27, 5-10

Davison, Brian 1-24, 4-79, 4-90, 4-91

Dawson, Martha 1-24, 5-28

de Laguna, W. 3-11, 4-51 de Nordwall, H. J. 4-30

Dean, O. C. 3-6, 3-8, 3-11, 3-13, 4-5

DeCicco, Steve 4-99

Decontamination $1-9,2-8,3-3$, 4-47, 4-70

Defense production reactors $4-15$

Dejacketing 4-68

Delozier, Jess 5-9

Delzer, D. B. 4-117

Demonstrations 4-55

Denis, D. J. 3-6, 3-10

DePaoli, David 1-24, 4-101, 4-102, 4-103

DePaoli, Susan 4-104

Department of Defense (DOD) 1-20

Department of Transportation (DOT) 4-18

Desalination 3-1, 4-95

Design Section xx, 1-22, 2-1, 2-2, $2-5,2-20,2-29,5-7$

Desorption 3-10

Detroit, Michigan 4-113

Deuterium ions 4-109

DeVall, B. G. 4-48

Dexter, Bill 5-24

Dickerson, Leonard 1-24, 4-18, 4-75, 4-76, 4-77

Dillon, R. S. 4-52

Dillow, Tom 1-24

Dinsmore, George 4-86, 4-89, 4-100, 4-102, 5-25

Dinsmore, Stan 4-78, 4-79, 4-80

Dinsmore, Tom 4-86, 4-89, 4-100, 5-28

DiSalvo, Ray 4-20

Disposal of radioactive wastes $2-9$, 3-9, 3-11

Dissolution 3-3, 4-68

Dissolvers 3-4, 4-114

Do You Remember 5-25

Doan, R. L. 1-11

Dodson, Brian 1-24

Dodson, Karen 4-25, 4-27

DOE Headquarters 5-32

DOE Model 4-53

Dole, Les 4-50, 4-54, 4-55, 4-57

Donaldson, T. L. 1-25, 4-62, 4-75, 4-76, 4-79, 4-86, 4-89, 4-90, 4-91, 4-102

Doss, F. A. $4-46$

Doucet, Allen 1-25

Douglas, D. A. 3-12

Dow Chemical Co. 4-53, 5-23

Drake, Millicent 5-28

Drinking water 4-78, 4-92

Drop and puncture testing 4-16
Druhm Process 2-28, 2-34, 4-66

Dry Fluoride Process 2-31, 2-35, 4-44

Du Pont Explosives Department 1-11, 2-38

Dubna, U.S.S.R. 5-10, 5-11

Duff, Bob 4-45, 4-46, 5-13

Duggan, H. G. 3-7

Duke University 4-81

Duluth, Minnesota 4-85

Dunn, W. E. 4-46

Dunning, D. E. 4-111

Dyer, Frank 4-28, 4-30

E

Early, Bill 4-108, 4-109

Eastwood, E. E. 3-11

Ebert, K. 5-8

EBR 2-29

Education 1-20, 4-106

Edwards, Mike 4-74

Egan, B. Z. xi, 1-25, 4-78, 4-79, $4-84,4-85,4-86$

Eglin AFB 4-102

E. I. du Pont de Nemours and Company (Du Pont) 1-2, 1-3, $1-9,1-10,1-11,1-14,1-15$, $1-16,1-17,1-22,2-5,2-7$, 2-16, 4-18, 4-69, 4-106, 5-7, $5-9,5-16,5-20,5-22$

Einstein, Albert 1-2

Einsteinium 4-32, 4-40, 4-41, 4-67

Einsteinium Activation Program 4-40

Eister, Warren xi, xiii, 1-13, 2-5, $2-13,2-24,5-2,5-6$

Eklund, Sigvard 3-11

Eldridge, Bill 5-28

Electric Power Research Institute (EPRI) $x x, 2-11,4-22$

Electric utilities 4-1

Electro-Nucleonics, Inc. 4-82

Electromagnetic separations 1-2, $1-9,4-31$

Element 104 (Kurchatovium) 4-41

Element 105 4-41

Element T 2-19

Ellett, Julian 2-6

Ellis, Jewel 5-5

Ellison, Charles 2-8

Emergency Core Cooling System 4-20

Emlet, Logan B. 4-107

Emmett, M. J. 4-54

Emory River 5-29, 5-30, 5-31

Empson, F. M. 3-11 
Emulsion Phase Contactor 4-62

Endelman, Fred 4-75

Energy conservation 1-20

Energy Division 4-93

Energy Research and Development Administration (ERDA) $x i$, xiii, 4-21

Energy resources 4-96

Engineering and Mechanical Division 4-46

Engineering Coordination and Analysis Section 4-12, 4-74

Engineering Development Section $1-9,4-100,4-105$

Engineering Division 4-100, 4-112

Engineering Research Division 5-13

Engineering Technology Division 4-19, 4-27

Engineering Test Reactor fuel assemblies 4-52

England 2-16

English, J. L. 3-11

English, Spofford 1-12

Enriched Breeder Reactor 2-1

Environmental and Health Protection 4-41

Environmental control technology studies $4-75$, 4-98

Environmental impact statements 2-17, 4-55

Environmental Sciences Division 2-17, 4-11, 4-86, 4-91

Enzymatic Hydrolysis 490

Enzyme-catalyzed reactions 4-79

Equipment rack concept 4-35

Equipment Tests 2-32

Erbium 4-108

Ergen, Bill 5-12

Emst, W. S. 3-13

Ethanol Production 4-90

Eubanks, Perry 4-79, 4-86, 4-87

Eurochemic Plant 2-16, 2-34, 3-1, 4-68

European Common Market 2-15

Evans, B. S. 1-25, 4-91

Evans, Bob 4-30

Evans, C. W. 1-23, 4-36

Evans, John 4-112, 4-113

Evaporation 2-1, 4-49

Evaporator explosion 2-9

Eversole, R. E. 1-25

Excer Process 2-28, 2-34, 3-9, 4-66

Experimental Breeder Reactor fuel 2-13, 2-24
Experimental Engineering Section 4-74, 4-105

Experimental Gas-Cooled Reactor (EGCR) 2-28, 4-66, 4-111

Extraction 3-1, 5-18, 5-19

Exxon Corporation 2-4, 2-5, 4-69

$\mathbf{F}$

Fairchild, L. 4-30

Faison, Brenda 1-24, 4-79, 4-90

Fardy, John 4-4

Farmer, Jim 2-19, 4-48, 5-12

Farr, L. L. 1-25, 4-91

Farrell, J. B. 3-13

Fast Flux Test Facility 4-14

Fast reactors 2-3, 2-5

Feder, Hal 5-2

Feed materials 2-28, 4-66

Feldman, Mel 4-112

Felker, Kevin 4-25

Felkner, L. K. 1-23

Fellows, Bob 4-30, 4-64

Ferguson, Don xxi, 2-7, 2-24, 2-26, 2-27, 3-2, 3-3, 3-5, 3-11, 3-12, 3-13, 3-14, 3-15, 4-5, 4-31, 4-33, 4-44, 4-45, 4-59, 4-74, 4-75, 4-97, 4-98, 5-7, 5-14, 5-24

Fermi, Enrico 1-2, 1-12, 1-14, 5-16

Fermi Pile (reactor) 2-7, 2-31

Fermium 4-40, 4-41

Fernald Feed Materials Production Center 1-22, 2-37

Fernald, Ohio 2-37, 4-86

Ferrada, Juan 1-24, 4-18

Ferris, L. M. 3-10, 3-11, 3-12, 3-13, 4-49

Feuerstein, Horst 4-19

Fields, L. J. 1-25

Filtration 4-75

Finland 2-20

Finney, B. C. 3-12, 4-6, 4-11, 4-16, 4-116, 5-27

First International Conference on the Peaceful Uses of Atomic Energy xxi, 2-8

Fiser, John 1-16

Fisher, Ray 2-8

Fissile fuel materials $2-3$

Fission 1-14

Fission-product release team 4-21

Fission products $1-3,1-9,1-16$, $1-21,1-22,2-4,2-19,2-23$, 2-29, 2-36, 2-37, 3-2, 3-4, 3-5, 3-15, 4-19, 4-20, 4-21, 4-24, $4-27$
Fitzgerald, Curt 4-50, 4-53

Fitzgerald, Donna 5-28

Flanary, Chris 1-25, 5-5

Flanary, J. R. 3-2, 3-4, 3-6, 3-7, 3-8, 3-11, 3-12, 3-13

Flint, Michigan xxiv

Flood-drain water 4-49

Fluidized bed 4-61, 4-75, 4-86

Fluidized-bed biodentrification plant 4-102

Fluoride volatility $2-26,2-28$, 2-31, 2-35, 4-44, 4-45, 4-46, 4-66, 5-21

Fluoride Volatility Process Plant, Building 3019 2-35, 4-5, 4-44, 4-46, 4-111

Fluorine 2-26, 4-44

Fluorox Process 2-28, 2-34, 4-66

Food and Drug Administration 4-43

Ford, George 4-112, 5-5

Ford, President Gerald 4-97

Formed Under Elevated Temperature and Pressure (FUETAP) 4-50

Forrester, Richard 4-74

Forsberg, Charles 1-24, 4-14, 4-16

Fort Peck, Montana 2-23

Fort S. Vrain 2-27, 2-33

Forty-nine 1-10,1-1i

Fossil fuels 3-1

Foster, Cathleen 5-24

Foster, D. L. 1-25, 3-2, 3-3, 3-7, 3-11

Foster Wheeler Company 2-23, 2-29, 4-35

Fourth International Conference on the Peaceful Uses of Atomic Energy $x x i, 3-14$

Fowler, Vic 2-27, 4-6, 4-7, 4-8, $4-45,4-46,4-48,4-49,4-100$, 4-101, 5-25, 5-27, 5-29

Fox, C. L. 4-46, 4-111, 4-116

Fractional distillation 2-35

Frame, Jack 2-6

France 2-5, 2-15, 2-16, 2-20, 4-56, $4-68,4-69,5-11$

Francis, C. L. 1-25, 4-86

Frankford Arsenal 4-10

Frankfurt, Germany 4-43

Franklin, Jack 1-18

Frederick, Ed 1-12, 2-24, 3-7, 4-11, 4-51, 4-52, 5-2

Freeman, Maurice 4-78, 4-80

Fry, John 2-10

Ft. Lewis, Washington 4-75, 4-85

Fuel cycle cost $3-6,3-15,4-14$ 
Fuel preparation 1-13, 1-19, 2-28, 2-32, 4-5, 4-66

Fuel Recycle Division 2-17, 4-111, 4-113, 5-24

Fuel reprocessing 1-20, 2-10, 2-20, 2-21, 2-26, 2-27, 2-28, 2-32, $2-33$

FUETAP program 4-50, 4-105

Fulkerson, W. 5-32

Fuqua, S. M. 1-25

Fused Salt-Fluoride Volatility Pilot 3-10

Fusion energy 1-20

Fuzek, John F. 4-107

G

Gaintanis, M. J. 4-46

Gaitan, Eduardo 4-92, 4-93, 4-118

Galloway, G. F. 1-23

Garber, Bea 4-4

Gardner, Kathy 4-94

Garland, Sid 4-56

Gas Research Institute (GRI) 4-86

Gas-cooled reactors $2-3,2-15$

Gaseous diffusion 1-2, 1-9, 2-8, 2-34

Gaseous waste disposal 2-1

Gate, Elza 5-17

Gatlinburg, Tennessee 2-16, 4-107

Gatwick, England 4-43

Gehrs, Carl 4-91

GeMSAEC 4-82

General Atomic 2-27

General Electric Company 2-4, 4-66, 4-69

General Motors 4-113

Geneva conference 2-8, 3-1, 2-15, 2-16, 2-20, 2-23, 2-26, 3-1, 3-5, 3-8, 3-11, 3-14, 3-15, 4-2

Geneva papers 3-1

Gens, T. A. 3-11, 3-12, 3-13

Genung, Richard xxiii, 1-24, 4-53, 4-54, 4-75, 4-79, 4-82, 4-83, $4-89,4-99,4-108$

Geological disposal 2-26, 3-11, 4-50, 4-105

Georgia 1-16

Gerberich, C. L. 2-36

Germany 1-2, 2-15, 2-16, 2-27, 4-19, 4-30, 4-50, 4-90, 5-11

Gerrard, Martha 4-97

Gheen, Carolyn 4-4

Gibson, J. R. 1-25, 4-46, 4-109

Gibson, Randy 1-24, 4-30, 4-75

Gibson, Sherry 4-89

Gillespie, Dan 4-103
Gillette, John 1-14, 4-107

Gilliam, T. M. 1-25, 4-50, 4-56, 4-102, 5-28

Gissel, W.Y. 2-39

Glass Formation 2-22, 4-50

Glass, Ron 2-27, 4-58, 5-28

Glendenin, L. E. 2-37

Glenn T. Seaborg Award xxi

Glove box 4-34, 4-39, 4-60

Glover, J. C. 1-23

Godbee, Herschel xi, 4-11, 4-16, 4-22, 4-49, 4-50, 4-51, 4-53, 4-57, 4-117, 5-11

Goeller, Hal xi, 2-13, 2-23, 2-24, 2-27, 2-32, 2-36, 3-4, 3-7, 4-93, 4-94, 4-95, 4-96, 4-97, $5-2,5-3,5-19,5-24,5-26$

Goitrogenic compounds 4-92, 4-93

Goldberg, Steve 5-25

Goldman, A. E. 3-10, 4-46

Goldsmith, S. 5-13

Goode, J. H. 3-11, 3-12, 3-13, 4-24

Googin, John 2-12, 5-23

Gorchev, H. 4-118

Gove, Ruth 4-18

Graham, Brooks 4-44

Grand Junction, Colorado 5-23

Granitic rocks 4-2

Grant, Norbert 4-112

Graphite 2-30, 2-35

Graphite fuel elements 2-27, 3-12, 3-13, 4-68

Graphite reactor 1-3, 1-4, 1-6, 1-7, $1-9,1-14,1-16,1-17,2-1,2-6$, 2-13, 4-1, 4-110, 5-3, 5-18

Graves, Duane 4-86

Greager, O. H. 1-12

Great Britain 2-15, 4-68

Green, A. B. $4-44$

Green, D. F. 4-60

Green, Vicki 1-24, 4-18

Greenbaum, Elias xi, 1-24, 4-78, 4-79, 4-86, 4-87

Greene, Charles 4-6, 5-9

Greenewalt, C. H. 1-11, 2-7

Gregory, Al 4-112

Gresky, Al 2-14, 3-1, 3-2, 3-4, 3-5, 3-7, 3-8, 3-11, 3-12, 5-7, 5-24

Greter, W. J. 4-46, 4-47

Grieneisen, Andre 5-19

Griffin, Guy 4-85

Griffith, Bill 4-89

Grimes, Warren 2-14, 4-48

Grind-leach 3-13

Grisham, Bill 4-109

Gronier, Bill 4-112

Gross, I. G. 1-25
Groundwater 4-102

Grout Technologies 4-105

Grover, John 2-16

Groves, Leslie R. 1-2, 1-13, 5-17

Grubb, R. G. 1-25

Gulf Oil Corporation 2-4

Gung-ho attitudes 2-1, 2-10

Guthrie, Chuck 2-14, 3-7, 3-12, 4-46, 5-24, 5-26

Guthrie, Miriam 4-97

Guymon, R. H. 3-10

H

H-Coal process $4-74,4-75,4-84$, 4-85, 4-99

Haas, Paul xi, 1-24, 2-27, 3-11, 3-12, 3-13, 4-5, 4-6, 4-7, 4-58, 5-2

Haire, R. G. 3-13, 3-14, 46, 4-38, 4-39

Hall, R. 1-25, 4-58, 4-104

Halperin, Joe 1-14, 2-37, 4-112

Hamel, W. R. 4-113

Hamilton, D. H. 4-118

Hamley, Becky 5-28

Hammerling, Frank 4-97

Hammond, Phil 4-93

Hampson, Don 4-112

Hanaford, Bruce 4-45

Hancher, Chuck 4-50, 4-78, 4-79, $4-86,4-89,4-99,4-117,5-23$

Hanford xiii, 1-3, 1-10, 1-12, 1-18, $1-19,1-13,1-22,2-4,2-5$, 2-15, 2-20, 2-23, 2-24, 2-29, 4-50, 4-52, 4-109, 5-1, 5-22

Hanford plant 1-6, 1-10, 1-16, 2-14, 4-19, 4-42, 4-105

Hanford slag and crucible waste 2-30

Hanford slugs $1-13,5-3$

Hanford tank-farm wastes $2-30$

Hannaford, B. A. 3-12, 4-48, 4-49

Hannon, F. L. 3-14

Hanon, F. L. 3-12

Hardwick, W. H. 2-22

Hardy, C. J. 3-13, 3-14, 5-18

Harkey, Amy 4-98

Harmon, H. E. 4-109

Harrington, Frank xi, xiii, 2-4, $2-24,4-22,4-52,5-2,5-3$

Harris, John 5-14

Harris, Mike 1-24, 4-89, 4-99

Harris, Warren 4-82

Harrison, Glen 4-18

Harshaw Chemical Company 1-2

Hartley, Sir Harold 3-2 
Hartsell, Mike 5-28

Harvard University 1-2

Harvey, Howard 4-112

Harwell, United Kingdom 2-9, 5-8

Hastelloy C 4-36

Hatch, L. P. 2-21

Hatcher, Don 4-82

Havorka, George 2-6

Hawkins, Bill 2-12

Haws, Claude 2-27, 3-13, 3-14, 4-5, 4-6, 5-2

Haydon, Paul 5-24, 5-26

Hazardous Waste Development, Disposal, and Demonstration (HAZWDDD) Program 4-54

Hazardous wastes 1-21

HAZWRAP 4-57, 4-91

Head-end reprocessing 2-28, 3-10, 3-13, 4-24, 4-66

Health and Safety Research Division 4-85

Health and toxicology 1-12,4-92

Health Division 1-12, 4-83

Health Physics Division 2-14, 2-21, 4-11, 4-47, 4-50, 4-51, 4-52, 4-105, 5-30

Heatherly, Dale 4-79

Heavy Element Production Program 2-33

Heavy-water 1-2

Heavy-water reactors 2-3

Helton, Dennis 2-19, 2-20, 3-13

Hemphill, L. 3-11

Hendrix, Dave 5-9

Henley, L. C. 4-112

Henry, J. B. 4-46

Henry, W. T. 4-46

Hensley, A. W. 1-25

Hensley, L. C. 4-113

HEPEX 4-35

Herald, G. R. 1-25

Hermann, Bill 4-13

Hernandez, Lourdes 1-24, 4-88

Herndon, Joe 4-112, 4-113

Hess, Rachelle 1-24

Hewitt, J. D. 1-25, 4-75, 4-89, 4-99, 4-100, 4-101, 4-104

Hewlett, R. G. 4-69, 4-74

Hexone 2-8, 2-29

Hexone Process, see process 23 and 25

Heyse, Ed 4-103

Hickman, Elaine 4-98

Higgins, Irwin xi, 2-6, 2-19, 2-31, $2-37,3-3,3-5,3-8,3-9,3-11$, $5-20$

High Aswan Dam 4-95
High-burnup (HBU) tests 4-21

High-flux reactors 1-6, 1-18

High-Flux Isotope Reactor (HFIR) 2-27, 2-33, 4-32, 4-33, 4-34, 4-35, 4-36, 4-38, 4-41

High-level radioactive wastes $1-21$, 2-21, 2-26, 4-15, 4-49, 4-50

High-Level Hot Cell Facility 3-14

High-pressure liquid chromatography 4-78

High-Temperature Gas-Cooled Reactor (HTGR) 2-27, 2-28, 2-32, 2-33, 2-35, 4-12, 4-24, 4-30, 4-66, 4-68, 4-111

High-temperature (HT) tests 4-21

Higher education 4-106

Hightower, Bob xi, 1-25, 2-26, 4-24, 4-26, 4-44, 4-45, 4-46, 4-48, 4-49, 4-64, 4-74, 4-75, 5-28

Hikido, T. 3-12

Hilberry, Norman 1-14

Hill Air Force Base 4-102, 4-103

Hill, G. S. 4-116

Hill, L. G. 1-25, 4-45

Hill, M. C. 4-46, 4-47

Hill, Ronald H. 4-84

Hinchey, G. P. 4-46

Hinkel, Vicki 4-98

Historically Black Colleges and Universities (HBCUs) waste program 4-54

Hodge, Steve 4-27

Hoeschele, Jim 4-38

Hoinkis, Ernst 4-19, 4-30

Holcomb, Roland 4-51, 4-117

Holladay, Dave 1-25, 4-79, 4-86

Hollaender, Alex 2-16

Holland 2-16

Holland, Mike 4-84, 4-85

Hollenbeck, P. E. 4-54, 4-55, 4-57

Holmes, John 4-51, 4-52, 4-74, $4-93,4-94,4-117,5-25$

Homogeneous reactor xiii, 1-6, $1-9,1-18,2-1,2-28,2-32$, 2-34, 3-2, 3-5, 3-11, 4-66, $4-67,5-23$

Homogeneous Reactor Experiment $1-9,2-28,4-66$

Honors 1-26

Hope Project 2-32, 5-3

Horner, D. E. 3-12, 3-13

Horton, R. W. 3-10, 3-12, 3-13, 4-45, 4-46

Hot cells 1-6, 1-21, 2-6, 2-9, 2-35, 4-31, 4-45, 4-69

Howerton, Bill 4-3
Hubbard, C. P. 2-36

Hubbard, Les 5-28

Hudson, B. 4-16

Hume, Dave 1-13

Humphrey, G. D. 4-54

Hungerford, Tom 2-9

Hunt, L. K. 4-54

Hunt, Rodney 1-24

Hurst, Fred xi, 3-13, 4-1, 4-3, 4-4

Hutchens, Richard 4-84

Hydrocarbonization process 4-74, 4-75, 4-76

Hydrofracture 2-22, 4-51, 4-105

Hydrogen Isotopes Separation 4-89

Hydrometallurgical processing 3-13

Hylton, T. D. 1-25, 4-102, 4-110, 5-32

Hypervelocity jet sampler 4-9

l

I\&C Division 4-28, 4-82, 4-84, 5-30

Idaho $1-9,2-13,2-14,2-15,2-32$, 4-68

Idaho Chemical Processing Plant xiii, 1-10, 2-1, 2-8, 2-13, 2-21, $2-23,2-24,2-25,2-29,5-2$

Idaho Falls, Idaho xix, 1-18, 1-22, 2-4, 2-20, 4-19, 4-113

Idaho Gang 4-112

Idaho Materials Testing Reactor 2-31

Idaho National Engineering Laboratory 2-25

Illite clay 4-51

Impact (Target) Pads 4-18

Impoundment residues 4-57

In situ stabilization 4-105

Incineration 4-56

India $2-5,2-16,2-20,4-68,4-94$, 5-11

Indiana Ordnance Works 2-6, 5-16

Information Division 4-97, 4-98

Information meetings 2-14

Inspection Engineering Department 4-47

Institute of Nuclear Energy Research, Taiwan 5-12

Instrumentation and Controls Division 4-41, 4-46, 4-47, 4-78, 4-80

Instrumentation Laboratories 4-82 Integrated Data Base Program 4-14, 4-15

Intermediate-level radioactive waste (ILW) 4-49, 4-51, 5-13 
International Atomic Energy Agency (IAEA) 2-16, 3-11, 3-14, 5-10

International Conference for the Peaceful Uses of Atomic Energy 3-1

International Nuclear Target Development Society (INTDS) 4-107

Iodine 2-26, 2-38, 4-68

lon-exchange $1-10,1-19,2-1$, 2-37, 3-6, 3-7, 4-2, 4-6, 4-34, 4-67, 4-72, 4-101, 5-4, 5-9, 5-10, 5-22, 5-23

Iowa State University 1-14, 2-8

IR-100 Award xxiii, 4-2, 4-61, 4-81, 4-82, 4-109

Irradiated uranium slugs 5-1

Irvine, Al 2-27, 3-11, 3-12, 4-16, 4-111, 5-12

Isotope Research Materials Laboratory 4-31, 4-107

Isotopes xiii, 1-2, 1-19, 1-20, 2-8, 2-9, 4-31, 4-69, 4-108, 5-18

Isotopes Division 2-1, 2-37, 4-20, 4-31, 4-107

Isotopes Section 4-105

Israel 4-94

Italy $2-20$

J

J. A. Jones Construction Company I-15

Jackson, H. Kirk 2-24, 3-4, 3-8, 4-46, 4-74, 4-110, 5-2

Jacobs, Vivian 4-98

Jacobus, R. A. 4-57, 4-58, 4-118

Jansen, Jim 4-82

Japan 1-2, 2-5, 2-20, 4-20, 4-27, $4-68,4-69,5-11$

Jarvis, J. P. 4-48, 4-111

Jealous, A. C. $3-4,5-7$

Jeffers, R. L. 4-56

Jennings, H. L. 1-25, 4-86, 4-89, 4-91, 4-100, 4-102, 4-103, 4-104

Jerigan, Tom 4-111

Jernigan, Jackie 1-25

Johns, E. R. 4-113, 5-24

Johns Hopkins University $x x, 2-16$, 4-81

Johnson City, Tennessee 5-16

Johnson, Don 2-6

Johnson, Ed 2-6

Johnson, G. L. 1-23

Johnson, Kaye xi, 1-25, 5-24
Johnson, M. 1-25

Johnson, N. D. 1-25

Johnson, Paul 4-16, 4-17, 4-18

Johnson Space Center 4-82

Johnson, Warren C. 1-12

Johnson, Wayne 4-80, 4-82, 4-83, 4-84

Johnsson, K. O. 3-10

Johnston, C. P. 4-44

Johnston, Melba 1-12

Jolley, Bob 1-24, 3-10, 3-12, 4-7, 4-44, 4-45, 4-53, 4-54, 4-55, 4-56, 4-57, 4-75, 4-77, 4-78, 4-80, 4-81, 4-91, 4-92, 4-93, 4-118, 5-29, 5-31

Jolley, Richard 5-29, 5-31

Jones, C. H. 4-47

Jones, Guy 4-80, 4-84, 4-85

Jones, Haydn 1-12

Jones, John E. 4-19

Jones, Merv 2-12

Joule-Thompson Effect 5-14

Joy, Dave 4-16, 4-17, 4-74

Jubin, R. T. 4-112

Jury, S. H. 3-8

Justice, Vaughn 4-100

K

K-25 1-9, 1-15, 4-57

Kackler, Charles 4-100

Kansas State University 5-4

Kao, John 4-85

Kappelmann, F. A. 3-12, 3-13, 3-14, 4-36, 5-6

Kapps, Kathy 4-88

Karkov 2-21

Karlsruhe, Germany 4-19, 4-20

Karns, Tennessee 1-16

Karraker, Dave 5-7

Kasten, Jennifer 4-56

Kasten, Paul 2-27, 5-12

Katz, Sidney 4-45, 4-77, 4-78, 4-80, 4-81, 4-91

Kearsley, Bill 2-14, 2-24, 5-2

Keck, Claude 1-14

Kee, Charles W. 4-13, 4-14, 4-15, 4-48

Keely, R. B. 3-10, 4-46

Keirnan, Clarence 5-22

Keller, Lou 4-33

Kelley, Minton 4-28

Kellogg 2-14

Kelly, J. L. 3-13

Kelmers, A. D. 3-6, 4-49, 4-78, 4-79

Kemeny Commission 4-22
Kennerly, J. M. 4-54, 4-55, 4-56, 4-57

Kent, Tim 4-104

Kentucky 4-93

Kibbe, R. K. 1-25

Kibbey, Arlene xi, 2-19, 2-20, 3-3, $3-11,3-12,3-13,4-11,4-16$, 5-11

Kidd, Joe 4-112

Kilorod project 3-13, 4-5

Kilpatrick, F. G. 4-45

Kimmett, Stan 1-25

Kimmitt, Rod 4-56

King, D. C. 1-14

King, Jerry $x i, 1-25$

King, L. J. 3-14, 4-22, 4-36, 4-40, 4-43, 4-44, 4-47, 5-25

King, Veneeta 1-24

King-Jones, Kathryn 1-25, 4-98

Kingston Demolition Range 1-13

Kingston, Tennessee 1-13

Kington, Dan 4-113

Kinser, H. B. 3-12, 3-14

Kirkland, O. L. 4-21, 4-27

Kirkpatrick Chemical Engineering Honor Award 4-2

Kirslis, Stan 4-45, 5-13

Kitts, F. G. 1-25, 3-7, 3-11, 3-12, $4-6,4-11,4-46,4-47,4-116$, 5-25, 5-27, 5-30

Klasson, L. T. 5-32

Klein, Jerry 1-24, 4-14, 4-16, 4-49, 4-75

Kleinsteuber, A. T. 3-13, 4-5

Klima, B. B. 3-6, 3-10, 4-16

Klotts 2-14

Klotzbach, Bob 1-13, 2-8, 2-14, $2-24,2-32,5-2,5-3,5-7,5-24$

Knauer, J. B. 1-23, 4-22, 4-38, 4-44

Knauer, Linda 5-28

Knolls Atomic Power Laboratory (KAPL) 2-4, 2-8, 2-20

Knoxville, Tennessee xxiv, 2-6, 4-89, 4-100, 5-5, 5-24

Kobisk, Edward 4-107, 4-108, 4-109

Kosiancic, E. J. 3-13

Kosinski, Ed 1-25

Kovac, Francis 1-24, 4-18

Kraus, Kurt 5-22

Krichinsky, A. M. 1-25

Krypton 2-27, 2-35, 4-22, 4-68

Kuehn, Paul 4-109

Kugan, Mike 4-112

Kuna, Ed 4-45

Kwajalein Atoll 4-91, 4-104 


\section{$\mathbf{L}$}

Laboratory Council 1-11

Laboratory for Aerosol Physics and Filtration Technology 4-19

Laboratory Section 1-10, 2-1, 5-2

Lacey, W. J. 3-11

Lackey, Jack 4-7

Ladd, Carolyn xix, xxi, xxii

Laing, W. R. 4-46

Lamb, Gene 4-31, 4-46, 4-47, 4-107, 4-109

Land, Fred 2-19, 2-20, 2-26, 4-49

Landry, J. W. 3-2, 3-3, 3-7, 4-7, 4-8, 4-9, 4-10, 4-116, 5-24, 5-26, 5-29, 5-30

Landisberg, Hans 4-95

Lane, Jim 1-10, 2-13, 4-93

Lanham, Bill 2-8, 3-4

Lanthanum 1-3, 1-13, 2-1, 2-9, 2-19, 2-29, 2-30, 2-31, 4-67, 5-9

Lanthanum fluoride $1-3,1-6$

Lantz, P. M. 3-8

Lapinski, w. 5-13

Laramie, Wyoming 4-74

Larson, Clarence 2-9, 5-23

Laundry wastes 4-102

Lawrence Berkeley Laboratory (LBL) 4-41

Lawrence, E. O. 1-2, 5-16

Lawrence, Jack 4-49

Lawrence Livermore National Laboratory (LNL) 4-40, 4-43, 4-102

Lawrencium 4-41

Lawroski, Steve 2-7

Laxon, Bob 5-5

Laxson, R. R. 1-23

Lay, S. L. 1-23

Leach process 4-68

Leach test ANS 16.1 4-53

Leaching Tests 3-6, 4-53

Lee, Chung-Shin 1-24

Lee, Doug 1-24, 4-75, 4-77, 4-86, $4-89,4-90$

Lee, Norman 1-25, 4-78, 4-80, $4-82,4-83,4-84,4-85,4-86$, 4-88, 4-92

Lee, Virginia 4-94

Leinart, C. W. 1-25

Leningrad 2-21

Leuze, Rex xi, xiii, 1-13, 2-27, 3-8, 3-10, 3-11, 3-12, 3-13, 3-14, 4-4, 4-6, 4-34, 4-44, 4-59, 5-4, $5-5,5-14,5-28$

Levenson, Milton 1-17, 5-2
Leverett, Miles xi, xiii, 1-9, 1-10, $1-11,1-12,1-18,2-5,2-13$, 2-38, 5-1

Levy, Henry 1-12

Lewin, Joe 2-21, 2-22, 2-23

Lewis, A. 5-13

Lewis, Ben E. 4-112

Lewis, Susan 4-90

Lewis, W. H. 3-8, 3-11, 4-46, 4-110

Lichtenberger, Harold 2-13, 2-14

Lieberman, Joe 2-21, 4-46, 5-10

Lietzke, Milt 5-29

Light, Brenda 1-24, 5-5, 5-24

Light-water reactors (see LWR) $2-3,2-5,2-15,4-6,4-14$

Lignites $4-2$

Lin, K. H. 1-25, 4-75

Lindauer, Dick 2-20, 2-38, 3-9, 3-10, 4-46, 4-47, 4-48, 4-49, 5-24, 5-26

Lindemer, Terry 1-24, 4-23, 4-30

Linden, New Jersey 5-22

Lindsey, Bill 4-36, 5-30

Liquefaction 4-75

Liquid metal fast breeder reactors 2-3, 2-33, 2-35, 3-14, 3-15, 4-14, 4-68, 4-111

Liquid waste disposal 2-1

Liquid-liquid extraction 2-35

Lithium isotope separation $2-19$, 2-24

Lithium-6 2-20

Litman, A. P. $4-46$

Littleton, Frances xi

Littleton, M. E. 1-23

Livingston, Bob 4-31

Lloyd, Milt 2-27, 3-12, 3-13, 3-14, 4-6, 4-44, 5-6

Lockmiller, J. F. 4-110, 4-113, 5-24

Lockwood, Chris 1-24

LOFT (Loss of Flow Test) program 4-19

Loftis, T. C. 1-25

Loghry, S. L. 1-25

Lomenick, Tom xi, 4-49, 4-52, 4-53, 4-54, 4-57

Londono, David 1-24

Long, J. T. 3-10, 4-46, 4-74

Long-Range Planning Committee 2-10, 2-14, 5-7

Lopez, Diego 1-24

Lorenz, Dick xi, 4-18, 4-19, 4-20, 4-21, 4-22, 4-23, 4-24, 4-26, 4-27, 4-28, 4-30

Los Alamos 1-6, 1-17, 2-29, 2-30, $2-37,4-23,4-31,4-42,5-9$
Los Alamos National Laboratory (LANL) 4-40, 4-41, 4-43, 5-4

Los Angeles 4-43

Lotts, Pete 2-27, 3-12, 3-13, 3-14, 3-15

Loudon, Tennessee 4-90

Louisville and Nashville (L\&N) Railroad 1-15

Louisville, Kentucky 4-18, 4-102

Love, Pat 4-97

Loveday, Linda 5-28

Lovelace, R. C. 1-25, 4-82, 4-105

Low-burnup (LBU) tests 4-21

Low-enriched uranium fuels 2-3

Low-Intensity Test Reactor (LITR) $1-9$

Low-level radioactive wastes (LLW) 2-21, 2-22, 4-15, 4-16, 4-49, 4-51, 4-104, 5-11, 5-13

Low-Level Waste Disposal, Development, and Demonstration (LLWDDD) Program 4-54

Lowrie, Bob 2-27, 3-6, 3-10, 4-45, 4-46, 4-47

Lucero, Andrew 1-25, 4-91, 4-102, 4-104

Ludwig, Scott xi, 1-24, 4-12, 4-14

LWR aerosol studies 4-28

LWR reactor 4-16, 4-12, 4-15, 4-24

LWR safety information 4-19, 4-20, 4-23, 4-24

Lyle, Arnold 5-29, 5-30

Lynch, J. M. 1-25

Lynchburg, Virginia 4-22

Lyons, Kansas 2-26, 3-16, 4-52, 4-53

Lyttle, Sandi xi

\section{M}

M. Hartman 5-28

MacInnis, Jean 1-24, 4-86

MacIntosh, Alex 2-23

Macromolecular Separations 4-79

Magnesium jackets 3-7

Maguire, Jack 1-25

Mahlman, Harvey 1-14

Maienschein, Fred 4-31

Mailen, Jim 1-24, 4-30, 4-45, 4-48, $4-49,4-74,4-82,4-84$

Malinauskas, A. P. 4-20, 4-21, 4-22, 4-23, 4-27, 4-56

Mallinckrodt Chemical Works 2-37

Malone, Virginia 5-24

MAN Program 4-78 
Manhattan District 1-2, 1-3, 1-9, $1-11,1-13,1-15$

Manhattan Project ix, xi, xiii, $x x$, 1-1, 1-3, 1-9, 1-10, 2-7, 2-39, 4-18, 4-64, 4-69, 5-7, 5-10, 5-20, 5-22

Mann, S. 3-10, 4-46, 4-47, 4-48

Manning, S. R. 4-21

Manowitz, Bernard 1-17

Mansfield, R. G. 3-3, 3-12

Manthey, R. D. 4-59

Marable, Jim 4-14

Marcoule, France 2-21

Margolis, Pearl 1-12

Marinsky, J. A. 3-9

Mark-42 Processing Program 4-40, 4-41, 4-43

Marquette University High School 4-88

Marshall, George C. 1-2

Marshall, John 4-16

Martin Marietta Energy Systems, Inc. xiii, 4-18, 4-53, 5-28

Martin, W. J. 3-8, 4-19, 4-20, 4-23

Martina Marietta and the Seven Benefits 5-28

Mason, Ed 4-93, 4-94

Mass transfer 4-59

Massachusetts Institute of Technology (MIT) 4-93

Massey, Byron J. 4-107

Materials Chemistry Division 4-1

Materials Testing Reactor (MTR) $1-9,1-18,1-22,2-1,2-13$, 2-23, 2-24, 2-29, 2-32, 2-37, 3-5, 3-14, 4-19, 4-71

Matherne, J. L. 3-13, 3-14, 4-36, 4-110

Mathis, Beverly xi

Maxwell, Alice 4-94

McBride, John P. 1-12, 1-13, 1-14, 2-26, 2-27, 3-13, 4-6, 4-11, 4-116, 4-117

McCarter, R. 3-14

McChord Air Force Base 4-91

McClain, W. C. 3-16, 4-45, 4-52, 4-53, 4-105

McClellan Air Force Base 4-42

McClure, Lloyd 2-25

McConnell, T. T. 1-23

McCorkle, Ken 2-27, 3-12, 4-5, 4-53

McCullough, Fred 1-13, 2-38

McDaniel, E. W. 1-24, 1-25, 4-50, 4-105, 4-117

McDaniel, Sue 1-24

McDougald, Beth 4-56
McDowell, W. J. 3-10

McDuffee, W. T. 3-5, 3-7, 3-8, 3-11, 3-12, 3-14, 4-36, 4-47

McGinnis, Phil xi, 1-24, 4-54, 4-55, 4-57, 4-58, 4-59, 4-91, 4-118, 5-28

McGuire, S. C. 4-43

McLeod, H. M. 3-6

McLoud, W. A. 4-47

McNabb, Gail 1-24

McNair, Steven 4-88

McNamee, R. J. 4-45

McNeely, J. W. 1-23

McNees, Bob 2-26, 3-5, 3-11

McNeese, L. E. xxv, 2-17, 2-26, 3-9, 4-31, 4-45, 4-48, 4-74, 4-75, 5-32

McNeilly, David 4-84

McNutt, Z. R. 4-46

McTaggart, Don 4-99, 4-100, 4-101

McVey, W. H. 3-15

McWherter, J. R. 3-14, 4-75, 4-86, 4-89

McWilliams, Alice 1-25, 5-25, 5-27

Meacham, Sam 4-113

Mead, Vernon 4-110

Medicine 3-1

Medley, Larry 4-18

Melendez, Omaria 1-24

Melton Hill Lake 4-113, 4-116, 5-32

Melton Valley Storage Tanks 4-101

Melville, Robert 4-81

Memphis State College xxii

Mendall, John 4-53

Mercury Processing 3-6, 3-8

Meriweather, J. R. 3-12

Merriman, Bob 2-27

Meservey, A. B. 3-12, 4-6

Messing, A. F. 3-11

Metal Recovery Plant xiii, 1-10, 2-1, 2-28, 2-30, 2-34, 2-37, 3-8, 3-11, 4-66, 4-67, 4-110

Metal waste tanks $2-30$

Metallex Process 2-28, 2-34, 4-66

Metallurgical Laboratory 1-2,1-3, $1-9,1-10,1-11,1-12,1-14$, $1-16,1-17,2-31,2-38,5-16$

Metallurgy 2-12, 2-16

Metals and Ceramics Division $2-10,2-13,2-17,4-5,4-7$, 4-11, 4-31, 4-36, 4-77, 5-30

Methyl isobutyl ketone 2-4, 3-4

Metz, Curtis 4-113

Miami 4-43

Michel, John 4-93, 4-94

Michigan State University xxiv
Midwest Fuel Recovery Plant (MFRP) 2-4, 4-66

Miles, F. W. 3-10, 3-13, 4-46, 4-47

Milford, Bob 2-8, 2-14, 3-9, 3-10, 3-13, 4-46, 4-47, 4-117, 5-24, 5-26

Miller, C. H. 4-47

Million, Dan 4-89

Milton, H. T. 4-31

Milwaukee, Wisconsin 4-88

Mining and milling 2-3

Minority Educational Institutes 4-57

Mississippi 1-16

Mitchell, A. D. 4-27

Mixed wastes 1-21

Mixer-settlers 2-8

Mobile Wastewater Treatment $4-99$

Mol, Belgium 2-16, 2-34, 3-1

Molten salt 4-45

Molten Salt Reactor (MSR) fuel 2-11, 2-33, 2-35, 4-67

Molten Salt Reactor Experiment (MSRE) 2-38, 4-13, 4-48, 4-66, 4-67, 4-111

Molten Salt Reactor Program 2-26, 4-48

Molten-salt breeder reactor 2-33

Molten-salt fluoride volatility 4-44

Molybdenum 3-7, 4-47

Monazite sands 4-2

Moncrief, E. C. 3-12, 4-45, 4-46, 5-13

Monet, Gil 5-22

Monex process 2-28, 2-37, 4-66

Monitored Retrievable Storage facility 4-15

Monsanto Chemical Company xiii, $1-6,1-18,2-38,4-106,5-2$, $5-4,5-22$

Monsanto, Illinois 5-4

Moore, Fletcher 3-13

Moore, J. G. 3-6, 3-9, 3-10, 3-12, 3-13, 3-15, 4-50, 4-51, 4-105, 5-11

Moore, R. E. 4-116, 4-117

Moore, Scott 4-16

Morgan, I. L. 1-25

Morgan, Marv 4-50

Morgantown, West Virginia 4-74

Morris, Illinois 2-4, 4-66

Morris, Mike 1-24, 4-55, 4-56, 4-57, 4-101

Morris, Ruth 5-5

Morrison, B. H. 3-8

Morrison, Wayne 4-14, 4-16

Morrissey, Mike 4-86 
Morrow, Brenda 1-24

Morrow, R. W. 4-56

Morse, Leon 1-13, 2-26, 4-6, 4-98

Moscow 2-21, 5-11

Mound Laboratory 4-42

Mrochek, John 1-24, 4-59, 4-75, 4-78, 4-80, 4-82, 4-83, 4-84, $4-93,4-94,4-118$

Mt. View, California 4-82

Mud and dust 1-16

Murphee, Eger V. 1-2

Murphy, Edgar 5-25

Murphy, Mrs. 5-25

Murray, Ray 2-12

Muscle Shoals, Alabama 4-93

Myers, O. H. 3-11

Mynatt, Fred 4-58

\section{N}

Nader, Clair 4-93

Nagao, Hiroyuki 4-20

Nakamura, Take 4-26, 4-27

Napier, Taylor 5-24, 5-26

NASA $4-82$

Nashville, Tennessee $x x i i$

National Academy of Sciences 3-16, 4-40, 4-95

National Bureau of Standards 1-2, 4-32

National Cancer Institute (NCI) 4-80

National Center for Toxicological Research 4-82

National Defense Research Committee 1-2

National Engineering Laboratory (INEL) 4-53

National Institute of General Medical Sciences 4-79

National Institutes of Health 4-78

National Lead Company 2-4

National Materials Advisory Board (NMAB) 4-95

National Reactor Testing Station 2-32

National Research Council xx, xxii, 4-95

National security 1-19

National Transplutonium Program 4-38

Natural Resource Adequacy 4-96

Nautilus submarine fuel 4-47

Naval Ocean Systems Center 4-42

Naval Ordnance Station 4-102

Navratil, J. D. 4-43, 4-44
Navy submarines 4-1, 4-42, 4-47, 4-102

Neal, Mary Ann 5-28

Nehls, J. W. 4-27

Neill, W. J. 3-9

Nelson, Fred 5-22

Nelson, Roy 5-8

Nelson, Sharon 4-109

Neptex process 3-8

Neptunium 2-31, 2-36, 2-37, 3-5, $3-6,3-8,3-12,4-49$

Nessle, G. J. 4-46

Nestor, Bill 4-13

Neutrino emissions 1-14

Neutron activation analysis 4-43

Neutron sources 4-42

Nevada 4-9, 4-15

New York 2-14, 2-23, 2-29, 4-43, 4-57

Newman, D. H. 1-23

Newman, Gene xi, 4-31, 4-50, 4-105

Newman, Pete 5-29

Newson, Henry 1-12

Newton, D. E. 1-25

Nichol, R. G. 4-46

Nichols, Jere 2-17, 3-12, 3-13, 4-13, 4-14, 4-15, 4-53, 4-74, 4-75, 5-10

Nicholson, Ed xi, xiii, 1-13, 2-21, $2-24,2-32,3-11,3-12,3-13$, $4-48,4-111,5-2,5-3,5-7$

Nicol, R. G. 4-46

Nielsen, Bob 4-53

Nier, Alfred O. 1-2

Niobium 3-7

Nobel Prize 1-10

Nogueira, Eduardo 4-49

Norman, Roy 4-6

Norton, W. D. 4-98

Norway 2-20, 4-21

Norwood, K. S. 4-24, 4-26

Notre Dame University 1-10

Notz, Karl xi, 1-24, 4-6, 4-15, 4-16, 5-2

Novelli, Dave 2-16, 4-79

Novovoranezh 2-21

NRX reactor fuel 4-71

Nuclear Analyses 4-12

Nuclear chain reaction 1-14

Nuclear energy ix, 1-10, 1-20, 2-3, 2-17, 3-1, 3-11, 3-12, 4-1, 4-14

Nuclear fuel cycle ix, 1-21, 2-33, 3-1, 4-14, 4-15, 4-112

Nuclear Fuel Services (NFS) 2-4, 2-34, 4-58, 4-68, 4-69, 4-70, 4-111
Nuclear processing wastewaters 4-89

Nuclear Regulatory Assistance Programs 4-10

Nuclear Regulatory Commission xxiv, 4-18, 4-21, 4-24, 4-27, 4-53

Nuclear shock wave 4-9

Nuclear technology 1-19

Nuclear waste disposal 1-21

Nuclear Waste Programs 4-49

Nurmi, E. O. 3-7

Nyer, Warren 1-12

O'Kelley, G. D. 1-23

Oak Ridge Associated Universities 2-23, 4-41, 4-98

Oak Ridge Conference 4-81

Oak Ridge Institute of Nuclear Studies 4-98

Oak Ridge Model 4-53

Oak Ridge National Laboratory (ORNL) xiii, 1-1, 1-9, 2-2

Oak Ridge Research Institute 4-91

Oak Ridge Research Reactor 3-14, 4-19

Oak Ridge Reservation 4-55

Oak Ridge School of Reactor Technology (OSORT) 2-13

Oak Ridge, Tennessee xiii, 1-1, $1-3,1-16,1-18,2-5,2-10$, 2-12, 2-19, 4-19, 4-89, 5-24

Obninsk 2-21

Office of Scientific Research and Development 1-2, 1-14

Oil shale 4-8, 4-10

Olander, B. R. 3-8

Oliver, J. R. 3-12, 5-28

Oliver Springs, Tennessee 1-13

Oody, Robin 1-24

Operations Division 2-22, 2-23, 2-29, 4-31, 4-32, 4-105, 4-107, $5-13$

Operations studies 4-45

Oppenheimer, J. Robert 1-2, 5-17

ORACLE 2-36

Ore processing 1-23, 2-37, 3-1, 3-6, 3-10

OREX Process 2-19, 2-19, 2-20, 2-24, 4-19

Organization 1-11, 2-11

Organization for European Economic Cooperation 2-20 
Organization of Economic Cooperation and Development xxiv, 2-15

Organization of Petroleum Exporting Countries (OPEC) 4-74

ORIGEN computer code xxiv, 2-14, 2-36, 4-12, 4-13, 4-15, 4-28

ORNL Curium Program 3-14

ORNL director's fund 4-91

Orr, P. B. 4-4, 4-22, 4-44

ORSD $1-11$

Orth, D. C. 3-8, 5-7

Osborne, Morris 1-24, 2-27, 4-19, 4-20, 4-23, 4-24, 4-26, 4-30, 4-31, 4-54

Osborne, S. C. 1-25

Osborne-Lee, Irvin 1-24

Oswald, George 4-99

Overbeck, Wilcox 1-12

Overholt, Don 1-13, 3-4, 3-5, 3-8, 5-9

Overton, Jim 4-79, 4-82, 4-84, 4-86

Owen, G. D. 1-23

Owen, S. C. 1-23

Owsley, D. B. 1-23

Oxide Fuel 4-14

\section{$\mathbf{P}$}

P-9 Project 1-12

Pacific Northwest Laboratory 4-41, 4-86

Paducah fluorination ash 2-37

Paehler, Joe 4-32

Palo Alto, California $\mathrm{xx}$

Pannell, Karen 5-28

Pardue, Vic 1-25

Paris 2-21

Park Hotel $2-8$

Parker, Frank 2-21, 2-22, 2-23, 3-11

Parker, Garrett 5-24

Parker, George xi, 1-12, 1-13, $1-24,2-21,3-6,3-8,3-11$, 4-18, 4-19, 4-20, 4-21, 4-23, 4-24, 4-25, 4-28, 5-16

Parrott, J. R. 1-25, 3-7, 3-9, 3-11, 4-58, 4-86

Parrott, Jr., John xi, 4-89, 4-90m 4-98, 4-101, 4-102, 4-104, 4-111, 5-28, 5-29

Parsons, Howard 1-12

Partitioning/Transmutation 4-15

Patarin, L. 5-8

Patents 1-26
Patrick, Charlene 1-24

Pattengill, M. D. 3-13

Patterson, John 4-97

Pattison, Bill 1-24, 2-26, 4-28, 4-29

Patton, B. D. 1-25, 4-58, 4-100

Pawlicki, Berard 1-12

Payne, Ralph 4-48, 4-49

PCBs 4-56, 4-91, 5-32

Peaceful application 3-1, 4-10

Peach Bottom gas-cooled reactor 4-30

Pearl Harbor Day 5-20

Pearson, Ray 4-30, 4-78, 4-79

Peishel, Frank 2-24, 2-27, 3-14, 4-35, 4-111

Pellissippi State Technical Community College 4-88

Penneman, Bob 5-9

Pennington, Ruth 5-24

Pensacola, Florida 4-102

Pepper, May 4-111

Perge, Alex 2-21

Perhac, Ralph 4-97

Perlman, Isadore 1-14, 2-38, 5-21

Perona, J. J. xi, 1-25, 3-7, 3-11, 4-52, 4-104, 4-106, 4-117

Peroxide oxidation 1-3

Perry, Lu 2-7

Petek, Mitcha 1-24

Peterson, A. V. 1-11

Peterson, M. D. 1-10, 1-13, 1-17, 1-18, 2-7, 2-13, 2-19, 5-2, 5-22, 5-23

Peterson, S. xxii, 3-4

Petrie, Lester M. 4-14

Ph.D. program 4-106

Phenol degradation 4-89

Phifer, B. R. 1-23

Philippone, Dick 4-94, 4-112

Phillips, H. X. 1-25

Phillips Petroleum Company 2-24

Phosphates 4-2

Phosphorous 2-38

Photographic wastes 4-101

Photosynthesis 1-21

Photosynthetic hydrogen 4-86

Physicists ix

Pierce, G. E. 4-47

Pigford, Tom 4-22

Pile experiments 1-2

Pilot plant 1-3, 1-4, 1-6, 1-10, $1-15,1-22,2-4,2-5,2-20$, 2-28, 2-29, 4-64, 4-65, 4-70, 4-74, 4-109, 4-111, 5-2, 5-3

Pilot Plant Section 2-1, 2-2, 2-24, 4-36, 4-47, 4-48, 5-5

Pitchblende ore 2-15
Pitt, Wilson xi, 2-4, 4-44, 4-45, 4-46, 4-48, 4-78, 4-79, 4-80, $4-81,4-82,4-84,4-89,4-102$, 4-117

Pittsburg 4-93

Plainsboro, New Jersey xxii

Plant and Equipment Division (P\&E) 4-41, 4-47, 4-80, 4-82, 4-84, 4-100, 4-111, 5-30

Plato 1-1

Platt, Al 2-21, 4-74

Please Mr. Collar 5-25

Plowshare Program 3-1, 4-2, 4-7

Plurix process 2-28, 4-66

Plutonium metal reduction slag 2-37

Plutonium pilot plant 1-14

Plutonium production 1-2, 1-3, 1-6, 1-10, 1-14, 1-15, 2-3, $2-15,5-22$

Plutonium-238 2-9, 2-36, 3-11

Plutonium-240 4-41

Plutonium-242 3-14, 4-31, 4-32, $4-35,4-38,4-41$

Pocatello, Idaho 2-23

Polycyclic aromatic hydrocarbons (PAHs) 4-82

Polyethylene 4-53, 5-13

Polymers 4-53

Pomerance, H. S. 2-36

Pope, Nancy 5-28

Pope, Ron 1-24, 4-18

Portsmouth Gaseous Diffusion Plant 4-42, 4-86, 4-104

Posey, J. A. 1-23, 5-5

Postma, Herman xi, xiii, 1-19, 4-4, 4-74, 4-75

Pot calculation 4-49

Potglass (fixation of wastes) 4-49

Power Reactor Fuels 3-7, 3-12, 4-68

Prados, John 4-106

President Carter 2-3, 2-5, 4-22

Pressley, Roscoe 1-14

Pressurized-water reactors (PWRs) 2-3, 4-14

Preston, M. K. 3-14

Princeton University 1-10

Proaps, C. A. 4-54

Process 23 (23 process) 2-1, 2-8, 2-28, 2-29, 4-66, 4-67

Process 25 (25 process) 2-8, 2-13, 2-19, 2-28, 2-29, 3-11, 4-66, 4-67, 5-2, 5-3

Process chemistry 3-1

Process Design Section 1-10, 4-12, 4-35, 4-48, 4-49 
Process liquors 4-2

Process Waste Treatment Plant 4-100

Production and distribution of radioisotopes 4-1

Production of fission products 2-36

Project Coach 4-8

Project Council 1-10

Project Gasbuggy 4-10

Project Gnome 4-8, 4-10

Protactinium 2-31, 2-33, 2-37, 2-38, 3-4, 3-5, 3-12, 4-48

Pruett, Dave 1-24

Publications Division 4-97, 4-98

Puerto Rico 4-88

Pugh, Luther 4-48

Pulsed columns 2-8

Purdue University 4-18, 5-16

Purex process xiii, 1-10, 1-18, $1-22,2-1,2-4,2-5,2-8,2-28$, 2-29, 2-30, 2-34, 2-36, 3-8, 3-11, 3-12, 3-15, 4-40, 4-47, 4-58, 4-66, 4-67, 4-69, 4-71, 4-109, 4-110, 5-2, 5-3

Purification 3-1

Pyroplasma Technology 4-57

\section{Q}

Quail Roost, North Carolina 4-81 Quehanna, Pennsylvania 4-35

Quinby, Tom 4-109

Quincy, Brad 5-9

\section{R}

Radcliffe, C. I. 1-25

Radiation effects $1-12,1-17,2-19$, 3-3

Radiation hazard 1-14

Radioactive waste 2-32, 3-23-11, 3-15, 4-14, 4-15, 5-22

Radiochemical Engineering Development Center (REDC) 2-27, 4-34, 4-41, 4-42, 4-43

Radiochemical processing 1-14, $1-18,1-19,2-1,2-32,3-9,4-74$

Radioiodine 2-36

Radioisotopes 1-1, 1-3,1-6,1-13, $1-19,2-9,4-1,4-67$

Rainey, Bill 4-80, 4-118

Rainey, R. H. 3-7, 3-11, 3-12, 3-13, 3-14, 5-9, 5-27

RaLa process xiii, 1-10, 2-1, 2-7, $2-19,2-28,2-29,2-38,2-38$, 4-66, 4-67, 5-3

Ramey, Dan 4-109
Ramey, Joann 4-109

Ramsey, Mansel 4-109, 4-116

Randolph, John 4-113

Ratledge, Bill 5-13

Ratledge, Joe 4-18

Raw-material processing 2-28, 2-37, 3-10, 4-66, 5-18

Rawl, Rick 1-24, 4-18

Reactor accidents 4-27

Reactor Chemistry Division 4-20, 4-46, 4-48

Reactor Division 2-17, 5-12

Reactor effluent system analysis 2-9

Reactor Experimental Engineering Division 2-23

Reactor fuel processing 2-10

Reactor Fuel Dissolution 3-2, 3-3

Reactor physics calculations 4-13

Reactor safety 3-1, 4-14

Reactor Safety Research Building 4501 4-18, 4-31, 4-111

Reactor Technology 1-19, 2-12

Reactor Technology Division 1-9

Reactors, CP-2 and CP-3 2-31, 4-71

Recreational Activities 5-29

Red Indian pottery clay $4-51$

Redox 1-18, 1-22, 2-1, 2-4, 2-7, 2-8, 2-19, 2-28, 2-31, 2-34, 3-11, 4-66, 4-67, 4-71, 5-2, 5-3

Reeves, M. E. 1-25, 4-86, 4-91, 4-102

Refinery wastes 4-2

Refining 2-3

Reich, Bill 1-24, 4-16

Reichle, Donna 1-25, 4-98

Reid, D. G. $1-10,1-13,2-5,3-4$, 4-110, 5-2, 5-7

Remediation Technology 4-102

Remote operations 1-6, 1-17

Renier, John-Paul 4-14

Rennich, Mark 4-18

Repository 4-70, 4-104

Reprocessing 2-3, 2-15, 4-106

Republic of China 5-13

Resource recovery 3-15, 4-75, 4-95

Retread Campaign 5-10

Retrievable Surface Storage Facility 4-53

Revis, Nathaniel 4-93

Reynolds, Sam 5-6

Ribonucleic acids 4-78, 4-79

Rich, S. L. 4-113

Richardson, S. A. 1-25, 4-113

Richland, Washington 5-22

Ricker, Glen 2-6, 2-8

Rigstad, Nelmar 2-6, 2-8, 5-2

Rimshaw, Stanley 1-14
Riordan, Larry 1-16, 5-6, 5-7

Rivera, A. L. 4-54, 4-55, 4-56, 5-1

Roane-Anderson Company 1-15, $1-16$

Roberts, C. E. $1-23,5-5$

Roberts, J. Tom 2-19, 3-8, 3-9, 3-13, 3-15, 4-50, 4-51, 4-106, 5-23, 5-24, 5-26

Robertson, Paul 2-14, 2-24

Robinson, Cindy 4-98

Robinson, S. M. 1-25, 4-6, 4-102, 4-104, 5-32

Robotics and Process Systems Division 4-111, 4-113

Roche Laboratories 4-82

Rochelle, Jim 4-28

Rochester 2-12

Rochester University 1-10

Rockwell Hanford 4-105

Roddy, Bill 4-16

Rodger, Walton 1-17, 5-2, 5-3

Rodgers, Bill 1-24, 4-75, 4-77

Rodler, J. 2-22

Rogers, Frank 5-24

Rolfe, Vicky xi

Rom, Al 1-12, 2-24, 5-2, 5-3

Rome, Italy 4-5

Roosevelt, President F. D. 1-2, 1-14, 5-18

Rose, Jack 4-99

Rosenbaum, R. E. 1-25

Rosenthal, Murray 2-11, 4-74

Roslyn, Virginia 4-96

Ross, R. G. 1-23, 4-44

Ross, W. J. 3-10

Rotary kiln coal gasification project 4-101

Rover 2-28, 4-66

Row, Tom 2-17

Roy, Gene 4-111

Ruch, John 2-24, 3-10, 4-46, 5-2

Rule, Jim 5-5

Runion, Charles 2-8

Rupp, Art 2-9, 4-109

Russell, Bill 2-17

Russell, Liane 2-17

Russian exhibit 2-20

Ruthenium volatility 4-50

Ryon, A. D. 3-6, 3-9, 3-10, 4-3, 4-6, 4-7, 4-79, 5-19

$\mathbf{S}$

S-1 Committee 1-2,1-11

Sadowski, George 1-13, 3-7, 3-8, 3-9, 3-11, 4-74, 5-24

Safety Procedures 2-6 
Safety record 1-21

Saine, V. L. 3-6

Salmon, Royes 1-24, 3-15, 4-16, 4-74, 4-77

Salt Domes 3-16, 4-52

Salt Lake City, Utah 4-102

Sampling 3-3

Sams, Terry 4-77

San Francisco cable cars 4-8

San Francisco, California 2-23, $4-8,4-43$

Sandia National Laboratories 4-16, 4-24

Sandidge, Prescott 1-18

Savage, Cliff $4-49$

Savannah River xiii, 1-19, 1-22, 2-4, 2-7, 2-8, 2-16, 2-17, 2-20, $2-24,2-30,2-32,2-37,3-14$, 4-32, 4-34, 4-35, 4-36, 4-38, 4-40, 4-41,

Savannah River Laboratory 4-42, 4-69, 4-70, 4-109, 5-4, 5-7, 5-9, 5-32

Savolainen, Joe 1-13, 2-6, 3-2, 3-3, 3-5, 3-7, 3-11, 5-7

Scanlan, Tom 4-56

Scarboro School 1-16

Scates, Otis 5-28

Scavenging-precipitation ion-exchange process $4-49$, 4-50, 4-51

Schafer, A. C. 3-11

Schaffer, W. F. 3-12, 3-13, 4-49, 4-111, 4-112, 4-113, 5-19

Schaich, Bob 5-4

Scheitlin, Frank 4-31, 4-98

Schersten, Clair xi, xiii, xix, 1-13, 5-6

Schilling, Chuck 2-26, 4-5, 4-44, 4-49, 5-14

Schlessinger $2-17$

Schmitt, J. M. 3-12, 3-13

Schnelle, Phil 5-4

School Daze 5-25

Schulz, W. W. 4-43, 4-44

Schulze, Gerry 4-84

Schumate, Wes 4-82, 4-89

Schuresko, Dan 4-82, 4-84

Schwartz, W. 5-13

Scott, C. D. xi, 2-17, 2-27, 4-48, 4-62, 4-74, 4-78, 4-80, 4-82, 4-83, 4-84, 4-86, 4-89, 4-90, $4-99,5-10,5-28$

Scott, Tim 1-24, 4-22, 4-59

SCRUP program 2-32
Seaborg, Glenn T. 1-2, 1-3, 2-8, 2-10, 3-1, 3-2, 3-11, 3-14, 4-32, 4-33, 4-65

Seagren, R. D. 4-16

Sealand, M. O. 3-11

Sears, Mildred 4-49

Sease, J. D. 3-13, 3-14, 4-5

Second International Conference on the Peaceful Uses of Atomic Energy xxi, 3-9

Sedlmeier, M. A. 1-25

Seeley, F. G. 3-13

Segram, Harry 4-116

Semi-Continuous Ion Exchanger 2-31

Semi-Works 1-12, 2-5, 2-6, 2-8, $2-29,5-6,5-21,5-22$

Separation plant facilities 1-17

Separations chemistry 1-1, 1-12, 4-1, 4-59, 5-19

Separations Development Division 1-12,1-13

Separations Development Section $1-10$

SERI 4-86

Service, Robert W. 5-15

Severe Accident Sequences Analysis 424

Shaffner, Jim 4-111

Shales 4-2

Shank, Earl 2-13, 2-21, 3-6, 3-7, 3-9, 3-11, 3-13

Shannon, Bill 4-22

Shannon, Bob 4-46, 4-47, 4-113

Shannon, Janice 5-24

Shapiro, E. 1-12

Shappert, Cathy 4-12, 4-98

Shappert, Larry xi, 1-24, 4-16, 4-18, 5-24, 5-26

Shaw, Jr., J. W. 1-25

Shaw, Milton 4-20

Shear development 2-9, 4-114

Shear-Leach Process 2-34

Shell, S. E. 1-23, 4-6, 5-30

Shelton, E. B. 3-14

Sherrow, Susan 4-25

Shields, Glenna 4-86

Shipman, Calvin 4-45, 5-13

Shippingport Reactor 4-111

Shockley, Bill 2-19, 4-27, 4-51

Shor, Joel 1-24

Shoun, Richard 1-24, 4-4

Shumate, Wes 4-79, 4-90

Shurr, Sam 4-95

Simmons, Cathy 4-29

Sims, Anita 1-25

Sims, T. M. $4-43$
Singh, Suman 1-24, 4-53, 4-54, $4-55,4-56,4-57,4-77,5-28$

Sisson, Warren 1-24, 4-48, 4-61

Site 7600 4-112

Sky Lab experiments 4-109

Slippery Rock, Pennsylvania 4-88

Slippery Rock University $4-88$

Slurrex Process 2-28, 2-37, 4-66

Slusher, John 2-16

Smith, Fred 4-49

Smith, James C. 4-107

Smith, Nancy $x i$

Smith, O. J. 4-47

Smoot, C. M. 1-23

SNAP heat sources $3-14,4-71$

Snider, J. W. 1-25, 4-5, 4-6, 4-22, 4-59, 4-75, 4-111

Snow, Donna 5-28

Snyder, K. D. 1-25

Soard, Frank 4-13, 4-45, 5-13

Society for Technical Communication 4-98

Socrates 1-1

Sodium-24 4-41

Softball 5.29

Soil-venting demonstration 4-102

Sol-gel process $1-18,2-27,3-12$, 4-5, 4-6, 4-61, 4-67, 4-72

Sole, Harvey 4-53

Solid State Division 4-31, 4-107

Solidification 2-22, 4-58

Solvent extraction 1-3,1-10,1-18, $2-1,2-4,2-7,2-12,2-29,2-30$, 2-37, 3-2, 3-3, 3-4, 3-6, 3-7, 3-10, 3-13, 4-2, 4-4, 4-35, 4-40, 4-59, 4-64, 4-67, 4-72, 4-79, 4-111

Solvent-Refined Coal 4-75, 4-85

Solway Bridge 5-6

Sombret, C. 2-22

South Africa 2-20

South Charleston 5-2

Southern Railway 1-15

Soviet Union 2-21, 2-5, 4-69, 5-11

Space Power Program 4-35

Spain 2-20

Spangler, D. E. 4-110, 4-113

Special Engineering Detachment of the Army 1-9

Spence, R. D. 1-25, 4-6, 4-24, 4-28, 4-61

Spencer, Barry 4-112

Spent fuels 2-5, 4-14, 4-110

Spiewak, Irv 4-93

Spill Spotter 4-82

Spin-off company 4-79 
Spitsyn, Professor V. 1. 2-21, 2-22, $2-23$

Springfield, England 2-21

Squires, Art 4-93

SRP fuel 4-71

St. Louis, Missouri 1-6, 5-5

St. Patrick's Day dances 2-17, 5-7, 5-24, 5-29

Stable Isotopes 4-31, 4-32

Stack gas $1-13$

Stacy, R. G. 1-23, 4-24

Stagg Field 1-2, 1-12, 5-17

Stainker, S. H. 4-45

Stainless steel-clad fuels 1-6, 2-14, 2-33, 2-34, 3-7, 3-10, 3-12

Standard Oil Company 1-2

Stangby, J. G. 1-12

Starnes, B. W. 1-25

Starr, Chauncy 2-18

Steahly, Frank xix, 1-9, 1-10, 1-13, $1-18,2-5,2-14,3-5,5-2,5-6$

Steinberg, E. P. 2-37

Sterling Forest, New York 5-7

Stevens, Debbie xi, 1-25, 4-98

Stewart, Martha xi, 4-47, 4-97, 5-25

Stimson, Henry L. 1-2

Stines, Bill 5-30

Stockdale, W. G. 3-4, 3-7, 4-111

Stone and Webster Engineering Corporation 1-15

Stooksbury, Kyle 5-24, 5-26, 5-28

Storage 1-6, 1-10, 4-70

Storch, Steve 1-24, 4-16

Stoughton, Ray 1-12, 1-14, 2-37, 3-4, 4-112

Stout, Perry 4-93, 4-21

STR 2-29

Strandberg, G. W. xi, 1-25, 4-78, 4-79, 4-89, 4-90, 4-91, 4-101

Strandell, Erik Axel 5-19

Stratton, Dave 4-7, 4-23

Strauss, Admiral 2-8

Strauss, Lewis L. 4-32

Striplin, M. 4-93

Strohecker, John 2-12

Strontium-90 4-50

Struxness, E. G. 3-9, 3-11

Stulberg, Mel 4-78

Sturch, E. 3-8

Subna, Russia 2-22

Sulfex Process 2-34, 3-12

Sullivan, W. H. 2-36

Summers, D. G. 4-110

Supercompaction 4-56

Supercritical research facility 4-62

Sutton, Al 4-25

Sverdlovsk 2-22
Swanks, Jerry 4-108

Swartout, John 2-7, 2-13, 5-22

Sweden 2-15, 2-20

Sweeden, Beverly 5-28

Swimming Pool Reactor 3-5

Sybron Biochemicals 4-89

Synthoil process $4-74$

Szilard, Leo 1-2, 5-17

\section{T}

Tacoma, Washington 4-91

Taiwan 4-27

Takacs, Teresa 1-24

Talbot, Jan 5-28

Tallent, O. K. 4-30, 4-39

Tamalpais project $4-8,4-9$

Tamura, Tammy 4-51, 4-94, 4-105

Target fabrication 4-36, 4-107

Tarrytown, New York 4-86

Taylor, Don 5-30

Taylor, Ellison 2-19, 4-33

Taylor, Joan 1-24

Taylor, John 4-79

Taylor, P. A. 1-25, 4-104

Teaming 2-10

Technetium 4-2, 4-19

Technical accomplishments 1-23

Technical Achievement Award 4-2

Technical Advisory Group (TAG) 4-22

Technical Division xiii, $\mathbf{x x}, \mathbf{x x i}$, $1-1,1-9,1-11,1-12,1-13$, $1-17,1-18,1-20,1-22,2-1$, $2-5,2-13,2-29,2-38,5-2,5-6$

Technology transfer 1-20

Tel Aviv 4-95

Television 1-6

Teller, Edward 5-17

Tellurium release rates $4-27$

Tennessee Eastman xx, 4-107

Tennessee Technological University, Cookeville xxi, 2-7, 4-106

Tennessee Valley Authority 4-10

Tevault, Ginger 1-24, 4-86

Texas A\&M University 4-102

Thacker, Karen 5-5

Thacker, Lou 4-80, 4-82

The Devil Made Us Do It 5-25

The KKK, Kollar's Kemical Kollege 5-25, 5-27

The Scissor-Frantics 5-24, 5-26

The Wonderful World of Collar 5-25

Theoretical Physics Group 1-14

Thermal breeder 4-2
Thermal neutron analysis 4-43

Thermal process $4-56,4-58$

Thermodynamic calculations 4-23

Thermonuclear Division 2-21

Third International Conference on the Peaceful Uses of Atomic Energy xxi

Thoma, R. E. 4-46

Thomas, Iran 4-3

Thomas, Jan 5-5

Thompson, C. T. 4-49

Thompson, G. R. 4-47

Thompson, H. C. 4-46

Thompson, Homer 5-5

Thompson, Jim 1-24, 4-78, 4-86, 4-87, 4-90, 4-92

Thompson, Lee E. 4-113

Thompson, Stanley G. 1-3

Thompson, Warren 4-100

Thompson, William xi, 1-13

Thorex 1-18, 1-22, 2-1, 2-28, 2-31, 3-12, 4-66, 4-67, 4-70, 4-71, 4-72, 4-110, 4-111, 5-2

Thorex Pilot Plant 3-6, 3-7, 3-11

Thorium 1-6, 1-9, 1-18, 1-22, 2-1, $2-27,2-28,2-29,2-31,2-32$, 2-33, 2-34, 2-35, 3-1, 3-4, 3-5, $3-6,3-7,4-5,4-32,4-67,4-73$

Thorium breeder 2-33

Thorium fuel cycle 2-7, 2-26, 3-13

Thorium ores 3-9, 3-10

Thorium-Uranium Recycle Facility (TURF) 4-111

Three Mile Island 4-21, 4-25, 4-69, 5-8

Thule, Greenland 4-69

Thumbser, Bill 5-6

Tiffany, Tom 4-82

Tinley, Joe 5-30

Tober, F. E. 3-8

Todd, Mary F. 2-36

Tokai-Mura Plant, Japan 4-69

Tomlin, W. E. 3-5

Tong, Y. C. 4-26

Top Policy Group 1-2

Toth, Mac 1-24, 4-24, 4-25, 4-27

Tower Shielding Facility (TSF) 4-16, 4-17

Towns, R. L. 4-21, 4-30

Tracy, Joe 4-31

TRAMEX process 2-28, 4-35, 4-66

Transcurium elements $4-34$

Transfer-ribonucleic acids (t-RNAs) 4-2, 4-79, 5-10

Transplutonium elements 3-12, $3-13,4-32,4-36,4-40,4-44$

Transporation Studies 4-16 
Transuranic elements 1-19, 2-23

Transuranium Element (TRU)

Processing 2-15, 2-27, 4-32, 4-67

Transuranium Processing Plant (TRU) 2-27, 2-28, 2-33, 4-33, 4-36, 4-37, 4-44, 5-4, 5-6

Trauger, Don $x i, x i i i, x x i, 1-21$, 2-27

Travis, Jim 1-24, 4-21, 4-24, 4-26, 4-31

TREAT reactor 4-19, 4-20

Tributyl phosphate (TBP) process $1-10,2-1,2-11,2-30,2-37,3-8$, 4-67

Tributyl Phosphate 1-22, 2-4, 2-8, 2-28, 2-29, 2-30, 2-31, 3-2, $3-3,3-4,3-5,3-12,4-66,4-67$

Tripp, Arthur 5-18

Tritium 4-8, 4-89

Trivelpiece, A. W. 5-32

Trotter, Troy R. 4-113

Trout, Jim 4-111

TRU waste 4-15, 4-52

Truett, Delia 4-88

TRUG 4-66

Tsai, Kwang-Fu 1-24

Tumulus Disposal Demonstration 4-56

Turley, Jim 4-36

Turner Construction Company 1-15 Turner, T. L. 1-23

TVA 4-93

\section{U}

U.S. Army Corps of Engineers 1-2, 1-3, 1-10, 1-11

U.S. Department of Energy xi, xiii, $1-20,2-18,4-18,4-62$

U.S. Environmental Protection Agency 1-20, 4-81

U.S. Geological Survey 4-10, 4-89, 4-95

U.S. State Department Diplomat School 4-96

Ullmann, Jack 2-10, 2-14, 2-20, 2-36, 3-6, 3-7, 3-12, 3-13, 4-117, 5-24, 5-26

Ulrich, Bill 4-52

Underwater maintenance 2-32

Underwood, J. 4-48

Unger, Bill xi, 2-19, 2-27, 2-38, 3-7, 3-11, 3-12, 4-35, 4-111, $4-112,5-2,5-3,5-12,5-24$
Union Carbide Corporation xiii, xix, 1-9, 4-75, 4-82, 4-106, 5-2, 5-22, 5-28

Union Carbide Research Division 2-14, 4-86, 5-6

Unit operations 1-10, 1-22, 2-5, $2-12,2-20,4-45,5-2,5-7$

Unit Operations Section 2-1, 2-2, 2-24, 4-35, 4-48, 4-74

United Kingdom 2-5, 2-16, 2-20, 2-22, 4-24, 4-26, 4-27, 4-69, 5-11

United Nations 3-1, 3-14

United States 5-11

University of Alabama 4-92

University of California 1-10, 1-14

University of California at Berkeley 1-2

University of California at Davis 4-93

University of Chicago xiii, 1-2, $1-3,1-6,1-9,1-10,1-11,1-12$, 1-14, 2-7, 4-18, 5-16, 5-20, 5-21

University of Hartford 4-90

University of Indiana 1-10

University of Kentucky Medical Center 4-43

University of Maine 5-20

University of Michigan 4-82

University of Minnesota 1-2

University of Mississippi 4-92

University of Mississippi Medical Center 4-92

University of North Carolina 2-12

University of Tennessee xxi, xxiii, xxiv, 2-6, 2-17, 4-24, 4-91, 4-97, 4-106, 5-16

Uranium and transuranic elements, buildup 2-36

Uranium hexafluoride $1-2,2-26$, 2-34, 2-35, 3-8, 3-10, 4-12, $4-44,4-45,4-46,4-48,5-13$, $5-21$

Uranium metal $1-3$

Uranium ores 2-9, 3-6, 3-10

Uranium production 4-110

Uranium recovery $1-9,1-23$

Uranium-232 2-37, 2-38, 4-32

Uranium-233 1-13, 1-22, 2-8, 2-9, $2-13,2-29,2-31,2-32,2-33$, 2-36, 3-2, 3-4, 3-1 1, 4-34, $4-48,4-111$

Uranium-233-bearing fuels 3-13

Uranium-234 2-36, 4-32

Uranium-236 2-36

Uranium-237 2-36, 3-5
Urbana, Illinois xxiii

Urey, Harold C. 1-2, 2-19, 5-16

Uriarte, A. L. 3-13

Urine analyzer 4-80

Uttar Pradesh 4-94

UV analyzer 4-80, 4-81

V

Van Cleve, J. E. 3-13, 3-14, 4-5, 4-36, 4-56

Van Hoesen, Dirk 4-56

Van Horn, B. E. 4-46

Vanadium 3-6

Vanderbilt University $\quad 4-106$

Varagona, J. J. 3-13

Vaughan, R. H. 3-7

Vaughen, V. C. A. 3-8, 3-13, 3-14, 3-15, 4-24, 4-35, 4-45

Vaughn, Arky 5-29

Vavruska, John 4-6

Veach, Al 4-31

Vedder, R. J. 1-23, 4-58

Villiers-Fisher, John 4-100, 4-104

Vincentown, New Jersey 4-10

Vissers, Don 4-78, 4-80

Vitrification plants $4-15$

VOCs 5-32

Volatile iodine 4-23

Volatility process $1-3,2-1,2-4$, 2-11, 4-69, 4-72

Voloxidation process $2-28,4-66$

Vondra, B. L. xxii

W

W pile 1-12

W site 1-10

Walker, A. B. 1-25, 4-91, 4-103, 4-104

Walker, Bill 4-80, 4-82, 4-84

Walker, Joe 4-77, 4-86, 4-91, 4-99, 4-102, 4-104

Wall, G. C. 3-13

Wallace, Henry A. 1-2

Wallace, Horace 4-48

Walters, Bruce 4-45

Wang, U. M. 4-27

Wankerl, Max 1-24, 4-18

Ward, Frank 1-10, 2-13

Ward, W. T. 3-10

Warren, Buddy 5-2

Warren, K. S. 3-13, 4-78, 4-80

Washburn, T. N. 3-15

Washington and Lee University 4-88

Washington, D. C. 4-95 
Washington University (St. Louis) $1-6,1-10$

Waste Confidence Rulemaking 4-14

Waste disposal 2-26, 3-1, 4-31, 4-105, 4-106

Waste Handling and Packaging Plant 4-104

Waste Isolation Pilot Plant (WIPP) 4-15

Waste management $1-20,2-3$, 2-20, 2-21, 3-1, 4-14

Waste Management Technology Center (WMTC) 4-53, 4-54

Waste minimization 2-4, 4-102

Waste Operations Division 4-50

Waste ponds 4-90

Waste processing 1-6, 3-2, 4-12, 4-58, 4-70

Waste solidification 2-9, 3-2, 3-16, 4-105

Waste storage tanks $1-8$

Wastewaters 4-86, 4-92, 4-100

Water Chlorination 4-78, 4-91

Waters, Rob 5-30

Watsky, Mel 4-82

Watson, Clyde 2-9, 2-34, 3-7, 3-11, 3-12, 3-13, 4-112, 5-12, 5-19, $5-24$

Watson, Jack 4-49, 4-62, 4-77, 4-90

Wayland, A. E. 1-23

Weapons 2-3, 2-12, 4-71

Weaver, B. S. 3-12, 3-14, 4-4, 5-6, 5-19

Weaver, Debbie 5-28

Weber, C. F. 4-27

Webster, Charlie 1-24, 4-21, 4-24, 4-26, 4-31

Webster, D. S. 3-14

Weekday at Begovich's 5-28

Weekly seminars 2-14

Weeren, Herman 4-49, 4-51, 4-78, 4-79

Weil, Bradley 4-112, 5-28

Weinberg, Alvin xi, xiii, 1-1, 1-9, $1-14,1-17,1-18,1-23,2-9$, $2-13,2-19,2-22,2-23,2-26$, 4-1, 4-33, 4-35, 4-93, 4-94, 4-95, 5-12

Weisbin, Chuck 4-14

Weiss, Joe 4-78, 4-79

Welch, Mimi 1-24, 4-18

Welch, Tim 1-24, 4-16

Welles, Brad 1-24, 4-18

Werner, Louis 2-39, 5-18, 5-21

Wesson, Illinois 4-113
West, Colin 4-31

West, G. A. 3-11, 3-12, 3-13

West Germany $2-5,2-20$

West, Jerry 5-30

West Stands 2-7

West Valley, New York 2-34, 4-58, 4-70

Westinghouse 4-20, 4-42, 4-53, 4-105

Westinghouse Plasma Systems 4-57

Westmoreland, Phil 4-75

Wet-oxidation 4-75

Wet-process phosphoric acid 4-2, 4-3

Wham, R. M. 1-23, 4-43, 4-77, 5-28

Whatley, M. E. 3-5, 3-9, 3-10, 3-12, 3-13, 4-46, 4-48, 4-106, 4-112, 5-2, 5-14, 5-15, 5-29

Wheeler, Foster 2-14

Whetsel, Howard 4-97

Whitaker, M. D. 1-11,1-12

White, J. C. 3-9, 4-112

White Oak Creek 2-22

White water activities 5-29

White Wing ferry 1-15

Whitmarsh, C. L. 3-10, 4-46, 4-117

Whitney, I.B. 2-38

Whitson, Bill 4-36

Wichner, R. P. 4-24, 4-27, 4-30

Wiethaup, R. R. 3-6, 3-10

Wiggins, J. T. 1-23, 4-35, 4-44

Wigner, Eugene 1-2, 1-11, 1-14, $2-12,2-19,2-32,5-3$

Wilder, A. V. 4-46

Wilhelm, Juergen 419

Wilker, Becky xi

Wilkes, Ed 1-24

Wilkinson, Michael K. 4-107, 4-109

Williams, D. F. $1-23,4-6,4-65$

Williams, Joy xi

Williams, L. C. (Red) 4-56

Williams, Roger 1-11

Williamson, Andy 4-18

Williamson, H. E. 2-36

Willis, Dick 4-82

Wilmington, Delaware 2-6

Wilson, Archie 4-102

Wilson, J. H. 1-25, 4-30, 4-77, 4-102, 4-103

Wilsonville, Alabama 4-75

Windscale, United Kingdom 2-21

Winget, Ray H. 4-110

Wiped-film evaporator 4-51, 4-104

Wisbey, S. J. 4-27
Wischow, R. P. 3-3, 3-5

Wischusen, Eric 5-4

Witherspoon, J. P. 4-116, 4-117

Witte, H. O. 3-13

Wollan, Emie 1-14

Woods, W. M. 3-12, 4-45

Woodward, Charlene 1-24, 4-90

Woodward, Jonathan 1-24, 1-25, 4-79, 4-86, 4-87, 4-88, 5-28

Worden, Mark 4-89

Work, Joe 2-7

Work-for-Others 1-20

World Energy Conference 4-96

World War II 1-6

Wright, A. L. 4-24, 4-26, 4-27, 4-28, 4-29

Wurtsmith AFB 4-104

Wyatt, E. I. 4-46, 4-47

Wymer, Ray xi, xiii, xxii, 2-20, 3-2, 3-3, 3-7, 3-8, 3-10, 3-11, 3-12, 4-4, 4-6, 4-7, 4-31, 4-74, 4-97, 5-2, 5-28

$\mathrm{X}$

$X$ pile $1-12$

$X$ Research Program 1-11

$X$ site $1-10,1-12,2-31$

$\mathrm{X}-10$ site $1-3,1-5,1-13,1-15,2-1$, $2-2,2-6,2-12,2-38,4-64$

Xenon 1-12, 4-68

$\mathbf{Y}$

Y-12 1-9, 1-15, 2-12, 2-14, 2-20, 2-24, 2-39, 4-31, 4-56, 4-79, 4-91, 4-105

Y-12 Research Division 4-1

Y-12 Sludge Detoxification 4-57

Y-12 Waste 4-56

Yamashita, Toshiuki 4-28

Yankee Atomic 2-34

Yarbro, Orlan 2-27, 3-14, 4-22, 4-35, 4-36, 4-37, 4-111

Yarosh, Marv 4-94

Yee, Bill 4-93, 4-94, 5-12

Young, Donna 1-24

Young, Gale 4-94

Young, V. R. 4-46

Youngblood, Lloyd xi, 1-24, 4-44, 4-46, 4-47, 4-49, 4-77

Younghanse, John 5-28

Yucca Mountain 4-15, 4-16

Yugoslavia 2-20 
Z

Zachary, Glenna Shields 4-89

Zeitlin, H. R. 3-7

Zeolites 2-19, 4-51, 4-101

Zevenbergen, L. A. $1-25$

Zircaloy 2-3, 3-7, 3-12, 4-20, 4-36
Zircaloy-clad fuel rods $2-34,3-13$, $4-5,4-23$

Zircex Process 2-28, 2-34, 4-66

Zirconium-based fuels 2-33, 2-34, 3-7, 3-10, 4-44, 4-45, 4-47, 4-72
Zirflex 2-28, 2-34, 3-12, 4-66, $4-67,4-68$

Zucker, Alex 4-96 
List of Drawings and Photos

ORNL DWG 92A-205R

ORNL PHOTO 4015

ORNL PHOTO NO. 3428-85

ORNL PHOTO NO. 4983-87

ORNL PHOTO NO. 1751-91

ORNL PHOTO NO. 2062-89

ORNL PHOTO NO. 3113-90

ORNL HSTRY-183

ORNL PHOTO 47331

ORNL HSTRY-211

ORNL HSTRY-259

ORNL HSTRY-169

ORNL HSTRY-115

ORNL HSTRY -185

ORNL HSTRY -140

ORNL PHOTO 5447-92

ORNL PHOTO 88306

ORNL PHOTO 3153-86

ORNL PHOTO 652-90

ORNL NEWS 14934

ORNL PHOTO NO. 0713-73

ORNL PHOTO 9368-91

ORNL PHOTO 9371-91

ORNL PHOTO 9369-91

ORNL PHOTO 9367-91

ORNL PHOTO 9370-71

ORNL HSTRY 76A

ORNL HSTRY 268A

ORNL NEWS 14445

ORNL NEWS 1-01-076

ORNL PHOTO 5818-78

ORNL PHOTO 96762

ORNL PHOTO 0858-80

ORNL PHOTO 12-80

ORNL PHOTO 94009

ORNL PHOTO 65604

ORNL PHOTO 99006A

ORNL PHOTO 0785-72A

ORNL PHOTO 89484

ORNL PHOTO 5447-78

ORNL NEWS 13645

ORNL-LR-DWG 46466

ORNL PHOTO 46045

ORNL PHOTO 8640-81

ORNL PHOTO 2582-78

ORNL PHOTO 7883-84
ORNL PHOTO 4452-85

ORNL PHOTO 2447-85

ORNL PHOTO 6000-87

ORNL PHOTO 0337-84

ORNL PHOTO 9660-85

ORNL PHOTO 8759-85

ORNL PHOTO 2479-85

ORNL PHOTO 83715

ORNL PHOTO 14480

ORNL PHOTO 90626

ORNL PHOTO 83677

ORNL PHOTO 83153

ORNL PHOTO 83675

ORNL PHOTO 83678

ORNL PHOTO 1841-74

ORNL PHOTO 83286

ORNL PHOTO 1276-75

ORNL PHOTO 84202-A

KIPH87-0200

KIPH87-0198

KIPH87-0207

ORNL PHOTO 1625-80

ORNL PHOTO 1626-80

ORNL PHOTO 3856-78

ORNL PHOTO 6603-81

ORNL PHOTO 3887-86

ORNL PHOTO 1034-85

ORNL PHOTO 0456-83

ORNL PHOTO 3261-75

ORNL PHOTO 5607-80

ORNL PHOTO 4760-80

ORNL PHOTO 0270-84

ORNL PHOTO $3310-83$

ORNL PHOTO 0844-79

ORNL PHOTO 2943-80

ORNL PHOTO 0219-73

ORNL PHOTO 4926-82

ORNL PHOTO 4136-84

ORNL PHOTO 5811-84

ORNL PHOTO 5434-89

ORNL PHOTO 7987-91

ORNL PHOTO 2106-82

ORNL PHOTO 5797-84

ORNL NEWS PHOTO NO. 14930

ORNL PHOTO 5914-91

ORNL PHOTO 9021-81
ORNL PHOTO 9244-85

ORNL PHOTO 0069-79

ORNL PHOTO 9553-85

ORNL PHOTO 2324-86

ORNL PHOTO 9695-90

ORNL PHOTO 1122-88

ORNL PHOTO 3012-92

ORNL PHOTO 374-84

ORNL PHOTO 552-80

ORNL PHOTO 6887-76

ORNL NEWS PHOTO 1715-R

ORNL PHOTO 2059-75

ORNL PHOTO 3286-77

ORNL PHOTO 4495-78

ORNL PHOTO 0647-80

ORNL PHOTO 2060-75

ORNL PHOTO 6020-76

ORNL PHOTO 7589-92

ORNL PHOTO 4706

ORNL PHOTO 2685-77

ORNL PHOTO 5723-78

ORNL PHOTO 11537-92

ORNL PHOTO 90788

ORNL HSTRY 329

ORNL NEWS 15983

ORNL NEWS 23279

ORNL PHOTO 96639

ORNL DWG 92A-858

ORNL DWG $92-560$

ORNL DWG 92A-656

ORNL DWG 92A-657

ORNL DWG 92A-659A

ORNL DWG 92A-6598

ORNL HSTRY 269

ORNL HSTRY 270

ORNL PHOTO 85329

ORNL PHOTO 63804

ORNL PHOTO 69536

ORNL HSTRY 209

ORNL HSTRY 31

ORNL PHOTO 41371

ORNL PHOTO 14625

ORNL PHOTO 69509

ORNL PHOTO 57391

ORNL PHOTO 69511

ORNL PHOTO 86786 
ORNL PHOTO 4495-78

ORNL PHOTO 0647-80

ORNL PHOTO 2060-75
ORNL PHOTO 2060-76

ORNL PHOTO 552-80

ORNL PHOTO 6887-76
ORNL NEWS 1715R

ORNL PHOTO 2059-75

ORNL PHOTO 3286-77 